\title{
Archeological Data Recovery Excavations along Becerra Creek (41WB556), Webb County, Texas
}

Richard B. Mahoney

Raymond P. Maudlin

Steve A. Tomka

Raba Kistner

Follow this and additional works at: https://scholarworks.sfasu.edu/ita

Part of the American Material Culture Commons, Archaeological Anthropology Commons, Environmental Studies Commons, Other American Studies Commons, Other Arts and Humanities Commons, Other History of Art, Architecture, and Archaeology Commons, and the United States History Commons

Tell us how this article helped you.

This Article is brought to you for free and open access by the Center for Regional Heritage Research at SFA ScholarWorks. It has been accepted for inclusion in Index of Texas Archaeology: Open Access Gray Literature from the Lone Star State by an authorized editor of SFA ScholarWorks. For more information, please contact cdsscholarworks@sfasu.edu. 


\section{Archeological Data Recovery Excavations along Becerra Creek (41WB556), Webb County, Texas}

\section{Licensing Statement}

This is a work produced for the Texas Department of Transportation (TxDOT) by the report producer. TxDOT and the report producer jointly own all rights, title, and interest in and to all intellectual property developed under TXDOT's contract with the report producer. The report may be cited and brief passages from this publication may be reproduced without permission provided that credit is given to both TXDOT and the report producer. Permission to reprint an entire chapter, section, figures or tables must be obtained in advance from either the Supervisor of the Archeological Studies Branch, Environmental Affairs Division, Texas Department of Transportation, 125 East 11th Street, Austin, Texas, 78701 or from the report producer. 


\section{Archeological Data Recovery Excavations along Becerra Creek (4IWB556), Webb County, Texas}

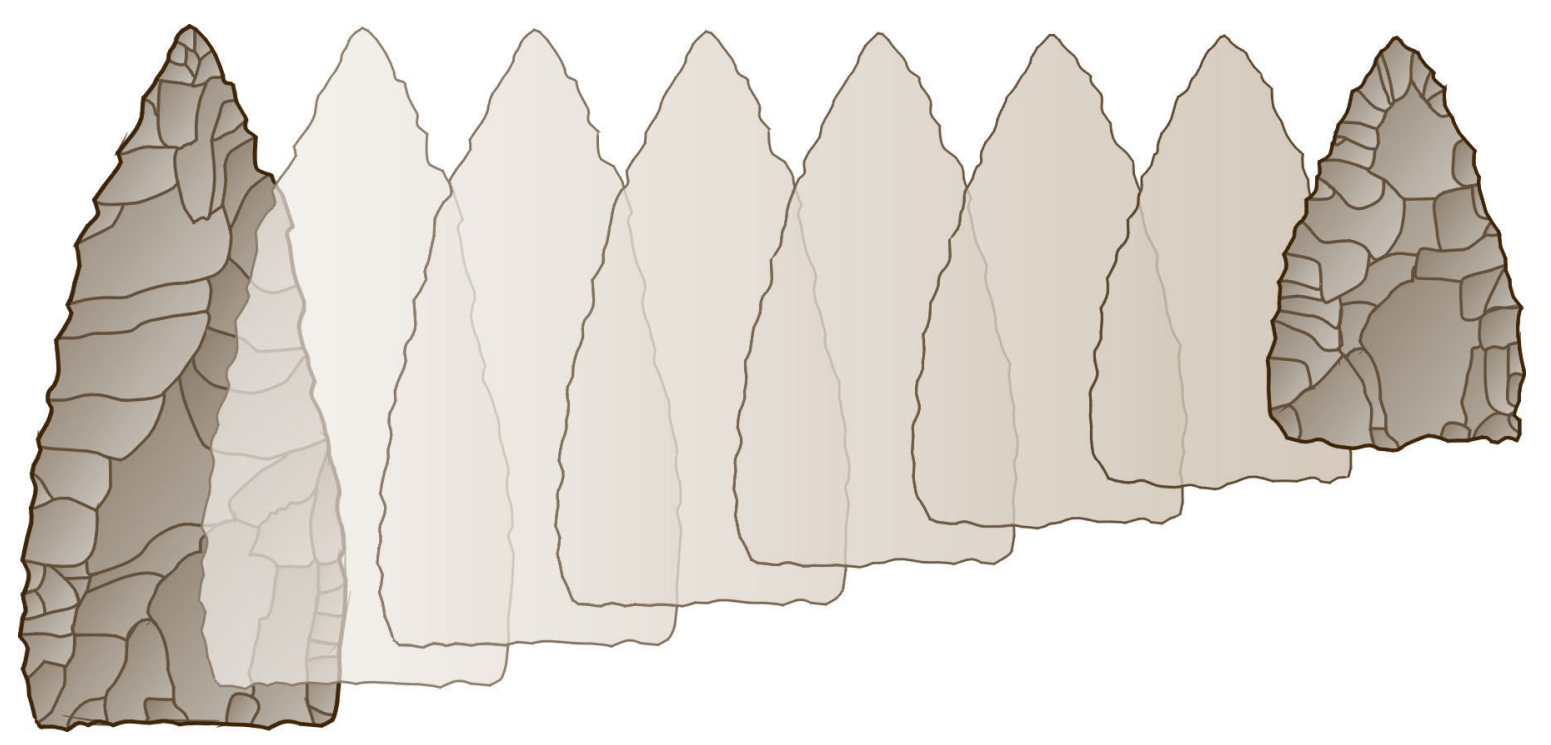

by

Richard B. Mahoney, Raymond P. Mauldin, and Steve A. Tomka

with contributions by

\section{Britt Bousman, J. Philip Dering, Mary E. Malainey,}

Kris L. Malisza, and Barbara A. Meissner

Environmental Affairs Division

Texas Department of Transportation

Archeological Studies Program, Report No. 44
Center for Archaeological Research

The University of Texas at San Antonio Archaeological Survey Report, No. 321 
ISBN: 1-930788-20-7 


\title{
Archeological Data Recovery Excavations along Becerra Creek (4IWB556), Webb County, Texas
}

\section{by \\ Richard B. Mahoney, Raymond P. Mauldin, and Steve A. Tomka}

\author{
with contributions by \\ C. Britt Bousman \\ J. Philip Dering \\ Mary E. Malainey \\ Kris L. Malisza \\ Barbara A. Meissner
}

\section{Texas Antiquities Committee Permit No. 2412 \\ Raymond P. Mauldin \\ Principal Investigator \\ and \\ Robert J. Hard \\ Former Principal Investigator}

Prepared for:

Environmental Affairs Division

Texas Department of Transportation Archeological Studies Program, Report No. 44

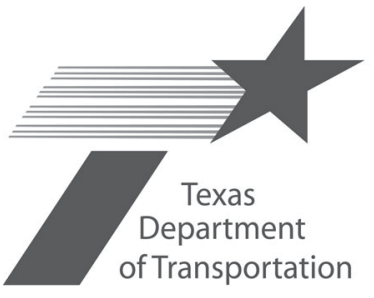

Prepared by:

Center for Archaeological Research The University of Texas at San Antonio Archaeological Survey Report, No. 321

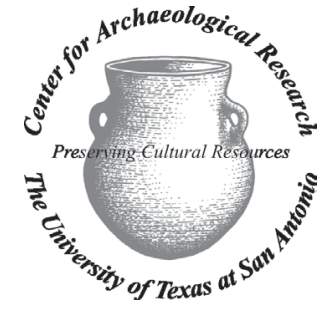




\title{
Archeological Data Recovery Excavations along Becerra Creek (41WB556), Webb County, Texas
}

\author{
Copyright ${ }^{{ }} 2002$ \\ Texas Department of Transportation (TxDOT) and Center for Archaeological Research, \\ The University of Texas at San Antonio (CAR-UTSA)
}

\section{All rights reserved}

TxDOT and CAR-UTSA jointly own all rights, title, and interest in and to all data and other information developed for this project under Contract 57-0XXPF001. Brief passages from this publication may be reproduced without permission provided that credit is given to TxDOT and CAR-UTSA. Permission to reprint an entire chapter, section, figures or tables must be obtained in advance from the Supervisor of the Archeological Studies Program, Environmental Affairs Division, Texas Department of Transportation, 125 East 11th Street, Austin, 78701. Copies of this publication have been deposited with the Texas State Library in compliance with the State Depository requirements.

Printed by Kwik Kopy Printing on Main, San Antonio, Texas

2002

jointly published by

Texas Department of Transportation

Environmental Affairs Division

Archeological Studies Program

Nancy A. Kenmotsu, Ph.D., Supervisor

Archeological Studies Program, Report No. 44

A. McGraw, Series Editor

and

Center for Archaeological Research

The University of Texas at San Antonio

Archaeological Survey Report, No. 321

Printed on acid-free, 60 lb. paper

ISBN: 1-930788-20-7 


\section{Abstract:}

From June through August 2000, The Center for Archaeological Research of The University of Texas at San Antonio conducted archeological data recovery for prehistoric site 41WB556, under contract with Texas Department of Transportation. The investigations were conducted under Texas Antiquities Permit Number 2412. The Phase III data recovery consisted of excavation of $641-\mathrm{m}^{2}$ units across the site in order to investigate significant cultural deposits encountered during the previous survey and testing phases. In concert with the archeological field investigations, the following special analyses and studies were performed to aid the determination of site integrity and chronology: geoarcheology, radiocarbon dating, lithic, lipid residue, vertebrate faunal, carbon/nitrogen isotope, macrobotanical, and magnetic soil susceptibility. The synthesis of these analyses provides substantive insights into the lifeways of the region's prehistoric hunter-gatherers. 


\section{Table of Contents:}

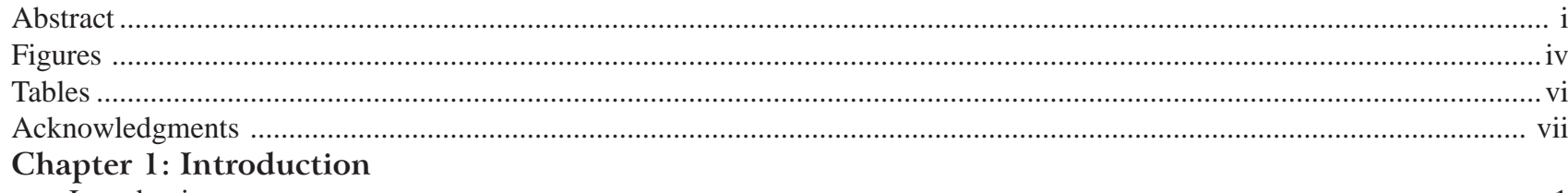

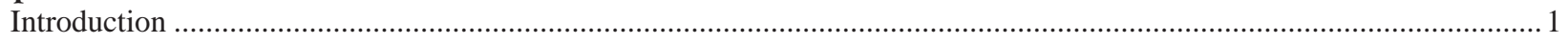

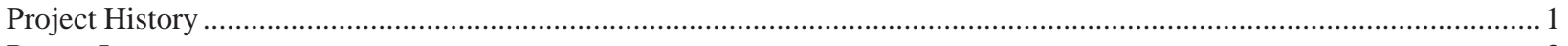

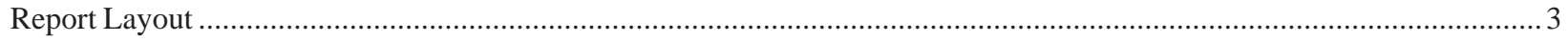

Chapter 2: Environmental Setting

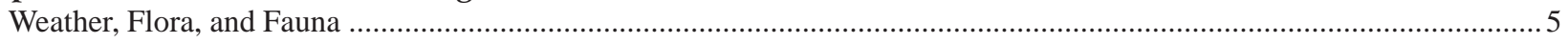

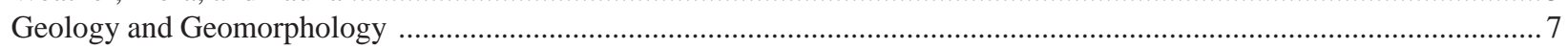

Chapter 3: Archeological Background

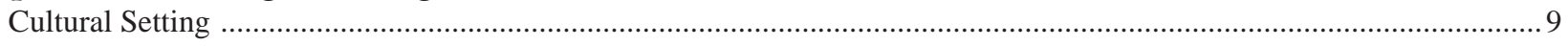

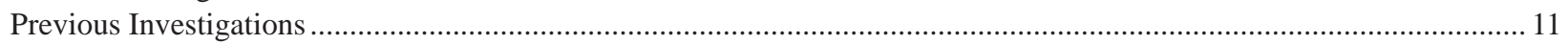

Chapter 4: Research Perspective

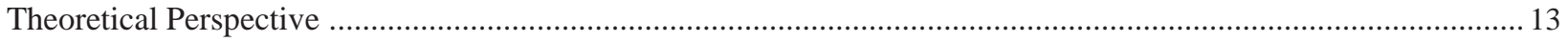

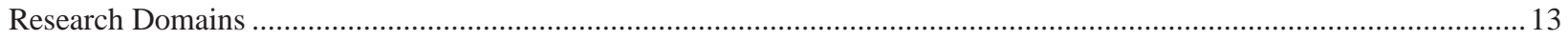

Chapter 5: Field and Laboratory Methods

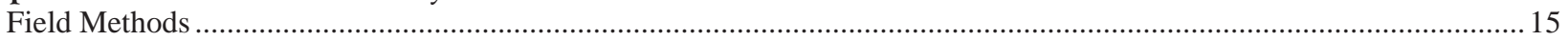

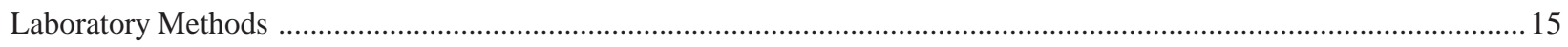

Chapter 6: Results of Investigations

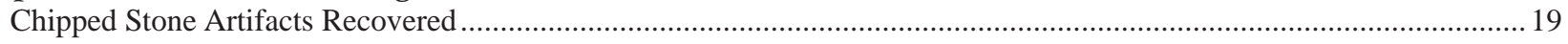

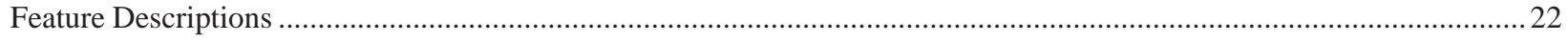

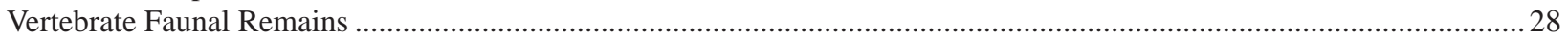

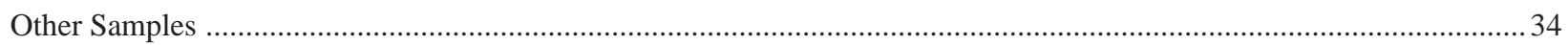

Chapter 7: Site Integrity and Chronology

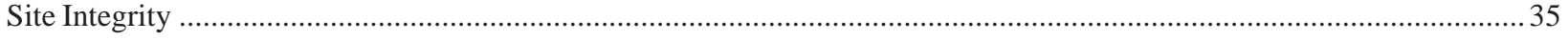

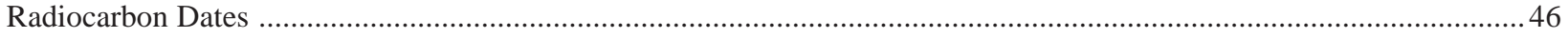

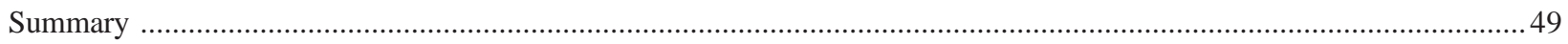

Chapter 8: Thermal Feature Technology

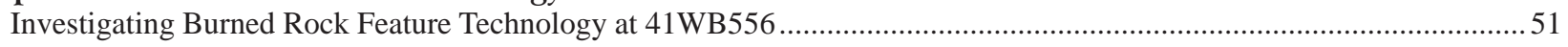

Investigating Feature Use through Isotopic and Fatty Acid Residue Analysis of Burned Rock .....................................55

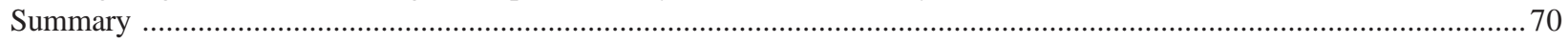

Chapter 9: Projectile Points and Beveled Tools, An Assessment of Typology and Function

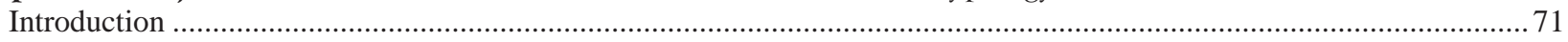

A Historical Overview and Summary of Common Projectile Point and Tool Forms ....................................................76

A Technological Analysis of Tool Forms, Designs, and Use-Life Histories ................................................................. 85

A Metric and Technological Comparison of Matamoros-Tortugas and Abasolo-Refugio-Catán Points ......................... 119

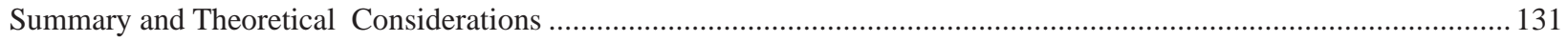

Chapter 10: Summary

Summary

References

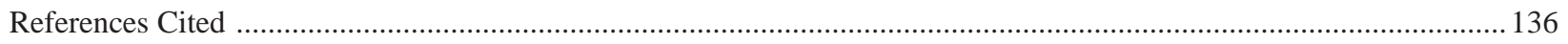

Appendix A: Limited Geomorphological Studies by C. Britt Bousman

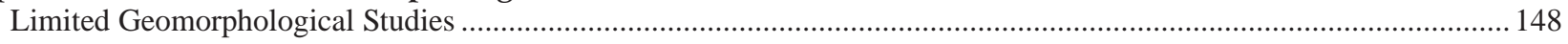

Appendix B: Radiocarbon Results

Radiocarbon Results

Appendix C: Lipid Residue Analysis by Mary E. Malainey and Kris L. Malisza

Lipid Residue Analysis .... 
Appendix D: Macrobotanical Analysis by J. Philip Dering

Macrobotanical Analysis

Appendix E: Magnetic Sediment Susceptibility by Raymond P. Mauldin

Magnetic Sediment Susceptibility ....................................................

Appendix F: Artifact and Ecofact Recovery by
Artifact and Ecofact Recovery by Unit and Level

Appendix G: Glossary of Lithic Analysis Terms

Glossary of Lithic Analysis Terms 


\section{Figures:}

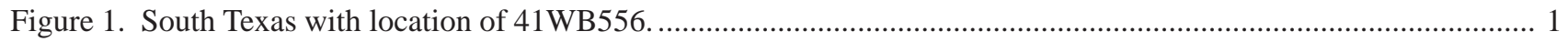

Figure 2. Regional project setting with location of 41WB556 and 41WB557.......................................................... 2

Figure 3. Project area in relationship to Natural Regions of Texas. ............................................................................ 5

Figure 4. Core area of 41WB556 with all excavation areas identified. ........................................................................ 16

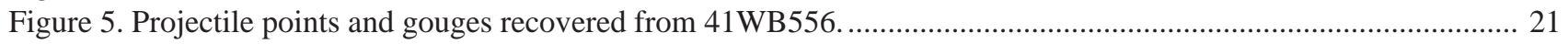

Figure 6. Distribution of features across excavation block by level. ....................................................................... 24

Figure 7. Feature 21 (N42-43/E10-11), Level 6, plan view. ............................................................................... 25

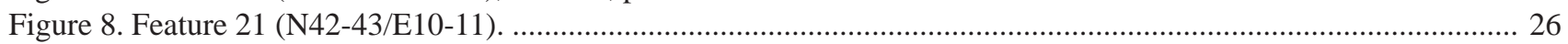

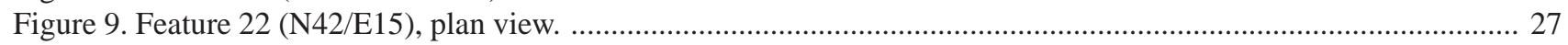

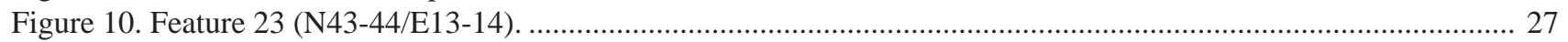

Figure 11. Profile of southern edge of excavation block (E10 through E13). ........................................................ 36

Figure 12. Profile of southern edge of excavation block (E14 through E17). ............................................................ 37

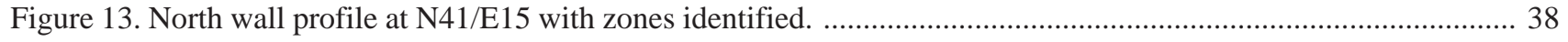

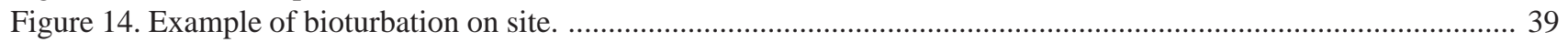

Figure 15. Plan view of N42/E14, Level 8, depicting a charcoal-lined rodent den. ..................................................... 40

Figure 16. Average number of debitage per 1-m² by level................................................................................... 41

Figure 17. Number of cortical and non-cortical flakes by level for N42/E14. .......................................................... 41

Figure 18. Number of cortical and non-cortical flakes by level for N44/E13. ......................................................... 42

Figure 19. Number of cortical and non-cortical flakes by level for N40/E17. ............................................................. 42

Figure 20. Debitage, probably from a single nodule, in Level 8, N41/E17 ........................................................... 43

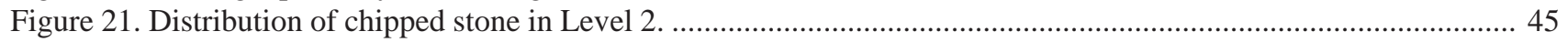

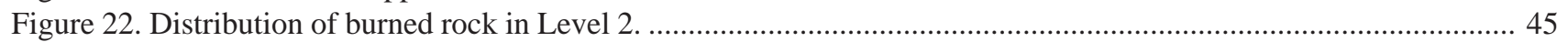

Figure 23. Radiocarbon dates from the excavation block at 41WB556.............................................................. 48

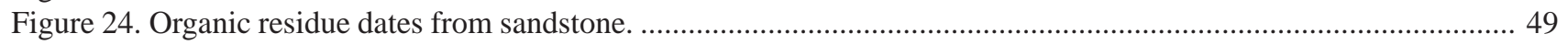

Figure 25. Scatter plot of average rock weight and number of rocks in features at 41WB556. ................................... 53

Figure 26. Fire-cracked rock weights for Feature 21 (top) and Feature 22 (bottom) at 41WB556............................... 54

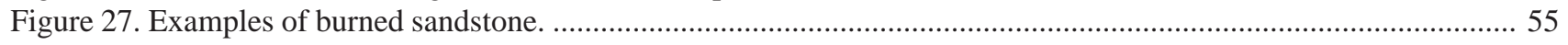

Figure 28. An idealized representation of carbon and nitrogen isotopes in terrestrial ecosystems. ............................... 57

Figure 29. Distribution of carbon isotopic values for modern and historic plants and animals in South Texas. ............... 59

Figure 30. Distribution of nitrogen isotopic values for modern and historic plants and animals in South Texas.............. 59

Figure 31. Carbon isotopic values from sandstone residue at 41BR556 overlain on modern South Texas data................ 61

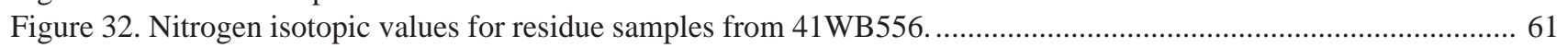

Figure 33. Carbon (top) and nitrogen (bottom) isotopic values by feature at 41WB556............................................. 62

Figure 34. Relationship between weight of nitrogen analyzed and the delta ${ }^{15} \mathrm{~N}$ value for $41 \mathrm{WB} 556$ samples. ............... 65

Figure 35. Comparison of carbon and nitrogen isotopic values of known residues from burned rock with their modern

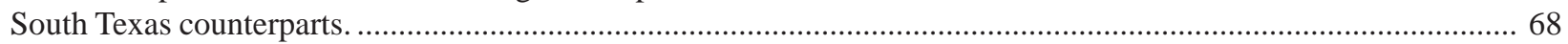

Figure 36. Comparison of delta ${ }^{13} \mathrm{C}$ values provided by two different labs on the same rock. ....................................... 69

Figure 37. List of metric projectile point attributes and their measurements. ............................................................ 72

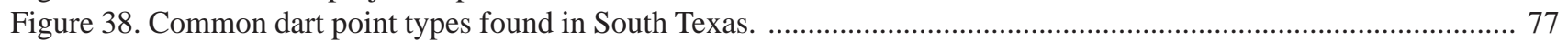

Figure 39. Distally beveled tool forms common in South Texas sites. ...................................................................... 84

Figure 40. Manufacture failed round-base projectile point blanks. ............................................................................ 92

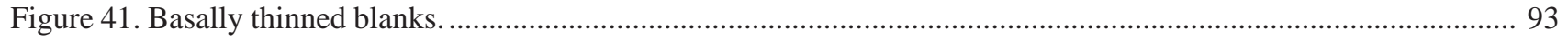

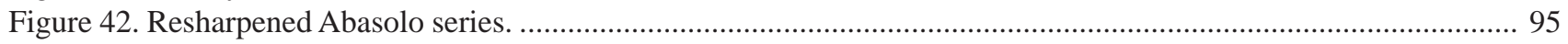

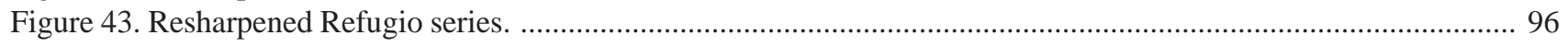

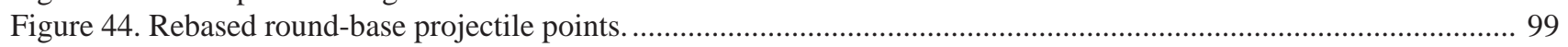

Figure 45. Partially unifacial Tortugas points made on relatively straight billet flakes. ................................................ 103

Figure 46. Manufacture failed Tortugas and Matamoros blanks. ............................................................................... 104 
Figure 47. Changes in projectile point morphology and size due to resharpening. ..................................................... 106

Figure 48. Invasive nature of beveled resharpening onto base thinning flakes. .......................................................... 107

Figure 49. Use failures and base rejuvenations on triangular projectile points. ............................................................ 109

Figure 50. Longitudinal cross-sections of triangular preforms and points. ................................................................... 110

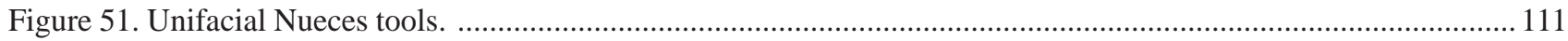

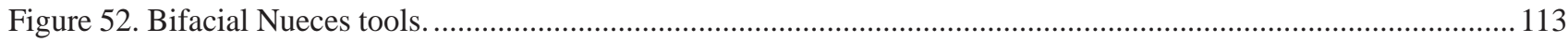

Figure 53. Olmos bifaces made on recycled projectile points. .............................................................................. 117

Figure 54. Olmos bifaces with burin scars off the corners of the working edges. ....................................................... 120

Figure 55. Maximum lengths of complete Tortugas points. .................................................................................. 122

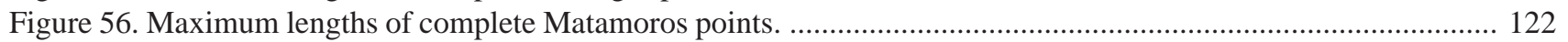

Figure 57. Maximum lengths of complete Refugio points. .................................................................................. 123

Figure 58. Maximum lengths of complete Abasolo points. .................................................................................... 123

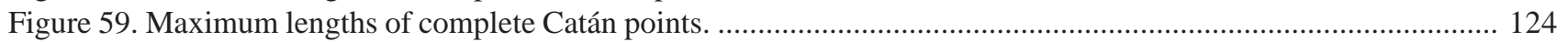

Figure 60. Maximum lengths of complete Tortugas and Matamoros points. ............................................................... 125

Figure 61. Maximum lengths of complete Abasolo, Catán, and Refugio points. ......................................................... 125

Figure 62. Maximum widths of complete Tortugas points. .................................................................................... 126

Figure 63. Maximum widths of complete Matamoros points. ................................................................................... 126

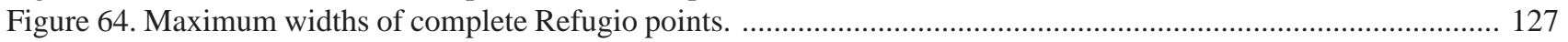

Figure 65. Maximum widths of complete Abasolo points. ..................................................................................... 128

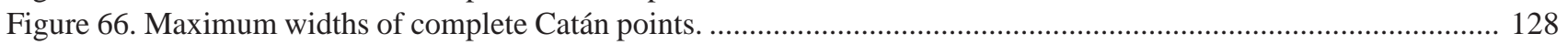

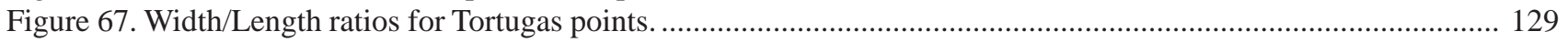

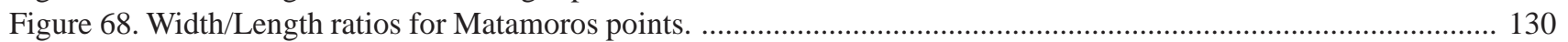

Figure A-1. Location of geomorphological column samples within excavation block............................................... 148 


\section{Tables:}

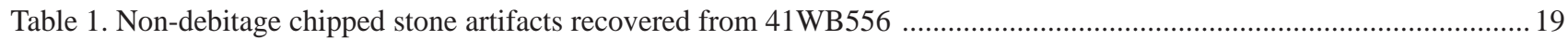

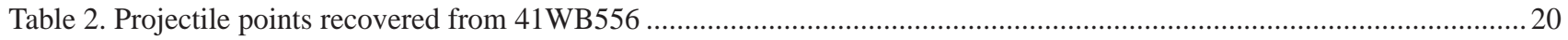

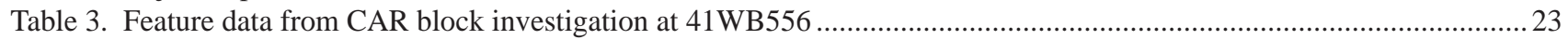

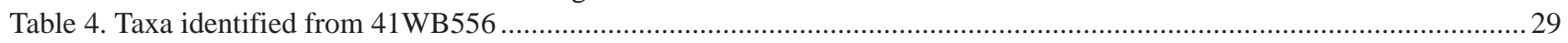

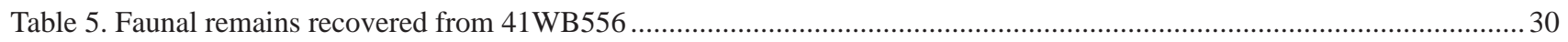

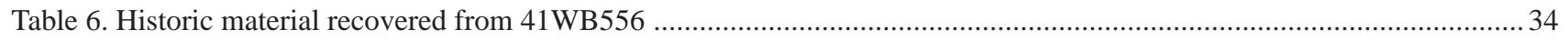

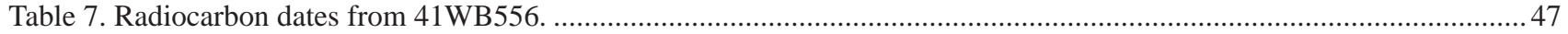

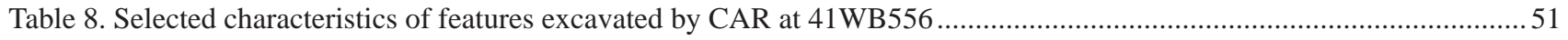

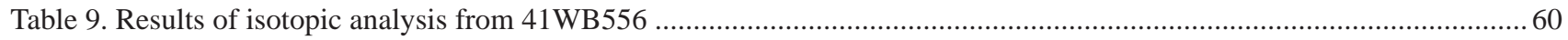

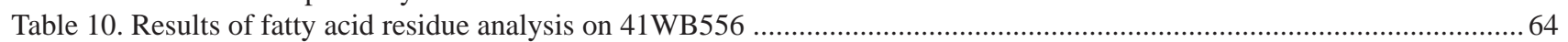

Table 11. Analysis attributes measured and recorded on projectile points analyzed for this study .......................................73

Table 12. Comprehensive list of metric and non-metric attributes employed in the study of distally beveled tool forms ........... 75

Table 13. Projectile point varieties and dimensions for the common South Texas-North Mexico types ................................78

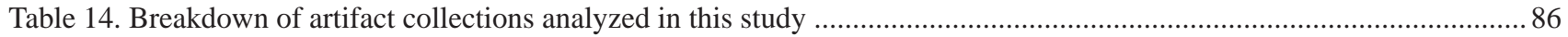

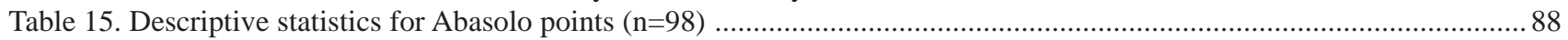

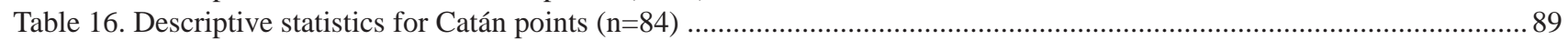

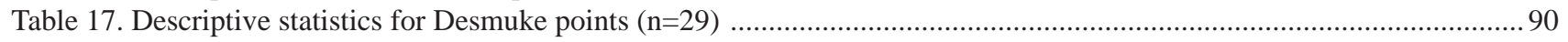

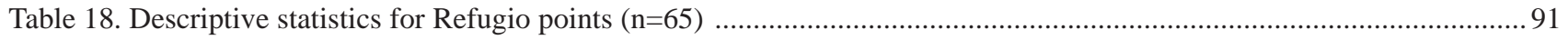

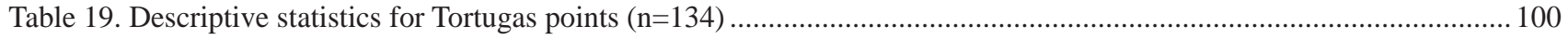

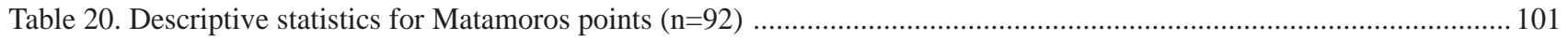

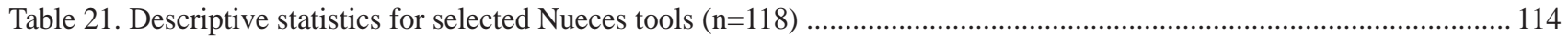

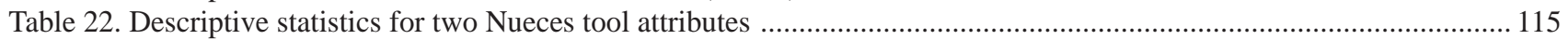

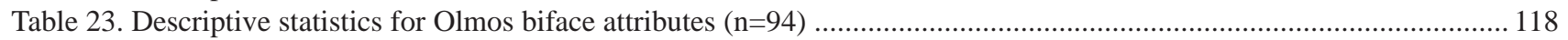

Table C-1. Summary of average fatty acid compositions of modern food groups generated by hierarchical analysis .............. 192

Table C-2. Criteria for the identification of archeological residues …....................................................................... 193

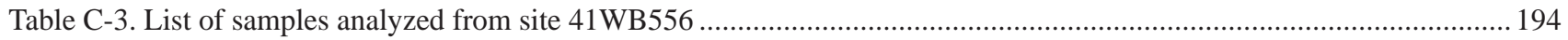

Table C-4. Fatty acid composition and identification of residues from site 41WB556 ...................................................... 198

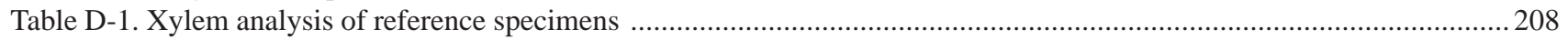

Table D-2. Identification of charred wood samples from 41WB556 and 41WB557 ....................................................210

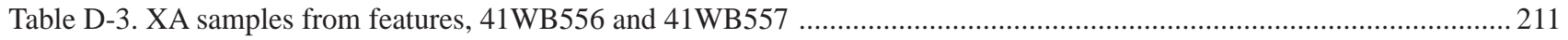

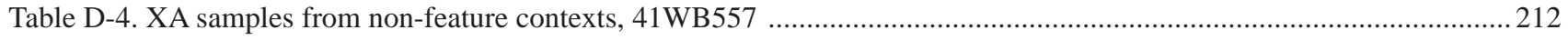

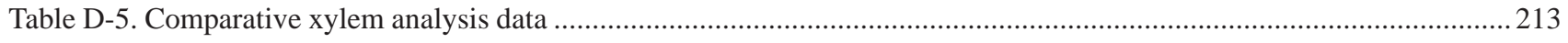

Table E-1. Magnetic sediment susceptibility data for a variety of substances .................................................................2219

Table E-2. Presence/absence of cultural material and mass specific sediment susceptibility scores for $41 \mathrm{BR} 473 \ldots \ldots \ldots \ldots \ldots . . . .220$

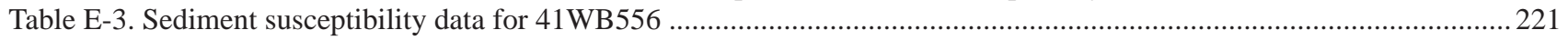

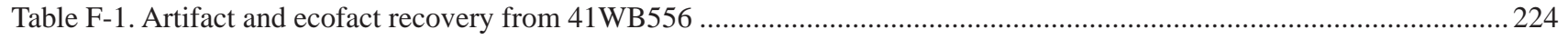




\section{Acknowledgments:}

CAR would like to thank the many employees of TxDOT who aided us during this project. In particular, we would like to thank Jim Abbott, TxDOT Geoarcheologist, and Tim Meade, TxDOT Staff Archeologist, who visited the site and contributed valuable site-related information. Melisa Montemayor, TxDOT Environmental Specialist, Laredo District, offered logistical support. We would also like to acknowledge Mr. Philippe Prevost, of Laredo, who received and fed the CAR crew during a memorable weekend and also lent us his family collection of lithic artifacts from sites on his property. Similar thanks also go out to Dr. Darrell Creel and Laura Nightengale, of the Texas Archeological Research Laboratory in Austin, for allowing us access to the Riley collection from South Texas. Both collections contributed significantly to our understanding of South Texas lithic technology. Finally, the senior author would like to thank Mike Quigg, TRC Mariah archeologist, who gave freely his valuable time and knowledge of South Texas.

Fieldwork for this project was conducted by Diane Cargill, Larkin Hood, Richard Jones, Anthony Lyle, Rich Mahoney, Preston McWhorter, Clemente Murguia, Ricky Robinson, Lisa Shaddox, and Sydney Wimbrow. Laboratory work was performed under the direction of Marybeth Tomka, CAR Collections Manager, by Carol Leezer, Barbara Meissner, Clemente Murguia, Gloria Murguia, Jennifer Neel, Pam Popejoy, Ricky Robinson, and Amy Rose. Bruce Moses and Rick Young of CAR drafted the computer-generated illustrations in the report, while Jason Weston sketched the stone tool figures. Johanna Hunziker and Maryanne King, CAR editors, were responsible for report layout. Mike Wright, CAR accountant, and Sherrilyn Suñaz and Tammy Hosek, CAR administrative staff, facilitated a much-appreciated field itinerary. 



\section{Chapter 1:}

\section{Introduction}

The Center for Archaeological Research (CAR) of The University of Texas at San Antonio was contracted by Texas Department of Transportation (TxDOT; Work Authorization No. 57017PF001 to Contract No. 570XXPF001), Austin, Texas, to conduct mitigation for a previously recorded prehistoric archeological site (41WB556). The purpose of the current excavations was to investigate a relatively dense area of stratified deposits at site 41WB556. The site is located within the right-ofway (ROW) of U.S. Highway 83, south of Laredo, in southern Webb County, Texas (Figure 1). Site 41WB556 will be impacted by the proposed expansion of U.S. Highway 83. The investigations were conducted under Texas Antiquities Permit Number 2412, with Dr. Raymond P. Mauldin and Dr. Robert J. Hard of CAR serving as Principal Investigators. Dr. C. Britt Bousman of Southwest Texas State University conducted the geomorphological studies.
Archeological site 41WB556 is located along the right descending bankline of Becerra Creek in the southwestern portion of Webb County, Texas (O'Keefe Lake, TX USGS topographic quadrangle; Figure 2). Based on previous investigations at the site (Quigg and Smith 2000), 41WB556 was thought to contain evidence of Late Archaic and Late Prehistoric occupations with some potential for stratification.

\section{Project History}

Located on gently sloping terrain on the north side of Becerra Creek, 41WB556 was identified by TxDOT during a 1999 survey (Meade et al. 1999). Seven backhoe trenches (BHT), and a single $1-\mathrm{m}^{2}$ test unit (TU), placed on the site by TxDOT, suggested the possibility that archeological deposits with some degree of stratification were present. TRC Mariah placed an additional eight backhoe trenches and excavated eleven

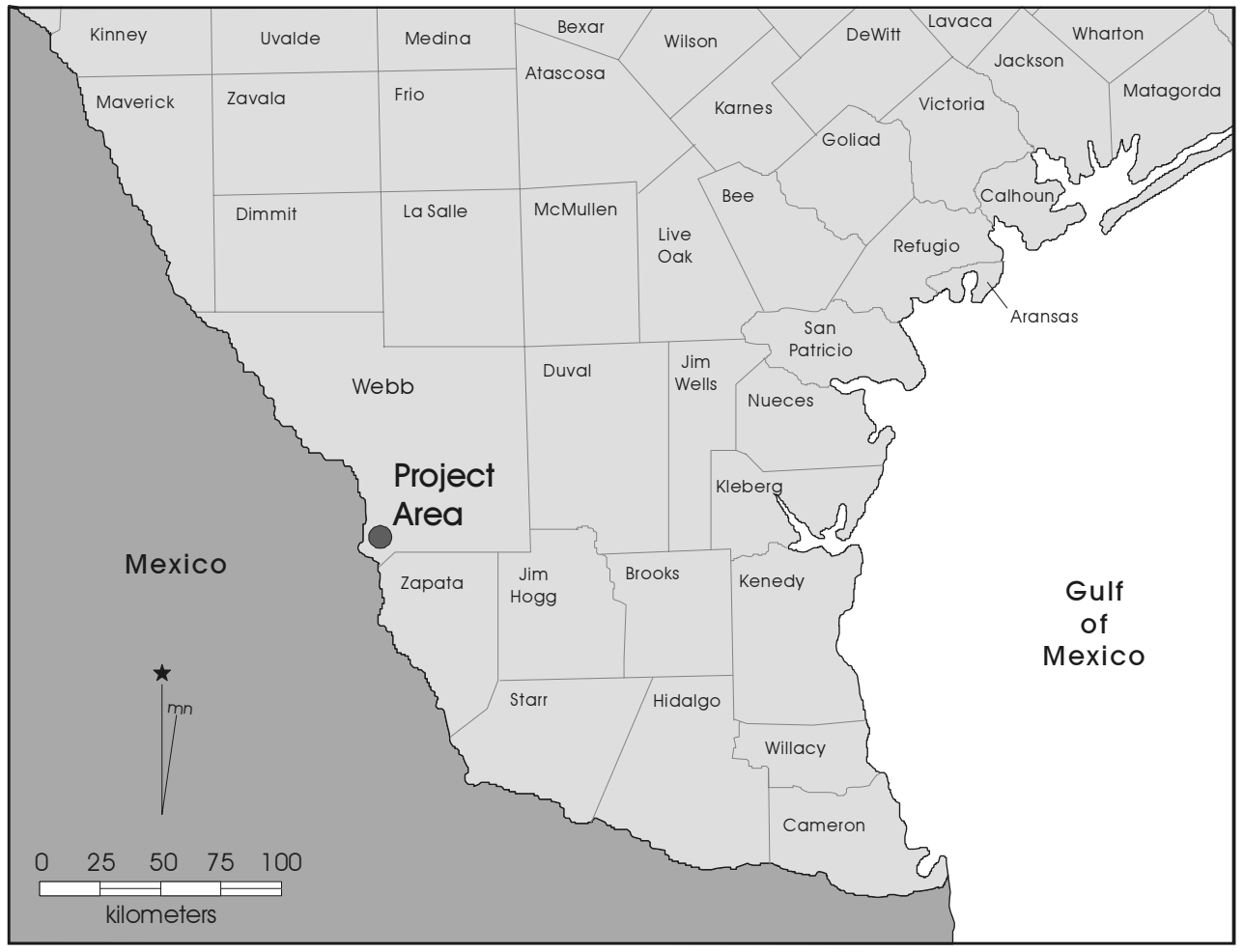

Figure 1. South Texas with location of 41WB556. 
This page has been

redacted because it

contains restricted

information. 
$1-\mathrm{m}^{2}$ test units in 41WB556 in February of 2000 (Quigg and Smith 2000).

This TRC Mariah testing, coupled with TxDOT's earlier work, revealed that sediments consist primarily of a $60-70 \mathrm{~cm}$ thick layer of alluvial and colluvial deposits, possibly with some eolian reworking. The upper units are primarily sands of both alluvial and eolian origins. These deposits probably represent a continuous depositional sequence. While insect and rodent turbation was observed in these deposits, the presence of recognizable features suggested that only minimal displacement of cultural material had occurred. A contact zone, representing alluvial deposits, is present at roughly $60-90 \mathrm{~cm}$ below the surface. The contact zone of this basal unit, a unit consisting of an indurated sandy loam, probably represents an erosional unconformity. Both lagged gravel deposits and an increase in cultural material sitting immediately atop the unit seem to support this interpretation. The lower depositional unit appears to be middle to early Holocene in age as indicated by Stage I carbonates, but an earlier age is also possible. Unfortunately, little data is available on the timing or the relationship of the cultural material to this erosional event.

The TRC Mariah testing confirmed the presence of deposits with potential significance at this site. The testing also delineated the area of greatest research potential at the site to a 70-meter by 30 -meter section. Within this area, testing demonstrated a concentration of artifacts and burned rock, with some evidence of stratified cultural deposits. Specifically, the testing data suggested that at least one cultural zone, roughly 20 to $45 \mathrm{~cm}$ below datum (bd), contains both artifacts and features. Though no chronometric dates were available, the presence of three arrow points recovered during testing suggested that this zone may represent at least one Late Prehistoric occupation. The testing results also suggested that a second cultural zone, consisting of features and artifacts, could be present at between 55 and $70 \mathrm{~cm} \mathrm{bd}$. The recovery of a Tortugas point suggests that this lower zone may be of Middle to Late Archaic age (Hester 1995; Quigg and Smith 2000).

\section{Report Layout}

This report is divided into ten chapters and contains seven appendices. Following this introductory chapter (Chapter 1), the Environmental Setting chapter (Chapter 2) briefly discusses the general physical environment of the project area. Chapter 3, Archeological Background, provides a brief overview of the prehistory and history of the region. Research Perspective, Chapter 4, describes the theoretical perspective and research domains investigated as part of this report. Chapter 5 summarizes the field and laboratory methodologies employed during the investigations and lists the special studies and analyses performed. Chapter 6, Results of Investigations, discusses the chipped stone artifacts and faunal remains recovered and describes the features identified at 41WB556. Site Integrity and Chronology, Chapter 7, combines stratigraphic information with the results of magnetic sediment susceptibility studies, artifact distribution patterns, and radiocarbon analyses of both charcoal and burned rock residue, to characterize the depositional integrity and age of the archeological deposits. Chapter 8 investigates aspects of thermal feature technology. Specifically, we investigate patterning in burned rock features, including a detailed investigation of isotopic and fatty acid residue analyses of burned rocks. Projectile Points and Beveled Tools, Chapter 9, addresses the results of the lithic analyses dealing with South Texas projectile point typology, distally beveled tool function, and the nature of regional Archaic tool assemblages. The final chapter, Summary, provides a summary of the data recovery efforts at 41WB556. Appendix A contains the geomorphologic analysis of the block excavation. Appendix B provides results of the radiometric assays. Appendix $C$ presents results of the lipid residue analysis. Appendix D presents the results of the macrobotanical studies, including a new method of rainfall reconstruction using mesquite wood charcoal. Appendix E presents the results of magnetic sediment susceptibility testing and its implications for the stratigraphic integrity of the site. Appendix $\mathrm{F}$ is the final database of artifacts and ecofacts recovered by unit and level in tabular format. Finally, Appendix G contains the glossary of selected lithic analysis terms used in Chapter 9. 



\section{Chapter 2: $\quad$ Environmental Setting}

This chapter presents a summary of the environment of the Rio Grande River Valley region to provide a background for the interpretation of prehistoric and historic human adaptations to the South Texas Brush Country vegetation region (Figure 3 ).

\section{Weather, Flora, and Fauna}

Webb County has a semi-arid subtropical climate, with warm winters and hot summers. The average winter temperature is $58^{\circ} \mathrm{F}\left(14^{\circ} \mathrm{C}\right)$ and the average summer temperature is $97^{\circ} \mathrm{F}\left(36^{\circ} \mathrm{C}\right)$. The average length of the growing season is just under 300 days a year, and the region seldom has any hard freezes. The prevailing winds are light and predominately flow from the southeast.

The primary seasonal shift appears to be related to rainfall. The average annual precipitation is 19.8 inches $(502.9 \mathrm{~mm})$, with over 60 percent of it falling between May and September (Sanders and Gabriel 1985:104). However, yearly precipitation is highly variable. The coefficient of variation in total annual precipitation in Webb County is .34 and the monthly coefficients of variation are even higher, ranging from 1.01 in April to .80 in September at Encinal, in southwest LaSalle County along the north-central Webb County border. This means that while one can depend on a particular amount of precipitation falling during a year with about a 34 percent degree of certainty, it is very unlikely that the same amount of precipitation will fall in a particular month from year to year. Much of the variability, at least in summer rainfall, is due to variability in Pacific tropical storms and Atlantic hurricanes, and droughts associated with the persistence of the anticyclone of northern Mexico (Norwine 1995). Bomar (1983) reports that Pacific storms impact the area roughly three out of five years, and Atlantic hurricanes occur roughly once every seven years. These storms, especially the Atlantic hurricanes, can deposit a tremendous amount of water over a short period of time.

The project area lies within the western Tamaulipan biotic region of South Texas, a region characterized by thorny brush, including mesquite, acacia, white brush, and prickly pear (Blair 1950). The net aboveground primary productivity $\left(\mathrm{g} / \mathrm{m}^{2} / \mathrm{yr}\right)$ derived from Owen and Schmidly (1986) indicates that Webb County has one of the lowest primary productivity levels $\left(650 \mathrm{~g} / \mathrm{m}^{2} / \mathrm{yr}\right)$ among counties in the Rio Grande Plains. Biomes with low net primary productivity have low primary biomass. More importantly, plants in vegetation communities characterized by low primary biomass (e.g., shrubs,

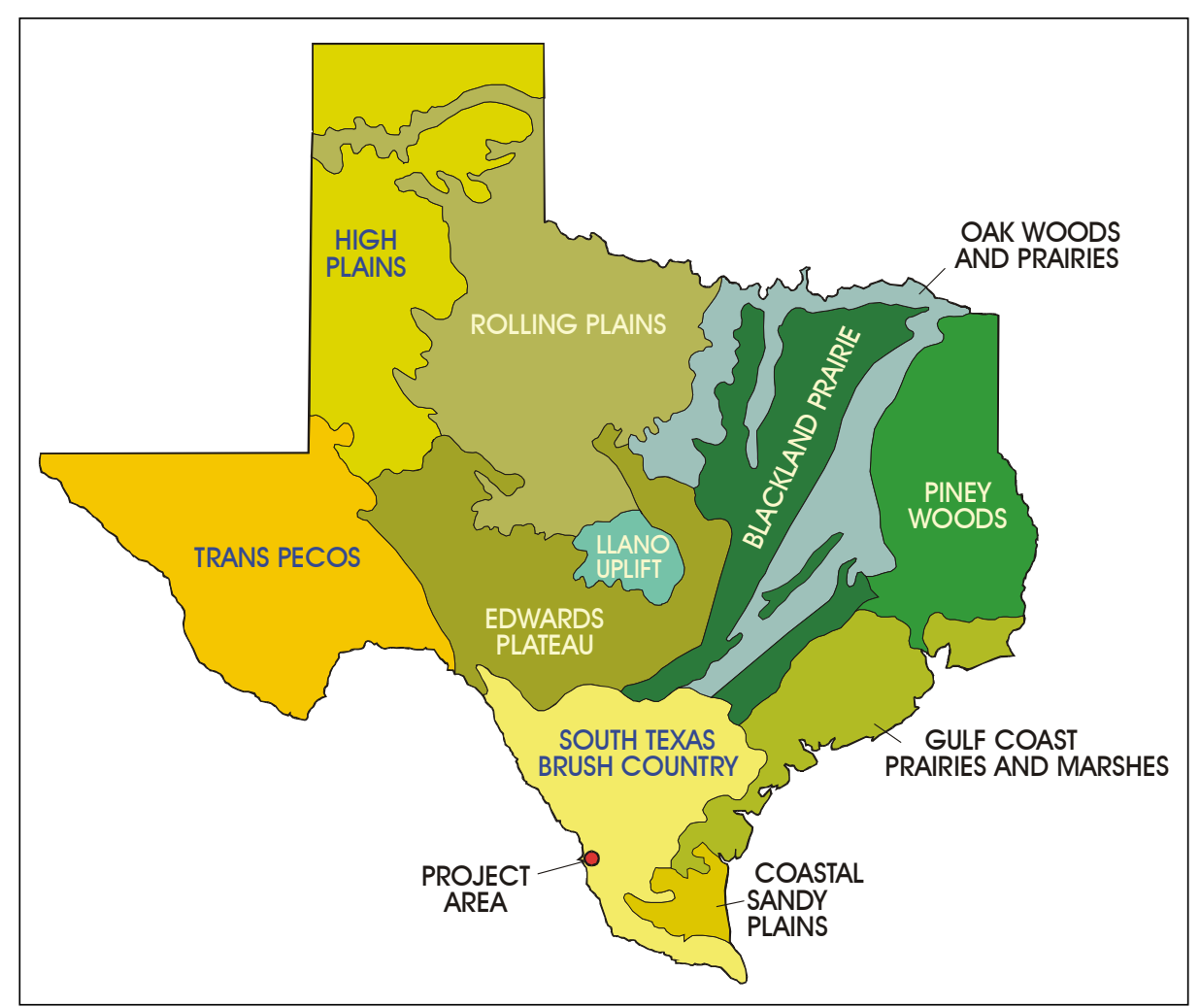

Figure 3. Project area in relationship to Natural Regions of Texas. 
grasses) tend to invest a large proportion of their energy in reproductive structures (e.g., seeds) and subsurface storage organs (e.g., roots and tubers). In addition, the secondary biomass, the fauna inhabiting these settings, tends to be of a mix of small to medium body size animals, inhabiting both terrestrial and burrowing habitats, and gregarious in spatial distribution (see Whittaker 1970).

For instance, of the 61 species of mammals found throughout the Rio Grande Plains, including Webb County, 31 (51\%) are the size of mice, rats, and pocket gophers. Hares and rabbits are also relatively common throughout the region, as are deer. The majority of the modern fauna of this region can be encountered along rural stretches of U.S. Highway 83 during dawn or dusk, either in their "natural" state or the victims of vehicular incidence. Due to human encroachment of this territory, several once abundant species, such as larger carnivores, bison, and pronghorn antelope, have been extirpated or greatly reduced in numbers. A natural area survey conducted during the mid-1970s revealed that Mexican ground squirrel, hispid pocket mice, jackrabbit, and coyote were the most abundant mammals encountered along the Rio Grande (Kennard 1976; Scudday and Scudday 1976:55). Beaver and cottontail rabbit were noted, but their presence had markedly decreased since pre-1950s accounts within the region (Scudday and Scudday 1976:55).

A review of Weniger's (1997) comprehensive digest of early Texas travelers' accounts reveals an assemblage similar to the modern biotic community, with a few notable exceptions. Carnivores noted include ocelot, cougar, jaguar, coyote, and "several varieties of wolf" throughout this stretch of the Rio Grande (Weniger 1997:63). These several varieties probably included the coyote, red wolf, and gray wolf. Accounts during the mid-1800s describe an abundance of wolves from San Antonio south to Camargo, Mexico (Weniger 1997:64). Omnivores consisted of the standard lot of javelina, badger, skunk, opossum, and prairie dog. Herbivores were composed of white-tailed deer, pronghorn antelope, bison, beaver, and rabbit.

The degree to which this modern and historic biotic community is characteristic of the Late Archaic period or even the Late Prehistoric period, the periods of occupation at 41WB556, is not clear. A variety of historic accounts of the South Texas region suggest that significant modification of the environment occurred during the historic era (Bolton 1959; Hatcher 1932; West 1905). The major changes seem to involve a dramatic increase in the frequency and distribution of mesquite (see Doughty 1983; Hall 1985), a lowering of the water table and resultant drying up of springs and creeks (Brune 1981), and significant alterations in animal density, distribution, and type (Doughty 1983).

Typical paleoenvironmental indicators, such as fossil pollen and macrobotanicals, rarely survive the archeological record in the soil types present in South Texas. Accordingly, due to the dearth of paleoenvironmental indicators for this region, prehistoric faunal resources for the area can only be extrapolated by modern presence, historic accounts, and the scant faunal remains recovered from the archeological record. Addressing the latter, a review of three previously excavated sites in close proximity (41MV120, 41WB437, and 41ZP364) reveals a total of only $4.27 \mathrm{~g}$ of recovered faunal remains from approximately $125.63 \mathrm{~m}^{3}$ of excavated material (Vierra 1998; Quigg et al. 2000; Quigg and Cordova 2000, respectively). Indeed, while the current project yielded an abundant, relative to this tricounty region, return of faunal material $(21.70 \mathrm{~g})$ from a prehistoric context (see Chapter 6), only one specimen (jackrabbit) was identifiable to the species level.

Conversely, sites located in the northern portion of South Texas within a zone characterized by numerous perennial streams, have produced truly abundant assemblages of faunal material. Excavations at Loma Sandia returned such an assemblage that only a portion thereof could feasibly be analyzed. Specifically, Area A of 41LK28 alone produced over 40,000 bone fragments (Hellier et al. 1995:803). This large data set included a diverse collection of specimens, including rabbit/hare, various rodent species, badger, skunk, pronghorn and/or deer, bird, and snake. Similarly, several of the sites included in the Choke Canyon investigations returned high counts of faunal material with comparable assemblage diversity (Hall et al. 1982:Table 35). It must be noted, though, that these sites are over $170 \mathrm{~km}$ to the northeast of site 41WB556, and comparisons over such a distance might not be applicable, nor relevant to or representative of the region of extreme South Texas. 
It is likely that the difference in archeological faunal assemblages between the more xeric southern portion of South Texas and the northern, more riverine setting is a true reflection of dramatic differences in subsistence bases between the two areas. That is, the secondary biomass resources in xeric South Texas consist primarily of small body size animals although medium and large body size animals are also present, on an intermittent basis. On the other hand, the riverine portion of South Texas is relatively abundant in secondary biomass and although some of that biomass is tree dwelling, a high proportion is terrestrial and available for consumption. Specifically, because of higher levels of mast production due to the greater density of hardwood forests, the abundance of medium-sized species, and in particular deer, would have been higher than in the more xeric portion of South Texas. Such a difference in resource structure could generate hunter-gatherer faunal assemblages with greater densities of faunal remains in the riverine zones compared to lower densities in the xeric south.

\section{Geology and Geomorphology}

The geology of Webb County consists primarily of Cenozoic formations beginning with the Paleocene Wilcox and Midway Groups in the northwest and concluding with the Miocene Goliad Formation in the southeast. Located in the upland Eocene Laredo Formation of thick sandstones and clays (Barnes 1976), 41WB556 is situated within Holocene alluvial deposits of Becerra Creek, less than $1.5 \mathrm{~km}$ from its confluence with the Rio Grande. A lens of what appears to be Pleistocene or Pliocene Uvalde gravels has been exposed along the current road cut of U.S. Highway 83.

Patches of Uvalde gravels (Reynosa Formation) blanket uplands and many of the knolls throughout the county and in combination with Quaternary terrace deposits along the Rio Grande are two of the richest chert-bearing formations in Webb County. While the Uvalde gravels tend to occur as patchy resource zones, some cherts can also be found in Tertiary-Eocene Yegua Formation (Ey) outcrops cross-cutting (N-S) the east-central portion of the county. Some cherts also are found in TertiaryPliocene Goliad Formation ( $\mathrm{Pg}$ ) outcrops occurring in the southwest corner of the county. Cherts are not found in abundance in either of these formations.
While the cherts found in these chert-bearing formations may be the same as those found farther north on the Edwards Plateau (i.e., Edwards Formation), the sizes of the pieces are much smaller and rarely does one find nodules larger than five inches in maximum dimension. In addition to cherts, the Uvalde and Rio Grande gravels and terrace deposits contain a variety of raw materials including petrified wood, chalcedony, rhyolites of various colors (e.g., black, red, and gray), and small quantities of agates and jaspers.

Although some of the streams in Webb County flowed year-round prehistorically, it is probable that the majority of them were perennial. The small perennial creeks and drainages would not have carried major gravel loads and therefore few would have offered the classic concordance of both lithic and edible resources so common in the more riverine portion of South Texas located north of the Nueces River. In combination with the widespread distribution of edible resources, this lithic landscape would have furthered the need for high rates of mobility, both in terms of number of moves and distances traveled, as an adaptive land use strategy.

Previous geomorphological observations at this site (Abbott 1999; Quigg and Smith 2000) indicate complex deposition via alluvial, colluvial, and eolian origins. Subsurface testing in the form of two series of backhoe trenches $(n=10)$ revealed the site's location along a slope grading down to a terrace along the meander of the stream. The site's proximity to the stream has afforded stratified alluvial deposition, primarily in the southern portion of the site. Colluvial deposition has taken place across the site due to its location along the slope and terrace. Eolian reworking of primarily alluvial sands was evidenced in backhoe trenches across the site (Quigg and Smith 2000).

The project area is within the West Gulf Coastal Plain section of the Coastal Plains physiographic region (Fenneman 1931). The Copita-Maverick Association of moderately deep and shallow, nearly level to gently sloping, non-saline, loamy soils comprises the area of current investigations, which generally conforms to the published soil descriptions of the various components (Sanders and Gabriel 1985). More specifically, the soil is further delineated as Copita fine sandy loam forming the upland and associated terraces along Becerra Creek 
in the immediate region, with sandy loam to sandy clay loam $\mathrm{A}, \mathrm{Bk} 1$, and $\mathrm{Bk} 2$ horizons and indurated sands to weakly cemented sandstone Crk horizon.

As Bousman discusses in Appendix A, a single buried A horizon was noted in samples recovered from the excavation block. Most sediment examined can be classified as sandy loam with slightly more silt in a few isolated samples. The distinguishing characteristics of the buried A horizon, though, were a darker color and friable sandy loam with firmer sediments below the buried A horizon. Calcium carbonate nodules were not noted in the samples, however, fine calcium carbonate filaments were encountered below the buried A horizon during manual excavation. 


\section{Chapter 3: $\quad$ Archeological Background}

This chapter presents a brief overview of the aboriginal cultural setting of South Texas relative to the project area and a synopsis of previous archeological investigations conducted in Webb County and the surrounding area. These summaries are based, in part, on more comprehensive reviews of cultural chronologies and archeological investigations found in Black (1989), Hester (1995), Tomka et al. (1997), and Vierra (1998).

\section{Cultural Setting}

The cultural setting of Webb County is discussed relative to the chronology exhibited by the radiocarbon dates recovered from in situ features excavated at 41WB556. This discussion begins with the Middle Archaic and continues through the Late Prehistoric for South Texas as defined by Hester (1978). It should be noted that while the chronology for Central Texas is more complete, has a finer resolution, and is based upon robust data, little is known of the coeval paleoenvironment of extreme South Texas. Consequently, comparisons regarding adaptation to such a dissimilar environmental setting as the Rio Grande Plain (Black 1989:39) would be speculative, at best. With this in mind, limited inferences will be drawn from previously investigated sites located within the southern Central Texas and the northern South Texas archeological regions.

Predominantly triangular projectile points, an increase in the diversity of stone tools, and promulgation of burned rock features distinguish the Middle Archaic from earlier periods. The paucity of paleoenvironmental indicators such as charred plant remains, fossil pollen, and other macrobotanicals has left primarily the lithic artifact classes to interpret this interval of the Archaic era of the Rio Grande Plain.

One notable exception, however, is the encounter of over 200 burials with associated grave goods at the Loma Sandia site (41LK28) in Live Oak County (Taylor and Highley 1995). Located atop an upland landform adjacent Hackberry Creek, a tributary of the Frio River, the site provides a glimpse into the mortuary practices of the peoples of the Middle Archaic in South Texas few other sites offer. Prior to these extensive excavations, very limited data regarding true cemeteries existed for the region as a whole (Steele and Olive 1989), and certainly so for extreme South Texas. Steele and Olive (1989:Table 3 ) note that only one prehistoric burial site (41WB58) has been encountered in Webb County. A review of the Texas Archeological Sites Atlas, though, indicates evidence of a "possible cremation" and not a true burial. The remains were, however, associated with the prehistoric component of the multicomponent site 41WB58.

Hester (1995:438) cites the presence of Tortugas, Abasolo, and Carrizo dart points as "region-specific" and temporally diagnostic indicators of the South Texas Middle Archaic. Indeed, roughly 82 percent of the typeable dart point assemblage recovered from 41WB556 consists of Tortugas and Abasolo type specimens (see Chapter 9). Refugio type specimens comprise the balance of the typeable dart point assemblage.

Scrapers, gouges, choppers, and wedges round out the formal stone tool forms typically recovered. The variety of this collection suggests subsistence and adaptation diverse from the mobile bands of the Early Archaic of South Texas (Hester 1995:436). Black (1989:51) proposes that this shift in strategy may have been central in the inferred population increase during this time. Excavations at Choke Canyon (Hall et al. 1986:402) have recovered macrobotanical remains of mesquite and acacia in association with burned rock features and grinding tools, suggesting a greater reliance on vegetation. Further, Holloway (1986:448) suggests a stable environment, consistent with modern taxa, to at least 6000 вр. The majority of the gouges show use-wear consistent with woodworking and/or possible vegetation resource procurement. With the encounter of numerous hearths during the Choke Canyon investigations, Hall et al. (1986) similarly suggest an increased dependence on vegetation resources, including the aforementioned mesquite and acacia. Following Holloway's conclusions, a diverse array of succulents, semi-succulents and legumes may have similarly been available during the Middle Archaic of Webb County. 
The transition from the Middle Archaic to the Late Archaic witnesses an increase in site densities, a proliferation of burned rock features, and a shift to generally smaller projectile points (see, however, Chapter 9). Paleoenvironmental indicators in the form of charred plant remains and faunal material become more visible in the archeological record. Small vertebrates, such as rodent, rabbit/hare, reptile, and fish comprise the majority of the Late Archaic faunal assemblage of recovered materials from the Choke Canyon investigations (Hall et al. 1982:471). Focus on these smaller faunal resources suggests more xeric conditions during this time, with larger mammals either migrating from the region and/ or, albeit in smaller numbers, relegated to the less abundant riparian zones within South Texas.

Radiocarbon assays from Late Archaic sites in the Choke Canyon project verify the increase in site densities during this time. Of note are the 44 sites containing evidence of Late Archaic occupation recorded during the Choke Canyon investigations (Hall et al. 1986:400). It is conceivable then, that an increase in burned rock features during this time is attributable to an increasing reliance on the consumption of xeric-adapted plant species such as sotol, agave, and prickly pear.

Lithic technology appears to be the greatest division between the Middle and Late Archaic periods. In the northern portion of South Texas, small side-notched and corner-notched dart points such as Ensor and Fairland types are index markers of the Late Archaic at the Choke Canyon sites (Hall et al. 1982:465). These dart points, along with the Frio type, form the Ensor-Frio-Fairland component of Central Texas. Collins (1995:384, Table 2) considers these three point types contemporaneous and, together as a point style interval, as constituting one of the later intervals of the Late Archaic period for Central Texas. At the Panther Springs Creek site (41BX228), 41BX300, 41BX1, and the Cibolo Creek Crossing site (41BX377) these point types have been excavated in similar contexts with good integrity (Black and McGraw 1985; Katz 1987; Lukowski 1988; Kibler and Scott 2000, respectively). The Ensor-Frio-Fairland component straddles the latter part of the Uvalde Phase and is a portion of the representative artifact assemblage of the succeeding Twin Sisters Phase in Central Texas (Prewitt 1981:81).
However, given the dramatically different resource base characteristic of the southern part of South Texas (i.e., south of the Nueces River), the distinctiveness of the material culture (e.g., dominance of triangular and subtriangular points, distally beveled tool forms), and the greater affinities with cultural manifestations found in northern Tamaulipas, one may question the validity of reconstructing the prehistory of this xeric portion of South Texas through the perspective of Central Texas chronologies and adaptations. Regional-scale analyses of material culture (e.g., projectile points and burial goods; Tomka et al. 1997) and burial practices (see also Perttula 2001) suggest that a cultural boundary may have existed prehistorically, separating much of the northern riverine portion of South Texas from the more xeric southern portion which extended into northern Mexico.

In the more xeric portion of South Texas, the cornernotched projectile points that are temporal markers of the Late Archaic are scarce and appear to be replaced by triangular and subtriangular forms that are smaller versions of the common, apparently Middle Archaic, forms (Hester 1995:442). The Matamoros and Catán points that appear to be common during the Late/ Transitional Archaic are similar to the Tortugas and Abasolo forms present during the Middle Archaic. A similar pattern of decreasing projectile point size appears to have occurred in Tamaulipas as well (MacNeish 1958). The validity of this seeming trend, and the typological distinction between these morphologically similar large and small forms will be discussed in Chapter 9 .

The Late Prehistoric in South Texas has been likened to the same chronology in Central Texas (Black 1989:52), sharing similar delineations of the Austin and Toyah intervals. Transition from the Late Archaic to the Late Prehistoric is arguably accepted to occur with the change in hunting techniques and weapons technology from the atlatl and dart to the bow and arrow. It is likely, however, that this shift was not a wholesale change but rather a gradual incorporation of both technologies as complementary elements of the day-to-day hunting practices. Hester (1995:443) notes, for instance, that smaller dart points such as Matamoros and Catán have been recovered in Late Prehistoric contexts and these finds may be indicative or either the contemporaneity of the 
two methods or of the actual shift from the atlatl to the bow and arrow. Hester (1995) further suggests the existence of a true Transitional Archaic for South Texas, with Late Archaic dart point types such as Frio and Ensor carrying over well into the Austin interval. The Transitional Archaic for this region of Texas would be generally coeval with the Austin interval, and, as suggested at recent investigations at 41BX1421 (Mahoney 2002), may have actually subsumed the entire interval.

For Central Texas, Prewitt (1981:Figure 3) identifies the initial Late Prehistoric interval as the Austin interval, occurring from the termination of the Late Archaic II until approximately $650 \mathrm{BP}$. Aside from the aforementioned changes in technology, Prewitt ascribes only a slight increase in the dependence upon hunting as a means of subsistence and a marked increase in the occurrence of "true cemeteries" as an indicator of period change (Prewitt 1981:74). Edwards and Scallorn arrow points are representative artifacts associated with this interval.

The relatively short-lived Toyah interval, as defined by Prewitt (1981), is characterized by the "dramatic" shift in subsistence from hunter-gatherer to that of an economy based primarily upon hunting. According to data from Dillehay (1974), bison once again reappear in the faunal assemblage of archeological sites within Central Texas. An intermediate shift to a generally wetter, mesic, environment is attributed to this increase in ungulate dependence (Johnson 1995). The material culture of this time period appears to reflect subsistence based on the procurement of bison in the form of various stone tools utilized for bison procurement and processing, such as Perdiz arrow points, along with various scrapers and other stone tools.

\section{Previous Investigations}

A number of authors (e.g., Black 1989; Hester 1995; Quigg and Cordova 2000, Quigg et al. 2000) provide introductions and background to the archeology of extreme South Texas. Professional archeology within the region began with investigations associated with the construction of Falcon Reservoir along the Rio Grande in the 1950s (e.g., Hartle and Stephenson 1951). Sparse development throughout the majority of South Texas south of San Antonio obviated extensive professional investigations for the following two decades. However, beginning in the 1970s, a number of larger survey projects were conducted in the region, including a series of surveys supplemented by testing at Choke Canyon Reservoir along the Frio River in Live Oak and McMullen counties (e.g., Brown et al. 1982; Hall et al. 1982, 1986). Similarly, the development of Interstate Highway 37 connecting San Antonio and Corpus Christi necessitated and brought about the archeological investigations carried out at Loma Sandia (41LK28; Taylor and Highley 1995). In addition to these larger projects, some significance testing and numerous surveys also have been conducted throughout Webb County (see Warren 1986, 1989a, 1989b, 1992a, 1992b). These surveys have contributed significantly to document lowvisibility archeological sites often consisting of no more than sparse scatters of lithic debris and they have also provided important regional-scale information on prehistoric land use (Warren 1989a, 1989b).

Aside from these projects, intensive investigations did not begin to proliferate in South Texas until the late-1980s and early-1990s. According to the Texas Archeological Sites Atlas, professional surveys did not begin in Webb County until the 1970s, only two testing projects and one mitigation project were conducted during the 1980s (SDHPT 1981; Bement and Rowan 1988; and McReynolds 1981, respectively), and eleven testing projects and two mitigation projects (Miller et al. 2000; Quigg et al. 2000) were conducted during the 1990s.

One of the earliest testing projects in the county was the work conducted by Texas Department of Transportation archeologists at 41WB206, a low-density archeological site in the development area of the Laredo-Colombia Solidarity International Bridge (McGraw and Thompson 1998). The testing uncovered a light scatter of surface artifacts and prehistoric materials buried to a depth of three meters within the upper river terrace. The materials consisted of fire-cracked rocks, lithic debris, and mussel shells. Humate dates suggested that the deposits ranged from 3350 в.с. to the fifteenth century A.D. The subsurface deposits were poorly stratified and the density of materials and their lack of stratification severely limited research potential. 
With the exception of McReynolds' 1981 emergency exhumation project at the Laredo Cemetery Site (41WB22 - historic), TRC Mariah's excavation of the Lino Site (41WB437) was the first Data Recovery project conducted in Webb County (Quigg et al. 2000). SWCA's mitigation of 41WB314, part of the 22-mile Camino Colombia Toll Road investigations (Miller et al. 2000), comprises the only other data recovery effort conducted in Webb County prior to the current project. At the same time TRC tested site 41WB556, on the south banks of Becerra Creek they tested and later mitigated 41WB557. Results of the data recovery work conducted at 41WB557 was published (Quigg et al. 2002) as the authors were revising this report. Where feasible, conclusions from the 41WB557 data recovery report were incorporated into the present report. As of the publication of this report, at least 90 professional archeological investigations have been conducted in Webb County (Texas Archeological Sites Atlas).

Both data recovery projects represent important contributions to the prehistory of Webb County, particularly because they help to anchor in time the common South Texas projectile point types. As briefly summarized below, these data recovery projects, in combination with other works in the region, provide important dated contexts in a region that is sadly devoid of deeply stratified sites that could help build the regionspecific chronological framework. For instance, the 41WB314 excavations identified two Tortugas point manufacture features and dated them to $2740 \pm 50$ BP (Miller et al. 2000:67). At the Lino site (41WB437), Quigg et al. (2000:Figure 13.1) recovered two Refugio points in Occupation 5, dating roughly to 3,260-3,400 years ago. A second Refugio point came from Occupation 3 , dated to roughly 2,700 years ago, and in association with Tortugas points, suggesting either continued use, contemporaneity, recycling, or some degree of mixing of deposits. Tortugas points at 41WB437 appear as early as 3,000 years ago (Occupation 4) and continue until 2,000 years before the present (Occupation 1). Feature 111 at the Loma Sandia site, a small cluster of mortuary items (Taylor and Highley 1995), also yielded two Tortugas points in association with a Refugio point. Associated charcoal dates suggest an age range of between 2,400-2,800 years before the present for the feature. A well-defined Tortugas occupation at 41SR42 (Hartle and Stephenson 1951) was charcoal dated to
4,650 \pm 300 years ago (see Suhm et al. 1954:565), while at 41ZP364, Quigg and Cordova (2000:123) obtained dates ranging between 3900-5100 BP for Occupation 3, containing a single Tortugas point. At the same site, Occupation 2, containing a single Matamoros point, appears to date roughly to $2550 \mathrm{BP}$ (Quigg and Cordova 2000:123). At site 41LK67 in the Choke Canyon project, three triangular Tortugas points were recovered (see Brown et al. 1982:Figure 11, p-r) in deposits dating to between 2,750-2,350 years ago (Hall et al. 1982:309). A Matamoros point was also recovered from the same deposits (Brown et al. 1982:49-50, Figure 11, t). Within the Choke Canyon sites, unstemmed triangular points similar to the Tortugas type appear to have been most common between roughly 4450-2350 BP (Hall et al. 1986:399). At Loma Sandia, a number of burials and/or associated features seem to contain what appear to be both Tortugas and Matamoros points. These features seem to date to the period between 2400-2800 BP. At 41WB314, a discrete Tortugas reduction station was dated to $2740 \pm 60$ вP (Miller et al. 2000:67).

In summary, in spite of the large number of recorded sites in the county, and an increase in survey and excavation projects within the South Texas region, surprisingly little is known regarding the prehistory of Webb County. While a review of the Webb County data in the Texas Archeological Sites Atlas in November of 2000 suggests that over 500 sites have been recorded, 209 of these have numbers assigned, but lack site forms and 66 have questionable data. More important, for our understanding of the prehistory of the region, is the low number of excavated sites, especially for certain time periods. For example, while Archaic sites in the region have been investigated by several authors (e.g., Quigg and Cordova 2000; Quigg and Smith 2000; Quigg et al. 2000; Quigg et al. 2002), there is a surprising lack of information on Late Prehistoric use of the area. No excavated Late Prehistoric sites could be located for Webb County, and what is known about the adaptation is surmised from surrounding regions. 


\section{Chapter 4: Research Perspective}

This chapter briefly outlines the research perspective that has guided the analytical procedures and data collection at site 41WB556. A number of issues are addressed, including the general theoretical basis for interpretation of the archeological record. This is followed by the identification of three research domains investigated with data from 41WB556 in subsequent chapters. These research domains are 1) site integrity and chronology, 2) feature technology, and 3) lithic technology.

\section{Theoretical Perspective}

At a general level, our interpretive scheme comes, in part, from a theoretical background that can be classified as cultural ecology. We view cultural systems as adaptive and differentiated. By adaptive we mean that cultural systems are continually responding to changes in the natural and social realms, including changes that are a product of their own actions. Of particular concern in this regard are the strategies and tactics used to acquire food, fuel, and raw material resources from the environment. By differentiated, we mean that different activities are conducted at different times and places depending on specific circumstance. That is, the activities conducted at a location may vary considerably depending on a variety of specific circumstances, and the material remains left by those activities at a location will also vary. Consequently, individuals operating within the same cultural system may generate radically different material cultural remains.

Changes in cultural systems are, under this position, the result of changing parameters in the natural and social environments. Currently, our understanding of the mechanisms of change in the societal realm are not as well-developed as our understanding of the impact of changes in the natural realm. Especially critical in the latter arena are strategies and tactics related to energy capture, including technology, mobility, and settlement strategies used in resource acquisition. It is in this realm, where cultural systems interact with the paleoenvironment, that extant adaptive strategies are molded and constantly modified. We see changes in those strategies as a result, to a large degree, of interactions at this cultural and natural interface.
We suggest that the archeological record is a current, static phenomenon rather than a fossilized record of past cultural adaptations. That is, the archeological record contains no direct data on the dynamics of past behavior. The record simply consists of artifacts and features spread across the landscape at varying densities. While the artifacts and features were, by definition, created by people at points in the past, a variety of processes have impacted those artifacts and features. These processes include natural and cultural alterations that interact to produce the current record. Researchers then observe that record and interpret that record using a series of conventions. From our perspective, the goal of archeology is to understand those processes that both create the archeological record and shape our interpretations of that record. These processes include culturally organized behavior, taphonomic processes, methodological decisions, and the conceptual schemes used by archeologists. We are competent at understanding some of these processes, yet there are certainly others that we have not even recognized.

This conception of the archeological record has many implications. One of the critical implications for the current project has to do with the value of archeological deposits. From our perspective, the value of any given archeological deposit is dependent on the research questions asked rather than on any absolute qualities of a site as such. Because archeological deposits possess unique formation histories and characteristics, they provide individual opportunities for improving both our knowledge of the past as well as understanding the implications of our methodological and interpretive decisions. Sites that have mixed deposits, such as 41WB556, can still provide important insights, though the data may be applicable to a more narrow range of research domains or applicable at a scale other than the individual site.

\section{Research Domains}

In the research design associated with the Data Recovery Plan for 41WB556 (Quigg and Smith 2000) and as summarized in the CAR Interim Report (Mahoney et al. 2000), a series of broad research questions were proposed 
to document baseline chronological and paleoenvironmental conditions and investigate adaptive strategies as manifested in subsistence, technology, and site structure. However, following the fieldwork and during the preparation of the interim report (Mahoney et al. 2000), it became evident that several of the analyses proposed in the Data Recovery Plan for the site were unlikely to yield significant information. These primarily involved research domains centered on areas of investigations that relied on high artifact and feature integrity.

Given our preliminary assessment, we reoriented our investigation to focus on three research domains. The first of these considers issues related to the integrity and chronology of the site. Using a variety of data sets, we will argue that aspects of the assemblage at 41WB556, specifically some portion of the chipped stone assemblage, charcoal, and matrix within features, have been mixed. As such, the utility of these data sets for addressing specific site questions has been reduced. We will also argue that thermal features at the site, which primarily consist of concentrations of burned sandstone, have not been dramatically impacted by turbation. This data set forms the basis for our second research domain, a focus on thermal feature technology. Finally, a segment of the turbated chipped stone tool assemblage from 41WB556 is used in the third research domain, the investigation of lithic technology. First, we construct a projectile point analysis protocol system applicable to commonly found regional point types. Using the protocol, we investigate technological and typological aspects of the projectile points. Finally, using a larger regional sample augmented by the 41WB556 specimens, we also investigate the functional aspects of distally beveled tools common in South Texas. That is, this research domain uses aspects of the 41WB556 data to investigate lithic technology at a larger spatial scale. At this scale, the turbated nature of this component of the 41WB556 data has little relevance to the questions investigated.

A number of specific data types and special analyses were carried out within each of these three research areas. Our investigation and documentation of site integrity and chronology, presented in Chapter 7, relies on the distribution of various artifact categories (e.g., historic and modern artifacts, unmodified lithic debitage, temporally sensitive projectile point types) within the excavated block, as well as the results of special analyses including descriptions of site stratigraphy and geomorphology, investigations of potential patterns in magnetic sediment susceptibility, and selected radiocarbon dating of both charcoal and residues in burned sandstone.

The investigation of feature technology, presented in Chapter 8, is concerned with developing an understanding of how these features were used, including what materials were processed using these features. Here, we cannot rely on traditional methods, such as macrobotanical analysis of sediment collected from features, as some unknown component of matrix is likely to have been disturbed. Rather, we employ several recently developed methods that rely on organic residue potentially present in burned sandstone. Specifically, we use the analysis of fatty acids (lipids) and carbon and nitrogen isotopes from residues extracted from burned rock to investigate thermal feature technology.

The investigation of lithic technology, presented in Chapter 9, is concerned with constructing a projectile point analysis protocol system and investigating functional aspects of selected tool forms. Using data from 41WB556 in conjunction with three other collections from South Texas sites, we focus on a number of metric and nominal attributes to develop an analysis protocol that will allow a more consistent definition and characterization of projectile point types. We also investigate the morphological and/or technological relationships between various point forms to establish whether they represent valid chronological markers. Finally, we investigate a variety of distally beveled tools, variously known as Dimmit scrapers, unifacial and bifacial Nueces tools, and Olmos bifaces, using both metric and nominal attributes. Macroscopic and lowpower micro-wear analyses, conducted on selected distally beveled tools, and comparisons with replicated tools used in a series of known tasks, were employed to aid the functional identification of these South Texas tool forms. 


\section{Chapter 5: $\quad$ Field and Laboratory Methods}

The initial section of this chapter summarizes the field methods used during our work at 41WB556. A section that summarizes laboratory procedures and identifies the principal individuals and institutions that conducted specialized analyses closes this chapter.

\section{Field Methods}

Based upon previous testing results, a single $64-\mathrm{m}^{2}$ excavation block was located within the central portion of 41WB556, the area that exhibited apparent stratified cultural deposits. The block was situated between Backhoe Trench 1 (BHT 1) and associated Test Unit 1 (TU 1), excavated during the initial survey, and BHT 14 and associated TU 12, excavated during testing (Figure 4). Grid north was oriented roughly parallel with Highway 83 at $\mathrm{N} 37^{\circ} \mathrm{W}$, and each datum was established using a transit and stadia rod. All data were subsequently recorded with a Sokkia SET 6E total data station.

Initially, a 2 x 8-m block longitudinally oriented east/west was excavated to prospect for feature and artifact densities that would dictate the placement of the remainder of the excavation units (XUs). Interestingly, feature counts were greater in the western half of the block while formal stone tool counts (based on field identification) were greater in the eastern portion of the block. As such, the eight meter width was maintained northward for an additional five meters, totaling $56,1-\mathrm{m}^{2}$ excavation units.

At this point, formal stone tool counts had decreased and less than 35 percent of the features encountered had been in the eastern portion of the block. Thus, the remaining eight $1-\mathrm{m}^{2}$ units were situated along the western edge of the block in order to investigate the greater feature density. Figure 4 provides a plan view of the core site excavation area, with previous backhoe trenches and test units, along with the recent CAR excavation area identified.

All horizontal proveniences were maintained in $1-\mathrm{m}^{2}$ units, with large (ca. $>5 \mathrm{~cm}$ ) in situ burned rock, large $(\mathrm{ca} .>3 \mathrm{~cm})$ artifacts, and temporally diagnostic artifacts point-provenienced whenever possible. Due to the indistinct texture and color changes in the stratigraphy, arbitrary $10-\mathrm{cm}$ levels were excavated. Vertical excavation levels did not exceed $10 \mathrm{~cm}$ in thickness. All excavated sediments were screened through 1/4-inch hardware cloth.

All cultural material encountered during excavation was collected and recorded on field forms relative to their provenience. Various samples were collected in the field to provide relevant data. These included the collection of all snail shell, faunal, and other ecofactual material observed. A two liter soil sample was collected from each arbitrary 10-cm level.

\section{Laboratory Methods}

Upon completion of each ten-day session, all recovered artifacts and special samples, along with associated paperwork, were submitted to the laboratory at CAR for processing. Initial processing consisted of artifact washing and a general category sort. Subsequent to this initial laboratory processing, the various artifact categories were submitted to specialists for analyses.

Formal tools, including all projectile points recovered from 41WB556, were separated from bulk debitage. Dr. Steve Tomka (CAR) classified the stone tools into functional groups. He also classified all points into typological categories.

After being washed, dried, and bagged by unit and level, all faunal material was given to Ms. Barbara Meissner (CAR) for analysis. The bone was identified to the most specific taxon possible using the comparative collection at CAR, as well as several reference texts (Cohen and Serjeantson 1996; Gilbert 1990; Hillson 1986; Olsen 1964, 1968; Sobolik and Steele 1996). All bone was weighed and any evidence of exposure to heat was noted. Element, portion of element, side, evidence of immaturity, butcher marks, and pathologies were noted on bone identified to the order taxonomic level. When bone could be identified only to class (e.g., mammal, bird, etc.) an estimate of the size of the animal was made when possible. After the analysis, Meissner bagged the 


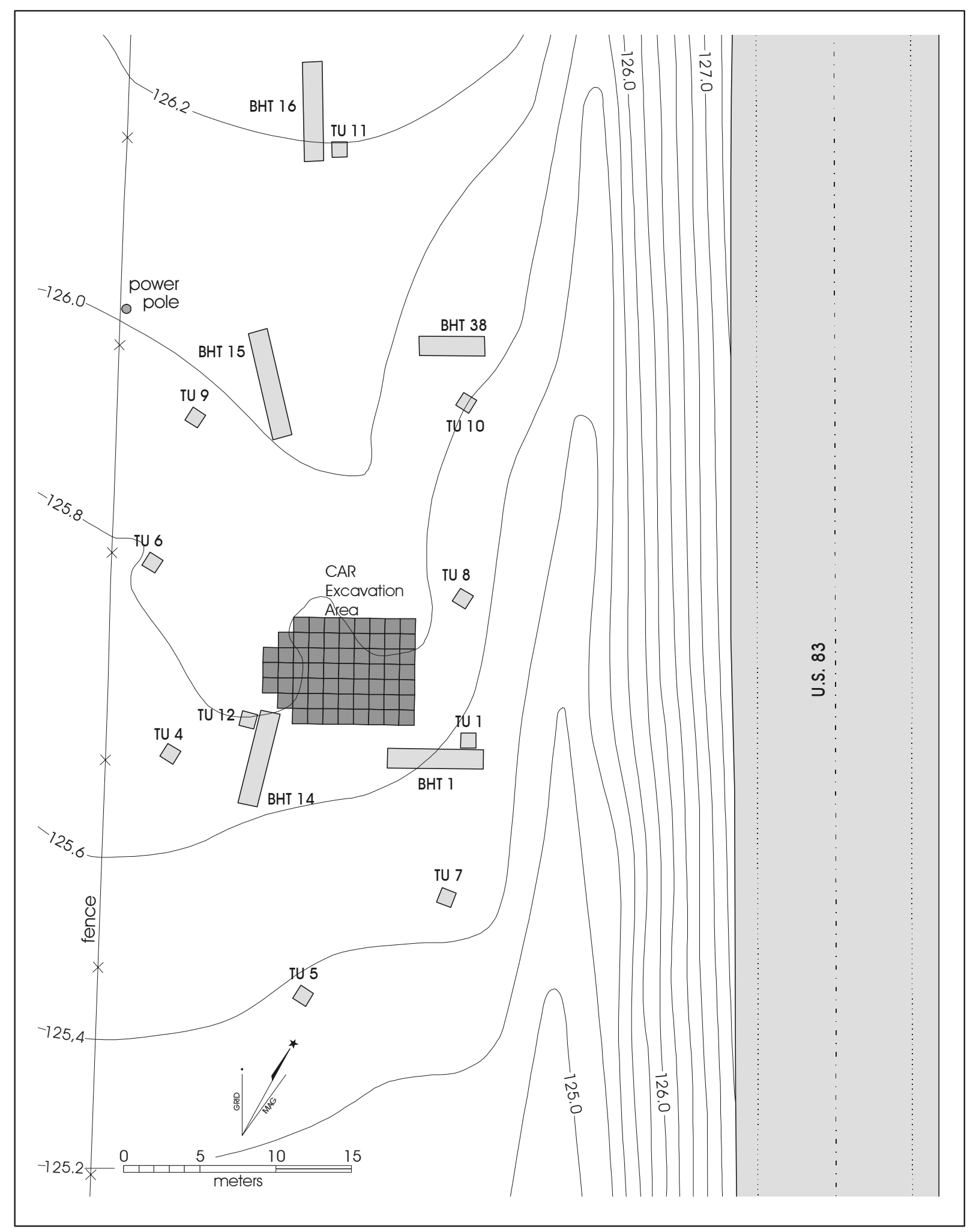

Figure 4. Core area of 41 WB556 with all excavation areas identified. 
material by unit and level. Bone identified to at least the order taxonomic level was bagged separately and included in the unit-level bags.

Dr. Britt Bousman (Southwest Texas State University) provided a geomorphic description of four column samples of sediment. These samples were collected in the field and provided to Dr. Bousman. Typical geomorphological observations were conducted in the field during or immediately following archeological excavations. Due to a communication error, however, the construction consultant infilled the excavation block and covered the entire site with approximately one meter of road material subsequent to the archeological work and prior to the geomorphological work. Consequently, the formal, limited analysis of the geomorphology of 41WB556 was relegated to the study of these four columns of sediment. Samples, collected at 10-cm arbitrary levels, were analyzed from N44/E08 (Levels 1-8), N46/E14 (Levels 1-8), N44/E17 (Levels 1-8), and N40/E16 (Levels 1-11). In this manner, soil texture, color, and firmness could be determined and, through comparison with excavation unit level forms, a relatively complete stratigraphic description was possible. The results of this analysis are presented in Appendix A.

Over 150 small charcoal samples were collected from the excavation. Each charcoal sample recovered was placed in an aluminum foil packet and stored in the controlled laboratory setting at CAR. Beta Analytic conducted the radiocarbon analysis of 13 of these charcoal samples. In addition, Beta Analytic ran 14 radiometric assays on residues extracted from burned sandstone at their laboratory. The results of the radiocarbon dating are presented in Appendix B.

Thirty samples of burned sandstone were selected from 13 distinct burned rock features for stable carbon and nitrogen isotope analysis. Each sample was pulverized using a ceramic mortar and pestle and screened with a U.S. Standard Testing Sieve at $1.0 \mathrm{~mm}$ (0.039 in). The resultant powder was placed in individual glass vials for preparatory decalcification conducted by Paul Lehman, Austin, Texas. Following the decalcification, the samples were submitted to Dr. David Harris of the University of California at Davis, Stable Isotope Facility, for final isotope analysis.
Thirty samples of burned sandstone were selected for lipid residue analysis. Very little in the way of laboratory preparation was necessitated by CAR. The samples were packaged in polypropylene bags and sent to Dr. Mary E. Malainey, Manitoba, Canada, for analysis. The results of the lipid residue analysis are presented in Appendix C.

Dr. J. Philip Dering, Associate Director for Macrofossil Analyses, Paleoethnobotany Laboratory, Texas A\&M University, performed macrobotanical analyses of materials recovered from the block excavation. Due to the turbated nature of the sediments throughout the excavation block, however, the analysis strategy changed markedly from the original research proposal. Consequently, the macrobotanical results from 41WB556 were incorporated into a comparative study utilizing xylem analysis across several sites in South Texas. Charcoal samples and flotation samples submitted from this project and the concurrent investigations at 41WB557 were analyzed along with results from previous investigations in the region. The results of the xylem analysis are presented in Appendix D.

Dr. Raymond Mauldin (CAR) conducted the magnetic susceptibility analysis. The process of measuring the change in magnetic susceptibility of the sediments involves collecting small soil samples at regular intervals throughout the vertical column of a unit. In the current context, the analysis has implications for identifying buried surfaces within the deposits at 41WB556. Soil samples were recovered from three columns throughout the excavation block to test for magnetic sediment susceptibility. Representative columns included N44/E14 (Levels 1-8), N44/E11 (Levels 1-7), and N42/E10 (Levels 1-7). These samples were placed in plastic bags and stored in a controlled laboratory at CAR until analysis was performed. Prior to analysis, all sediment samples were air dried on a non-metallic surface. After drying, the samples were then ground to a uniform grain size using a ceramic mortar and pestle. This was done to standardize particle size and make the material both easier to handle and pack into sample containers. The ground samples were placed into a MS2B Dual Frequency Sensor that, in conjunction with a MS2 Magnetic Susceptibility Meter, provided the magnetic susceptibility of each sample. The results of these analyses are presented in Appendix E. 
The results of these various analyses were incorporated into the final curation database. All data were entered into a Microsoft Access $2000^{\circ}$ database. The list of artifacts and ecofacts recovered by unit and level is presented in Appendix F. Final curatorial processing was conducted in accordance with 36CFR79 (Curation of Federally Owned and Administered Archeological Collections), and other proprietary standards adhered to by CAR. CAR is the permanent curatorial facility for the materials from this project. 


\section{Chapter 6: $\quad$ Results of Investigations}

CAR's excavation at 41WB556 produced a variety of different data sets. These data sets include collections of stone tools, debitage, faunal remains, modern material, and samples of charcoal. In addition, 14 features were encountered. This chapter provides a summary of these various data sets. Aspects of each of these data sets are then used to address the three research domains of site integrity and chronology, thermal feature technology, and stone tool technology in subsequent chapters.

\section{Chipped Stone Artifacts Recovered}

A total of 9,252 chipped stone artifacts was recovered from 41WB556. As always, unmodified lithic debitage dominates the collection ( $\mathrm{n}=9,045,98 \%)$, with tools constituting only about two percent $(n=207)$. A range of functional tool forms have been identified within the tools, including projectile points $(\mathrm{n}=37,18 \%)$, scrapers $(\mathrm{n}=33,16 \%)$, gouges/adzes $(\mathrm{n}=17,8 \%)$, knives $(\mathrm{n}=10$, $5 \%)$, choppers $(\mathrm{n}=7,3 \%)$, multi-functional tools $(\mathrm{n}=2$, $1 \%$ ), one perforator, and one wedge (Table 1 ). In addition, $51(25 \%)$ bifacially and $9(4 \%)$ unifacially flaked artifacts could not be classified into functional categories either because they were complete but use-wear could not be identified, were broken in manufacture and were never used, or were too small to classify. These artifacts were categorized as miscellaneous bifaces and miscellaneous unifaces, respectively. Finally, one of the largest artifact categories from the site consists of 39 (19\%) cores.

Nineteen $(51 \%)$ of the 37 projectile points are arrow points (Table 2). Of these, ten (53\%) are typed, six (32\%) are untypeable, and three $(16 \%)$ are arrow point blanks. The Caracara (Figure 5a), Starr (Figure 5c), and Toyah (Figure 5d) types are represented by three specimens each. One each of the Starr and Toyah specimens are preforms. The final typed arrow point is a Perdiz medial fragment (Figure 5b). A sufficient portion of the stem remains allowing it to be classified to this type.

Eighteen $(49 \%)$ of the projectile points are dart points. Of these, $11(61 \%)$ are typed, four (22\%) are dart point blanks, and three $(17 \%)$ are untypeable fragments. Tortugas specimens $(\mathrm{n}=5,28 \%)$ are the most common, followed by Abasolo ( $\mathrm{n}=4,22 \%)$, and Refugio $(\mathrm{n}=2$, $11 \%)$ points. One each of the Tortugas, Abasolo, and Refugio points is a preform.

Table 1. Non-debitage chipped stone artifacts recovered from 41WB556*

\begin{tabular}{|c|c|c|c|c|c|c|c|c|c|c|}
\hline Count of Tool Type & Level & & & & & & & & & \\
\hline Tool Type & 1 & 2 & 3 & 4 & 5 & 6 & 7 & 8 & 9 & Grand Total \\
\hline arrow point & 1 & 3 & 6 & 8 & & 1 & & & & 19 \\
\hline biface & 2 & 6 & 18 & 11 & 3 & 7 & 2 & 1 & 1 & 51 \\
\hline cobble tool (chopper) & & 1 & 3 & & 1 & 1 & 1 & & & 7 \\
\hline core & 1 & 6 & 7 & 6 & 5 & 7 & 3 & 4 & & 39 \\
\hline dart point & & 5 & 8 & 2 & 1 & 1 & 1 & & & 18 \\
\hline end scraper, expedient & & & 1 & 1 & & & & 2 & & 4 \\
\hline end scraper, min., retouched & & & 1 & & & . & & & & 1 \\
\hline gouge & & 4 & 5 & 2 & 5 & 1 & & & & 17 \\
\hline knife, expedient & & 4 & 2 & 2 & 1 & 1 & & & & 10 \\
\hline multifunctional gouge/graver & & & 1 & & & & & & & 1 \\
\hline multi-functional knife/side scraper & & & & & & 1 & & & & 1 \\
\hline perforator & & & & & 1 & & & & & 1 \\
\hline side scraper, expedient & 1 & 6 & 7 & 4 & 3 & 4 & & & 2 & 27 \\
\hline side scraper, min., retouched & & & & & & & & 1 & & 1 \\
\hline uniface & & 2 & 2 & 2 & 1 & 1 & 1 & & & 9 \\
\hline wedge & & & 1 & & & & & & & 1 \\
\hline Grand Total & 5 & 37 & 62 & 38 & 21 & 25 & 8 & 8 & 3 & 207 \\
\hline
\end{tabular}

*does not include 11 specimens recovered from the site during TxDOT survey. 
Table 2. Projectile points recovered from 41WB556

\begin{tabular}{|c|c|c|c|c|c|c|c|c|c|c|}
\hline Count of Point Type & Level & & & & & & & & & \\
\hline Point Type & 1 & 2 & 3 & 4 & 5 & 6 & 7 & 8 & 9 & Grand Total \\
\hline Abasolo & & 1 & 1 & & & 1 & & & & 3 \\
\hline Abasolo preform & & 1 & & & & & & & & 1 \\
\hline arrow point blank & & & 4 & 1 & & 1 & & & & 6 \\
\hline Caracara & & & 2 & 1 & & & & & & 3 \\
\hline dart point blank & & 1 & 2 & 1 & & & & & & 4 \\
\hline Perdiz & & & & 1 & & & & & & 1 \\
\hline Refugio & & & 1 & & & & & & & 1 \\
\hline Refugio preform & & & 1 & & & & & & & 1 \\
\hline Starr & 1 & & & 1 & & & & & & 2 \\
\hline Starr preform & & 1 & & & & & & & & 1 \\
\hline Tortugas & & & 3 & & 1 & & & & & 4 \\
\hline Tortugas preform & & 1 & & & & & & & & 1 \\
\hline Toyah & & 1 & & 1 & & & & & & 2 \\
\hline Toyah preform & & & & 1 & & & & & & 1 \\
\hline untypeable arrow point & & 1 & & 2 & & & & & & 3 \\
\hline untypeable dart point & & 1 & & 1 & & & 1 & & & 3 \\
\hline Grand Total & 1 & 8 & 14 & 10 & 1 & 2 & 1 & 0 & 0 & 37 \\
\hline
\end{tabular}

Scrapers constitute the largest of the non-projectile point tool categories $(n=33)$. Side scrapers $(n=28,85 \%)$ significantly outnumber end scrapers $(n=5,15 \%)$. One side and one end scraper each are minimally retouched. The remaining specimens are expedient forms representing unmodified debitage employed in the performance of scraping tasks. The same can be said of the ten expedient knives recovered from the site. Scrapers and knives were most common in Levels $2-4$, the levels with the highest chipped lithic artifact counts. The higher frequencies in these levels may simply be the product of larger artifact sample sizes.

Gouges constitute the second highest number of functional tools $(n=17)$. Based on morphological characteristics, these tools range from Dimmit tools (Figure $5 \mathrm{~h}$ ) to Nueces scrapers (Figure 5i and 5j) named by Hester et al. (1969). The small collection suggests a morphological continuity between Dimmit and Nueces tools, shown in the three examples in Figure $5 \mathrm{~h}-\mathrm{j}$. The tools appear to have been hafted tools used as gouges, scrapers, and adzes based on the types and distribution of use-wear.

These multi-functional gouges are most common in Levels 3 and 5 ( $n=5$ specimens each), followed by Level $2(n=4)$. They are not found in the three deepest levels of the site (Levels 8, 9, and 10). Nine (53\%) of the seventeen gouges occur in the same levels (Levels 2 and 3$)$ as $13(72 \%)$ of the dart points from the site. Only an arrow point blank was found in the two deepest levels (Levels 5 and 6) of the site where the six (35\%) deepest gouges were recovered.

Seven cortex-backed choppers and one wedge recovered from the site may be complementary elements of a woodworking tool kit as suggested by the multifunctional gouges from the site. The highest number of choppers and the single wedge are from Level 3, the level that contains five $(29 \%)$ of the gouges.

Miscellaneous bifaces are most common in Levels 3 and 4 and occur in moderate numbers in Levels 2 and 6. Cores, representing uni- and multi-directional flake blank production are nearly evenly distributed between Levels 2-6. Miscellaneous unifaces are slightly more common in Levels 2-4 than below. There are no notable patterns in the distribution of the two multi-functional tools and the perforator recovered from the site.

The preferred raw material employed in tool manufacture is chert. Rhyolite $(n=3)$ and chalcedony $(n=2)$ are the only non-chert materials present in the collection. Although not systematically tallied, cursory indications are that roughly between 25-35 percent of the chert tools exhibit heat treatment. Heat-treated specimens were also 


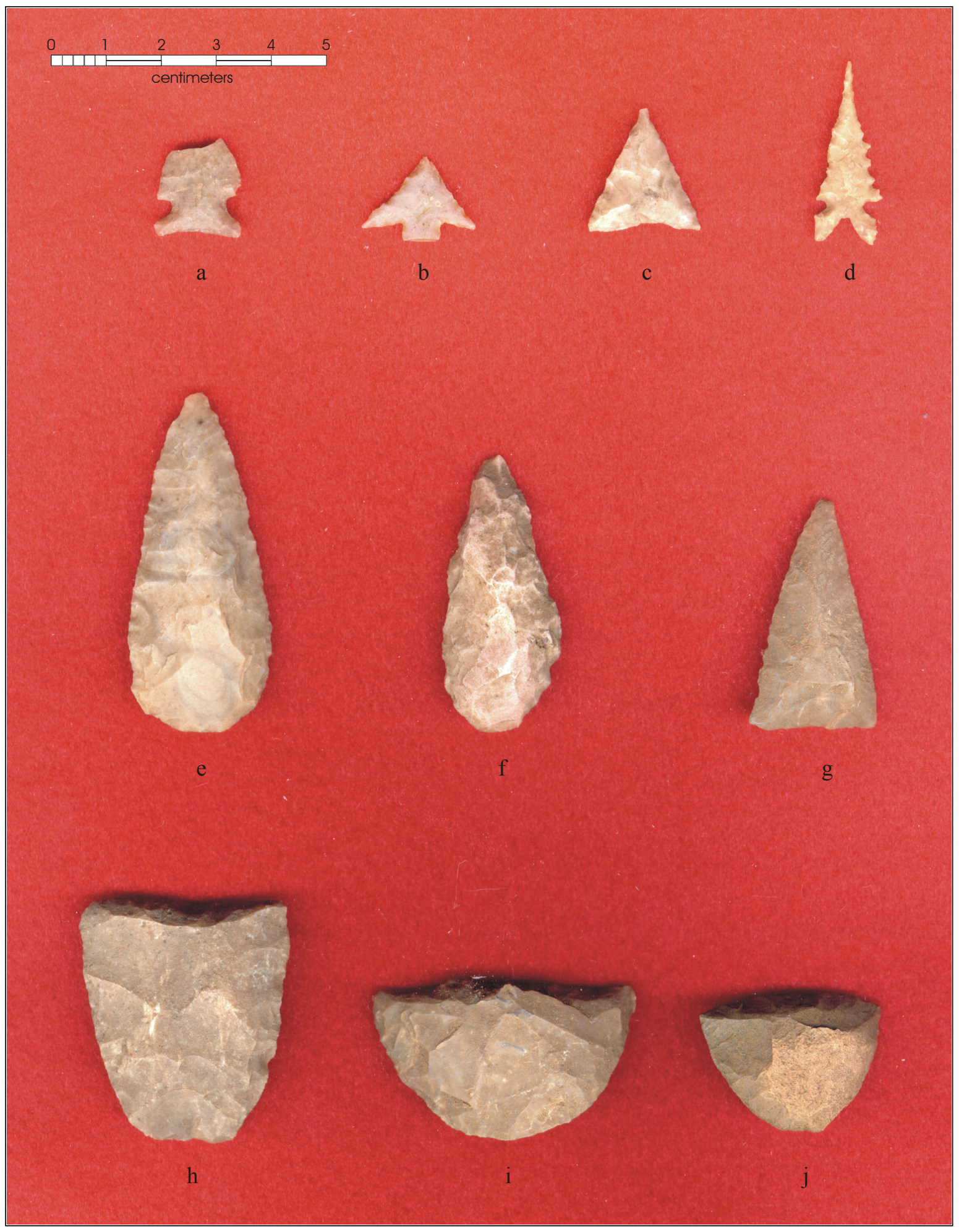

Figure 5. Projectile points and gouges recovered from 41WB556. a) Caracara arrow point; b) Perdiz arrow point; c) Starr arrow point; d) Toyah arrow point; e) Abasolo dart point; f) Refugio dart point; g) Tortugas dart point; h) Dimmit tool; i and j) Nueces tools. 
common among the unmodified debitage examined. Chipped stone artifacts made of clearly non-local raw materials have not been observed in the collection.

Overall, the assemblage of tools recovered from 41 WB556 is dominated by the products of tool manufacture (e.g., unmodified debitage, cores, and miscellaneous bifaces and unifaces), hunting equipment (e.g., arrow and dart points), woodworking tools (e.g., gouges, cobble tools, and a wedge), and expedient tools used in daily maintenance tasks such as tool manufacture and repair and food processing (e.g., expedient scrapers and knives). It is likely, however, that many of the formal hafted tools (e.g., dart points and gouges) represent multifunctional specimens. Use-wear analysis of a select number of Tortugas points from 41ZP364 (Church 2000[1997]:Figure D-3) indicates that these tools, in addition to serving as projectile points, were used in a range of tasks including scraping, sawing and cutting.

\section{Feature Descriptions}

Fourteen features were identified and recorded during the current phase of investigations. Ten features, consisting of clusters of tabular and sub-rounded burned sandstone with no associated charcoal or oxidized soils, were recorded during the previous survey and testing phases at 41WB556 (Meade et al. 1999; Quigg and Smith 2000, respectively). Feature numbers 1 through 4 and 8 were recorded during the survey phase, and feature numbers 9 through 13 were recorded during the testing phase. Feature number designations 5, 6, and 7 were not assigned during the survey phase. The current data recovery investigations, therefore, will continue with feature descriptions beginning with number 14 .

Fourteen features were recorded by CAR during the current project. Figure 6 presents the distribution of these features by level. The figure plots the core areas of the features, not their overall dimensions. Table 3 provides their maximum dimensions. Features were recorded from Levels 2 through 7.

Thirteen of the 14 features recorded on the current project are classified as burned rock clusters of indeterminate function. These features had maximum dimensions ranging from less than $40 \mathrm{~cm}$ to nearly $200 \mathrm{~cm}$ (Table 3).
Many of these features occurred as surface features with no indication of associated pits. The matrix surrounding each feature encountered was riddled with rodent and/ or insect burrows. Whether a possible organic content of the surrounding soil attracted the burrowers, or a less compacted soil was preferred in the sometimes-indurated sands, remains unclear. What is evident is the potential lack of integrity of the feature matrices.

The bulk of burned material recovered from these features is tabular and sub-rounded sandstone cobbles, averaging approximately $10-15 \mathrm{~cm}$ in diameter. However, burned or fire-cracked chert cobbles and associated heat spalls were recovered from several of the features. Several of the burned chert fragments exhibit breakage that allows refit, indicating the features remain primarily in situ. Similarly, the majority of the features contain burned sandstone fragments allowing refit, further indicating these features have not been significantly disturbed since their deposition.

Associated chipped stone debitage recovered includes primary, secondary, tertiary, and biface thinning flakes. Based upon field observations, a portion of the debitage exhibits indication of thermal alteration.

\section{Feature 14}

Two small $(40 \mathrm{~cm}$ in diameter and $20 \mathrm{~cm}$ in diameter), roughly circular concentrations of burned sandstone and burned chert were encountered in XU N40/E14 and recorded as Feature 14 (Figure 6). Terminal elevations of the feature averaged $20 \mathrm{~cm}$ bd. The surrounding matrix is a light yellowish-brown, slightly clayey fine-grained sandy loam with no indication of in situ thermal alteration. Several of the burned rock fragments exhibit breakage that allows refit, indicating the feature remains in situ. Lithics recovered include primary, secondary, tertiary, and biface thinning flakes.

\section{Feature 15}

A dispersed scatter of primarily burned sandstone spanning five $1-\mathrm{m}^{2}$ excavation units (N40/E10, N40/E11, N40/E12, N41/E10, and N41/E11) was recorded as Feature 15 (see Figure 6). The upper portion of the feature was encountered at $22 \mathrm{~cm}$ bd in XU N40/E10 and XU N40/E11 and terminated at $38 \mathrm{~cm}$ bd in XU N41/ E10. The feature exhibited only slight relief across its 
surface, and the variances indicated in the unit/level designations and depths below datum are attributable to the current ground surface undulation. Numerous $(n=161)$ burned sandstone cobbles and fragments comprise the majority of recovered cultural material. Few specimens of burned quartzite were present in the assemblage. Chipped stone artifacts include debitage, one core, and one biface. No charcoal was recovered in direct association with this feature.

\section{Feature 16}

A single, moderate-sized $(70 \times 45 \mathrm{~cm})$ cluster of primarily burned sandstone was encountered in XU N41/E10 and recorded as Feature 16 (see Figure 6). The burned rocks occurred from 54 to $60 \mathrm{~cm}$ bd and were contained within a light yellowish-brown silty loam matrix. The feature was contained wholly within this unit/level. Several $(n=32)$ burned sandstone cobbles and fragments comprise the majority of the artifact assemblage of Feature 16. Chipped stone artifacts consist of debitage $(n=15)$ only; no expedient or formal stone tools or temporally diagnostic artifacts were encountered in direct association with this feature. Feature 16 contained charcoal.

\section{Feature 17}

A single cluster of 15 burned sandstone pieces and one burned chert nodule was encountered in XU N41/E13 and recorded as Feature 17 (see Figure 6). Appearing as a roughly circular concentration, the feature measured approximately $85 \mathrm{~cm}$ in diameter. The feature was contained within arbitrary Level 7 at 60 to $70 \mathrm{~cm}$ bd. The surrounding matrix consisted of a friable light yellowish-brown silty loam with few natural pebble inclusions. It is possible that the feature weathered at ground surface over a period of time. This assumption is based on the rounded, smooth nature of the superior surfaces of the rocks in contrast to the flat, sub-angular aspect of the inferior surfaces. No temporally diagnostic artifacts were encountered in direct association with this feature, however, charcoal was present.

\section{Feature 18}

A cluster of burned sandstone cobbles $(n=33)$ was encountered in Levels 3 and 4 of XU N42/E10 and recorded as Feature 18 (see Figure 6). The feature occurred from 25 to $34 \mathrm{~cm}$ bd and was contained within the typical light yellowish-brown silty loam matrix. The
Table 3. Feature data from CAR block investigation at $41 \mathrm{WB} 556$

\begin{tabular}{|c|c|c|c|c|}
\hline F\# & Unit & Level & Description & Dimensions \\
\hline 14 & $\mathrm{~N} 40 \mathrm{E} 14$ & 2 & Burned Stone Cluster & $65 \times 95 \mathrm{~cm}$ \\
\hline \multirow[t]{4}{*}{15} & $\mathrm{~N} 40 \mathrm{E} 10$ & 3 & \multirow[t]{4}{*}{ Burned Stone Cluster } & \multirow[t]{4}{*}{$135 \times 155 \mathrm{~cm}$} \\
\hline & N40E11 & 3 & & \\
\hline & N41E10 & 3 & & \\
\hline & N41E11 & 3 & & \\
\hline 16 & N41E10 & 6 & Burned Stone Cluster & $70 \times 45 \mathrm{~cm}$ \\
\hline 17 & N41E13 & 7 & Burned Stone Cluster & $90 \times 80 \mathrm{~cm}$ \\
\hline 18 & $\mathrm{~N} 42 \mathrm{E} 10$ & 3 & Burned Stone Cluster & $75 \times 50 \mathrm{~cm}$ \\
\hline 19 & $\mathrm{~N} 42 \mathrm{E} 11$ & 3 & Burned Stone Cluster & $85 \times 85 \mathrm{~cm}$ \\
\hline 20 & $\mathrm{~N} 42 \mathrm{E} 14$ & 3 & Burned Stone Cluster & $35 \times 20 \mathrm{~cm}$ \\
\hline \multirow[t]{4}{*}{21} & $\mathrm{~N} 42 \mathrm{E} 10$ & 5 & \multirow[t]{4}{*}{ Burned Stone Cluster } & \multirow[t]{4}{*}{$120 \times 110 \mathrm{~cm}$} \\
\hline & N42E11 & 5 & & \\
\hline & N43E10 & 5 & & \\
\hline & N43E11 & 5 & & \\
\hline 22 & N42E15 & 7 & Burned Stone Cluster & $70 \times 55 \mathrm{~cm}$ \\
\hline \multirow[t]{4}{*}{23} & N44E13 & $3-7$ & \multirow[t]{4}{*}{ Unlined Hearth } & \multirow[t]{4}{*}{$100 \times 100 \mathrm{~cm}$} \\
\hline & N44E14 & $3-7$ & & \\
\hline & $\mathrm{N} 45 \mathrm{E} 13$ & $3-7$ & & \\
\hline & N45E14 & $3-7$ & & \\
\hline 24 & $\mathrm{~N} 44 \mathrm{E} 12$ & 5 & Burned Stone Cluster & $70 \times 65 \mathrm{~cm}$ \\
\hline 25 & N45E11 & 4 & Burned Stone Cluster & $90 \times 75 \mathrm{~cm}$ \\
\hline 26 & N46E15 & 5 & Burned Stone Cluster & $40 \times 25 \mathrm{~cm}$ \\
\hline \multirow[t]{4}{*}{27} & N43E08 & 4 & \multirow[t]{4}{*}{ Burned Stone Cluster } & \multirow[t]{4}{*}{$185 \times 110 \mathrm{~cm}$} \\
\hline & N43E09 & 4 & & \\
\hline & N44E08 & 4 & & \\
\hline & N44E09 & 4 & & \\
\hline
\end{tabular}

central mass of the feature occurred as a generally circular concentration roughly $50 \mathrm{~cm}$ in diameter. There were, however, additional rocks dispersed from this central location, presumably as a result of post-depositional processes. Including these rocks, the maximum east-west axis of Feature 18 was $75 \mathrm{~cm}$. A friable light yellowishbrown silty loam matrix surrounded the feature with no noticeable inclusions. No temporally diagnostic artifacts were encountered in direct association with this feature. Similarly, no charcoal was recovered.

\section{Feature 19}

A dispersed scatter of burned sandstone cobbles was encountered in Levels 3 and 4 of XU N42/E11, XU N41/ E11, XU N41/E12, and XU N42/E12. The scatter was nebulous, with indistinct margins in all but XU N42/ E11 (see Figure 6). Within this XU, the roughly $80 \mathrm{~cm}$ diameter scatter was densest. This dense concentration 


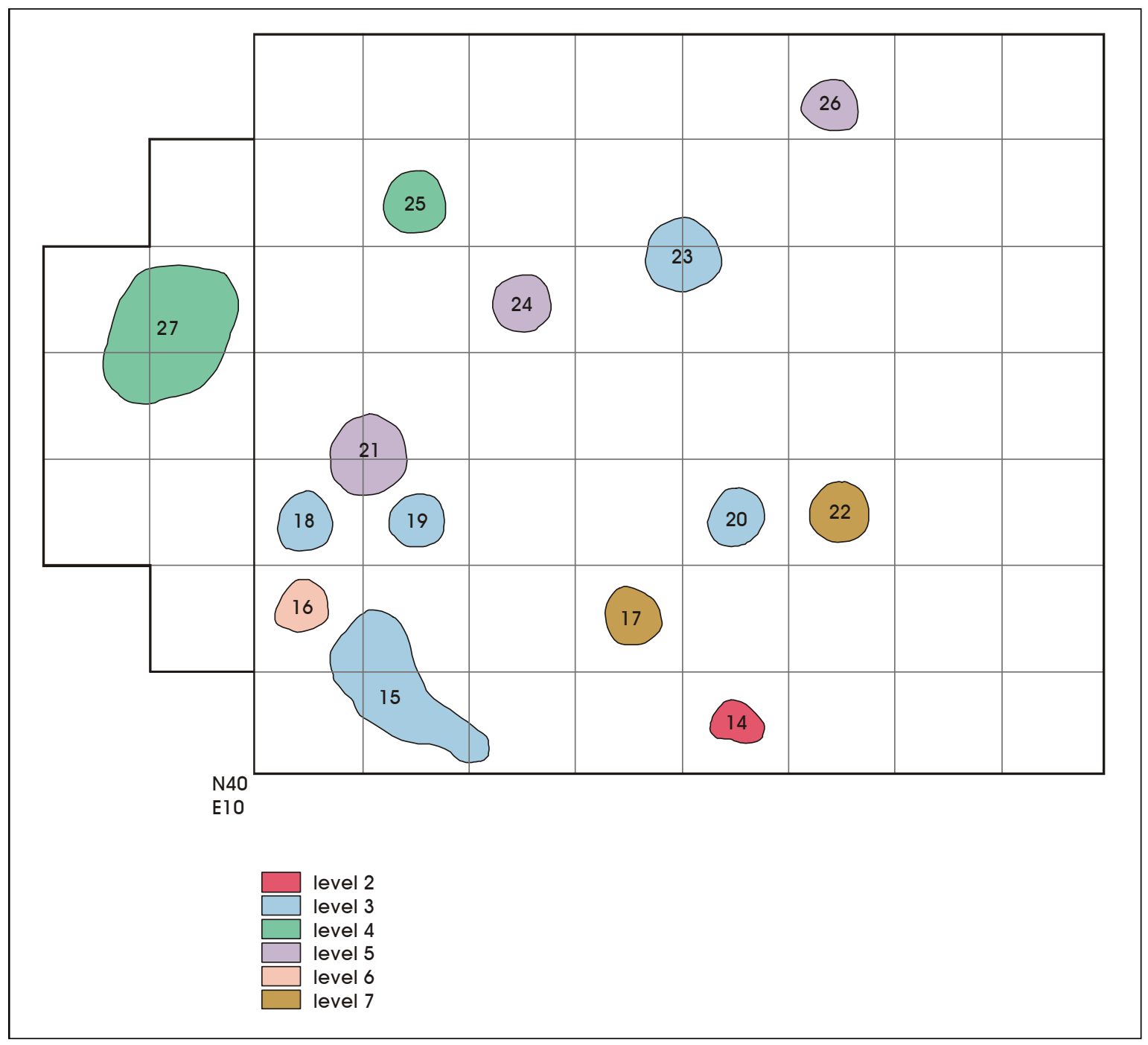

Figure 6. Distribution of features by level across excavation block.

occurred from 21 to $30 \mathrm{~cm}$ bd. This area probably represents the primary locus of Feature 19. The surrounding soil matrix consisted of a light yellowishbrown silty loam and contained few inclusions. A single tool was recovered in association with the feature. Not temporally diagnostic, the tool is a complete chert cobble tool blank and is representative of early reduction stage. Feature 19 contained charcoal.

\section{Feature 20}

A small scatter of burned rock and associated ashy fill was recorded as Feature 20 (see Figure 6). XU N42/E14 contained the majority of the feature, including all of the burned rock and approximately 67 percent of the ashy fill material. The remainder of the fill material was recorded in XU N42/E15. Level 3 contained the feature in both units, with elevations ranging from 23 to 
$28 \mathrm{~cm}$ bd. In cross-section, the feature exhibited only a slight concavity. Among the burned rock clusters, this is the only feature that exhibited any significant amount of associated burned material. The material consisted of a light, silty ash with charcoal located between and under the burned rocks. This, in concert with the slight concavity exhibited in cross-sectional profile, would suggest an in situ hearth. However, no oxidation was observed in the surrounding soil matrix. No temporally diagnostic artifacts were encountered in direct association with this feature. However, a rhyolite flake (catalog no. 413) was recovered in Level 3 of XU N42/E14.

\section{Feature 21}

Feature 21 consisted of a cluster of primarily burned sandstone roughly $110 \mathrm{~cm}$ in diameter. The feature spanned excavation units N42/E10, N42/E11, N43/E10, and N43/ E11 (Figures 7 and 8; also see Figure 6). The upper portion of the feature was encountered at $41 \mathrm{~cm}$ bd in XU N43/ E11. The feature terminated at $60 \mathrm{~cm}$ bd across the four units. The feature exhibited relatively substantial relief across its surface, due primarily to slight doming occurring in the central portion of the feature. Numerous $(n=642)$ burned sandstone cobbles and fragments comprise the majority of recovered cultural material. Throughout this wide area, no other artifacts were encountered in

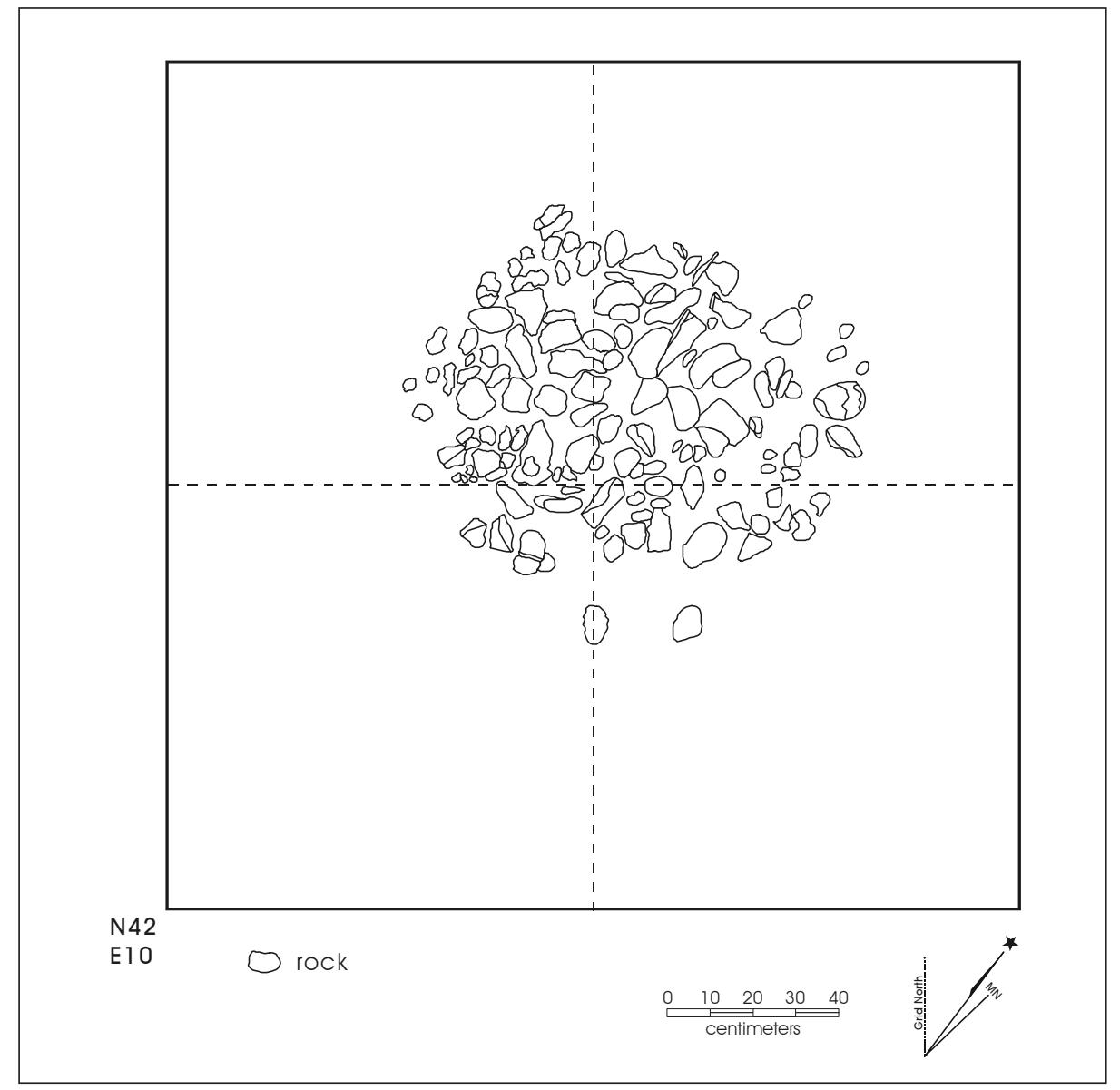

Figure 7. Feature 21 (N42-43/E10-11), Level 6, plan view. 


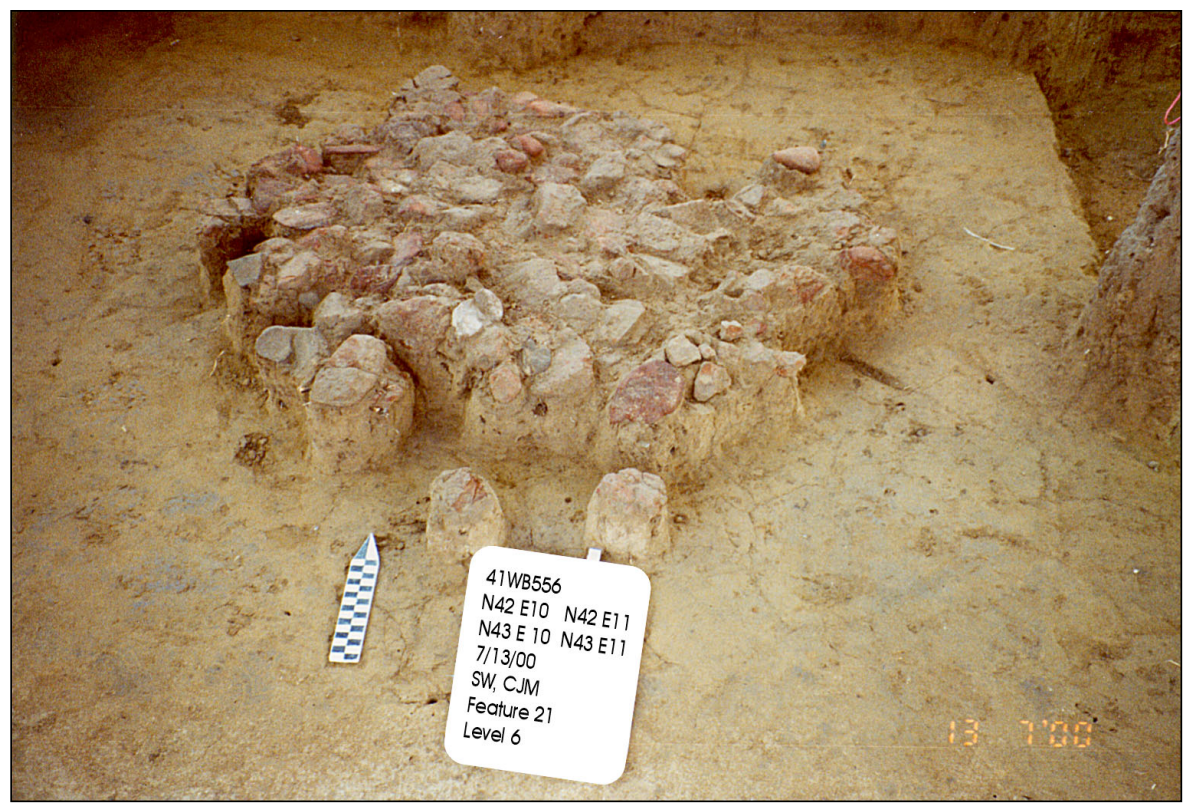

Figure 8. Feature 21 (N42-43/E10-11).

association with the cluster. In addition, no charcoal was recovered in direct association with this feature, thus, no charcoal samples were collected.

\section{Feature 22}

An irregular shaped cluster of burned sandstone was encountered in Level 7 of XU N42/E15 and recorded as Feature 22 (Figure 9; also see Figure 6). The feature measured roughly $70 \mathrm{~cm}$ by $55 \mathrm{~cm}$, with a vertical thickness of $11 \mathrm{~cm}$. The upper portion of the cluster was encountered at $59 \mathrm{~cm}$ bd and terminated by $70 \mathrm{~cm}$ bd. The feature was contained within the typical yellowishbrown sandy loam matrix. Several $(n=22)$ burned sandstone cobbles and fragments comprise the majority of recovered material associated with the feature. One burned chert cobble was included in the feature assemblage. The feature contained charcoal.

\section{Feature 23}

Feature 23 (see Figure 6) appeared to be an unlined hearth with an encirclement of sandstone cobbles. These cobbles were located at the uppermost portion of the feature, which was recorded at approximately $30 \mathrm{~cm}$ bd. At the upper portion of the feature, the diameter was roughly one meter. Sparse to moderate amounts of charcoal flecking occurred at this level. Unique to this feature, oxidized sediments were encountered within the pit from ground surface to terminal elevations. By 50 $\mathrm{cm} \mathrm{bd}$, the upper aspect of a charred log with sparse amounts of burned chert occurred (Figure 10). The terminal depth of the charred material extended to about $70 \mathrm{~cm}$ bd. The pit may have continued at least an additional $6 \mathrm{~cm}$.

\section{Feature 24}

A circular cluster of primarily burned sandstone cobbles was encountered in Level 5 of XU N44/E12 and recorded as Feature 24 (see Figure 6). The cluster measured roughly $70 \mathrm{~cm}$ in diameter, with a vertical thickness of about $5 \mathrm{~cm}$. The upper portion of the cluster was encountered at $45 \mathrm{~cm}$ bd and the feature terminated by $50 \mathrm{~cm}$ bd. The feature was contained within the typical yellowish-brown sandy loam matrix. Several $(n=77)$ burned sandstone cobbles and fragments comprise the majority of recovered material associated with the feature. Other cultural material recovered in association with the feature includes debitage and burned chert. No charcoal samples were recovered. 


\section{Feature 25}

A disperse scatter of burned sandstone was encountered in Level 4 of XU N45/E11 and recorded as Feature 25 (see Figure 6). The feature was oblong in shape and measured $90 \mathrm{~cm}$ by $75 \mathrm{~cm}$, with a vertical thickness of about $9 \mathrm{~cm}$. The upper portion of the feature was encountered at $29 \mathrm{~cm}$ bd and terminated by $40 \mathrm{~cm}$ bd. Typical yellowish-brown sandy loam contained the feature. Several $(n=49)$ burned sandstone cobbles and fragments comprise the majority of the artifact assemblage. Chert debitage and a single tool were also recovered in association with the feature. Not temporally diagnostic, the tool is a complete gouge preform and is representative of late reduction stage. Charcoal was recovered from Feature 25.

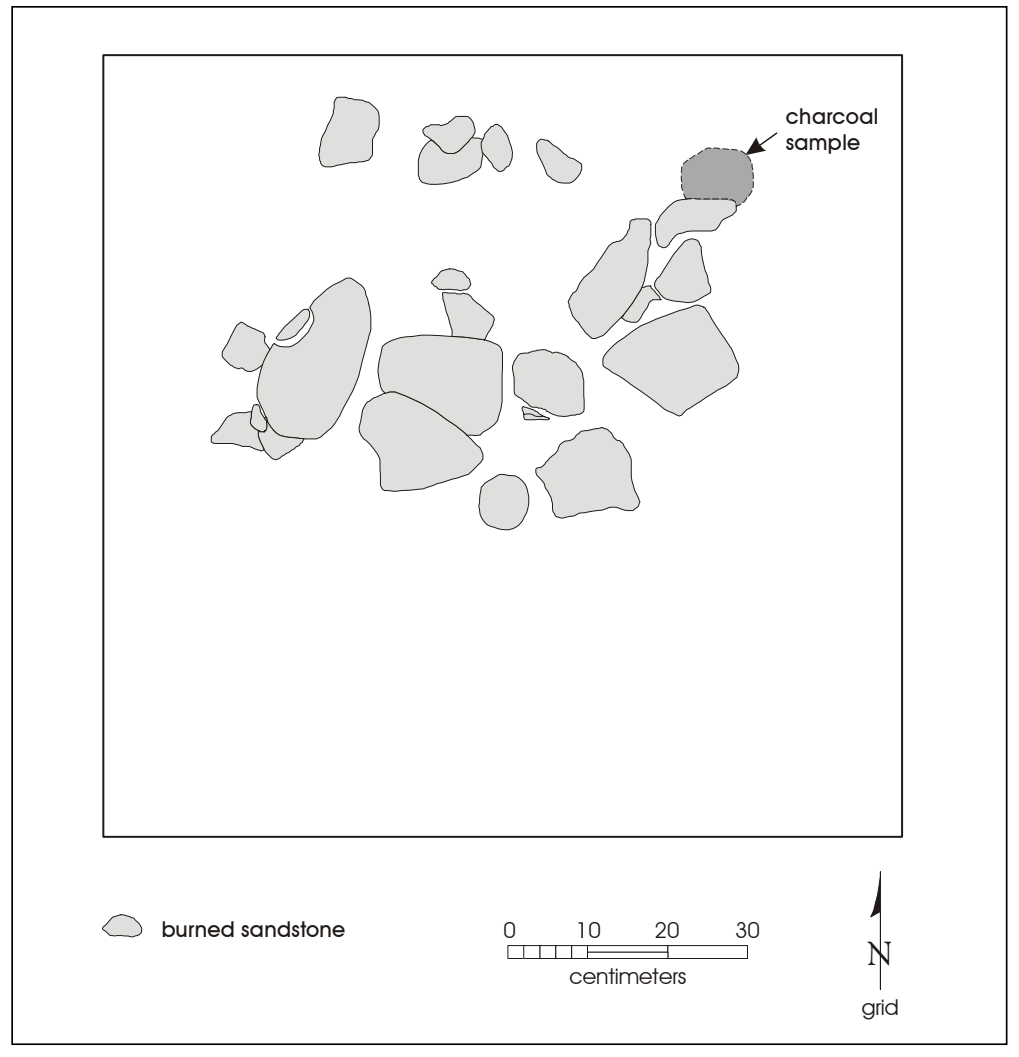

Figure 9. Feature 22 (N42/E15), plan view.

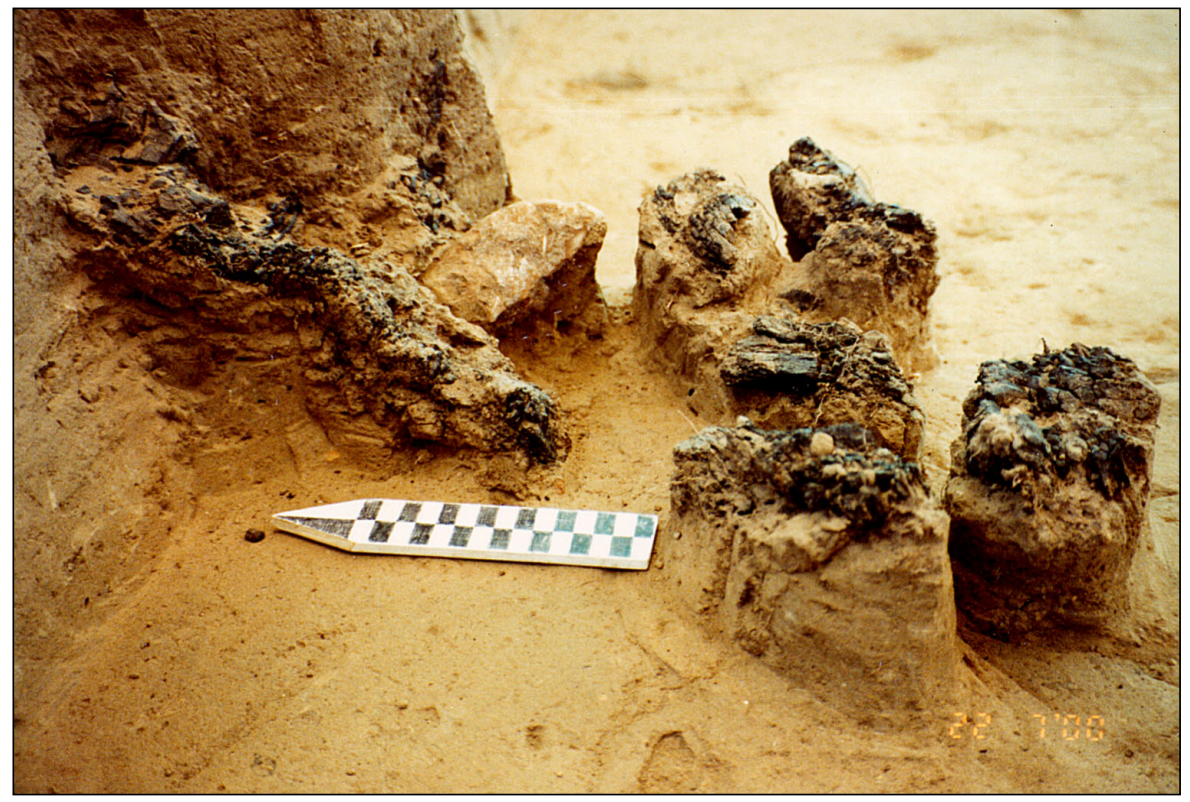

Figure 10. Feature 23 (N44-45/E13-14). 


\section{Feature 26}

A small cluster of burned sandstone cobbles was encountered in Level 5 of XU N46/E15 and recorded as Feature 26 (see Figure 6). The cluster was irregular in shape and measured $40 \mathrm{~cm}$ by $25 \mathrm{~cm}$. The feature was contained within the yellowish-brown sandy loam matrix. Several $(n=15)$ burned sandstone cobbles comprise the artifact assemblage associated with the small feature. No other associated cultural material was encountered. No temporally diagnostic artifacts were encountered in direct association with this feature. Similarly, no charcoal was recovered.

\section{Feature 27}

A large, irregularly-shaped cluster of primarily burned sandstone spanning four 1- $\mathrm{m}^{2}$ excavation units (N43/E08, N43/E09, N44/E08, and N44/E09) was the final feature encountered (see Figure 6). The upper portion of Feature 27 occurred at $25 \mathrm{~cm}$ bd and terminated in Level 5 across the four units. The feature exhibited relatively substantial relief across its surface, due primarily to slight doming occurring in the northern portion of the feature. The southern portion occurred as a more disperse scatter. Numerous $(n=167)$ burned sandstone cobbles and fragments comprise the majority of recovered cultural material. Few other artifacts were encountered in association with the cluster. Charcoal was recovered from this feature.

\section{Vertebrate Faunal Remains \\ by Barbara A. Meissner}

A total of 610 vertebrate faunal remains, weighing $92.09 \mathrm{~g}$, was recovered during the project. A list of taxa identified for all bone is shown in Table 4. A complete provenienced list of all data acquired from the bone assemblage is listed in Table 5.

Most of the bone was in good to excellent condition, allowing 64.9 percent $(n=396)$ to be identified to at least the genus taxonomic level. However, 60.7 percent of the total bone count was fragments of the dermal carapace of armadillos (Dasypus novemcinctus). Other identified species included skunk (Mephitis mephitis), two native rats (Sigmodon hispidus and Neotoma sp.), and blacktailed jackrabbit (Lepus californicus).

It should be noted that only five percent of the bone identified to the genus taxonomic level was found below Level 2, ca. $20 \mathrm{~cm}$ below ground surface. The excellent condition of the majority of the identified bone suggests that most of the bone is intrusive on the site, and not related to the prehistoric occupation. Additional evidence for this observation is the fact that armadillo, which constitutes 93.4 percent of the identified bone, was not present in Texas during the prehistoric occupation of the site (see Davis and Schmidly 1994:85).

Only a few bones, including several tooth fragments of a cow- or bison-sized animal, and small fragments of long bones of a deer-sized animal, appear to be related to the prehistoric occupation of the site. When bones that showed no sign of pitting or other weathering, and very fragile bones that were unbroken were discounted, only 93 (15\%) bones remained, of which only one jackrabbit femur could be identified to genus. These bones are all highly fragmented and most display at least some surface pitting consistent with chemical weathering of bone by biologic (i.e., bacterial and fungal) activity. Only four bones showed any evidence of heat alteration. 
Table 4. Taxa identified from 41WB556

\begin{tabular}{|c|c|c|c|}
\hline Taxon & Common Name & Count & Weight (g) \\
\hline Mammalia & Mammals & & \\
\hline Chiroptera & Bats & 1 & 0.06 \\
\hline Dasypus novemcinctus & Armadillo & 370 & 43.78 \\
\hline Lepus californicus & Blacktailed jackrabbit & 2 & 0.68 \\
\hline Mephitis mephitis & Striped skunk & 8 & 3.74 \\
\hline Neotoma sp. & Woodrats & 3 & 0.74 \\
\hline Peromyscus sp. & Field mice & 1 & 0.05 \\
\hline Rodentia & Rodents & 30 & 1.49 \\
\hline Sigmodon hispidus & Cotton rat & 3 & 0.17 \\
\hline Sylvilagus sp. & Cottontail rabbit & 1 & 0.86 \\
\hline Mammal--very small & Rat, mouse-sized & 7 & 0.37 \\
\hline Mammal--small & Rabbit-sized & 10 & 2.85 \\
\hline Mammal--medium & Dog-sized & 1 & 0.67 \\
\hline Mammal--large & Deer, sheep-sized & 7 & 9.06 \\
\hline Mammal--very large & Cattle, bison, horse-sized & 3 & 2.16 \\
\hline \multirow[t]{2}{*}{ Mammal } & Size indeterminate & 80 & 11.22 \\
\hline & Total Mammals & 527 & 77.90 \\
\hline Aves & Birds & & \\
\hline Callipepla squamata & Scaled Quail & 1 & 0.19 \\
\hline Mimidae & Mockingbirds and thrashers & 1 & 0.04 \\
\hline Aves--small & Mockingbird-sized & 4 & 0.22 \\
\hline \multirow[t]{2}{*}{\begin{tabular}{|l|} 
Aves--large \\
\end{tabular}} & Chicken-sized & 1 & 0.46 \\
\hline & Total Birds & 7 & 0.91 \\
\hline Reptilia & Reptiles & & \\
\hline Colubridae & Non-poisonous snakes & 2 & 0.20 \\
\hline Elaphe sp. & Rat snakes & 3 & 0.07 \\
\hline Emydidae & Sliders and Box turtles & 4 & 3.27 \\
\hline Phrynosoma sp. & Horned lizards & 1 & 0.22 \\
\hline Squamata & Lizards & 4 & 0.32 \\
\hline Terrepene sp. & Box turtles & 3 & 2.08 \\
\hline \multirow[t]{2}{*}{ Testudines } & Turtles & 8 & 3.09 \\
\hline & Total Reptiles & 25 & 9.25 \\
\hline \multirow[t]{2}{*}{ Vertebrata } & Unidentified bone & 51 & 4.03 \\
\hline & Overall Totals & 610 & 92.09 \\
\hline
\end{tabular}

In conclusion, of the 610 bones recovered during this project, most are probably of recent origin. They do not reflect subsistence practices during the prehistoric occupation of the site. Open campsites in South Texas often have few vertebrate faunal remains (Hester 1995:439), but it is difficult to say whether there are so few bones because of poor preservation, because of cultural activities that render bone more susceptible to destruction, or because there were few bones deposited in the first place. In this particular site, the small numbers of even unidentifiable fragments suggests that few bones were deposited at the site. One possible reason for this is the practice described by Cabeza de Vaca (1961 [1871]:103) in which bones of both land animals and fish were pounded into a fine meal and eaten. Another possibility is that most of the animals consumed at the site were either small mammals or small fish, which would have been eaten whole (Sobolik 1991:110). 


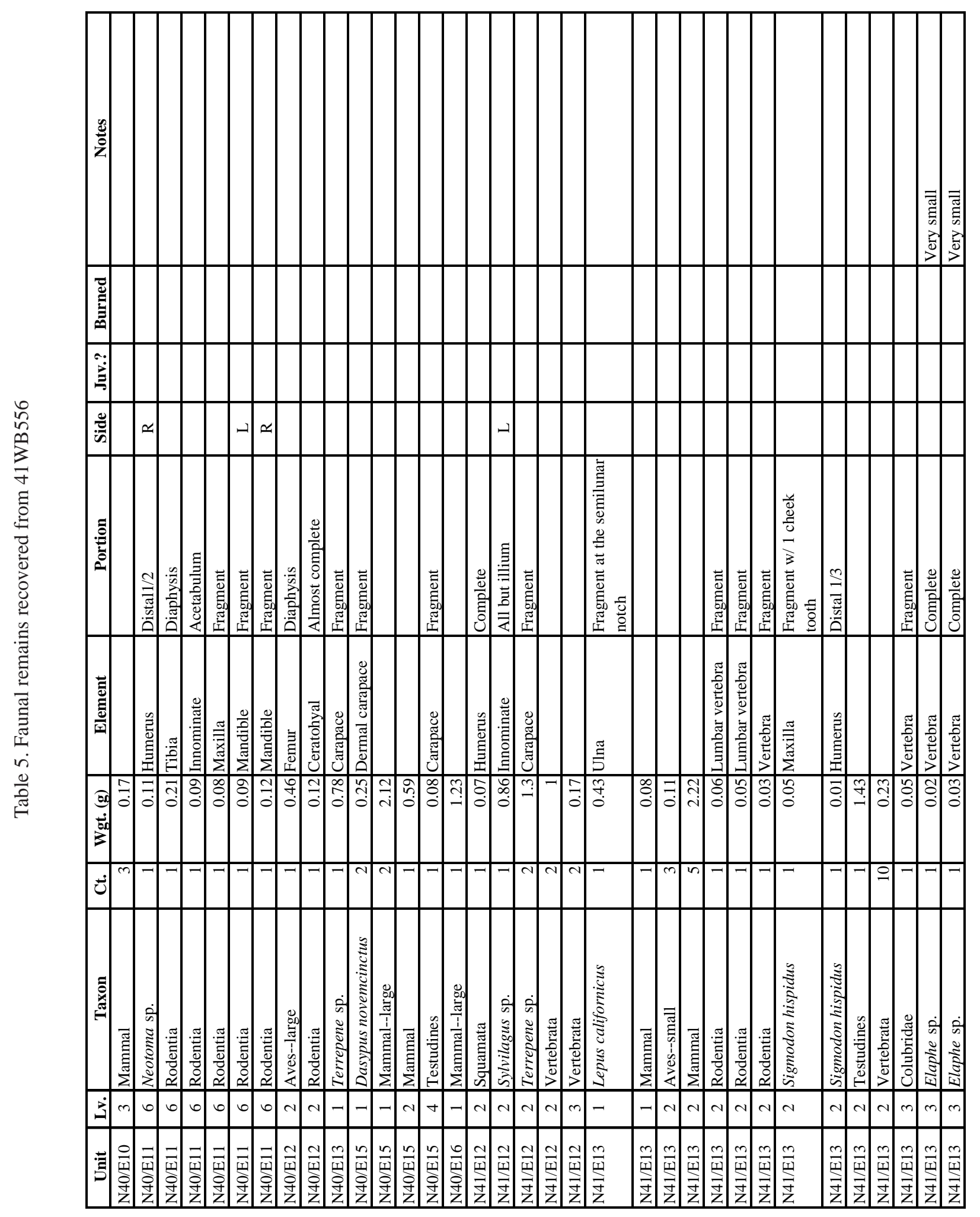




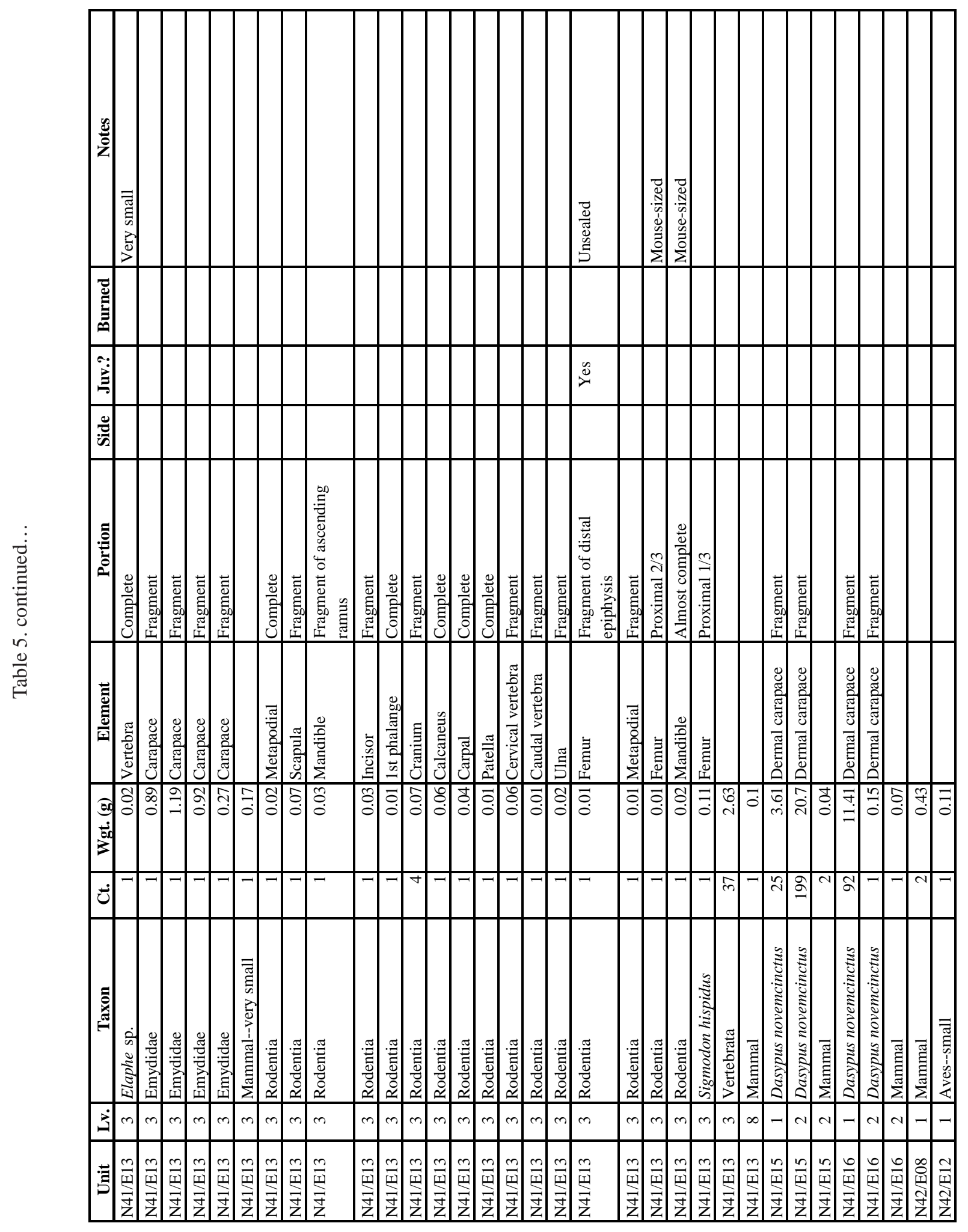




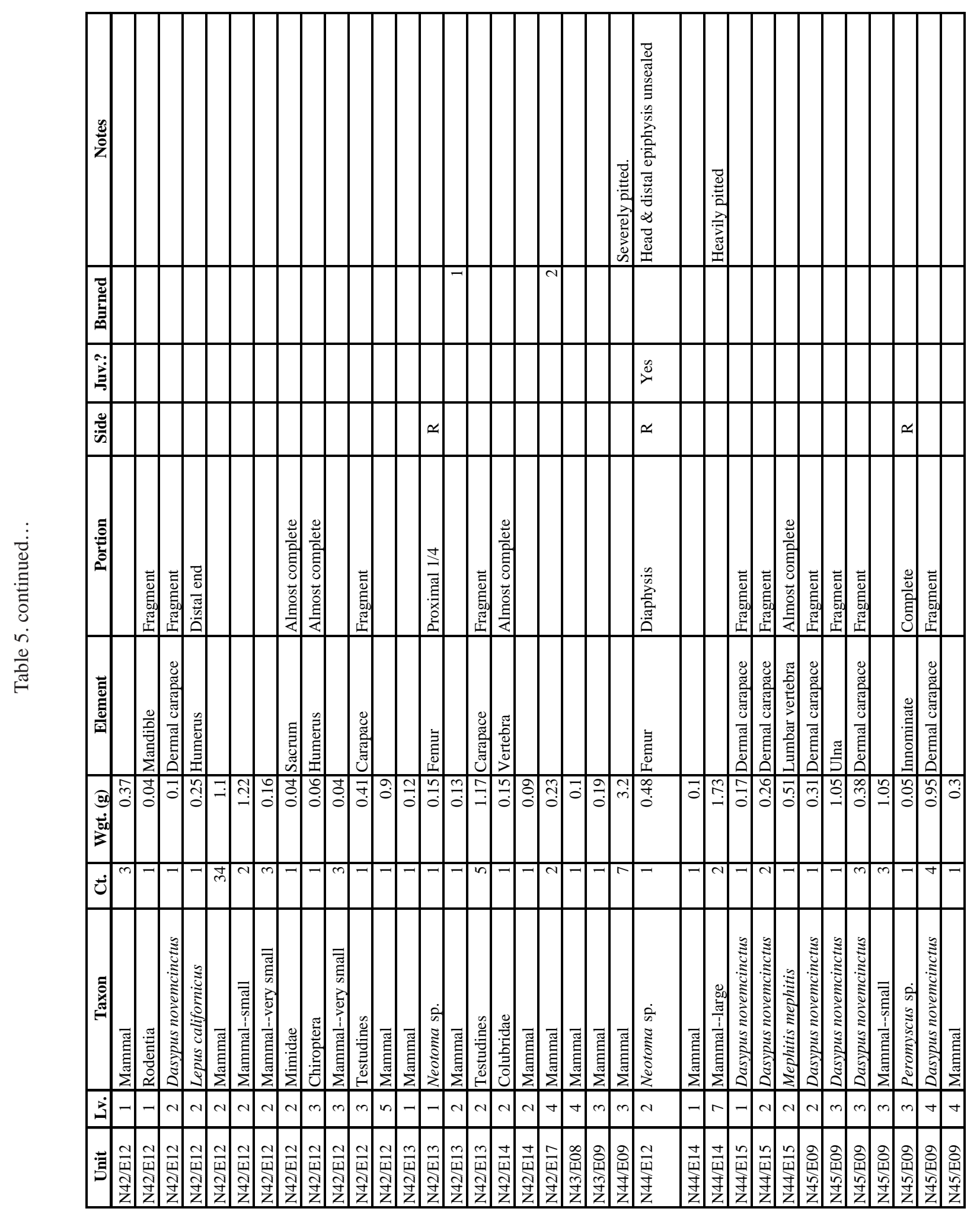




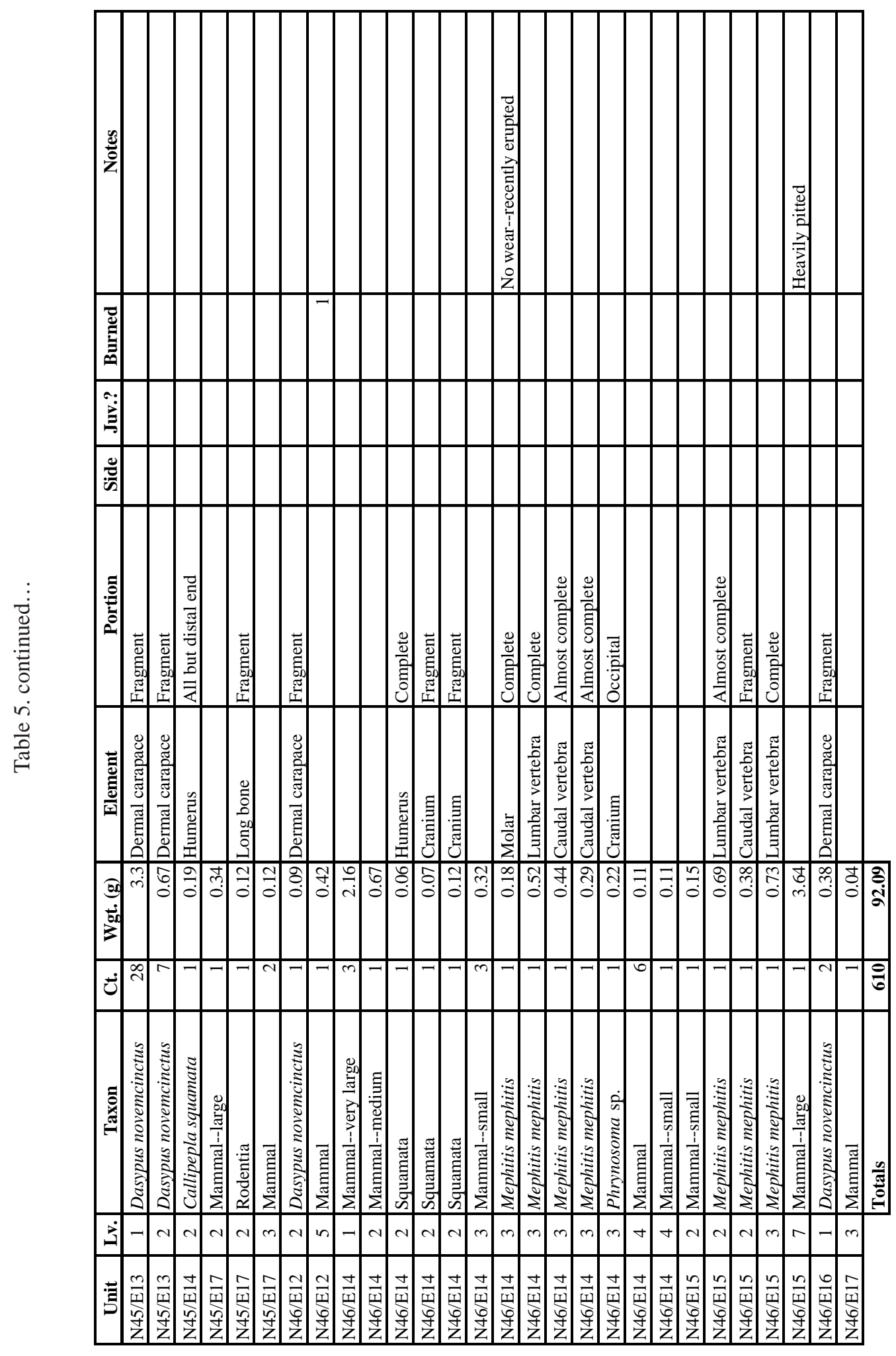




\section{Other Samples}

One hundred and fifty-five charcoal samples, totaling 2,151.7 g, were recovered from point-provenienced locations at the site, though most come from relatively unreliable contexts. As noted in the previous chapter, sediment samples were collected from the site. However, given the level of turbation of the fine matrix, we were unsure of the context of these samples. Terrestrial snail shells, principally representing the genera Rabdotus and Polygyra, were also present, though not in great numbers. The snail shells are extremely fragmentary, and snails were present at some frequency throughout the deposits. These species are probably post-depositional in nature. Several other classes of remains, primarily comprised of metal and glass, were recovered from the excavation. Of the 13 proveniences with metal and glass, 93 percent were within the upper $30 \mathrm{~cm}$ of the deposits, and 79 percent were within the upper $20 \mathrm{~cm}$. Only one historic item (metal) was recorded below $30 \mathrm{~cm}$ (Table 6).

Table 6. Historic material recovered from 41WB556

\begin{tabular}{|c|c|c|c|c|c|c|c|c|c|c|c|}
\hline Unit & Level & Depth & Bullet & $\begin{array}{c}\text { Cast Iron } \\
\text { Washer }\end{array}$ & $\begin{array}{l}\text { Fence } \\
\text { Staple }\end{array}$ & Glass & Metal & $\begin{array}{c}\text { Shotgun Shell } \\
\text { Head }\end{array}$ & $\begin{array}{c}\text { Shotgun Shell Headstamp } \\
\text { "Western 410..." }\end{array}$ & Staple & Total \\
\hline $\mathrm{N} 41 \mathrm{E} 12$ & 2 & $10-20 \mathrm{cmbs}$ & & & & & 1 & & & & 1 \\
\hline N41 E13 & 3 & $20-30 \mathrm{cmbs}$ & 1 & & & & 1 & & & & 2 \\
\hline N41 E14 & 1 & $0-10 \mathrm{cmbs}$ & & & 1 & & & & & & 1 \\
\hline N41 E15 & 2 & $10-20 \mathrm{cmbs}$ & & & & & 1 & & & & 1 \\
\hline $\mathrm{N} 42 \mathrm{E} 13$ & 1 & $0-10 \mathrm{cmbs}$ & & & & & 1 & & & & 1 \\
\hline $\mathrm{N} 42 \mathrm{E} 13$ & 2 & $10-20 \mathrm{cmbs}$ & & & & 1 & 1 & & & & 2 \\
\hline N42 E13 & 6 & $50-60 \mathrm{cmbs}$ & & & & & 1 & & & & 1 \\
\hline N42 E15 & 2 & $10-20 \mathrm{cmbs}$ & & & & & 1 & & & & 1 \\
\hline N43 E17 & 2 & $10-20 \mathrm{cmbs}$ & & & & 1 & & & & & 1 \\
\hline N44 E14 & 1 & $0-10 \mathrm{cmbs}$ & & 1 & & & & & & & 1 \\
\hline N44 E15 & 2 & $10-20 \mathrm{cmbs}$ & & & & & & 1 & & & 1 \\
\hline N46 E14 & 1 & $0-10 \mathrm{cmbs}$ & & & & & & & 1 & & 1 \\
\hline N46 E17 & 1 & $0-10 \mathrm{cmbs}$ & & & & & & & & 1 & 1 \\
\hline & & Tot & 1 & 1 & 1 & 2 & 7 & 1 & 1 & 1 & 15 \\
\hline
\end{tabular}




\section{Chapter 7: $\quad$ Site Integrity and Chronology}

This chapter reviews the integrity of the archeological deposits excavated at 41WB556 and discusses the age of the archeological manifestations present at the site. Information from five distinct data types is brought together to address depositional integrity and chronology. The data types consist of site stratigraphy, magnetic sediment susceptibility results, the vertical distributions of both unmodified debitage and temporally diagnostic artifacts, and results of radiocarbon assays.

\section{Site Integrity}

\section{Site Stratigraphy}

The CAR block excavation unit is located adjacent to and between BHTs 14 and 1 excavated by TRC (Quigg and Smith 2000) and TxDOT (Abbott 1999; Meade et al. 1999), respectively. It is located on the T0 terrace of Becerra Creek, sufficiently high that the alternating lenses of over bank deposits noted closer to the modern channel at the toeslope of the bank were not present. The stratigraphy present in BHT 14 excavated by Quigg and Smith (2000:Figure 5), and located immediately adjacent to the southwest corner of the CAR excavation block (see Figure 4), indicates the presence of an upper modern eolian A horizon blanketing a 2Bk horizon probably composed of a mixture of eolian and slopewash deposits. Judging from the presence of pedogenic carbonates, this intermediate depositional unit was probably stable enough to experience significant soil formation over time. The basal 3Bk depositional unit appears to represent an older sandy loam alluvium. A significant amount of bioturbation was noted in the upper $30-40 \mathrm{~cm}$ of this basal unit. The bulk of the archeological materials was encountered in the 2Bk horizon, although a significant proportion of the cultural materials seemed to rest on top of the basal unit.

Because no depositional subunits could be noted within the intermediate $2 \mathrm{Bk}$ horizon that contained the bulk of the cultural materials, standard arbitrary $10-\mathrm{cm}$ levels were excavated per each $1-\mathrm{m}^{2}$ unit throughout the vertical column. During the current phase of investigations, four stratigraphic zones $(1,2,2 \mathrm{a}$, and 3$)$ were encountered across the excavation block, and, with only minor variances due to surface undulations, maintained consistency (Figures 11, 12, and 13).

Zone 1 represents the modern humic layer consisting of a very friable, coarse-grained sandy loam replete with root masses from ground cover vegetation. The zone is characterized by a grayish-brown sandy loam that represents the A horizon across the site. A variety of recent historic material was encountered within this approximately $10-20 \mathrm{~cm}$ thick zone, including Styrofoam, shotgun shell casings, and plastic debris (see Figure 11; see also Table 6). Along the southeastern edge of the block, this zone extended to a thickness of $40 \mathrm{~cm}$ (unit N40/E16; see Appendix A). Across the block, a discontinuous lens of charcoal was encountered at approximately $5 \mathrm{~cm}$ below ground surface (see Figure 12). Due to its vertical provenience and the association with primarily historic materials, the charcoal lens is most likely associated with a relatively recent burn episode. Contact with Zone 2 occurs as a gradual wavy boundary.

Zone 2 occurs as a zone of sandy loam ranging from 20 $35 \mathrm{~cm}$ in thickness. In some units, this zone consisted of the B and/or 2B horizons (unit N44/E08; see Appendix A) while in others it also retained a transitional $A B$ horizon (unit N40/E16; see Appendix A). It seems to be equivalent to the $2 \mathrm{Bk}$ horizon identified during testing. Roughly three-quarters of the recovered debitage and formal stone tools occur within this stratigraphic zone. Moderate bioturbation in the form of insect krotovinae and root disturbance are common throughout the block. Numerous probable desiccation cracks appear in profile. As with other types of soil cracking (e.g., vertic), these fissures commonly cause the downward movement of sediments and smaller artifacts and ecofacts. Figure 11 is most representative of the occurrence of cracking encountered throughout the block.

The geomorphic investigation of selected soil columns suggests that a buried $2 \mathrm{~A}$ horizon appears to be present in two units (N46/E14 and N40/E16; see Appendix A). The 2A horizon appears to extend from $20-50 \mathrm{~cm}$ bd in unit N46/E14, and from 20-40 cm bd in unit N40/E16. The inspection of unit profiles from excavation also 


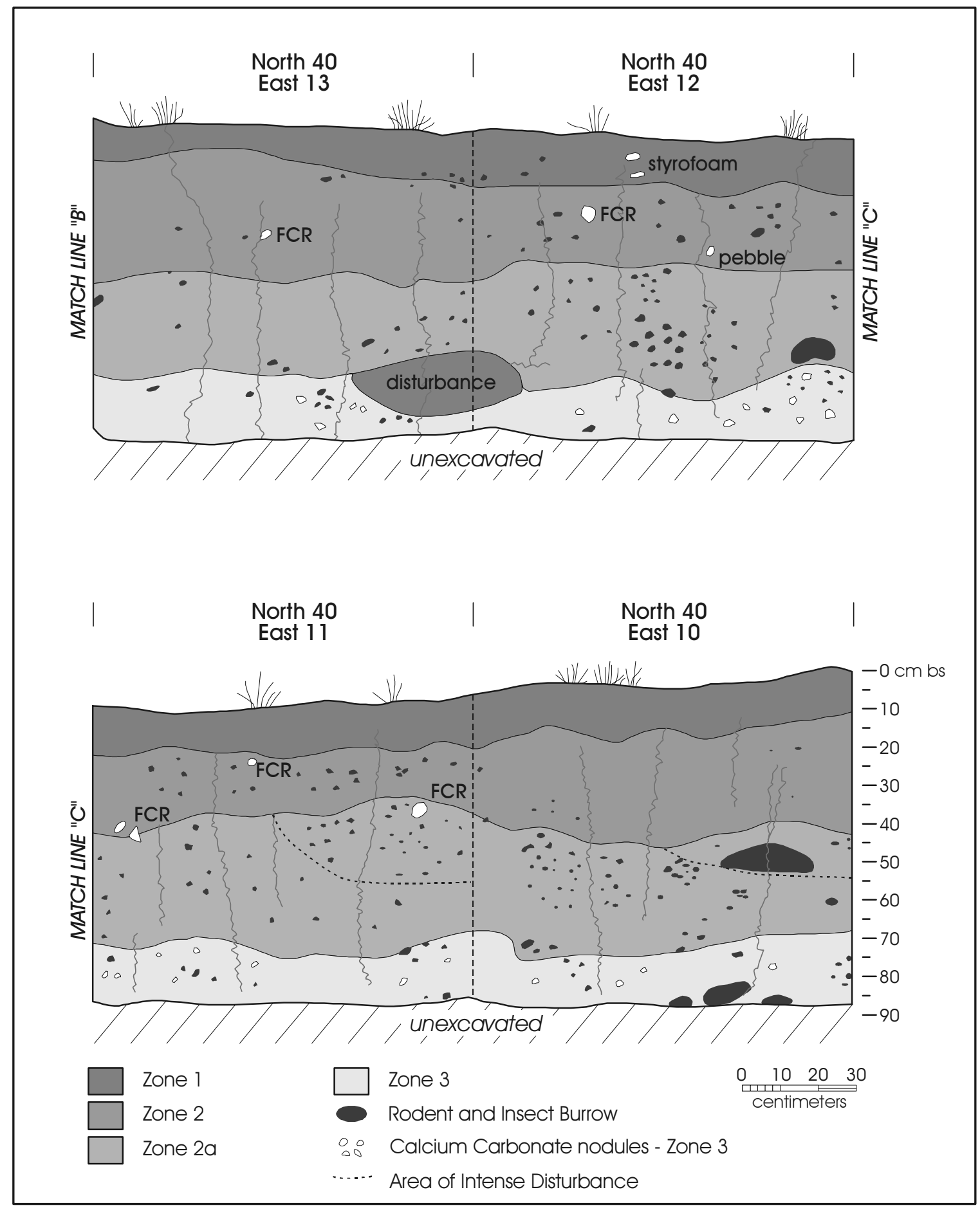

Figure 11. Profile of southern edge of excavation block (E10 through E13). 


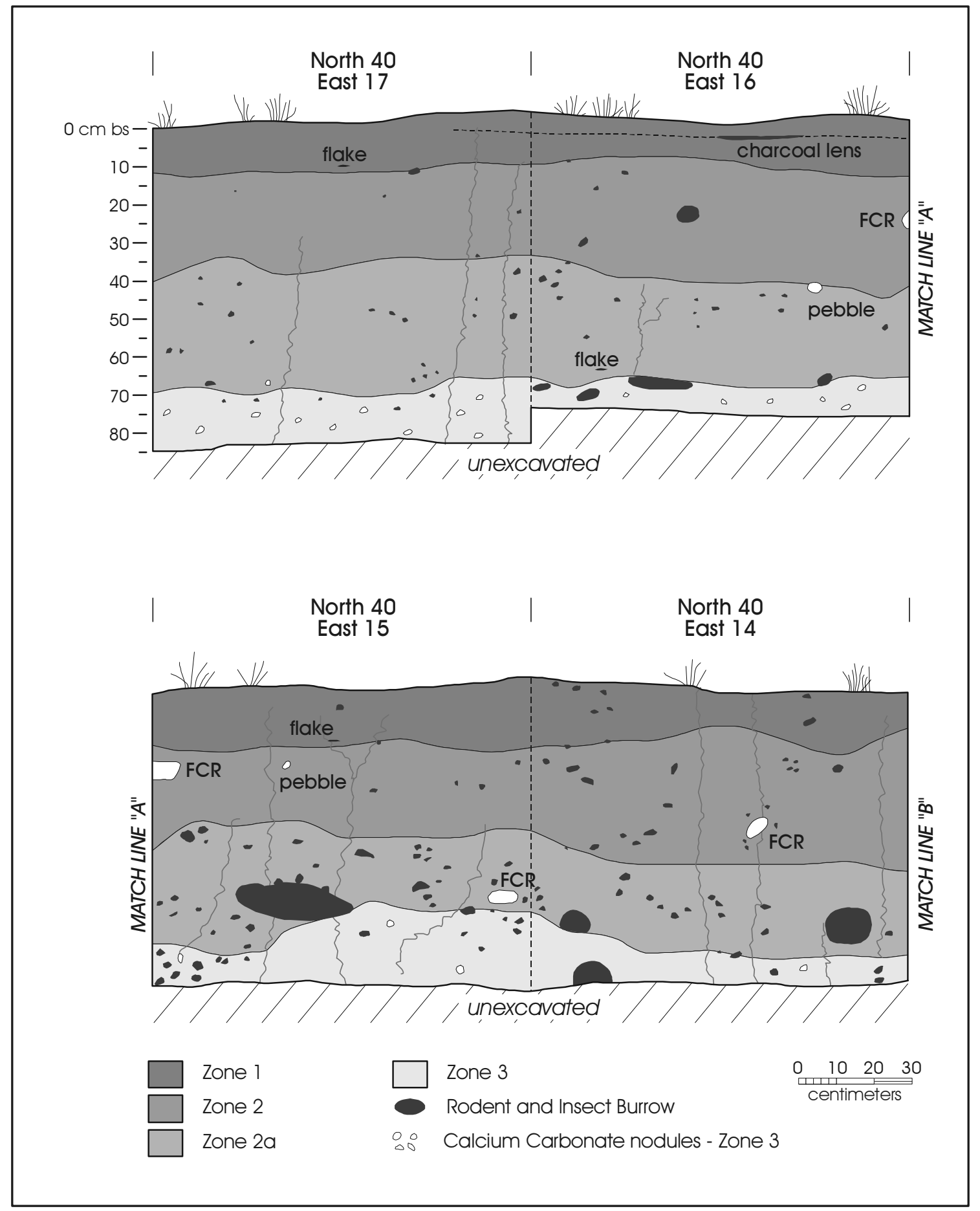

Figure 12. Profile of southern edge of excavation block (E14 through E17). 


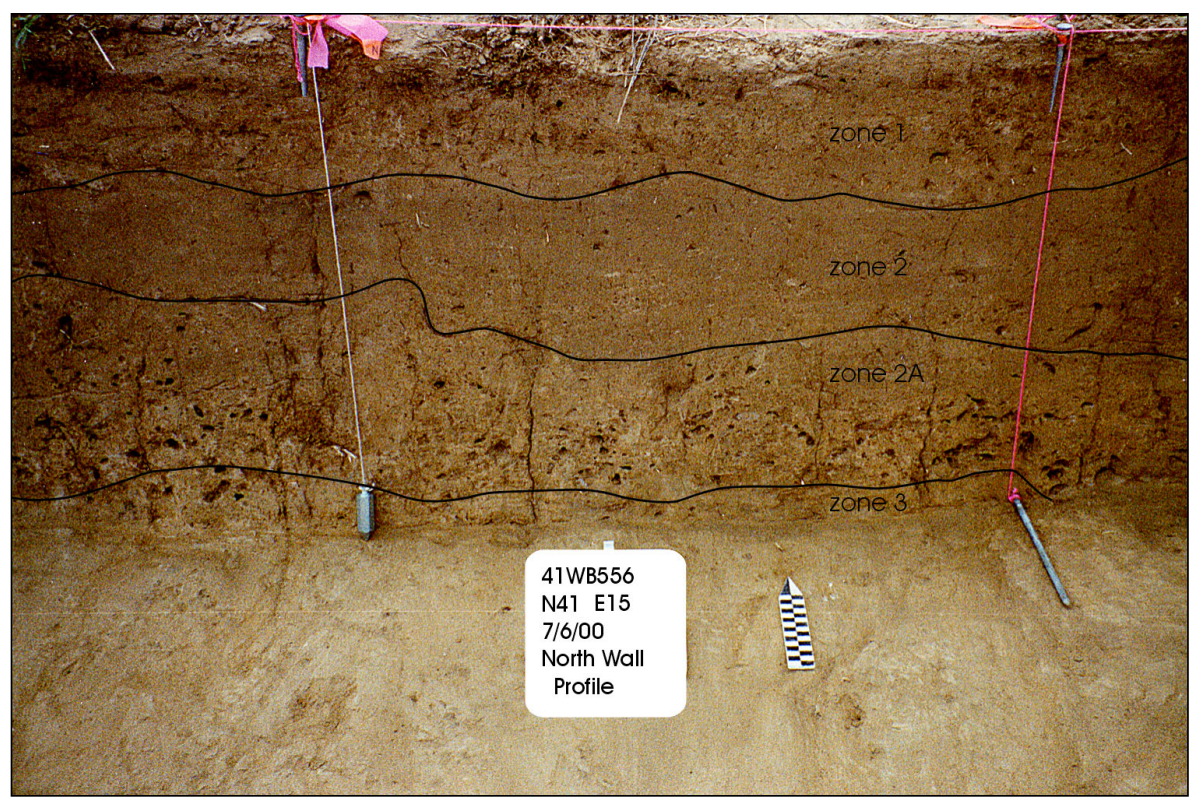

Figure 13. North wall profile at N41/E15 with zones identified.

seems to show a dark organic zone underlying the A horizon in portions of the block. Finally, a cutbank located immediately west of the excavation block, but on private property, also seemed to contain a buried A horizon. Although, the 2A horizon appears to be buried by only $15-20 \mathrm{~cm}$ of matrix, it is possible that it was formerly capped by a thicker layer that has since been partially eroded and thinned. While alternating $\mathrm{A}$ and $\mathrm{C}$ horizons were noted in previous work at the site (Quigg and Smith 2000), these were present in the profiles of BHTs located immediately next to the creek channel rather than on the $\mathrm{T} 0$ terrace. While the geomorphological study suggests that this buried 2A horizon was probably present throughout the excavation block, it was not identified during the fieldwork and as such it does not have its own zone designation.

Zone $2 \mathrm{a}$ is actually the exaggerated wavy boundary between Zones 2 and 3. It ranges in thickness from 20$30 \mathrm{~cm}$ and it also contains portions of the $\mathrm{B}$ and/or $2 \mathrm{~B}$ horizons. The zone is subsumed in the $2 \mathrm{Bk}$ horizon identified during testing. Some archeological materials as well as burned rock features (Features 21, 22, and 23) were encountered within this zone. Massive bioturbation, in the form of insect and rodent burrowing, has all but obliterated the former contact of these two zones. The comparison of the various zones (see Figures 11, 12, and 13) clearly shows that bioturbation is most abundant within Zone 2a. The stratigraphy is further obscured through translocation of the darker-stained sandy loam material downward into Zone 2a. If a $2 \mathrm{~A}$ buried paleosol was present across the block, its upper aspect would be encountered near the top of Zone 2, while its lower aspect would be well within Zone 2a. It is possible that Zone 2 represents the buried $2 \mathrm{~A}$ horizon and that its base is the erosional break that seems to be represented by the exaggerated wavy boundary between Zones 2 and 3. A similar erosional break was noted in BHT 12 excavated at the site during testing (Quigg and Smith 2000:17).

Zone 3 consists of the basal alluvium (i.e., 3Bk) as identified during the testing phase (Quigg and Smith 2000), and provided the terminal bound for vertical excavation. The zone represents the firm sandy loam C or $2 \mathrm{C}$ horizon underlying the entire site. The sediment consists of an extremely compact sandy loam with calcium carbonate filaments occurring at the top of the zone grading downward to increasing nodules at terminal elevations. The vertically oriented fissures noted within the previous zones continue into Zone 3 . These cracks probably account for the relatively sparse cultural material encountered within this unit. It is interesting to 
note that along the southern baseline of the excavation block this basal unit was encountered at an average of $80 \mathrm{~cm} \mathrm{bd}$, and less than four meters north, was encountered at less than $60 \mathrm{~cm}$ bd. This indicates a landform inconsistent with the current ground surface; moreover, that the southern portion of the block possibly exposes a portion of a former terrace along Becerra Creek, suggesting closer site proximity to the stream.

Widespread bioturbation exhibited across the site was attributable to both insect and rodent activity. Extensive subterranean termite colonies spanned the vertical column and had displaced sediments from all four of the zones encountered. Curiously, none of the termite colonies were active during the data recovery phase and no termites were encountered in or around the site. Similarly, abundant rodent burrows were encountered, primarily in the lower levels, but again, none were active.

A single active subterranean ant colony was, however, located along the southern portion of the site. Hundreds of large ants were observed entering and exiting an evident main artery to the underground nest. Worker ants exiting the orifice were typically carrying peds of sediments, it is inferred, to clear the array of tunnels comprising their complex. Of note, though, was a particular ant carrying a charcoal fragment out of the hole and away from the nest (Figure 14). This behavior is of archeological importance if burrowing colonydwelling insects systematically remove or displace charcoal during the course of burrow construction and/ or maintenance.

Of equal importance is the apparent association between rodents, rodent burrows, and charcoal. The majority of the rodent burrows encountered, which numbered in the hundreds, contained some evidence of charcoal. This cooccurrence was initially dismissed as happenstance until the lower portion of a burrow and abandoned den was profiled during excavation. The burrow and roof of the den was encountered in Level 7 ( $70 \mathrm{~cm}$ bd) of XU N42/ E14, with the basin of the trap bend extending to approximately $90 \mathrm{~cm}$ bd. A small amount of charcoal was present in the basin of the trap bend. The den, however, was replete with charcoal, lining the floor of the $10 \times 20-\mathrm{cm}$ chamber (Figure 15). The fact that rodents

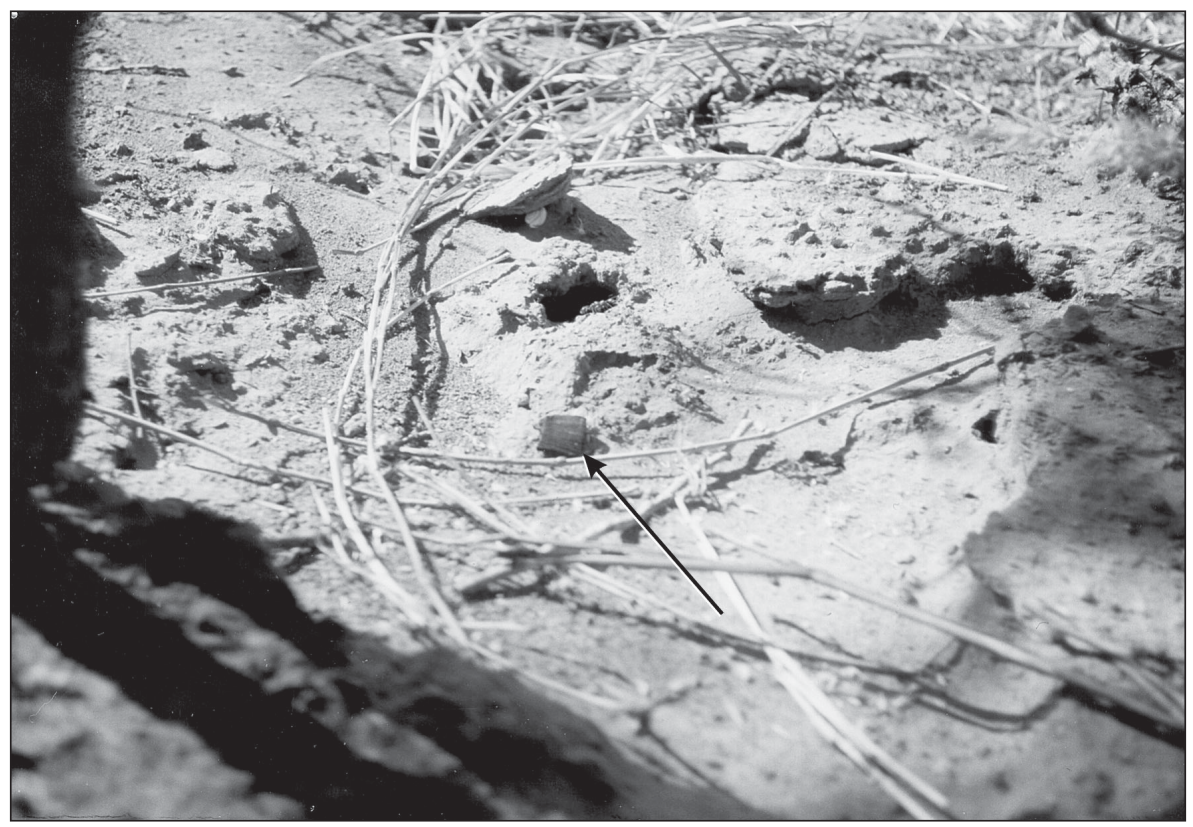

Figure 14. Example of bioturbation on site. Note ant carrying a charcoal fragment out of and away from its subterranean colony. 


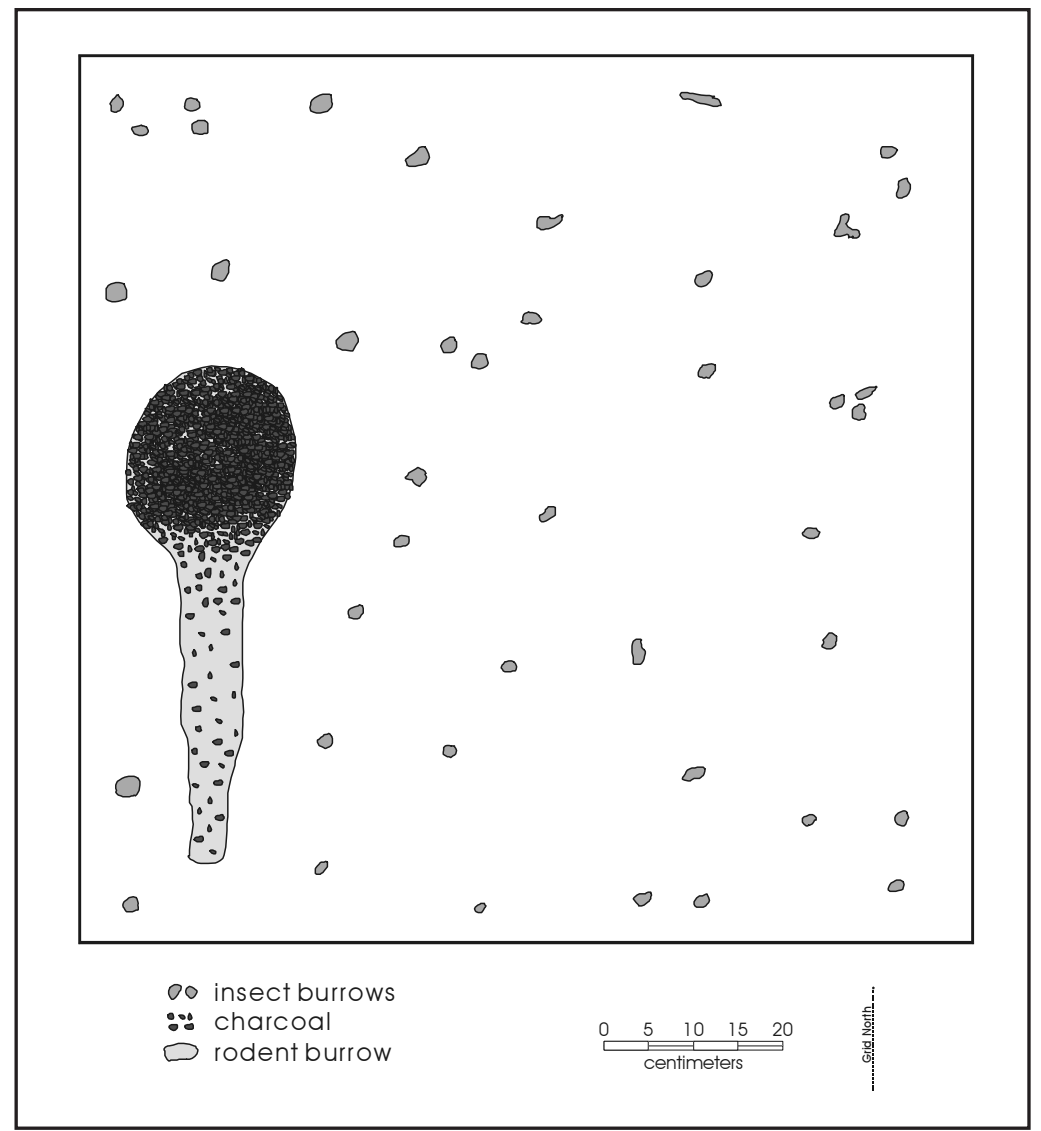

Figure 15. Plan view of N42/E14, Level 8, depicting a charcoal-lined rodent den. that there is no indication of a former living surface within the columns examined. This would suggest that if the buried $2 \mathrm{~A}$ horizon was present within these three excavation units, extensive bioturbation of the sediments may have severely impacted the deposits creating a matrix that appears to be homogenous throughout the vertical column.

\section{The Distribution of Unmodified Debitage and Temporally Diagnostic Artifacts}

This section focuses on the vertical distribution of unmodified lithic debitage and projectile points. Figure 16 presents the overall distribution of the chipped stone debitage by level for the excavation block. The bars represent the average number of debitage present in a $1-\mathrm{m}^{2}$ unit for a given level. Clearly, at the block level, only a single peak is present in Level 3, with a gradual fall-off below that level. Though not shown, at the block level, the distributional pattern produced by the number of burned rock is similar. Only a single peak is present in the upper levels of the deposit. may indeed collect charcoal in their dens raises serious questions about the recovery context of any fragments of carbonized wood that are not in direct association with cultural features. In addition, the matrix surrounding each feature was riddled with rodent and/or insect burrows. Therefore, the associational integrity of charcoal fragments recovered even from the matrix of rock-lined hearth features may be called into question (i.e., if the charcoal is not wedged between two rocks or under a rock).

\section{Magnetic Sediment Susceptibility}

A total of 22 samples comprising three vertical columns (N42/E10, N44/E11, and N44/E14) in the excavation block was subjected to magnetic sediment susceptibility testing (see Appendix E). Most susceptibility values have a relatively narrow range between 33 and 40, suggesting
The peaks in unmodified debitage and burned rock fall approximately at the boundary between Zones 2 and 2a and are just slightly below the buried $2 \mathrm{~A}$ horizon suggested by the geomorphic investigations of the site (see Appendix A). However, the combined block-level analysis significantly over simplifies the range of variability in recovery noted in distinct units. Figures 17, 18, and 19 provide similar debitage distributional graphs for three units selected at random for a more detailed consideration of the patterns. Interestingly, each of the units has patterns very different from the block pattern shown in Figure 16. In each of the graphs, at least two distinct peaks are present, though they occur at different depths.

The most interesting case is depicted in Figure 19 for N40/E17. Here, Level 8, which contained 67 pieces of chipped stone, is clearly isolated from Levels 7 and 9. 


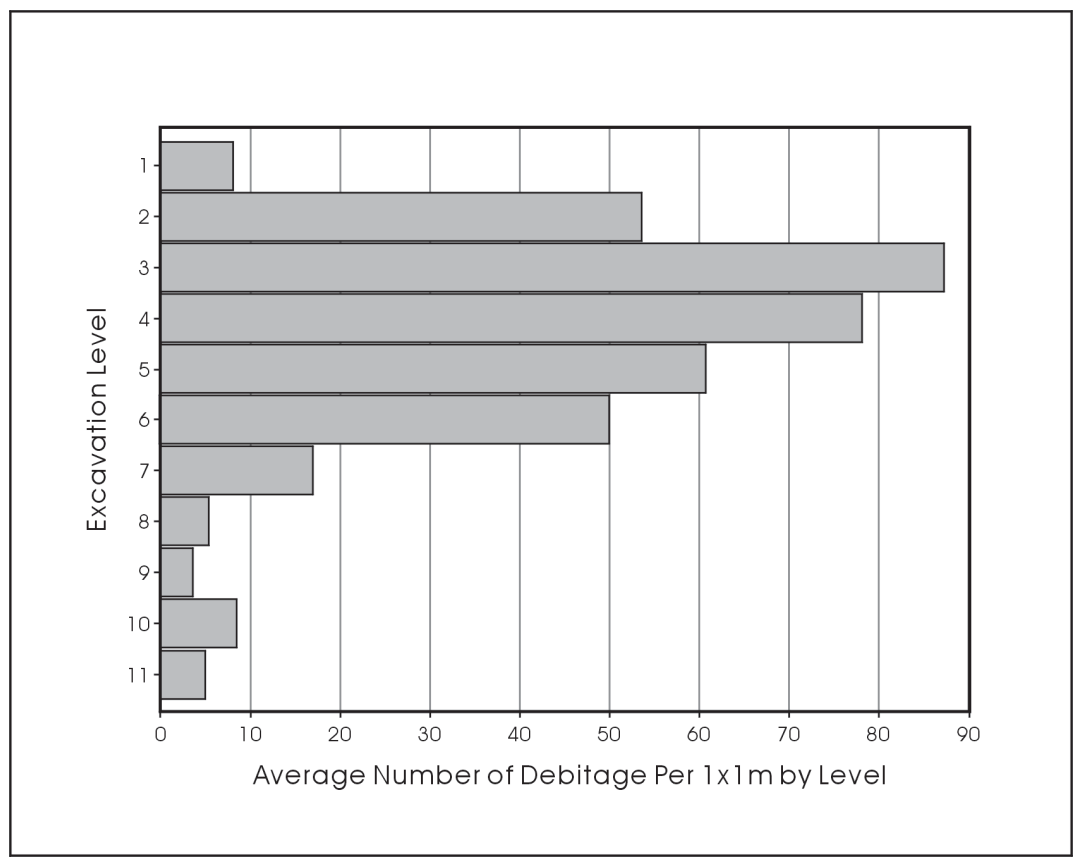

Figure 16. Average number of debitage per 1-m² by level.

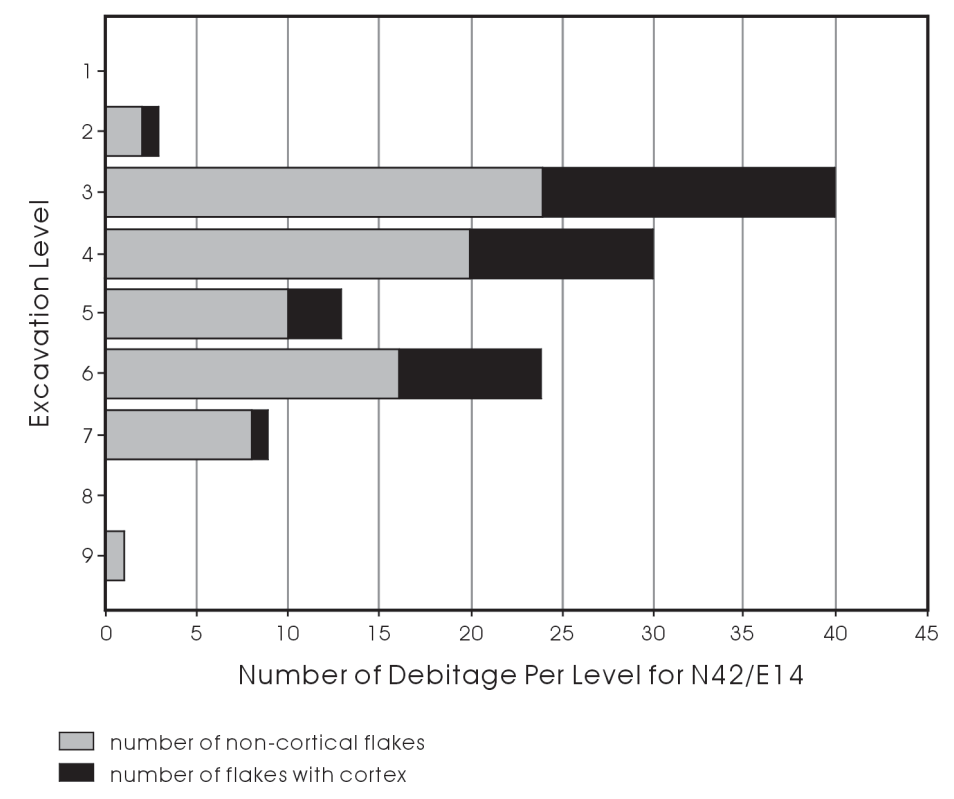

Figure 17. Number of cortical and non-cortical flakes by level for N42/E14. 


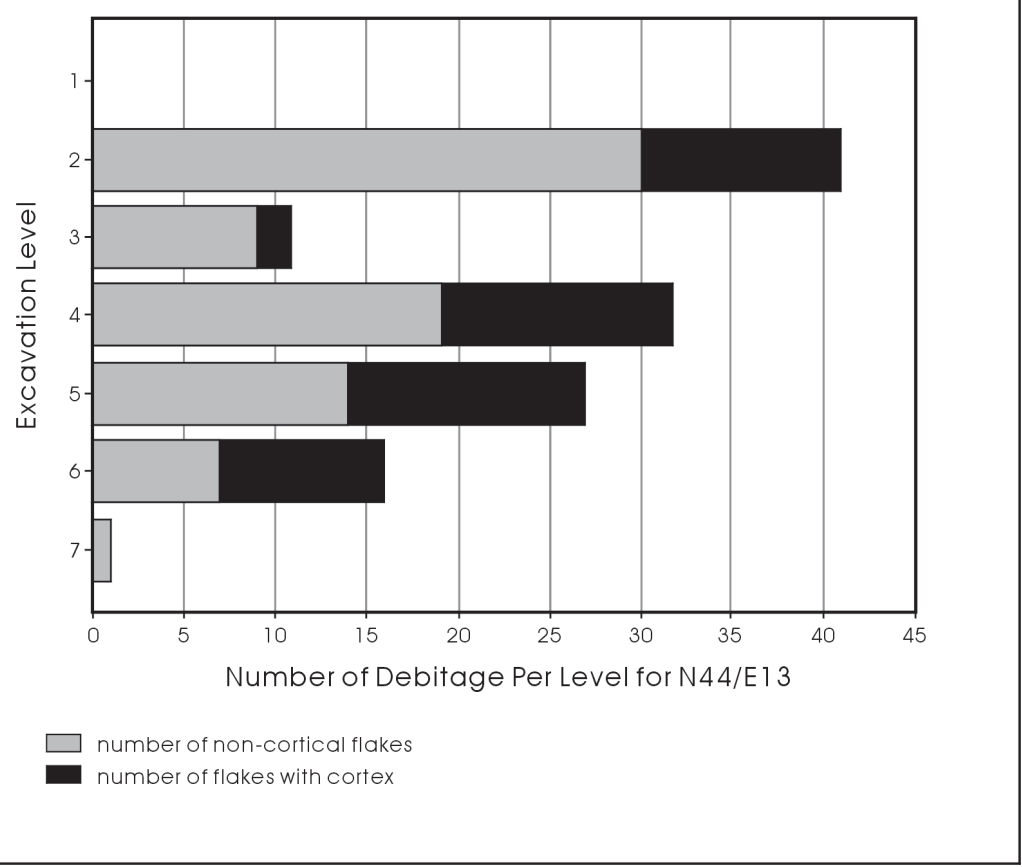

Figure 18. Number of cortical and non-cortical flakes by level for N44/E13.

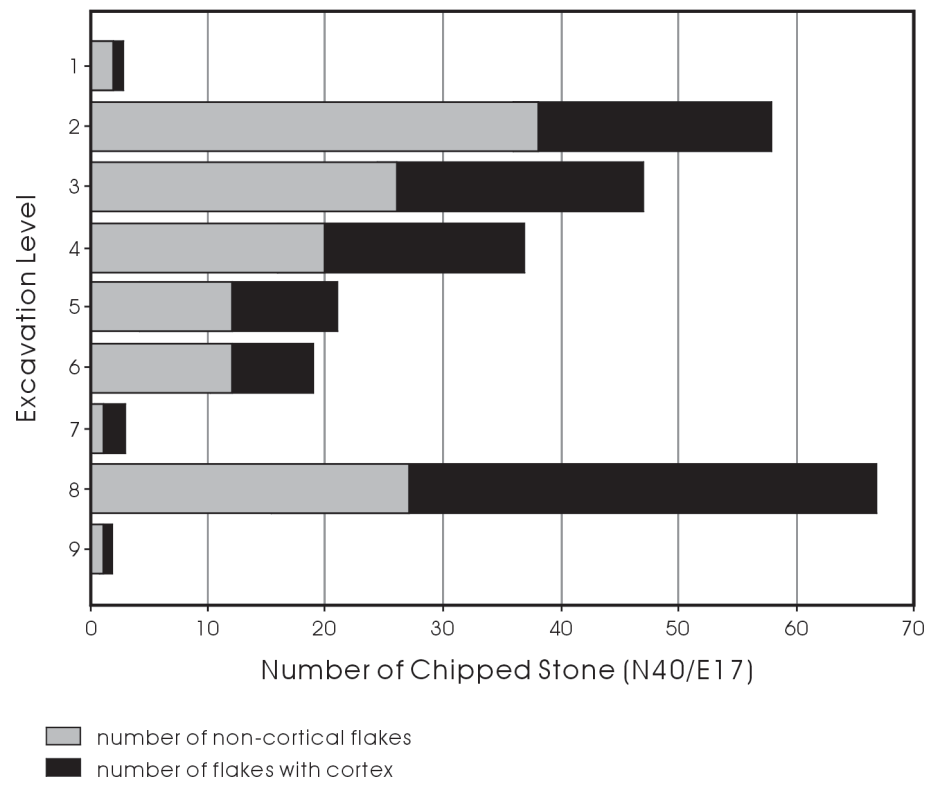

Figure 19. Number of cortical and non-cortical flakes by level for N40/E17. 
This level also had radically different percentages of flakes with cortex relative to the upper levels, and the assemblage within this level was dominated by only a few distinctive raw material types. Figure 20 presents a photograph of one of these tool stone types. The raw material depicted probably represents the reduction of a single nodule, as the internal structure, color, and cortex of the flakes are identical. This raw material was not present in the upper mode within this unit, and was not represented in the debitage from the other two $1-\mathrm{m}^{2}$ units examined. Given the wide variety of debitage sizes represented, the discrete nature of the distributional patterns for Levels 7, 8, and 9, and the concentration of this material to a single level, it is probable that, in this case, the material is in situ. However, given the overall distributional pattern, the level of bioturbation documented in the block, and the mixed chronological indicators, the pattern in Level 8 of N40/E17 must be considered an exception.

In addition, the distribution of chipped stone within the block was considered by level for Levels 2 through 8 . Each level was examined for patterning in this data set. While several intriguing peaks and voids at a small scale were seen, only in Level 2, depicted in Figure 21, were there larger scale patterns. Figure 21 clearly demonstrates that within this level, a low density pattern of roughly 12 square meters, centered on N43/E15, is present. This

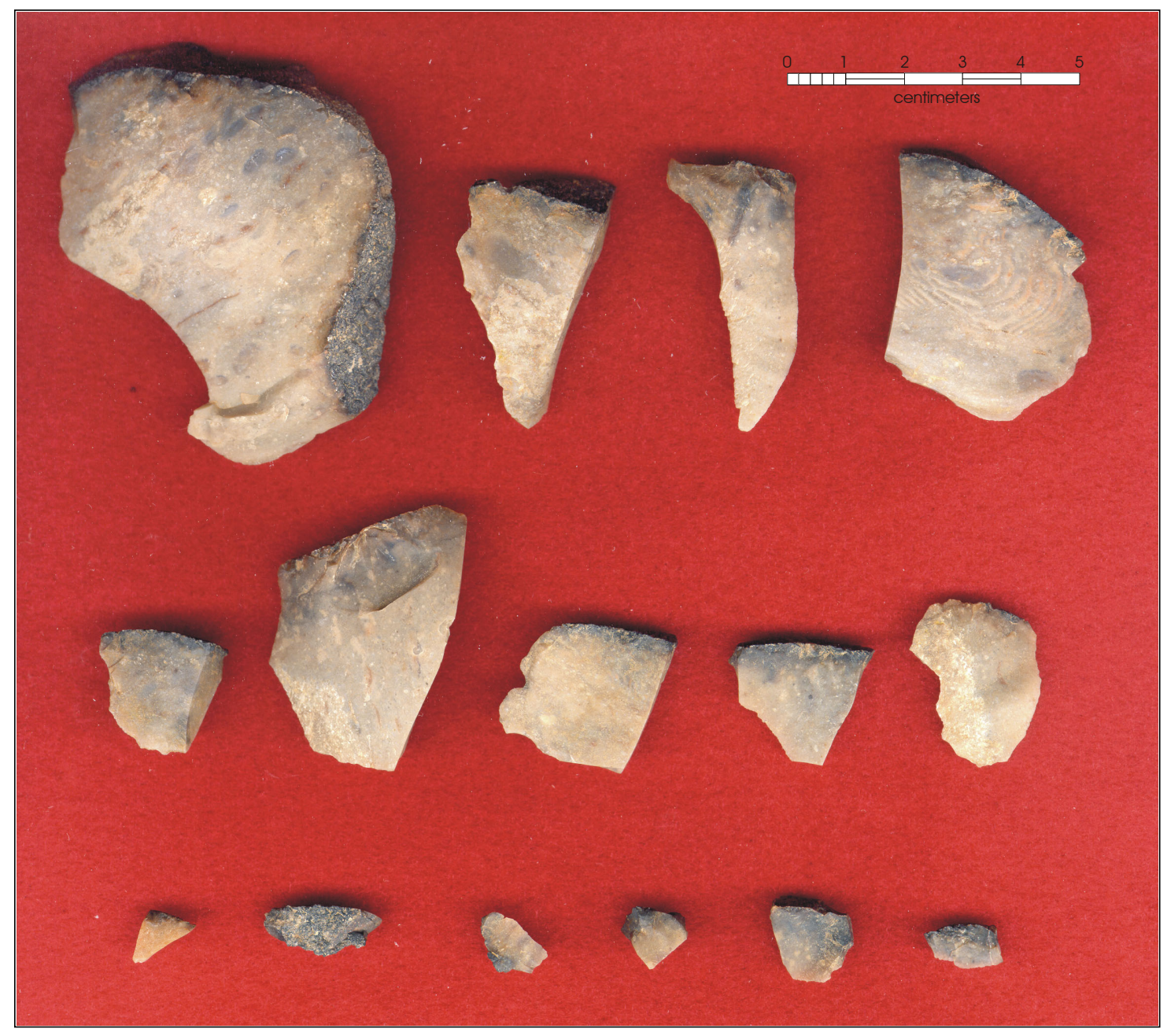

Figure 20. Debitage (Lot \#320), probably from a single nodule, in Level 8, N40/E17. 
area is surrounded on three sides by higher spikes in debitage. Figure 22, which shows the distribution of burned rock in Level 2, reveals that this same low density area is present in that data set. A variety of possibilities may account for the similarities in the two distributions. However, given the overall level of disturbance, it is unlikely that these patterns can be cleanly attributed to human behavior.

Arrow points were most common in Level $4(42 \%)$, followed by Level 3 (32\%; see Table 2 [Chapter 6]). Only one arrow point, a distal blank fragment, came from below Level 4 (N41/E12, Level 6). The remaining arrow points came from Level $2(n=3)$ and Level $1(n=1)$ of the site. The Caracara points are from Level $3(n=2)$ and Level $4(n=1)$, the single Perdiz is from Level 4, while the three Starr points were spread between Levels 1, 2, and 4 of the site. The Toyah points are from Levels 2 $(n=1)$ and $4(n=2)$ of the site. The largest number of dart points comes from Level 3 ( $n=8,44 \%)$, followed by Level $2(n=5,28 \%)$ of the site. A total of 28 percent of the dart points come from Level 4 or deeper. Tortugas points were found in Levels $2(\mathrm{n}=1), 3(\mathrm{n}=3)$, and $5(\mathrm{n}=1)$, while Abasolo points were in Levels $2(n=2), 3(n=1)$, and $6(n=1)$. The Refugio points both came from Level 3 of the site.

Arrow points such as the Caracara, Perdiz, and Starr types have been clearly established as dating to the Late Prehistoric period (see Turner and Hester 1993). The chronological position of the dart point types found at the site is a little less clear, although for the most part the dart points are thought to predate the arrow points. Tortugas points have a broad date range from roughly 4450 to about 2350 BP (see Hall et al. 1986:399), and Refugio points may be roughly contemporaneous dating from 3400 to about 2400 BP based on specimens from 41WB437 and 41BX28 (see Quigg et al. 2000:Figure 13.1; Taylor and Highley 1995:188). Although it was assumed that in Texas Abasolo points date between 5000-3000 в.с. (Suhm et al. 1954:400), specimens from 41BX28 appear to date as late as 2810-2500 BP (Taylor and Highley 1995). Based on this limited number of specimens derived from dated contexts, it appears that all three types may be roughly contemporaneous at least during the later part of the Middle Archaic and part of the Late Archaic periods.
With this chronological breakdown as background, it is notable that excavation Levels 2 and 3 both contain a higher number of dart points than arrow points. Five dart points consisting of two Abasolo, one Tortugas, one untypeable fragment, and a point blank were recovered from Level 2, in addition to a Starr, a Toyah, and an untypeable arrow point fragment. Level 3 produced eight dart points and six arrow points. The dart points include three Tortugas, two Refugio, and one Abasolo among the typed specimens. Two Caracara arrow points were also recovered from the level. Interestingly, arrow points are more common than dart points in Level 4. Here, eight arrow points were recovered while only two dart points were found, one was an untypeable fragment the other was a probable dart point bank. The arrow points include all four types found at the site: Caracara, Perdiz, Starr, and Toyah.

It is clear from these distributions that the arrow and dart point-sized lithic artifacts are moving both up and down within the deposits of the site. The actual pattern of disturbance or any directionality within the process is difficult to discern. At least two different possible scenarios may explain the patterns described. One possibility is that the pattern reflects reversed stratigraphy and the washing in of dart points on a previously stable surface occupied during the Late Prehistoric. A second possibility is that a stable surface, the buried $2 \mathrm{~A}$ horizon, was present somewhere between $20-30 \mathrm{~cm}$ bd and this surface was exposed long enough to be occupied by both Archaic and Late Prehistoric groups. Due to extensive bioturbation it may be possible that the smaller of the artifacts would have moved down through the profile and the larger artifacts would have moved up through the profile generating the pattern visible in the projectile point distributions.

The analysis of 600 pieces of unmodified debitage from a total of 17 randomly chosen units indicates that the stable surface scenario may not explain the patterns in projectile points. Level 1 has the highest mean debitage size (20.2 mm, $\mathrm{n}=15$ ) while Level 2 has the smallest mean debitage size (17.8 mm, n=124). However, mean debitage size increases from Level 3 through 5 from $18.9 \mathrm{~mm}$ $(\mathrm{n}=195)$ to $19.9 \mathrm{~mm}(\mathrm{n}=42)$, respectively. We would expect quite the opposite pattern with increasing depth below a stable occupation/deposition surface. That is, 


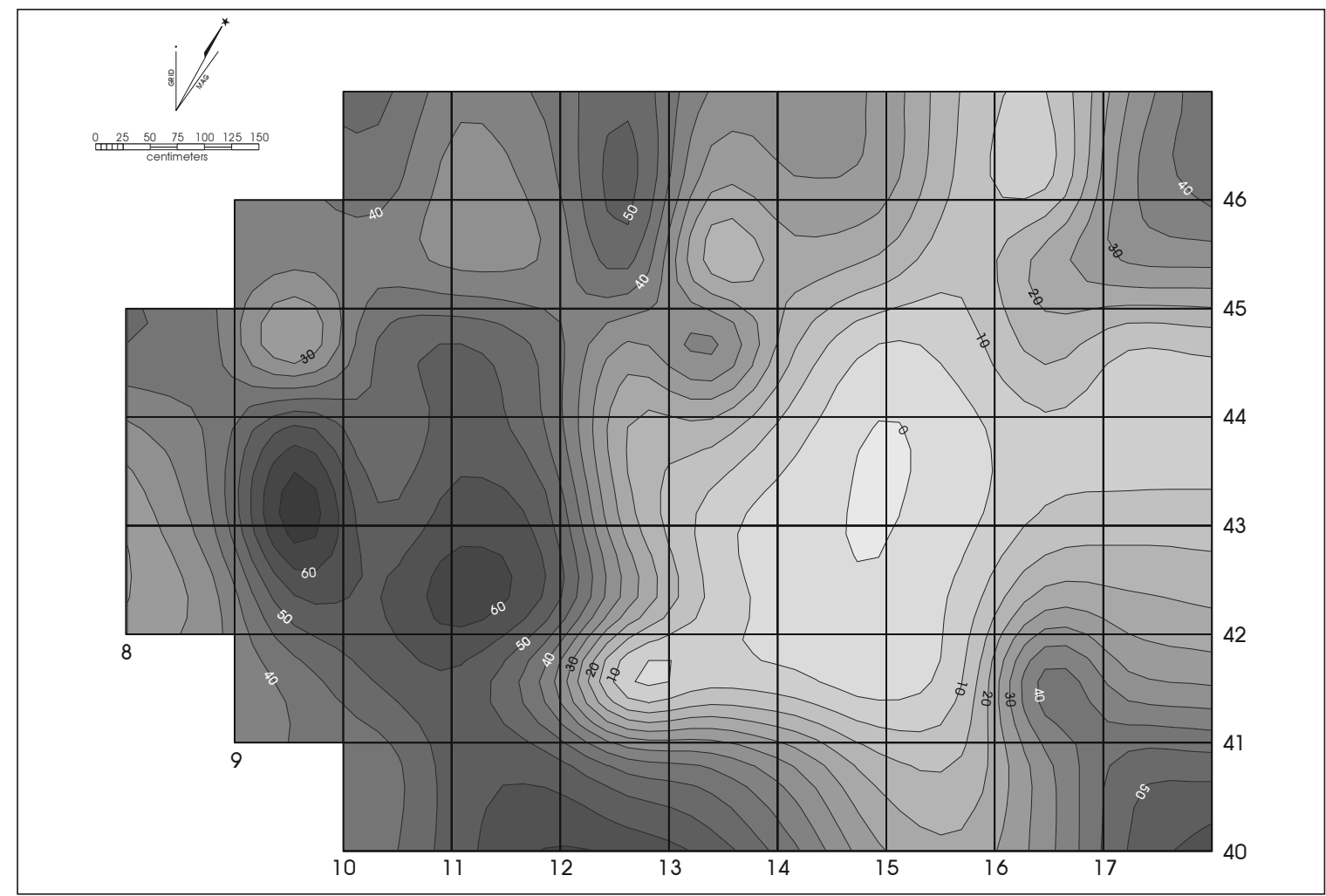

Figure 21. Distribution of chipped stone in Level 2.

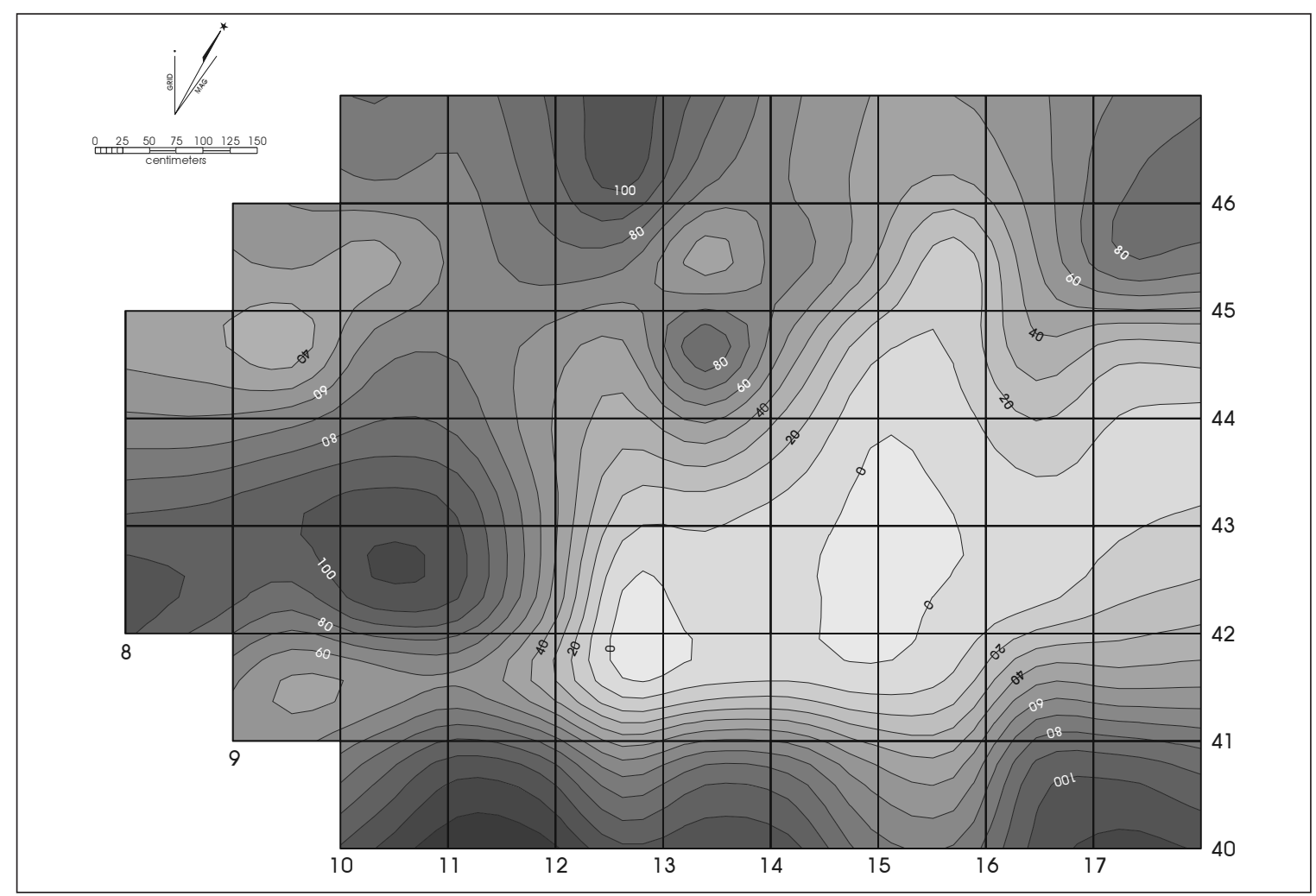

Figure 22. Distribution of burned rock in Level 2. 
mean debitage sizes should decrease with increasing depth, rather than increase as is the case at 41WB556.

In summary, general observations about the characteristics of the depositional zones excavated at the site, the numerous signs of bioturbation, the vertical distribution of diagnostic projectile points, and the patterns in unmodified debitage maximum dimension all indicate that the deposits are heavily disturbed. However, as noted in the previous chapter, 14 discernible features were uncovered in the excavation block. These features were characterized by discrete clusters of sandstone. In several instances individual rocks could be refit, suggesting that there was minimal movement of these larger-sized stones. The evidence suggests, then, that while burned rock from within recognizable features may not be subject to extensive vertical movement, other data sets, including items in the size ranges of arrow points and dart points, have been dramatically impacted by bioturbation. These other data sets include charcoal.

\section{Radiocarbon Dates}

Twenty-seven samples were submitted to Beta Analytic, Inc. for radiometric assays. While 155 charcoal samples, totaling 2,151.7 grams, were recovered from pointprovenienced loci, due to the obvious bioturbated nature of the sediments only 13 samples $(16.2 \mathrm{~g}$ ) recovered from apparently in situ features were submitted for analysis. An additional 14 samples of organic residue, obtained from burned sandstone nodules from the same features as the charcoal samples, also were submitted for radiometric analysis.

Table 7 presents the corrected radiocarbon ages of the 27 samples, along with their Beta Analytic sample numbers, provenience information, feature association, material dated, and cluster groupings. Additional information on these samples can be found in Appendix B. The cluster groupings are derived from clustering procedures suggested by Ward and Wilson (1978; Wilson and Ward 1981). All radiocarbon dates from the excavation block were tested using Ward and Wilson's Case II assumptions and the DSPLIT radiocarbon program (Kintigh 1992:83-85). Ten different groups were identified by this procedure, and the cluster group identifications are ranked from 1, the most recent group, to 10 , the oldest group. Comparison of the cluster groupings with either individual features or by levels suggests little relationship with the dating groups. While samples from the two youngest groups, clusters 1 and 2, are primarily confined to the upper levels, samples from older groups (e.g., groups 4, 5, and 7) are also present in these upper levels. Conversely, Level 7 had a date from group 3, a date from group 4, and a date from group 5 . Similarly, when individual features are considered, no apparent relationship is present. It appears, based on these data, that the samples are from a turbated deposit.

Reference to Figure 23 (see also Table 7), which plots the probability curves from each of the dates using the OxCal calibration program (Ramsey 2000), reinforces that impression. Individual dates from features in Level 3 are statistically indistinguishable from dates in Level 7. The oldest dates in the excavation are from two samples from Feature 26, Level 6, which are roughly 1,700 years older than Level 5 dates, and roughly 800 years older than Level 7 dates.

As noted previously, evidence for bioturbation of the deposits was extensive. Zones $2 \mathrm{a}$ and 3 , in particular, exhibited many signs of turbation. The repeated association of charcoal with animal burrows also brings into question the associational integrity between charcoal, a relatively light and small component of the archeological matrix, and burned rock features. Since at least within well-defined burned rock concentrations, the association of specific burned rocks with features was less questionable (i.e., wedged between other rocks, fire cracked in situ), it seems probable that dates from sandstone would provide a more reliable method of feature dating. Unfortunately, the comparison of charcoal and organic dates from the same features (Figure 23) further complicates rather than illuminates the ages of the various features. The pattern in Figure 23 does suggest that in two cases, Feature 25 and Feature 23, radiocarbon dates from organic material within burned sandstone appear to be reasonably close. However, reference to Table 7 clearly indicates that in no case do dates on sandstone from the same feature cluster into a common group. Charcoal dates fair only slightly better with two cases of clustering, one in Feature 19 and one in Feature 23. Unfortunately, both features date to the same cluster group (3), though they are from different levels of the excavation. 
Table 7. Radiocarbon dates from 41WB556

\begin{tabular}{|c|c|c|c|c|c|c|c|}
\hline $\begin{array}{c}\text { Car Sample } \\
\text { ID \# }\end{array}$ & $\begin{array}{c}\text { Beta } \\
\text { Analytic \# }\end{array}$ & $\begin{array}{c}\text { Excavated } \\
\text { Unit }\end{array}$ & Level & Feature & Material Dated & $\begin{array}{c}\text { Corrected } \\
\text { Age }\end{array}$ & $\begin{array}{c}\text { Cluster } \\
\text { Grouping }\end{array}$ \\
\hline 1 & 149847 & N40 E14 & 2 & 14 & Charcoal & $220+/-40$ & 2 \\
\hline 2 & 149848 & N40 E15 & 3 & 14 & Charcoal & $100+/-40$ & 1 \\
\hline 3 & 149860 & N40 E14 & 3 & 14 & Burned Sandstone & $10+/-30$ & 1 \\
\hline 4 & 149861 & N40 E14 & 3 & 14 & Burned Sandstone & $760+/-40$ & 4 \\
\hline 5 & 149851 & N42 E11 & 3 & 19 & Charcoal & $600+/-40$ & 3 \\
\hline 6 & 149852 & $\mathrm{~N} 42 \mathrm{E} 13$ & 3 & 19 & Charcoal & $480+/-80$ & 3 \\
\hline 7 & 149864 & N42 E11 & 3 & 19 & Burned Sandstone & $1680+/-40$ & 7 \\
\hline 8 & 149865 & N42 E11 & 3 & 19 & Burned Sandstone & $830+/-40$ & 5 \\
\hline 9 & 149853 & N42 E14 & 3 & 20 & Charcoal & $300+/-40$ & 2 \\
\hline 10 & 149857 & N45 E11 & 4 & 25 & Charcoal & $1710+/-50$ & 7 \\
\hline 11 & 149858 & N45 E11 & 4 & 25 & Charcoal & $580+/-40$ & 3 \\
\hline 12 & 149870 & N45 E11 & 4 & 25 & Burned Sandstone & $900+/-40$ & 5 \\
\hline 13 & 149871 & N45 E11 & 4 & 25 & Burned Sandstone & $640+/-50$ & 3 \\
\hline 14 & 149859 & N43 E09 & 4 & 27 & Charcoal & $620+/-40$ & 3 \\
\hline 15 & 149873 & N43 E09 & 4 & 27 & Burned Sandstone & $340+/-40$ & 2 \\
\hline 16 & 151640 & N43 E09 & 4 & 27 & Burned Sandstone & $1130+/-40$ & 6 \\
\hline 17 & 149855 & N44 E13 & 5 & 23 & Charcoal & $610+/-60$ & 3 \\
\hline 18 & 149868 & N44 E13 & 5 & 23 & Burned Sandstone & $640+/-40$ & 3 \\
\hline 19 & 149869 & N44 E13 & 5 & 23 & Burned Sandstone & $720+/-50$ & 4 \\
\hline 20 & 149856 & N44 E14 & 5 & 23 & Charcoal & $500+/-60$ & 3 \\
\hline 21 & 149849 & N41 E10 & 6 & 16 & Charcoal & $1040+/-40$ & 6 \\
\hline 22 & 149862 & N41 E10 & 6 & 16 & Burned Sandstone & $3040+/-40$ & 9 \\
\hline 23 & 149863 & N41 E10 & 6 & 16 & Burned Sandstone & $3410+/-40$ & 10 \\
\hline 24 & 149850 & N41 E13 & 7 & 17 & Charcoal & $2130+/-40$ & 8 \\
\hline 25 & 149854 & N42 E15 & 7 & 22 & Charcoal & $640+/-40$ & 3 \\
\hline 26 & 149866 & N42 E15 & 7 & 22 & Burned Sandstone & $960+/-40$ & 5 \\
\hline 27 & 149867 & N42 E15 & 7 & 22 & Burned Sandstone & $690+/-40$ & 4 \\
\hline
\end{tabular}

Perhaps more persuasive with regard to problems with dating at 41WB556 is the visual comparison between the overall date pattern in either burned rock or charcoal in Figure 23. Even if we could discount the two early dates on rock from Feature 16, there is minimal change in dates throughout the sequence. Even if we were to discount all charcoal dates due to questionable associations with burned rock features, the distribution of organic dates alone would not invite greater confidence in the integrity of the deposits. Figure 24 represents such a plot. Here, we have plotted, at a 2-sigma range, all organic residue dates for Levels 3 through 7 . Inconsistency remains even within this data set. Dates from samples collected from Level 7 are statistically indistinguishable from dates from Levels 5, 4 and 3. In addition, dates from multiple specimens from within the same level overlap only in two cases. While it is certainly possible that the overall deposition within the block was rapid and that the lack of patterning through the levels in the block reflect that rapid sedimentation, this would not account for the dramatic reversals between Levels 6 and 7 shown in the figure. 


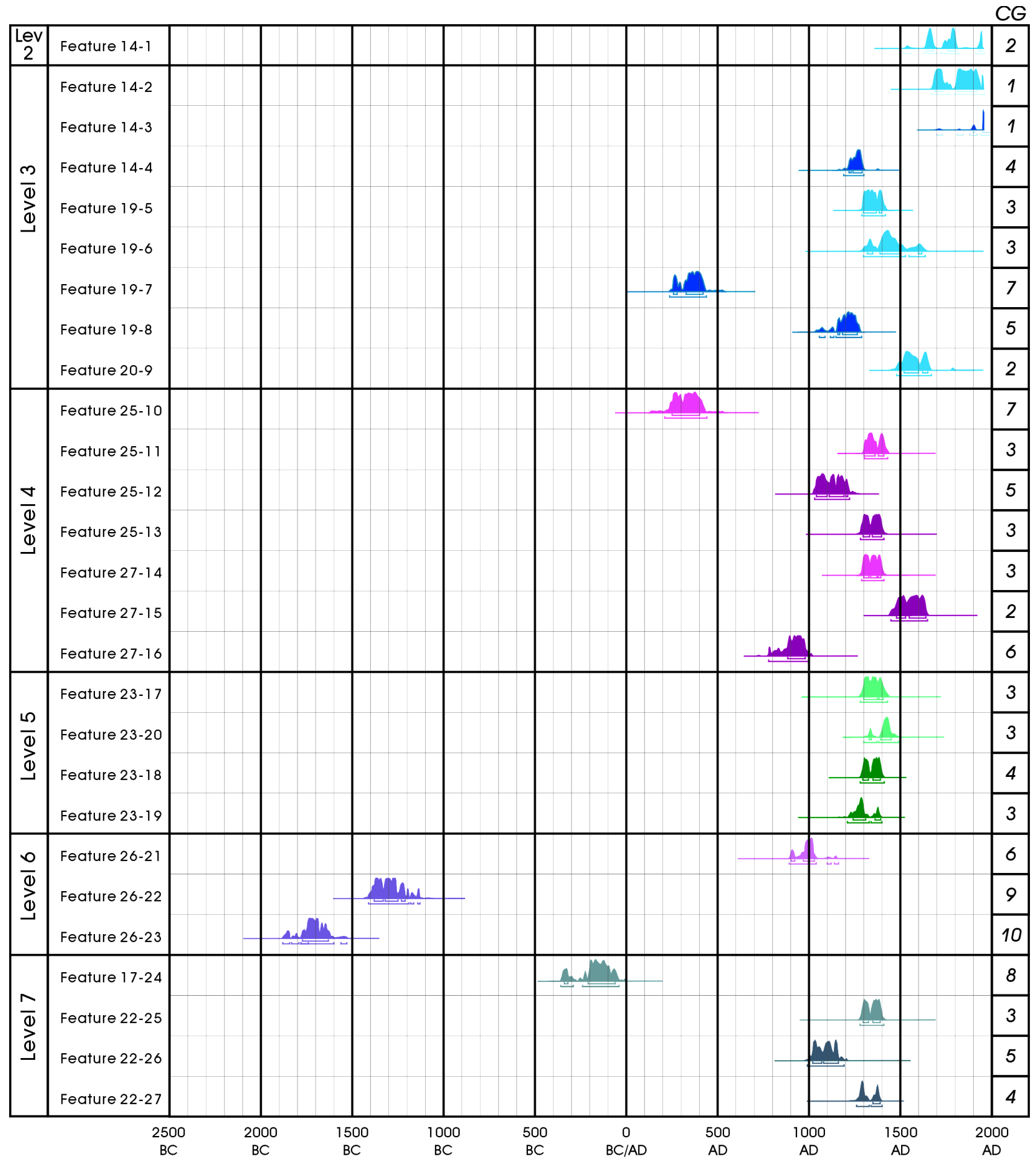

Note: Dark shades are organic dates on burned sandstone.

Figure 23. Radiocarbon dates from the excavation block at 41 WB556 (CG=Cluster Groups). 


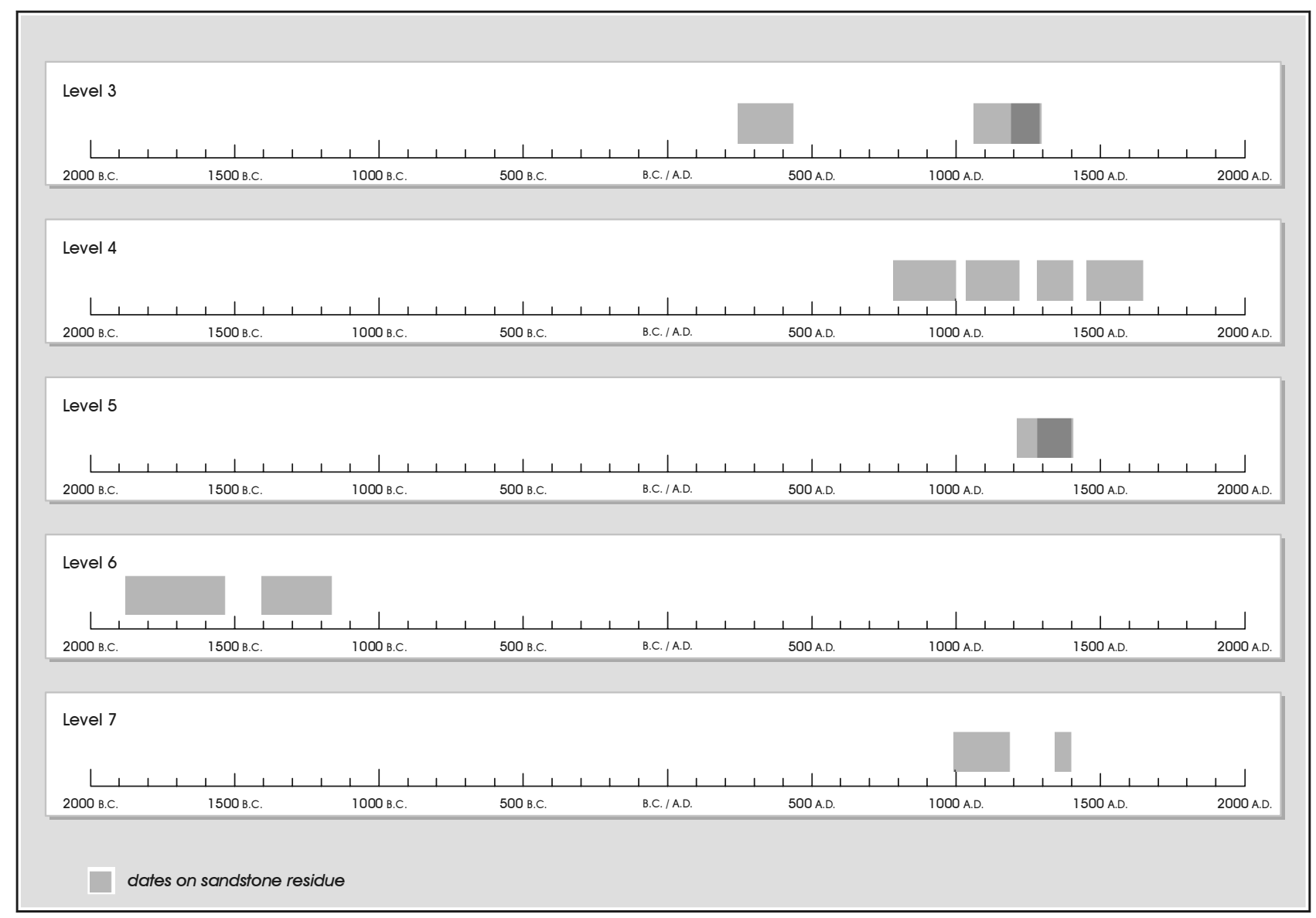

Figure 24. Organic residue dates from sandstone.

\section{Summary}

Using information derived from a variety of distinct data types, this chapter has considered the integrity and chronology of site 41WB556. Patterning in these data sets clearly suggest that extensive bioturbation has significantly mixed the majority of the deposits at this site. This mixing, the result of both rodent and insect activities, has probably differentially impacted smaller sized items, including temporally diagnostic artifacts and charcoal. Interestingly, neither the charcoal radiocarbon dates nor the organic dates on sandstone provide adequate temporal control of features or associated deposits. While it is likely that the charcoal is not in context, the feature descriptions presented in Chapter 6 suggest that the burned rocks within features are unlikely to have been significantly moved. The rock selected for dating was consistently within the larger size ranges. The lack of patterning in the radiocarbon dates on residues from these features is probably related to problems with the dating technique, as such, rather than any movement of the larger rocks through the deposits. Unfortunately, our current data sets lack any information that would allow clarification of the nature of this dating problem. 



\section{Chapter 8: $\quad$ Thermal Feature Technology}

As summarized in the previous chapter, the context of many of the artifacts and ecofacts at $41 \mathrm{WB} 556$ is questionable. This includes the context of most of the charcoal samples collected, as well as several of those processed for radiocarbon dates, and the fine matrix associated with the numerous burned rock features at the site. While we are confident, given the tight clustering of larger sandstone and chert nodules, as well as multiple incidences of refitting among broken rocks within a feature, that the feature rock has good spatial integrity, this confidence is not borne out by the radiocarbon dates on the residues from several of those rocks. In our view, this reflects problems with dating of residues in rock. Some of the features may be accurately dated by this method, though it is impossible in the current context to judge which features are in that group.

In spite of the lack of support for contextual integrity provided by the radiocarbon results, we are confident that the integrity of features at this site is adequate to investigate selected aspects of feature technology. In the current chapter, then, we are concerned with developing an understanding of how these features were used, as well as understanding what items were processed in these features. We begin that investigation by reviewing previous suggestions regarding feature use, such as the stone-boiling scenario recently proposed by Quigg et al. (2000), for the features at 41WB556. We then focus on developing an understanding of what materials were processed with these features. Given the results presented in the previous chapter, however, we cannot rely on traditional methods such as macrobotanical analysis of sediment collected from features, faunal material associated with features, or an analysis of artifacts from the immediate area around the features. Rather, we employ several recently developed methods that rely on organic residue potentially present in burned sandstone. We use the analysis of fatty acids (lipids) and carbon and nitrogen isotopes from residues extracted from burned rock to investigate thermal feature technology.

\section{Investigating Burned Rock Feature Technology at $41 \mathrm{WB} 556$}

As summarized in Chapter 6, the features excavated at 41WB556 on the current project seem to share a similar morphology. As can be seen in Table 8, most appear as roughly circular to oval clusters of tabular and/or subrounded burned sandstone, with no associated pits. They

Table 8 . Selected characteristics of features excavated by CAR at 41WB556

\begin{tabular}{|c|l|c|c|c|c|c|}
\hline Feature \# & \multicolumn{1}{|c|}{ Type } & Length $(\mathbf{c m})$ & Width $(\mathbf{c m})$ & Charcoal & $\begin{array}{c}\text { Number of } \\
\text { rocks }\end{array}$ & $\begin{array}{c}\text { Rock Weight } \\
(\mathbf{k g})\end{array}$ \\
\hline 14 & Burned Sandstone Cluster & 95 & 65 & yes & 140 & 3.67 \\
\hline 15 & Burned Sandstone Cluster & 155 & 135 & no & 161 & 8.54 \\
\hline 16 & Burned Sandstone Cluster & 70 & 45 & yes & 32 & 1.17 \\
\hline 17 & Burned Sandstone Cluster & 90 & 80 & yes & 71 & 6.25 \\
\hline 18 & Burned Sandstone Cluster & 75 & 50 & no & 33 & 4.32 \\
\hline 19 & Burned Sandstone Cluster & 85 & 85 & yes & 60 & 2.31 \\
\hline 20 & Burned Sandstone Cluster & 35 & 20 & yes & 20 & 0.47 \\
\hline 21 & Burned Sandstone Cluster & 120 & 110 & no & 642 & 22.25 \\
\hline 22 & Burned Sandstone Cluster & 70 & 55 & yes & 22 & 4.48 \\
\hline 23 & Unlined Hearth & 100 & 100 & yes & 66 & 0.06 \\
\hline 24 & Burned Sandstone Cluster & 70 & 65 & no & 77 & 5.54 \\
\hline 25 & Burned Sandstone Cluster & 90 & 75 & yes & 49 & 3.61 \\
\hline 26 & Burned Sandstone Cluster & 40 & 25 & no & 15 & 1.66 \\
\hline 27 & Burned Sandstone Cluster & 185 & 110 & yes & 167 & 14.37 \\
\hline
\end{tabular}


varied in area from covering roughly 1.7 square meters to as small as .06 square meters. The number of rocks within a feature also showed considerable variability, ranging from as few as 15 rocks in Feature 26, to as many as 642 rocks in Feature 21. Charcoal was present in nine of the 14 features, and in only a single case (Feature 23) was there some evidence of oxidation. Feature 20, a burned rock cluster, may have had a basinshaped pit associated with the rock, defined by ashy soil. These features seem to be similar to many of those identified during survey and testing at this site. While those features were not completely excavated, and thus are not included in the current analysis, they seem to be burned sandstone clusters with no associated charcoal and no clearly identified pits.

These feature types, characterized by amorphous concentrations of burned rock with no discernible associated pit, appear to be common at prehistoric sites in South Texas (e.g., Miller et al. 2000; Vierra 1998). These rock clusters are frequently not associated with burned soil, abundant charcoal, or other evidence of in situ burning. With few exceptions (e.g., 41WB314, Feature M-2 [Miller et al. 2000:131]), the clusters consist primarily of sandstone. A number of different functions can be imagined for these thermal features. They could reflect discard from use of rock in stone boiling (Quigg et al. 2000). They could reflect communal dumps, with each recorded burned rock feature accounting for a single or limited number of dumping events. These features could also represent general hearths that, as a result of the bioturbation of sediments, no longer have a visible associated pit. In this chapter, we consider each of these three alternatives for the 41WB556 features.

At the Lino Site (41WB437), Quigg et al. (2000) used spatial patterns in burned rock clusters and pit features, in combination with differences in the characteristics of burned rock, to argue that burned rock clusters were the result of stone boiling activities. Stone boiling, such as suggested by Quigg and others (Quigg et al. 2000:Figure 13.6), could, through dumping of the rocks once they have served their purpose, produce an end result similar to the burned rock clusters seen at 41WB556. That is, this process could account for the amorphous clusters of burned rock, lack of an associated pit, lack of associated oxidized soil, sparse charcoal, and little to no other charred remains. While detailed ethnographic or experimental information on the use of sandstone in stone boiling could not be located, stone boiling has certainly been documented in ethnographic cases (see Driver and Massey 1957; Hodges 1907). The technique involves the heating of rocks on an open fire and the transport of the rocks from that fire into a container with water and food. The rocks dissipate the heat into the water, raising the temperature of the water and cooking the food. When the rocks cool, they are removed and replaced with other heated stones at a sufficient rate to maintain an appropriate temperature for cooking.

Stone boiling, as a result of high levels of thermal shock, should produce a high incidence of rock breakage. If long-term cooking is required, this cooking technique should result in relatively dense concentrations of smaller, broken rocks, as well as remains of a fire where rocks were initially heated, probably in close proximity. This pattern of rock size and accumulation is similar to that expected for communal dumping. The cleaning out of repeatedly used features would probably result in discard piles of smaller rock. Depending on the scale of the excavation, the original hearth features from which the rocks were removed may or may not be discovered, but they are unlikely to be in close proximity to the dump area. Finally, if these features represent general hearths that no longer have visible associated pits as a result of the bioturbation of sediments, we might expect larger rocks to dominate the features, though smaller rocks should certainly be present as a result of thermal shattering during feature use.

Using rock weight as a proxy for rock size, Figure 25 plots the average rock weight by the number of rocks for each of the 14 features CAR excavated at 41WB556. Note that only a single feature, Feature 21, falls within the area of the graph that would conform to our suggestions regarding stone boiling or dumping of expended rock. That is, stone boiling or communal dump features should have smaller rocks and a high number of rocks. Similarly, only Feature 22 conforms to some of our suggestions for in situ burning with subsequent bioturbation destroying evidence of any associated pit. We expect that such features would have fewer numbers of rocks, with larger average rock size.

Figure 26 presents histograms of the individual rock weights for Feature 21 (top) and Feature 22 (bottom) 


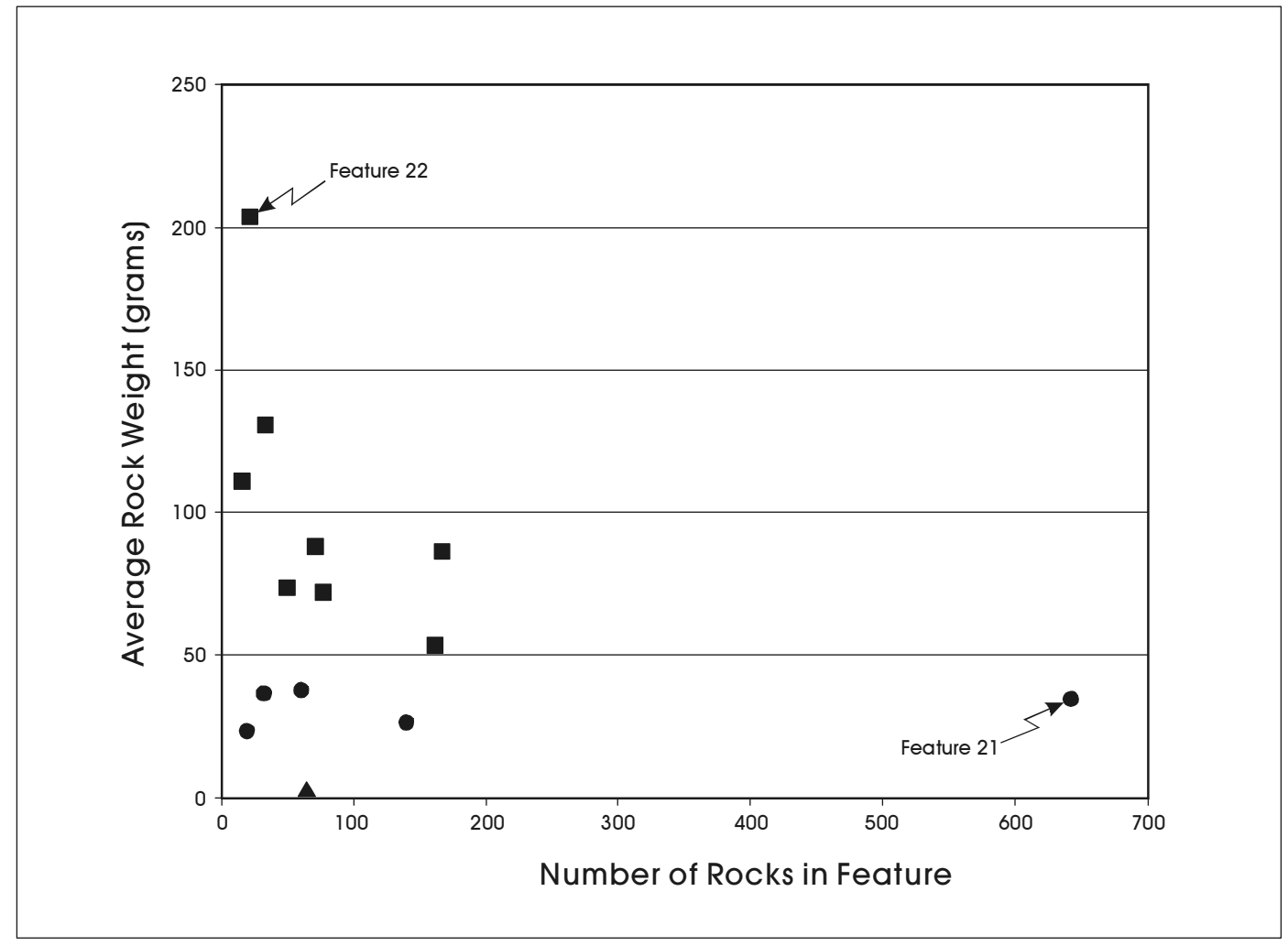

Figure 25. Scatter plot of average rock weight and number of rocks in features at 41 WB556.

that further highlight the differences in these two features. While both features have individual stones heavier than 500 grams, the distribution for Feature 21 is dominated by rocks that are less than 50 grams. Though not shown by the figure, over 60 percent of the rocks in Feature 21 are actually less than 10 grams in weight. Conversely, only about four percent of the Feature 22 rocks are less than 10 grams, with most of the rocks weighing in excess of 50 grams. The dominance of items in the smaller size range for Feature 21 is consistent with both the stone boiling and the communal dump notions of feature use. Conversely, the distribution for Feature 22 rocks is consistent with a general hearth focus.

This analysis, then, suggests that only Feature 21 is consistent with the expected pattern of stone boiling or communal dumping of hearth debris. This is the only feature that has a large number of small rocks and a virtual absence of larger rock. Of course, we have no quantification for terms such as "small" or "large" when we consider theses various alternatives. It certainly may be the case that stone boiling on a limited basis could result in only a small number of broken rocks. If so, several features with smaller average rock size, including Features 14, 16, 19, and 20 (identified by circles in Figure 25), are consistent with the notion of stone boiling or short-term dumping. However, note that Feature 20 was the only feature that may have had an associated pit, a component more consistent with general hearths than either a stone boiling or communal dumping model of use. Similarly, general hearths, depending on patterns of reuse, are not necessarily dominated only by large rocks. That is, repeated use without cleaning could result in a smaller average rock size. Features 15, 17, 18, 24, 25, 26, and 27 (identified by squares in Figure 25) may be consistent with that general hearth pattern. Feature 23, the triangle in Figure 25 , is the only clear unlined hearth feature. Finally, note that while we have assumed that cooking was likely the primary activity associated with these features, other non-food related activities (e.g., heat-treatment of cherts) could also be imagined for these features. 

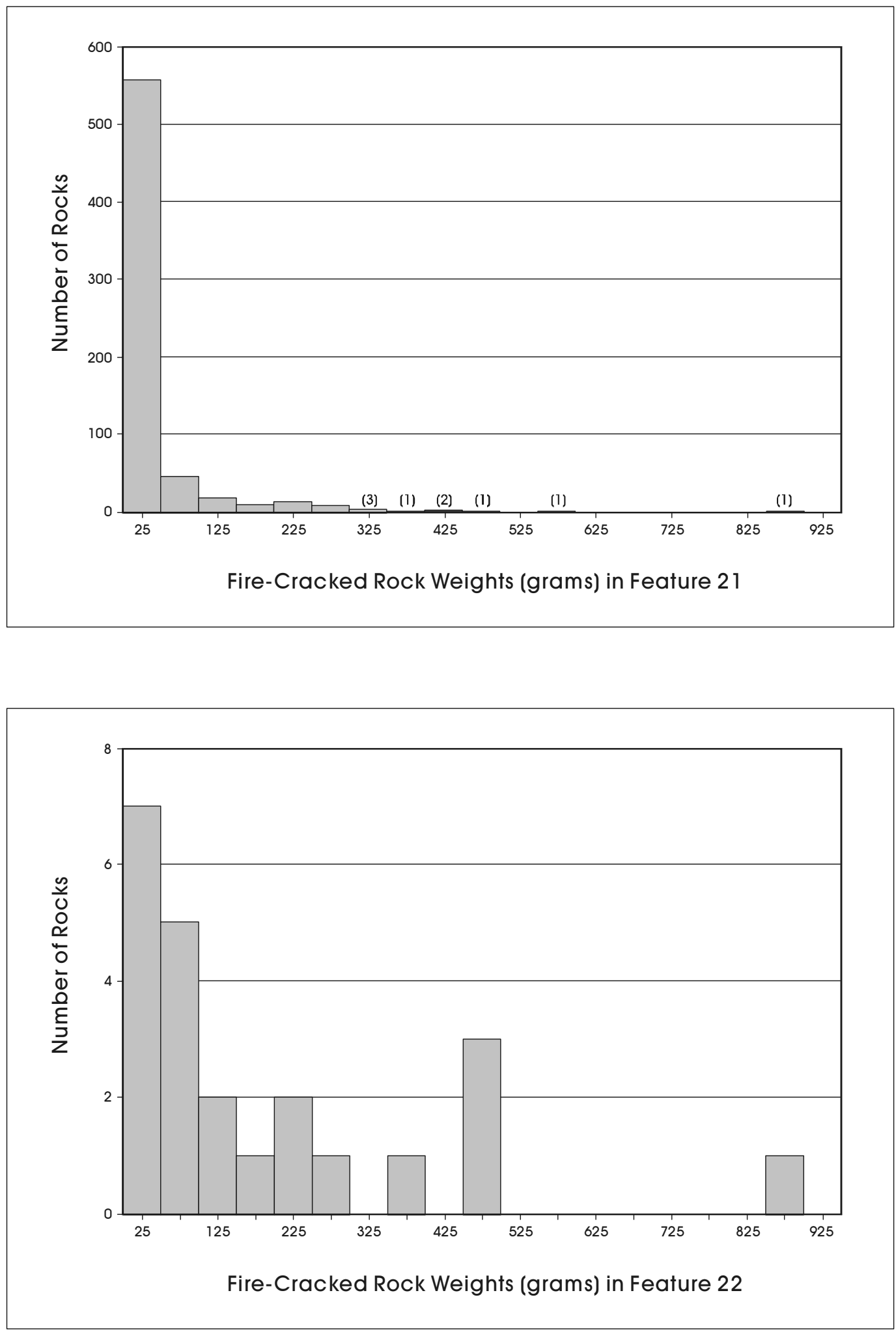

Figure 26. Fire-cracked rock weights for Feature 21 (top) and Feature 22 (bottom) at 41 WB556. 


\section{Investigating Feature Use through Isotopic and Fatty Acid Residue Analyses of Burned Rock}

Clearly, investigating what these features represent in terms of cooking or heating technology is a difficult task. Investigating what these features were used for has also proven challenging, primarily because sites in South Texas frequently have little data on subsistence. 41 WB556 is no exception, with low recovery rates for prehistoric faunal remains and questionable context for any feature matrix. Recently, Quigg (Quigg and Cordova 1999, 2000; Quigg et al. 2000) has undertaken research to derive subsistence data, and indirectly information on feature technology, from chemical analysis of burned sandstone. Using a combination of isotopic analysis and recent work on fatty acid (lipid) residues, Quigg has inferred, at a general level, aspects of subsistence and feature technology for occupations at a series of sites in South Texas.

Following Quigg's lead, we submitted 30 samples of burned sandstone to Dr. David Harris at the University of California-Davis for carbon and nitrogen isotope analyses. In addition, we submitted 30 samples of burned sandstone to Dr. Mary Malainey of the University of Manitoba for lipid residue analyses. Each sample was extracted from individual stones recovered from cultural features, and in 12 cases, stones were of sufficient size that both sets of samples could be extracted from the same stone. Each feature sampled is thought to represent one of three possibilities: the features could represent the remains of a hearth where foodstuffs were cooked on top of the stones; the features could be the remains of expedient ovens created by the stones; or the stones could have been used in stone boiling.

In each of the proposed scenarios organic residues from cooked foods could potentially permeate the porous sandstone and remain available for analyses. Archeological samples of burned sandstone do, on occasion, have darker areas within the rock. We have been able to simulate these patterns in some cases. For example, Figure 27 presents two specimens, with "a" being a sandstone rock from an archeological context and " $b$ " being a sandstone fragment that was exposed to heat and cooking oil. Dark areas are visible in the interior of both samples. This suggests that residues can potentially permeate sandstone. In addition, it is conceivable that such residues may be related to the use of the rocks.

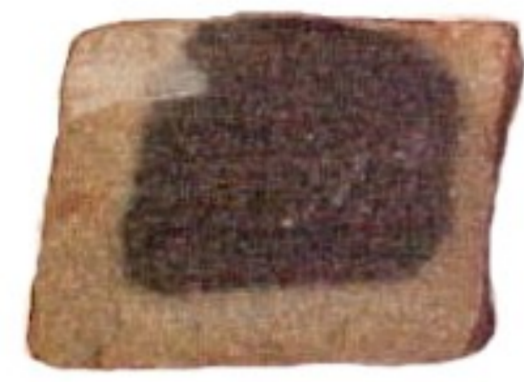

a.

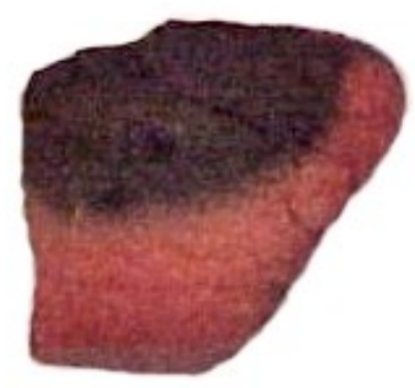

b.

Figure 27. Examples of burned sandstone. a) Archeological example of possible organic residue; b) Experimental example of organic residue. 


\section{Stable Isotopic Analysis}

Stable isotopic analyses are generally conducted on bone collagen, and, less frequently, on soil matrices. As noted, the application of isotopic analyses on burned rock is quite recent, with the majority of the reports spanning only the previous three years (e.g., Quigg and Cordova 1999, 2000; Quigg et al. 2000). Assuming that the results of these analyses are, at least to some degree, analogous to results from standard isotopic analyses, then the isotopic data sets would consist of similar components. The following discussion introduces the components, evaluates aspects of South Texas with regard to these components, and considers our current data set from 41WB556.

\section{Carbon Isotopes in Terrestrial Plants and Animals}

Terrestrial plants use one of three photosynthetic pathways to assimilate carbon dioxide from the atmosphere. Known as $\mathrm{C}_{3}, \mathrm{C}_{4}$, and CAM, each of these pathways result in different patterns of carbon isotope fractionation that are manifested in plants as different concentrations of ${ }^{13} \mathrm{C}$. The different pathways are probably adaptations to different environmental conditions (Teeri and Stowe 1976; Tieszen 1994).

Plants using a $\mathrm{C}_{3}$ pathway thrive in temperate climates, moderate to high soil moisture levels, and moderate to low intensity sunlight. $\mathrm{C}_{3}$ vegetation consists of shrubs, legumes, trees, and some grasses that prefer cooler growing seasons. The form of $\mathrm{CO}_{2}$ fixation present in $\mathrm{C}_{3}$ vegetation occurs in one manner through a single type of chloroplast. A carbon dioxide molecule is combined with an enzyme, ribulose biphosphate, forming a 6carbon compound. This compound further breaks down into two separate molecules of 3-carbon molecules (hence, $\mathrm{C}_{3}$ ), which allow for the synthesis of glucose in the plant (see O'Leary 1988). This particular pathway discriminates against ${ }^{13} \mathrm{CO}_{2}$, resulting in vegetation that has relative low ${ }^{13} \mathrm{C}$ values. The delta ${ }^{13} \mathrm{C}$ range for $\mathrm{C}_{3}$ vegetation is from approximately -35 to $-20 \%$, with an average of roughly $-27.1 \%$ (Ehleringer 1989, 1991; O'Leary 1988).

Vegetation adapted to higher temperatures, relatively low soil moisture levels, and high intensity sunlight comprise the photosynthetic pathway know as $\mathrm{C}_{4}$ Vegetation with this pathway consists primarily of tropical grasses, including maize. Carbon dioxide fixation for $\mathrm{C}_{4}$ vegetation follows the initial photosynthetic process of the $\mathrm{C}_{3}$ group. However, $\mathrm{C}_{4}$ plants use a different enzyme (PEP) that discriminates less against ${ }^{13} \mathrm{CO}_{2}$. Consequently, the delta ${ }^{13} \mathrm{C}$ range for $\mathrm{C}_{4}$ vegetation is higher than $\mathrm{C}_{3}$ plants, being between -16 and $-7 \%$ o (Ehleringer 1989, 1991) with an average of approximately $-13.1 \%$ o (O'Leary 1988). The ${ }^{13} \mathrm{C}$ values for both $\mathrm{C}_{4}$ and $\mathrm{C}_{3}$ plants are distinct and do not overlap (Smith and Epstein 1971).

The third photosynthetic pathway, known as crassulacean acid metabolism (CAM), appears to be an adaptation to arid environments and canopied woodlands possessing relatively reduced amounts of available soil. CAM plants include succulents, such as cacti and agaves. Depending on whether CAM plants uptake $\mathrm{CO}_{2}$ at night or during the day, they can use pathways that mimic either a $\mathrm{C}_{4}$ or $\mathrm{C}_{3}$ isotopic signature (O'Leary 1988; Pate 1994). CAM plants have isotopic signatures that range between -10 and $-22 \%$, overlapping both the $\mathrm{C}_{3}$ and $\mathrm{C}_{4}$ range. However, CAM plants cluster into two distinct groups based on whether they are nocturnal or diurnal (Pate 1994). The ${ }^{13} \mathrm{C}$ values for day-growing CAM plants mimic those of the $\mathrm{C}_{3}$ group, with a range of between -24 to $-30 \%$, while the nocturnal CAM plants mimic $\mathrm{C}_{4}$ plants, with a range of between -10 and -14\%o (Ehleringer 1989, 1991; O’Leary 1988; Pate 1994).

When animals consume plants, the isotopic signatures of the plants are incorporated into their bodies, frequently with an additional enrichment of ${ }^{13} \mathrm{C}$. However, the relationship between the bulk diet of animals and the isotopic values produced in animals is complex and not completely understood (see Hare et al. 1991; Krueger and Sullivan 1984). A complication for our current work is that different components of the body have different patterns of fractionation. For bone collagen, the fractionation appears to be between about -3 to $-5 \%$ o (DeNiro and Epstein 1978; Schwarcz and Schoeninger 1991) while flesh values appear to be enriched by about +2\%o (Spielmann et al. 1990; Tieszen 1994). Lipids, conversely, may have fractionation patterns that are more negative than flesh and bone collagen. Liden and others (1995) have suggested that isotopic values for lipids in bone may be depleted by as much as $7 \%$ orelative to bone protein. Consequently, a herbivore subsisting only on 
$\mathrm{C}_{4}$ plants (-13.1\%o) would have flesh with values of about $-11.1 \%$, collagen values of between -10.1 and $-8.1 \%$, and bone lipid values on the order of $-16.1 \%$.

\section{Nitrogen Isotopes in Terrestrial Plants and Animals}

Analysis of stable isotope ratios of nitrogen $\left({ }^{15} \mathrm{~N}\right)$, frequently in combination with an analysis of ${ }^{13} \mathrm{C}$, has been used in the further delineation of diet in archeological research (e.g., Ambrose 1987, 1991; Schwarcz et al. 1985). Like carbon isotopic work, much of this research has concentrated on nitrogen signatures in human bone. However, interpreting variation in delta values of ${ }^{15} \mathrm{~N}$ is much more difficult as isotopic values vary widely in both plants and animals, variation that does not seem to be well-studied.

Terrestrial vegetation obtains nitrogen either primarily from the atmosphere or from the soil. As most plants are unable to process nitrogen $\left(\mathrm{N}_{2}\right)$ directly from the air, those plants that fix nitrogen through the atmosphere usually do so through a symbiotic relationship with bacteria or algae. The bacteria are able to process the $\mathrm{N}_{2}$ and, as such, afford the host plant the requisite ${ }^{15} \mathrm{~N}$. The delta ${ }^{15} \mathrm{~N}$ values for these types of vegetation are usually lower, due to the lower levels of ${ }^{15} \mathrm{~N}$ in atmospheric $\mathrm{N}_{2}$. Those plants that rely on soil nitrogen, absorbed through root systems, typically have higher delta ${ }^{15} \mathrm{~N}$ values (Heaton 1987; Sealy et al. 1987).

Isotopic values of ${ }^{15} \mathrm{~N}$ increase along the food chain. That is, herbivores tend to have higher ${ }^{15} \mathrm{~N}$ values than plants, and carnivores have higher values than herbivores. However, fractionation of ${ }^{15} \mathrm{~N}$ through the various trophic levels is not well understood. Ambrose $(1987: 93,1991)$ provides a general, idealized distribution of nitrogen isotopes through the food chain. Figure 28, based on Ambrose's Figure 4-1 (1987), provides a model for tracking nitrogen isotopic changes, in combination with carbon isotopic groups, that is instructive. Reference to that figure shows that there exists overlap between trophic levels, but fractionation, perhaps on the order of +3 to $+5 \%$, is apparent between average values of trophic levels.

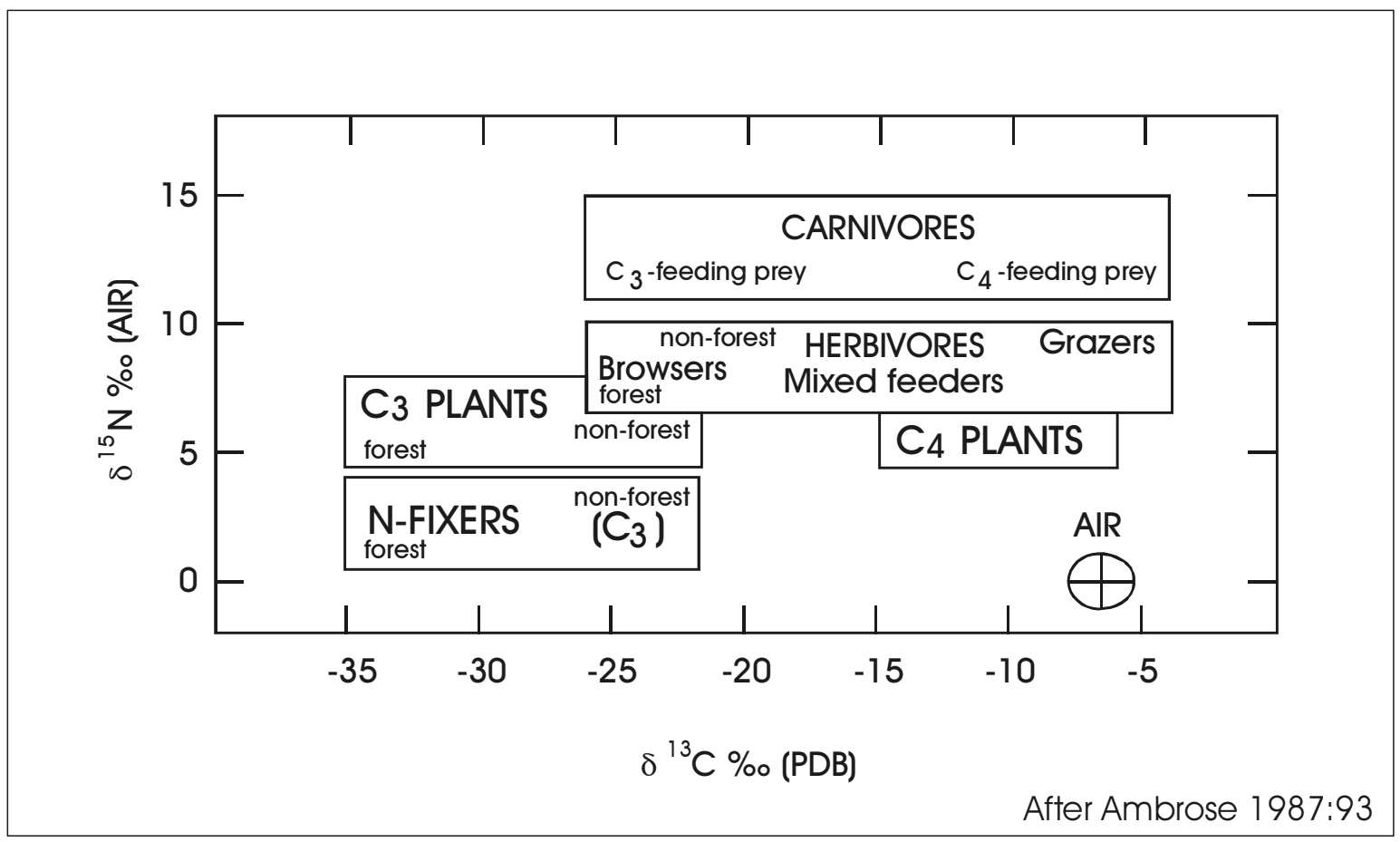

Figure 28. An idealized representation of carbon and nitrogen isotopes in terrestrial ecosystems. 
The pattern outlined in Figure 28 provides only a general model for interpretation of ${ }^{15} \mathrm{~N}$ values. Nitrogen values for terrestrial animals vary significantly, probably as a function of water balance both within animals and within a given ecosystem (see Ambrose 1987, 1991; Ambrose and DeNiro 1986; Steele and Daniel 1978). As with the isotopic signatures of carbon, delta values for ${ }^{15} \mathrm{~N}$ appear to be different for different components of an animal, with blood having higher ${ }^{15} \mathrm{~N}$ values than flesh (Steele and Daniel 1978).

\section{Carbon and Nitrogen Variability in South Texas}

As an important component of research into the potential use of isotopic signatures in investigating subsistence and feature technology in South Texas, Quigg (Quigg 2000; Quigg et al. 2000) has analyzed 52 samples of modern, as well as pre-1950, plants and animals from the region for carbon and nitrogen isotopes. These results provide critical baseline data for our interpretations.

Figure 29 presents the distribution of the carbon isotopes from 51 samples of this modern and historic data set. Focusing on the plants, two groups are clearly apparent. The first is composed of a cluster of $35 \mathrm{C}_{3}$ plants with isotopic values between -29.24 and $-21.77 \%$ o and a mean of $-25.38 \%$. The second group is composed of 11 CAM and $\mathrm{C}_{4}$ plants with a range of -13.64 to $-12.05 \%$ and a mean of $-12.96 \%$. While historic environmental modification discussed previously could potentially have had an effect upon CAM ${ }^{13} \mathrm{C}$ values, the figure clearly suggests that in the current environment, the CAM plants analyzed are in the nocturnal group and can be aligned with $\mathrm{C}_{4}$ plants. Also shown in the figure is the distribution of animal values. Only deer is represented in the sample. An initial peak, centered at $-22 \%$, is derived from deer flesh, skin, and tendons. These values suggest a diet of $\mathrm{C}_{3}$ plants with an average isotopic signature of around $-24 \%$ o. The single, more negative peak (centered at -30\%o) is derived from deer bone marrow. In conformance with the previous discussion, the negative peak probably represents fats concentrated in the marrow.

Figure 30 shows the delta ${ }^{15} \mathrm{~N}$ distribution of plants and animals for the modern and historic South Texas data sets. The distribution has an overall mean of $5.4 \%$ and a range of between -1.82 and $14.28 \%$ o. Consistent with the previous discussion on nitrogen isotopes, animals (i.e., deer, in this case) have higher nitrogen values $($ mean $=12.3 \%$ o $)$ than plants $($ mean $=4.7 \%$ o $)$. There is, however, considerable overlap between the two data sets. There is also substantial variability within a given plant. For example, delta ${ }^{15} \mathrm{~N}$ values for mesquite beans vary between $-1.77 \%$ ond $9.13 \%$, while values for prickly pear fruit range from $6.98 \%$ o to $12 \%$ o. Given our current lack of understanding of isotopic variation in nitrogen values, the overlap of values between some plants and animals, and the variability within a given plant demonstrated by this data set, the utility of this element for dietary studies like those conducted here is greatly reduced relative to carbon isotopes. However, when used in combination with carbon isotopic analysis, an analysis of nitrogen isotopic values may have some utility in distinguishing certain classes of plants from animals.

\section{Isotopic Results from 41 WB556}

Table 9 presents the results of the carbon and nitrogen isotope analysis conducted on burned rock. In addition, provenience information, including associated feature numbers, are provided. Thirteen features are represented, with all features having a minimum of two rocks tested, and four features having three rocks sampled.

Focusing first on the delta ${ }^{13} \mathrm{C}$ results, the 30 samples have a mean of $-20.0 \%$, with a range of $-23.9 \%$ o to $-16.6 \%$. The mean value suggests that, as a group, residues in the burned rock reflect a combination of $\mathrm{C}_{3}$ and $\mathrm{C}_{4} / \mathrm{CAM}$ plants and animals. Figure 31 presents the carbon signatures for the individual rocks overlain onto the modern carbon isotopic data presented previously (Figure 29). Only five of the archeological samples overlap with the $\mathrm{C}_{3}$ plant and animal group. There are no cases falling within the $\mathrm{C}_{4} / \mathrm{CAM}$ area of the graph. Assuming that the isotopic results accurately reflect those foods processed, and assuming that the modern data set is reflective of the range of potential plants, the distribution suggests that individual rocks also reflect a mixture of $\mathrm{C}_{3}$ and $\mathrm{C}_{4} / \mathrm{CAM}$ foods. There are no cases in which rocks were used only in the preparation of $\mathrm{C}_{4} /$ CAM foods, and only a few possible cases of rocks being used to exclusively process $\mathrm{C}_{3}$ foods. Using the known ranges of all $\mathrm{C}_{3}(-35 \%$ o to $-2 \%), \mathrm{C}_{4}(-16 \%$ o to $-7 \%$ o $)$ and nocturnal CAM (-14\%o to $-7 \%$ o) plants as a comparative base produces essentially the same conclusion, but expands the possible number of cases where $\mathrm{C}_{3}$ plants were the only plants processed. 


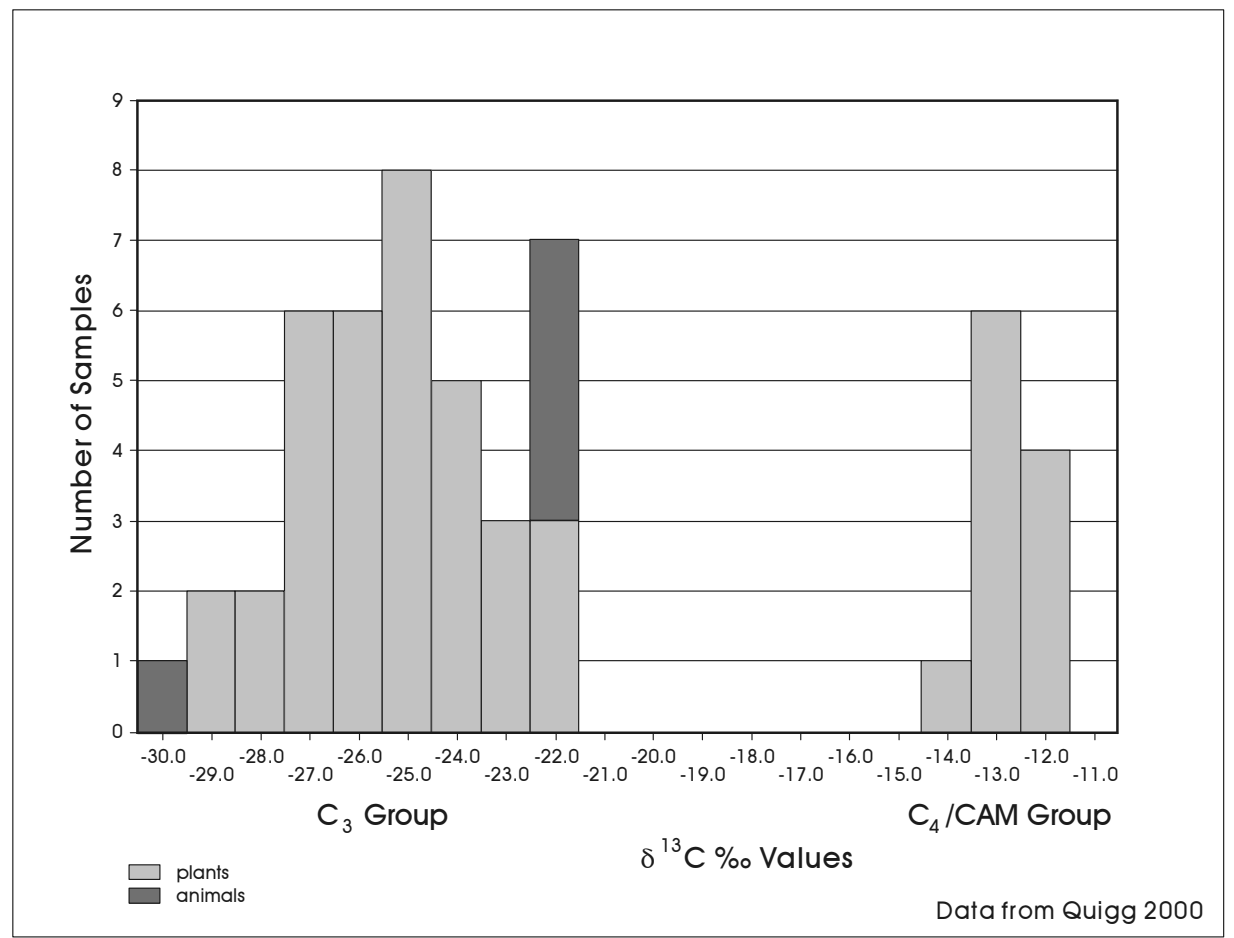

Figure 29. Distribution of carbon isotopic values for modern and historic plants and animals in South Texas.

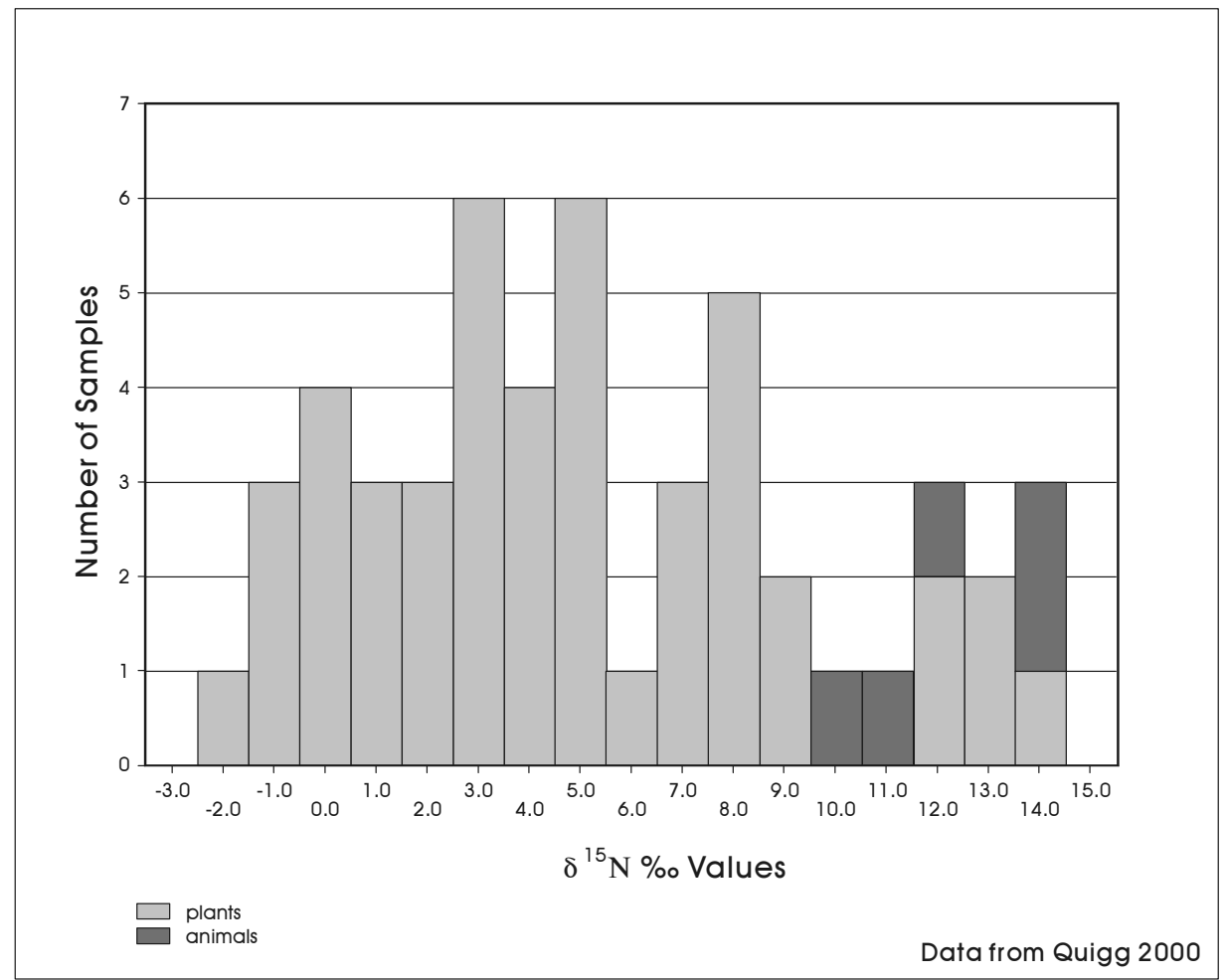

Figure 30. Distribution of nitrogen isotopic values for modern and historic plants and animals in South Texas. 
Table 9. Results of isotopic analysis from 41WB556

\begin{tabular}{|c|c|c|c|c|c|c|c|c|}
\hline $\begin{array}{c}\text { CAR } \\
\text { Sample } \\
\end{array}$ & $\begin{array}{r}\text { Catalog } \\
\text { Number } \\
\end{array}$ & Unit & Level & $\begin{array}{l}\text { Feature } \\
\text { Number } \\
\end{array}$ & ${ }^{13} \mathrm{C}$ & $\begin{array}{l}\text { Micrograms of } \\
\text { Carbon }\end{array}$ & ${ }^{15} \mathrm{~N}$ & $\begin{array}{c}\text { Micrograms of } \\
\text { Nitrogen }\end{array}$ \\
\hline 1 & $1492-4-1 \mathrm{C}$ & N40 E14 & 3 & 14 & -20.57 & 49.0 & 8.30 & 10.0 \\
\hline 2 & $1492-4-2 \mathrm{C}$ & N40 E14 & 3 & 14 & -20.06 & 56.1 & 5.72 & 7.6 \\
\hline 3 & 1552-1-3B & N41E10 & 4 & 15 & -20.74 & 22.1 & 2.16 & 4.3 \\
\hline 4 & 1552-1-4B & N41E10 & 4 & 15 & -19.93 & 32.6 & 4.71 & 6.0 \\
\hline 5 & $217-1-1 \mathrm{C}$ & N41E10 & 6 & 16 & -23.31 & 25.9 & 5.17 & 4.6 \\
\hline 6 & $217-1-2 \mathrm{C}$ & N41E10 & 6 & 16 & -22.97 & 38.9 & 0.32 & 6.1 \\
\hline 7 & 257-1-3B & N41E13 & 7 & 17 & -19.07 & 25.3 & 3.04 & 4.5 \\
\hline 8 & $257-1-4 \mathrm{~B}$ & N41E13 & 7 & 17 & -18.96 & 22.7 & 4.70 & 4.3 \\
\hline 9 & 402-21-3B & N42E10 & 3 & 18 & -18.53 & 28.7 & 7.97 & 3.2 \\
\hline 10 & $402-21-4 \mathrm{~B}$ & N42E10 & 3 & 18 & -18.75 & 23.5 & 5.63 & 3.1 \\
\hline 11 & $403-1-1 \mathrm{C}$ & N42 E11 & 3 & 19 & -19.41 & 208.3 & 7.10 & 25.1 \\
\hline 12 & $403-1-2 \mathrm{C}$ & N42 E11 & 3 & 19 & -21.24 & 91.1 & 3.96 & 11.2 \\
\hline 13 & 684-1-4B & N43E11 & 6 & 21 & -17.72 & 64.5 & 8.44 & 10.5 \\
\hline 14 & 684-1-5B & N43E11 & 6 & 21 & -18.39 & 31.0 & 8.86 & 7.2 \\
\hline 15 & 684-1-6B & N43E11 & 6 & 21 & -21.42 & 32.8 & 0.41 & 5.9 \\
\hline 16 & 489-18C & N42 E15 & 7 & 22 & -23.90 & 23.3 & -2.61 & 3.7 \\
\hline 17 & $489-6 \mathrm{C}$ & $\mathrm{N} 42 \mathrm{E} 15$ & 7 & 22 & -22.87 & 13.4 & 0.90 & 1.9 \\
\hline 18 & $865-1-1 \mathrm{C}$ & N44 E13 & 5 & 23 & -17.81 & 156.1 & 7.68 & 17.1 \\
\hline 19 & $865-1-2 \mathrm{C}$ & N44 E13 & 5 & 23 & -19.09 & 99.5 & 5.67 & 9.8 \\
\hline 20 & 804-1-4B & N44E12 & 6 & 24 & -20.54 & 46.1 & 5.17 & 6.5 \\
\hline 21 & 804-1-5B & N44E12 & 6 & 24 & -16.60 & 60.6 & 8.83 & 7.9 \\
\hline 22 & $804-1-6 B$ & N44E12 & 6 & 24 & -18.64 & 32.1 & 0.82 & 3.2 \\
\hline 23 & 976-1-1C & $\mathrm{N} 45 \mathrm{E} 11$ & 4 & 25 & -21.93 & 56.6 & 8.07 & 6.7 \\
\hline 24 & 976-1-2C & N45E11 & 4 & 25 & -19.15 & 106.3 & 6.83 & 13.5 \\
\hline 25 & 1223-1-4B & N46E15 & 5 & 26 & -21.02 & 43.8 & 8.79 & 5.1 \\
\hline 26 & 1223-1-5B & N46E15 & 5 & 26 & -20.04 & 30.8 & 3.96 & 3.4 \\
\hline 27 & 1223-1-6B & N46E15 & 5 & 26 & -19.70 & 77.3 & 4.98 & 5.6 \\
\hline 28 & 1311-1-1C & N43E09 & 4 & 27 & -19.07 & 65.5 & 5.95 & 6.7 \\
\hline 29 & $1311-1-2 \mathrm{C}$ & N43E09 & 4 & 27 & -20.85 & 42.9 & 4.32 & 5.6 \\
\hline 30 & 1311-1-4B & N43E09 & 4 & 27 & -17.98 & 54.2 & 0.13 & 6.7 \\
\hline
\end{tabular}

The delta ${ }^{15} \mathrm{~N}$ isotopic values for the 30 samples have a mean of $4.9 \%$, with a range of between $-2.61 \%$ and $8.86 \%$. Figure 32 presents the distribution of individual values. The values are plotted on the same scale as Figure 30, the ${ }^{15} \mathrm{~N}$ distribution for modern South Texas plants and animals. A comparison between the two figures suggests that the rock residue isotopic values are within the range of plants, and below the range for animals. While the sample of animals consists only of deer, and while the range of values for nitrogen in plants and animals is both highly variable and not well understood, the ${ }^{15} \mathrm{~N}$ distribution in Figure 32 suggests that individual rocks were used in the processing of plants, rather than animals.
Figure 33 plots the distribution of ${ }^{13} \mathrm{C}$ (top) and ${ }^{15} \mathrm{~N}$ (bottom) values for each of the 13 features. At a feature level, several of the ${ }^{13} \mathrm{C}$ values seem to cluster. Features $14,15,16,17,18$, and, to a lesser extent, Features 21 and 26 all have ${ }^{13} \mathrm{C}$ values that are reasonably close together. While the number of samples from any one feature is small, this is consistent with a scenario in which these features either had a small number of uses and/or were used to process resources with the same general ${ }^{13} \mathrm{C}$ signatures. The greater spread of the values for other features at the site suggests a pattern of repeated, more generalized use. However, consideration of the ${ }^{15} \mathrm{~N}$ values for features does not support this specialized/generalized scenario. No clustering at a feature level is apparent. 


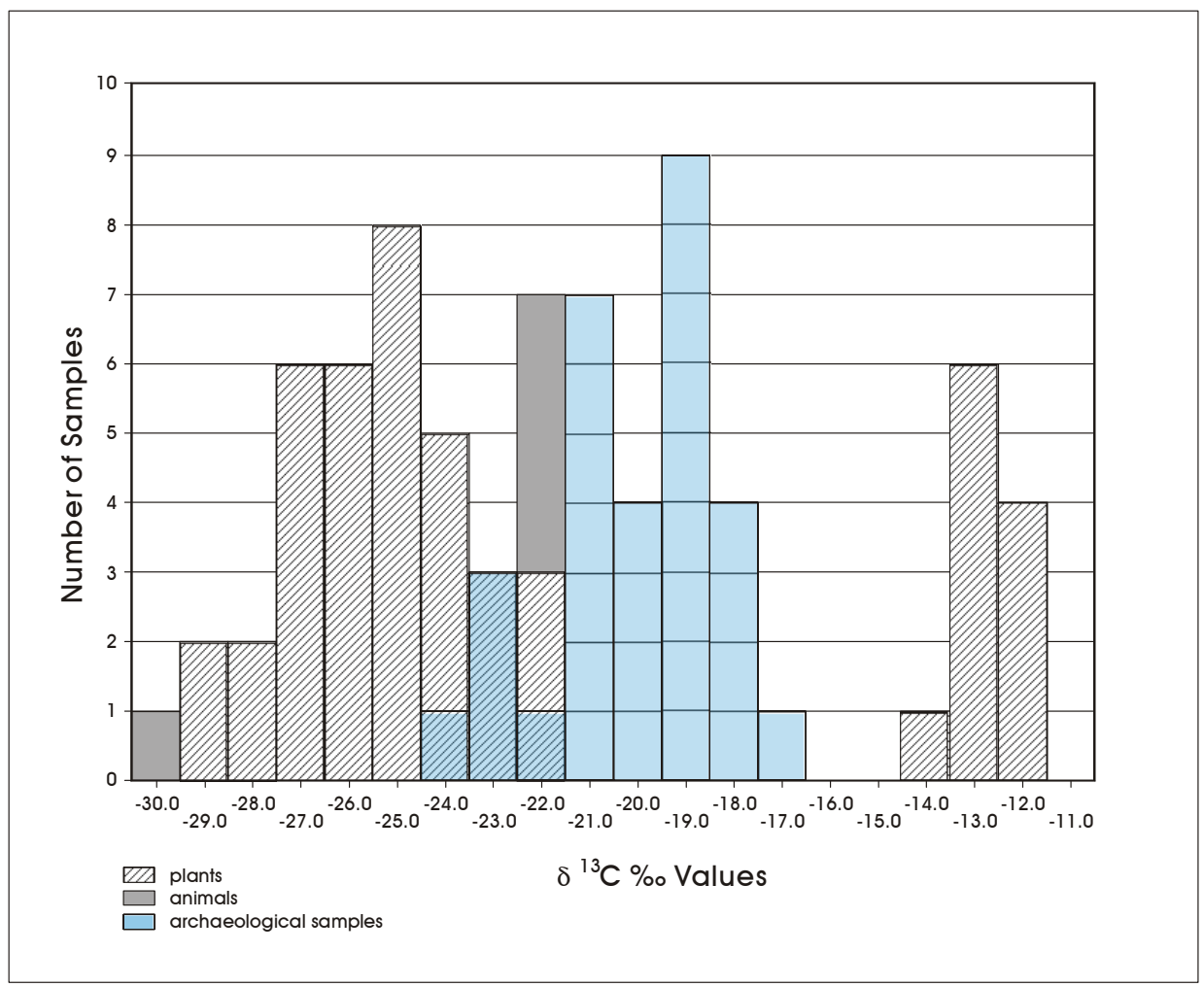

Figure 31. Carbon isotopic values for samples from sandstone residue at 41 BR556 overlain on modern South Texas data.

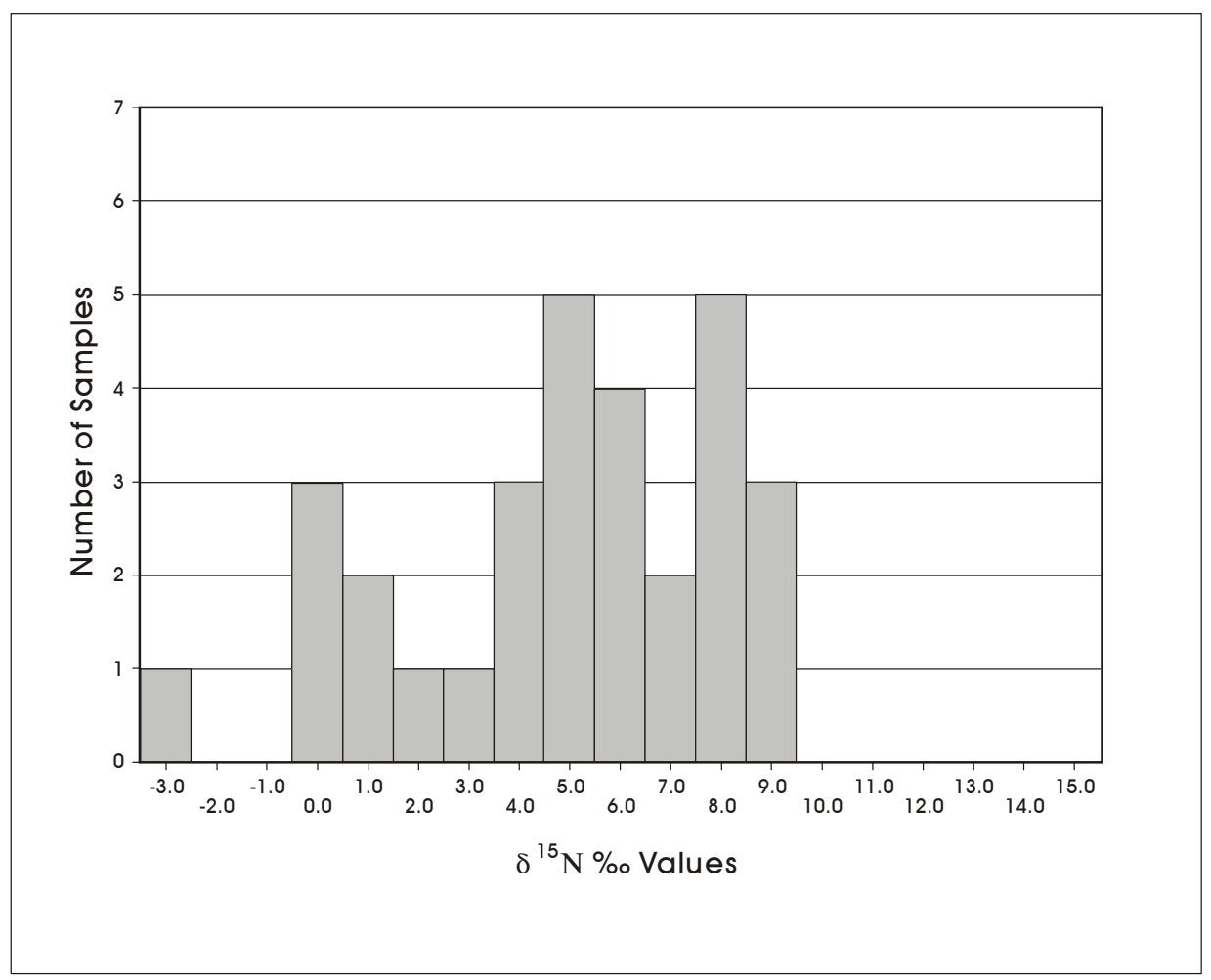

Figure 32. Nitrogen isotopic values for residue samples from 41 WB556. 


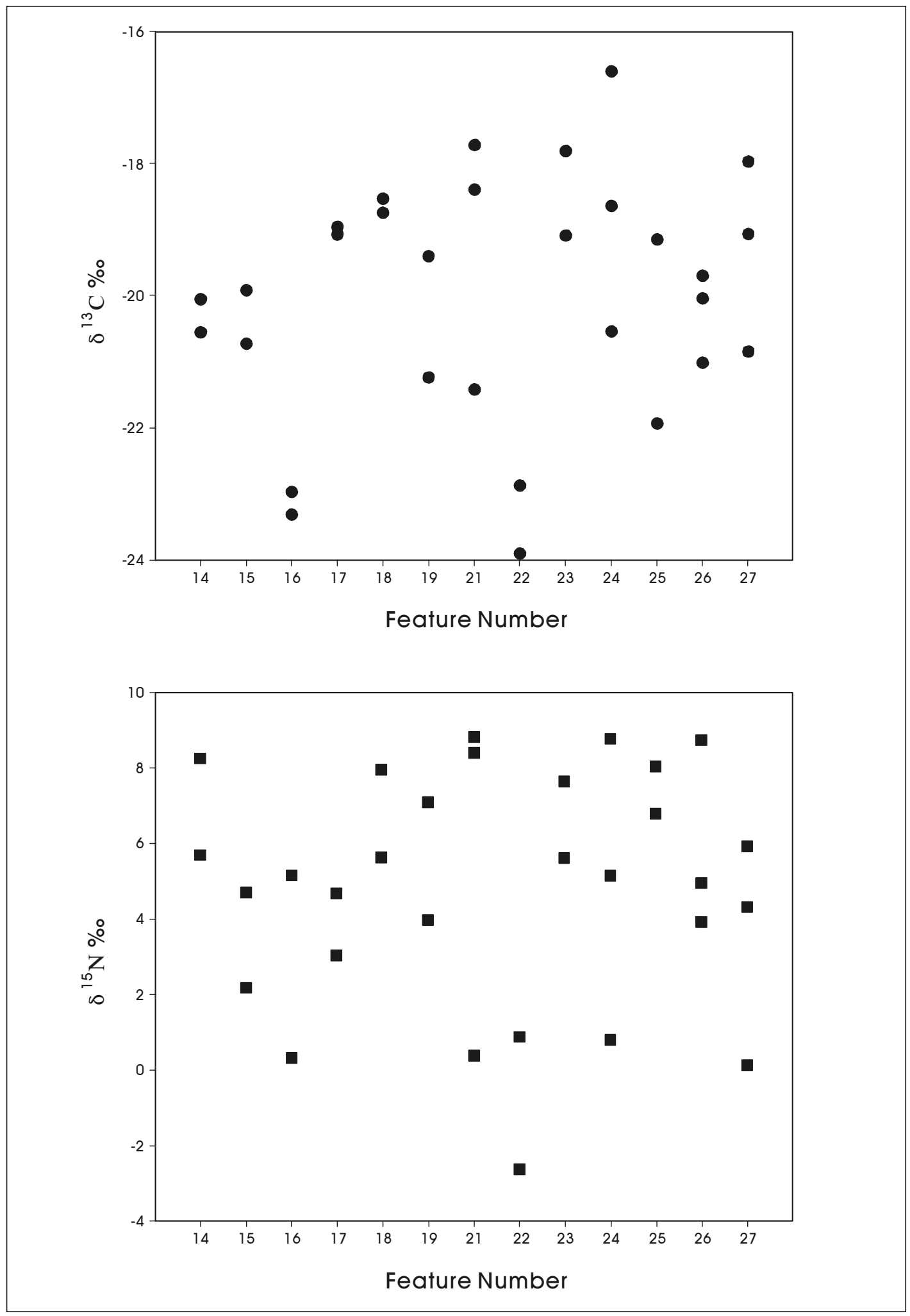

Figure 33. Carbon (top) and nitrogen (bottom) isotopic values by feature at 41 WB556. 
Considered as a group, the isotopic results suggest that burned rocks from features at 41WB556 reflect a generalized subsistence pattern, with a focus on plants. No cases of residues with isotopes exclusively attributable to $\mathrm{C}_{4} / \mathrm{CAM}$ plants, such as cacti or agave, were present. No clear indication of animal processing was present, though any interpretations of the nitrogen data are problematic. Rather, the isotopic signatures for both the individual rocks, as well as the overall pattern of samples considered as a group, are consistent with a mix of $\mathrm{C}_{3}$ and $\mathrm{C}_{4} / \mathrm{CAM}$ plants. At a feature level, the carbon isotope data hint at a limited number of uses for several features. However, this pattern is not supported by the nitrogen isotope data.

\section{Fatty Acid (Lipid) Residue Analysis}

As noted above, a second component of our investigation of subsistence and feature technology using burned rock at 41WB556 focused on the analysis of fatty acid (lipid) residues. The analysis of lipids from archeological specimens, first used by Condamin et al. (1976), has recently been expanded through the work of Marchbanks (1989), Skibo (1992), Loy (1994), and Malainey (2000). Lipids are abundant in plants and animals, and different groups of plants and animals have fatty acids with different molecular structure. These varying molecular signatures of fatty acids can be identified in modern plants and animals, and potentially used in archeological situations (see also Quigg et al. 2001). Several broad groups of plant and animal signatures have been developed based on fatty acid composition. These include distinctive fatty acid compositions for potential food groups such as large mammal fat, large mammal meat, fish, greens, roots, and seeds/nuts/berries/medium-sized mammals. In combination with experimental data that considered degradation of these fatty acids and the investigation of fatty acid compositions for several South Texas plants (see Malainey 2000; Quigg and Cordova 2000), the analysis of lipid residues from burned sandstone has provided insights into both subsistence and feature technology in South Texas (see Quigg et al. 2001).

A total of 30 burned rock samples was submitted from 41WB556 for analysis of fatty acid (lipid) residues. These samples represent 13 different features, with all features having at least two rocks analyzed. As noted in the introduction to this section, in 12 cases rocks were large enough to allow portions of the same rock to be submitted for isotopic analysis as well as fatty acid residue analysis. A comparison of the results suggested by these two analytical approaches for these 12 samples is presented in a subsequent section.

\section{Fatty Acid Residue Results from 41 WB556}

Table 10 presents the sample catalog number, lab (UT) sample number, provenience information, and broad fatty acid group assignment of the burned sandstone. Additional information, including a discussion of the background of the analytical approach, laboratory methods, and detailed discussion of these results can be found in Appendix C.

Reference to Table 10 suggests that several broad subsistence groups are represented in the lipid residues. The largest group consists of 11 samples with fatty acid residue compositions that are associated with large herbivores. Nine of the 11 samples are consistent only with large herbivores. The tenth sample (UT 9) has residue consistent with large herbivore meat and plants, or large herbivore marrow. The eleventh sample (UT 5) has patterns that are close to those of several groups, including large herbivore meat and plants, large herbivore bone marrow, or foods such as mesquite or corn. The second largest group, consisting of seven samples, is consistent with residue patterns for medium fat content foods such as mesquite or corn. A number of other smaller groups are present, including residue patterns consistent with moderate-high fat content foods (UTs $17,21,23)$ such as Texas ebony seeds and fatty meat of medium-sized mammals, and residues consistent with medium-low fat content foods (UTs 15 and 28), such as prickly pear. A number of other more ambiguous patterns are also present in these sample results. Some of these (e.g., UTs 11 and 12) fall between established patterns. Others, such as the residues from UTs 7, 8, and 22, may reflect the use of such plants as cholla or sotol. Finally, in two cases (UTs 6 and 24) fatty acid residues were recovered, but the composition suggests that the residues are natural in origin.

At a feature level, six of the 13 feature samples had fatty acid residues that were essentially the same. These were Features 14, 15, 17, 19, 23, and 26. In addition, Features 18 and 27 had similar, though not identical, residue 
Table 10. Results of fatty acid residue analysis on 41WB556

\begin{tabular}{|c|c|c|c|c|c|}
\hline $\begin{array}{c}\text { UT } \\
\text { Number } \\
\end{array}$ & $\begin{array}{c}\text { Catalog } \\
\text { Number }\end{array}$ & Unit & Level & $\begin{array}{c}\text { Feature } \\
\text { Number } \\
\end{array}$ & Signature is Consistent With \\
\hline 1 & 1492-4-1B & N40 E14 & 3 & 14 & Mesquite / Corn \\
\hline 2 & 1492-4-2B & N40 E14 & 3 & 14 & Mesquite / Corn \\
\hline 3 & $1552-1-1$ & N41E10 & 4 & 15 & Large Herbivore \\
\hline 4 & $1552-1-2$ & N41E10 & 4 & 15 & Large Herbivore \\
\hline 5 & $217-1-1 \mathrm{~B}$ & N41E10 & 6 & 16 & Borderline Between Groups \\
\hline 6 & $217-1-2 B$ & N41E10 & 6 & 16 & Natural? \\
\hline 7 & $257-1-1$ & $\mathrm{~N} 41 \mathrm{E} 13$ & 7 & 17 & Unknown Plant \\
\hline 8 & $257-1-2$ & $\mathrm{~N} 41 \mathrm{E} 13$ & 7 & 17 & Unknown Plant \\
\hline 9 & $402-21-1$ & N42E10 & 3 & 18 & Large Herbivore with Plant or Marrow \\
\hline 10 & $402-21-2$ & N42E10 & 3 & 18 & Large Herbivore \\
\hline 11 & 403-1-1B & N42 E11 & 3 & 19 & Mesquite / Corn or Prickly Pear \\
\hline 12 & $403-1-2 B$ & N42 E11 & 3 & 19 & Mesquite/ Corn or Prickly Pear \\
\hline 13 & $684-1-1$ & N43E11 & 6 & 21 & Large Herbivore \\
\hline 14 & $684-1-2$ & N43E11 & 6 & 21 & Large Herbivore \\
\hline 15 & $684-1-3$ & N43E11 & 6 & 21 & Prickly Pear \\
\hline 16 & 489-18B & N42 E15 & 7 & 22 & Large Herbivore \\
\hline 17 & $489-6 \mathrm{~B}$ & N42 E15 & 7 & 22 & Texas Ebony/ Beaver \\
\hline 18 & $865-1-1 \mathrm{~B}$ & N44 E13 & 5 & 23 & Large Herbivore \\
\hline 19 & $865-1-2 B$ & N44 E13 & 5 & 23 & Large Herbivore \\
\hline 20 & $804-1-1$ & N44E12 & 6 & 24 & Large Herbivore \\
\hline 21 & $804-1-2$ & $\mathrm{~N} 44 \mathrm{E} 12$ & 6 & 24 & Texas Ebony / Beaver \\
\hline 22 & $804-1-3$ & N44E12 & 6 & 24 & Unknown Plant \\
\hline 23 & $976-1-1 \mathrm{~B}$ & $\mathrm{~N} 45 \mathrm{E} 11$ & 4 & 25 & Texas Ebony / Beaver \\
\hline 24 & $976-1-2 B$ & $\mathrm{~N} 45 \mathrm{E} 11$ & 4 & 25 & Natural? \\
\hline 25 & $1223-1-1$ & $\mathrm{~N} 46 \mathrm{E} 15$ & 5 & 26 & Mesquite / Corn \\
\hline 26 & $1223-1-2$ & $\mathrm{~N} 46 \mathrm{E} 15$ & 5 & 26 & Mesquite / Corn \\
\hline 27 & $1223-1-3$ & N46E15 & 5 & 26 & Mesquite / Corn \\
\hline 28 & 1311-1-1D & N43E09 & 4 & 27 & Prickly Pear \\
\hline 29 & 1311-1-2B & N43E09 & 4 & 27 & Mesquite / Corn \\
\hline 30 & $1311-1-3$ & N43E09 & 4 & 27 & Mesquite / Corn \\
\hline
\end{tabular}

results. In the case of Features 21, 22, and 24 dramatically different food residue patterns were present on rocks from the same feature. Finally, what are probably nonfood residues were recovered on one of two samples from Feature 16 and one of two samples from Feature 25. Comparisons for consistency between samples are not possible in these cases.

When considered as a group, the fatty acid residue results suggest that sandstone rocks were primarily involved with processing large herbivores, with a secondary focus on medium fat content foods consistent with mesquite. Residues from foods consistent with Texas ebony seeds or medium-sized mammals, and prickly pear, are also present, along with several unidentified foods groups. At a feature level, residue comparisons for individual rocks suggest that at least six, and possibly as many as eight of 11 features where comparisons were possible probably had limited or specialized use.

\section{Comparison of Isotopic and Fatty Acid Residue Results at 41WB556}

The isotopic and fatty acid residue analyses produce radically different pictures of subsistence at 41WB556. The isotopic work suggests a focus on a mixture of $\mathrm{C}_{3}$ and $\mathrm{C}_{4} / \mathrm{CAM}$ plants. No exclusive focus on $\mathrm{C}_{4} / \mathrm{CAM}$ plants was apparent. No indication of animals being 
processed was revealed by the nitrogen data. Fatty acid residues suggest a focus on large herbivores and plants such as mesquite and prickly pear. The isotopic interpretation that animals were not a focus of features at 41WB556 is a result of the low nitrogen values.

For this comparison, we will dismiss the nitrogen values in the analysis, and assume that both the carbon isotope results and the lipid analysis are correct. This dismissal is, in part, due both to our lack of understanding of nitrogen variability in the natural environment and the magnitude of that variability. Figure 34 presents a third reason for being suspicious of the nitrogen results, at least in this case. The figure plots the weight of nitrogen (micrograms) relative to the isotopic value of the sample $\left({ }^{15} \mathrm{~N}\right)$ using values presented in Table 9. Note that samples with higher delta ${ }^{15} \mathrm{~N}$ readings tend to come from larger samples. While the correlation is far from perfect, it is statistically significant (Pearson's $\mathrm{R}=.403, \mathrm{p}=.027$; Spearman's $\mathrm{R}=.491, \mathrm{p}=.006)$. Minimally, this relationship suggests that there may be significant problems with this particular data set. It also suggests that some concern regarding sample sizes of nitrogen will be required for reliable results.

When we drop out the nitrogen values, a slightly more consistent picture emerges of subsistence and feature use at 41WB556, at least for some features. Below, we discuss each feature from that perspective.

In Feature 14, both rocks had residues that were consistent with foods like corn and mesquite. The carbon isotopic readings of $-20.57 \%$ and $-20.06 \%$, taken from the same rocks, are much too low to be consistent with corn, $\mathrm{a} \mathrm{C}_{4}$ plant. However, these readings are high relative to values for mesquite. Mean values for mesquite beans

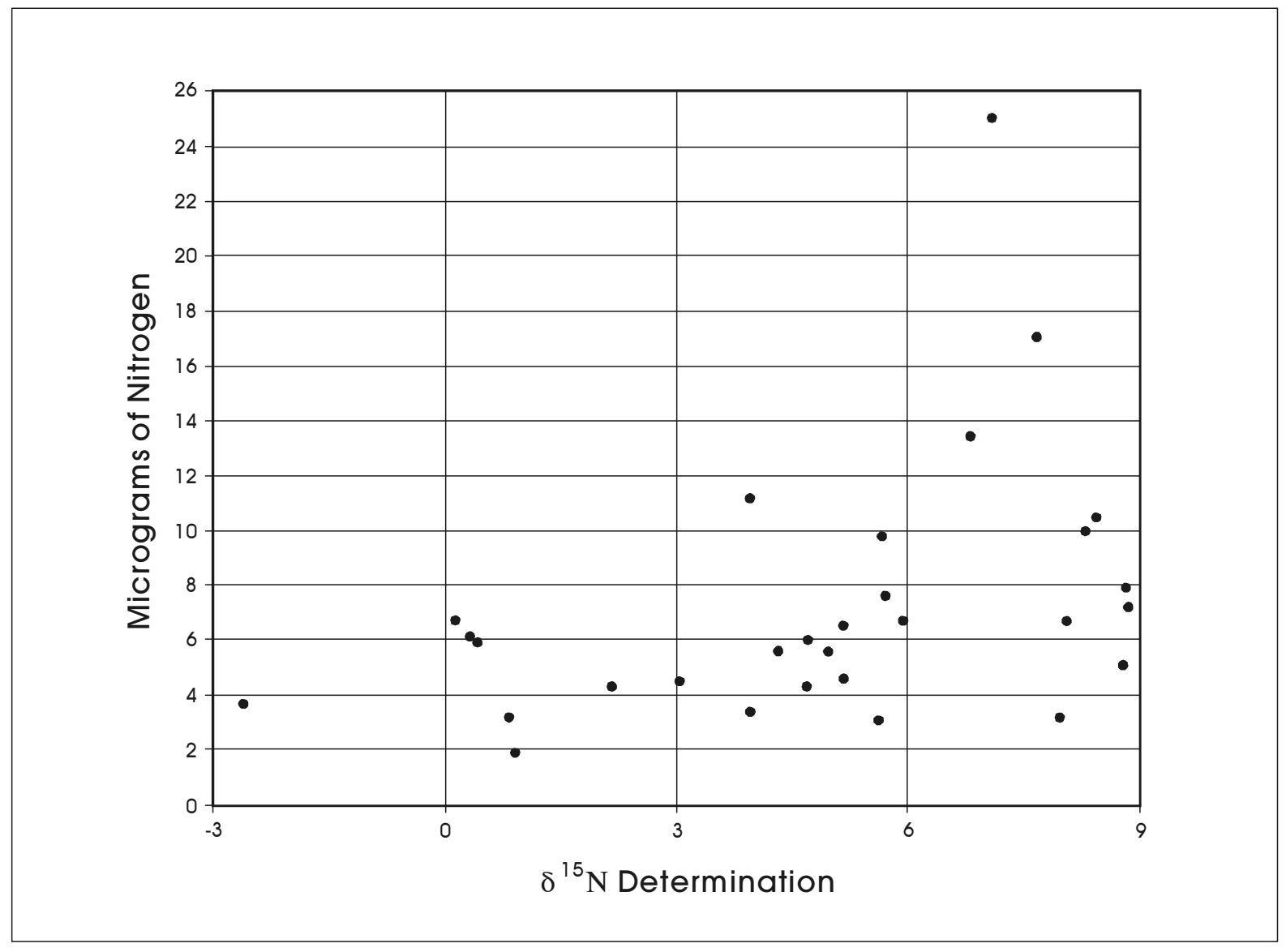

Figure 34. Relationship between weight of nitrogen analyzed and the delta ${ }^{15} \mathrm{~N}$ value for $41 \mathrm{WB} 556$ samples. 
in the South Texas data are $-26.03 \%$. Even taking into consideration that modern samples are likely to be depleted by about $1.5 \%$ as a result of fossil fuel use (see Tieszen and Fagre 1993), values of -20\%o are unlikely to reflect mesquite. If we assume that both the carbon isotopic data and the residue results are correct, then the feature must have been used to process another $\mathrm{C}_{3}$ plant with a medium fat content.

Fatty acid residues from Feature 15 rocks were consistent with large herbivore. While no paired samples exist for this feature, carbon isotopic values are consistent, and average about $-20.3 \%$, suggesting that the herbivore subsisted on $\mathrm{C}_{3}$ plants. Deer or antelope are likely candidates.

One of the two samples of lipid residues from Feature 16 is ambiguous, being on the borderline between large herbivore cooked with plants, large herbivore bone marrow, and plant foods such as mesquite or corn. The second probably reflects non-food lipids. We have paired samples for this feature. The carbon isotopic signature for the food residue sample was $-23.31 \%$. This effectively eliminates bone marrow, though no additional conclusions are possible. The signature for the non-food residue sample was $-22.97 \%$.

Both rocks from Feature 17 had food residues of an unknown plant. Malainey (Appendix C) suggests likely candidates to be cholla, sotol, and tasajillo berries. Values for ${ }^{13} \mathrm{C}$ from residues in the rocks are internally consistent and hover around $-19 \%$, well outside of the range expected for these particular $\mathrm{CAM} / \mathrm{C}_{4}$ plants.

Residues from Feature 18 suggest large herbivore, probably cooked with plants. While the carbon isotopic signatures are consistent and average about $-18.6 \%$, they provide no additional information as to what animals or plants are present. That is, depending on the mix and possibly the quantity of plants and animals represented, any large herbivore, including bison, and a variety of $\mathrm{C}_{3}$ plants could produce these results.

Feature 19 had residues that were ambiguous with regard to food groups with results being close to both medium-low fat content plants and medium fat content foods. Carbon isotopic values of $-19.41 \%$ and $-21.24 \%$ o provide no additional information on what foods may be represented.
Feature 21 had two fatty acid residue patterns that reflect large herbivore, and a third rock with residues consistent with foods like prickly pear. Carbon isotopic signatures were also variable, with a range of between $-17.72 \%$ o and $-21.04 \%$. While we have no paired samples for this feature, none of the values are consistent with prickly pear. One of the samples $(-21.04 \%)$ may be consistent with deer, and possibly antelope.

Feature 22 had two different fatty acid residues reflected in the rocks. One was consistent with a large herbivore while the other was consistent with plants such as Texas ebony seeds or medium-sized mammals such as beaver. In both of these cases, isotopic data were derived from the same rocks as the fatty acid residues. A delta ${ }^{13} \mathrm{C}$ isotopic value of $-23.90 \%$ was recorded for the large herbivore sample. This value is consistent with deer, and possibly antelope. The isotopic value of the second sample was $-22.87 \%$, a value consistent with Texas ebony seeds (ca. $-24.65 \%$ o to $-22.50 \%$ ).

Feature 23 had two fatty acid residue samples that were identified as large herbivore. The carbon isotopic signatures, which come from the same two rocks, were $-17.81 \%$ and $-19.09 \%$ o. These values, though a little high compared to the modern isotopic average for deer in the sample (-22.105\%), are probably within the range of deer diets, though antelope may also be a possibility.

Feature 24 had three fatty acid residue samples, each of which reflected different food groups. One reflected large herbivore, a second was consistent with a moderate-high fat content food such as Texas ebony $\left(\mathrm{C}_{3}\right)$ or medium-sized mammal, and the third was a food residue of an unknown type, possibly reflecting tasajillo berries, sotol, or cholla $\left(\mathrm{C}_{4} / \mathrm{CAM}\right)$. The three isotopic signatures range from $20.54 \%$ o to $-16.60 \%$. While not from the same rocks, they are consistent with a mix of $\mathrm{C}_{3}$ and $\mathrm{C}_{4} / \mathrm{CAM}$ resources, though no exclusive $\mathrm{C}_{4} / \mathrm{CAM}$ signatures are present.

From Feature 25, we had paired samples. Fatty acid residue results from one sample indicated plants consistent with Texas ebony and/or medium-sized mammal. The carbon isotopic signature for this sample was $-21.93 \%$, a value consistent with Texas ebony, though medium-sized mammal cannot be ruled out by this value. The second sample, which produced a non-food fatty acid residue pattern, had an isotopic value of $-19.15 \%$. 
Feature 26 had three residue samples, all of which appeared to result from the preparation of medium fat content foods, such as mesquite or corn. While we have no paired samples for this feature, the isotopic values, which range between $-19.70 \%$ and $-21.02 \%$, are certainly not consistent with corn. In addition, they appear to be too high for mesquite (ca. -26.03\%o).

Feature 27 also had three residue samples. The first sample produced lipids consistent with prickly pear while the second and third sample residues were consistent with mesquite or corn. We have paired carbon isotopic results for two of these samples. The lipid residue sample identified as prickly pear produced a ${ }^{13} \mathrm{C}$ reading of $-19.07 \%$. This value is well out of the range of modern prickly pear. The second sample produced a ${ }^{13} \mathrm{C}$ value of $-20.85 \%$, well out of the range of corn and probably too high for mesquite.

At a site level, then, we can make a number of statements regarding broad subsistence practices. Using the above summaries, we can suggest that while bison cannot be excluded (e.g., Feature 18), deer and/or antelope may have been the primary large herbivores processed at the site. The suggested use of many of the stones for processing foods consistent with corn and mesquite is not supported. No carbon values within the range of corn were present, and values were commonly too high for mesquite, though other $\mathrm{C}_{3}$ plants with a medium fat content may be present. The isotopic data do not support the identification of prickly pear on stones, though it is possible that other, non-CAM plants are within the medium-low fat content plant group. Finally, the use of moderate-high fat plant foods, consistent with Texas ebony, is supported in some cases, though this pattern may also reflect medium-sized mammals.

\section{Evaluation and Suggestions for Future Research on Residues}

Ignoring the problematic nitrogen isotopic values, and comparing only the carbon isotope values to the fatty acid residue results, helps clarify some of the feature use patterns, as well as aspects of the overall subsistence base at the site. Nevertheless, comparisons of the results from the two different techniques frequently produced ambiguous patterns. Considering the background for the two techniques, it is clear that the analysis of fatty acids found on archeological artifacts has a long history of research (see review in Malainey 1997). While limited in terms of specific identifications, and while plagued by problems of residue degradation, several experimental studies, including samples involving burned rock (e.g., Quigg et al. 2001), suggest that the methodology is increasingly well-established.

Unfortunately, the same statements cannot be made regarding stable isotope analysis of samples from burned rock. While we know a great deal about isotopic analysis and about how carbon isotopes are manifested in plants and animals, the link between that knowledge base and similar analysis in burned rock has not been established. Does cooking deer, with a flesh ${ }^{13} \mathrm{C}$ value of $-24 \%$, on or with sandstone produce residues in that sandstone that have a ${ }^{13} \mathrm{C}$ value of $-24 \%$ ? Does stone boiling a mixture of equal parts of $\mathrm{C}_{3}$ and $\mathrm{C}_{4} / \mathrm{CAM}$ plants produce ${ }^{13} \mathrm{C}$ values in that stone that are intermediate between the two plant groups? While we currently lack sufficient theoretical information to answer such questions, the limited experimental and archeological data we do have suggest that any relationships between resources, residues, and isotopes in rock are unlikely to be simple.

For example, Figure 35 presents the results of a series of experimental samples where sandstone was heated with modern plants (see Quigg 2000). Note that while the number of experimental samples is small $(n=4)$, a consistent pattern of nitrogen depletion is present when these results are compared to values from the same South Texas plants. On average, ${ }^{15} \mathrm{~N}$ values are depleted $8.28 \%$ o in burned rock relative to the modern ${ }^{15} \mathrm{~N}$ sample values. This may explain, in part, the lack of high nitrogen in the prehistoric samples discussed above, though that archeological data set obviously has a variety of problems.

Encouragingly, the delta ${ }^{13} \mathrm{C}$ value for the single modern burned rock item exposed to mesquite is similar to the average ${ }^{13} \mathrm{C}$ values for modern South Texas mesquite. However, there is an apparent depletion of ${ }^{13} \mathrm{C}$ in both the deer and prickly pear samples. The burned rock sample exposed to deer is depleted by $-2.495 \%$ o relative to the modern samples. The two burned rock prickly pear samples are, on average, depleted in delta ${ }^{13} \mathrm{C}$ by $-6.305 \%$ o relative to the modern carbon signatures. While, like the relationship between the nitrogen depletion and the apparent absence of animal signatures, this depletion may account for the absence of $\mathrm{C}_{4} / \mathrm{CAM}$ plants in our 30 


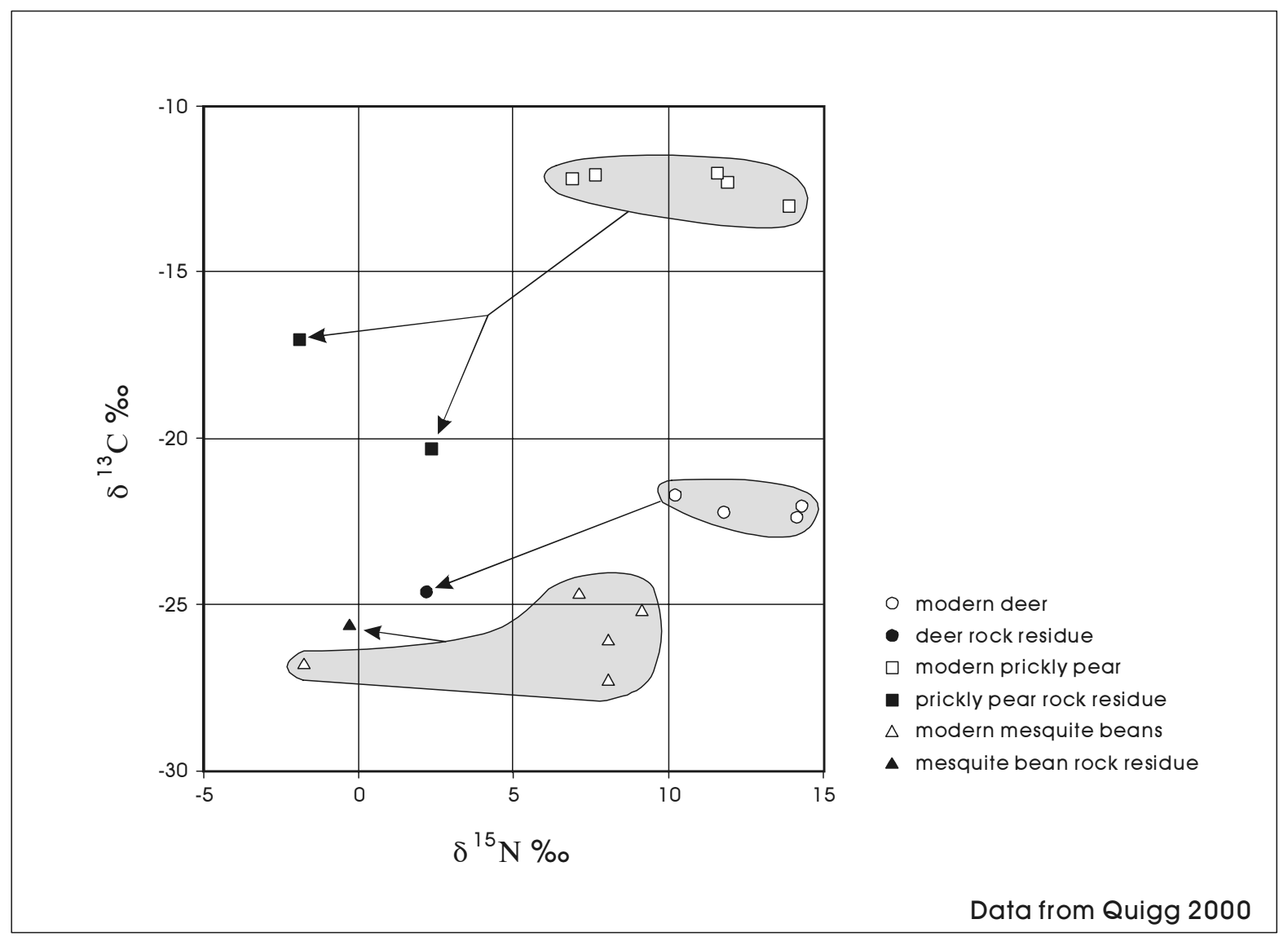

Figure 35. Comparison of carbon and nitrogen isotopic values of known residues from burned rock with their modern South Texas counterparts.

archeological samples, these data call into question even the relatively modest goal of identifying $\mathrm{C}_{3}$ and $\mathrm{C}_{4} / \mathrm{CAM}$ plants as broad groups. A review of previous burned rock residue samples, including nine burned rock samples from 41ZP364 (Quigg and Cordova 2000) and 53 burned rock samples from 41WB437 (Quigg 2000), also produced no residue with a delta ${ }^{13} \mathrm{C}$ value reflecting $\mathrm{C}_{4} /$ CAM plants or animals. In fact, the highest reported value in all three data sets is $-16.6 \%$. While it may be the case that these 92 samples consistently reflect a mixture of $\mathrm{C}_{4} / \mathrm{CAM}$ and/or $\mathrm{C}_{3}$ plants and animals, it may also be the case that the lack of $\mathrm{C}_{4} / \mathrm{CAM}$ values is related to patterns of depletion consistent with these limited experimental data.
An additional complication is highlighted by the presence of "non-food" residues identified on two samples of burned rock on the present project. Both of these nonfood residues had ${ }^{13} \mathrm{C}$ values reported that were indistinguishable from the general values reported for food residues. These non-food residues could represent the influence of fuel used in the fire, or other contaminants trapped in the rock. It is unclear how common these nonfood residues are. It is also unclear if food resources would mask these non-food residues when both were present within a rock. As the delta ${ }^{13} \mathrm{C}$ value for a sample represents the overall isotopic composition of the sample, the presence of these non-food residues could dramatically change the interpretation of an individual sample. 
Figure 36 presents a final complication. Here, we plot the delta ${ }^{13} \mathrm{C}$ provided by UC Davis with those provided on the same rocks by Beta Analytic. In 12 of the 13 samples, the values reported by Beta are more positive. The average difference is a value of $2.41 \%$, and in two of the 13 cases the difference is over $4 \%$. These types of systematic differences are likely to be the result of different pretreatment methods used by the two laboratories. Different pretreatment methods, designed to remove contaminants, can differentially impact both non-organic and organic compounds. Changes on the order of $4 \%$ in isotopic values could significantly impact interpretations. Clearly, the impact to food residues of these pretreatment procedures needs to be assessed.
There are, then, several significant problems that must be overcome before carbon stable isotopic analysis of food remains in burned rock residues can be considered a viable methodology for providing data on prehistoric diet. None of these problems can be systematically investigated with additional archeological samples. We suggest that progress can be made with an extensive, well-controlled, experimental program comparing the results provided by fatty acid residues and stable carbon isotopes from sandstone used to cook known plants and animals. Such a program of investigation would quickly determine the potential utility of the isotopic work, as well as provide additional data for the refinement of the fatty acid residue signatures.

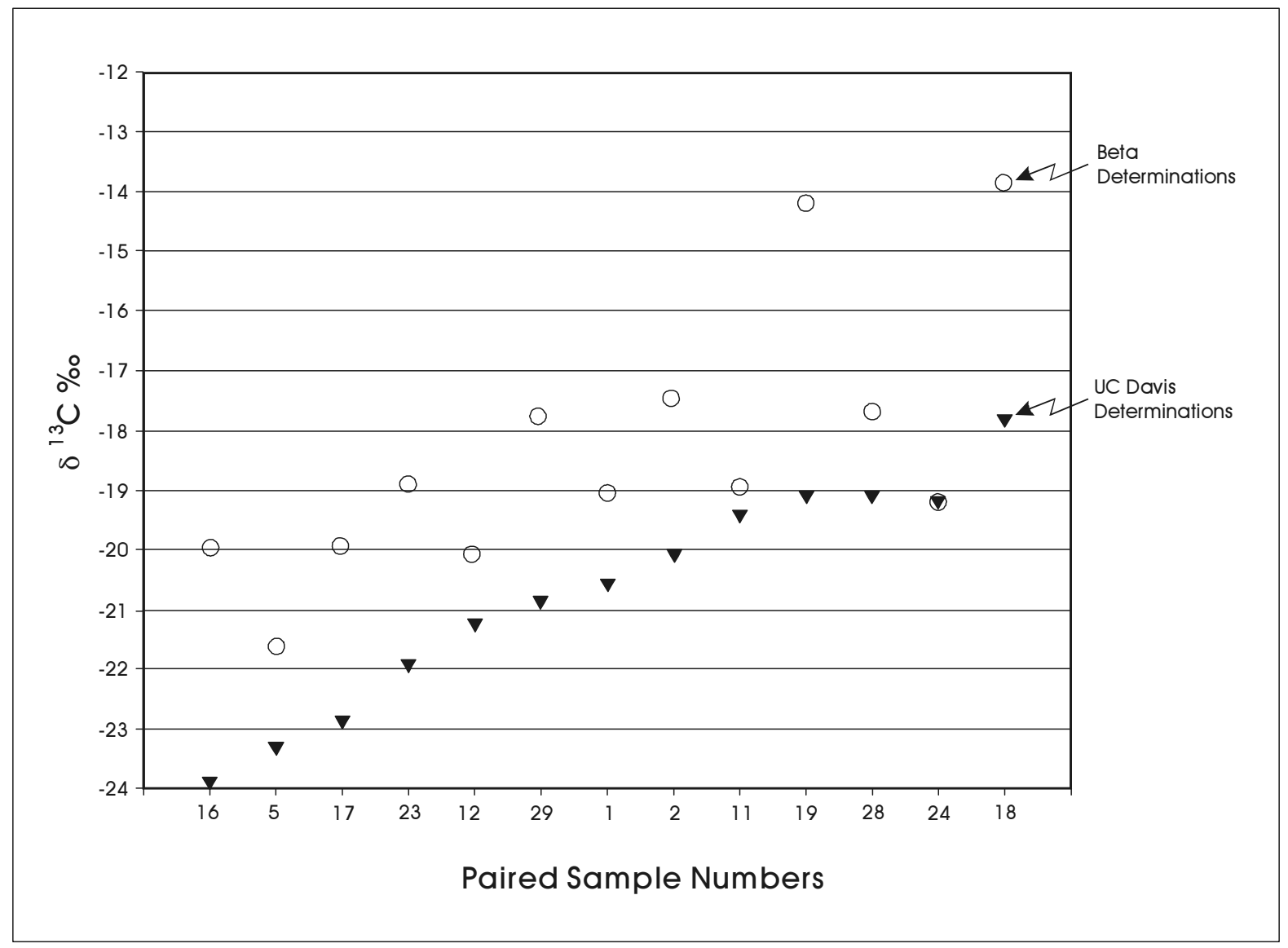

Figure 36. Comparison of delta ${ }^{13} \mathrm{C}$ values provided by two different labs on the same rock. Note: paired sample numbers are from Table 7 in Chapter 7. 


\section{Summary}

The investigation of thermal feature technology at 41WB556 has produced ambiguous results. The patterns of features within the excavation block are not consistent with any single model of feature use. Relying on patterns in rock size and number, we suggest that Feature 21, and possibly Features 14, 16, 19, and 20, are consistent with the notion of stone boiling or short term dumping. Features 22 and 23, and possibly Features 15, 17, 18, $24,25,26$, and 27, may represent hearths, though only Feature 23 has a clearly defined pit that would be expected for such features.

The analysis of fatty acids (lipids) and carbon and nitrogen isotopes from residues extracted from burned rock also produced ambiguous, and sometimes contradictory, results. Exploring this contradiction has, however, identified several critical areas that can be addressed by future research. 


\section{Chapter 9: $\quad$ Projectile Points and Beveled Tools An Assessment of Typology and Function}

\section{Introduction}

The investigation of lithic technology operates at a scale where integrity of the deposits at 41WB556 is not critical. The broadening of the scope of this lithic analysis was precipitated by a desire to address research issues that have both broader methodological and theoretical implications as well as regional and site-specific relevance. Beginning with the lithic artifact collection from 41WB556 and complementing it with the analysis of selected collections from other South Texas sites, the lithic technology module has two main objectives:

1) construction of a projectile point analysis protocol system applicable to point types commonly found in the region; and

2) functional identification of tool forms commonly found on South Texas sites.

The construction of a projectile point analysis protocol system applicable to point types common to South Texas has two main goals. One of the goals is to standardize the analysis of triangular and subtriangular projectile points so that the definition and characterization of types will be more readily accomplished using easily replicable and less subjective metric and non-metric attributes. The second goal is to provide systematic data that can help investigate the morphological and/or technological relationships between various point types to establish whether they represent valid chronological markers or simply similar forms distinguished based on size differences resulting from different degrees of point rejuvenation.

The second objective of the lithic analysis research design is to identify the function of some distally beveled tool forms common in South Texas lithic assemblages. These tool forms are variously known as Dimmit scrapers and unifacial and bifacial Nueces tools, and Olmos bifaces. Such knowledge regarding the function of these tools is critical for the accurate reconstruction of site use and function and therefore would provide broadly applicable results for regional archeological projects.
Figure 37 presents a graphical illustration of selected projectile point metric analysis attributes. Table 11 presents a comprehensive list of the analysis attributes, including metric and nominal observational attributes. Metric attributes were measured to the nearest $.1 \mathrm{~mm}$ with Mitutoyo digital calipers using the guidelines outlined in Figure 37.

One key to the functional identification of South Texas tool forms is a systematic program of macroscopic and microscopic use-wear studies. To accomplish this aspect of the lithic analysis, all Dimmit/Nueces and Olmos tools included in this study were examined for macroscopic use-wear evidence (step fracturing, polish, edge rounding). Next, selected specimens that exhibited traces of macroscopic use-wear were subjected to low-power microscopic analysis $(20-80 \mathrm{X})$ to identify the manner of tool use (i.e., scraping, cutting, planing, gouging). A small sub-sample of specimens was also examined using the UTSA high-power Scanning Electron Microscope (SEM). While the low-power analysis was very useful in identifying wear traces and tool use, the SEM could not be accessed regularly and the few specimens analyzed did not exhibit clear wear patterns at the higher range of magnification.

As an additional aspect of this analysis, a number of metric and nominal attributes were recorded on each tool. These attributes are listed in Table 12. As in the case of the projectile point attributes, the measurements are designed to characterize the different tool forms while the nominal attributes are designed to capture other sources of morphological variability between groups such as tool blank production and selection criteria (i.e., heat treatment, platform location, cortex presence), manufacture strategies (i.e., unifacial and bifacial forms and degree of ventral face retouch), and rejuvenation characteristics. To aid the reader with some of the more technical terms used in this chapter, a glossary is presented in Appendix G.

A number of distally beveled tool forms that occur in southern Texas and northern Mexico have been identified through years of archeological investigations. 
SITE NUMBER:

PROJECTILE POINT TYPE:

LENGTH:
A Maximum Length:
$\mathrm{mm}$
B Distance of Max. Thickness from Base: $\mathrm{mm}$ WIDTH:

C Maximum Width: $\mathrm{mm}$

D Maximum Base Width: $\mathrm{mm}$

E 2-mm Distal Width: $\mathrm{mm}$

THICKNESS:

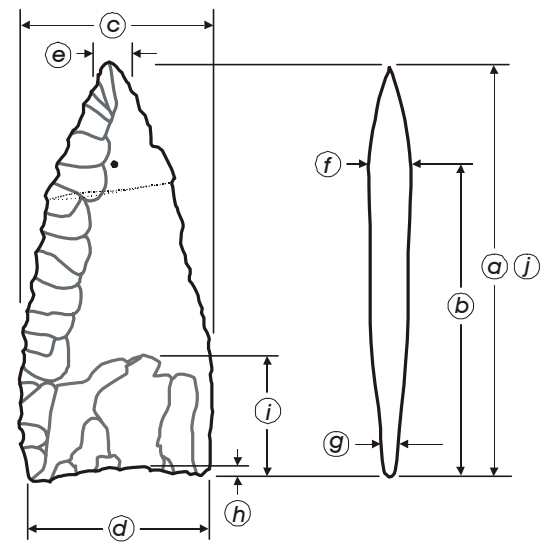

Tortugas

F Maximum Thickness: $\mathrm{mm}$

G 5-mm Base Thickness: $\mathrm{mm}$

BASE DEPTH:

$\mathrm{H}-$ $\mathrm{mm}$ for concave and notched

$\mathrm{H}+$ $\mathrm{mm}$ for convex

H $0 \mathrm{~mm}$ for straight

\section{FLUTED POINTS:}

I Max. Length of Thinning Flake Scar

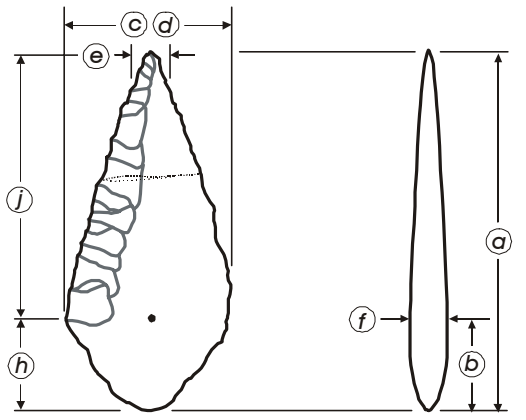

$$
\begin{aligned}
& \text { Face } 1=\ldots \mathrm{mm} \\
& \text { Face } 2= \\
& \mathrm{mm}
\end{aligned}
$$

$\mathrm{J}$ Length of resharpening

Face $1=$ $m m$

Face 2 = $\mathrm{mm}$

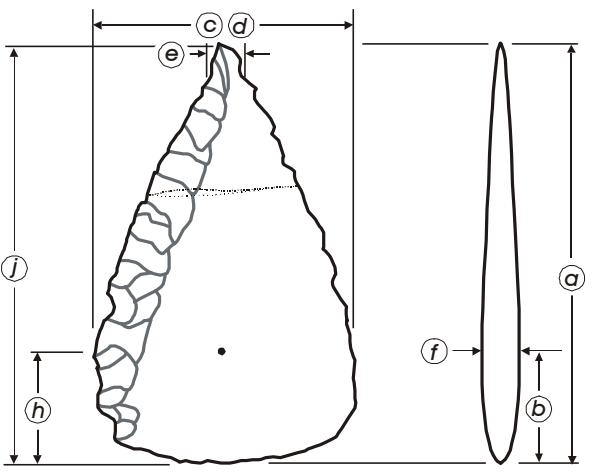

Abasolo 
Table 11. Analysis attributes measured and recorded on projectile points analyzed for this study

Section A. Comprehensive list of projectile point analysis attributes measured on round base and triangular points.

\section{Part I. Metric Attributes}

Maximum Length: $\quad$ measured on complete and incomplete specimens

Distance of maximum thickness from center of base

Length of longest base thinning flake Face 1

Length of longest base thinning flake Face 2

Length of longest resharpening and/or beveling on either edge of Face 1:

measured from tip to base, measured on complete and fragmentary specimens

Length of longest resharpening and/or beveling on either edge of Face 2:

measured from tip to base, measured on complete and fragmentary specimens

Maximum Width measured on complete specimens and fragments when available

Maximum Base Width: $\quad$ measured on complete specimens and proximal fragments

Width $2 \mathrm{~mm}$ from tip: $\quad$ measured on complete specimens and distal fragments

Maximum Thickness: measured on complete specimens and fragments when available

Maximum Thickness $5 \mathrm{~mm}$ from base:

measured at center of base on complete and proximal fragments

Base Depth: $\quad$ _ _ $\quad$ mm for concave [or notched] based points

$+\ldots$ mm for convex based points

$0 \mathrm{~mm}$ for straight based points

Part II. Non-metric Observational Attributes

$\begin{array}{lllllll}\text { Raw Material Type: } & \text { f-g chert } & \text { c-g chert } & \text { chalcedony } & \text { rhyolite } & \text { agate/jasper } & \text { quartzite } \\ \text { Heat Treatment: } & \text { present } & \text { absent } & \text { indeterminate } & & \\ \text { Completeness: } & \text { complete } & \text { proximal } & \text { medial } & \text { distal } & \text { longitudinal }\end{array}$

Number of base thinning scars Face 1

Number of base thinning scars Face 2

Blade Beveling:

alternate left

alternate right

irregular

absent

Break Morphology/Cause:

perverse snap

impact scar burin scar

post-depositional indeterminate 
Table 11. continued...

Section B. Comprehensive list of metric and nominal attributes employed in the study of distally beveled tool forms.

\section{Part I. Metric Attributes}

$\begin{array}{ll}\text { Maximum Length: } & \text { measured on complete specimens and fragments } \\ \text { Maximum Width: } & \text { measured on complete specimens and fragments when available } \\ \text { Maximum Thickness: } & \text { measured on complete specimens and fragments when available } \\ \text { Thickness @ } 5 \mathrm{~mm} \text { above base: } & \text { measured on complete and proximal fragments } \\ \text { Working edge angle: } & \text { measured with goniometer } \\ \text { Ventral face protrusion: } & \text { measured as protrusion from vertical }\end{array}$

Part II. Non-metric Observational Attributes

\begin{tabular}{|c|c|c|c|c|c|c|}
\hline Raw material type: & f-g chert & c-g chert & chalcedony & rhyolite & agate/jasper & quartzite \\
\hline Flake blank platform location: & proximal & lateral & distal & indeterminate & & \\
\hline Flake blank cortex: & present & absent & indeterminate & & & \\
\hline Manufacture strategy: & unifacial & bifacial & indeterminate & & & \\
\hline Ventral face retouch: & slight & moderate & extensive & & & \\
\hline Working edge shape: & concave & straight & convex & & & \\
\hline Heat Treatment: & Present & absent & indeterminate & & & \\
\hline Completeness: & complete & proximal & medial & distal & longitudinal & \\
\hline Ventral face polish: & minimal & moderate & extensive & & & \\
\hline Ventral face step fractures: & minimal & moderate & extensive & & & \\
\hline Ventral face shape: & concave & convex & straight & recurved & & \\
\hline
\end{tabular}


This section focuses on the Archaic projectile points and distally beveled tools. Whether we view projectile point types and tool forms as cultural identifiers or not, because they represent the material culture that allowed the populations to interact with their natural environment, these technological components must have provided some advantages to their users that allowed these tools to function and evolve with only minor changes over a 3,200 year span of the Archaic era. This chapter has two main goals: 1) to describe and consider the morphological variability in projectile points in terms of manufacture and rejuvenation technology and consider the diagnostic criteria differentiating these types and the validity of the types themselves; and 2) to describe the common technological and functional characteristics of selected distally beveled tool forms.
In a recent review of the archeology of South Texas, Hester (1995:438), following Hall et al.'s (1986) lead, remarks that the Middle Archaic represents "specific regional cultural patterns ca. 2500 B.C., emphasizing unstemmed dart points and smaller bifacial and unifacial beveled tools." This pattern continued into the Late Archaic lasting approximately 3,200 years. A brief survey of limited resources from northern Mexico (Nuevo León and Tamaulipas) indicates that this pattern may have even more antiquity there (McClurkan 1966; MacNeish 1958; Nance 1992; Gustavo Ramirez, INAH-Tamaulipas, personal communication 2001). To provide some background to the detailed lithic analysis, the next section consists of a historical overview and morphological descriptions of the common South Texas projectile points and tool forms.

Table 12. Comprehensive list of metric and non-metric attributes employed in the study of distally beveled tool forms

\section{Part I. Metric Attributes}

Maximum Length

Maximum Width

Maximum Thickness

Maximum Thickness at break

Working edge angle

Ventral face protrusion measured on complete specimens

measured on complete specimens and fragments when available

measured on complete specimens and fragments when available

measured with goniometer

measured as protrusion from vertical

Part II. Non-metric Observational Attributes

Raw material type

Flake blank platform location

Flake blank cortex

Manufacture strategy

Ventral face retouch

Working edge shape

Heat Treatment

Completeness

Ventral face polish

Ventral face step fractures

$\begin{array}{llllll}\text { f-g chert } & \text { c-g chert } & \text { chalcedony } & \text { rhyolite agate/jasper } & \text { quartzite } & \text { Other } \\ \text { proximal } & \text { lateral } & \text { distal } & \text { indeterminate } & \\ \text { present } & \text { absent } & \text { indeterminate } & & \\ \text { unifacial } & \text { bifacial } & \text { indeterminate } & & \\ \text { slight } & \text { moderate } & \text { extensive } & & \\ \text { concave } & \text { straight } & \text { convex } & & \\ \text { Present } & \text { Absent } & \text { Indeterminate } & & \\ \text { Complete } & \text { Proximal } & \text { Medial } & \text { Distal } & \text { Longitudinal } \\ \text { minimal } & \text { moderate } & \text { extensive } & & & \\ \text { minimal } & \text { moderate } & \text { extensive } & & \end{array}$

Other use-wear attributes comparing traits on experimental and archaeological specimens 


\section{A Historical Overview and Summary of Common Projectile Point and Tool Forms from South Texas and Northern Mexico}

\section{Selected South Texas Projectile Point Types}

Although some less common and less widely distributed point types (i.e., Carrizo, perhaps Kinney) also exist in South Texas and northern Mexico, the most common Middle and Late Archaic projectile point types consist of Abasolo, Catán, Desmuke, Matamoros, Refugio, and Tortugas (Figure 38). The following section provides a brief historic review of the definition of these types in alphabetic order.

\section{Abasolo}

Abasolo Round-base or Abasolo was named by MacNeish (1958) based on a large number of surface $(n=845)$ and a smaller sample of excavated $(n=155)$ specimens from the Sierra de Tamaulipas. MacNeish described the type as having a roughly teardrop shape with a convex base that gradually merges into convex sides. Suhm et al. (1954:400) describe the outline as ranging from weakly convex to well-rounded, almost semicircular. Thinning of the base using large flakes was uncommon on these specimens. MacNeish (1958:64) remarked that often the tips of the points had been steeply beveled on opposite edges and sides. Hester et al. (1969) describe the type as having a trianguloid outline, convex base and straight to slightly convex blade edges. One of the key characteristics of the type is that its maximum width occurs very near the base of the point. Another of its diagnostic characteristics is that by definition, only teardrop shaped specimens that are greater than $40 \mathrm{~mm}$ in maximum length have been defined as Abasolo (Suhm et al. 1954:400).

McClurkan (1966:25-27) differentiates three varieties in the sample from Cueva de la Zona de Derrumbes. The Variety I specimens are narrow in relation to their length, are leaf-shaped in outline and have convex sides and well-rounded bases. This group is also relatively thin in cross-section (thickness ranges from $6-10 \mathrm{~mm}$; see Table 13). The Variety II specimens also are leaf-shaped but are relatively wide in relation to their length and are thick in cross-section (see Table 13). Finally, the Variety III Abasolo points constitute a median group and exhibit no distinguishing features.

Distribution: The type is widespread in Tamaulipas and it seems to be most common in the Rio Grande Valley below Laredo. Campbell (1964; cited in Hester 1969) and Newton (1963; cited in Hester 1969) have both reported the type from Kleberg County. Campbell also found Abasolo specimens at the Kent-Crane site in Aransas County (Campbell 1952) and in the Webb Island site collection from Nueces County (Campbell 1956). Prewitt's (1995:88) distributional analysis indicates that small numbers of specimens occur in the Lower Pecos and in Central Texas. The core area of distribution appears to be South Texas, including the coastal counties. This general triangular round-based form is also rather common throughout North and South America. However, because such forms can also serve as a blanks for the manufacture of many notched point types, low frequency occurrences of triangular round-based forms may not represent the true use of the specimens as finished projectile points. According to MacNeish (1958) the form is similar to the large variety of Desmuke points in southern Texas.

Temporal Range: MacNeish's (1958) work in Tamaulipas has been roundly criticized for oversimplifying stratigraphy and cultural sequences and ignoring the complex and sometimes mixed nature of deposits (Epstein 1980; Taylor 1960). Nonetheless, since it is the work that laid the chronological foundation for subsequent research in both northeastern Mexico and parts of South Texas, the temporal position of the points named by MacNeish (1958) will be presented in the following discussion. According to MacNeish (1958), in Tamaulipas, Abasolo points first appear in earliest Nogales times (7,000-5,000 years ago) and are the dominant type. They continue in relatively large numbers though the Almagre Phase (4,200-3,500 years ago) and then occur as a minority in subsequent parts of the sequence. At Cueva de la Zona de Derrumbes, Abasolo points occur throughout Levels 2-18, dating between 1500 B.C. and A.D. 800 (3450-1150 BP). The Variety I Abasolo points, the largest variety, are most common in Levels 4-8, dating roughly between A.D. 100-800 (1850$1150 \mathrm{BP})$. Variety III points, the smaller variants, are most 


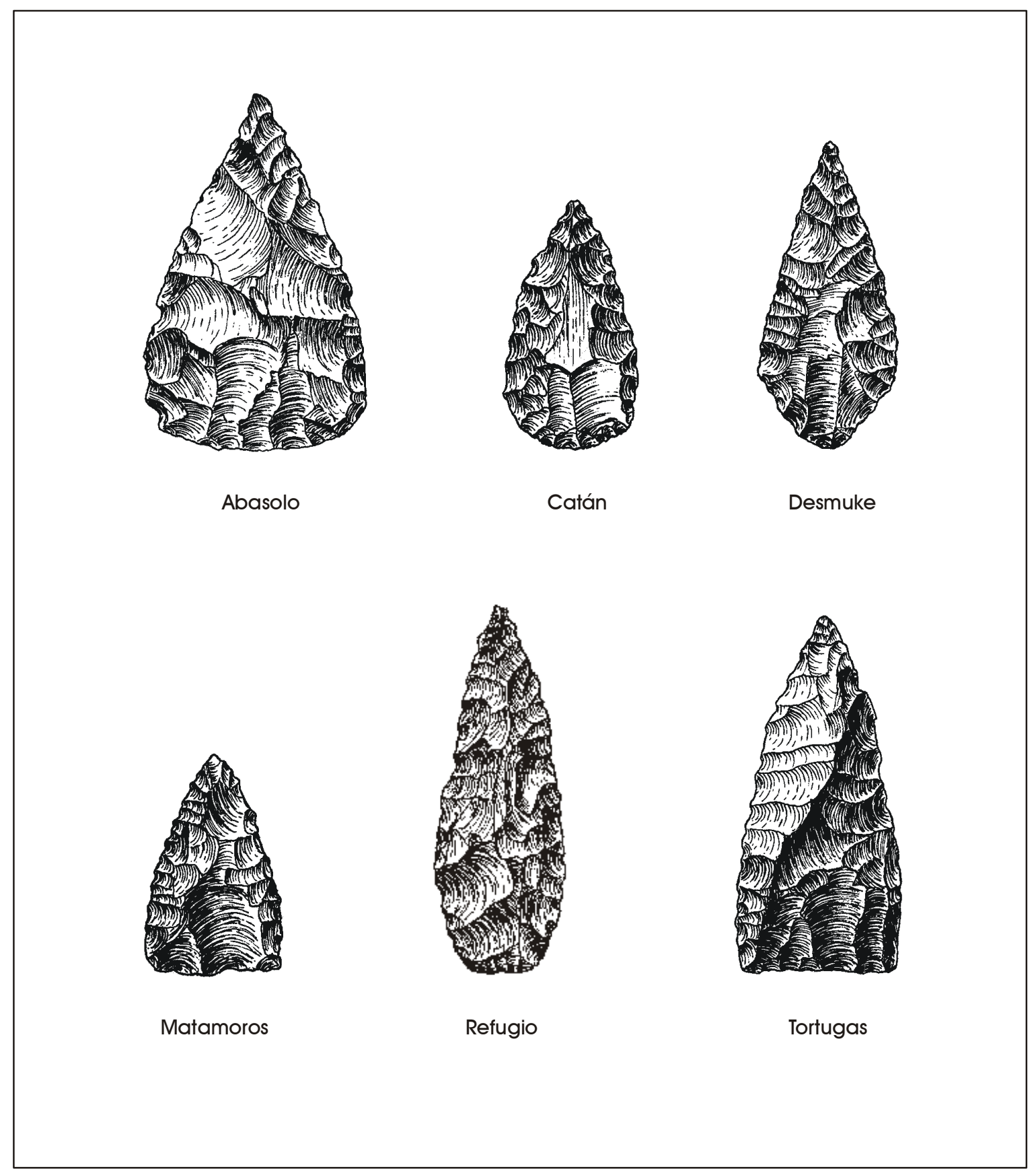

Figure 38. Common dart point types found in South Texas. Adapted from Turner and Hester 1993. 
Table 13. Projectile point varieties and dimensions for the common South Texas-North Mexico types

\begin{tabular}{|c|c|c|c|c|c|c|}
\hline Type Name & Max. Length & Max Width & Max. Thickness & Sample & Reference & Named by \\
\hline Abasolo Round-Base & $38-76$ & $20-42$ & $8-17$ & & MacNeish 1958 & MacNeish 1958 \\
\hline Abasolo & $40-55$ & $21.5-29.5$ & $6.5-10$ & & Hester et al. 1969 & \\
\hline Abasolo & $40-80$ & $20-50$ & & & Suhm et al. 1954 & \\
\hline Abasolo Variety I & $48-67$ & $26-30$ & $6-10$ & & McClurkan 1966 & McClurkan 1966 \\
\hline Abasolo Variety II & $44-47$ & $26-31$ & $9-11$ & & McClurkan 1966 & McClurkan 1966 \\
\hline Abasolo Variety III & $39-48$ & $20-29$ & $5-10$ & & McClurkan 1966 & McClurkan 1966 \\
\hline Abasolo & $52-70$ & $26-33$ & $5-10$ & 36 & Bettis 1997 & \\
\hline Catan Round Base & $15-37$ & $15-26$ & $3-13$ & & MacNeish 1958 & MacNeish 1958 \\
\hline Catan & $31-48$ & $17.5-21$ & $5.5-8.5$ & & Hester et al. '69 & \\
\hline Catan & $20-45$ & $15-25$ & & & Suhm et al. 1954 & \\
\hline Catan Variety I & $31-40$ & $21-29$ & $4-9$ & & McClurkan 1966 & McClurkan 1966 \\
\hline Catan Variety II & $26-35$ & $17-25$ & $4-9$ & & McClurkan 1966 & McClurkan 1966 \\
\hline Catan Variety III & $27-38$ & $16-21$ & $5-9$ & & McClurkan 1966 & McClurkan 1966 \\
\hline Catan Variety IV & $18-24$ & $16-17$ & $4-6$ & & McClurkan 1966 & McClurkan 1966 \\
\hline Catan & $35-50$ & $17-22$ & $6-9$ & 57 & Bettis 1997 & \\
\hline Desmuke & $35-47$ & $15.5-24$ & $4-6$ & & Hester et al. 1969 & Suhm et al. 1954 \\
\hline Desmuke & $38-65$ & $19-26$ & $6-9$ & 46 & Bettis 1997 & \\
\hline Desmuke & $30-50$ & $15-25$ & & & Suhm et al. 1954 & \\
\hline Matamoros Triangular & $18-40$ & $16-26$ & $6-12$ & & MacNeish 1958 & MacNeish 1958 \\
\hline Matamoros & $20-40$ & $15-25$ & & & Suhm et al. 1954 & \\
\hline Matamoros & $25-38$ & $20-25$ & $4.5-7$ & & Hester et al. 1969 & \\
\hline Matamoros & $30-41^{*}$ & $20-24$ & $4-8$ & 47 & Bettis 1997 & \\
\hline Matamoros & $25-54$ & $14-29$ & $4-9$ & 70 & McClurkan 1966 & \\
\hline Matamoros & $25-29$ & $17-25$ & $3-5$ & 4 & Nance 1992 & \\
\hline Matamoros & $30-33$ & $19-20$ & & 2 & Hall et al. 1982 & \\
\hline Nogales Triangular & $40-70$ & $21-40$ & $3-6$ & & MacNeish 1958 & MacNeish 1958 \\
\hline Refugio & $60-100$ & $20-30$ & & & Suhm et al. 1954 & \\
\hline Refugio & $44-61$ & $18-27$ & $5-13$ & 14 & McClurkan 1966 & \\
\hline Tortugas Triangular & $38-75$ & $25-46$ & $3-8$ & & MacNeish 1958 & MacNeish 1958 \\
\hline Tortugas & $35-80$ & $20-40$ & & & Suhm et al. 1954 & \\
\hline Tortugas & $38-70$ & $20-33$ & $5-10$ & & Hester et al. 1969 & \\
\hline Tortugas & $41-45$ & $21-29$ & $4-6$ & 4 & & \\
\hline Tortugas Variety I & $41-80$ & $23-51$ & $?$ & & McClurkan 1966 & McClurkan 1966 \\
\hline Tortugas Variety II & $?$ & $?$ & $?$ & & McClurkan 1966 & McClurkan 1966 \\
\hline
\end{tabular}

common between Levels 10-18, dating roughly between 1500 B.C. and A.D. 100 (3450-1850 BP). Suhm et al. (1954:400) estimate its age in Texas to be between 5000 3000 в.с. $(6950-4950 \mathrm{BP})$ and surviving perhaps as late as A.D. 500 (1450 BP) and even as late as the eighteenth century along the lower Rio Grande. At the Loma Sandia site (41LK28), Abasolo points were recovered from the late Middle Archaic cemetery zone dating to circa 850 550 в.с. (2810-2500 BP; Taylor and Highley 1995). 
Catán

The Catán Round-base type also was named by MacNeish (1958) based on excavated specimens from sites in the Sierra de Tamaulipas $(\mathrm{n}=20)$, Sierra Madre $(\mathrm{n}=131)$, and surface collected and excavated coastal sites in Tamaulipas ( $\mathrm{n}=22)$, as well as 50 points from Texas. The type is defined as roughly teardrop-shaped in outline. Specimens have narrow, triangular blades with convex edges and convex to well-rounded bases. The Tamaulipas specimens tend to be percussion flaked and many display the flat ventral faces of the flake blanks used in their manufacture. The distal ends of about one-fourth of the Tamaulipas sample studied by MacNeish are beveled. Beveling seems to be less common on specimens from South Texas (Hester et al. 1969). As in the case of the Abasolo type, Catán specimens also tend to reach their maximum width near the base of the point. However, by definition (Suhm et al. 1954:410), they range from 20 to $40 \mathrm{~mm}$ in maximum length, although some specimens measuring $45 \mathrm{~mm}$ have been included in the type (Suhm et al. 1954:410; see Table 13). Those specimens greater than $40 \mathrm{~mm}$ tend to overlap with the smaller of the Abasolo points.

McClurkan (1966:27-28) distinguished four varieties within his collection from Cueva de la Zona de Derrumbes (see Table 13). The Variety I Catán specimens are leaf-shaped and have slightly convex sides and bases that are strongly convex to well-rounded. The average width/length index is 66 . The width/length index (referred to as length/width index in McClurkan 1966) was derived by dividing the mean maximum width of each variety group by the mean maximum length of the variety group and presenting the product as a whole number. The Variety II Catán have the same general outline as Variety I, but are somewhat smaller in overall dimensions, and are somewhat broader in relation to their length than Variety I specimens. The average width/ length index is 71 . Variety III specimens have the same general outline but are somewhat longer and narrower than Variety II, although not as long as Variety I. The average width/length index is 56. Finally, the Variety IV specimens are the smallest of the four varieties and are also the broadest in relation to length. The average width/ length index is 78 .
Distribution: Specimens of this type occur over most of Tamaulipas and adjacent parts of Texas, and the Gulf Coast of Texas. Prewitt's (1995:97) distributional analysis indicates that large numbers of Catán points occur in the central portion of South Texas, including the coastal counties, and smaller numbers occur in sites on the Gulf Coastal Plain and in the Lower Pecos. Large numbers have been noted in Travis County, however, many of these may be preforms for arrow points.

Temporal Range: In the Sierra de Tamaulipas this type occurs sparingly with all pottery horizons, but in the Sierra Madre it is numerous in the latest preceramic Guerra Phase, and also in the Laguna, Eslabones, and La Salta phases (2,600-1,100 years ago; MacNeish 1958). However, MacNeish (1958:69) admits that in his initial study many of the larger varieties of Catán Round-base points in the early ceramic levels were considered to be Abasolo points. Suhm et al. (1954:410) suggest that the point may have first appeared around A.D. 500 (1450 BP) and may have continued in use until the eighteenth century. At Cueva de la Zona de Derrumbes, Variety IV specimens, the smallest variant, occur only in Levels 18-19 and 21-22, dated to between $2800-1500$ в.с. (4800-3450 вP). In addition, only two Catán Variety I points, the larger variants, occur above Level 9, tentatively dated around A.D. 800 (1150 BP). The early occurrence of Catán points at Cueva de la Zona de Derrumbes is quite different from MacNeish's late temporal assignment of the point. In considering the distinctions between Abasolo and Catán points, McClurkan (1966:28) states that MacNeish's data (1958:68-69) do not show a difference in temporal distribution. Nunley et al. (1965:52) also indicate that there is no particular distributional difference between large (Abasolo) and small (Catán) points in the Amistad Reservoir samples. The same pattern seems to hold for the Cueva de la Zona de Derrumbes. In considering the relationship between the Abasolo and Catán types, McClurkan (1966:73) indicates that the two types are related in form and were divided into morphological varieties on the basis of size and other characteristics. The morphological varieties proved to have little temporal significance. In general, the Abasolo-Catán specimens seemed to behave as a single group being distributed throughout the cultural deposit. Most interestingly, the large specimens (Variety I Abasolo) tended to cluster in 
higher levels (4-8), while smaller specimens (Variety IV Catán) occurred in lower levels (Levels 18-22; see McClurkan 1966:90-91 and Figure 25). In addition, the smallest Abasolo varieties and the larger Catán varieties occur throughout the deposit.

\section{Desmuke}

Suhm et al. (1954:416) first described the Desmuke type. It is characterized by a lozenge-shaped outline, with straight or convex blade edges that meet the stem at a rather distinct angle. The stem edges tend to contract and have either straight or slightly rounded edges, or a combination of both, and terminate in a pointed, convex, or even straight base (i.e., specimens from 41WB557; J. Michael Quigg, personal communication 2001). It is this feature, the easily discernible division between the blade and the stem, which seems to be employed as the primary diagnostic criteria of the type. The frequency of blade beveling is low and, unlike Abasolo and Catán points, the maximum width of the point tends to occur farther above the base than on those two types. Table 13 presents the metric dimensions characterizing the type.

Distribution: The distribution of the type is very similar to that of the Abasolo and Catán points (Prewitt 1995:88, 97), being concentrated in the central and southern portion of South Texas and having smaller numbers in Central Texas and the Lower Pecos. The type is also found in the coastal counties in South Texas but it does not appear to extend onto the Gulf Coastal Plains. Suhm et al. (1954:416) suggest that the Desmuke is most frequent along middle parts of the Frio and Nueces River valleys, occurring in lower frequencies south of there. Hester et al. (1969:161) have shown that although the type is scattered over much of southern Texas, it tends to be concentrated in southern La Salle County (though it does extend into northern La Salle) where the county adjoins Webb, Duval, and McMullen counties. According to MacNeish (1958:64), the Desmuke points known from southern Texas are similar to the larger Abasolo forms from Tamaulipas. If this observation is correct, it may be possible to extend its distribution into southeastern Tamaulipas.

Temporal Range: MacNeish's comment (1958:64) suggests that, at least in Tamaulipas, Desmuke points should be considered contemporaneous with Abasolo points. Suhm et al. (1954:416) originally could only assign the type to the Archaic period. Turner and Hester (1993:105) assign the type to the Late Archaic period.

\section{Matamoros}

The Matamoros Triangular type was defined by MacNeish (1958:68) based on 515 surface collected and 35 excavated specimens obtained from sites in the Sierra de Tamaulipas. The specimens are roughly equilateral or isosceles triangles similar in outline to the larger Tortugas type. The bases range from straight to slightly convex and slightly concave, while the blade edges are straight or just slightly convex, although specimens with slightly concave lateral edges also exist (Hester et al. 1969). On concave-based specimens, the depth of the concavity is always less than $2 \mathrm{~mm}$. The Tamaulipas specimens were manufactured primarily by percussion flaking and a portion of the collection displayed part of the ventral face of the parent flake. About one-fourth of the points from Tamaulipas have beveled edges. Bases are thinned either by retouching, the removal of large flute-like scars (MacNeish 1958:68), or short vertical flakes (Hester 1969:14-15) on either surface. By definition (MacNeish 1958:68), one of the diagnostic characteristics of the points is that they range from 20 to $40 \mathrm{~mm}$ in maximum length, although some specimens longer than this may also be included (see McClurkan 1966:34). Unfortunately, it is unclear what diagnostic criteria are used to place these larger specimens into the Matamoros rather than Tortugas type. Table 13 presents the range in metric dimensions characterizing the type.

Distribution: The type is common in Tamaulipas (MacNeish 1958) and it is also present in Nuevo León as indicated by specimens from the Cueva de la Zona de Derrumbes (McClurkan 1966:34-35), La Calsada (Nance 1992:38, 40), and San Isidro (Epstein 1969:2324). Prewitt's distribution analysis indicates that it also occurs in small numbers in the Lower Pecos and in the coastal bend counties (i.e., Aransas, San Patricio, Nueces, Kleberg, and Kenedy; see Campbell 1947, 1952, 1956, and 1958; Corbin 1963; Newton 1963, cited in Hester 1969). Apparently, some points of this type have been encountered as far north as Williamson County (Prewitt 1995:117). 
Temporal Range: According to MacNeish (1958:68), this type begins with the earliest pottery in the Sierra de Tamaulipas and reaches its greatest concentration in the Los Angeles Phase (A.D. 1200-1780). McClurkan (1966:34) recovered a total of 70 specimens that he classified as Matamoros from Cueva de la Zona de Derrumbes. Although seven of them came from within Levels $11-16$, tentatively dated to between 1500 B.c. and A.D. 100 (1850-1150 BP), the majority were from within Levels $1-8$, dated to between A.D. 100-800 or slightly later. McClurkan (1966:70) provides a date range of A.D. 6001000 (1350-950 BP) for Matamoros points from Cueva de la Zona de Derrumbes based on radiocarbon dates from the site. However, an examination of his report indicates that McClurkan's Tortugas Variety II and Matamoros points are morphologically nearly identical and the former is actually even slightly smaller than Matamoros points (McClurkan 1966:34, 71). An examination of the distribution of the Variety II Tortugas (McClurkan 1966:Figure 25) indicates that they occur exclusively within Levels 11-16. This distribution is identical to the lower zone of Matamoros points mentioned earlier and suggests that, based on size alone, triangular projectile points matching the Matamoros type occur throughout the Cueva de la Zona de Derrumbes deposits.

In Texas, Suhm et al. (1954:448) suggest that the type may have first appeared about A.D. 500 (1450 BP) and may have survived into the historic period. At 41ZP364, a welldefined Occupation 2 containing a single Matamoros point appears to date roughly to A.D. 600 (1350 BP; Quigg and Cordova 2000:123). A Matamoros point was also recovered from 41LK67 from deposits dating between A.D. 500-800 (1450-1150 BP; Brown et al. 1982:49-50, Figure 11, t). At Loma Sandia, a number of burials and/or associated features seem to contain what appear to be both Matamoros and Tortugas points (see F11-L, F-12, F-124A, F161, F173, and F192 in Taylor and Highley 1995:131, $140,197,224,237$, and 258). These features seem to date to the period between A.D. $450-850$ (1500-1100 BP). Although from an undated context, two Matamoros points also have been recovered from 41LK106, from a hearth also containing 41 undecorated bone-tempered pottery sherds (Creel et al. 1979:23).

\section{Refugio}

The Refugio type was first described by Suhm et al. (1954:474) as being leaf-shaped with a long and slender blade. In describing the traits of the Carrollton and Elam Foci of the no-longer-used Trinity Aspect of the Archaic, Crook and Harris (1954) call points similar to the Refugio type "Wheeler Leaf." The blade edges of Refugio points are convex but can occasionally be nearly straight. The bases vary from convex to nearly semicircular and convex but with a straight middle segment. The body of the point is rather thick and the base is usually thinned by short thinning flakes. One of the diagnostic characteristics of the point is that it often exhibits a rather long blade and parallel blade edges. Therefore, it is often the case that the maximum width of the blade does not occur near the base of the point but rather farther up on the blade. Table 13 presents the range in metric dimensions that characterize the type.

Distribution: MacNeish (1958) does not recognize the type in his materials from southeastern Tamaulipas. McClurkan (1966:36), on the other hand, identified 14 Refugio points from his excavations at Cueva de la Zona de Derrumbes. Prewitt's (1995:127) distributional analysis indicates that the type is common in the southwestern part of South Texas extending as far north as Bexar County and surrounding counties. Smaller numbers are found in the Lower Pecos and on sites in the Coastal Bend counties (Campbell 1956:22; Corbin 1963:22).

Temporal Range: At 41WB437, Quigg et al. (2000:Figure 13.1) recovered two Refugio points in Occupation 5, dating to roughly 3,260-3,400 years ago. A second Refugio point came from Occupation 3, dated to about 2,700 years ago, and was in association with Tortugas points, suggesting either continued use, contemporaneity, recycling, or some degree of mixing of deposits. A single Refugio point associated with two Tortugas points in Feature 111 from the Loma Sandia site was dated to between 2,400-2,800 years before the present (Taylor and Highley 1995:188). These finds also support the contemporaneity of the two types. 


\section{Tortugas}

The Tortugas point (Tortugas Triangular Blade [Kelley 1947]; Tortugas Triangular [MacNeish 1958]) was originally named by Kelley (1947) and more fully discussed by Suhm et al. (1954:482 and Plate 120). MacNeish's description of the type refers to about 1,000 specimens, only 111 of which came from excavated sites in the Sierra de Tamaulipas (MacNeish 1958:64). The Tortugas type is described as having large triangular blades with straight to slightly convex edges. Blades vary from rather narrow to relatively broad. MacNeish (1958:64) originally included only concave base specimens in the definition reserving the Nogales type name (ibid:64) for triangular specimens with convex bases. Nogales points also were characterized by a lack of large base thinning flakes that created a "fluted" appearance and were contemporaneous with Abasolo points (ibid:64). Later definitions of the point by other authors incorporated the entire range of basal shapes and base treatments in the type. In discussing specimens from sites in La Salle County, Hester et al. (1969:142) indicate that the basal edges of these Tortugas points are generally straight, although a number of slightly concave-edged and convex-based specimens are also present. In the majority of the specimens, basal thinning is achieved through the removal of several short longitudinal flakes on one or both faces (Hester et al. 1969:142). On a smaller number of specimens, basal thinning has been achieved by the removal of a single flake or two parallel large flakes (accompanied by smaller, vertical flakes) on one or both faces (Hester et al. 1969:142). About onehalf of the collection in Tamaulipas, on which the type was defined, have alternately beveled edges near their tips. A smaller number of specimens are beveled only along one edge of one face, while some appear to have no beveling present. There is a considerable size range in these points. One of the diagnostic characteristics of the type is that, in general, only triangular points matching the above-described attributes and exceeding $40 \mathrm{~mm}$ in maximum length are defined as Tortugas. Nonetheless, some specimens that are as small as $34 \mathrm{~mm}$ have been included in the type (Hester 1969:16). These smaller specimens overlap with Matamoros points in dimensions (Hester 1969:15).

McClurkan (1966:37-38) distinguishes two varieties (I and II) based on work at Cueva de la Zona de Derrumbes (see Table 13). Variety I Tortugas points are relatively large, triangular points. Sides and bases may vary from slightly convex to straight to slightly concave. Basal corners are generally sharp and well-defined, but may occasionally be slightly rounded. Beveling is absent from the Cueva de la Zona de Derrumbes sample while basal thinning is present in most of the specimens. These specimens range from 41 to $80 \mathrm{~mm}$ in maximum length and 23 to $51 \mathrm{~mm}$ in maximum width. The Variety II Tortugas has the same general outline as the Variety I specimens, however, the Variety II specimens are smaller in size and are broader in relation to their length than the Variety I specimens. The Variety II specimens range from $20-41 \mathrm{~mm}$ in length, $19-34 \mathrm{~mm}$ in width, and $4-8 \mathrm{~mm}$ in thickness. They are similar to the Matamoros type in length. Beveling is not common on these specimens while basal thinning is present on most. Although they are similar to Matamoros points, according to McClurkan (1966:38), the two types differ in their width/length index. The average width/length index of the Variety II Tortugas is 83 , the same figure for the Matamoros is 63, the Variety I Tortugas have a width/length index of 61 . As mentioned earlier, at Cueva de la Zona de Derrumbes, the small Variety II Tortugas occurred in levels also containing the Matamoros type (McClurkan 1966:125).

Distribution: The type is common throughout Tamaulipas and Nuevo León (McClurkan 1966; Nance 1992) in Mexico. They are most common in South Texas, in counties adjacent the Falcon Reservoir, although they extend into the Lower Pecos and are also present in coastal counties extending north to the coastal bend (Campbell 1952, 1956, 1964 [cited in Hester 1969]; Corbin 1963; Nunley and Hester 1966; Prewitt 1995:132).

Temporal Range: In the Sierra de Tamaulipas, Tortugas points first appear in Late Nogales times (7,000-5,000 years ago), and reached their maximum concentration in La Perra times (5000-4200 BP), and diminished to a minority type during the Almagre period (4200-3500 BP). MacNeish (1958:64) remarks that although points matching the Tortugas definition are occasionally found in components belonging to later phases, he does not think that the type is made after Almagre times. Based on radiocarbon dates from Cueva de la Zona de Derrumbes, McClurkan (1966:70) identifies the date range for Tortugas as between 1200 B.C. to 400 B.C. (3150-2350 BP). However, if the Matamoros points from 
the upper zones are nothing more than heavily resharpened Tortugas, it would greatly expand the temporal range of the type into Late Prehistoric times. Hester (1995) considers the Tortugas point as a common South Texas point type with its greatest occurrence during the Middle Archaic (2500-400 B.C. [4500-2350 BP]). In northern Tamaulipas and adjacent parts of Texas the type may have lasted until somewhat later.

Within the Choke Canyon sites, unstemmed triangular points similar to the Tortugas type appear to have been most common between roughly 4450-2350 BP (Hall et al. 1986:399). At site 41LK67 in the Choke Canyon project, three triangular Tortugas points (see Brown et al. 1982:Figure 11, p-r) were recovered in deposits dating to between 2,750-2,350 years ago (Brown et al. 1982:309). A triangular point from 41LK67 was associated with charcoal radiocarbon dated to between $800-400$ B.C. (Brown et al. 1982:309). Triangular point fragments from 41LK31/32 date between 3380-2340 B.C. (Brown et al. 1982:309). Tortugas points at 41WB437 appear as early as 3,000 years ago (Occupation 4) and continue until 2,000 years before the present (Occupation 1). Feature 111, a small cluster of mortuary items at the Loma Sandia site (Taylor and Highley 1995), yielded two Tortugas points in association with a Refugio point. Associated charcoal dates suggest an age range of between 2,400-2,800 years before the present for the feature. Tortugas occupation at 41SR42 (Hartle and Stephenson 1951) was charcoal dated to $4,650 \pm 300$ years ago (see Suhm et al. 1954:565), while at 41ZP364, Quigg and Cordova (2000:123) obtained dates ranging between 3900-5100 BP for Occupation 3, containing a single Tortugas point. At $41 \mathrm{WB} 314$, a discrete Tortugas reduction station was dated to $2740 \pm 60$ вр (Miller et al. 2000:67).

\section{Selected South Texas Distally Beveled Tools}

A number of consistently recurring tool forms have been identified as a result of the numerous archeological investigations conducted at the regional level across South Texas. These distally beveled tools include Dimmit and Nueces tools and Olmos bifaces (Figure 39). Although the temporal range of these forms is not well defined, this writer (SAT; see also Hester 1995) assumes that they are Middle to Late Archaic forms and therefore each of the types will be discussed in turn below.

\section{Nueces Scrapers}

This tool form was originally defined by Hester et al. (1969:131) based on specimens from the Oulline Site and other sites in La Salle County. Nueces scrapers were defined as having a distinctive trapezoidal outline with straight to convex edges. The working edge is steeply beveled, and varies from slightly convex, to straight and slightly concave. Both bifacial and unifacial specimens have been noted, and accordingly, their transverse crosssections vary from biconvex to plano-convex. Finally, an additional tool form described by Hester et al. (1969) is the Lunate scraper from the Oulline site. These specimens are roughly lunate in outline, with planoconvex cross-sections. The widest edge (bit) varies from straight to concave, and is always steeply beveled; the opposite edge is convex and rarely shows evidence of use. Both unifacially and bifacially manufactured tool forms were included in the original definition. Based on the characteristics of working edge rejuvenation, these tool forms may represent Nueces scrapers with heavily resharpened working edges.

Distribution: A number of distally beveled tool forms were recovered from the Choke Canyon project where, because of the morphological classificatory system being used, they were identified as Group 3 short, broad, triangular to subtriangular distally beveled bifaces and unifaces (Brown et al. 1982:326-328, Figures 72 and 73). Of the 63 distally beveled tools, 21 specimens were identified as Form 3, triangular to subtriangular forms identical to the Nueces scrapers defined by Hester et al. (1969).

The Nueces scrapers are found primarily on sites in the northern part of South Texas. Hester (1969) describes a number of them from site 41MC1 in northern McMullen County. Although distally beveled tool forms were found at Choke Canyon, they appear to be less common than farther south of the Three Rivers area. Lunate scrapers are widespread in southern Texas, occurring in Dimmit, Duval, McMullen, Webb, and Zavala counties.

\section{Dimmit Scrapers}

These distally beveled scrapers were defined by Nunley and Hester (1966:233-253) based on work in Dimmit County. The scraper is triangular in form and 


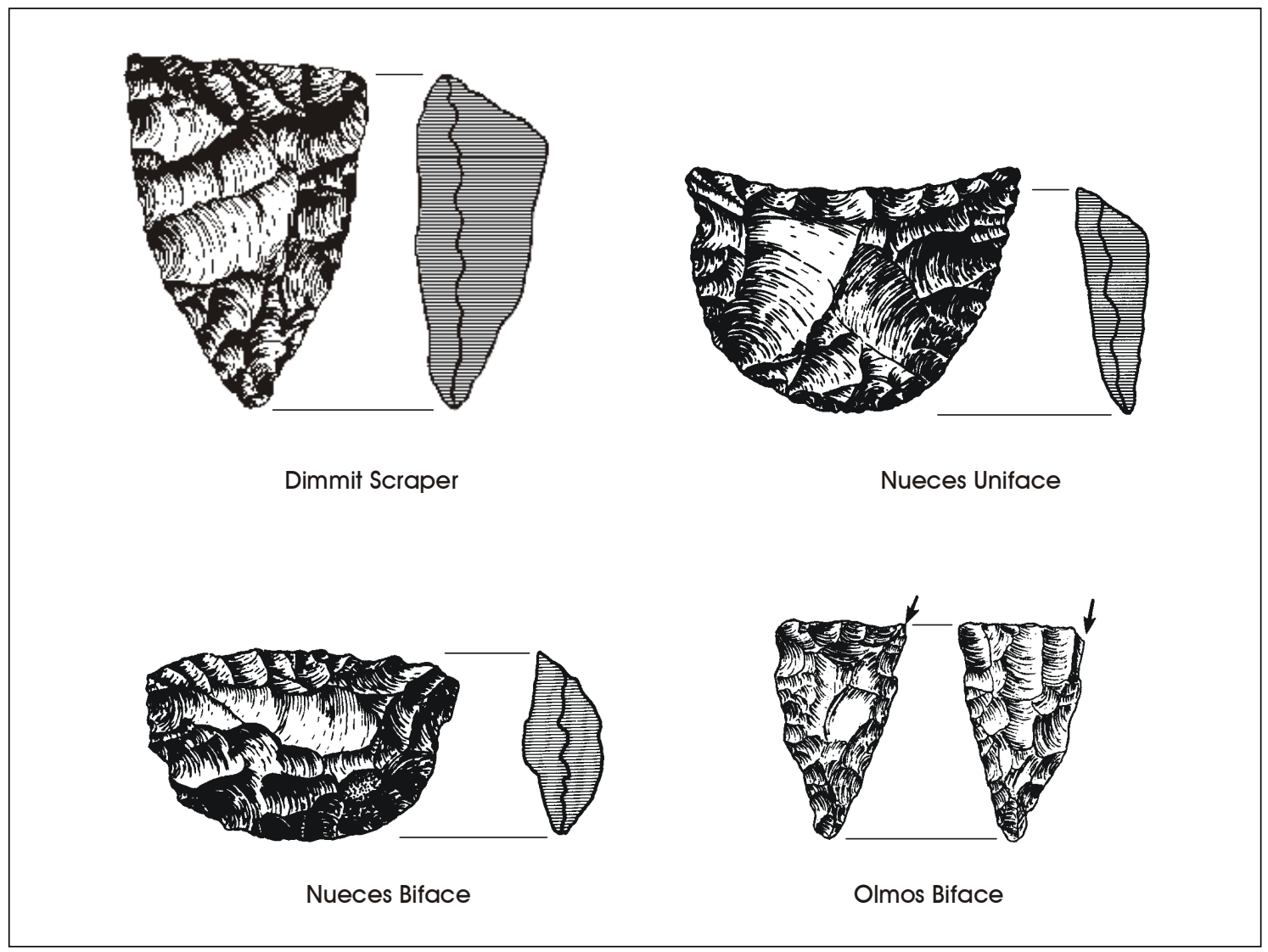

Figure 39. Distally beveled tool forms common in South Texas sites. Adapted from Turner and Hester 1993.

plano-convex in cross-section. The two specimens illustrated in Nunley and Hester (1966:Figure 2g) appear to have pointed proximal ends. Dimmit scrapers are unifacially worked and have a plano-convex, humpbacked appearance. The flat face is very smooth and often highly polished. This scraper is the same as Ray's (1941:154-155) "Clear Fork 2" or "Planner Gouge," although it should not be considered a Clear Fork tool.

A number of distally beveled tool forms recovered from the Choke Canyon project and identified as Group 3, Form 1 (triangular, proximal end pointed) and Form 2 (triangular, proximal end rounded), probably represent Dimmit scrapers (Brown et al. 1982:326, 328). Although the type was originally defined as a unifacial tool form, only some of the specimens included in Forms 1 and 2 are unifacial (eight in each form), while the majority is bifacially made (14 and 12 specimens, respectively). Nonetheless, the morphological similarity and the macro and microscopic use-wear indicate that both unifacial and bifacial tool forms were used in an identical manner, and therefore should be considered the same functional tool.

Distribution: The distribution of Dimmit scrapers appears to be roughly equivalent to that of Nueces scrapers, centered primarily in the southwestern portion of South Texas including Dimmit, Maverick, Starr, Webb, and Zapata counties (Hester et al. 1969:152).

\section{Olmos Bifaces}

Hester (1969:33) defined this distally beveled bifacial tool form based on work conducted in Kleberg and Kenedy counties. Olmos tools are small triangular bifaces with straight or slightly convex lateral edges and straight to slightly convex distal ends that are steeply beveled. 
Working edge angles are often greater than 60 degrees and the maximum thickness of the specimens tends to be found immediately proximate of the working edge. The tools range from plano-convex to biconvex in transverse cross-sections.

Distribution: When originally defined, the small sample suggested that the form had a relatively limited distribution having originally been found in Kleberg County but also having been noted in collections from southeastern Duval County (Rios-Santa Cruz locality) and Nueces County (Campbell 1956). Based on a more comprehensive study of their distribution, Shafer and Hester (1971:7) identify the distribution of Olmos bifaces as concentrating within a narrow band, 70-80 miles wide, extending from western Kleberg County on the east to central Webb County on the west. In addition, however, small numbers of these tool forms have been recovered in other counties along the Texas-Mexico border (Starr and Zapata counties) and south of the border in northern Tamaulipas (Ciudad Mier, Tamaulipas; see Shafer and Hester 1971:8).

\section{A Technological Analysis of Tool Forms, Designs, and Use-Life Histories}

The analysis of any tool forms, be they single- or multifunctional, is most productive when the analysis looks not only at the morphology of a tool but also attempts to explain the design characteristics of the tool in terms of functional requirements and performance characteristics. Furthermore, the more complete the understanding of the changes in tool morphology through the use-life of the tool, the more likely that the morphological variants generated through the use-life of a form will be recognized as representative of the same functional, and perhaps typological, category at different stages of rejuvenation.

The following section discusses the sequence of manufacture, resharpening, and rejuvenation (i.e., repair) of the principal and most common unstemmed projectile point types and distally beveled tools reviewed in the previous section. The goals of this section are threefold: 1) document the changes in projectile point morphology during the use-life of the various types; 2) relate this variability to the diagnostic attributes used to define these types and/or functional categories; and 3) consider the validity of the projectile point types and the ease of their consistent recognition.

The sample of artifacts used in this analysis consists of three main collections: the Loma Sandia (41BX28) points, the Prevost Family Collection, and selected specimens from the Riley Family Collection. A number of triangular and round-base points were analyzed from the Loma Sandia collection (Table 14). In some instances typological designations were changed compared to their original assignments in Taylor and Highley (1995) and as they were cataloged at the CAR curation facility. The Prevost collection is a collection of projectile points and tools from the privately owned property found immediately across the fence and to the west of 41WB556 and 41WB557. The collection comes from three campsites found on the banks of Becerra Creek but some two to three miles upstream from sites 41WB556 and 41WB557. The collection was acquired over many years of surface collecting. Both triangular and round-base points and Nueces/Dimmit and Olmos tools were present in the collection (Table 14). The Riley Family Collection is an enormous collection of tools and arrow and dart points from throughout South Texas and northern Mexico in the vicinity of the international border. Only a small fraction of the thousands of projectile points and tools were formally analyzed (Table 14), although thousands were inspected to assure that the analyzed samples are representative of the collection. Finally, a small fraction of the analyzed sample comes from 41WB556 (Table 14).

The assignment of the distally beveled tool forms to either Nueces or Olmos forms was not difficult given the significant morphological differences between them (see Historical Overview section). Dimmit scrapers were not analyzed for this study.

Prior to analysis of the projectile points, it was hoped that the data would be measured, recorded, and entered into the computer and used as the basis from which to generate the typological groupings. As the analysis began, it became evident that it would be useful to assign a type to each point analyzed based on the diagnostic criteria summarized in the previous section. In assigning the types, complete round- and/or convex-based, teardrop-shaped points smaller than or equal to $41 \mathrm{~mm}$ in maximum length were assigned to the Catán type. Specimens larger than $41 \mathrm{~mm}$ 
Table 14. Breakdown of artifact collections analyzed in this study

\begin{tabular}{llc} 
Analyzed Collection & Artifact Category & Analyzed Sample \\
\hline Loma Sandia (41BX28) & Triangular points & 58 \\
& Round base points & 34 \\
& Nueces tools & 0 \\
& Olmos tools & 0 \\
Prevost Family Collection & Triangular points & 73 \\
& Round base points & 50 \\
& Nueces tools & 100 \\
Riley Family Collection & Olmos tools & 3 \\
& Triangular points & 201 \\
& Round base points & 203 \\
& Nueces tools & 118 \\
& Olmos tools & 91 \\
& Triangular points & 3 \\
& Round base points & 2 \\
\hline Total Sample & Nueces tools & 0 \\
& Olmos tools & 0 \\
\hline & & 936
\end{tabular}

under one section. Similarly, given the similarity in the manufacture of triangular projectile points, regardless of size, the Tortugas and Matamoros types also will be discussed as a single group. This does not necessarily mean that the author (SAT) assumes that the six types can and should be lumped into two main types. Rather, it is due to the fact that so much similarity in manufacture techniques is present within these groups that individual point type descriptions would yield too many repetitive statements without contributing substance to the descriptions. Nonetheless, where differences exist in the manner in which one or another feature of a type is manufactured or responds to failure probability, the intragroup differences will be highlighted and discussed. were assigned to the Abasolo type. Similarly, complete triangular points measuring less than or equal to $41 \mathrm{~mm}$ in maximum length were grouped into the Matamoros type. Those larger than $41 \mathrm{~mm}$ were assigned to the Tortugas type. In the case of both the round-base and triangular forms, proximal fragments measuring less than $41 \mathrm{~mm}$ in maximum length were typed as indeterminate. As the analysis continued, it became evident that some technological features of the points may be more accurate indicators of projectile point type than maximum size. Therefore, in addition to classifying the points in terms of traditional diagnostic criteria (i.e., maximum size), all points were also classified into types based on technological characteristics indicative of their manufacture, resharpening, and rejuvenation histories. This classification allowed many proximal fragments that otherwise were classified as indeterminate to be classified into a type group based on morphological/technological features rather than maximum size. Therefore, each projectile point received two type classifications: one based on traditional diagnostic criteria ("traditional type" i.e., maximum length), and one based on technological criteria ("technological type").

Given that the manufacture techniques involved in the making of round-base projectile point types are relatively similar regardless of size, the manufacture of Abasolo, Catán, Desmuke, and Refugio points will be discussed

\section{The Abasolo-Catán-Desmuke-Refugio Group}

A total of 98 Abasolo points, 84 Catán, 65 Refugio, and 29 Desmuke points were analyzed. Of the 98 Abasolo points, $65(66 \%)$ have rounded bases, $32(33 \%)$ have convex bases, while the remaining specimen has a slightly convex base. Among the Catán projectile points, convex-base points are more common $(n=51,61 \%)$ than rounded bases $(n=33,39 \%)$. A variety of base shapes can be observed in the small Desmuke sample. Contracting and pointed bases are the most common (ten specimens each), followed by rounded and straight bases, with four specimens each. Among the Refugio specimens, rounded bases are the most common $(n=40$, $61.5 \%)$ followed by convex bases $(n=24,37 \%)$. Descriptive statistics on the metric attributes recorded on this sample are presented in Tables 15-18.

\section{Point Manufacture and Failure}

Based on the examination of a sample of complete and fragmentary manufacture failed specimens, the manufacture of the round-base points in this group begins with relatively large and thick hard hammer flake blanks or small nodular cores. Since even the early stage blanks examined from the Prevost and Riley collections lacked 
cortex on their faces, the relative frequency of nodule cores versus flake cores could not be established from the samples studied. No doubt, the manufacture of the larger forms (Abasolo and Refugio) could have begun with nodule cores. Unfortunately, the reductive nature of lithic technology tends to eliminate the diagnostic indicators of the core type as one continues along the reduction sequence from early to late. The smaller size of the Catán points would suggest that their manufacture begins with medium-sized flake blanks. However, at least some complete round-base points that measure less than $41 \mathrm{~mm}$ in maximum length may have started out as larger forms (i.e., Abasolo and/or perhaps even Refugio points). The same is possible for at least those Desmuke points that exhibit a well-defined blade as opposed to stem segment developed as a result of blade resharpening

Once the blank is produced or selected, the specimen is thinned and shaped using percussion flaking with either small hard hammerstones or small billets or a combination of both. The use of pressure retouch may also be introduced relatively early in the reduction depending on blank form and size. The earliest manufacture failures tend to occur during the initial thinning of the blanks. Failure to properly thin a blank often resulted in the production of thick stacked areas of material surrounded by step- or hinge-fractured removal scars (Figure 40). Specimens showing such features tend to represent the early to middle stages of reduction. Given that such features would inhibit the thinning of the blank, specimens possessing such features were often discarded.

If and when the reduction proceeded beyond the middle stages, the next most common failure type appears to be the actual breakage of the blank from excessive force produced during lateral flake removal (i.e., perverse fractures). These lateral snaps produce a perverse snap fracture common of manufacture-failed specimens. In some instances, fractures initiated as a result of excessive force applied to the edge propagated until reaching an imbedded fracture line, eventually snapping the specimen along this line (see also Miller et al. 2000:Figure $7.5[150]$ ). Specimens exhibiting this type of breakage tend to be middle and late reduction stage bifaces.

Of the four types discussed in this section, complete Refugio points have the highest mean maximum length $(57.3 \mathrm{~mm})$ and maximum thickness (complete and fragmentary specimens; $8.3 \mathrm{~mm}$ ) dimensions, although they are relatively narrow in both maximum width and base width (Table 18). All things being equal, the added thickness of these specimens may provide them with greater resistance against bending fractures (i.e., snapping). Abasolo points have the next highest mean maximum thickness $(7.8 \mathrm{~mm})$ and their maximum and minimum values overlap quite nicely with those of the Refugio points (Table 15). The mean maximum thickness of the Desmuke points is nearly identical to that of Refugio points, although they are significantly shorter than their Refugio counterparts (Table 17). Catán points have the lowest mean maximum length and maximum thickness (Table 16). This, of course, is a product of the criteria used in defining the type.

The maximum width of Desmuke points is virtually identical to that of Refugio points, although their bases are significantly narrower than any of the other three types. Catán points are, by definition, the shortest and thinnest of the round-base points. They are also the narrowest points in terms of mean maximum width (Table 16). Abasolo points have the highest mean maximum widths and mean maximum base widths (Table 15), this again is a product of type definition.

Base thinning is initiated relatively early in the reduction process and it is carried out in a semicircular arc around the base of the point rather than concentrating on the midsection of the base (Figure 41). Early in the reduction, thinning flakes may be removed with a small hard hammer, while during the later stages of reduction removals appear to be the products of pressure flaking and rarely approach the length of the base thinning flakes noted on Tortugas points. Nonetheless, a total of $53(54 \%)$ of the Abasolo specimens have between one and two base thinning scars that rival in length those noted on Tortugas points (Table 15). On 25 (47\%) of these specimens base thinning flakes are present on both faces. Interestingly, $49(58 \%)$ of the Catán points have base thinning flakes and $21(43 \%)$ of these have at least one thinning flake on each of the two faces (Table 16). This proportion of base thinning flakes and their occurrence on both faces is similar to the Abasolo points and suggests a strong relationship between the two types. Desmuke points do not commonly exhibit base thinning flakes, as only three specimens $(10 \%)$ from the sample have this feature (Table 17). All three of them, however, retain at least one thinning flake per face. Only 


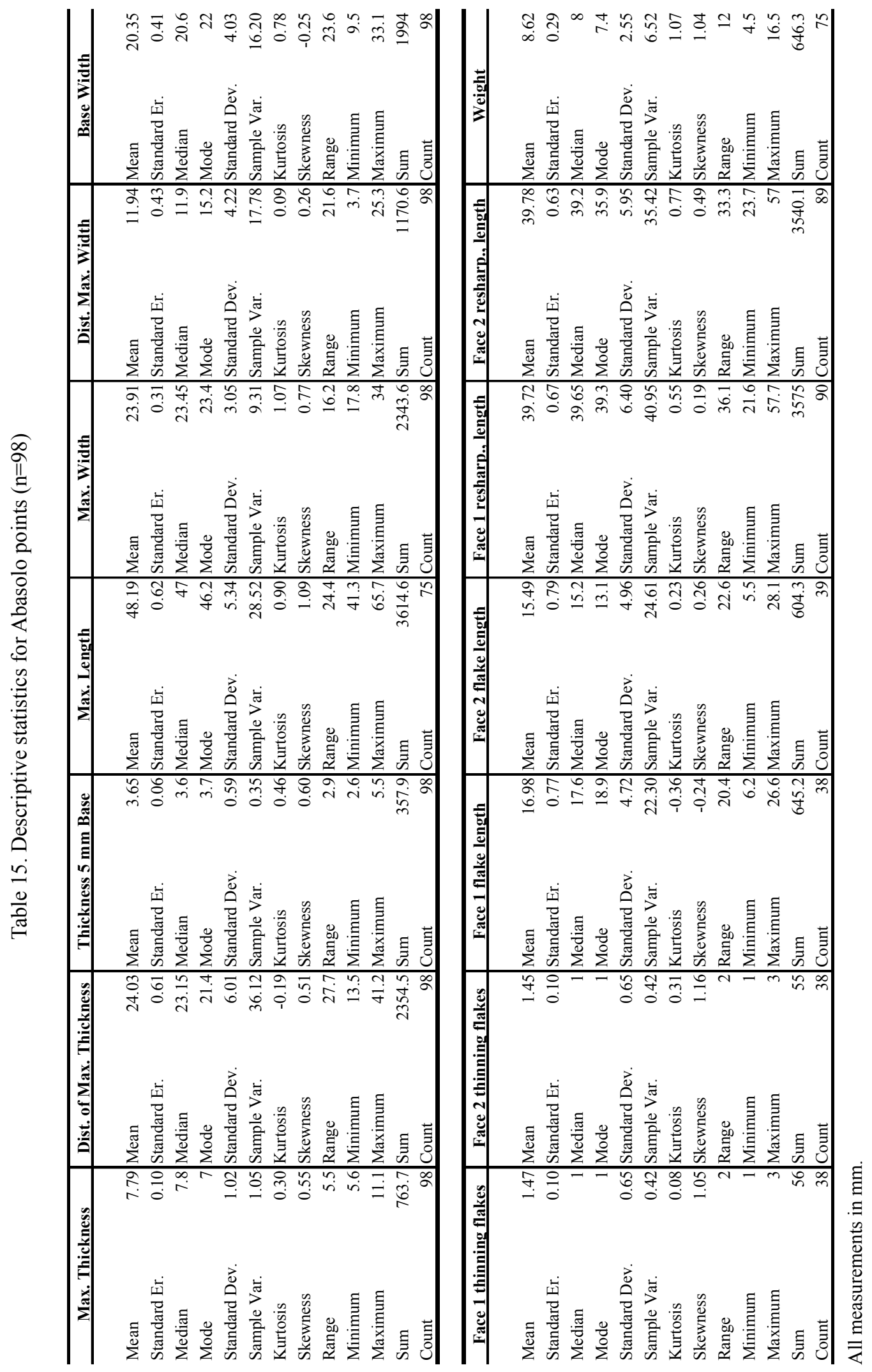




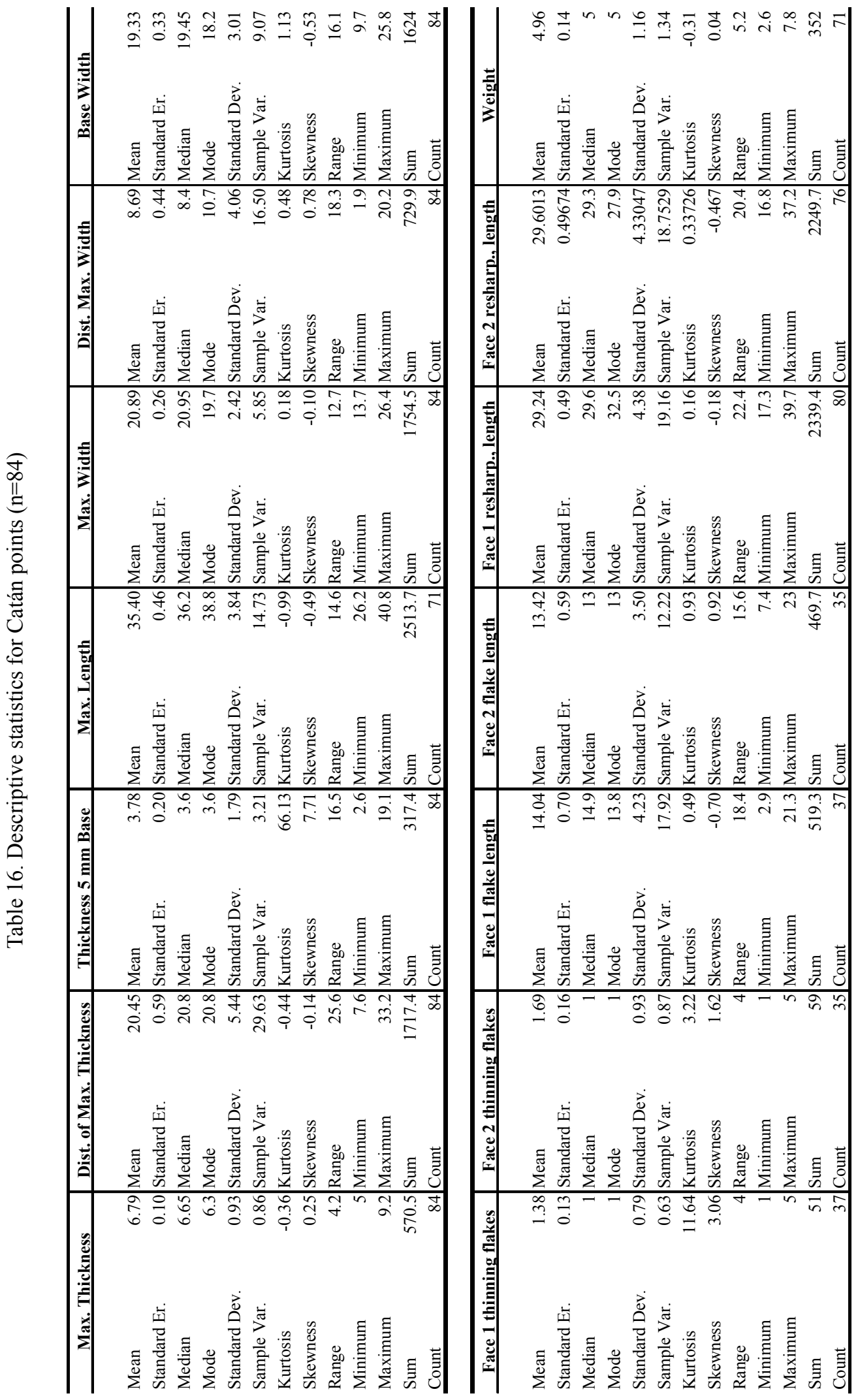




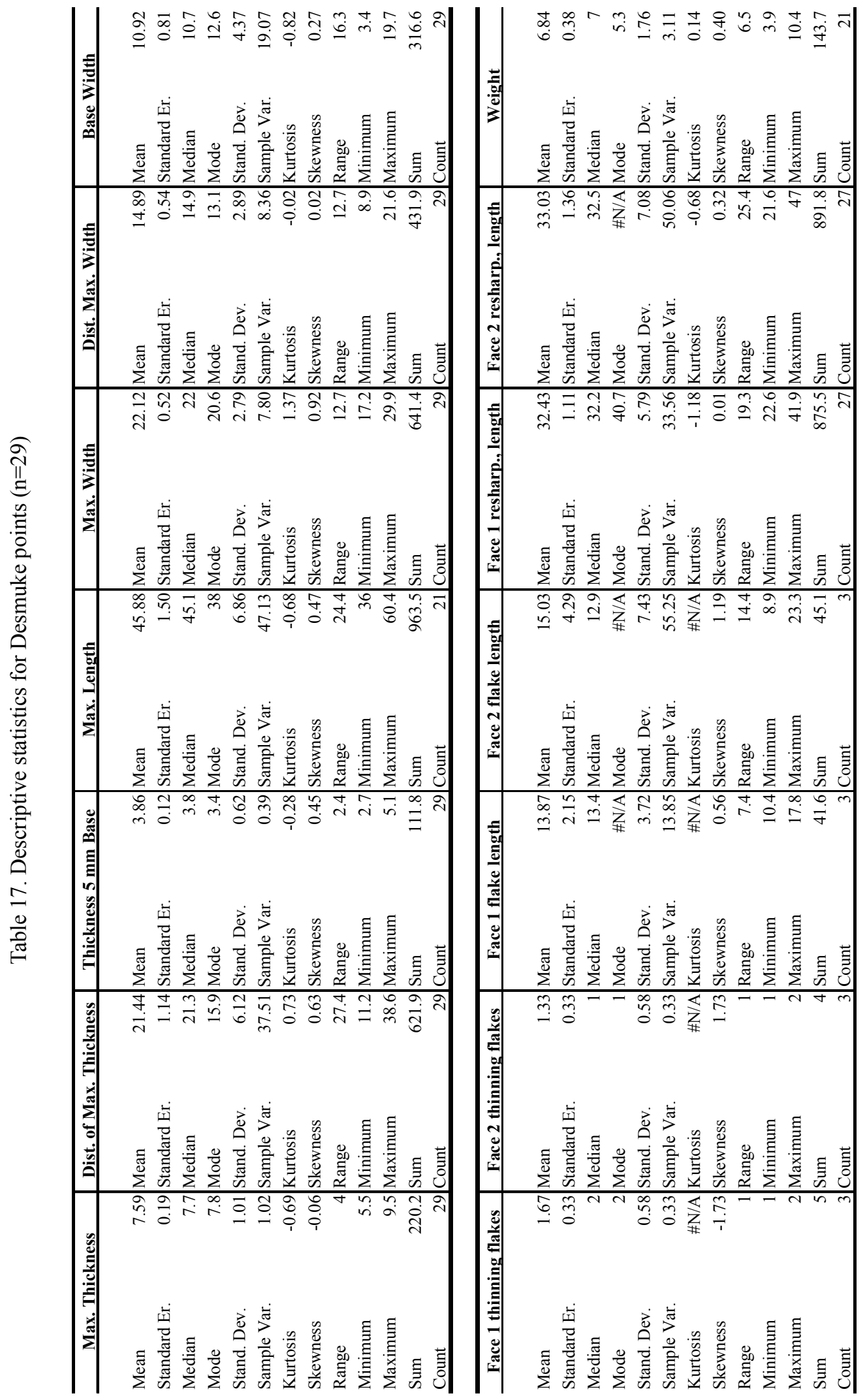




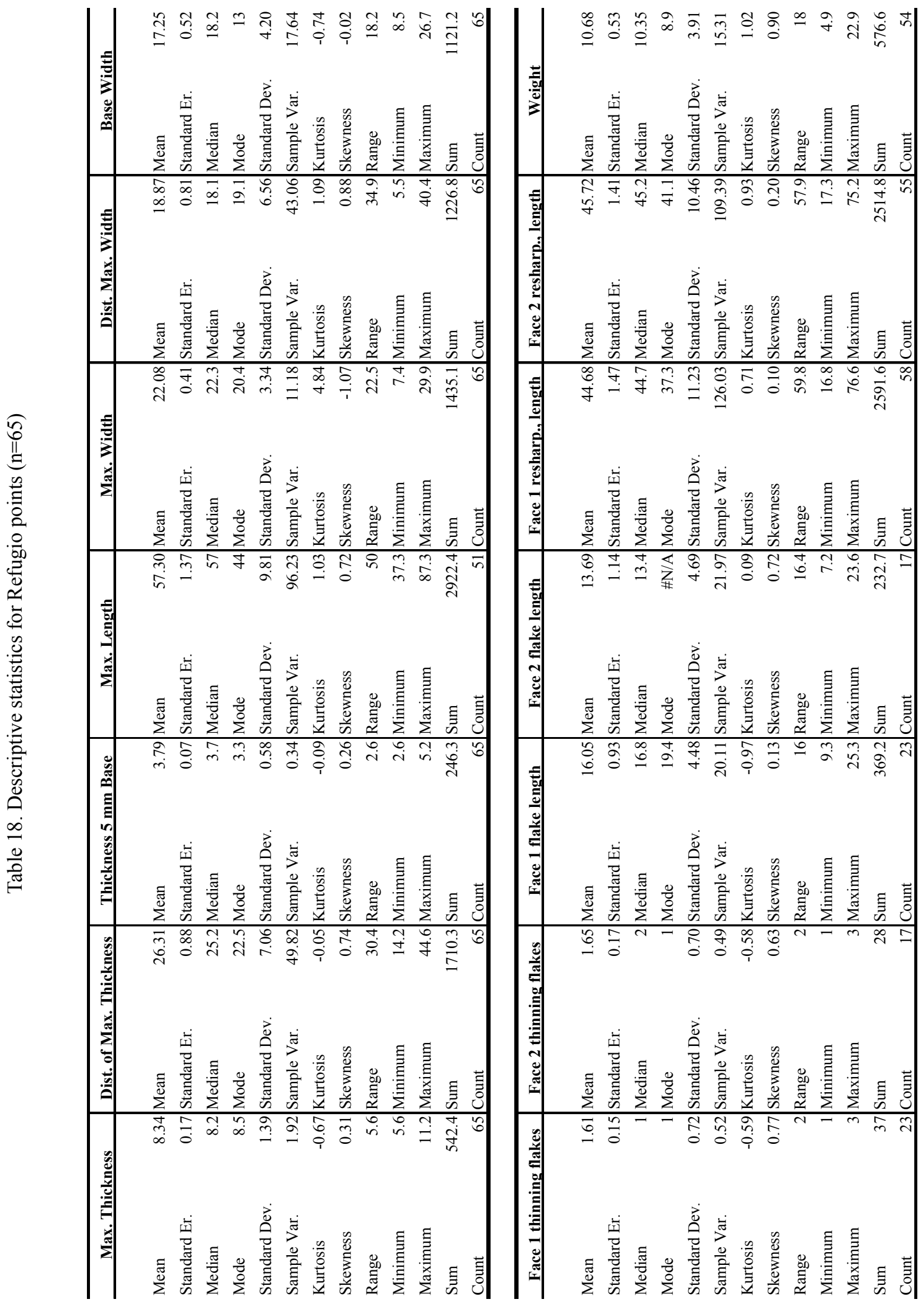




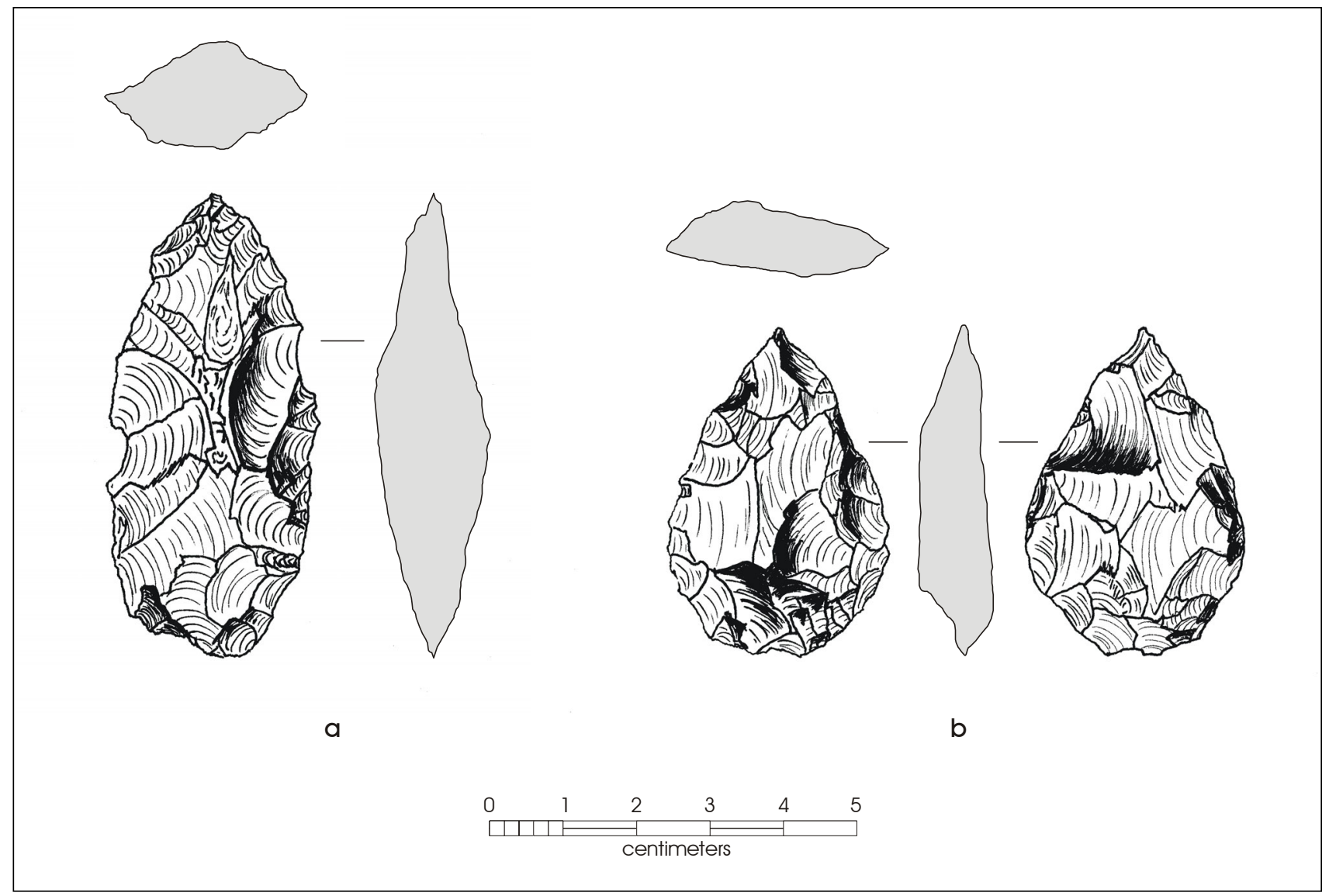

Figure 40. Manufacture failed round-base projectile point blanks: a) Refugio blank; b) Catán-Abasolo blank.

23 (35\%) of the Refugio points exhibit base thinning flakes and only $13(56 \%)$ of these retain thinning flakes on both faces (Table 18).

On Abasolo points, the mean length of the base thinning flakes ranges from 16.9 to $15.5 \mathrm{~mm}$ on the two faces, with the longest flakes reaching $28.1 \mathrm{~mm}$ and the shortest barely more than $6 \mathrm{~mm}$ in length (Table 15). The mean length of the base thinning flakes on Catán points is nearly identical on the two faces $(14.0$ and $13.4 \mathrm{~mm})$ and it is between 2-4 mm less than on Abasolo points (Table 16). This pattern is not surprising, however, since as points are resharpened, the lateral flake scars begin impinging on the basal thinning scars resulting in a gradual shortening of the maximum length of these scars with repeated resharpening. Base thinning flake scars on Desmuke points are only slightly longer than on Catán points (Table 17) but the small sample size does not allow a great deal of confidence in this pattern. The mean length of the base thinning flake scars on Refugio points is intermediate between Abasolo and Catán points, being slightly shorter than in the case of Abasolo points but longer than on Catán points (Table 18).

The common use of pressure flaking to thin the bases of these leaf-shaped points and the added thickness of the blank appears to reduced the possibility of end-shock snaps. Pressure flakers may reduce failure rates given the lesser amount of force they exert on the bifacial edges. The combined effect of the pressure thinning of bases and the lack of base notching may result in overall lower manufacture failure rates compared to certain stemmed types, where the flaking associated with notching can increase the likelihood of manufacture failures. 


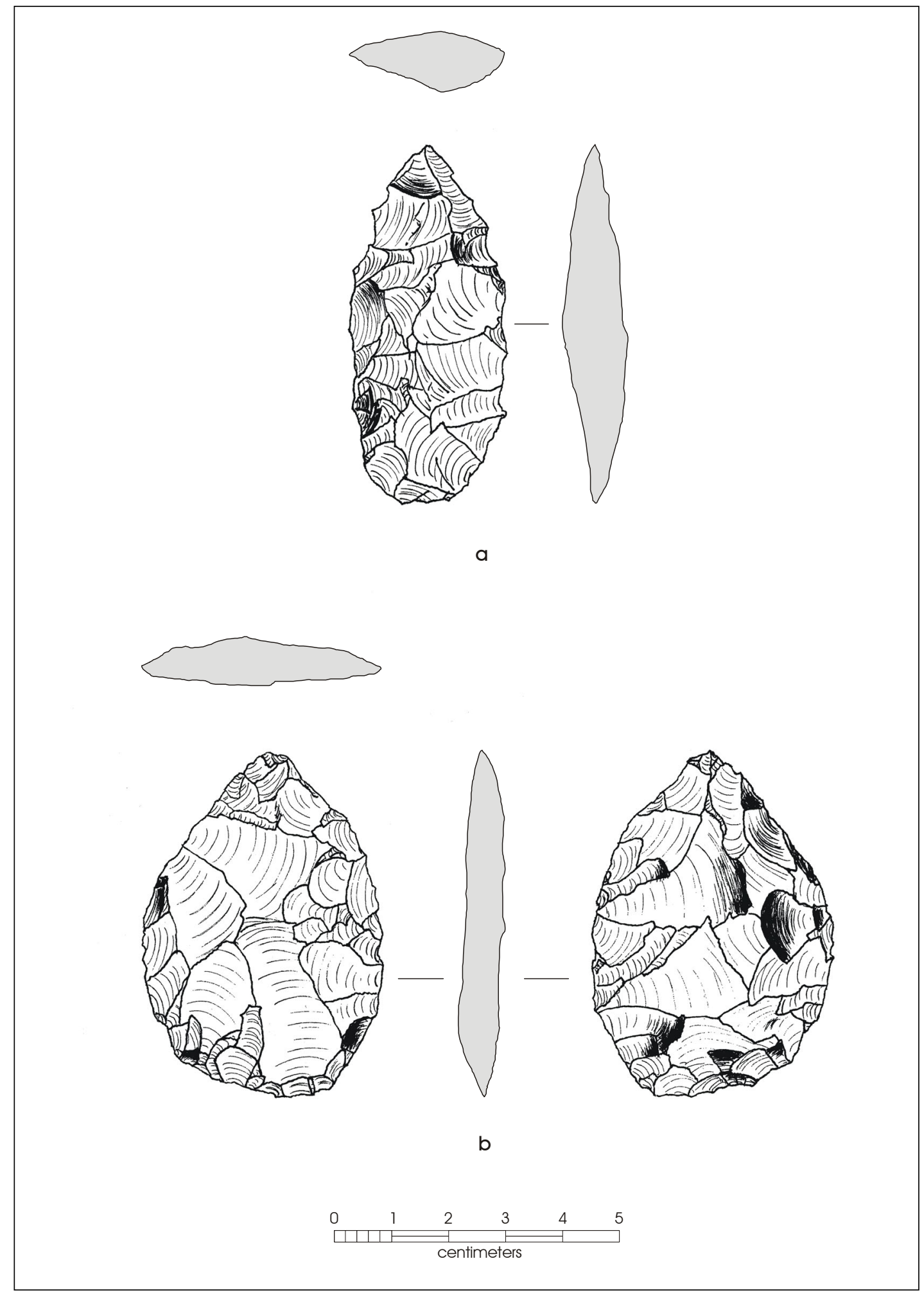

Figure 41. Basally thinned blanks: a) Refugio; b) Abasolo. 


\section{Resharpening}

The use of bifacial tools such as projectile points in cutting tasks necessitates a sharp working edge. Although perhaps less obvious, edge sharpness is also an important feature of projectile points in that it improves cutting efficiency and speeds up internal hemorrhaging leading to the death of an animal. Therefore, whether used as uni-functional (i.e., projectile points) or multi-functional tools, the use of these leaf-shaped specimens results in dulling of the working edges and their subsequent need for resharpening. Resharpening can be carried out using relatively invasive flakes that penetrate deep onto the face of the tool or using steeply angled removals that produce a steep bevel along the edge of the tool without invading the face. Although the first method resharpens a dulled edge it also decreases the strength of the tool by reducing the thickness of the blade. The beveled form of resharpening also refreshes the working edge while maintaining the thickness of the tool's body.

Beveling is relatively uncommon on Refugio points, the largest of the four types. Only $19(29 \%)$ of the points exhibit beveling, with alternate left beveling representing the bulk $(89.5 \%)$ of the occurrences. Their relatively narrow maximum width and base width dimensions in conjunction with their thickness makes it more difficult to resharpen these points. When resharpening does occur, it is not in the form of beveling. In total, 45 percent $(n=45)$ of the Abasolo points exhibit beveled resharpening. Alternate left beveling is present on 43 specimens, while alternate right beveling is observed on only two specimens. Their greater mean maximum width and base width dimensions extend the use-life of the Abasolo points by allowing for a greater number of resharpening episodes. Beveling is also common on Desmuke points $(n=13,46 \%)$ with all specimens having alternate left bevels. Finally, nearly half $(n=38,45 \%)$ of the Catán points have beveled edges. Alternate left beveling is again more common $(n=35,92 \%)$ than right beveling $(n=3$, $8 \%$ ). It is interesting to note that the larger the type, the smaller the percentage of alternately beveled specimens and conversely, the smaller the type, the more likely that many of its members have alternate beveling. This trend suggests that as a group, regardless of projectile point type affiliation, a decrease in point size is accompanied by an increase in beveling frequency. These figures, however, do not mean for instance that only 38 Catán points exhibit resharpening. On the contrary, of the nearly 1,000 specimens analyzed, only three specimens did not exhibit any recognizable signs of resharpening. It does mean, however, that on the remaining 45 Catán points (those without beveling) resharpening is irregular occurring either on only one face or a portion of it; or both faces but not in a systematic fashion.

Another aspect of resharpening that has the potential to directly influence projectile point shape is the length of the resharpening along the edges of the point. Resharpening that runs from the tip to the base or to the widest portion of the specimen can influence both the length and the maximum width of subtriangular specimens. Resharpening that stops short of the stem/ base may result in less change in the morphology of the projectile point. Figures 42 and 43 illustrate a sequence of resharpening and the corresponding changes in the morphology of Abasolo and Refugio points, respectively. It is clear that in both types the maximum length and the maximum width of the projectile points are altered as a result of resharpening.

It was mentioned earlier that the mean length of the complete Abasolo points studied here is $48.2 \mathrm{~mm}$. The mean length of the resharpening along the two edges of the blade is $39 \mathrm{~mm}$. In general then, resharpening stops about $9 \mathrm{~mm}$ short of the base of the Abasolo points. Given that Abasolo points have a convex to rounded base, this resharpening results in a decrease in the length of the point as well as a decrease in the maximum width of the point. In the case of the smaller Catán points, on average, resharpening stops 5-6 $\mathrm{mm}$ above the base. As in the case of the Abasolo points, this "degree" of resharpening results in both a decrease in the maximum length as well as the maximum width of the points, resulting in smaller and smaller versions of the original forms. In the case of the larger Refugio type, resharpening stops, on average, about $12 \mathrm{~mm}$ above the base. Similarly, among the Desmuke points, on average, resharpening stops $12-13 \mathrm{~mm}$ above the base of the points, and unlike in any of the other forms, it actually results in a well-defined shoulder described by the sudden end to point rejuvenation

Resharpening of a small bifacial knife replica made of black Georgetown flint, using a sharp deer antler tine as a pressure flaking tool, indicted that on average $1 \mathrm{~mm}$ (ranging between .8 to $1.2 \mathrm{~mm}$ ) of material is removed 


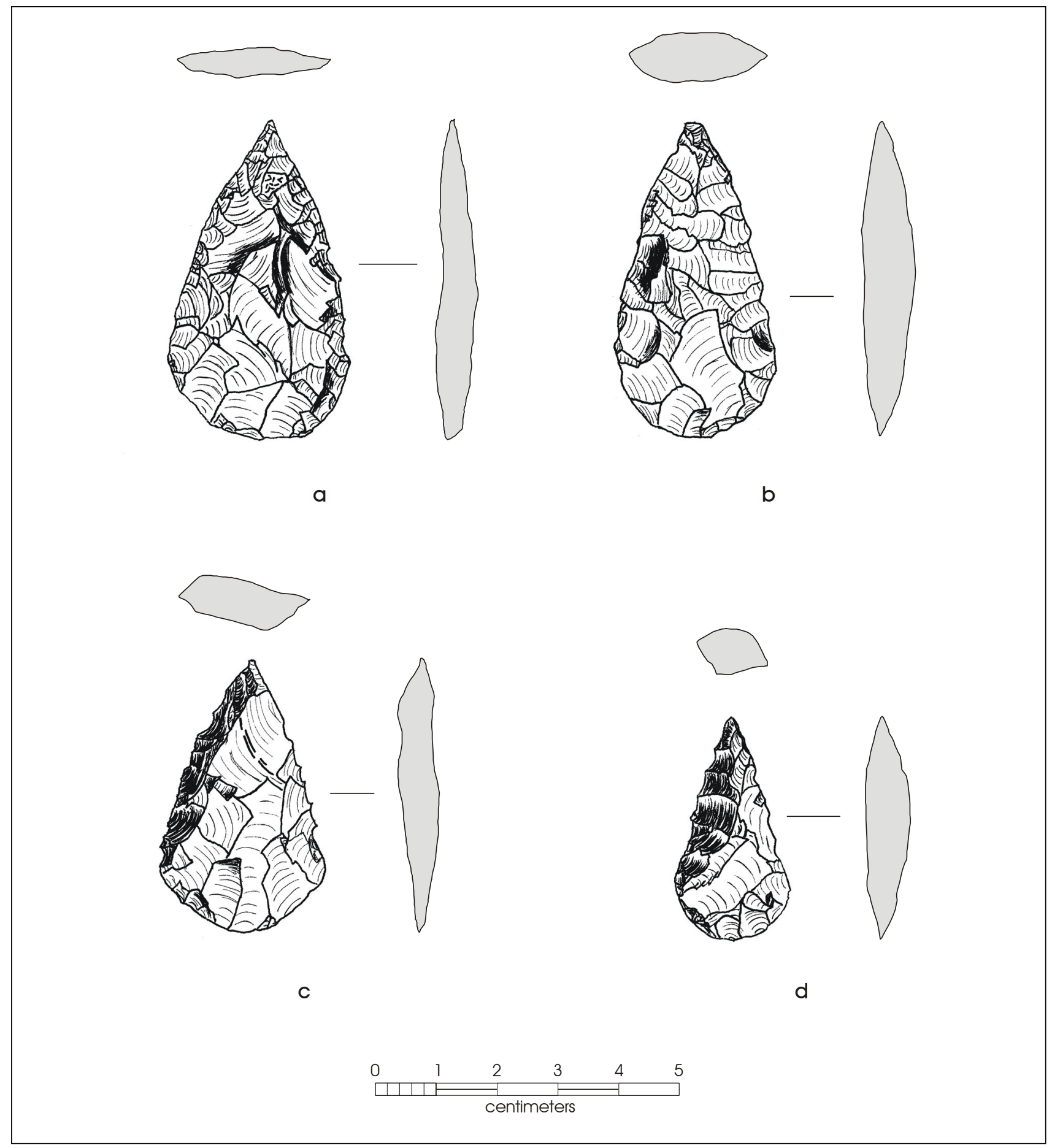

Figure 42. Resharpened Abasolo series: a) minimally resharpened; b) moderately resharpened; c) alternate left beveled; d) shortened and narrowed. 


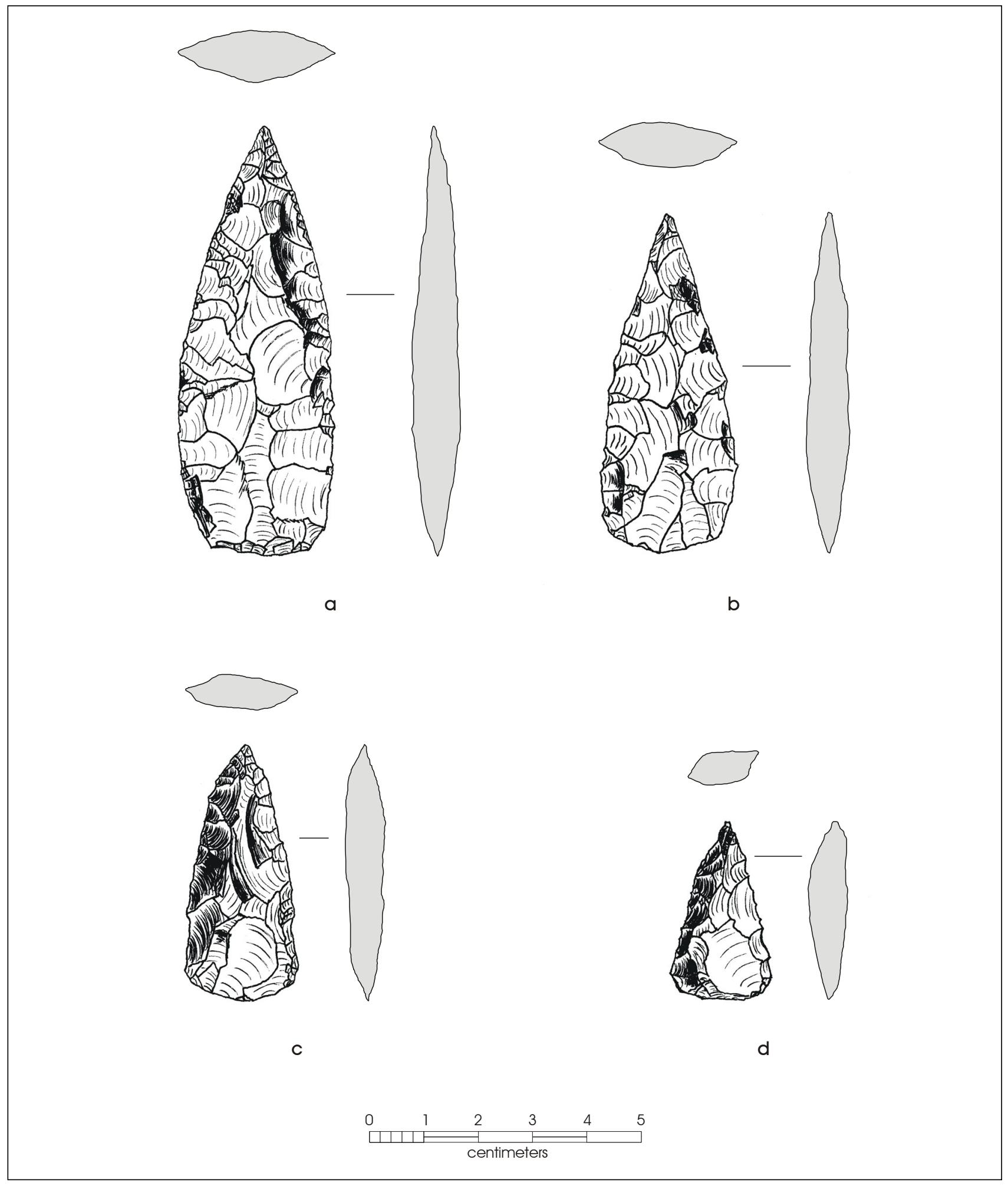

Figure 43. Resharpened Refugio series: a) minimally resharpened; b) moderately resharpened; c) alternate left beveled; d) shortened and narrowed. 
from the edge of the tool with each resharpening episode. This dimension represents the thickness of the platforms of resharpening flakes removed from the biface edge. This experimental study (carried out by SAT) indicates that tool attrition resulting from resharpening may be a relatively slow process. If we take the widest $(33.1 \mathrm{~mm}$ ) and narrowest $(9.5 \mathrm{~mm})$ base widths of Abasolo specimens as starting points and end points of resharpening, we can see that each point may be sharpened a maximum of 23 times $(33.1-9.5 \mathrm{~mm})$ before it reaches the narrowest form in the samples analyzed. Using the same logic, a Refugio point can be resharpened a maximum of 18 times $(26.7-8.5 \mathrm{~mm})$, and a Desmuke point can be resharpened 16 times (19.7-3.4 $\mathrm{mm}$ ) before reaching the narrowest form in the collection. Finally, a Catán point may be resharpened 16 times $(25.8-9.7 \mathrm{~mm})$ before reaching "the exhausted state," assuming that points do not break before they reach their narrowest state and that resharpening proceeds from the tip to the widest portion of the point, so that both width and length are diminished as the point is resharpened. This comparison indicates that, all things being equal, Abasolo points have the longest use-lives while the use-lives of all other forms range between 70 (Refugio) to 78 (Catán and Desmuke) percent of the Abasolo points.

The examination of the large Riley collection indicates that some specimens may end up being discarded even during resharpening. Two general reasons why a specimen may be discarded during resharpening are repeated step-fracturing of the resharpening scars or a lateral perverse break of the blade. The first failure yields a complete specimen with a series of step-fractured resharpening scars along the beveled blade edge. These scars prevent the removal of subsequent flakes from the same edge unless a substantial portion of the edge is sacrificed. Lateral perverse fractures occur as a result of excessive force developed during resharpening, either using small percussors or pressure flaking tools.

\section{Use Failures and Their Rejuvenation}

Eventually, during use these leaf-shaped tools will fail. Two use-failure types have been noted in the collections examined: 1) impact scars and burins; and 2) end shock. Impact scars and burins are the result of the use of the specimens as projectile tips and their contact with hard materials. The most common use break in such cases is a snap with a fracture plane that is perpendicular to the longitudinal axis of the specimen. However, in the case of some specimens, the distal ends fracture leaving a very noticeable flake scar running towards the base of the point. These are the more "classic" impact scars seen on some projectile points. Impacts can also result in the burination of the tip of a point. This type of break is less common in the samples analyzed and it is likely that on some specimens it represents the resharpening of a graver tip rather than a manufacture failure. Blade failures due to end shock were also observed in the larger samples from the Riley collection, but were not included in the eventual sample analyzed for this study.

Impact scars and burins are the clearest indication of projectile point use. However, it should not necessarily be assumed that the lack of impact scars rules out such use since many points may simply snap as a result of impact and some are rejuvenated following breakage, therefore removing all signs of previous impact failure. Abasolo points exhibited the smallest percentage of specimens bearing use-failure scars (5\%; i.e., impact and/ or end shock), while Catán points have only slightly higher percentages (7\%). Refugio and Desmuke points did not exhibit impact scars. The inspection of a much larger number of points from the Riley collection seems to also suggest that impact breaks are relatively infrequent on the larger Abasolo forms but are present, although infrequently, on the smaller Catán points.

Overall, this pattern may suggest that these triangular tool forms start out as large knives employed primarily in cutting tasks and as they are resharpened and rejuvenated, and reach the smaller forms that have more desirable aerodynamic properties, they may be employed as projectile points. This hypothesis may also be supported by the fact that the longer forms, with their longer blade edges, serve as more efficient cutting tools while the shorter forms are much less efficient as cutting tools, given their shorter effective cutting edges.

\section{Exhausted Specimens}

Abasolo and Refugio points that do not experience blade failure but continue to be resharpened during their uselife, gradually become narrower even though their length may not decrease substantially (see difference between Figure $42 \mathrm{a}$ and $\mathrm{b}$ and Figure $43 \mathrm{a}$ and $\mathrm{b}$ ). As the points 
become narrower, they may effectively be considered "exhausted" since there may be no remaining opportunities to resharpen the blade without its failure. The encounter of these narrow but complete points may be indicative of a preventive tool replacement strategy that is geared towards replacing tools within the context of "down time" rather than waiting for their failure during use. The second form of exhausted points are the short specimens that have been resharpened or rejuvenated as a result of blade failures (compare Figure $42 \mathrm{a}$ and $\mathrm{d}$ and Figure 43a and d). In these instances, while the tools may still function reasonably effectively as projectile points, since they maintain a piercing tip, their reduced length makes them less efficient in the performance of cutting tasks.

\section{Morphological Changes and Their Consequences}

As they move though their use-life the leaf-shaped specimens tend to decrease in length and width. Much of this change is caused by the resharpening of worn blade edges and tool rejuvenation to repair failed blades. Given that the key diagnostic distinction between Abasolo and Catán points, in particular, is maximum length, it is easy to see how the same point may start out as an Abasolo point and change into a Catán point during its use-life cycle (Figure 42). A similar morphological change can also occur in the case of the Refugio points (Figure 43). These changes in point morphology are due to point resharpening and rejuvenation and should be common during their use-life.

In a similar fashion, the inspection of a large number of points from the Riley collection suggests that certain forms of base failure rejuvenations among round-based and perhaps even straight-based unstemmed points may also result in the production of Desmuke-like forms. Figure 44 shows two examples of rebased points. It is evident in Figure 44 that rebasing a leaf-shaped point can change the morphology of the base so that it is more reminiscent of Desmuke bases.

The cautions raised by the changes in the morphology noted above do not necessarily mean that Abasolo, Catán, and Desmuke points did not represent distinct types of material culture manufactured and manipulated by distinct groups of people. However, types are contemporary analytical units established by archeologists, and the types of morphological changes described above do bring into question the archeologists' ability to consistently and accurately differentiate these morphological forms.

\section{The Tortugas-Matamoros Group}

A total of 134 Tortugas points and 92 Matamoros points were analyzed. Of the 134 Tortugas points, 74 (55\%) have straight bases, $42(31 \%)$ have slightly concave to concave bases, and $18(13 \%)$ have slightly convex to convex bases. On average, the depth of the basal concavity rarely reaches more than $2 \mathrm{~mm}$ in depth and convex bases rarely protrude more than $3 \mathrm{~mm}$ from the horizontal. Among the Matamoros projectile points, straight bases constitute about half of the collection $(n=47,51 \%)$, slightly concave to concave bases are relatively common $(n=28,30 \%)$, while only 17 specimens (18\%) have slightly convex to convex bases. In general, the breakdown of base shapes is relatively similar between the two types and suggests some potential technological relationships. Descriptive statistics on the metric attributes recorded on this sample are presented in Tables 19 and 20.

\section{Point Manufacture and Failure}

The manufacture of Tortugas points begins with hard hammer flake blanks that are relatively thick and possess large bulbs of percussion. Judging from the presence of few, rather thick and biconvex manufacture discards, in some instances these points may be made from smaller nodular cores. These nodular blanks, however, appear to be less common given the overall lack of manufacturefailed specimens with cortex on both faces. Nonetheless, some nodule cores could have been reduced to the degree that no diagnostic traits of the nature of the core would have been preserved, making it appear as if these core types were less often utilized.

The examination of triangular points from the extremely large Riley collection also identified a small number of finished specimens that retained a large portion of the parent flake's ventral surface (Figure 45). These flakes appear to have been removed by soft hammer, given their diffuse bulbs of percussion. Alternatively, they may 


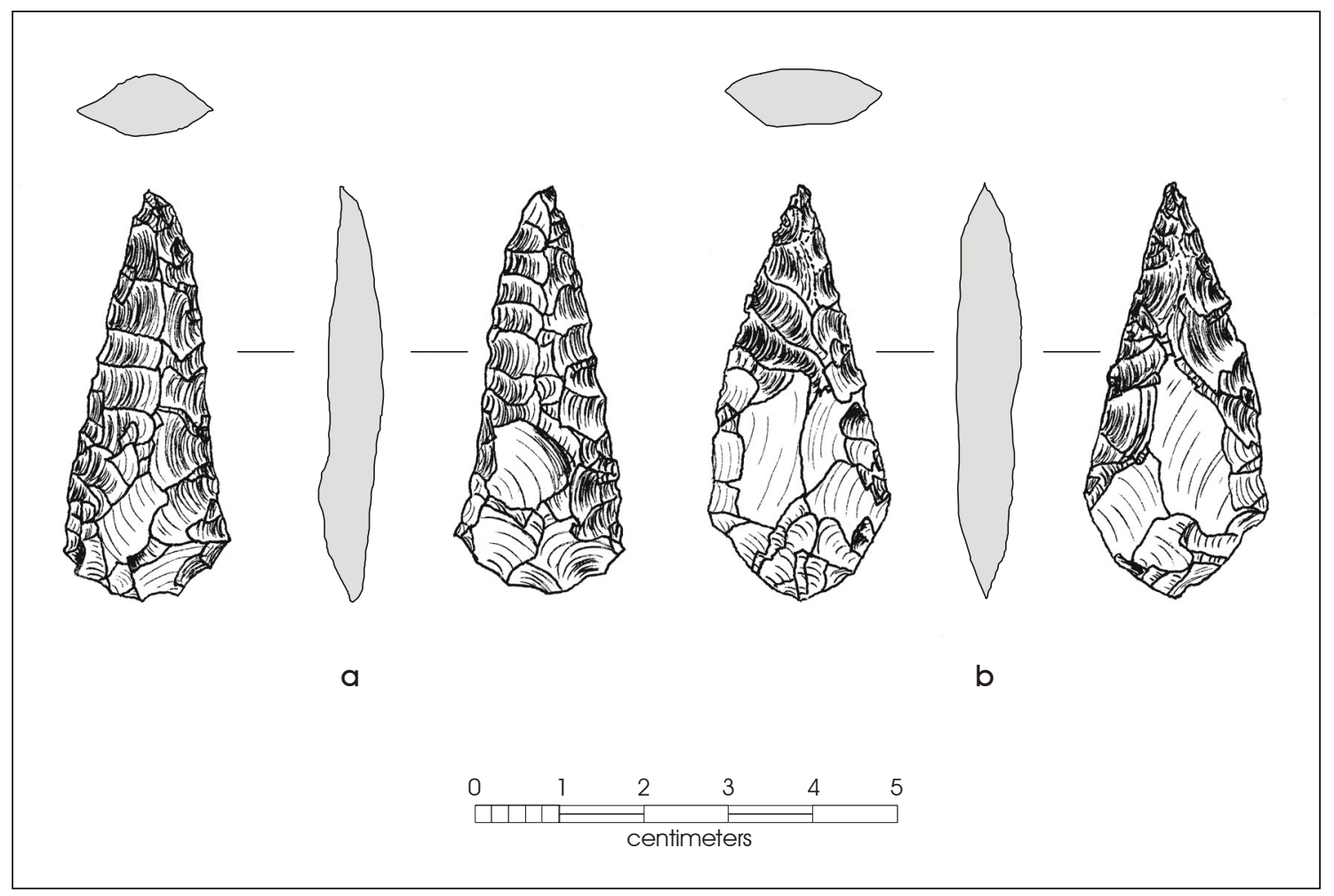

Figure 44. Rebased round-base projectile points: a) Catán-like; b) Desmuke-like.

represent the extremely well-controlled production of blanks using hard hammerstone percussors. These specimens are only marginally retouched on the ventral face of the blank and exhibit no base thinning flakes, although a series of 5-11 $\mathrm{mm}$ long pressure flakes were removed from the ventral face of the specimens along the entire length of the base. In general, the purpose of these flake removals appears to be the shaping of the concave base. Nonetheless, morphologically they have the triangular form characteristic of Tortugas points.

Following the selection of the flake blank, the reduction proceeds using percussion flaking with either small hard hammerstones or small billets, or a combination of both. The earliest manufacture failures tend to occur during the early and middle stages of reduction as the blank is shaped and thinned to the desired form and dimensions. As in the case of the round-base point types, failure to properly thin a blank will often result in thick specimens with multiple hinge- or step-fractured flake scars and stacked areas (Figure 46). Such specimens can be considered manufacture failures even though they are often discarded as complete artifacts.

As the manufacture sequence proceeds beyond the middle stage of reduction, the next most common failure type observed in the Prevost and Riley collections was the actual breakage of the blank from excessive force produced during lateral flake removal (i.e., perverse fractures). In a few instances, blank or biface failure resulted from fractures along imbedded fracture lines. Only a few incomplete manufacture-failed specimens were encountered, particularly in the Riley collection, due at least in part to the biased collection strategy employed.

It is no surprise that of the two point types discussed in this section, Tortugas points have the highest mean maximum length $(50.8 \mathrm{~mm})$, maximum thickness $(7.3$ $\mathrm{mm})$, and maximum width $(28.0 \mathrm{~mm})$ given that the specimens assigned to this group are restricted to those 


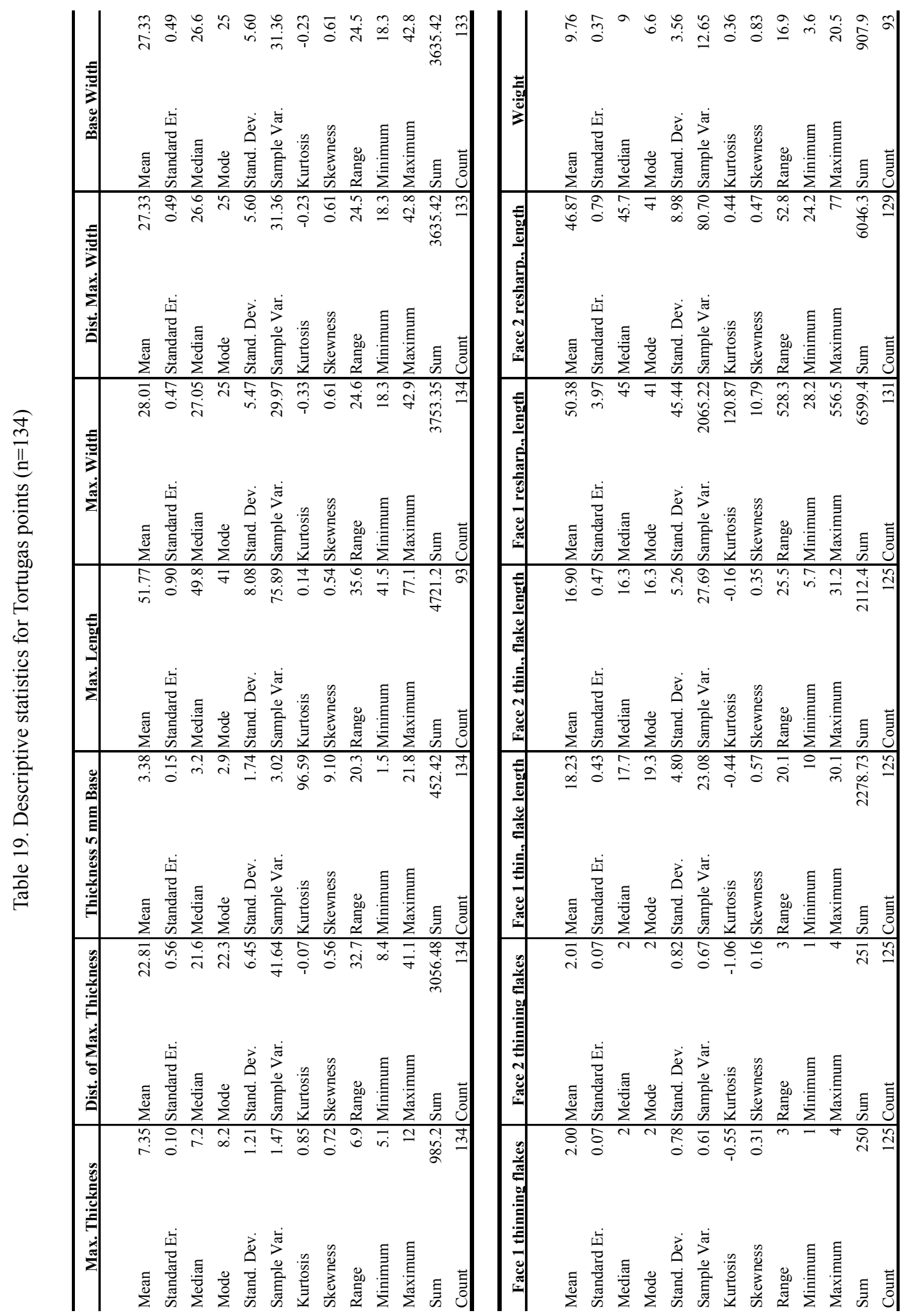



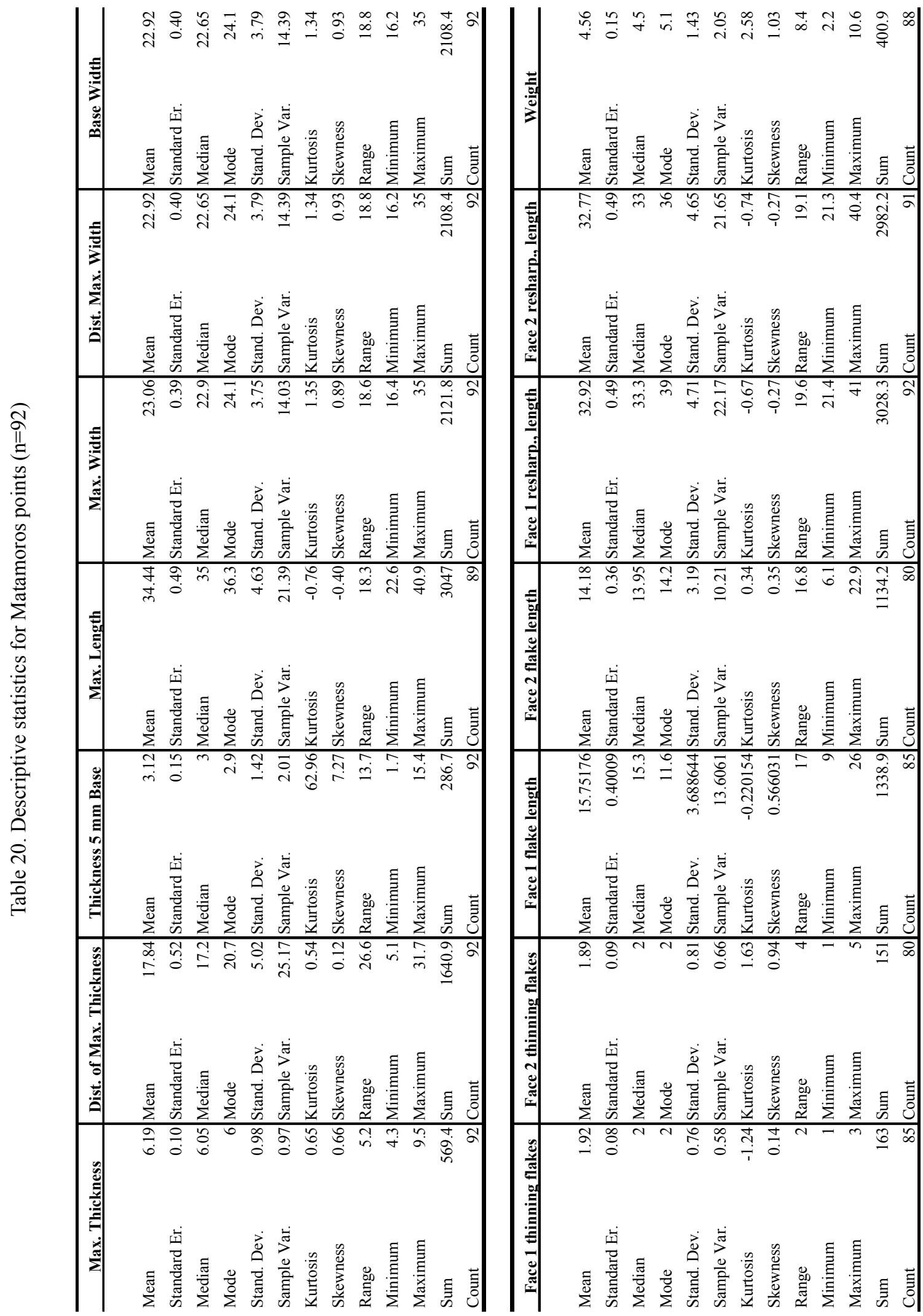
greater than $40 \mathrm{~mm}$ in length (Table 19). It is also no surprise that the mean maximum width and maximum thickness of the Matamoros points is less than that of the Tortugas (Table 20). Starting the manufacture process from a smaller overall blank may yield a smaller and thinner finished product, as would the repeated resharpening and rejuvenation of the larger Tortugas form as it progresses through its use-life. The range in minimum and maximum thickness and width values does suggest that the primary differences between the two types lie in the dimensions of length and thickness.

As in the case of the round-base points, base thinning also is initiated early in the reduction of triangular blanks with much of the thinning focused in the center of the blank and being accomplished with flake removals oriented parallel to the longitudinal axis of the blank (Figure 46a and c). In a few instances, thinning flakes may also be angled inward from the corners of the blanks, although these removals are not intended to round the corners of the specimen (see Figure 46b). The added thickness of the blank during the early stage of reduction reduces the possibility of end-shock snaps, however, as the reduction proceeds toward the late stage, the probability of end-shock failure increases. Failure of the blanks due to incorrect support during base thinning attempts may be relatively common in the case of these triangular points, although the thinning scars do not approach the width and length of those noted on Clovis and Folsom points. At least in the Prevost collection, including all classes of complete and incomplete lithic artifacts and debitage, and the material from 41WB556, the thinning of the base does not appear to have resulted in excessive rates of failure. This is an important observation when compared to the rates of failure that may occur among stemmed projectile points, where the flaking associated with the notching of the specimen can increase the likelihood of manufacture failure.

The break morphology resulting from end shock is similar to the break morphology resulting from snapping a knife during use (i.e., prying tasks). However, in most cases, it should be possible to identify the cause of the break either from the overall unfinished morphology of the broken blanks (Miller et al. 2000:Figures 7.5 and 7.6), or more appropriately, from the lack of use-wear on the margins of the specimen. Early in the reduction, thinning flakes may be removed with hard hammers, while during the later stages of reduction, removals may occur with small soft billets, judging from the shallowness of the negative bulbs of percussion.

A total of 125 (93\%) of the Tortugas points have between one and four base thinning scars on either one or both of their faces (Table 19). A similarly high proportion ( 85 of 92 specimens, 92\%) of Matamoros points retain base thinning flake scars on at least one face (Table 20). On Tortugas points, the mean length of the base thinning flakes ranges from 18.2 to 16.9 on the two faces, with the longest flakes reaching $31.2 \mathrm{~mm}$ and the shortest barely being $6 \mathrm{~mm}$ in length (Table 19). The mean length of the base thinning flakes on Matamoros points ranges from 15.7 to $14.2 \mathrm{~mm}$ on the two faces, with the longest thinning flake measuring $26 \mathrm{~mm}$ and the shortest only $6.1 \mathrm{~mm}$ (Table 20). The smaller size of the Matamoros thinning flakes is not surprising given that as points are resharpened the lateral flake scars begin impinging on the basal thinning scars resulting in a gradual shortening of the maximum length of these scars.

\section{Resharpening}

Regardless of whether Tortugas and Matamoros tools are projectile points, knives, or multi-functional tools, their repeated use in cutting tasks will dull their working edges reducing their efficiency. While resharpening of the working edges can re-establish tool efficiency, it may result in the weakening of the blade if it is done using relatively invasive flakes that penetrate deep into the face of the tool. Beveling, on the other hand, using short steeply angled removals, can resharpen the working edge without invading the face while preserving blade strength.

Beveling is present on 75 (56\%) of the Tortugas points in this study. Alternate left beveling is present on 81 percent $(n=61)$ of these specimens. A total of $61(66 \%)$ of the Matamoros points in this study have been beveled. Alternate left beveling dominates $(\mathrm{n}=55,90 \%)$, while few $(10 \%)$ points exhibit alternate right beveling. The manner and distribution of resharpening scars that form the bevel indicates that resharpening flakes tend to be longest adjacent the tip and the center of the blade and decrease as one moves towards the base. The lack of beveling on a point's edge does not necessarily indicate 


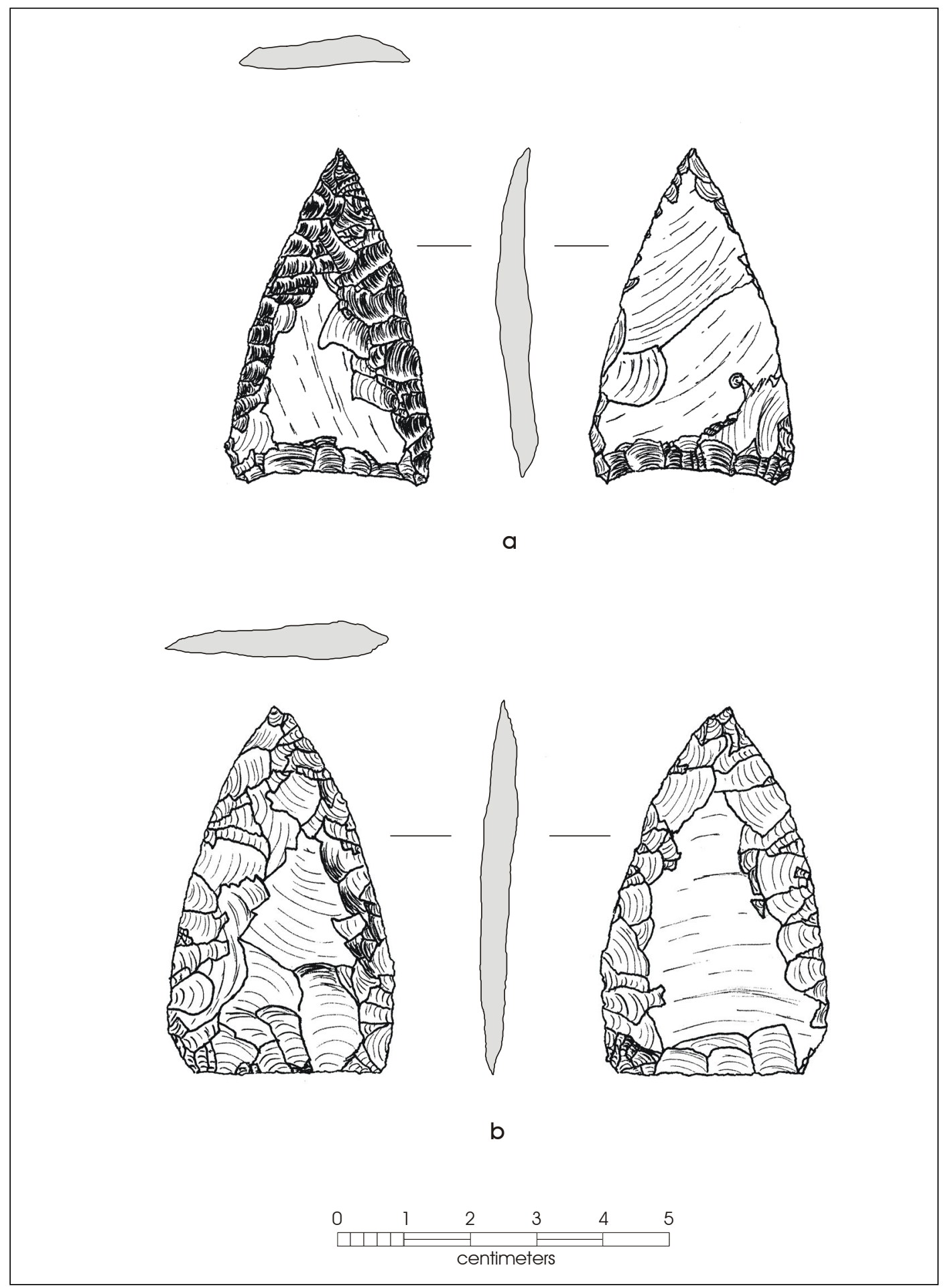

Figure 45. Partially unifacial Tortugas points made on relatively straight billet flakes. 


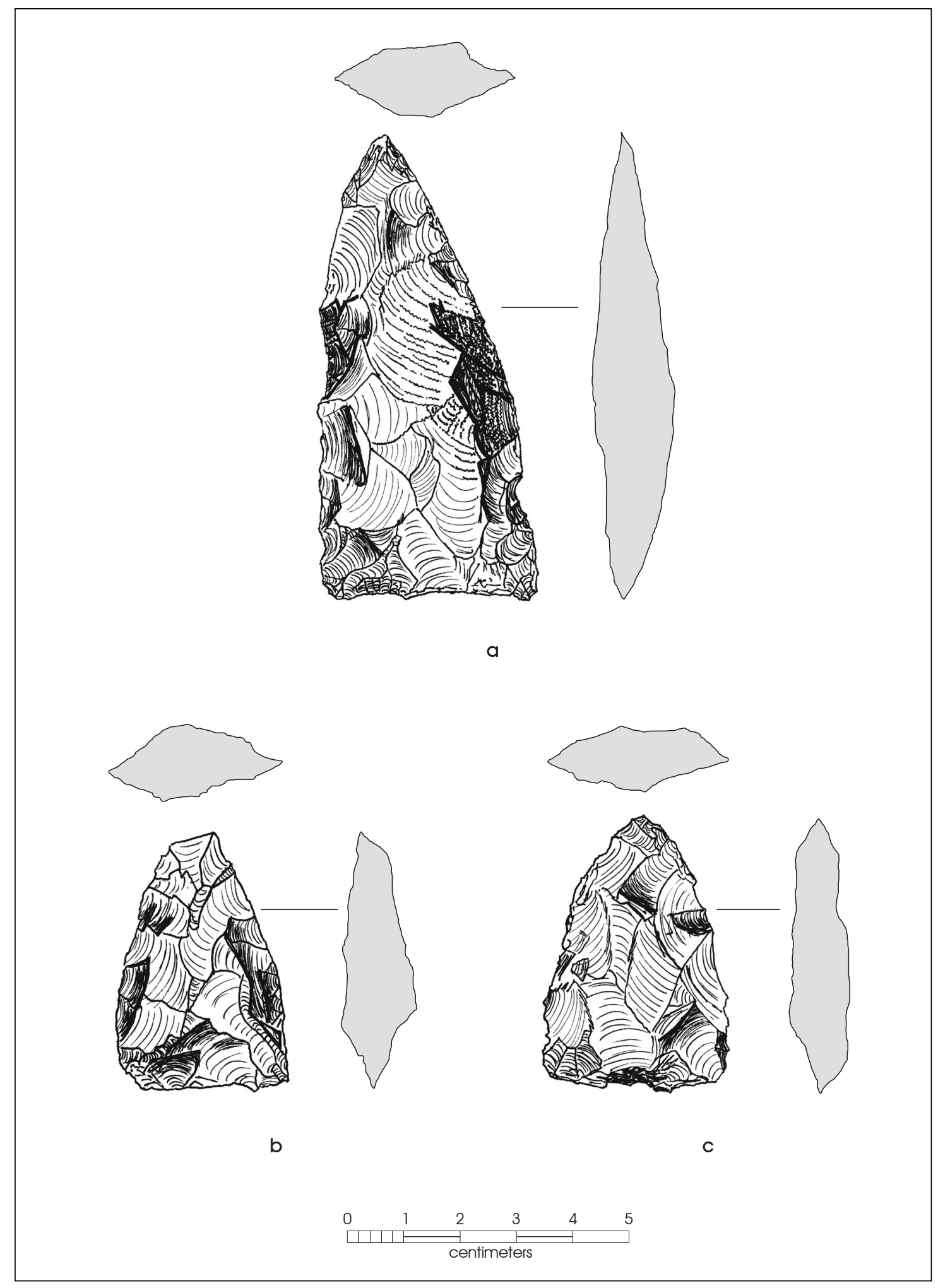

Figure 46. Manufacture failed Tortugas and Matamoros blanks: a) step-fractured thinning flakes; $b$-c) stacked step-fractured thinning flakes. 
that the point was not resharpened. It simply indicates that the resharpening was not sufficiently patterned and regular enough to produce a beveled edge. All Tortugas and Matamoros dart points in the study exhibited resharpening.

If we can assume, as before, that on average, each resharpening episode removes about $1 \mathrm{~mm}$ of material from the edge of a point, and if we take the widest (42.8 $\mathrm{mm})$ and narrowest $(18.3 \mathrm{~mm})$ base widths of Tortugas specimens as beginning and end points of resharpening, we see that each point may be sharpened a maximum of 25 times $(43-18 \mathrm{~mm})$ before reaching the narrowest form in the sample. Using the same logic, a Matamoros point can be resharpened a maximum of 19 times (35-16.2 $\mathrm{mm}$ ) before reaching "the exhausted state," assuming that points do not break before they reach their narrowest and that resharpening proceeds from the tip to the widest portion of the point, so that both width and length are diminished as the point is resharpened. This comparison indicates that, all things being equal, Tortugas points have the longest use-lives, while the use-lives of Matamoros points are only 76 percent of the larger form. Interestingly, similar figures were obtained among the round-base points with the smaller forms having a use-life that was between only 70 to 78 percent of the larger form (i.e., Abasolo).

Assuming that a triangular projectile point is not broken during its use-life, resharpening changes two aspects of the point's morphology, its length and its width. Figure $47 \mathrm{a}$ and $\mathrm{b}$ illustrate the manner in which projectile point length can decrease as a result of resharpening, while Figure $47 \mathrm{c}$ indicates how projectile point maximum width is narrowed during the use-life of a triangular specimen.

The mean length of complete Tortugas points analyzed is $50.8 \mathrm{~mm}$. On the other hand, the mean length of resharpening on the two edges of Tortugas points ranges from 46.9 to $50.4 \mathrm{~mm}$ (Table 19). It is clear that resharpening of the blade edges runs virtually the entire length of the points. In the case of the smaller Matamoros points, the mean maximum length is $34.2 \mathrm{~mm}$, while the mean length of resharpening on the two edges of these points ranges from 32.8 to $32.9 \mathrm{~mm}$. Again, on average, all but $1 \mathrm{~mm}$ of the maximum length of the point is not reached by resharpening.
This technique of resharpening triangular points from their tip to their base has important implications because it leads to morphological changes in the larger Tortugas points that can mimic smaller triangular forms (Matamoros points) and can lead to incorrect typological assignment. One of the diagnostic aspects of this degree of resharpening is the invasive nature of the resharpening or beveling flakes on the base thinning flake scars (see Figure 47a-c and Figure 48a-c). As resharpening continues, less and less of the original outline of the base thinning flakes will remain on the two faces of the point as it decreases in length and width. This type of resharpening strategy is quite distinctive from that employed for the resharpening of Early Triangular points manufactured during the Early Archaic. Often, in the case of this type, rejuvenation yields an equilateral triangle with concave blade edges and base so that it becomes difficult to differentiate the base from the blade edges. In other words, in resharpening Early Triangular specimens there is a real effort to preserve width, while in resharpening the Tortugas during the Middle Archaic the preservation of the width of the tool is not critical.

The examination of the large Riley and smaller Prevost collections contained specimens that appeared to have been discarded as a result of failure during resharpening. Two types of failures were noted: beveled proximal fragments with perverse break morphologies and complete specimens with multiple adjoining stepfractured resharpening flakes. These scars prevent the removal of subsequent flakes from the same edge unless a substantial portion of the edge is sacrificed. Lateral perverse fractures occur as a result of excessive force developed during resharpening carried out with pressure flake removals.

\section{Use Failures and Their Rejuvenation}

As these triangular tools progress through their use-life, they fail. A number of use-failure types have been noted in the collections examined, including: 1) impact scars and burins; 2) end shock; and 3) base snaps. Impact scars and burins are the result of the use of the specimens as projectile tips and their contact with hard materials. The most common use break in such cases is a snap with a fracture plane that is perpendicular to the longitudinal axis of the specimen. However, in the case of some 


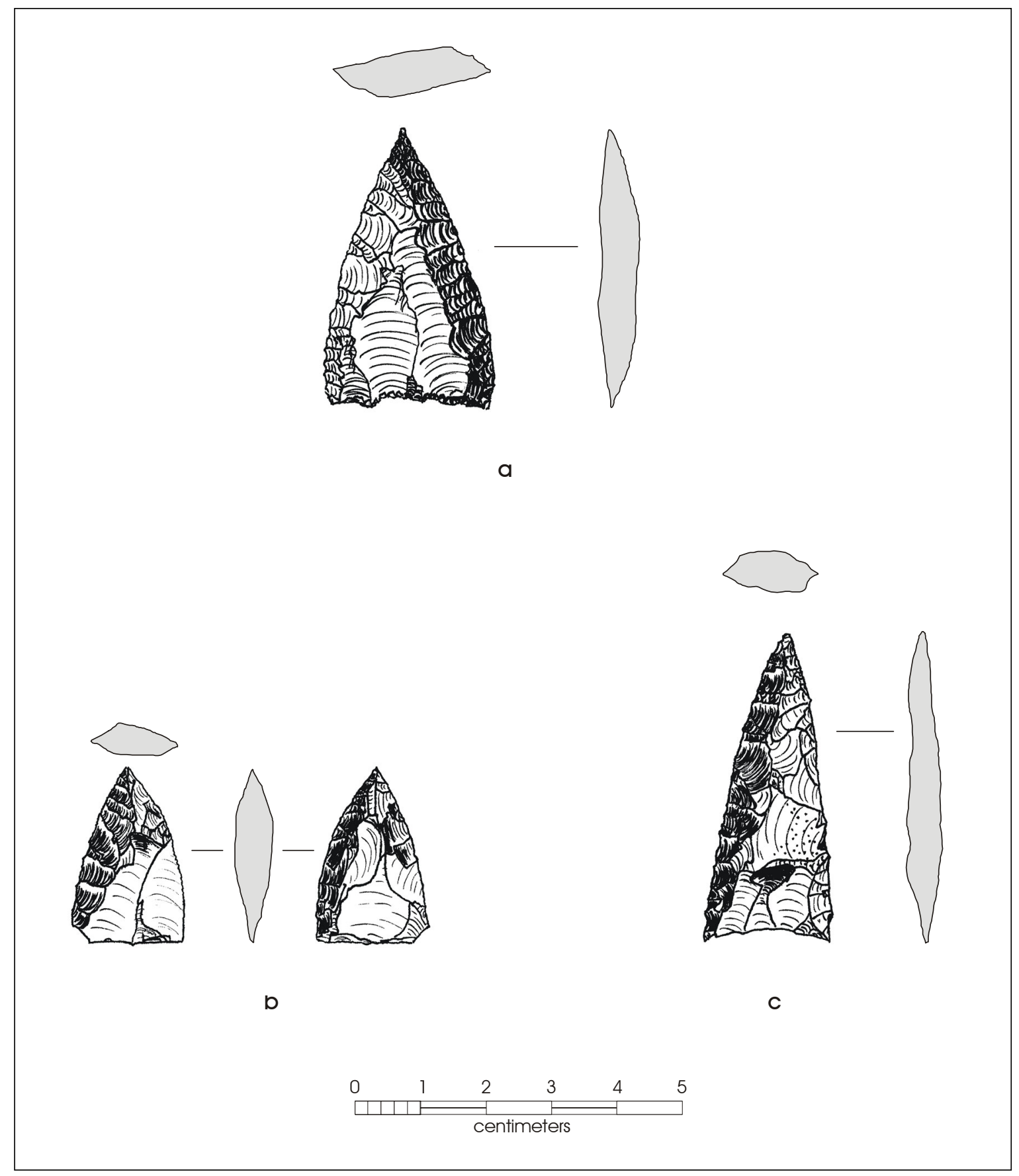

Figure 47. Changes in projectile point morphology and size due to resharpening: a) moderately shortened Tortugas; b) extremely shortened Tortugas; c) Tortugas with narrow blade. 


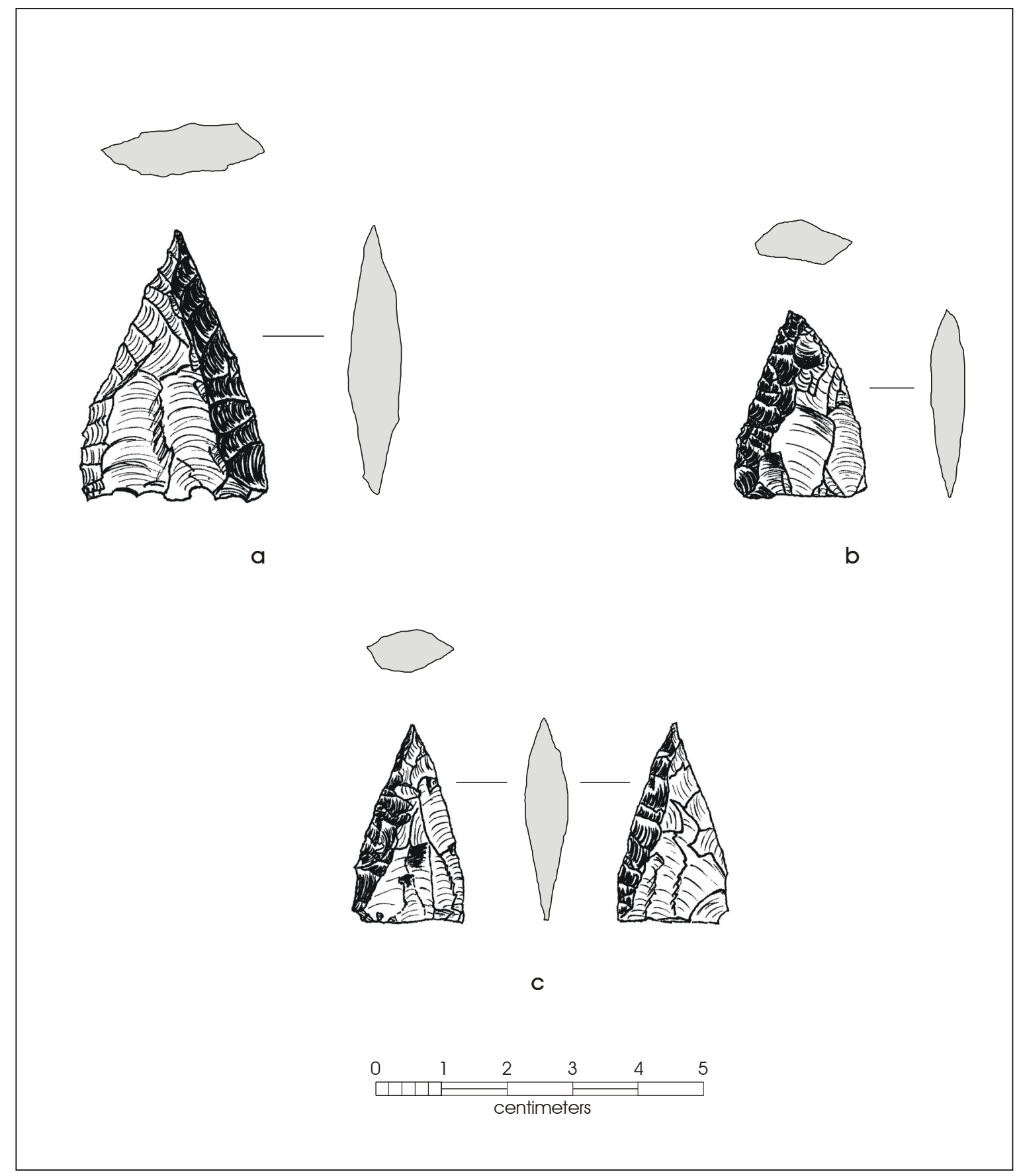

Figure 48. Invasive nature of beveled resharpening onto base thinning flakes: a-b) Tortugas points -technologically; c) Matamoros point. 
specimens, the distal ends fracture leaving a very noticeable flake scar running towards the base of the point (Figure 49a). These are the more "classic" impact scars seen on some projectile points. On triangular projectile points, burinated impact scars were noted only in the larger Riley collection, but none of the samples analyzed had this failure type. Finally, the majority $(n=35$, $85 \%)$ of the Tortugas and two $(66 \%)$ of the three Matamoros proximal fragments had snap fractures caused by bending forces exceeding the elasticity of the material.

Partial base snaps resulting from bending fractures are also present on a number $(\mathrm{n}=15,10 \%)$ of these triangular points (Tortugas and Matamoros combined; Figure 49b). Fragments with partial base snaps were considered complete for this analysis. Using the Cueva de Candelaria specimens as an example (Aveleyra Arroyo de Anda et al. 1956), it is assumed that the triangular forms are hafted in split fore shafts, with only a small portion of the base inserted into the haft with mastic and lashing immediately below the joint holding the two elements adjoined. This assumption is supported by the fact that on archeological specimens the resharpening scars extend the entire length of the point suggesting that the haft was not secured to the point using lashing as is the assumed hafting method of stemmed points.

Base snaps result from the hafting of only a short segment of the very thin base as it is held in the split fore shaft. The resulting fragment is similar to a narrow angular sliver that creates a flat concave break and a relatively thin break face. Due to its thinness, this face can easily be rejuvenated and can change the base shape of a point from a straight or slightly convex-based variant to a concave-based specimen (similar to the Nogales/Tortugas distinction made by MacNeish 1958). Examples of triangular points that have one or two long base thinning flakes adjacent their base, and three to four shorter flakes that were removed after the original thinning flakes to rebase a failed base are not uncommon in the collections (Figure 49c-d). This is not to say that all concave-based Tortugas points began as straight-based specimens, but that some specimens may have reached this morphology through use breakage and subsequent rejuvenation, and that some other concave-based points may have actually had their concavity deepened as a result of such failures. However, this type of rebasing is significant, because in some instances it does remove all previous indications of the base thinning flakes. When this happens, one of the key diagnostic characteristics of the type is removed, potentially causing mistyping of the specimen.

This form of rejuvenation, where only a section of the base needs to be re-flaked, is different from failures where the blade of the triangular point snaps at some distance from the base leaving sizable proximal and distal fragments. In at least one instance, an attempt to unsuccessfully rebase a blade fragment using the relatively thick break face as a platform was noted (Figure 49e). This attempt was unsuccessful because of the lack of suitable thin platform surfaces along the break face. It is perhaps this reason why few rejuvenation attempts of this type have been noted in the collections inspected.

Tortugas, as well as Matamoros, points tend to be thinnest near their tip and at the base. In the vicinity of the tip the points thicken very rapidly reaching maximum thickness not far below the tip. On the other hand, the base is thinned for an average length of about $17-18 \mathrm{~mm}$ on Tortugas points and 14-16 mm on Matamoros points. Figure 50 shows the longitudinal cross-section of a number of Tortugas and Matamoros points. It is evident that as the points become shorter in length, their maximum thickness moves closer and closer toward the tips of the points. As a result of this progression, the tips of the points become more resistant to bending fracture failure since they are located immediately behind the impact area. On the other hand, although the points are thinnest near their bases, they are also widest near their bases. It is possible that the increased width of these triangular points at the base compensates for the greater thinness of the specimens and therefore reduces failure risk. Therefore, it is possible that as these triangular points decrease in length their reliability increases due to reduced failure probability. This progression through their use-life would place two competing aspects of these points side-by-side. Decreased length would result in lowered cutting efficiency, but increased reliability as a projectile point.

\section{Exhausted Specimens}

Tortugas points that do not experience blade failure but continue to be resharpened during their use-life become gradually narrower even though their length may not 

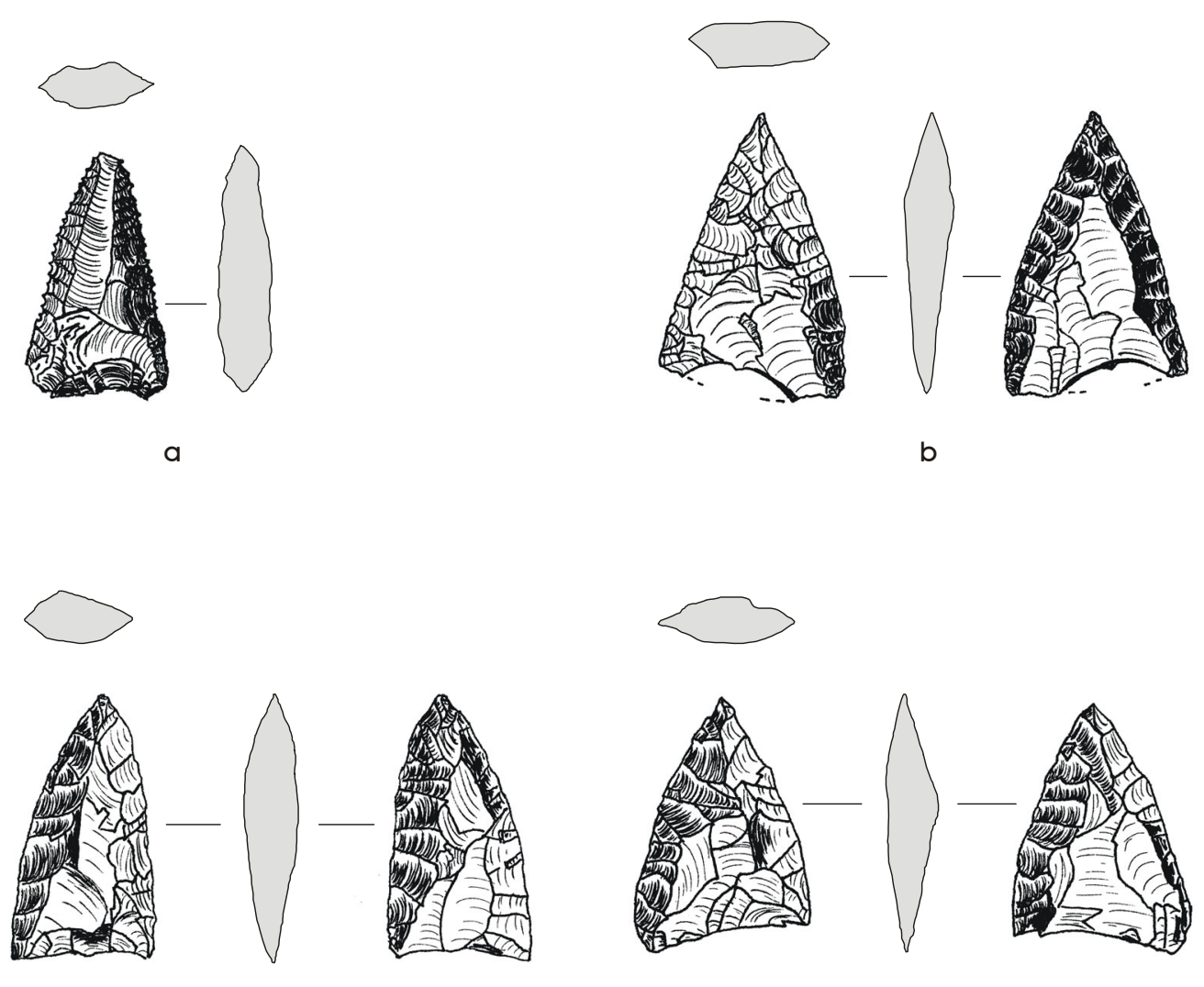

C
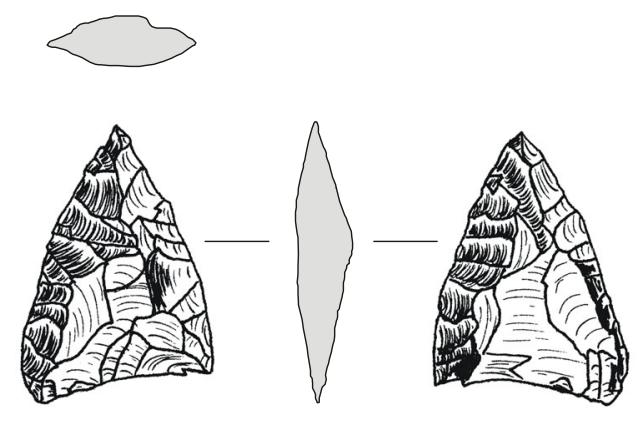

d
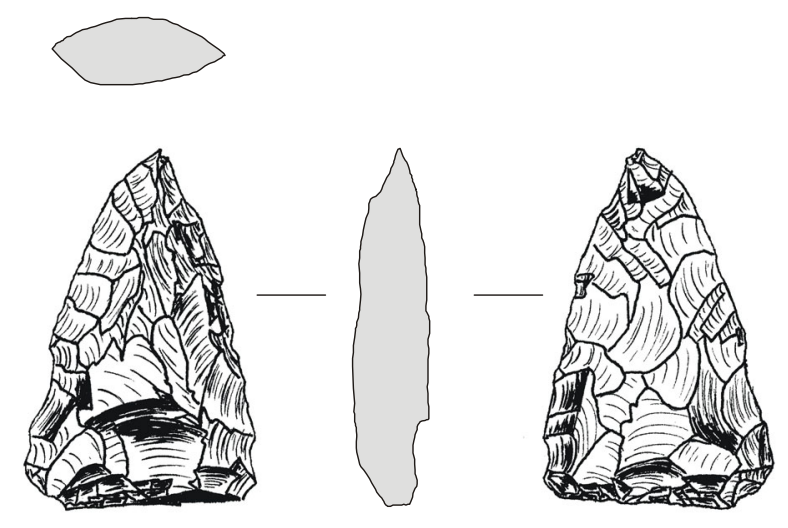

e

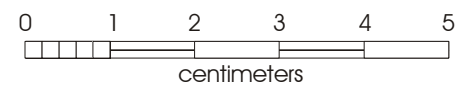

Figure 49. Use failures and base rejuvenations on triangular projectile points: a) impact scar; b) base failure; c-d) points with rejuvenated bases; e) blade failure with rejuvenation attempts. 


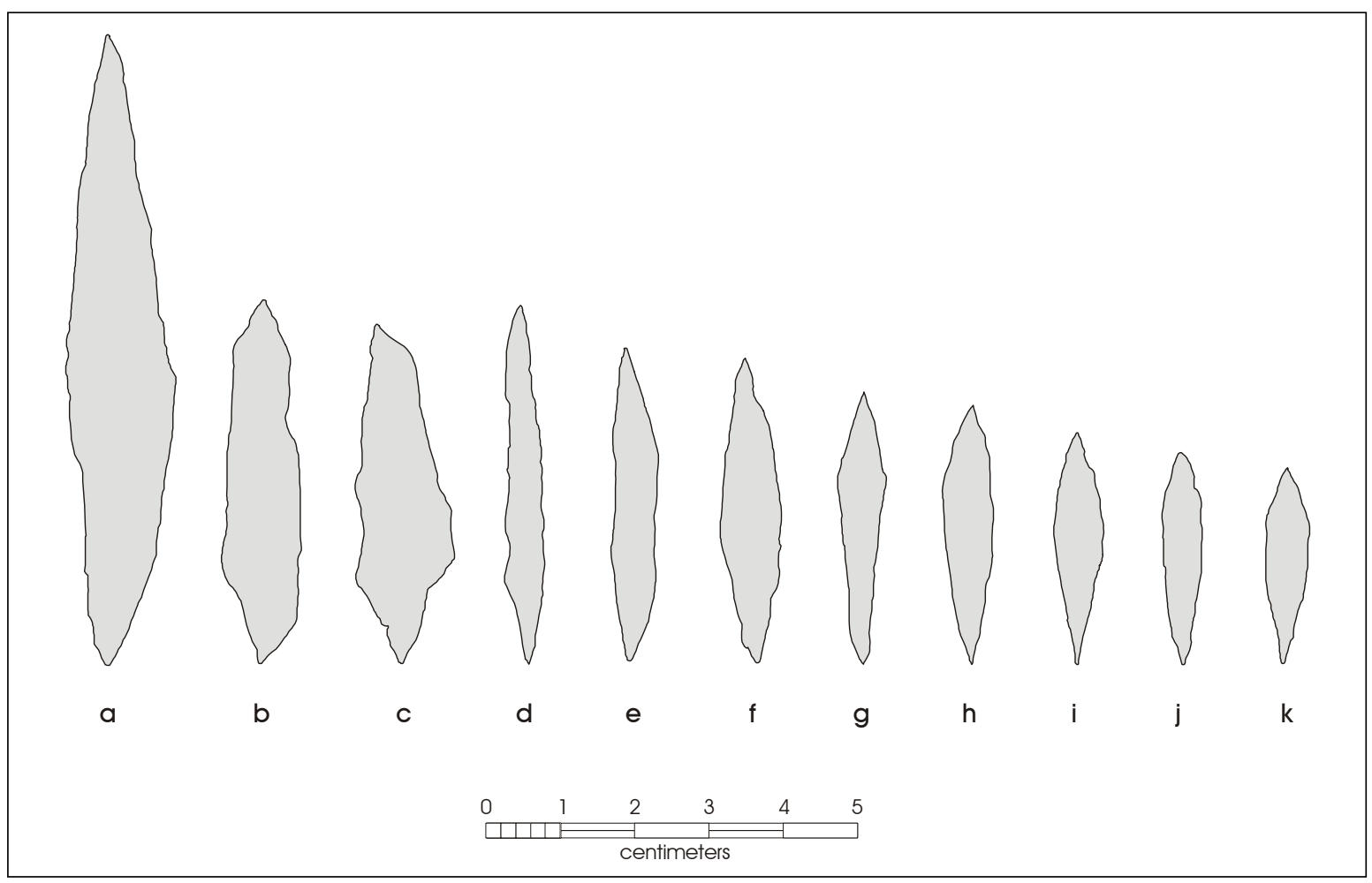

Figure 50. Longitudinal cross-sections of triangular preforms and points, note change in location of maximum thickness with decreasing point size: a-c) blanks; $d-k)$ points in various stages of resharpening.

decrease substantially (Figure 47c). Such specimens may be considered "exhausted" since there may be no remaining opportunities to resharpen the blade without its failure. As mentioned previously, the encounter of these narrow but complete points may be indicative of a preventive tool replacement strategy that is geared towards replacing tools within the context of "down time" rather than waiting for their failure during use. Due to the resharpening of Tortugas points along their entire length, the points automatically undergo a narrowing of their maximum width. If, in addition to this narrowing, the points suffer numerous blade failures they will not only become narrower, but will also become shorter, reaching an "exhausted" form as small and rather narrow variants of their original forms (Figures $47 \mathrm{~b}$ and $48 \mathrm{~b}-\mathrm{c}$ ).

\section{Nueces Tools}

A total of 218 distally beveled tools that fall within the Nueces tool category have been analyzed for this report. Slightly less than half $(\mathrm{n}=100,46 \%)$ are from the Prevost
Collection, while the remainder is from the Riley Family Collection. Morphologically these specimens range from semicircular, to crescent-shaped and triangular, and even pointed forms.

\section{Manufacture and Failure}

The analysis of the sample and visual inspection of a much larger number of similar specimens from the Prevost and Riley collections indicate that the manufacture of Nueces tools is characterized by two distinct trajectories, one unifacial (Figure 51) and the other bifacial (Figure 52). The unifacial forms are slightly more common in the sample analyzed $(n=118,54 \%)$ than their bifacial counterparts $(n=100,46 \%)$. Hard hammerstone flake blanks are employed when making the unifacial forms. Apparently decorticate flakes are preferred $(\mathrm{n}=177,81 \%)$ over corticated blanks $(\mathrm{n}=41$, $19 \%$ ) suggesting that the cores are well prepared to set up the preferred platform angle and flake morphology prior to blank removal. Care is taken to select and/or 
produce flake blanks that have very diffuse bulbs of percussion in the making of the unifacial form. The diffuse bulb provides better purchase for the haft element and assures that a long segment of the working edge contacts the surface to be worked at all times, since more convex edges would contact primarily in the center while more concave edges may contact solely at the two outer edges, unless the material being worked is curved.

The bifacial variants of the Nueces tools tend to have a bi-convex or plano-convex transverse cross-section (Figure 52). Based on the examination of a large number of these specimens in the Riley collection, and more importantly on the symmetrical shape and well-patterned flake scars over the entire surface of many of the bifacial Nueces tools, it would appear that many of these are the result of the rejuvenation of broken bifaces into distally beveled tools (see Figure 52b). The author's (SAT) experiments in replicating these forms resulted in highly diagnostic debitage that would be key in identifying whether similar rejuvenation methods create the archeological specimens. The evidence for at least some of the tools being made of recycled failed bifacial artifacts is even more clear in the case of failed projectile points (Figure 52c). In this example, the alternate left beveling present on a former triangular projectile point is a clear indication of the nature of the original blank employed in the manufacture of the tool. The examination of the larger Riley collection has indicated that while additional Nueces tools with beveled edges are present, they are not very common in the collection. This pattern might suggest that most Tortugas and/or Matamoros points may not be large enough in their broken state to be consistently and systematically recycled into Nueces tools.

The mean maximum length of the bifacial Nueces tools is $34.8 \mathrm{~mm}$, ranging from 68.1 to $19.8 \mathrm{~mm}$ (Table 21). This figure is about the same as the mean length of the Matamoros points and it is well under the mean length of Tortugas specimens (see Tables 19 and 20). The mean maximum width of the bifacial Nueces tools is $36.3 \mathrm{~mm}$ while their mean maximum thickness is $9.7 \mathrm{~mm}$. The

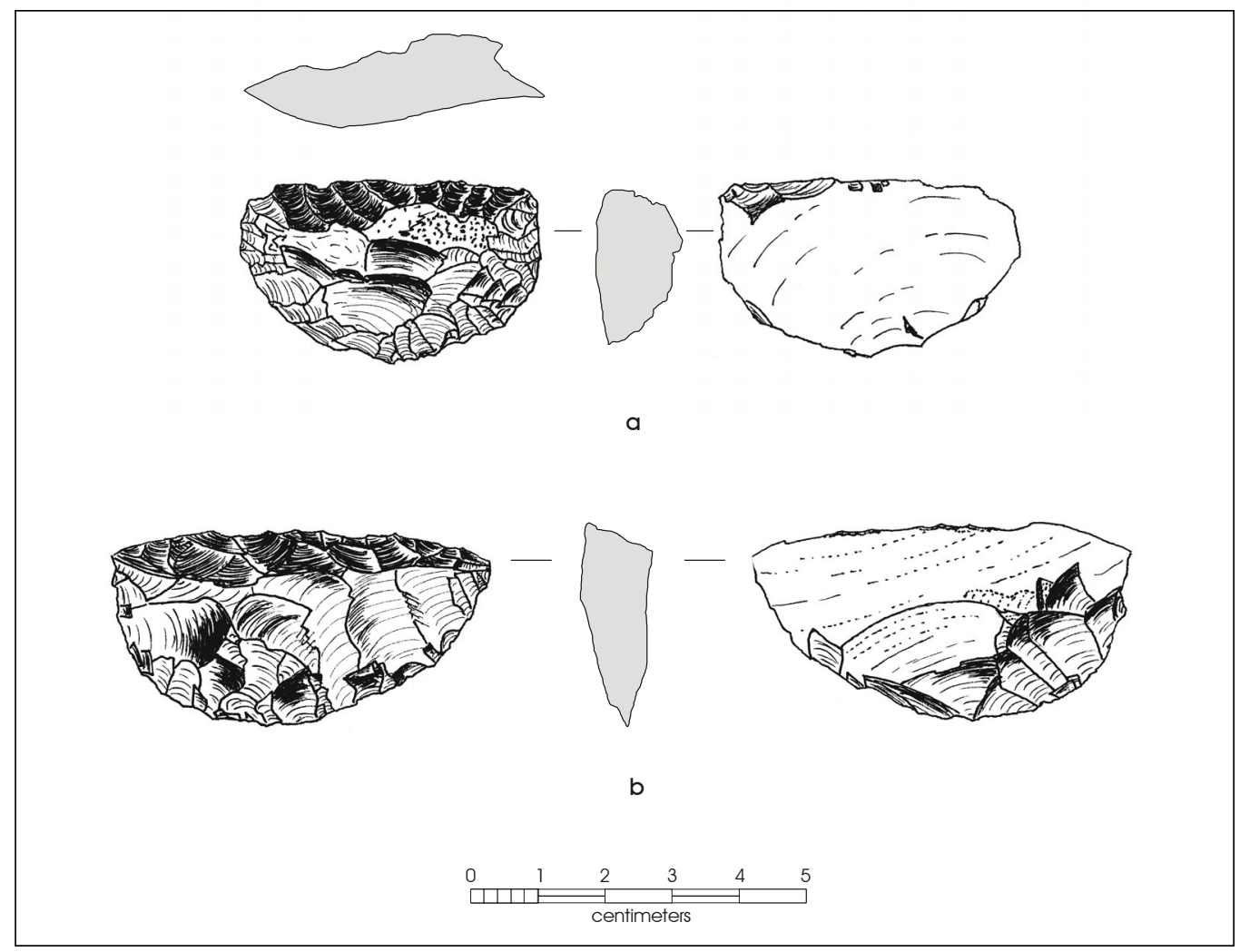

Figure 51. Unifacial Nueces tools: a) no bulbar thinning, note reuse flakes on distal end; b) moderate bulbar thinning. 
last two figures are greater than the mean maximum width and thickness values for Tortugas points suggesting, perhaps, that if bifacial Nueces tools are made from recycled bifaces, these artifacts are often not likely to be projectile points.

The mean maximum length of unifacial Nueces specimens is very similar to their bifacial counterparts (Table 21). However, unifacial specimens made from flake cores tend to be both thicker and wider than their bifacial counterparts (Table 21).

As a result of careful blank manufacture and/or selection, in looking at the profile of the working edges on these Nueces tools, it can be noted that among the unifacial forms straight and convex working edges occur in identical proportions ( $\mathrm{n}=41$ each, $35 \%$ each). Recurved or undulating edges $(n=27,23 \%)$ and concave edges $(n=9$, $8 \%$ ) are relatively infrequent. Among the bifacially manufactured Nueces tools, specimens with convex working edges constitute 51 percent of the collection followed by specimens with straight working edges (41\%). Seven $(8 \%)$ bifacial tools have recurved working edges.

Based on these figures, working edges with a convex ventral profile are relatively common among the Nueces tools. In order to gauge the degree of convexity of these working edges, measurements were taken of the protrusion of the ventral face from a vertical line connecting the two corners of the working edge. The mean ventral protrusion among all Nueces tools is 2.4 $\mathrm{mm}$, with a range of 7.5 to $.2 \mathrm{~mm}$ (Table 22). These measurements again reiterate that working edge profiles tend to be maintained relatively flat among the Nueces tools and that those tools that offer large areas of contact with the worked material (i.e., those tools that have a flatter edge profile) are likely to be more effective than the other shapes.

Identifying the location of the flake blank's platform can inform one about the strategy of blank production as well as tool orientation. Of the 88 unifacial specimens on which platform location could be identified, 45 (51\%) had platforms located on the side of the finished tool, that is, the parent flake's longitudinal edge was used as the tool's working edge. On an additional $35(40 \%)$ specimens, the parent flake's platform was located at the proximal end of the tool. Only in eight $(9 \%)$ identifiable cases was the parent flake's striking platform located at the distal or working edge of the tool. This distribution of platforms assures the craftsmen and tool user that the ventral surface of the working edge will be as flat as possible allowing for greater tool efficiency.

The production of flake blanks with diffuse bulbs of percussion is not an easy task and flakes often retain larger and more bulbous cones of percussion than can be accommodated by the hafting element into which the tools are mounted. In only 26 (22\%) of the unifacial forms was the bulb of percussion sufficiently diffuse not to require additional thinning of the blank's ventral face. Minimal retouch of the bulb of percussion had to be employed in $25(27 \%)$ of the remaining unifacial forms (Figure 51a), 43 (47\%) others had to be moderately thinned (Figure $51 \mathrm{~b}$ ), while 24 (26\%) of the specimens have been extensively retouched on their ventral faces.

\section{Resharpening}

The mean edge angle of Nueces tools is 63.1 degrees, and ranges from a maximum of 89 to a minimum of 41 degrees (Table 22). An examination of the 17 specimens that have edge angles higher than or equal to 80 degrees indicates that these working edges are heavily stepfractured due to failure to properly resharpen an already steep edge. Interestingly, a majority of these edges are also straight (75\%) or only slightly convex, and a concave edged specimen is also present in the group (Figure 52d), suggesting that resharpening reduces the degree of convexity of the working edges.

This observation is supported by the breakdown of working edge shapes within the overall Nueces tool collection. Convex edges $(n=153,70 \%)$ greatly outnumber all other shapes, and straight edges are present on only 26 percent $(n=56)$ of the collection. Concave edges on Nueces tools are infrequent $(n=9,4 \%)$. This breakdown in working edge shape suggests that the preferred shape is a convex edge and that as tools are resharpened their edges become straighter. 


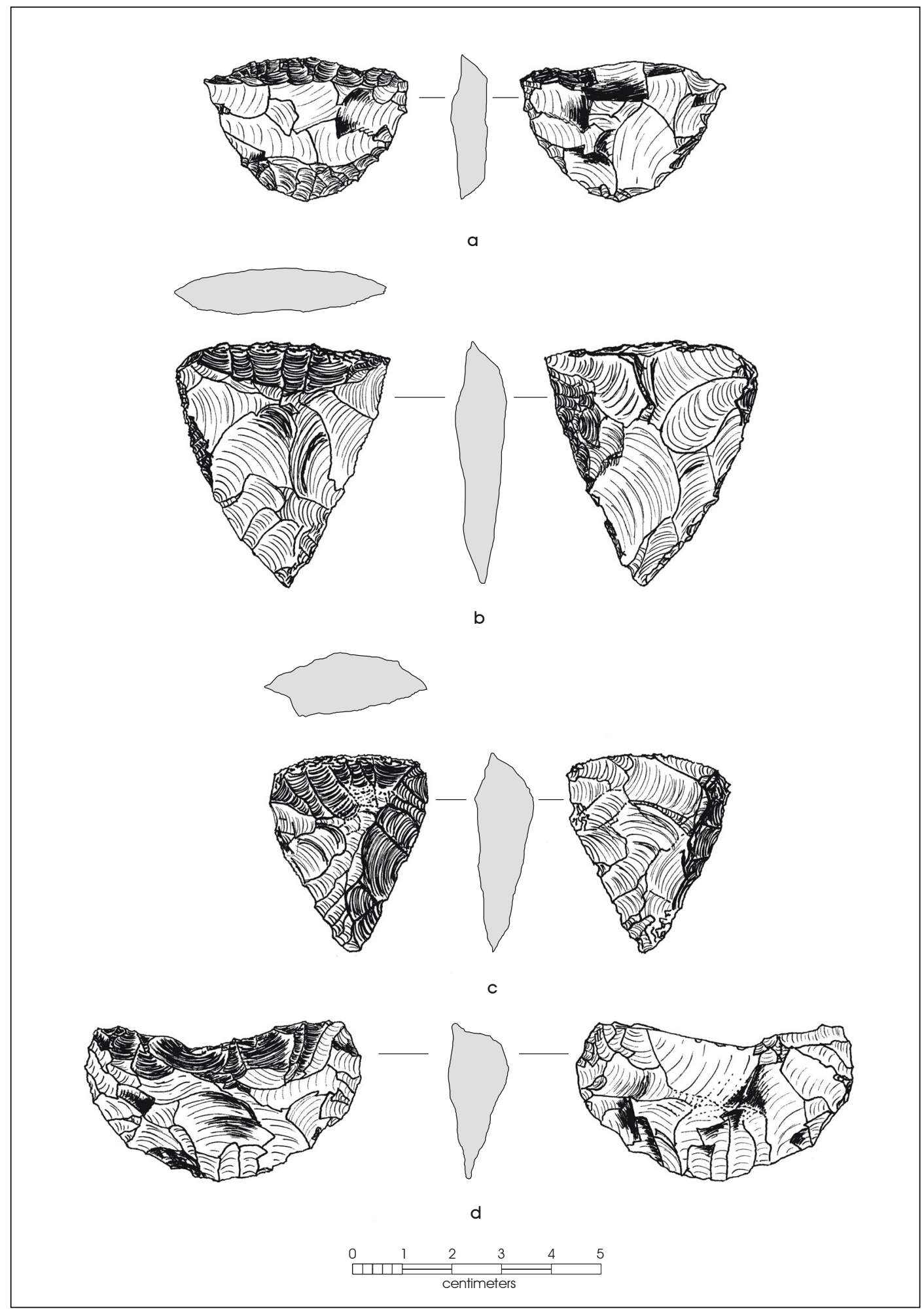

Figure 52. Bifacial Nueces tools: a-b) made on recycled biface fragments; c) made on recycled alternately beveled point fragment; d) heavily resharpened tool with concave working edge. 
Table 21. Descriptive statistics for selected Nueces tools $(n=118)$

Bifacial Nueces

\begin{tabular}{lr|lr|lr}
\hline \multicolumn{1}{r|}{ Max. Length } & \multicolumn{2}{c}{ Max. Width } & \multicolumn{2}{c}{ Max. Thickness } \\
& & & & & 9.72 \\
Mean & 34.62 & Mean & 36.33 & Mean & 0.24 \\
Standard Error & 0.86 & Standard Error & 0.62 & Standard Error & 9.4 \\
Median & 33.5 & Median & 35.8 & Median & 7.9 \\
Mode & 33.8 & Mode & 43.9 & Mode & 2.43 \\
Standard Deviation & 8.63 & Standard Deviation & 6.22 & Standard Deviation & 5.88 \\
Sample Variance & 74.55 & Sample Variance & 38.67 & Sample Variance & 2.15 \\
Kurtosis & 2.87 & Kurtosis & 0.67 & Kurtosis \\
Skewness & 1.27 & Skewness & 0.66 & Skewness \\
Range & 48.3 & Range & 33.5 & Range & 1.20 \\
Minimum & 19.8 & Minimum & 25.5 & Minimum & 12.9 \\
Maximum & 68.1 & Maximum & 59 & Maximum & 5.5 \\
Sum & 3461.5 & Sum & 3632.6 & Sum & 18.4 \\
Count & 100 & Count & 100 & Count & 972.2 \\
\hline
\end{tabular}

Unifacial Nueces

\begin{tabular}{lr|lr|lr}
\hline \multicolumn{1}{r|}{ Max. Length } & \multicolumn{2}{c}{ Max. Width } & \multicolumn{2}{c}{ Max. Thickness } \\
& & & & \\
Mean & 33.25 & Mean & 43.41 & Mean & 11.79 \\
Standard Error & 0.76 & Standard Error & 0.61 & Standard Error & 0.25 \\
Median & 31.85 & Median & 42.25 & Median & 11.6 \\
Mode & 30.4 & Mode & 41.8 & Mode & 10.2 \\
Standard Deviation & 8.24 & Standard Deviation & 6.63 & Standard Deviation & 2.68 \\
Sample Variance & 67.93 & Sample Variance & 44.00 & Sample Variance & 7.16 \\
Kurtosis & 3.63 & Kurtosis & 1.03 & Kurtosis \\
Skewness & 1.43 & Skewness & 0.65 & Skewness & 0.41 \\
Range & 51.5 & Range & 37.2 & Range & 0.43 \\
Minimum & 18.3 & Minimum & 30 & Minimum & 15.4 \\
Maximum & 69.8 & Maximum & 67.2 & Maximum & 5.6 \\
Sum & 3923.7 & Sum & 5121.93 & Sum & 21 \\
Count & 118 & Count & 118 & Count & 1391.7 \\
\hline \multicolumn{2}{r}{} & & & 118 \\
\hline
\end{tabular}

\section{Use-wear Analysis}

Two macroscopic aspects of use-wear were systematically investigated on all of the Nueces tools in the sample. One of these was the observation of use-polish on the ventral faces of the tools, concentrating primarily in the vicinity of the working edge. Prior to making these observations, tools were washed in warm water using dishwashing detergent. If doubt remained about the nature of the polish, the specific surface was cleaned with rubbing alcohol using a cotton swab. Each polished surface was than examined under direct light at $40 \mathrm{X}$ magnification. Tools were handled with white cotton gloves to prevent the deposition of oily substances on their surfaces.
Of the 218 specimens examined, 21 specimens (10\%) had no discernible polish on their ventral faces. In addition, the presence or absence of polish could not be determined on two chalcedony specimens that retained a high degree of natural polish. The majority $(n=124$, $64 \%$ ) of the remaining 195 specimens with polish retained minimal polish in localized areas across the ventral face of the tool. This polish tended to be strongest on flake scar ridges although low-lying areas of microtopography also retained polish. In the majority of these cases, the polish was not associated with striations. A moderate degree of polish was present on $64(33 \%)$ of the specimens while extensive polish was present on only seven $(3 \%)$ specimens. Although, even on specimens with moderate and heavy polish the flake scar ridges 
retained brighter polish; extensive polish also was present even in the low-lying areas of the faces. In addition to bright polish on the faces, it was noted that the working edges themselves were polished and micro-striations (grooves) were present along the edges. This bright polish, in combination with a lack of striations on the faces of these tools and polish and striations on the working edges, is similar to use-wear traces noted on hide scrapers replicated by this author.

In addition to polish and limited striations, many of the tools also retained single or multiple step fractures on their ventral faces, distributed immediately behind the working edge and originating from that edge. These step- and shallow hingefractured flake scars are superficial and expand broadly toward their distal ends (Figure 51a). Finally, the dorsal faces of the working edges of many of the tools retained multiple step-fractured flake scars. These scars ranged from $2-4.5 \mathrm{~mm}$ in maximum length and tended to be relatively narrow, $1.5-25 \mathrm{~mm}$. This author (SAT) was able to replicate both types of use-damage scars while using a hafted adze in chopping through seasoned Bois d'arc wood. The motion and force of the chopping action resulted in use-damage in the form of thin flake removals from both the ventral and dorsal faces of the working edge.

The combination of Nueces tools with bright polish and no striations, polished and striated working edges, and step-fractured use-wear flakes indicates that these tools were employed in a variety of tasks including the working of very soft and also very hard materials. Similarly, the occurrence of wear traces that are indicative of scraping (i.e., striations on the edges) in combination with those indicative of chopping suggests that the tool form is multi-functional, employed, perhaps opportunistically, in the performance of a variety of tasks and in the processing of a variety of materials.

\section{Olmos Bifaces}

A total of 94 distally beveled tools that fall within the Olmos biface category have been analyzed for this report. The large majority $(\mathrm{n}=91,94 \%)$ is from the Riley collection, with only three (6\%) coming from the Prevost
Table 22. Descriptive statistics for two Nueces tool attributes

\begin{tabular}{lr|lr}
\hline \multicolumn{1}{r|}{ Ventral Protrusion } & \multicolumn{2}{c}{ Edge Angle } \\
\hline & & & \\
Mean & 2.40 & Mean & 63.13 \\
Standard Error & 0.10 & Standard Error & 0.67 \\
Median & 2.1 & Median & 64 \\
Mode & 1.5 & Mode & 65 \\
Standard Deviation & 1.44 & Standard Deviation & 9.89 \\
Sample Variance & 2.08 & Sample Variance & 97.78 \\
Kurtosis & 1.11 & Kurtosis & -0.31 \\
Skewness & 1.02 & Skewness & 0.13 \\
Range & 7.3 & Range & 48 \\
Minimum & 0.2 & Minimum & 41 \\
Maximum & 7.5 & Maximum & 89 \\
Sum & 468.53 & Sum & 13763 \\
Count & 195 & Count & 218 \\
\hline
\end{tabular}

collection. Morphologically, these specimens form a much more homogeneous group than the Nueces tools. These specimens are triangular in outline, often have alternately beveled edges and always have beveled distal working edges. Some specimens retain burin scars off one corner of the working edge, although this is not a diagnostic trait of the tool.

\section{Tool Manufacture and Failure}

It is interesting that in attempting to reconstruct the blanks used in the manufacture of these tools, no specimens representing the early stages of manufacture were found in the collections. Rather, all Olmos bifaces in this study and all previously described Olmos bifaces encountered in the literature (see Bettis 1997; Hester 1969; Shafer and Hester 1971) appear to be finished specimens. That is, they are fully bifacially flaked and have steeply beveled distal ends.

In examining the overall morphology of the specimens in the sample, it was noted that a number had beveled lateral edges (Figure 53a). The systematic counting indicated that $38(40 \%)$ of the specimens were made on biface fragments with alternately beveled edges. Alternate left beveled specimens greatly outnumbered $(\mathrm{n}=30,79 \%)$ alternate right beveled specimens. This figure is similar to the high percentage of alternate left beveled Matamoros and Tortugas points. The presence 
of specimens with beveled lateral edges is puzzling yet probably indicative of the nature of the blank used in tool manufacture. The beveled edges seem to serve no practical purpose, especially since they are on the margins of the tools rather than their working edges.

Two other aspects of Olmos tool morphology are worthy of mention. One is the fact that some of these bifaces retain what appear to be former base thinning flake scars (Figure 53b) on their faces. However, the number of specimens that retain this characteristic is very low $(n=3)$. Another interesting aspect of the morphology of Olmos bifaces is the large number of specimens with broken proximal ends. An examination of the 94 specimens indicated that $56(60 \%)$ of the specimens have a small break off their pointed proximal ends (Figure 53c). A close scrutiny of the morphology of these breaks indicates that some of them clearly represent impact breaks. However, the remaining break morphologies suggest the intentional breakage of the pointed ends. Such an intentional breakage of pointed ends may make sense, if we consider the fact that pointed proximal ends do not provide a good purchase in a haft because the specimen will tend to simply pivot on this point. However, the intentional breakage of the proximal end broadens the area and provides a more stable purchase in the haft.

Overall, the presence of specimens with beveled edges, in combination with the presence of thinning flake remnants on the faces of some tools and the frequency of impact scarred proximal ends, strongly suggests that at least some of the tools were made on recycled dart point fragments. Given the predominance of beveled Tortugas and Matamoros points in South Texas, and the morphological affinities of Olmos tools to these points, it is not unreasonable to suggest that Olmos bifaces are contemporaneous with these projectile points and functioned in the same tool kit.

The mean maximum length of the Olmos bifaces is 28.7 $\mathrm{mm}$ and ranges from 44.8 to $17 \mathrm{~mm}$ (Table 23). This figure is smaller than the mean maximum length of the Matamoros points and it is well under the mean length of Tortugas specimens (see Tables 19 and 20). The mean maximum width of the Olmos bifaces is $22.5 \mathrm{~mm}$ while their mean maximum thickness is $7.0 \mathrm{~mm}$. The last two figures are about the same as the mean maximum width and thickness values for Matamoros points and the maximum thickness of Olmos bifaces is very similar to the maximum thickness of Tortugas points.

In looking at the profile of the working edges of Olmos bifaces, it was noted that all but one of the specimens have either straight or convex working edges and that the former shapes $(\mathrm{n}=49,52 \%)$ are slightly more common than the latter $(n=44,47 \%)$. A concave working edge profile was present on a single specimen. To quantify the degree of convexity of these working edges, measurements were taken of the protrusion of the ventral face from a vertical line connecting the two corners of the working edge. The mean ventral protrusion among all Olmos bifaces is $2.0 \mathrm{~mm}$, with a range from 4.5 to $0.2 \mathrm{~mm}$ (Table 23). As in the case of the Nueces tools, these working edge profiles again reiterate that working edge profiles also tend to be maintained relatively flat among Olmos bifaces.

\section{Resharpening}

The mean edge angle of Olmos bifaces is 63.9 degrees, and ranges from a maximum of 84 to a minimum of 45 degrees (Table 23). These figures are very similar to the respective figures among Nueces tools. The similarity may imply that the manner of use and the tasks in which the two forms are employed are relatively similar. As in the case of the Nueces tools, an examination of the five specimens that have edge angles higher than or equal to 80 degrees indicates that these working edges are heavily step-fractured due to failure to properly resharpen an already steep edge. Interestingly, a majority $(\mathrm{n}=51,54 \%)$ of these edges are convex, and straight working edges constitute only 38 percent of the collection. Seven specimens in the collection (7\%) have concave working edges. This pattern suggests that convex to slightly convex edges are preferred and that resharpening reduces the degree of convexity of the working edges.

\section{Use-wear Analysis}

As was the case with the Nueces tools, two macroscopic aspects of use-wear were systematically investigated on all of the Olmos bifaces in the sample. One of these was the observation of use-polish on the ventral faces of the tools, concentrating primarily in the vicinity of the 


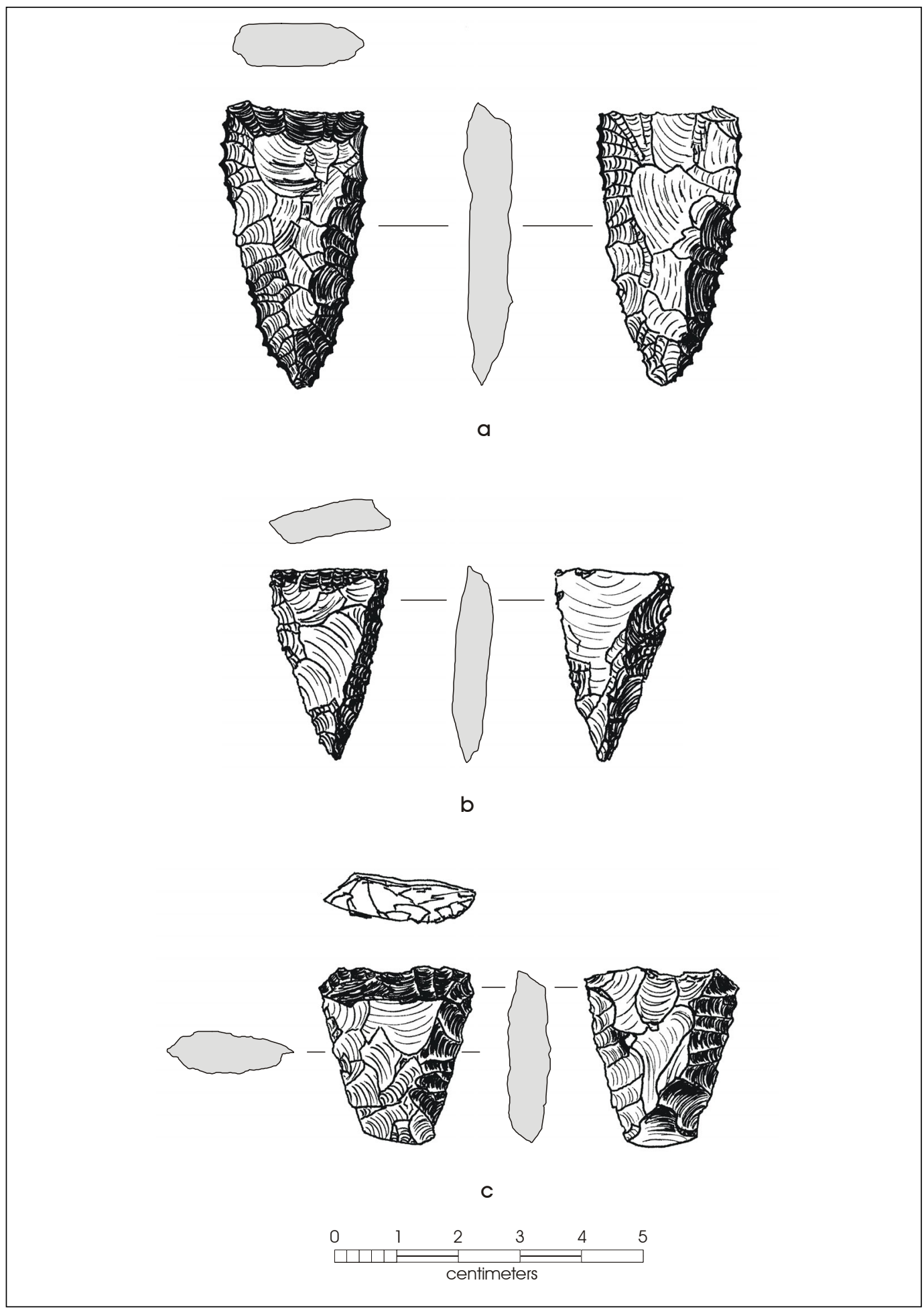

Figure 53. Olmos bifaces made on recycled projectile points: a) note alternate left beveled edges; b) note beveled edges and former base thinning scar on ventral face of tool; c) note beveled edges and former impact scar on proximal end of complete tool. 
Table 23. Descriptive statistics for Olmos biface attributes ( $\mathrm{n}=94)$

\begin{tabular}{|c|c|c|c|c|c|}
\hline \multicolumn{2}{|l|}{ Edge Angle } & \multicolumn{2}{|c|}{ Ventral Protrusion } & \multicolumn{2}{|c|}{ Thickness $5 \mathrm{~mm}$} \\
\hline Mean & 63.95 & Mean & 1.98 & Mean & 5.05 \\
\hline Standard Error & 0.87 & Standard Error & 0.09 & Standard Error & 0.12 \\
\hline Median & 64 & Median & 1.95 & Median & 4.85 \\
\hline Mode & 64 & Mode & 2.8 & Mode & 4.7 \\
\hline Standard Deviation & 8.47 & Standard Deviation & 0.89 & Standard Deviation & 1.20 \\
\hline Sample Variance & 71.69 & Sample Variance & 0.79 & Sample Variance & 1.44 \\
\hline Kurtosis & -0.04 & Kurtosis & 0.28 & Kurtosis & -0.41 \\
\hline Skewness & 0.09 & Skewness & 0.48 & Skewness & 0.37 \\
\hline Range & 39 & Range & 4.3 & Range & 5.5 \\
\hline Minimum & 45 & Minimum & 0.2 & Minimum & 2.6 \\
\hline Maximum & 84 & Maximum & 4.5 & Maximum & 8.1 \\
\hline Sum & 6011 & Sum & 186.22 & Sum & 474.55 \\
\hline Count & 94 & Count & 94 & Count & 94 \\
\hline Maximum Length & & Maximum & & Maximum T & \\
\hline Mean & 28.76 & Mean & 22.55 & Mean & 7.03 \\
\hline Standard Error & 0.52 & Standard Error & 0.35 & Standard Error & 0.11 \\
\hline Median & 28.5 & Median & 22.45 & Median & 6.85 \\
\hline Mode & 26.3 & Mode & 21.9 & Mode & 6.6 \\
\hline Standard Deviation & 5.07 & Standard Deviation & 3.44 & Standard Deviation & 1.03 \\
\hline Sample Variance & 25.74 & Sample Variance & 11.84 & Sample Variance & 1.05 \\
\hline Kurtosis & 0.07 & Kurtosis & -0.31 & Kurtosis & -0.34 \\
\hline Skewness & 0.28 & Skewness & 0.12 & Skewness & 0.43 \\
\hline Range & 27.8 & Range & 16.2 & Range & 4.7 \\
\hline Minimum & 17 & Minimum & 15.3 & Minimum & 4.9 \\
\hline Maximum & 44.8 & Maximum & 31.5 & Maximum & 9.6 \\
\hline Sum & 2703.8 & Sum & 2120.1 & Sum & 660.75 \\
\hline Count & 94 & Count & 94 & Count & 94 \\
\hline
\end{tabular}

working edge. Prior to observation, the specimens were treated in the same manner as described for the Nueces tools. Each polished surface was than examined under direct light at $40 \mathrm{X}$ magnification.

Of the 94 specimens examined, 15 (16\%) had no discernible polish on their ventral faces. In addition, the presence or absence of polish could not be determined on a single specimen that retained a high degree of natural polish. The majority $(\mathrm{n}=56,72 \%)$ of the remaining 78 specimens with polish retained minimal polish distributed across the ventral face of the tool adjacent to and behind (proximal to) the working edges. This polish tended to be strongest on flake scar ridges, although low-lying areas of micro-topography also retained light polish. No striations were noted on the polished surfaces. A moderate degree of polish was present on 18 (23\%) of the specimens with use-wear, while extensive polish was present on only four (5\%) specimens. Although, even on specimens with moderate and heavy polish the flake scar ridges retained brighter polish, extensive polish also was present in the low-lying areas of the faces. In addition to bright polish on the faces, it was noted that the working edges themselves were polished and micro-striations, similar to those noted on hide scrapers, were present along the edges. This wear pattern and distribution was identical to that noted on the Nueces types, the larger of the distally beveled tools. 
As in the case of Nueces tools, in addition to polish and limited striations, 13 (14\%) of the 94 Olmos bifaces also retained single or multiple step-fractured flake scars on their ventral faces, distributed immediately behind the working edge and originating from that edge (see Figure 54a-c; ventral faces of the specimens). These step- and hinge-fractured flake scars are very shallow and tend to either expand toward their distal ends (i.e., the proximal end of the tool) or have parallel sides. Shafer and Hester (1971:4) referred to these scars as "distal-to-proximaltrimming" and noted their presence on $17(27 \%)$ of the specimens they studied. On five of these specimens, these flakes occurred in combination with burin facets off the corners of the tools (Shafer and Hester 1971:5).

As mentioned earlier, burin scars occur occasionally on Olmos bifaces (Figure 54a-c). Of the 63 specimens examined by Shafer and Hester (1971:4-5), burin scars were present on $23(36.5 \%)$. In the collection examined in this study, burin scars appear on $23(24.5 \%)$ of the specimens, a slightly lower percentage than in the earlier Shafer and Hester study. Five (22\%) of the 23 Olmos bifaces with burin scars retain two scars, one from each of the corners.

Finally, and as in the case of the Nueces tools, the dorsal faces of the working edges of many of the tools retained multiple step-fractured flake scars. These scars are smaller than those on the larger tools forms, (i.e., ranging from $1.5-4.5 \mathrm{~mm}$ in maximum length) and tend to be either narrow or trapezoidal in shape. These use-wear flakes have been replicated on larger hafted tools used in chopping hardwood, and although the Olmos bifaces seem too small for such tasks, the presence of both these shallow scars on the ventral faces of the tools, as well as burin scars off the corners of the specimens, suggests a woodworking function for at least some of the Olmos bifaces studied. As was the case with Nueces bifaces, however, the combination of these more obvious usewear traces with use-polish without striations, and striated working edges that appear to derive from hide scraping, suggest that Olmos bifaces also were used in a variety of tasks and in the processing of a variety of hard and soft materials.

\section{A Metric and Technological Comparison of Matamoros-Tortugas and Abasolo-Refugio-Catán Points}

Based on technological characteristics alone there is little if any difference between Matamoros and Tortugas points on the one hand, and Abasolo, Refugio, and Catán points on the other. The two triangular points share similar base thinning approaches, both forms tend to have beveled blades, and both have similar overall shapes. In contrast, base thinning is not a common trait on the three subtriangular types, and blade beveling is also infrequent. Morphologically, Catán points are reminiscent of small Abasolo points with the maximum width on both types occurring near their bases. In addition, even with the artificial metric distinction between them, there seems to be some overlap in classifying the two forms (see Historical Overview section). Refugio points are in general narrower than Abasolo points and longer than either of the other two. The maximum width of Refugio points tends to occur well above the base of the points.

The classification of the 335 triangular points based on these technological criteria resulted in all but three points being classified as Tortugas points $(n=231)$. The three that were classified as Matamoros lacked base thinning flakes. However, it is possible that even some of these may have been Tortugas. A sub-sample of points $(n=89)$ was classified as indeterminate and twelve were identified as Early Triangular specimens.

As the previously summarized descriptions of the two forms indicate, the primary morphological difference between the two is that by definition the Matamoros points tend to be specimens less than $40 \mathrm{~mm}$ in maximum length, while Tortugas tend to be specimens greater than $40 \mathrm{~mm}$ in maximum length. When these criteria are applied for the classification, 134 specimens are classified as Tortugas and 92 are classified as Matamoros. The primary difference in the two classifications is that 63 points that were classified as Tortugas due to their technological characteristics are now classified as Matamoros due to their size. In addition, 27 fragmentary points that appear to have been smaller than $40 \mathrm{~mm}$ in their complete maximum length, also are classified as Matamoros. 


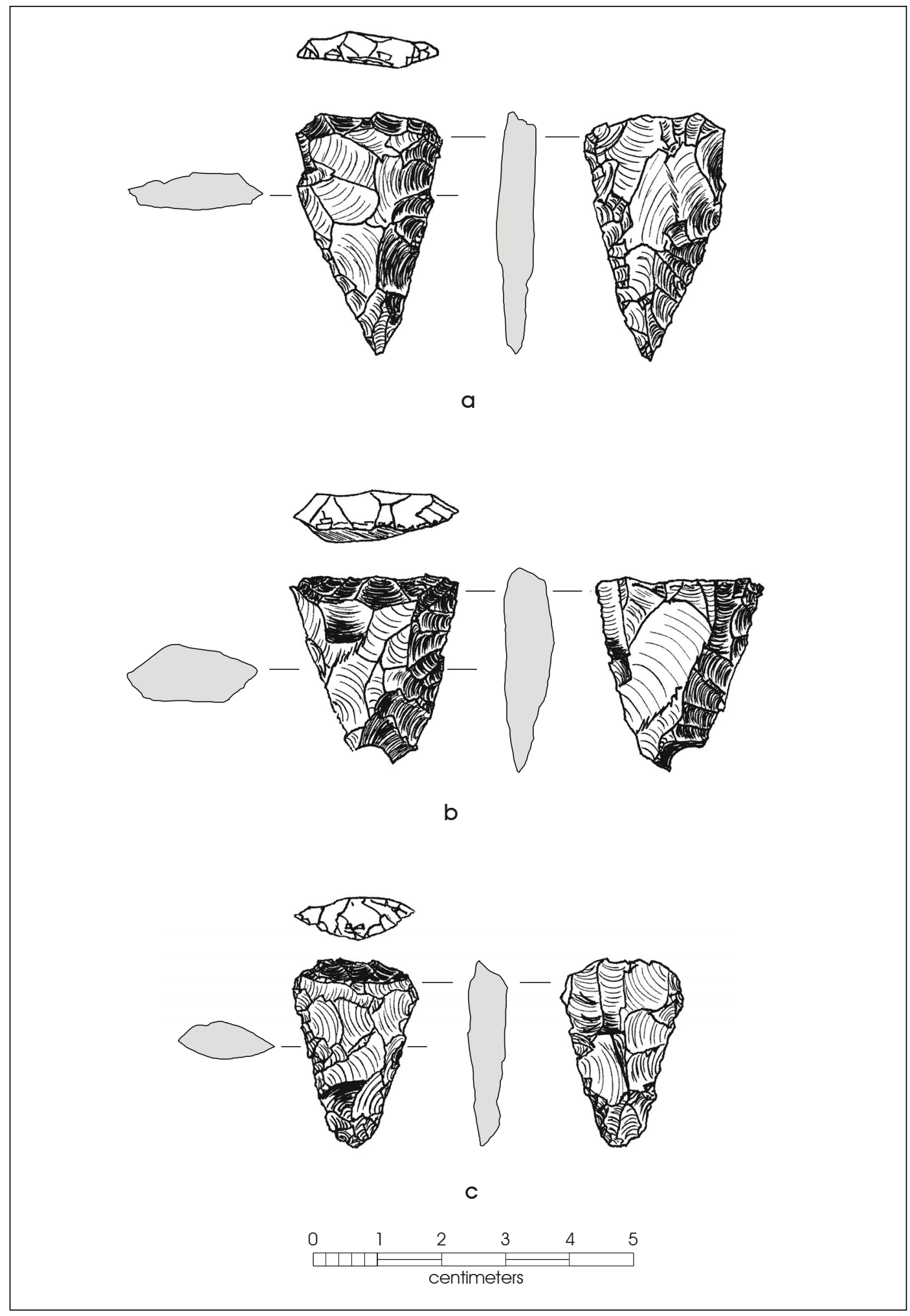

Figure 54. Olmos bifaces with burin scars off the corners of the working edges-also note transverse cross-sections and step fracturing off distal faces of working edges. 
The classification of the 289 round-base points based on the technological criteria described above resulted in 96 points being classified as Abasolo points, 65 as Refugio points, 86 specimens classified as Catán points, 29 as Desmuke points, and 13 as indeterminate specimens. As the historical overview section indicated, the primary morphological difference between the Catán and Abasolo types is that by definition the Catán points tend to be specimens less than $40 \mathrm{~mm}$ in maximum length, while Abasolo tend to be specimens greater than $40 \mathrm{~mm}$ in maximum length. When these criteria are applied to the classification of the 182 points previously classified as Abasolo or Catán, 98 specimens are classified as Abasolo and 84 are classified as Catán. More importantly, a total of 13 specimens (13.5\% of original group) previously classified as Abasolo are reclassified as Catán, and 16 specimens (19\% of original group) classified as Catán are grouped with Abasolo. The following section compares the Tortugas-Matamoros and Abasolo-Refugio-Catán type groups in terms of metric attributes and discusses the typological and functional implications of the patterns in these attributes.

The mean maximum length of complete Tortugas points is $51.7 \mathrm{~mm}$, with a range between $77.1 \mathrm{~mm}$ and $41 \mathrm{~mm}$. The median value is $50 \mathrm{~mm}$, while the mode is $41 \mathrm{~mm}$. The plot of the maximum lengths of the complete Tortugas points divided into $2 \mathrm{~mm}$ categories (Figure 55) indicates that the distribution is not normal and is right-skewed. The normal distribution curve is overlain on the histogram to show the deviations from normal. The mean maximum length of Matamoros points is 34.4 $\mathrm{mm}$, with a range between $40.9 \mathrm{~mm}$ and $22.6 \mathrm{~mm}$. The median value is $35 \mathrm{~mm}$, while the mode is $36.9 \mathrm{~mm}$. The plot of the maximum lengths of the complete Matamoros points divided into $1 \mathrm{~mm}$ categories (Figure 56) indicates that the distribution is not normal and is left-skewed.

The mean maximum length of complete Refugio points is $57.3 \mathrm{~mm}$, with a range between 87.3 and $37.3 \mathrm{~mm}$. The median value is $57 \mathrm{~mm}$, while the mode is $44 \mathrm{~mm}$. The plot of the maximum lengths of the complete Refugio points (Figure 57) indicates that the distribution is roughly normal and approximates a bell-shaped curve. The mean maximum length of complete Abasolo points is $48.2 \mathrm{~mm}$, with a range between 65.7 and $40.3 \mathrm{~mm}$. The median value is $47 \mathrm{~mm}$, while the mode is $46.2 \mathrm{~mm}$.
The plot of the maximum lengths of the complete Abasolo points divided into $2 \mathrm{~mm}$ categories (Figure 58) indicates that the distribution is not normal and is heavily right-skewed. The mean maximum length of complete Catán points is $35.4 \mathrm{~mm}$, with a range between $40.8 \mathrm{~mm}$ and $26.2 \mathrm{~mm}$. The median value is $36.2 \mathrm{~mm}$, while the mode is $38.8 \mathrm{~mm}$. The plot of the maximum lengths of the complete Catán points divided into $2 \mathrm{~mm}$ categories (Figure 59) indicates that the distribution is not normal and is left-skewed.

These aspects of the distributions illustrate the fact that the respective types within the triangular and round-base projectile point samples are artificially derived by dividing a continuum of sizes into small and large subgroupings or, in this case, types. Among the triangular Tortugas and Matamoros points, neither type represents a normal population. The right tail of the Matamoros distribution is missing as is the left tail of the Tortugas distribution. Among the round-base points, the distributions indicate that with the possible exception of the Refugio type, neither of the other two represent a normal population described by a bell-shaped curve. The Abasolo distribution seems to be missing the smaller sized specimens at the left side of the distribution, while the Catán distribution seems to be missing the larger specimens at the right side of the plot.

Not surprisingly, however, when the two triangular point samples are combined the resulting population has a distribution that approximates normal more closely by having both tails of the distribution (Figure 60). The same observation holds true for the three round-base point types (Figure 61). These aspects of the distributions simply illustrate the fact that the Matamoros-Tortugas and Abasolo-Catán populations are based on an artificial distinction in size. The relatively normal distribution of Refugio points may result from the possibility that some narrower Abasolo points are included in the Refugio category while the smaller of the Refugio are misclassified as Catán points, since only two Refugio points have been identified in the sample. As in the case of the Tortugas and Matamoros points, the critical aspect of these results is that a simple size-based division between the two types does not allow the clear-cut recognition of changes in types resulting from resharpening and rejuvenation. 


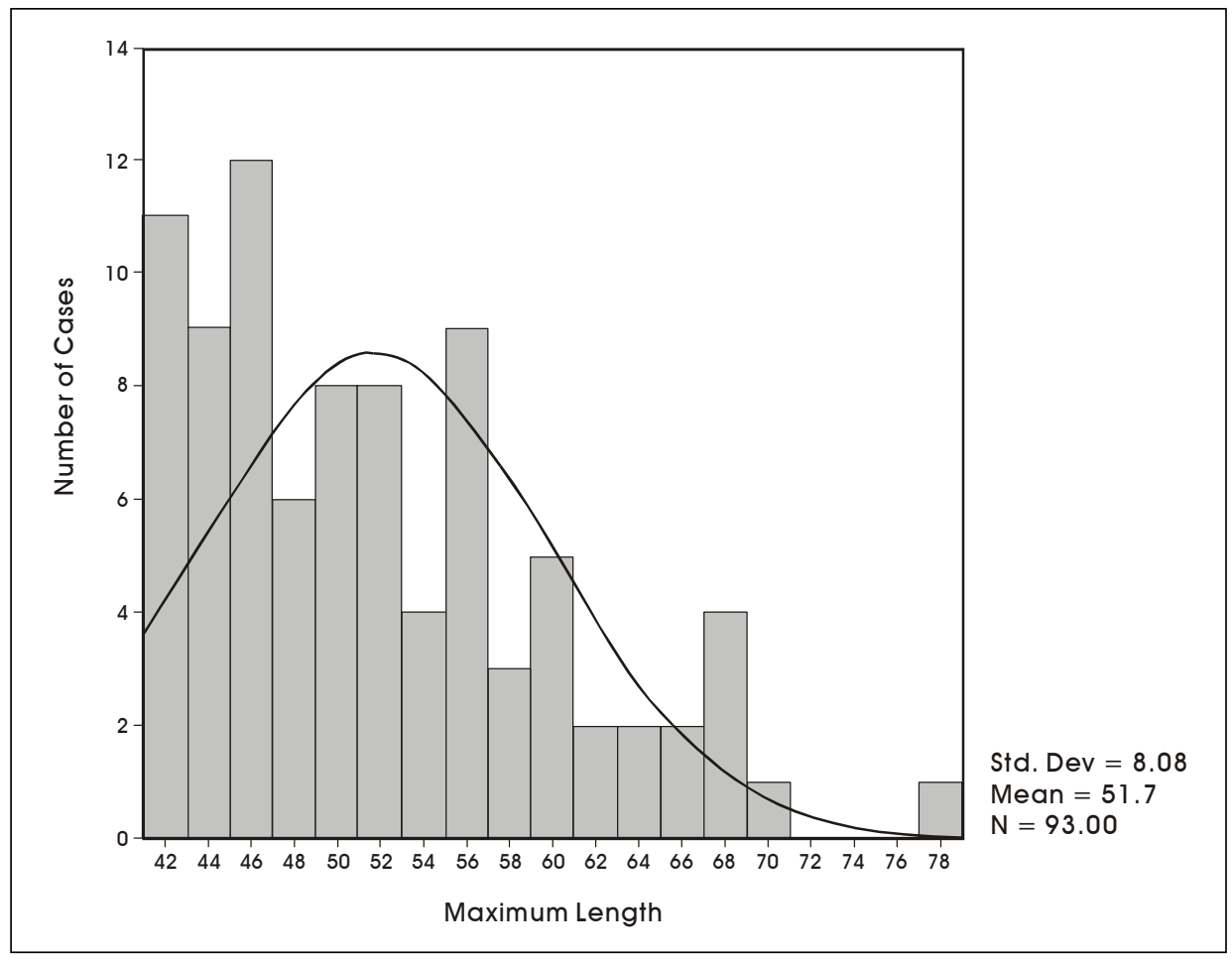

Figure 55. Maximum lengths of complete Tortugas points.

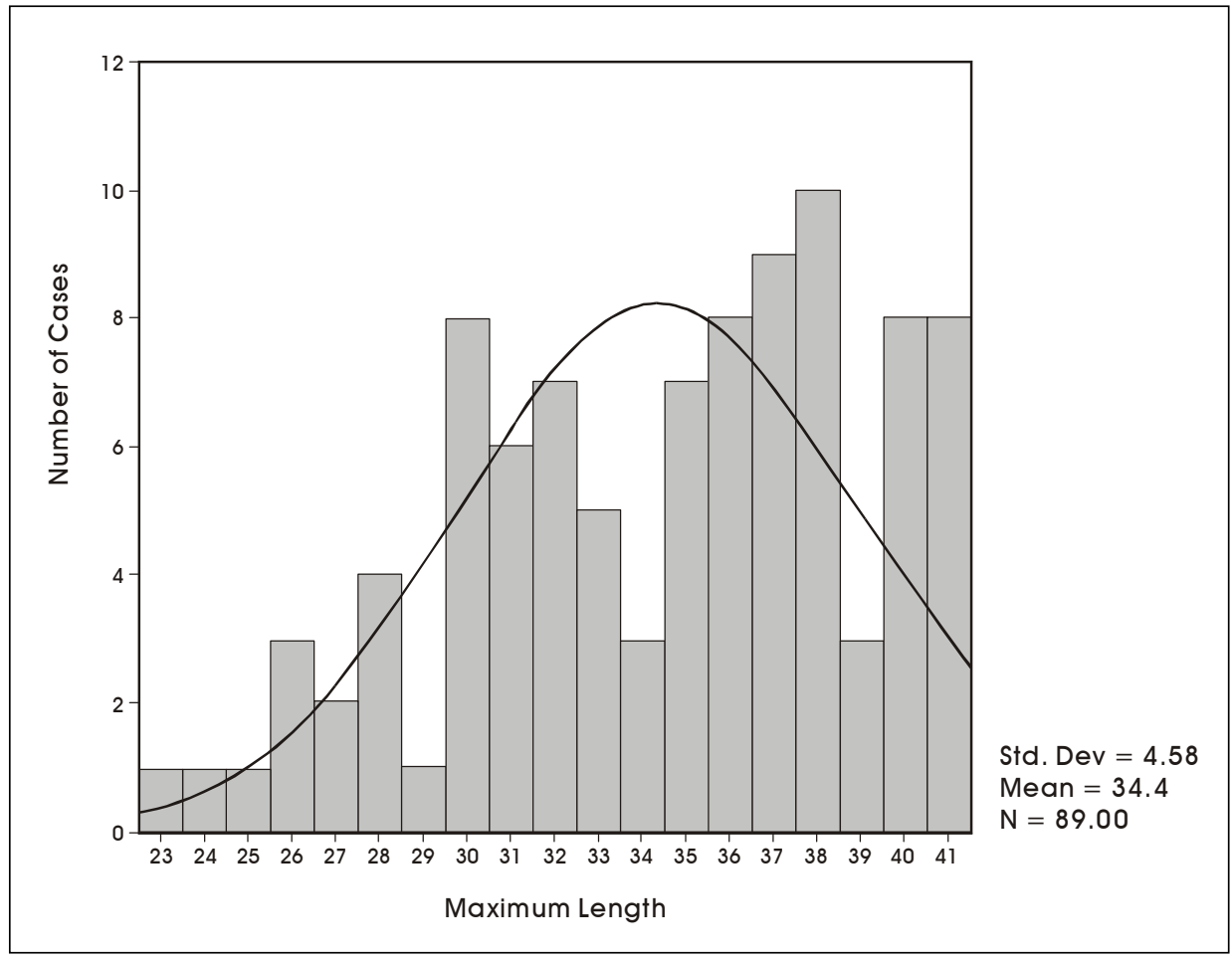

Figure 56. Maximum lengths of complete Matamoros points. 


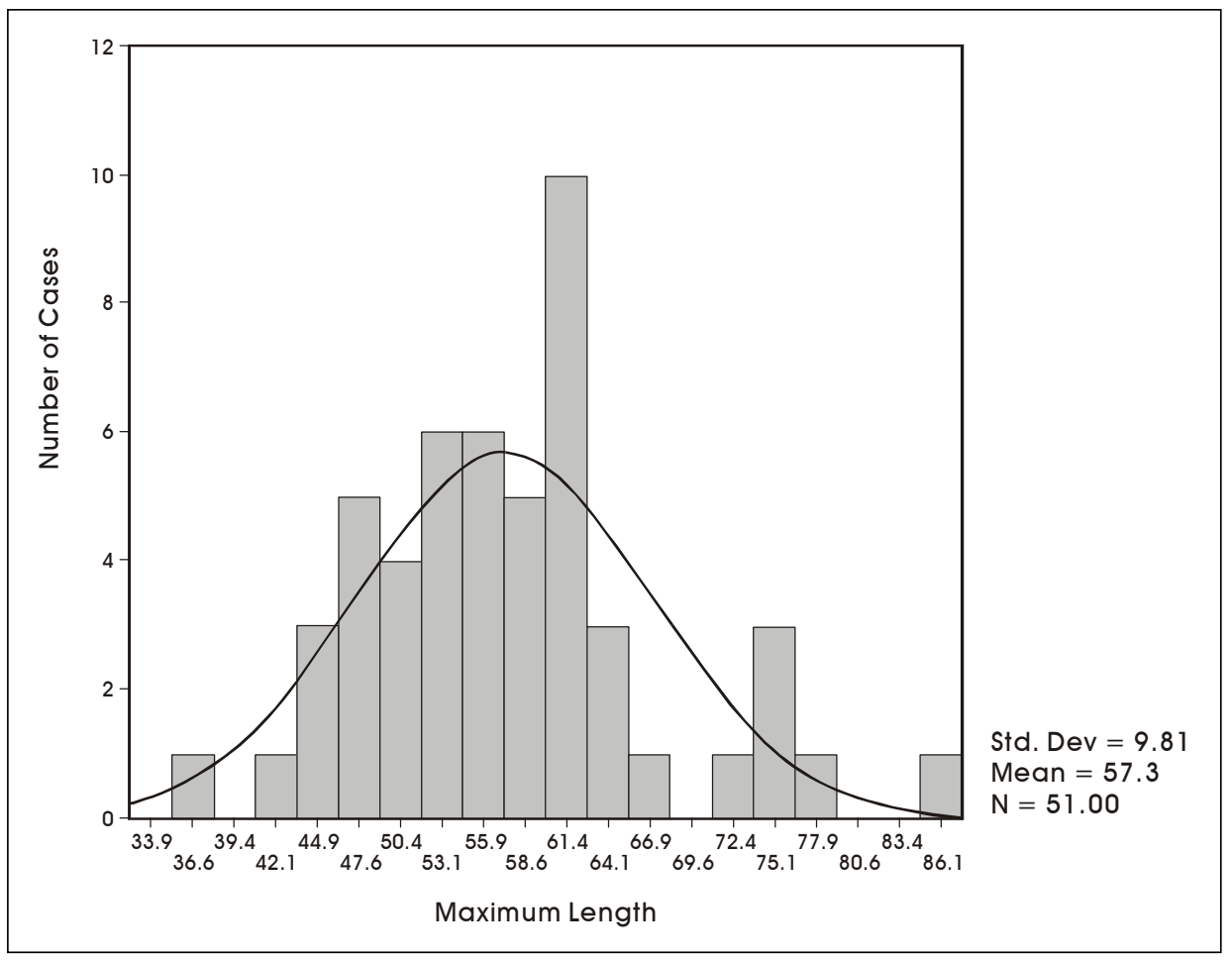

Figure 57. Maximum lengths of complete Refugio points.

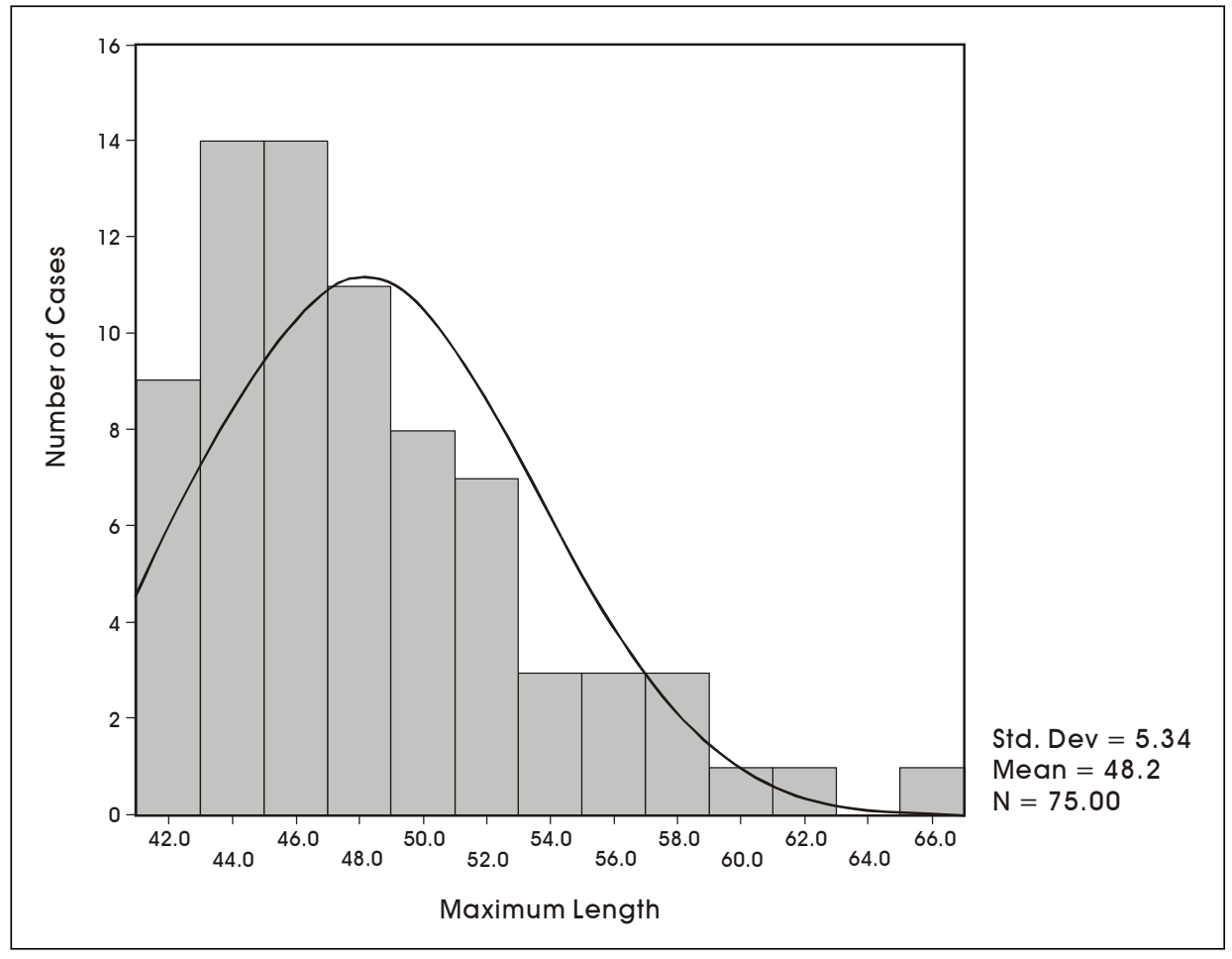

Figure 58. Maximum lengths of complete Abasolo points. 


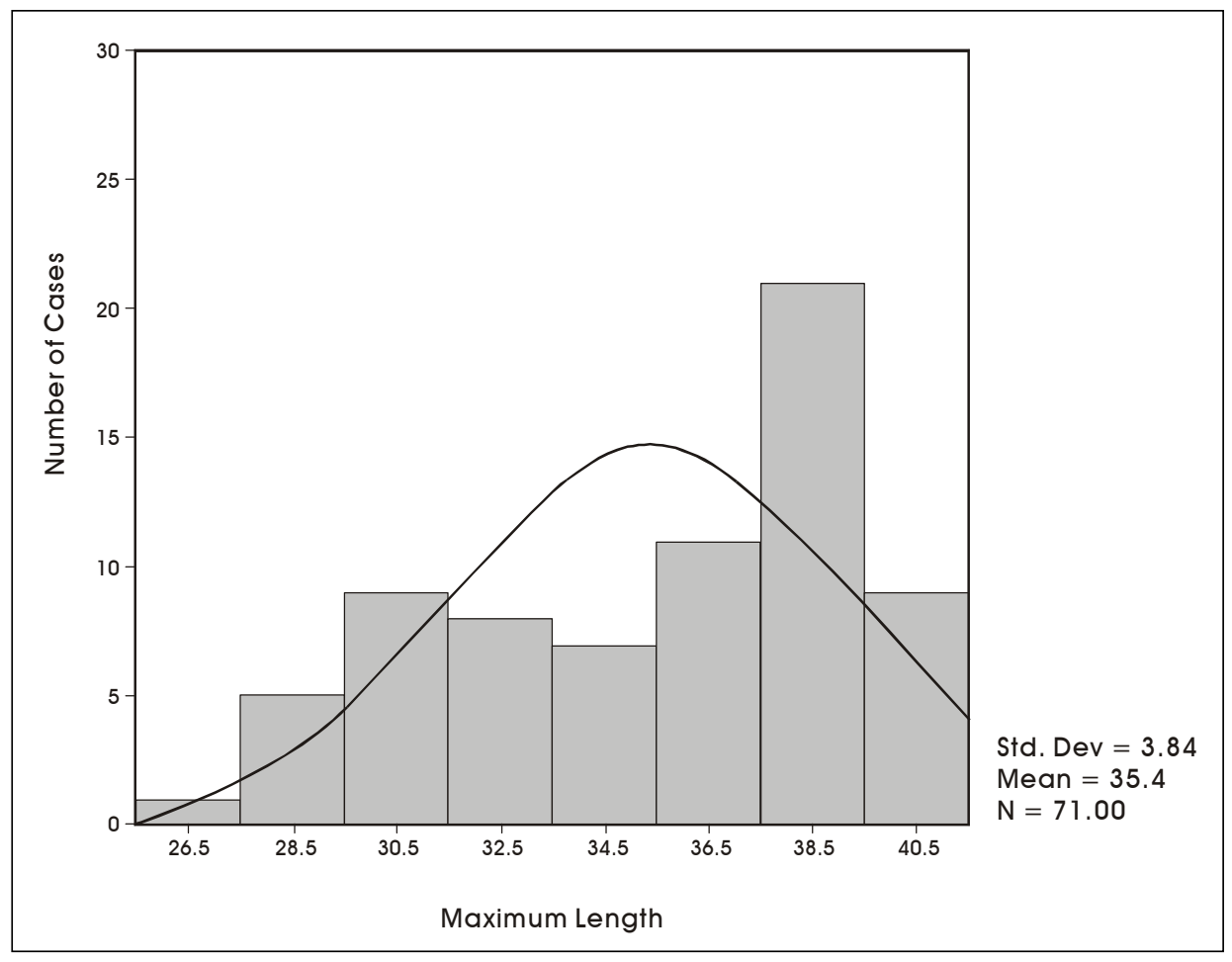

Figure 59. Maximum lengths of complete Catán points.

The mean maximum width of the complete Tortugas points is $28.8 \mathrm{~mm}$, with a range between $42.9 \mathrm{~mm}$ and $18.3 \mathrm{~mm}$. The median value is $28.2 \mathrm{~mm}$, while the mode is $21.8 \mathrm{~mm}$. The plot of the maximum widths of the Tortugas specimens, divided into $2 \mathrm{~mm}$ categories (Figure 62) shows a roughly normal distribution closely approximating a bell-shaped curve. The mean maximum width of the complete Matamoros points is $23 \mathrm{~mm}$, with a range from $35 \mathrm{~mm}$ to $16.4 \mathrm{~mm}$. The median is 22.8 $\mathrm{mm}$, and the mode is $24.1 \mathrm{~mm}$. As in the case of the Tortugas points, the plot of the maximum widths is normal and has a bell shape (Figure 63).

The mean maximum width of the complete Refugio points is $22.1 \mathrm{~mm}$, with a range between $29.9 \mathrm{~mm}$ and $7.4 \mathrm{~mm}$. The median value is $22.3 \mathrm{~mm}$, while the mode is $20.4 \mathrm{~mm}$. The plot of the maximum widths of the Refugio specimens (Figure 64), divided into $2 \mathrm{~mm}$ categories, shows a non-normal distribution that is heavily skewed to the left. Nonetheless, it is evident that only four Refugio specimens are $18 \mathrm{~mm}$ or narrower in the sample. The mean maximum width of the complete
Abasolo points is $24.1 \mathrm{~mm}$, with a range from $34 \mathrm{~mm}$ to $17.8 \mathrm{~mm}$. The median and mode are both $23.4 \mathrm{~mm}$. The plot of the maximum widths is right skewed (Figure 65). Only eight Abasolo specimens in the sample are narrower than $19 \mathrm{~mm}$ in maximum width. The mean maximum width of the complete Catán points is $21 \mathrm{~mm}$, with a range from $26.4 \mathrm{~mm}$ to $16.1 \mathrm{~mm}$. The median is 10.9 and the mode is $19.7 \mathrm{~mm}$. The plot of the maximum widths is normal (Figure 66).

While the maximum length distribution patterns are not normal and exhibit the affects of arbitrarily defining small and large types within both the triangular and subtriangular forms, the patterns in maximum width distributions do not appear to show this effect in either of the broad groups. The pattern indicates that regardless of what size group of points one examines, within the group (i.e., Matamoros, Tortugas, Abasolo, Catán) there will be some very broad as well as some very narrow points. This pattern is the product of two factors affecting projectile point morphology. During their use-life projectile points continually undergo resharpening. As 


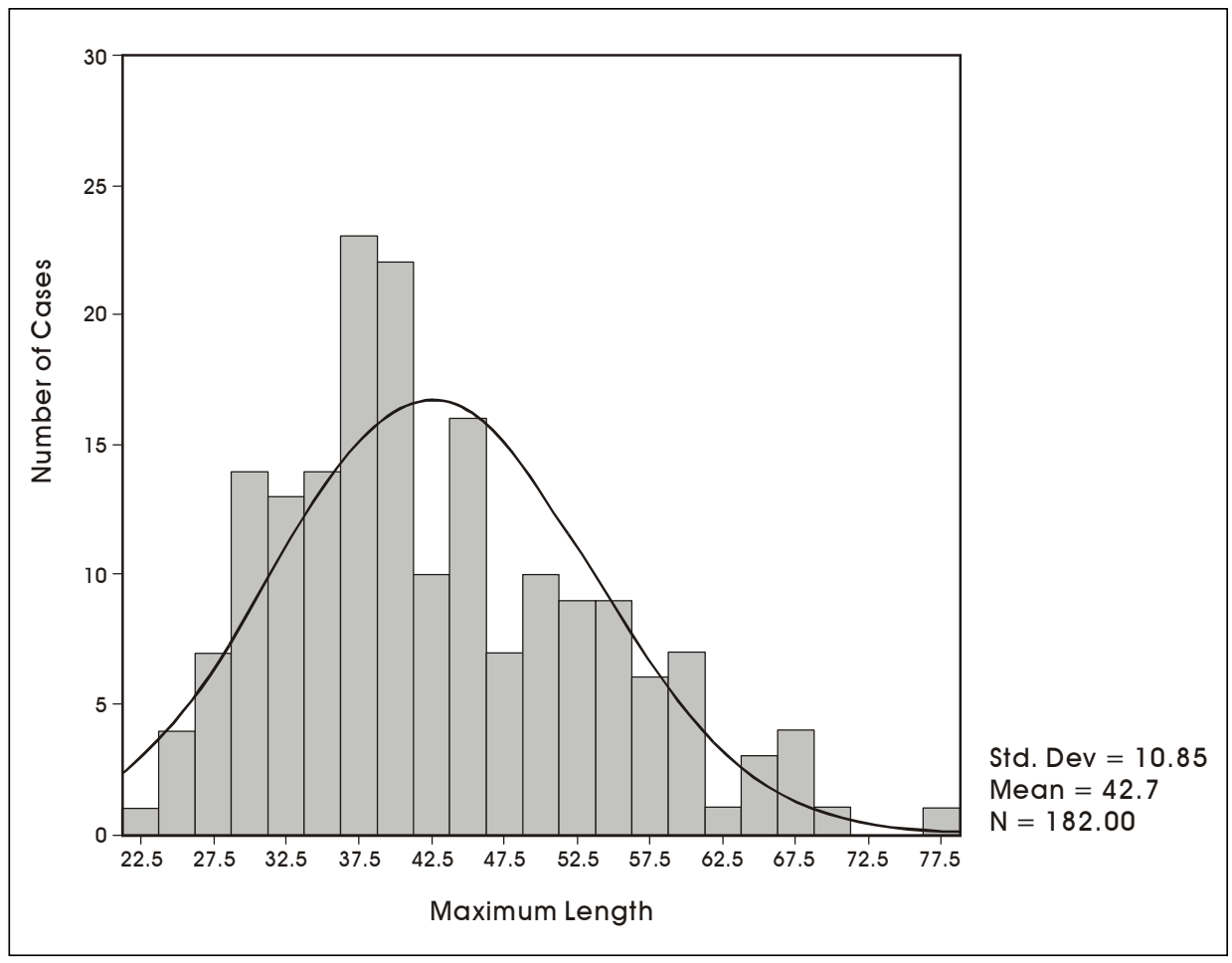

Figure 60. Maximum lengths of complete Tortugas and Matamoros points.

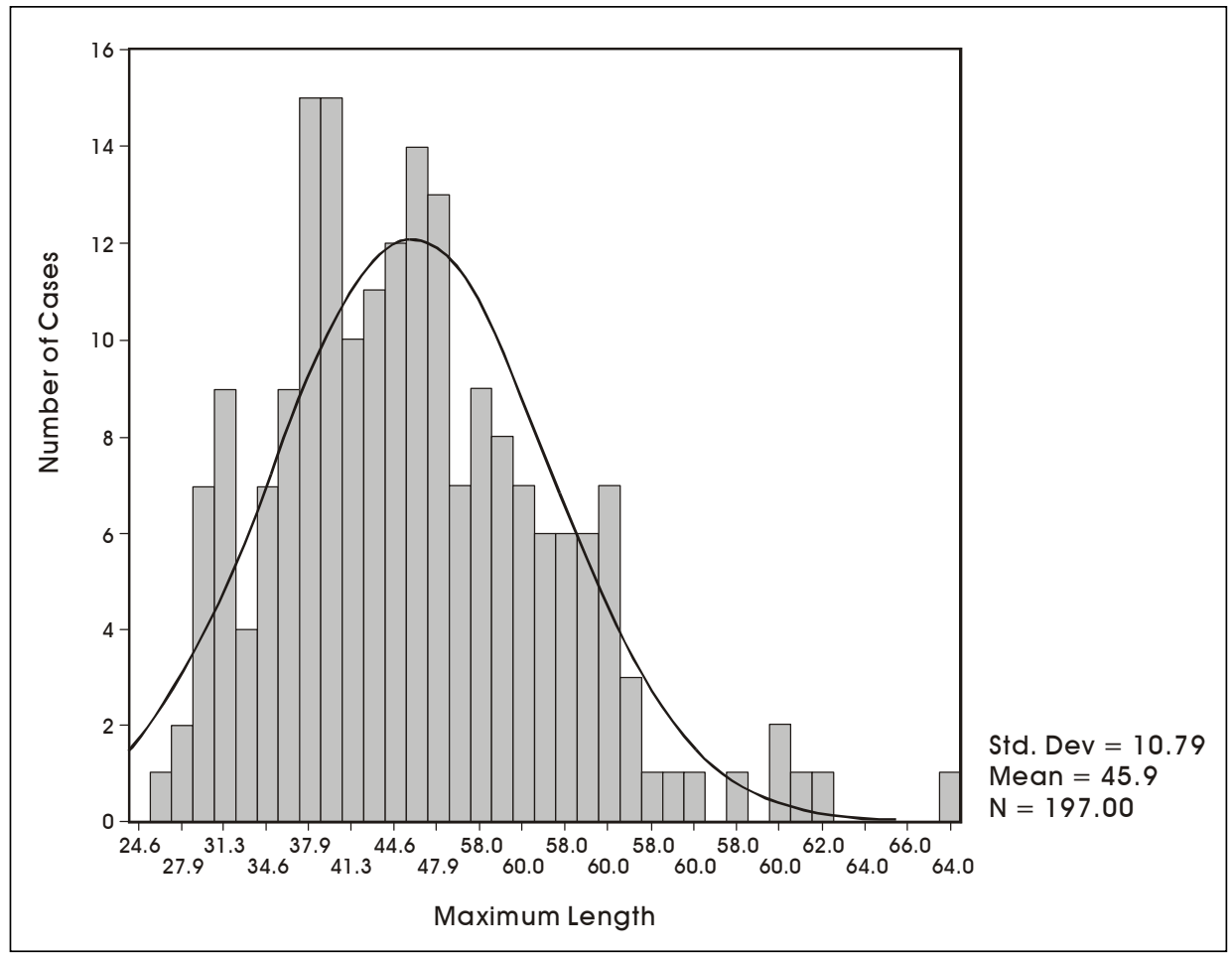

Figure 61. Maximum lengths of complete Abasolo, Catán, and Refugio points. 


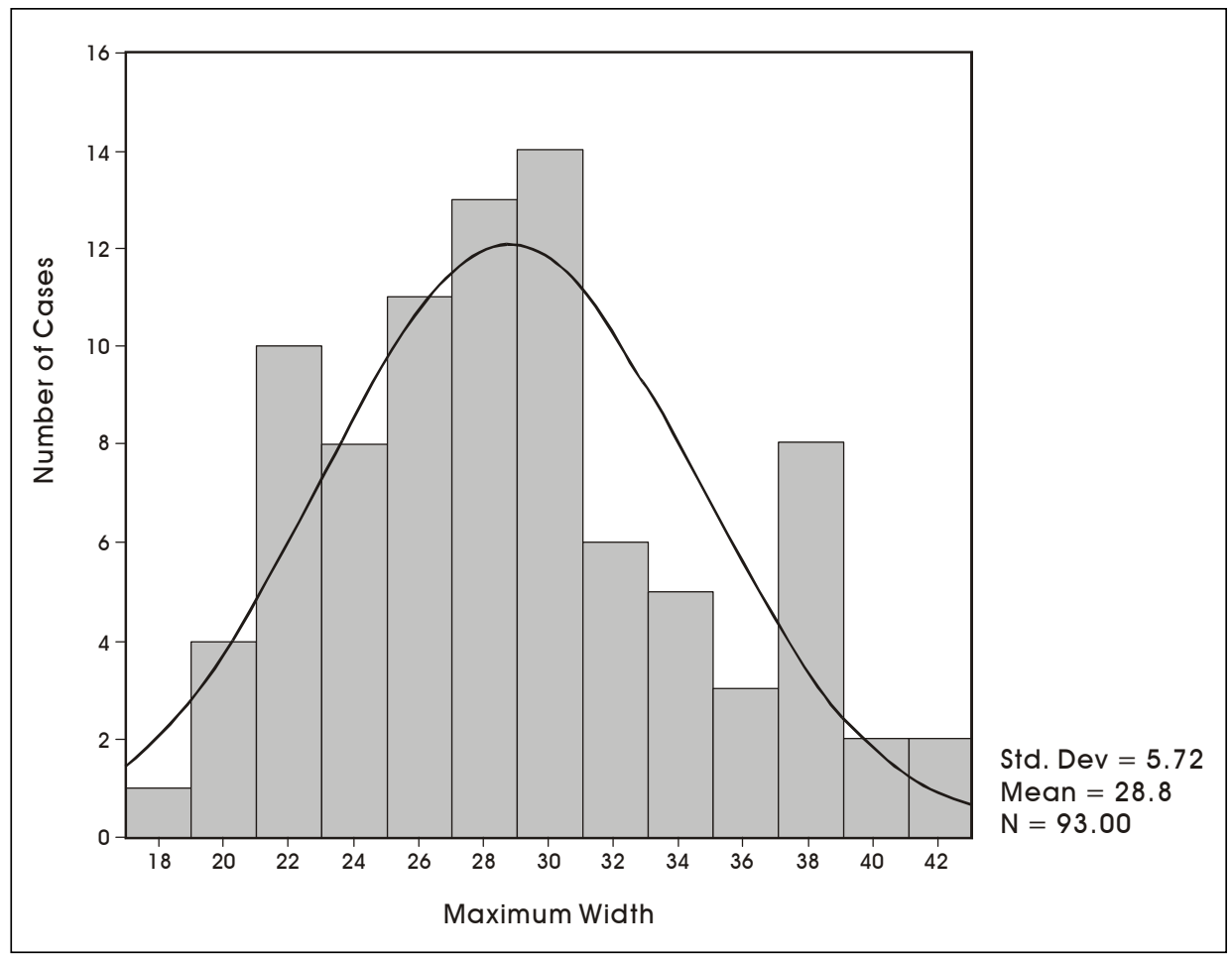

Figure 62. Maximum widths of complete Tortugas points.

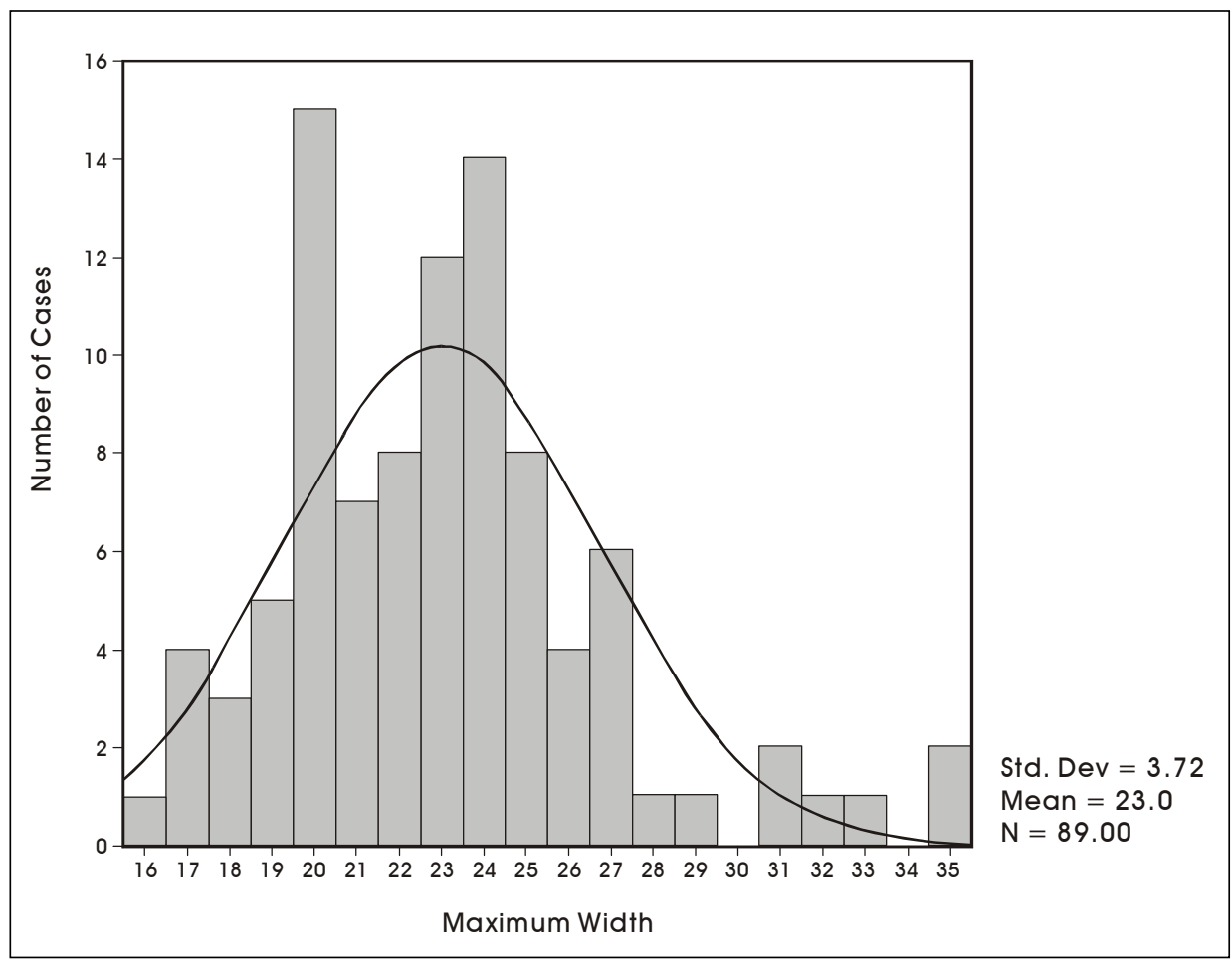

Figure 63. Maximum widths of complete Matamoros points. 


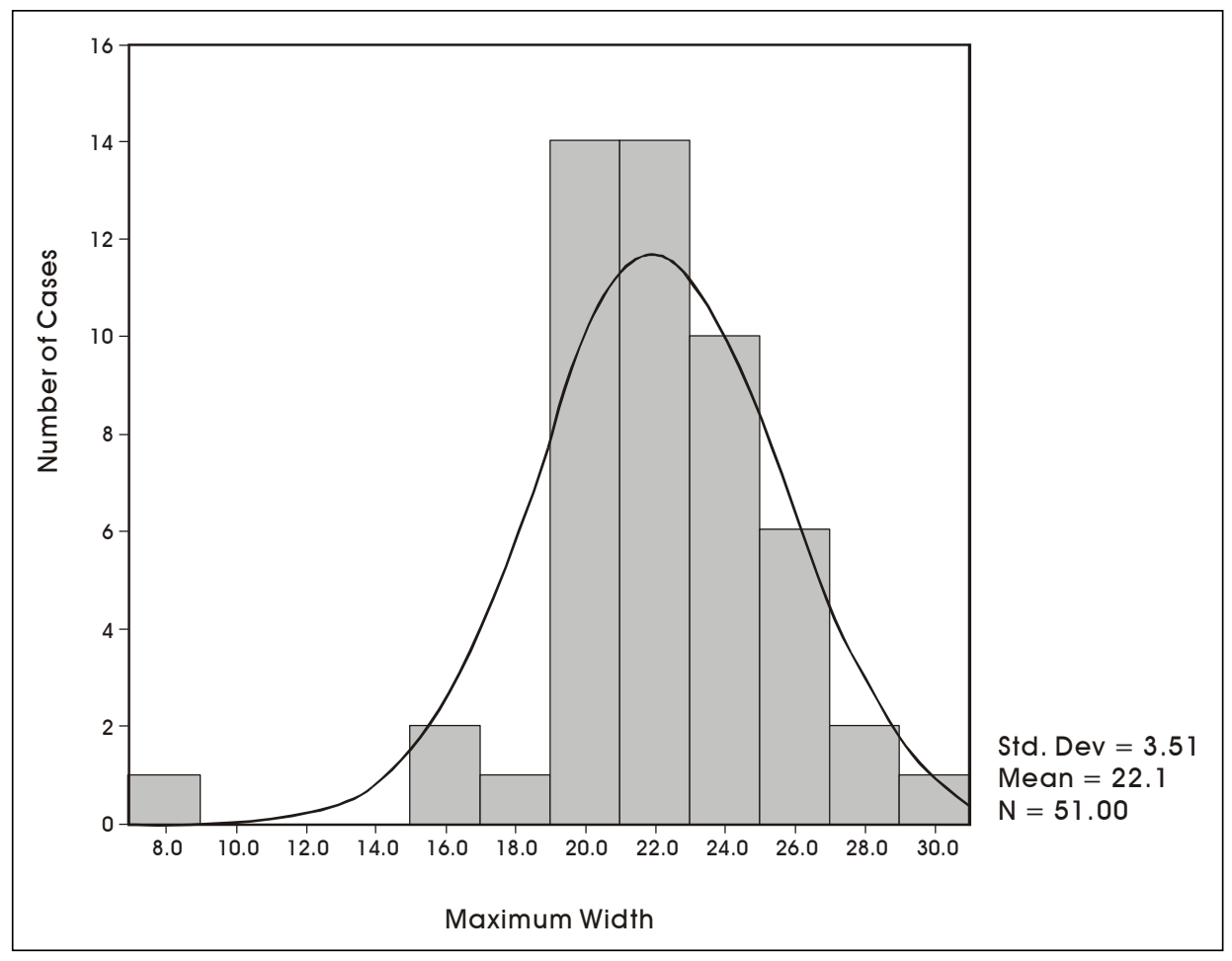

Figure 64. Maximum widths of complete Refugio points.

mentioned before, since resharpening affects the entire length of the point, it results in both a gradual narrowing as well as shortening of the projectile point with each resharpening episode. In addition, because some broken proximal fragments are rejuvenated into newly functional specimens through repointing, some relatively short but broad points are also introduced into the TortugasMatamoros and Abasolo-Catán groups. The combination of the two avenues of returning ineffective or failed points to a functional state appears to result in the normal distribution of maximum widths within both groups.

As described in the historical overview section, an additional aspect of the South Texas projectile point typology is the tendency on the part of some archeologists to define varieties within both the triangular and the roundbase points. The next section considers the analytical utility of these projectile point varieties in light of the technological aspects and typological implications mentioned above. Although, for the sake of brevity, the discussion will focus only on varieties within the triangular types, the general trends and conclusion presented apply to both triangular and round-base point types.
To define variants within the Matamoros and Tortugas points recovered from Cueva de la Zona de Derrumbes, McClurkan (1966) used differences in width/length ratios within and between types and variants. The width/length ratio (referred to as length/width ratio in McClurkan 1966) employed by McClurkan was derived by dividing the mean maximum width by mean maximum length and presenting the product as a whole number. The resultant width/length ratios and their relationships to types and variants are described in the historical section discussing the origins of the common South Texas types and will be referred to in this section as appropriate.

The plot of the width/length ratios for all complete Tortugas points (Figure 67) indicates that the mean ratio is 56 , that is, the maximum width of the specimen represents 56 percent of the maximum length of the point. Interestingly, only four specimens have ratios equal to or higher than 75 , meaning that in the case of these specimens, the width represents at least 75 percent of the length. The four specimens (5\%) have a mean length of $46.8 \mathrm{~mm}$ and a mean width of $36.3 \mathrm{~mm}$. These specimens are relatively broad compared to their length 


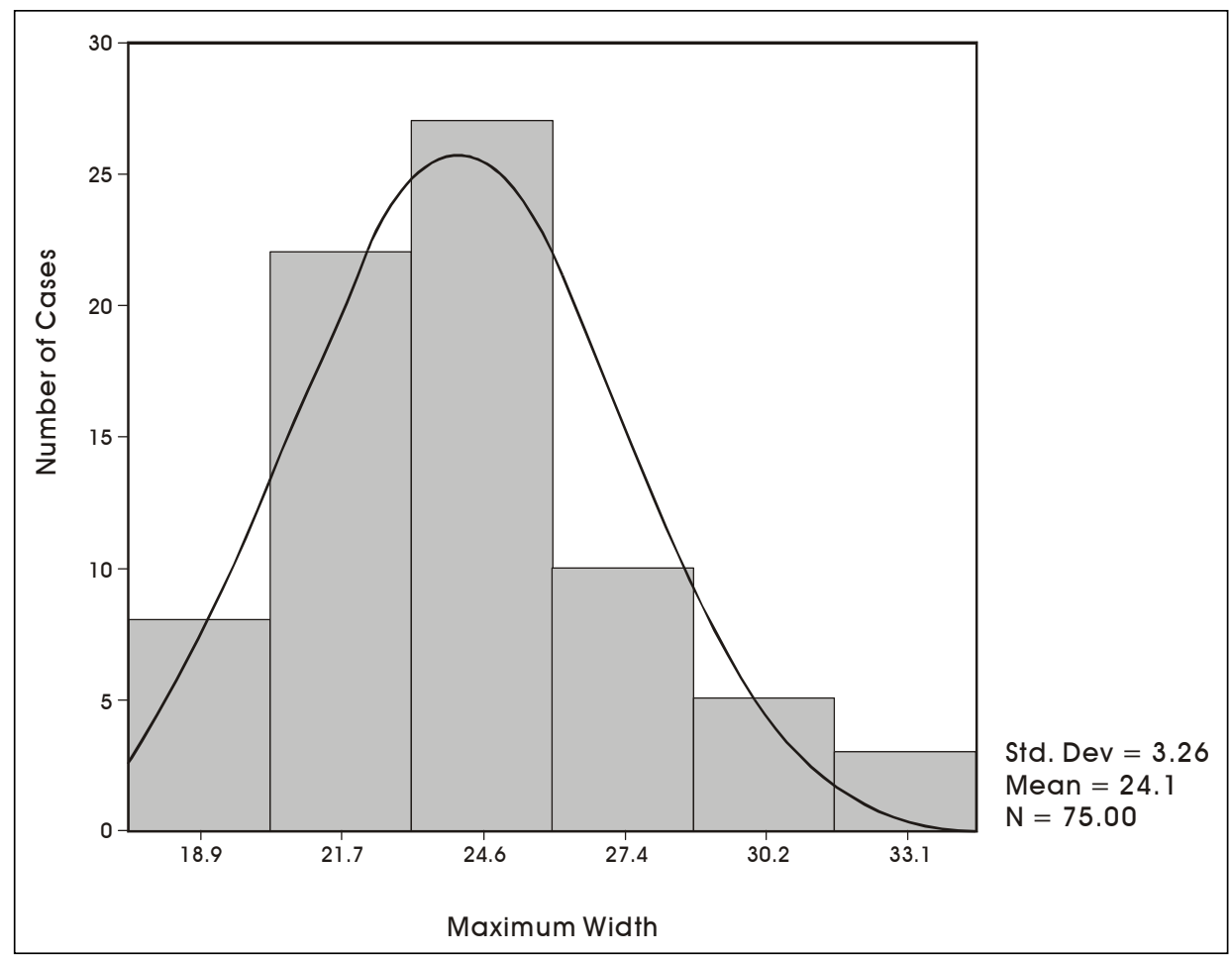

Figure 65. Maximum widths of complete Abasolo points.

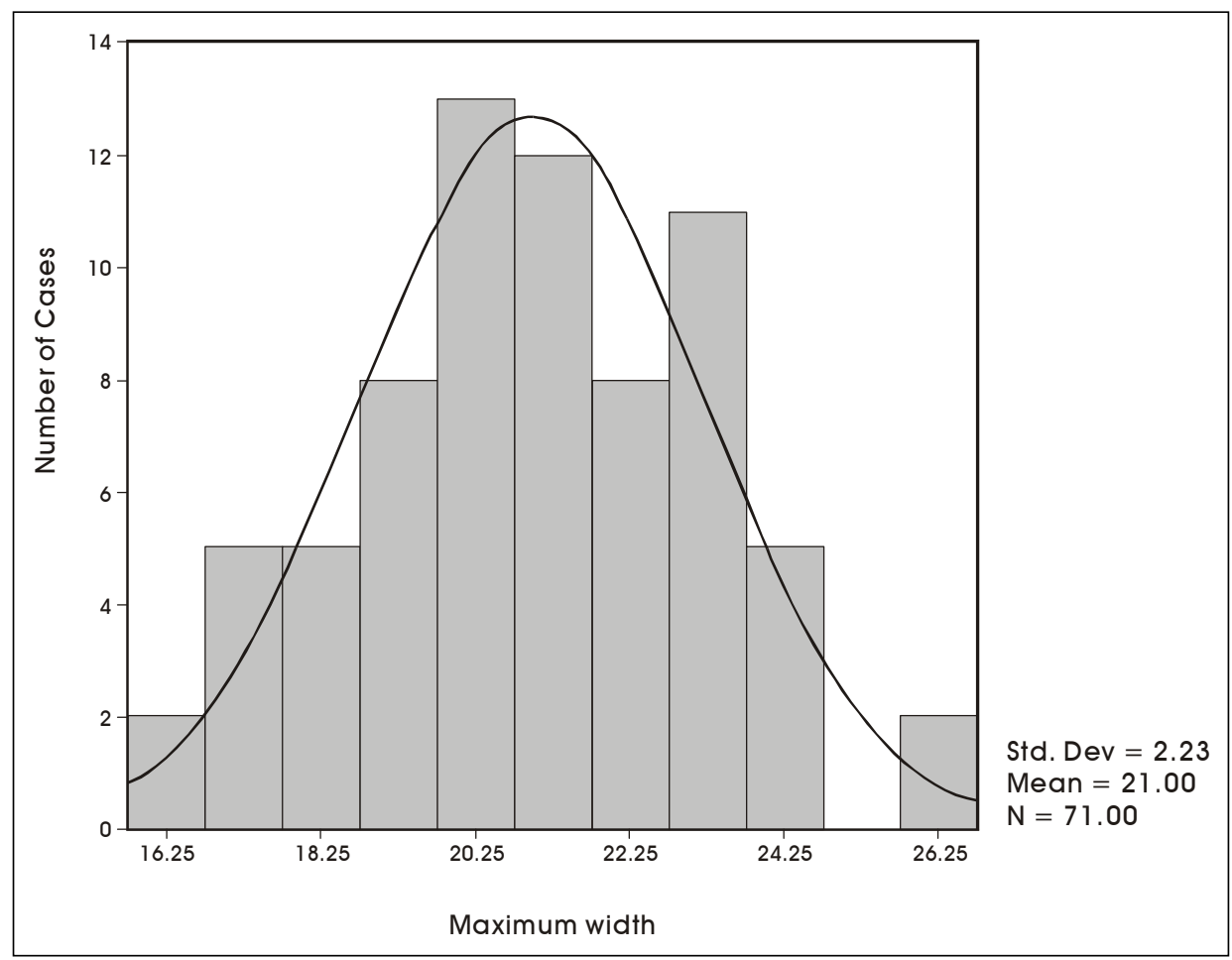

Figure 66. Maximum widths of complete Catán points. 
and approximate the characteristics of the Tortugas Variety II specimens defined by McClurkan (1966). At the opposite end of the ratio distribution, there are 28 specimens (32\%) that have ratios of 50 or less, indicating that the width of the points constitutes 50 percent or less of the length. These 28 specimens have a mean length of $53.8 \mathrm{~mm}$ and a mean width of $24.6 \mathrm{~mm}$. These specimens are somewhat longer and more than $10 \mathrm{~mm}$ narrower than those in the earlier group. Sixty-eight percent $(n=59)$ of all of the Tortugas points have maximum widths that are greater than 50 percent of their lengths. These 59 specimens have a mean length of $50.7 \mathrm{~mm}$ and a mean width of $30.7 \mathrm{~mm}$.

To begin to understand how projectile point design may be related to tool use it would be ideal to know the dimensions and/or ratios of new points (those that have not been resharpened). There are three Tortugas points that do not exhibit resharpening scars in the sample. Their mean width/length ratio is 65.8 , the mean length of the points is 54.7 while their mean width is 36 . On the other hand, the mean width/length ratio of four preforms from 41WB314 (PTs 2, 5, 6, and 8 in Miller et al. 2000:Table 7.31) is 47.3 , with the mean length being $71.4 \mathrm{~mm}$ and the mean width $33.8 \mathrm{~mm}$. These figures are somewhat more similar to the width/length ratio of the 12 longest Tortugas specimens in this sample. Their mean ratio is 52.2 , with the mean length of the specimens being $66.6 \mathrm{~mm}$ and their mean width being $34.8 \mathrm{~mm}$. Although not clearcut, perhaps these samples indicate that Tortugas points are made relatively long and broad. The length assures that the tool has an efficient cutting edge, and when the blade finally fails, it still leaves a relatively long portion of the point available for rejuvenation. A broad blade ensures relatively long use-life through repeated resharpenings. Although some newly made points may start out relatively long compared to their width (i.e., with low width/length ratios), once the tips break and the points are rejuvenated they may quickly be transformed into specimens with high width/length ratios, that is, into specimens with widths greatly exceeding their lengths.

The plot of the width/length ratios for all complete Matamoros points (Figure 68) indicates that the mean ratio is 67.4 , that is, the maximum width of the specimen

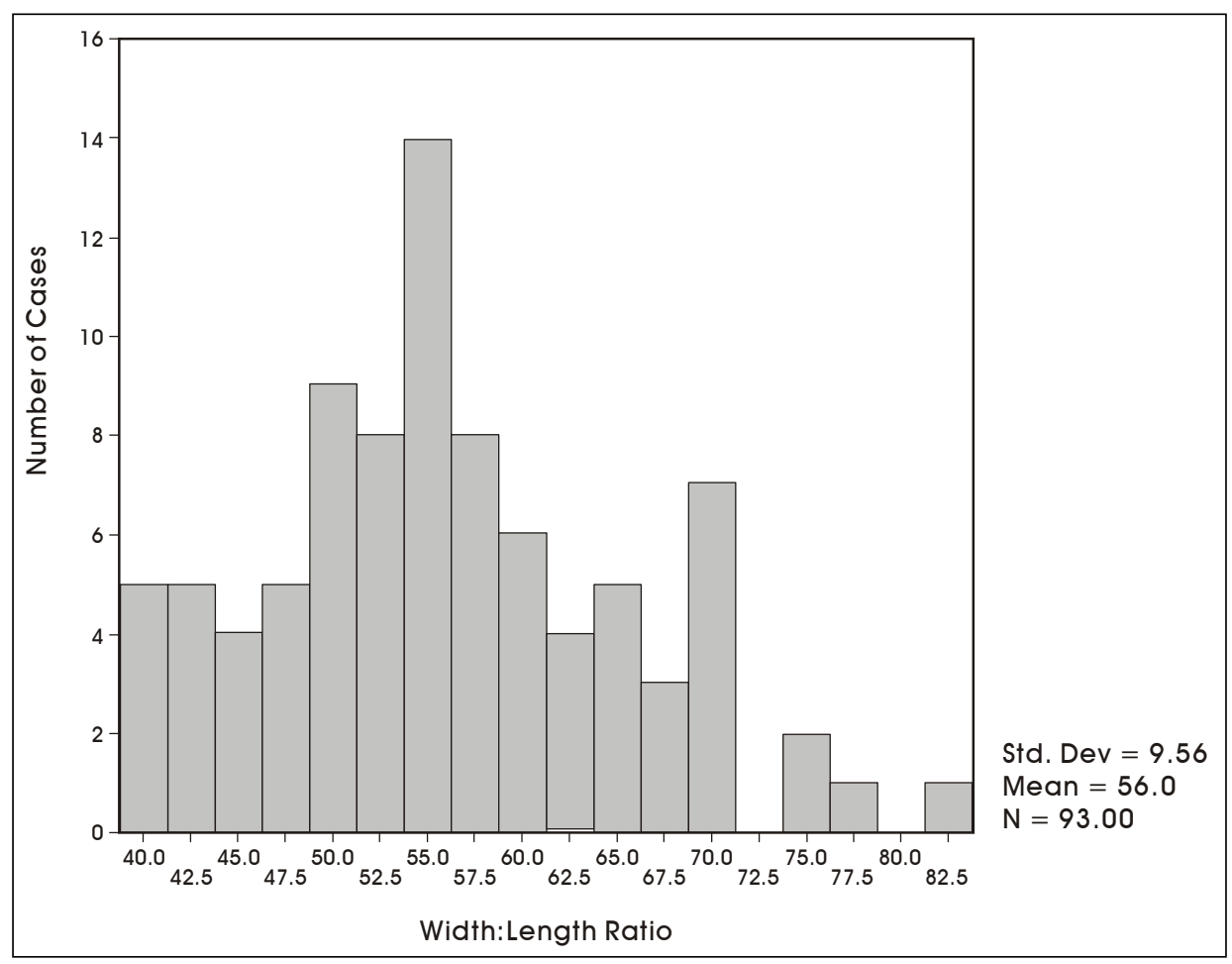

Figure 67. Width/Length ratios for Tortugas points. 
represents 67 percent of the maximum length of the point. These points tend to be relatively broad compared to their length. Nineteen specimens $(20 \%)$ have ratios equal to or higher than 75 , meaning that their widths represent at least 75 percent of their lengths. The nineteen specimens have a mean length of $31.1 \mathrm{~mm}$ and a mean width of $26 \mathrm{~mm}$. These points closely approximate the metric characteristics of Tortugas Variety II points defined by McClurkan (1966). At the opposite end of the ratio distribution, there are only two specimens that have ratios of 50 or less, indicating that the width of the points constitutes 50 percent or less of the length. The two specimens have a mean length of $36 \mathrm{~mm}$ and a mean width of $18.8 \mathrm{~mm}$. These two specimens are somewhat longer and narrower than those in the earlier group. Overall, ninety-eight percent $(\mathrm{n}=93$ ) of the Matamoros points have maximum widths that are greater than 50 percent of their lengths. These specimens have a mean length of $34.4 \mathrm{~mm}$ and a mean width of $23 \mathrm{~mm}$. As a group, the Matamoros points are in general much broader with respect to their length than the Tortugas points.
Whether one views these smaller points as Matamoros or heavily resharpened Tortugas, it is more significant to note what aspects remain functional and what may have led to the discard of these specimens. As projectile points, although the thickness of the points may reduce blade failure rates, the thickness of the distal ends, particularly near the tip, also may reduce penetration. This reduction in penetration may be countermanded by the narrowness of the smaller forms versus the larger Tortugas type. The broad widths of the points, relative to their blade lengths, indicates that they may continue to have remnant use-life and may allow for further use. Nonetheless, the short length of the cutting edge may severely limit the effectiveness of the tool as a cutting instrument. Given that these smaller forms may have functioned as projectile points with reasonable effectiveness, and with reduced failure rates, it is likely that their high rate of discard may be due to their decreased effectiveness as elements of compound cutting instruments (i.e., short blade length).

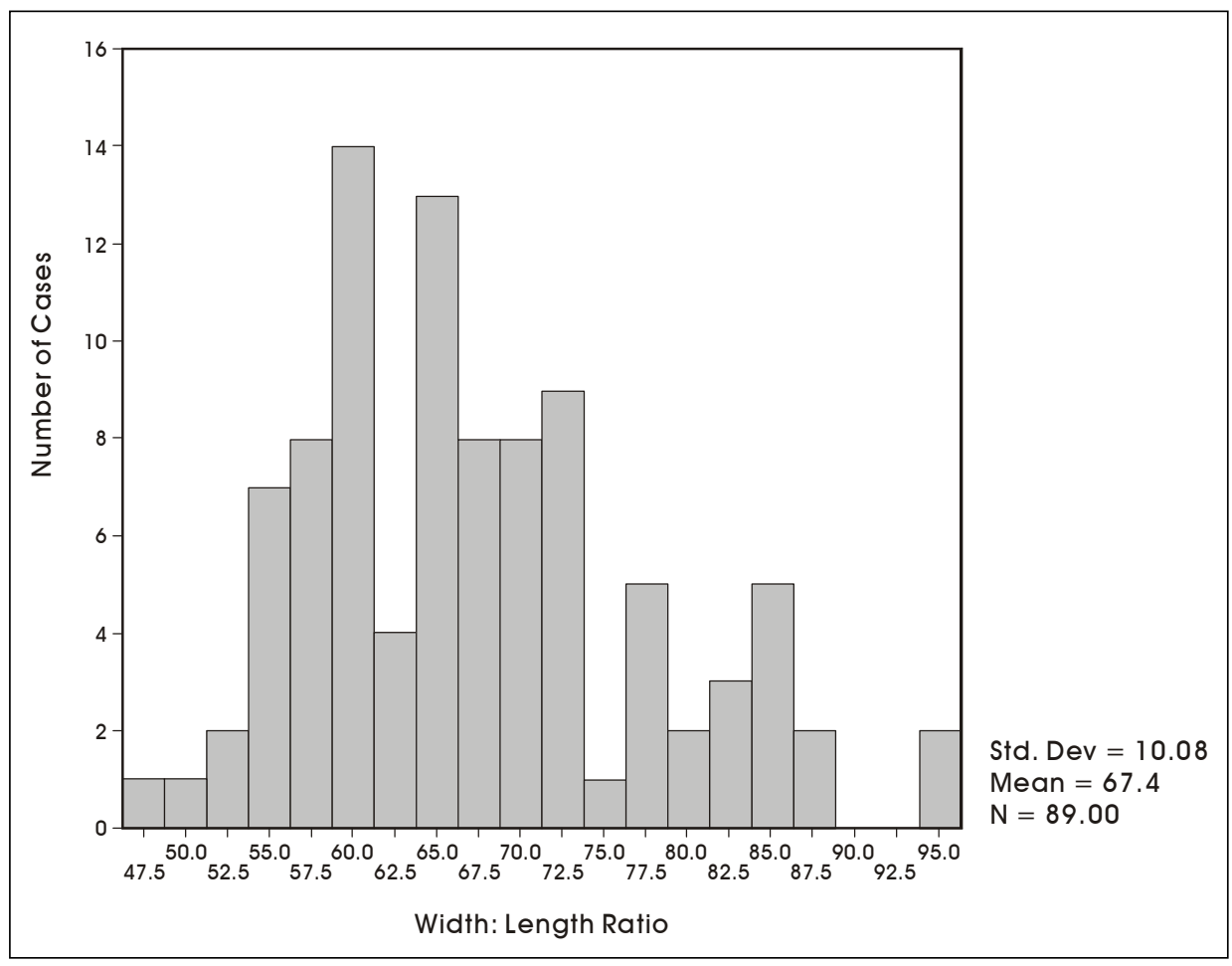

Figure 68. Width/Length ratios for Matamoros points. 


\section{Summary and Theoretical Considerations}

Overall, the historical review of the round-based (Abasolo, Catán, and Refugio) and triangular (Tortugas and Matamoros) projectile points indicates that, for typological purposes, each form has been divided into larger and smaller types (i.e., Abasolo and Catán; Tortugas and Matamoros). Based on MacNeish's original work, it appeared that the larger types exceeded $40 \mathrm{~mm}$ in maximum length while the smaller types were less than $40 \mathrm{~mm}$ in maximum length. In addition, MacNeish's (1958) excavations have suggested that the larger of the forms preceded the smaller forms, at least in Tamaulipas. Based on a handful of sites where the four point types have been recovered in situ (i.e., Loma Sandia; 41LK31/ 32; 41ZP364; 41WB314), it has been assumed that the general temporal affiliation of the larger and smaller forms of these triangular and subtriangular forms also applies to South Texas.

Projectile point types are analytical constructs defined by archeologists. Therefore, there is nothing inherently wrong with arbitrarily defining types based on size. The difficulty arises when the larger and smaller forms are employed as index markers indicative of the chronological position of one or another archeological manifestations. The technological and simple statistical analyses conducted here indicate that, at least in technological terms, there is a strong connection between the larger and smaller forms of morphologically similar types. In fact, the connections seem to be so strong that they suggest that many of the smaller points that are consistently typed as Catán and Matamoros based on the size criteria are simply heavily resharpened and rejuvenated versions of the larger forms (i.e., Abasolo and Tortugas). The implications of this statement for the continued use of the two smaller types as chronological markers is that they can no longer be employed as Late Archaic index markers with any degree of confidence. That is, assuming that small projectile points named by archeologists as Catán and Matamoros were really made during the Late Archaic, the rejuvenation and resharpening of Abasolo and Tortugas points, that were presumably made much earlier in time, results in the manufacture of small forms that would be consistently assigned to the Late Archaic.
High rates of projectile point resharpening may be encouraged by high hunter-gatherer mobility within a context of low lithic raw material predictability (see Paleoindian lithic technology). The triangular and subtriangular morphology of these forms may also decrease projectile point failure rates and encourage high rates of projectile point rejuvenation. That is, as Tortugas points are resharpened and rejuvenated their maximum thickness tends to move closer to their tip therefore reducing blade failure rates as well as shortening the segment of the blade that may fail. These aspects of projectile point design result in increased use-life and shorter projectile points at the time they are finally discarded. This pattern of resharpening and rejuvenation would account for the high frequencies of small complete triangular and subtriangular projectile points encountered on South Texas sites.

The prehistoric recycling of artifacts could further complicate site formation processes and typological assignments. Depositional settings throughout large portions of South Texas are not amenable to the formation of deeply stratified sites due to the lack of major streams. Many archeological assemblages remain exposed on surface for extended periods on relatively stable land surfaces. The high mobility of hunter-gatherers combined with the potentially unpredictable distribution of lithic resources may encourage the recycling of projectile points from exposed living surfaces and their continued use and rejuvenation and eventual incorporation into Late Prehistoric components where they would appear to have served as arrow points.

Another interesting and important outcome of this study relates to the nature of the distally beveled tool forms (Nueces tools and Olmos bifaces) and their technological and likely temporal relationship to other tools. This study indicates that at least the bifacially flaked Nueces tools may be manufactured from recycled bifacial artifact failures. Some of these artifacts may be bifaces that failed during the early to middle stages of reduction or projectile points that failed during use. Olmos bifaces seem to represent the apex of this strategy to recycle failed tools. The fact that a large proportion of these tools are made on failed alternately beveled dart point fragments is interesting since it suggests that either aspects of prehistoric land use, resource structure, or technological 
organization, have favored high rates of recycling of failed tools. The recycling of manufacture-failed bifaces into bifacial Nueces tools represents the extension of this strategy. In addition, the use of heavily beveled Tortugas failures as blanks for the manufacture of Olmos bifaces also allows archeologists to link the two tools into a single broadly contemporaneous tool kit. This is not to say that wherever one finds a Tortugas point there should also be an Olmos biface. It simply suggests that the makers of Tortugas projectile points also made and utilized Olmos bifaces. The high rates of artifact recycling exemplified by the Nueces tools and Olmos bifaces have not been documented in other parts of the state. The fact that it occurs in South Texas (and probably also northern Tamaulipas) may be influenced by, and telling of, cultural and technological responses to low-density broadly distributed resources, the overall lack of year-round water sources, and high hunter-gatherer mobility. The high incidence of what appear to be multi-functional tool forms in the Middle and Late Archaic tool assemblages of South Texas and northern Tamaulipas also bespeaks of, and has broader relationships with, edible and lithic resource distributions and mobility patterns. It is likely that the same factors that led to high incidences of tool recycling may also favor the use of versatile multifunctional tools.

Finally, the fact that triangular and related subtriangular forms dominated the projectile point technology in South Texas and northern Tamaulipas throughout the Middle and Late Archaic is remarkable and does not occur in any other part of Texas. The fact that this pattern may extend as far back as the late Paleoindian period (i.e., Lerma points) is even more astounding. A traditional normative perspective on this lack of change in projectile point types would suggest that the region was inhabited by only a few major cultural groups possessing a very conservative, non-changing technological repertoire. The seeming marginality of the region south of the riverine portion of South Texas, in combination with possibly low population densities, may support such an interpretation. While such an explanation may or may not be accurate, from the perspective of cultural adaptation it begs the question of why did the material culture and specifically the projectile point forms change so little over such a long time span? If the technological sphere is one aspect of cultural adaptation to its natural environment, the lack of identifiable change in projectile forms seems to suggest that perhaps the resource base and the structure of the resources changed very little over time. Although little is available to reconstruct the paleoenvironmental conditions in South Texas and northern Mexico, what is available (i.e., Gustavson and Collins 1998, Nordt 1998; Quigg and Cordova 2000; Turpin et al. 1994) suggests that some changes in paleoenvironmental conditions did take place, even during the past 3,000 to 4,000 years. If this was the case, one would have to assume either that the magnitude and impact of the changes was not sufficient to alter the resource base and structure or that the technological responses to those changes did not involve changes in projectile point morphology but took place in other aspects of technological organization (i.e., changes in mobility and land use, richness and diversity of tool kits, etc.). Unfortunately, the investigation of this latter scenario can be pursued only in temporally anchored large assemblages where one can define overall behaviorally related tool kits and compare and contrast the composition of the tool kits, observe changes in raw material procurement strategies, and monitor aspects of tool reliability in response to different degrees of risk and costs of risk experienced by hunter-gatherers. This does not mean, however, that research in lithic technology should be limited to such assemblages. It has been shown here that a great deal can be learned even from individual artifact categories if sufficiently large collections are available for study and well-circumscribed research questions guide the analysis. 


\section{Chapter 10:}

This report has provided a summary of CAR's data recovery efforts at 41WB556. In the original research design for the project, Quigg and Smith (2000) proposed a series of research questions including documenting a baseline chronology, paleoenvironmental conditions, and investigating aspects of the adaptive strategies manifested at 41WB556. CAR's fieldwork at the site recovered a wide variety of data, including over 9,000 chipped stone debitage and tools, information on 14 thermal features, and a variety of sediment and charcoal samples. However, during the preparation of the interim report (Mahoney et al. 2000), it became apparent that several of the analyses proposed in the Data Recovery Plan had a low probability of yielding significant results, primarily because of extensive mixing of the deposits.

Given our preliminary assessment of the data recovered from the site, we reoriented our research focus to consider three issues. The first of these was concerned with documenting and investigating the integrity and chronology of 41WB556. As outlined in Chapter 7, our analysis suggests that some portion of the chipped stone assemblage, the charcoal, and some of the sediment within features had been significantly turbated as a result of rodent and small insect activities. However, we also argued that the burned sandstone features at the site were unlikely to have been dramatically impacted by that turbation. We ran a series of radiocarbon dates from these features on both larger pieces of charcoal and on organic residue extracted from burned sandstone in the hope that the charcoal was associated with the respective features, and would provide an independent assessment of the validity of the residue dates. Unfortunately, the charcoal dates were clearly not in context, and therefore we lack any independent way to verify the residue dates. Even discounting the charcoal dates, however, the residue dates are widely scattered for a given feature. In addition, they do not pattern with the overall site stratigraphy. As the features have not been significantly disturbed by turbation, we conclude that the residue dates, in this instance, are clearly not providing an accurate assessment of when features were used. In some instances, the problem with the residue dates may be related to the presence of non-food residues identified by the analysis of fatty acids. In our view, without a better understanding of exactly what we are dating with this technique, and how it was incorporated into the sandstone, dates on residues extracted from burned rock will always be open to question. This is especially the case when we lack any other independent way to assess those dates.

The thermal feature data set forms the basis for our second research domain, investigating feature technology, discussed in Chapter 8. Using patterns in average rock weight at a feature level, as well as patterns in individual rock weights in two features, we suggested that several features may be the remains of general hearths that, as a result of bioturbation, had no associated pits visible. We also suggested that at least one feature (Feature 21), and possibly several others, were consistent with expectations for either stone boiling or use of the area as a communal dump. However, the resulting patterns were not straightforward, and the rock weight data from the site are consistent with a number of possible scenarios. We need to develop better expectations for what the results of stone boiling would look like. Experimental work can provide important background data in that regard.

Also in Chapter 8, we investigated what items may have been processed in features through an analysis of fatty acids (lipids) and carbon and nitrogen isotopes from residues extracted from burned rock. Comparison of the results of these two techniques sometimes produced contradictory results. Our exploration of these contradictions identified several critical issues in the use of both nitrogen and carbon isotopic data that should be addressed by future research. Specifically, we would suggest a series of blind-tests in which burned rock, exposed to known plants, animals, and mixes of plants and animals, is submitted for both isotopic and fatty acid analysis. Importantly, processing additional archeological samples will probably not add significantly to our understanding of the relationship between residues recovered in rocks and what was processed with those rocks.

Finally, in Chapter 9, a segment of the chipped stone tool assemblage from 41WB556 was used, in combination with several other South Texas data sets, 
to investigate our third research domain that concerned aspects of lithic technology. The analysis of Tortugas and Matamoros and Abasolo and Catán dart points indicates that these large and small forms represent ends of the same technological continuum. More importantly, if these forms represent chronological markers of the Middle Archaic (Abasolo, Tortugas) and Late Archaic (Catán, Matamoros) periods, our analysis shows that the large and small types can no longer be used with any degree of confidence as index markers of archeological components dating to these time periods.

Our analysis did not include the "Early Triangular" dart point that is sometimes found in South Texas and other parts of the state. The broad morphological similarity of the Early Triangular form with Tortugas points suggests that future analysis should also be focused on defining technological and statistical similarities and differences between these point types. The goal of these analyses should be to document and explore the technological similarities and differences between the types and quantify the metric and non-metric characteristics of the Early Triangular forms so that they can be identified consistently, even in mixed assemblages. A second aspect of South Texas projectile point technology that is worthy of future research is borne out of suggestions made in Chapter 9 that certain aspects of the morphology of triangular dart points may increase their reliability compared to stemmed point types. Quantifying base/stem and blade failure rates among triangular points may help explain whether it was the "appropriateness" of the projectile point technology that accounts for the continuity in form. We suggest that a systematic research program should be initiated to test and quantify the reliability and effectiveness aspects of various projectile point types (e.g., Tortugas, Pedernales, Marshall, etc.). Defining and quantifying whether, for instance, Tortugas points tend to suffer blade failures less often and of the shorter variety than Pedernales points has significant implications for understanding the systemic constraints under which the two types were employed. Similarly, quantifying how maximum blade width or blade thickness contribute to projectile point failure as well as use-life may help broadly characterize the projectile point morphologies that are best suited under different hunting conditions and for different prey.
The analysis of the Nueces tools and Olmos bifaces indicates that they often represent recycled, manufactureand/or use-failed bifaces and alternately beveled projectile point fragments (e.g., Tortugas). Overall, the degree of recycling and rejuvenation of elements of the lithic technology, in combination with the multifunctional nature of the tools (including projectile points), is rather unique in Texas and may reflect high huntergatherer mobility in response to resource scarcity and the dispersed nature of the resources. Finally, the long span of time during which triangular and subtriangular projectile points were manufactured throughout South Texas and Northern Mexico suggests that the resource base and the land-use practices of regional huntergatherer groups changed little or that whatever changes did take place did not necessitate a shift in projectile point technology.

Finally, though not discussed in the body of this report, Dering (Appendix D) presents a discussion of xylem analysis using, in part, archeological charcoal from 41WB556. The analysis indicates the possibility that changing regional conditions for tree growth during the late Holocene are reflected in mesquite wood charcoal. Changes in wood anatomy are measurable and appear to coincide with differences in annual precipitation, at least in a variety of modern samples. Xylem analysis, then, has potential for establishing a previously undeveloped proxy of precipitation.

In summary, this report has used several means to gather data from 41WB556, an open encampment with questionable artifact and chronological integrity. While the question of site integrity must be considered on a site-by-site basis, 41WB556 is probably not unlike many sites in similar settings in South Texas, as well as throughout the state, where artifact and chronological integrity is, to varying degrees, compromised by turbation. Despite these problems, however, this report has demonstrated that sites such as 41WB556 have research value, though the data may be applicable to a more narrow range of research domains or applicable at a scale other than that of the individual site. Just as critical from our perspective, the analysis of data from 41WB556 has provided us with an opportunity to learn about our analytical procedures and clarify future research needs. 
These procedures include areas such as the use of carbon and nitrogen isotopic analysis of residues, dating of residues in rock, the impacts and utility of typological classifications of some artifact types, and research into paleoclimate (e.g., Appendix D) and fatty acid residues (Appendix C). 


\section{References Cited}

Abbott, J. T.

1999 Geomorphic and Geoarcheological Observations Along the Northern Part of the Becerra Creek Segment, U.S. Highway 83, Webb County, Texas. Appendix A, in Archeological Survey Report: Completions of TxDOT Archeological Investigations, by T. Meade, J. Abbott, and C. Gonzalez. Texas Department of Transportation, Environmental Affairs Division. Austin

Ambrose, S. H.

1987 Chemical and Isotopic Techniques of Diet Reconstruction in Eastern North America. In Emergent Horticultural Economies of the Eastern Woodlands, edited by W. F. Keegan, pp. 87-107. Center for Archaeological Investigations, Occasional Paper No. 7. SIU Press, Carbondale, Illinois.

1991 Effects of Diet, Climate and Physiology on Nitrogen Isotope Abundance in Terrestrial Foodwebs. Journal of Archaeological Science 18:293-317.

Ambrose, S. H., and DeNiro, M. J.

1986 The Isotopic Ecology of East African Mammals. Oecologia 69:395-406.

Aveleyra Arroyo de Anda, L., M. Maldonao Koerdell, and P. Martínez del Rio

1956 Cueva de la Candelaria. Memorias de Instituto Nacional Antropología e Historia V, vol. 1, I.N.A.H. Mexico.

Barnes, V. E.

1976 Geologic Atlas of Texas: Laredo Sheet. Bureau of Economic Geology, The University of Texas at Austin.

Bement, L. C., and Y. M. Rowan

1988 Intensive Survey and Limited Site Testing in the Extended West Cole Uranium Mine, Webb County, Texas. Technical Report Series, No. 7. Texas Archeological Research Laboratory, The University of Texas at Austin.

Bettis, A. C., Jr.

1997 Chipped Stone Artifacts from the Killam Ranch, Webb County, Texas. TARL Research Notes 5(2):3-23. Texas Archeological Research Laboratory, The University of Texas at Austin.

Black, S.

1989 South Texas Plain. In From the Gulf Coast to the Rio Grande: Human Adaptation in the Central, South, and Lower Pecos Texas, by T. R. Hester, S. L. Black, D. G. Steele, B. W. Olive, A. A. Fox, K. J. Reinhard, and L. C. Bement, pp. 39-62. Research Series No. 33. Arkansas Archeological Survey, Fayetteville.

Black, S. L., and A. J. McGraw

1985 The Panther Springs Creek Site: Cultural Change and Continuity within the Upper Salado Creek Watershed, South-Central Texas. Archaeological Survey Report, No. 100. Center for Archaeological Research, The University of Texas at San Antonio.

Blair, W. F.

1950 The Biotic Provinces of Texas. Texas Journal of Science 2(1):93-117. 
Bolton, H. E.

1959 Spanish Exploration in the Southwest, 1542-1706. Reprinted. Barnes and Noble, New York. Originally published in 1908, Charles Scribner and Sons, New York.

Bomar, G. W.

1983 Texas Weather. University of Texas Press, Austin.

Brown, K. M., D. R. Potter, G. D. Hall, and S. L. Black

1982 Excavations at 41LK67, A Prehistoric Site in the Choke Canyon Reservoir, South Texas. Choke Canyon Series, vol. 7. Center for Archaeological Research, The University of Texas at San Antonio.

Brune, G.

1981 Springs of Texas, Volume 1. Branch-Smith, Fort Worth.

Cabeza de Vaca, A. N.

1961 [1871] Relation of Nuñez Cabeza de Vaca. Translated by B. Smith. Readex Microprint.

Campbell, T. N.

1947 The Johnson Site: Type Site of the Aransas Focus of the Texas Coast. Bulletin of the Texas Archeological and Paleontological Society 18:40-75.

1952 The Kent-Crane Site: A Shell Midden on the Texas Coast. Bulletin of the Texas Archeological and Paleontological Society 23:39-77.

1956 Archeological Materials from Five Islands in the Laguna Madre, Texas Coast. Bulletin of the Texas Archeological Society 27:7-46.

1958 Archeological Remains from the Live Oak Point Site. The Texas Journal of Science 10:423-442.

Church, F.

2000[1997] A Summary of the Results of a High Powered Use-Wear Analysis of a Sample of Chipped Stone Artifacts from Site 41ZP364, Zapata County, Texas. In Data Recovery at 41ZP364: An Upland Campsite at Falcon Reservoir, Zapata County, Texas, by J. M. Quigg and C. Cordova. Draft Report in Possession of Author, TRC Mariah Associates Inc., Austin.

Cohen, A., and D. Serjeantson

1996 A Manual for the Identification of Bird Bones from Archaeological Sites. Revised edition. Archetype Publications, London.

Collins, M. B.

1995 Forty Years of Archeology in Texas. Bulletin of the Texas Archeological Society 66:361-400.

Condamin, J., F. Formenti, M. O. Metais, M. Michel, and P. Blond

1976 The Application of Gas Chromatography to the Tracing of Oil in Ancient Amphorae. Archaeometry 18(2):195-201.

Corbin, J. E.

1963 Archeological Materials from the Northern Shores of Corpus Christi Bay, Texas. Bulletin of the Texas Archeological Society 34:5-30. 
Creel, D., A. J. McGraw, F. Valdez, Jr., and T. C. Kelly

1979 Excavations at 41LK106, A Prehistoric Occupation Site in Live Oak County, Texas. Archaeological Survey Report, No. 62. Center for Archaeological Research, The University of Texas at San Antonio.

Crook, W. W., Jr., and R. K. Harris

1954 Traits of the Trinity Aspect Archaic: Carrollton and Elam Foci. The Record 12(1):2-16.

Davis, W. B., and D. J. Schmidly

1994 The Mammals of Texas. Texas Parks and Wildlife, Austin.

DeNiro, M. J., and S. Epstein

1978 Influence of Diet on the Distribution of Carbon Isotopes in Animals. Geochimica et Cosmochimica Acta 42:495-506.

Dillehay, T.

1974 Late Quaternary Bison Population Changes on the Southern Plains. Plains Anthropologist 19(64):180-196.

Doughty, R. W.

1983 Wildlife and Man in Texas. Texas A\&M University Press, College Station.

Driver, H. E., and W. C. Massey

1957 Comparative Studies of North American Indians. Vol. 47. Transactions of the American Philosophical Society, Philadelphia.

Ehleringer, J. R.

1989 Carbon Isotope Ratios and Physiological Processes in Aridland Plants. In Stable Isotopes in Ecological Research, edited by P. W. Rundel, J. R. Ehleringer, and K. A. Nagy, pp. 41-54. Springer Velag, New York.

$1991{ }^{13} \mathrm{C} /{ }^{12} \mathrm{C}$ Fractionation and its Utility in Terrestrial Plant Studies. In Carbon Isotope Techniques, edited by D. C. Coleman and B. Fry, pp. 187-201. Academic Press, San Diego.

Epstein, J. F.

1969 The San Isidro Site, An Early Man Campsite in Nuevo Leon, Mexico. Anthropological Series, Department of Anthropology, No. 7. The University of Texas at Austin.

1980 Some Reflections on the nature of the Northeast Mexico Lithic Tradition and the Problem of its Origin. In Papers on the Prehistory of Northeast Mexico, edited by J. F. Epstein, T. R. Hester, and C. Graves, pp. 81-92. Special Report No. 9. Center for Archaeological Research, The University of Texas at San Antonio.

Fenneman, N.

1931 Physiography of the Western United States. McGraw Hill, New York.

Gilbert, B. M.

1990 Mammalian Osteology. Missouri Archaeological Society, Columbia.

Gustavson, T. C., and M. B. Collins

1998 Geoarcheological Investigations of Rio Grande Terrace and Flood Plain Alluvium from Amistad Dam To the Gulf of Mexico. Technical Report Series 49, Texas Archeological Research Laboratory, The University of Texas at Austin; Archeological Studies Program Report No. 12, Environmental Affairs Division, Texas Department of Transportation, Austin. 
Hall, G. D.

1985 Comparative Ecologies: The Texas Chaparral Versus the Australian Outback. La Tierra 12(3):6-19.

Hall, G. D., S. L. Black, and C. Graves

1982 Archaeological Investigations at the Choke Canyon Reservoir, South Texas: The Phase I Findings. Choke Canyon Series, vol. 5. Center for Archaeological Research, The University of Texas at San Antonio.

Hall, G. D., T. R. Hester, and S. L. Black (editors)

1986 The Prehistoric Sites at Choke Canyon Reservoir, Southern Texas: Results of the Phase II Archaeological Investigations. Choke Canyon Series, vol. 10. Center for Archaeological Research, The University of Texas at San Antonio.

Hare, P. E., M. L. Fogel, T. W. Stafford, A. D. Mitchell, and T. C. Hoering

1991 The Isotopic Composition of Carbon and Nitrogen in Individual Amino Acids Isolated from Modern and Fossil Proteins. Journal of Archaeological Science 18:277-292.

Hartle, D. D., and R. L. Stephenson

1951 Archaeological Excavations at the Falcon Reservoir, Starr County, Texas. In River Basin Surveys, prepared for the Smithsonian Institution, Washington D.C.

Hatcher, M. A.

1932 The Expedition of Don Domingo Terán de los Ríos into Texas. Preliminary Studies of the Texas Catholic Historical Society 11(1):1-67.

Heaton, T. H. E.

1987 The ${ }^{15} \mathrm{~N} /{ }^{14} \mathrm{~N}$ Ratios of Plants in South Africa and Namibia: Relationship to Climate and Coastal/Saline Environments. Oecologia 74:236-246.

Hellier, J. R., D. G. Steele, and C. A. Hunter

1995 Analysis of Nonhuman Vertebrate Faunal Remains. In Archaeological Investigations at the Loma Sandia Site (41LK28): A Prehistoric Cemetery and Campsite in Live Oak County, Texas, by A. J. Taylor and C. L. Highley, pp. 801-828. Studies in Archeology No. 20. Texas Archeological Research Laboratory, The University of Texas at Austin.

Hester, T. R.

1969 Archeological Investigations in Kleberg and Kenedy Counties, Texas. SBC Archeological Report No. 15, Draft. Texas Archeological Research Laboratory, The University of Texas, Austin.

1978 Background to the Archaeology of Chaparrosa Ranch, Southern Texas. Volume I: Studies in the Archaeology of Chaparrosa Ranch. Special Report No. 6. Center for Archaeological Research, The University of Texas at San Antonio.

1995 The Prehistory of South Texas. Bulletin of the Texas Archeological Society 66:427-459.

Hester, T. R., L. White, and J. White

1969 Archeological Materials from the Oulline Site (41LS3) and Other Sites in La Salle County, Texas. Texas Journal of Science 21(2):131-166. 
Hillson, S.

1986 Teeth. Cambridge University Press, Cambridge.

Hodges, F. W.

1907 The Narrative of Alvar Nunez Cabeza de Vaca, Spanish Explorer in the Southern United States, 15281543. Barnes and Nobel Publishing, New York.

Holloway, R. G.

1986 Macrobotanical Analysis of Phase II Materials from the Choke Canyon Reservoir Area, Texas. In Prehistoric Sites at Choke Canyon Reservoir, Southern Texas: Results of Phase II Archaeological Investigations, by G. D. Hall, T. R. Hester, and S. L. Black, pp. 437-451. Choke Canyon Series, No. 10. Center for Archaeological Research, The University of Texas at San Antonio.

Johnson, L., Jr.

1995 Past Cultures and Climates at Jonas Terrace 41ME29 Medina County, Texas. Office of the State Archeologist, Report 40. Texas Department of Transportation and Texas Historical Commission, Austin.

Katz, P. R.

1987 Archaeological Mitigation at 41BX300, Salado Creek Watershed, South-Central Texas. Archaeological Survey Report, No. 130. Center for Archaeological Research, The University of Texas at San Antonio.

Kelley, J. C.

1947 The Cultural Affiliations and Chronological Position of the Clear Fork Focus. American Antiquity 13:97-109.

Kennard, D.

1976 Rio Grande-Falcon Thorn Woodland: A Natural Area Survey, No. 13. Lyndon B. Johnson School of Public Affairs, The University of Texas at Austin.

Kibler, K. W., and A. M. Scott

2000 Archaic Hunters and Gatherers of the Balcones Canyonlands: Data Recovery at the Cibolo Crossing Site (41BX377), Camp Bullis Military Reservation, Bexar County, Texas. Reports of Investigations, No. 126. Prewitt and Associates, Inc., Austin.

Kintigh, K. W.

1992 Tools for Quantitative Archaeology. Tempe, Arizona.

Krueger, H. W., and C. Sullivan

1984 Models of Carbon Isotope Fractionation Between Diet and Bone. In Stable Isotopes in Nutrition, edited by J. R. Turnlund and P. E. Johnson, pp. 205-220. ACS Symposium Series Number 228. American Chemical Society, Washington D.C.

Liden, K., C. Takahashi, and D. E. Nelson

1995 The Effects of Lipids in Stable Carbon Isotope Analysis and the Effects of $\mathrm{NaOH}$ Treatment on the Composition of Extracted Bone Collagen. Journal of Archaeological Science 22:321-326. 
Loy, T.

1994 Residue Analysis of Artifacts and Burned Rock from the Mustang Branch and Barton Sites (41HY209 and 41HY202). In Archaic and Late Prehistoric Human Ecology in the Middle Onion Creek Valley, Hays County, Texas, Vol. 2: Topical Studies, by R. A. Ricklis and M. B. Collins, pp. 607-627. Studies in Archeology 19, Texas Archeological Research Laboratory, University of Texas, Austin.

Lukowski, P. D.

1988 Archaeological Investigations at 41BX1, Bexar County, Texas. Archaeological Survey Report, No. 135. Center for Archaeological Research, The University of Texas at San Antonio.

McClurkan, B. B.

1966 The Archeology of Cueva de la Zona de Derrumbes: A Rockshelter in Nuevo Leon, Mexico. Unpublished Masters Thesis, Department of Anthropology, University of Texas, Austin.

McGraw, A. J., and J. Thompson

1998 Campfires and Coal Dust on the Rio Grande: The Archeology and History of the Laredo-Colombia Solidarity International Bridge Site, Nuevo Leon, Mexico and Webb County, Texas. Archeological Studies Program, Report No. 8. Environmental Affairs Division, Texas Department of Transportation, Austin.

MacNeish, R. S.

1958 Preliminary Archaeological Investigations in the Sierra de Tamaulipas, Mexico. Transactions of the American Philosophical Society 48(6). American Philosophical Society, Philadelphia.

McReynolds, M. J.

1981 Archaeological Investigations at the Laredo Cemetery Site (41WB22), Webb County, Texas. Reports of Investigations, No. 11. Prewitt and Associates, Inc., Austin.

Mahoney, R. B.

2002 The Medio Creek Site (41BX1421): National Register Test Excavations, Bexar County, Texas. Archaeological Survey Report, No. 322, The University of Texas at San Antonio; Archeological Studies Program, Report No. 41, Environmental Affairs Division, Texas Department of Transportation, Austin. Draft Report. Copy on file at the Center for Archaeological Research,

Mahoney, R. B., R. P. Mauldin and S. A. Tomka

2000 An Interim Report on Archaeological Data Recovery Excavations at 41WB556, Webb County, Texas. Interim Report, copy on file at the Center for Archaeological Research, The University of Texas at San Antonio.

Malainey, M. E.

1997 The Reconstruction and Testing of Subsistence and Settlement Strategies for the Plains, Parkland, and Southern Boreal Forest. Unpublished Ph.D. Dissertation, University of Manitoba.

2000 Appendix K: Analysis of Fatty Acid Compositions of Burned Rock Residues from Site 41ZP364, Zapata County, Texas. In Data Recovery at 41ZP364: An Upland Campsite at Falcon Reservoir, Zapata County, Texas, by J. M. Quigg and C. Cordova, pp. 331-345. Technical Report No. 22317. TRC Mariah Associates Inc., Austin. 
Marchbanks, M. L.

1989 Lipid Analysis in Archaeology: An Initial Study of Ceramics and Subsistence at the George C. Davis Site. Unpublished MA thesis, University of Texas, Austin.

Meade, T., J. Abbott, and C. Gonzalez

1999 Archeological Survey Report: Completions of TxDOT Archeological Investigations. Texas Department of Transportation, Environmental Affairs Division, Austin.

Miller, K. A., O. S. Carpenter, L. C. Nordt, and C. W. Ringstaff

2000 Archaeological Investigations Along the Camino Colombia Toll Road, Webb County, Texas. SWCA Cultural Resource Report, No. 97-120. SWCA, Inc., Environmental Consultants, Austin.

Nance, C. R.

1992 The Archaeology of La Calsada, A Rockshelter in the Sierra Madre Oriental, Mexico. University of Texas Press, Austin.

Nordt, L. C.

1998 Chapter 7: Geoarchaeology of the Rio Grande and Elm Creek in the Vicinity of Site 41MV120. In 41MV120: A Stratified Late Archaic Site in Maverick County, Texas, by B. J. Vierra, pp. 43-77. Archaeological Survey Report, No. 251. Center for Archaeological Research, The University of Texas at San Antonio; Archeology Studies Program, Report No. 7, Environmental Affairs Division, Texas Department of Transportation, Austin.

Norwine, J. R.

1995 The Regional Climate of South Texas: Patterns and Trends. In The Changing Climate of Texas: Predictability and Implications for the Future, pp. 138-154. Cartographics, Texas A\&M University, College Station.

Nunley, P., and T. R. Hester

1966 Preliminary Archeological Investigations in Dimmit County, Texas. Texas Journal of Science 18:233-253.

Nunley, J. P., L. F. Duffield, and E. B. Jelks

1965 Excavations at Amistad Reservoir, 1962 Season. Miscellaneous Papers, No. 3. Texas Archeological Salvage Project, The University of Texas, Austin.

O'Leary, M. H.

1988 Carbon Isotopes in Photosynthesis. Bioscience 38:328-336.

Olsen, S. J.

1964 Mammal Remains from Archaeological Sites Part I; Southeastern and Southwestern United States. Peabody Museum, Cambridge.

1968 Fish, Amphibian, and Reptile Remains from Archaeological Sites Part I: Southeastern and Southwestern United States. Peabody Museum, Cambridge.

Owen, J. G., and D. J. Schmidly

1986 Environmental Variables of Biological Importance in Texas. Texas Journal of Science 38(2):99-119. 
Pate, D. F.

1994 Bone Chemistry and Paleodiet. Journal of Archaeological Method and Theory 1:161-205.

Perttula, T. K.

2001 Hunter-Gatherer Mortuary Practices in the Rio Grande Plains and Central Coastal Plains Archeological Regions of Texas. La Tierra 28(3/4):2-83.

Prewitt, E. R.

1981 Cultural Chronology in Central Texas. Bulletin of the Texas Archeological Society 52:65-89.

1995 Distributions of Typed Projectile Points in Texas. Bulletin of the Texas Archeological Society 66:83-173.

Quigg, J. M.

2000 Appendix M: Stable Carbon and Nitrogen Isotope Data on Modern Plant and Animal Resources from South Texas. In Data Recovery at 41ZP364: An Upland Campsite at Falcon Reservoir, Zapata County, Texas, J. M. Quigg and C. Cordova, pp. 353-364. Technical Report No. 22317. TRC Mariah Associates Inc., Austin.

Quigg, J. M., and C. Cordova

1999 Archeological Investigations at Upland Sites 41ZP39 and 41ZP176 for TransTexas Gas Well Site USA \#3, Falcon Reservoir, Zapata County, Texas. Technical Report, No. 23224. TRC Mariah Associates, Inc., Austin.

2000 Data Recovery at 41ZP364: An Upland Campsite at Falcon Reservoir, Zapata County, Texas. Technical Report No. 22317. TRC Mariah Associates Inc., Austin.

Quigg, J. M., C. Lintz, G. Smith, and S. Wilcox

2000 The Lino Site: A Stratified Late Archaic Campsite in a Terrace of San Idelfonzo Creek, Webb County, Southern Texas. Technical Report No. 23756, TRC Mariah Associates; Archeological Studies Program, Report No. 20, Environmental Affairs Division, Texas Department of Transportation, Austin.

Quigg, J. M., M. E. Malainey, R. Przybylski, and G. Monks

2001 No Bones About It: Using Lipid Analysis of Burned Rock and Groundstone Residues to Examine Late Archaic Subsistence Practices in South Texas. Plains Anthropologist 46:283-303.

Quigg, J. M., S. Pritchard, and G. Smith

2002 The Boiler Site (41WB557): Utilization of an Upland Setting Over the Last 4200 Years, Webb County, Texas. TRC Technical Report No. 27277, TRC Mariah Associates, Austin; Archeological Studies Program Report No. 45 Environmental Affairs Division, Texas Department of Transportation, Austin.

Quigg, J. M., and G. D. Smith

2000 An Interim Report: Archaeological and Geoarchaeological Investigations at 41 WB556 and 41 WB557 along U.S. Highway 83, Webb County, Texas. TRC Mariah Associates Inc., Austin, Texas.

Ramsey, C. B.

2000 OxCal Program Version 3.5. Radiocarbon Accelerator Unit, University of Oxford. Oxford, U.K.

Ray, C.

1941 The Various Types of the Clear Fork Gouge. Bulletin of the Texas Archeological and Paleontological Society 13:152-162. 
Sanders, R. R., and W. J. Gabriel

1985 Soil Survey of Webb County, Texas. USDA, Soil Conservation Service and Texas Agricultural Experimental Station.

Schwarcz, H. P., F. J. Melbye, M. A. Katzenberg, and M. Knyf

1985 Stable Isotopes in Human Skeletons of Southern Ontario: Reconstructing Paleodiet. Journal of Archaeological Science 12:187-206.

Schwarcz , H. P., and M. J. Schoeninger

1991 Stable Isotope Analysis in Human Nutritional Ecology. Yearbook of Physical Anthropology 34:283-321.

Scudday, J. F., and L. Scudday

1976 The Amphibian, Reptilian and Mammalian Fauna of the Subtropical Thorn Forest of Starr County, Texas. In Rio Grande-Falcon Thorn Woodland: A Natural Area Survey, No. 13, by D. Kennard, pp. 47-76. Lyndon B. Johnson School of Public Affairs, The University of Texas at Austin.

Sealy, J. C., N. J. Van Der Merwe, J. A. Lee Thorp, and J. L. Lanham

1987 Nitrogen Isotopic Ecology in Southern Africa: Implications for Environmental and Dietary Tracing. Geochimica et Cosmochimica Acta 51:2707-2717.

Shafer, H. J., and T. R. Hester

1971 A Study of the Function and Technology of Certain Bifacial Tools from Southern Texas. Texas Historical Survey Committee, Archeological Report No. 20, Austin.

Skibo, J. M.

1992 Pottery Function: A Use-Alteration Perspective. Plenum Press, New York.

Smith, B. N., and S. Epstein

1971 Two Categories of ${ }^{13} \mathrm{C} /{ }^{12} \mathrm{C}$ Ratios for Higher Plants. Plant Physiology 47:380-384.

Sobolik, K. D.

1991 Prehistoric Diet and Subsistence in the Lower Pecos as Reflected in Coprolites from Baker Cave, Val Verde County, Texas. Studies in Archeology No. 7, Texas Archeological Research Laboratory, the University of Texas at Austin.

Sobolik, K. D., and D. G. Steele

1996 A Turtle Atlas to Facilitate Archaeological Identifications. Mammoth Site of Hot Springs, SD, Inc., Rapid City, South Dakota.

Spielmann, K. A., M. J. Schoeninger, and K. Moore

1990 Plains-Pueblo Interdependence and Human Diet at Pecos Pueblo, New Mexico. American Antiquity 55:745765.

State Department of Highways and Public Transportation (SDHPT)

1981 Testing of Archeological Site 41WB23, IPE 900B, Webb County, IH 35: From the Missouri Pacific Railroad Underpass North of US 83, North 9.2 Miles. State Department of Highways and Public Transportation, Austin. 
Steele, K. W., and R. M. Daniel

1978 Fractionation of Nitrogen Isotopes by Animals: A Further Complication to the Use of Variations in the Natural Abundance of ${ }^{15} \mathrm{~N}$ for Tracer Studies. Journal of Agricultural Science 90:7-9.

Steele, D. G., and B. W. Olive

1989 Bioarcheology of Region 3 Study Area. In From the Gulf Coast to the Rio Grande: Human Adaptation in the Central, South, and Lower Pecos Texas, edited by T. R. Hester, S. L. Black, D. G. Steele, B. W. Olive, A. A. Fox, K. J. Reinhard, and L. C. Bement, pp. 93-114. Research Series No. 33. Arkansas Archeological Survey, Fayetteville.

Suhm, D. A., A. D. Krieger, and E. B. Jelks

1954 An Introductory Handbook of Texas Archeology. Bulletin of the Texas Archeological Society 25.

Taylor, A. J., and C. L. Highley

1995 Archeological Investigations at the Loma Sandia Site (41LK28): A Prehistoric Cemetery and Campsite in Live Oak County, Texas. 2 volumes. Studies in Archeology No. 20. Texas Archeological Research Laboratory, The University of Texas at Austin.

Taylor, W. W.

1960 Book Review of Preliminary Archaeological Investigations in the Sierra de Tamaulipas, Mexico written by Richard S. MacNeish [1958]. American Antiquity 25:434-436.

Teeri, J. A., and L. G. Stowe

1976 Climatic Pattern and the Distribution of $\mathrm{C}_{4}$ Grasses in North America. Oecologia 23:1-12.

Tieszen, L. L.

1994 Stable Isotopes on the Plains: Vegetation Analysis and Diet Determination. In Skeletal Biology in the Great Plains: Migration, Warfare, Health, and Subsistence, edited by D. W. Owsley and R. L. Jantz, pp. 261282. Smithsonian Institution Press, Washington.

Tieszen, L. L., and T. Fagre

1993 Carbon Isotope Variability in Modern and Archaeological Maize. Journal of Archaeological Science 20:24-40.

Tomka, S. A., T. K. Perttula, and R. J. Hard

1997 Archaeology of the Rio Grande and Central Coastal Plains, Texas: A Planning Document. Archaeological Survey Report, No. 266. Center for Archaeological Research, The University of Texas at San Antonio.

Turpin, S. A., H. H. Eling, Jr., and M. V. Moreno

1993 The Archaic Environment of Boca de Potrerillos, Nuevo Leon, Mexico. North American Archaeologist 15(4):331-357.

Turner, E. S., and T. R. Hester

1993 A Field Guide to Stone Artifacts of Texas Indians. Second edition. Gulf Publishing, Houston. 
Vierra, B. J.

1998 41MV120: A Stratified Late Archaic Site in Maverick County, Texas. Archaeological Survey Report, No. 251, Center for Archaeological Research, The University of Texas at San Antonio; Archeology Studies Program, Report No. 7, Environmental Affairs Division, Texas Department of Transportation, Austin.

Ward, G. K., and S. R. Wilson

1978 Procedures for Comparing and Combining Radiocarbon Age Determinations: A Critique. Archaeometry 20:19-31.

Warren, J. E.

1986 Los Quemados: Archeological Testing at the Highway 350 Sanitary Landfill in Laredo Webb County, Texas. Report No. 143. J. E. Warren Consulting, George West.

1989a A Cultural Resource Survey of the Palafox North Mining Permit Area, Webb County, Texas. Report No. 170. J. E. Warren Consulting, George West.

1989b A Cultural Resource Survey of the Rachal Mining Permit Area Webb County, Texas. Report No. 171. J. E. Warren Consulting, George West.

1992a Significance Testing of Four Archeological Sites in the Palafox North Mining Area Webb County, Texas. Report No. 210. J. E. Warren Consulting, George West.

1992b Significance Testing of Three Archeological Sites in the Rachal Mine Permit Area Webb County, Texas. Report No. 232. J. E. Warren Consulting, George West.

Weniger, D.

1997 The Explorers' Texas: The Animals They Found. Eakin Press, Austin.

West, E. H.

1905 De León's expedition of 1689. The Quarterly of the Texas State Historical Association 8:199-224.

White, T. D.

2000 Human Osteology. Academic Press, New York.

Whittaker, R. H.

1970 Communities and Ecosystems. MacMillan, London.

Wilson, S. R., and G. K. Ward

1981 Evaluation and Clustering of Radiocarbon Age Determinations: Procedures and Paradigms. Archaeometry 21:19-39. 


\section{Appendix A \\ Limited Geomorphological Analysis}

by

C. Britt Bousman 


\section{Appendix A: Limited Geomorphological Analysis of Block Excavation at 41WB556}

\section{Britt Bousman}

Sediments in pre-collected samples from four columns were inspected and described (Figure A-1). The author did not observe any of these profiles in the field due to the fact that construction had already destroyed and covered the excavation block. However, a natural cutbank on private property a few meters from the edge of the highway right-of-way and adjacent to the location of the block was observed. Unfortunately, access to the cutbank was restricted, so a profile was not described. Nevertheless, a buried soil was present in this cutbank, and it has similar characteristics to those in the sediments described in Columns 2 and 4 (following page). As the sediment descriptions were obtained from previously collected sediments that, to some unknown degree, were crushed, observations on soil structure, rodent burrowing,

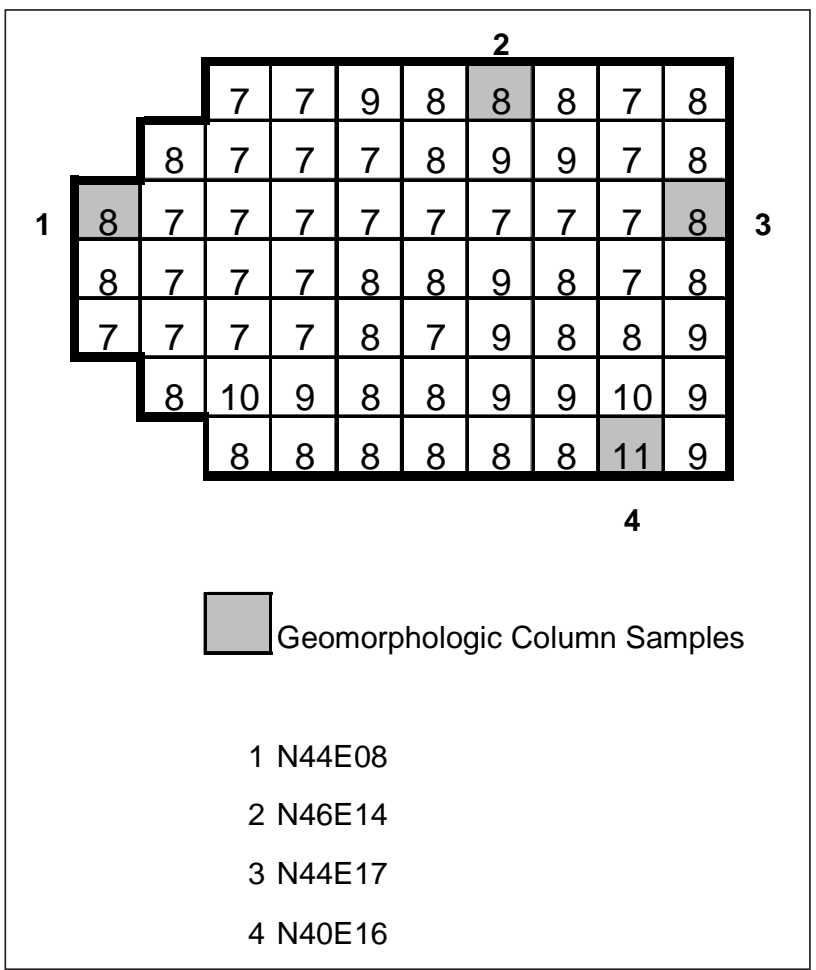

Figure A-1. Location of geomorphological column samples within excavation block. Note: numbers within units indicate number of levels excavated. calcium carbonate formation, various inclusions, soil horizon boundaries and many other attributes were not possible. However, in all cases, at least a few intact peds were present and firmness could be estimated. Also, estimates of soil texture and color were possible.

Most sediments can be classified as sandy loam with slightly more silt in a few isolated samples. In Columns 2 and 4, a buried A horizon could be identified in Samples 3-5 and Samples 3-4, respectively. The distinguishing characteristics of this buried A horizon were a darker color (dark grayish-brown sandy loam below a brown sandy loam), and friable sandy loam with firmer sediments below the buried A horizon. The firmness of the lower sediments was indicative of calcium carbonate cementation, probably in the form of filaments. No calcium carbonate nodules were observed. In Column 3 , below the surface A horizon was a lighter colored sandy loam that did not appear to be cemented (firm) in Samples 3-4; these were classified as an AB horizon. $\mathrm{B}$ horizon and $\mathrm{C}$ horizon sediments varied in color from a dark grayish-brown to a pale brown. The dark grayishbrown color in Column 1, Sample 6 was surprising, but could be due to sampling a krotovina or other form of common bioturbation described by archeologists in the field during excavation.

In general, the sediments described here support the field descriptions, and it is highly likely that a buried soil was present throughout the excavation block. In two of the sediment columns, distinct evidence of a buried soil was absent, but given the field observations and photographic record it is likely that the soil did extend over the entire block. 


\begin{tabular}{|c|c|}
\hline \multicolumn{2}{|c|}{ Column 1} \\
\hline Sample & Depth (cm) \\
\hline 1 & $0-10$ \\
\hline 2 & $10-20$ \\
\hline 3 & $20-30$ \\
\hline 4 & $30-40$ \\
\hline 5 & $40-50$ \\
\hline 6 & $50-60$ \\
\hline 7 & $60-70$ \\
\hline 8 & $70-80$ \\
\hline
\end{tabular}

Column 2

$\begin{array}{cl}\text { Sample } & \text { Depth }(\mathbf{c m}) \\ 1 & 0-10 \\ 2 & 10-20 \\ 3 & 20-30 \\ 4 & 30-40 \\ 5 & 40-50 \\ 6 & 50-60 \\ 7 & 60-70 \\ 8 & 70-80\end{array}$

\author{
Description \\ Grayish brown (10YR 5/2) friable sandy loam, A horizon. \\ Grayish brown (10YR 5/2) friable sandy loam, A horizon. \\ Grayish brown (10YR 5/2) friable silty loam, A horizon. \\ Grayish brown (10YR 5/2) friable silty loam, A horizon. \\ Brown (10YR 5/3) firm sandy loam, B horizon. \\ Dark grayish brown (10YR 4/2) firm sandy loam, B horizon. \\ Brown (10YR 5/3) friable sandy loam, B horizon. \\ Pale brown (10YR 6/3) firm sandy loam, C horizon.
}

\section{Column 3}

$\begin{array}{cl}\text { Sample } & \text { Depth }(\mathbf{c m}) \\ 1 & 0-10 \\ 2 & 10-20 \\ 3 & 20-30 \\ 4 & 30-40 \\ 5 & 40-50 \\ 6 & 50-60 \\ 7 & 60-70 \\ 8 & 70-80\end{array}$

\author{
Description \\ Brown (10YR 4/3) friable sandy loam, A horizon. \\ Brown (10YR 4/3) friable sandy loam, A horizon. \\ Dark grayish brown (10YR 4/2) friable sandy loam, 2A horizon. \\ Dark grayish brown (10YR 4/2) friable sandy loam, 2A horizon. \\ Dark grayish brown (10YR 4/2) friable sandy loam, 2A horizon. \\ Brown (10YR 5/3) friable sandy loam, 2B horizon. \\ Brown (10YR 5/3) firm sandy loam, 2B horizon. \\ Yellowish brown (10YR 5/4) firm sandy loam, 2C horizon.
}

\begin{tabular}{|c|c|c|}
\hline Sample & Depth (cm) & Description \\
\hline 1 & $0-10$ & Brown (10YR 5/3) friable sandy loam, A horizon. \\
\hline 2 & $10-20$ & Brown (10YR 5/3) friable sandy loam, A horizon. \\
\hline 3 & $20-30$ & Dark grayish brown (10YR 5/2) friable sandy loam, $2 \mathrm{~A}$ horizon. \\
\hline 4 & $30-40$ & Dark grayish brown (10YR 5/2) friable sandy loam, 2A horizon. \\
\hline 5 & $40-50$ & Brown (10YR 5/3) firm sandy loam, 2B horizon. \\
\hline 6 & $50-60$ & Brown (10YR 5/3) firm sandy loam, 2B horizon. \\
\hline 7 & $60-70$ & Brown (10YR 5/3) firm sandy loam, 2B horizon. \\
\hline 8 & $70-80$ & Yellowish brown (10YR 5/4) firm sandy loam, 2C horizon. \\
\hline 9 & $80-90$ & Light yellowish brown (10YR 6/4) firm sandy loam, 2C horizon. \\
\hline 10 & $90-100$ & Yellowish brown (10YR 5/4) firm sandy loam, 2C horizon. \\
\hline 11 & $100-110$ & Light yellowish brown (10YR 6/4) firm sandy loam, $2 \mathrm{C}$ horizon. \\
\hline
\end{tabular}

\author{
Description \\ Dark grayish brown (10YR 4/2) friable sandy loam, A horizon. \\ Dark grayish brown (10YR 4/2) friable sandy loam, A horizon. \\ Brown (10YR 5/3) friable silty loam, AB horizon. \\ Brown (10YR 4/3) friable sandy loam, AB horizon. \\ Brown (10YR 5/3) firm sandy loam, B horizon. \\ Brown (10YR 5/3) firm sandy loam, B horizon. \\ Brown (10YR 5/3) firm sandy loam, B horizon. \\ Yellowish brown (10YR 5/4) firm sandy loam, C horizon.
}





\section{Appendix B}

\section{Radiocarbon Results}




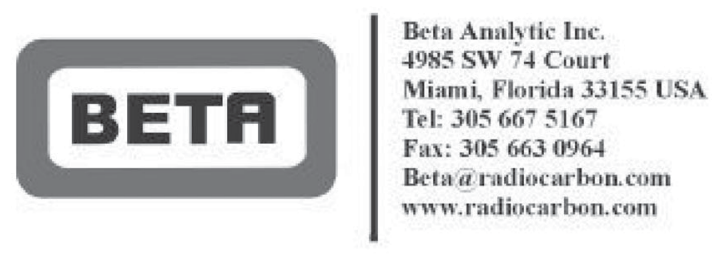

Dr. James Abbott

Texas Dept. of Transportation
Mr. Darden Hood

Director

Mr: Ronald Hatfield

Mr. Christopher Patrick

Deputy Directors

\begin{tabular}{|c|c|c|c|}
\hline Sample Data & $\begin{array}{c}\text { Measured } \\
\text { Radiocarbon Age }\end{array}$ & $\begin{array}{c}13 \mathrm{C} / 12 \mathrm{C} \\
\text { Ratio }\end{array}$ & $\begin{array}{c}\text { Conventional } \\
\text { Radiocarbon Age }\left(^{*}\right)\end{array}$ \\
\hline $\begin{array}{l}\text { Beta - } 149847 \\
\text { SAMPLE : } 1475 \\
\text { ANALYSIS : AMS-Standard delivery } \\
\text { MATERIAL/PRETREATMENT : } \\
2 \text { SIGMA CALIBRATION : }\end{array}$ & $\begin{array}{l}\qquad 200+/-40 \text { BP } \\
\text { y } \\
\text { (charred material): acid/alkali/acid } \\
\text { Cal AD } 1640 \text { to } 1680(\text { Cal BP } 310 \text { to } 260) \\
\text { Cal AD } 1930 \text { to } 1950(\text { Cal BP } 20 \text { to } 0)\end{array}$ & $-23.9 \mathrm{o} / \mathrm{oo}$ & $220+/-40 \mathrm{BP}$ \\
\hline $\begin{array}{l}\text { Beta - } 149848 \\
\text { SAMPLE : } 1492-1 \\
\text { ANALYSIS : AMS-Standard delivery } \\
\text { MATERIAL/PRETREATMENT : } \\
2 \text { SIGMA CALIBRATION : }\end{array}$ & $\begin{array}{l}\qquad 70+/-40 \text { BP } \\
\text { y } \\
\text { (charred material): acid/alkali/acid } \\
\text { Cal AD } 1670 \text { to } 1770(\text { Cal BP } 280 \text { to } 180) \\
\text { Cal AD } 1950 \text { to } 1950(\text { Cal BP } 0 \text { to } 0)\end{array}$ & $-23.3 \mathrm{o} / \mathrm{oo}$ & $100+/-40 \mathrm{BP}$ \\
\hline $\begin{array}{l}\text { Beta - } 149849 \\
\text { SAMPLE : } 202-1-1 \\
\text { ANALYSIS : AMS-Standard delivery } \\
\text { MATERIAL/PRETREATMENT : } \\
\text { 2 SIGMA CALIBRATION : }\end{array}$ & $\begin{array}{l}\qquad 1030+/-40 \text { BP } \\
\text { y } \\
\text { (charred material): acid/alkali/acid } \\
\text { Cal AD } 910 \text { to } 920 \text { (Cal BP } 1040 \text { to } 1030)\end{array}$ & $-24.4 \mathrm{o} / \mathrm{oo}$ & $1040+/-40 \mathrm{BP}$ \\
\hline $\begin{array}{l}\text { Beta }-149850 \\
\text { SAMPLE : } 258 \\
\text { ANALYSIS : AMS-Standard delivery } \\
\text { MATERIAL/PRETREATMENT : } \\
\text { 2 SIGMA CALIBRATION : }\end{array}$ & $\begin{array}{l}\qquad 2090+/-40 \text { BP } \\
\text { y } \\
\text { (charred material): acid/alkali/acid } \\
\text { Cal BC } 350 \text { to } 300 \text { (Cal BP } 2300 \text { to } 2250 \text { ) }\end{array}$ & AND Cal BC & $2130+/-40 \mathrm{BP}$ \\
\hline $\begin{array}{l}\text { Beta - } 149851 \\
\text { SAMPLE : } 404 \\
\text { ANALYSIS : AMS-Standard delivery } \\
\text { MATERIAL/PRETREATMENT : } \\
\text { 2 SIGMA CALIBRATION : }\end{array}$ & $\begin{array}{l}\qquad 610+/-40 \mathrm{BP} \\
\text { (charred material): acid/alkali/acid } \\
\text { Cal AD } 1290 \text { to } 1420(\text { Cal BP } 660 \text { to } 530)\end{array}$ & $-25.7 \mathrm{o} / \mathrm{oo}$ & $600+/-40 \mathrm{BP}$ \\
\hline
\end{tabular}




\begin{tabular}{|c|c|c|c|}
\hline Sample Data & $\begin{array}{c}\text { Measured } \\
\text { Radiocarbon Age }\end{array}$ & $\begin{array}{c}13 \mathrm{C} / 12 \mathrm{C} \\
\text { Ratio }\end{array}$ & $\begin{array}{c}\text { Conventional } \\
\text { Radiocarbon Age }\left(^{*}\right.\end{array}$ \\
\hline $\begin{array}{l}\text { Beta - } 149852 \\
\text { SAMPLE : } 405 \\
\text { ANALYSIS : Radiometric-Standard d } \\
\text { MATERIAL/PRETREATMENT : } \\
\text { 2 SIGMA CALIBRATION : }\end{array}$ & $\begin{array}{l}\qquad 510+/-80 \mathrm{BP} \\
\text { delivery (with extended counting) } \\
\text { (charred material): acid/alkali/acid } \\
\text { Cal AD } 1300 \text { to } 1530(\mathrm{Cal} \text { BP } 640 \text { to } 420)\end{array}$ & $-26.8 \mathrm{o} / \mathrm{oo}$ & $480+/-80 \mathrm{BP}$ \\
\hline $\begin{array}{l}\text { Beta - } 149853 \\
\text { SAMPLE : } 418 \\
\text { ANALYSIS : AMS-Standard delivery } \\
\text { MATERIAL/PRETREATMENT : } \\
2 \text { SIGMA CALIBRATION : }\end{array}$ & $\begin{array}{l}\qquad 320+/-40 \text { BP } \\
\text { (charred material): acid/alkali/acid } \\
\text { Cal AD } 1480 \text { to } 1660(\text { Cal BP } 470 \text { to } 290)\end{array}$ & $-26.3 \mathrm{o} / \mathrm{oo}$ & $300+/-40 \mathrm{BP}$ \\
\hline $\begin{array}{l}\text { Beta - } 149854 \\
\text { SAMPLE : } 480 \\
\text { ANALYSIS : AMS-Standard delivery } \\
\text { MATERIAL/PRETREATMENT : } \\
2 \text { SIGMA CALIBRATION : }\end{array}$ & $\begin{array}{l}\qquad 620+/-40 \mathrm{BP} \\
\text { (charred material): acid/alkali/acid } \\
\text { Cal AD } 1280 \text { to } 1410(\mathrm{Cal} \text { BP } 670 \text { to } 540)\end{array}$ & $-23.5 \mathrm{o} / \mathrm{oo}$ & $640+/-40 \mathrm{BP}$ \\
\hline $\begin{array}{l}\text { Beta - } 149855 \\
\text { SAMPLE : } 876-1 \\
\text { ANALYSIS : Radiometric-Standard d } \\
\text { MATERIAL/PRETREATMENT : } \\
\text { 2 SIGMA CALIBRATION : }\end{array}$ & $\begin{array}{l}\qquad 590+/-60 \text { BP } \\
\text { delivery (with extended counting) } \\
\text { (charred material): acid/alkali/acid } \\
\text { Cal AD } 1280 \text { to } 1430 \text { (Cal BP } 670 \text { to } 520)\end{array}$ & $-23.7 \mathrm{o} / \mathrm{oo}$ & $610+/-60 \mathrm{BP}$ \\
\hline $\begin{array}{l}\text { Beta - } 149856 \\
\text { SAMPLE : } 877-1 \\
\text { ANALYSIS : Radiometric-Standard d } \\
\text { MATERIAL/PRETREATMENT : } \\
\text { 2 SIGMA CALIBRATION : }\end{array}$ & $\begin{array}{l}\qquad 480+/-60 \mathrm{BP} \\
\text { delivery } \\
\text { (charred material): acid/alkali/acid } \\
\text { Cal AD } 1310 \text { to } 1360(\text { Cal BP } 640 \text { to } 590)\end{array}$ & $-23.9 \mathrm{o} / \mathrm{oo}$ & $500+/-60 \mathrm{BP}$ \\
\hline
\end{tabular}




\begin{tabular}{|c|c|c|c|}
\hline Sample Data & $\begin{array}{c}\text { Measured } \\
\text { Radiocarbon Age }\end{array}$ & $\begin{array}{c}13 \mathrm{C} / 12 \mathrm{C} \\
\text { Ratio }\end{array}$ & $\begin{array}{c}\text { Conventional } \\
\text { Radiocarbon Age }\left(^{*}\right)\end{array}$ \\
\hline $\begin{array}{l}\text { Beta - } 149857 \\
\text { SAMPLE : } 977 \\
\text { ANALYSIS : AMS-Standard delivery } \\
\text { MATERIAL/PRETREATMENT : } \\
2 \text { SIGMA CALIBRATION : }\end{array}$ & $\begin{array}{l}\qquad 1710+/-50 \mathrm{BP} \\
\text { (charred material): acid/alkali/acid } \\
\text { Cal AD } 230 \text { to } 430(\text { Cal BP } 1720 \text { to } 1520)\end{array}$ & $-25.0 \mathrm{o} / 00$ & $1710+/-50 \mathrm{BP}$ \\
\hline $\begin{array}{l}\text { Beta - } 149858 \\
\text { SAMPLE : } 978 \\
\text { ANALYSIS : AMS-Standard delivery } \\
\text { MATERIAL/PRETREATMENT : } \\
2 \text { SIGMA CALIBRATION : }\end{array}$ & $\begin{array}{l}\qquad 560+/-40 \text { BP } \\
\text { (charred material): acid/alkali/acid } \\
\text { Cal AD } 1300 \text { to } 1420 \text { (Cal BP } 650 \text { to } 530)\end{array}$ & $-23.7 \mathrm{o} / \mathrm{oo}$ & $580+/-40 \mathrm{BP}$ \\
\hline $\begin{array}{l}\text { Beta - } 149859 \\
\text { SAMPLE : } 1308-1-1 \\
\text { ANALYSIS : AMS-Standard delivery } \\
\text { MATERIAL/PRETREATMENT : } \\
2 \text { SIGMA CALIBRATION : }\end{array}$ & $\begin{array}{l}\qquad 610+/-40 \text { BP } \\
\text { y } \\
\text { (charred material): acid/alkali/acid } \\
\text { Cal AD } 1290 \text { to } 1410 \text { (Cal BP } 660 \text { to } 540)\end{array}$ & $-24.3 \mathrm{o} / 00$ & $620+/-40 \mathrm{BP}$ \\
\hline $\begin{array}{l}\text { Beta - } 149860 \\
\text { SAMPLE : 1492-4-1A } \\
\text { ANALYSIS : AMS-Standard delivery } \\
\text { MATERIAL/PRETREATMENT : } \\
2 \text { SIGMA CALIBRATION : }\end{array}$ & $\begin{array}{l}\qquad 101.1+/-0.4 \mathrm{pMC} \\
\text { (organic material): acid washes } \\
\text { Cal AD } 1950 \text { to beyond } 1960(\mathrm{Cal} \mathrm{BP} 0 \text { to } 0)\end{array}$ & $-19 \mathrm{o} / \mathrm{oo}$ & $10+/-30 \mathrm{BP}$ \\
\hline $\begin{array}{l}\text { Beta - } 149861 \\
\text { SAMPLE : 1492-4-2A } \\
\text { ANALYSIS : AMS-Standard delivery } \\
\text { MATERIAL/PRETREATMENT : } \\
2 \text { SIGMA CALIBRATION : }\end{array}$ & $\begin{array}{l}\qquad 640+/-40 \mathrm{BP} \\
\text { (organic material): acid washes } \\
\text { Cal AD } 1210 \text { to } 1290 \text { (Cal BP } 740 \text { to } 660 \text { ) }\end{array}$ & $-17.4 \mathrm{o} / \mathrm{oo}$ & $760+/-40 \mathrm{BP}$ \\
\hline
\end{tabular}




\begin{tabular}{|c|c|c|c|}
\hline Sample Data & $\begin{array}{c}\text { Measured } \\
\text { Radiocarbon Age }\end{array}$ & $\begin{array}{c}13 \mathrm{C} / 12 \mathrm{C} \\
\text { Ratio }\end{array}$ & $\begin{array}{c}\text { Conventional } \\
\text { Radiocarbon Age }\left(^{*}\right)\end{array}$ \\
\hline $\begin{array}{l}\text { Beta - } 149862 \\
\text { SAMPLE : } 217-1-1 \text { A } \\
\text { ANALYSIS : AMS-Standard delivery } \\
\text { MATERIAL/PRETREATMENT : } \\
\text { 2 SIGMA CALIBRATION : }\end{array}$ & $\begin{array}{l}\qquad 2980+/-40 \text { BP } \\
\text { y (organic material): acid washes } \\
\text { Cal BC } 1400 \text { to } 1190 \text { (Cal BP } 3350 \text { to } 3140 \text { ) }\end{array}$ & $-21.6 \mathrm{o} / \mathrm{oo}$ & $3040+/-40 \mathrm{BP}$ \\
\hline $\begin{array}{l}\text { Beta - } 149863 \\
\text { SAMPLE : } 217-1-2 \mathrm{~A} \\
\text { ANALYSIS : AMS-Standard delivery } \\
\text { MATERIAL/PRETREATMENT : } \\
\text { 2 SIGMA CALIBRATION : } \\
\text { COMMENT: } 13 \mathrm{C} / 12 \mathrm{C} \text { ratio estimate }\end{array}$ & $\begin{array}{l}\qquad 3410+/-40 \text { BP } \\
\text { (organic material): acid washes } \\
\text { Cal BC } 1770 \text { to } 1620 \text { (Cal BP } 3720 \text { to } 3570 \text { ) } \\
\text { ed. The sample was too small for an indep }\end{array}$ & $\begin{array}{l}-25.0 * \mathrm{o} / \mathrm{oo} \\
\text { dent measurem }\end{array}$ & $3410+/-40 \mathrm{BP}$ \\
\hline $\begin{array}{l}\text { Beta - } 149864 \\
\text { SAMPLE : 403-1-1A } \\
\text { ANALYSIS : AMS-Standard delivery } \\
\text { MATERIAL/PRETREATMENT : } \\
2 \text { SIGMA CALIBRATION : }\end{array}$ & $\begin{array}{l}\qquad 1580+/-40 \text { BP } \\
\text { y (organic material): acid washes } \\
\text { Cal AD } 250 \text { to } 430 \text { (Cal BP } 1700 \text { to } 1520 \text { ) }\end{array}$ & $-18.9 \mathrm{o} / \mathrm{oo}$ & $1680+/-40 \mathrm{BP}$ \\
\hline $\begin{array}{l}\text { Beta - } 149865 \\
\text { SAMPLE : 403-1-2A } \\
\text { ANALYSIS : AMS-Standard delivery } \\
\text { MATERIAL/PRETREATMENT : } \\
\text { 2 SIGMA CALIBRATION : }\end{array}$ & $\begin{array}{l}\qquad 750+/ \text { - } 40 \text { BP } \\
\text { (organic material): acid washes } \\
\text { Cal AD } 1160 \text { to } 1270 \text { (Cal BP } 790 \text { to } 680 \text { ) }\end{array}$ & $-20 \mathrm{o} / \mathrm{oo}$ & $830+/-40 \mathrm{BP}$ \\
\hline $\begin{array}{l}\text { Beta - } 149866 \\
\text { SAMPLE : } 489-6 \mathrm{~A} \\
\text { ANALYSIS : AMS-Standard delivery } \\
\text { MATERIAL/PRETREATMENT : } \\
\text { 2 SIGMA CALIBRATION : }\end{array}$ & $\begin{array}{l}\qquad 880+/-40 \mathrm{BP} \\
\text { (organic material): acid washes } \\
\text { Cal AD } 1000 \text { to } 1180 \text { (Cal BP } 950 \text { to } 780 \text { ) }\end{array}$ & $-19.9 \mathrm{o} / \mathrm{oo}$ & $960+/-40 \mathrm{BP}$ \\
\hline
\end{tabular}




\begin{tabular}{|c|c|c|c|}
\hline Sample Data & $\begin{array}{c}\text { Measured } \\
\text { Radiocarbon Age }\end{array}$ & $\begin{array}{c}13 \mathrm{C} / 12 \mathrm{C} \\
\text { Ratio }\end{array}$ & $\begin{array}{c}\text { Conventional } \\
\text { Radiocarbon Age( }\left(^{*}\right)\end{array}$ \\
\hline $\begin{array}{l}\text { Beta - } 149867 \\
\text { SAMPLE : 489-18A } \\
\text { ANALYSIS : AMS-Standard delivery } \\
\text { MATERIAL/PRETREATMENT : } \\
\text { 2 SIGMA CALIBRATION : }\end{array}$ & $\begin{array}{l}\qquad 610+/-40 \mathrm{BP} \\
\text { ry } \\
\text { (organic material): acid washes } \\
\text { Cal AD } 1270 \text { to } 1320 \text { (Cal BP } 680 \text { to } 630 \text { ) }\end{array}$ & -19.9 o/oo & $690+/-40 \mathrm{BP}$ \\
\hline $\begin{array}{l}\text { Beta - } 149868 \\
\text { SAMPLE : } 865-1-1 \text { A } \\
\text { ANALYSIS : AMS-Standard delivery } \\
\text { MATERIAL/PRETREATMENT : } \\
2 \text { SIGMA CALIBRATION : }\end{array}$ & $\begin{array}{l}\qquad 460+/-40 \text { BP } \\
\text { ry } \\
\text { (organic material): acid washes } \\
\text { Cal AD } 1280 \text { to } 1410 \text { (Cal BP } 670 \text { to } 540 \text { ) }\end{array}$ & -13.8 o/oo & $640+/-40 \mathrm{BP}$ \\
\hline $\begin{array}{l}\text { Beta - } 149869 \\
\text { SAMPLE : } 865-1-2 \mathrm{~A} \\
\text { ANALYSIS : AMS-Standard delivery } \\
\text { MATERIAL/PRETREATMENT : } \\
2 \text { SIGMA CALIBRATION : }\end{array}$ & $\begin{array}{l}\qquad 540+/-50 \text { BP } \\
\text { ry } \\
\text { (organic material): acid washes } \\
\text { Cal AD } 1230 \text { to } 1310 \text { (Cal BP } 720 \text { to } 640 \text { ) }\end{array}$ & $\begin{array}{l}-14.2 \mathrm{o} / \mathrm{oo} \\
\text { AND Cal AD }\end{array}$ & $720+/-50 \mathrm{BP}$ \\
\hline $\begin{array}{l}\text { Beta - } 149870 \\
\text { SAMPLE : } 976-1-1 \text { A } \\
\text { ANALYSIS : AMS-Standard delivery } \\
\text { MATERIAL/PRETREATMENT : } \\
2 \text { SIGMA CALIBRATION : }\end{array}$ & $\begin{array}{l}\qquad 800+/-40 \mathrm{BP} \\
\text { ry } \\
\text { (organic material): acid washes } \\
\text { Cal AD } 1030 \text { to } 1230 \text { (Cal BP } 920 \text { to } 720 \text { ) }\end{array}$ & $-18.8 \mathrm{o} / \mathrm{oo}$ & $900+/-40 \mathrm{BP}$ \\
\hline $\begin{array}{l}\text { Beta }-149871 \\
\text { SAMPLE : } 976-1-2 A \\
\text { ANALYSIS : AMS-Standard delivery } \\
\text { MATERIAL/PRETREATMENT : } \\
\text { 2 SIGMA CALIBRATION : }\end{array}$ & $\begin{array}{l}\qquad 540+/-50 \text { BP } \\
\text { ry } \\
\text { (organic material): acid washes } \\
\text { Cal AD } 1280 \text { to } 1410 \text { (Cal BP } 670 \text { to } 540 \text { ) }\end{array}$ & $-19.2 \mathrm{o} / \mathrm{oo}$ & $640+/-50 \mathrm{BP}$ \\
\hline
\end{tabular}




\begin{tabular}{|c|c|c|c|}
\hline Sample Data & $\begin{array}{c}\text { Measured } \\
\text { Radiocarbon Age }\end{array}$ & $\begin{array}{c}13 \mathrm{C} / 12 \mathrm{C} \\
\text { Ratio }\end{array}$ & $\begin{array}{c}\text { Conventional } \\
\text { Radiocarbon Age }\left({ }^{*}\right)\end{array}$ \\
\hline $\begin{array}{l}\text { Beta - } 149873 \\
\text { SAMPLE : } 1311-1-2 \mathrm{~A} \\
\text { ANALYSIS : AMS-Standard delivery } \\
\text { MATERIAL/PRETREATMENT : } \\
\text { 2 SIGMA CALIBRATION : }\end{array}$ & $\begin{array}{l}\qquad 220+/-40 \text { BP } \\
\text { y } \\
\text { (organic material): acid washes } \\
\text { Cal AD } 1450 \text { to } 1650 \text { (Cal BP } 500 \text { to } 300 \text { ) }\end{array}$ & $-17.7 \mathrm{o} / \mathrm{oo}$ & $340+/-40 \mathrm{BP}$ \\
\hline $\begin{array}{l}\text { Beta - } 149874 \\
\text { SAMPLE : WB557/564-5A-5 } \\
\text { ANALYSIS : AMS-Standard delivery } \\
\text { MATERIAL/PRETREATMENT : } \\
\text { 2 SIGMA CALIBRATION : }\end{array}$ & $\begin{array}{l}\qquad 1000+/-50 \text { BP } \\
\text { y } \\
\text { (charred material): acid/alkali/acid } \\
\text { Cal AD 970 to } 1160 \text { (Cal BP } 980 \text { to 790) }\end{array}$ & $-25.0 \mathrm{o} / \mathrm{oo}$ & $1000+/-50 \mathrm{BP}$ \\
\hline $\begin{array}{l}\text { Beta - } 149875 \\
\text { SAMPLE : WB557/1182-3-1A } \\
\text { ANALYSIS : AMS-Standard delivery } \\
\text { MATERIAL/PRETREATMENT : } \\
2 \text { SIGMA CALIBRATION : }\end{array}$ & $\begin{array}{l}\qquad 470+/-40 \mathrm{BP} \\
\text { y } \\
\text { (burned clay): acid/alkali/acid } \\
\text { Cal AD } 1300 \text { to } 1430 \text { (Cal BP } 640 \text { to } 520 \text { ) }\end{array}$ & $-19.8 \mathrm{o} / \mathrm{oo}$ & $560+/-40 \mathrm{BP}$ \\
\hline
\end{tabular}




\section{CALIBRATION OF RADIOCARBON AGE TOCALENDAR YEARS}

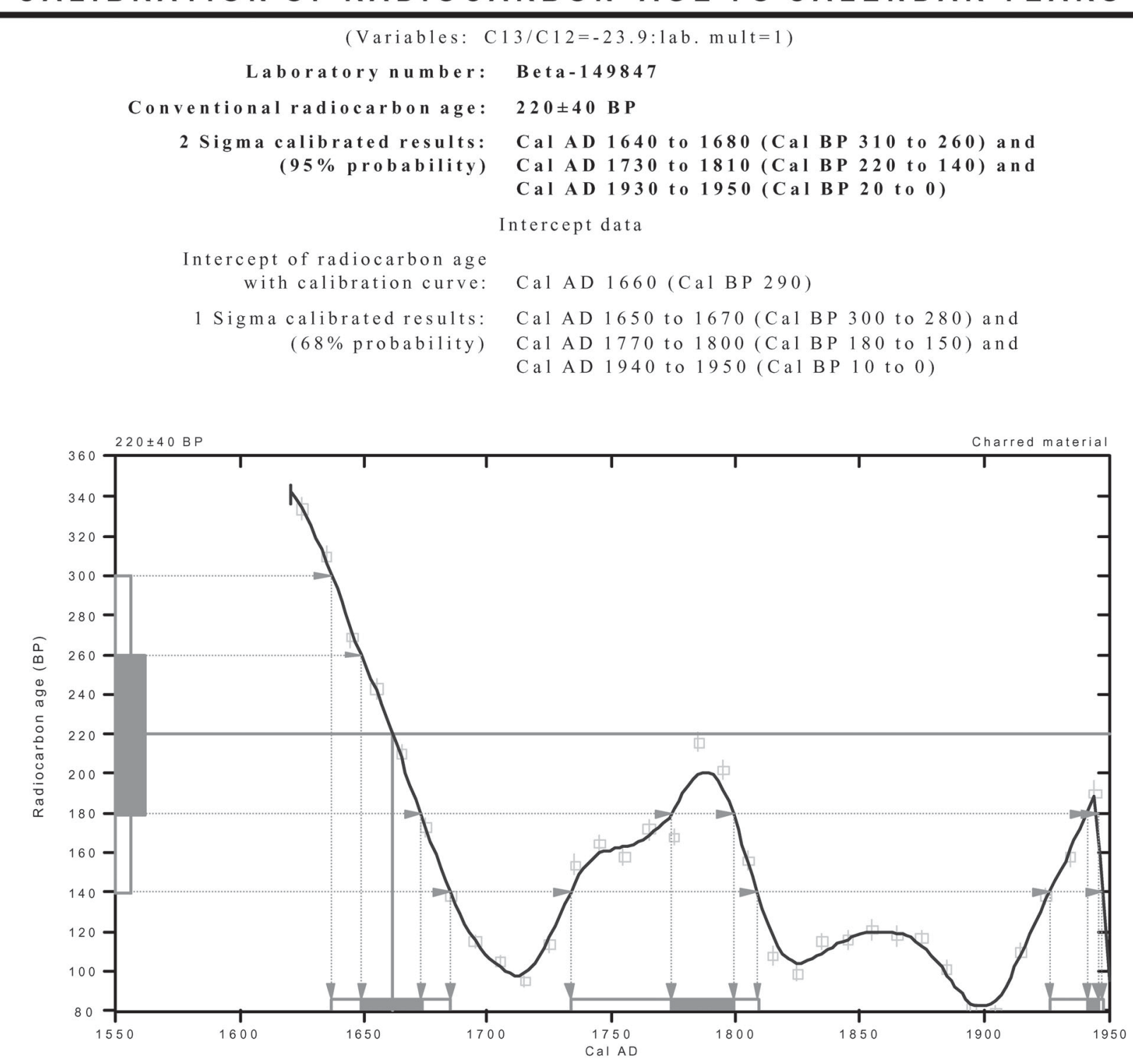

References:

Database used

Calibration Database

Editorial Comment

Stuiver, M., van der Plicht, H., 1998, Radiocarbon 40(3), pxii-xiii

INTCAL98 Radiocarbon Age Calibration

Stuiver, M., et. al., 1998, Radiocarbon 40(3), p1041-1083

Mathematics

A Simplified Approach to Calibrating C14 Dates

Talma, A. S., Vogel, J. C., 1993, Radiocarbon 35(2), p317-322

\section{Beta Analytic Inc.}

4985 SW74 Court, Miami, Florida 33155 USA $\cdot$ Tel: (305)6675167・Fax: (305)6630964·E-Mail: beta@radiocarbon.com 


\section{CALIBRATION OF RADIOCARBON AGE TO CALENDAR YEARS}

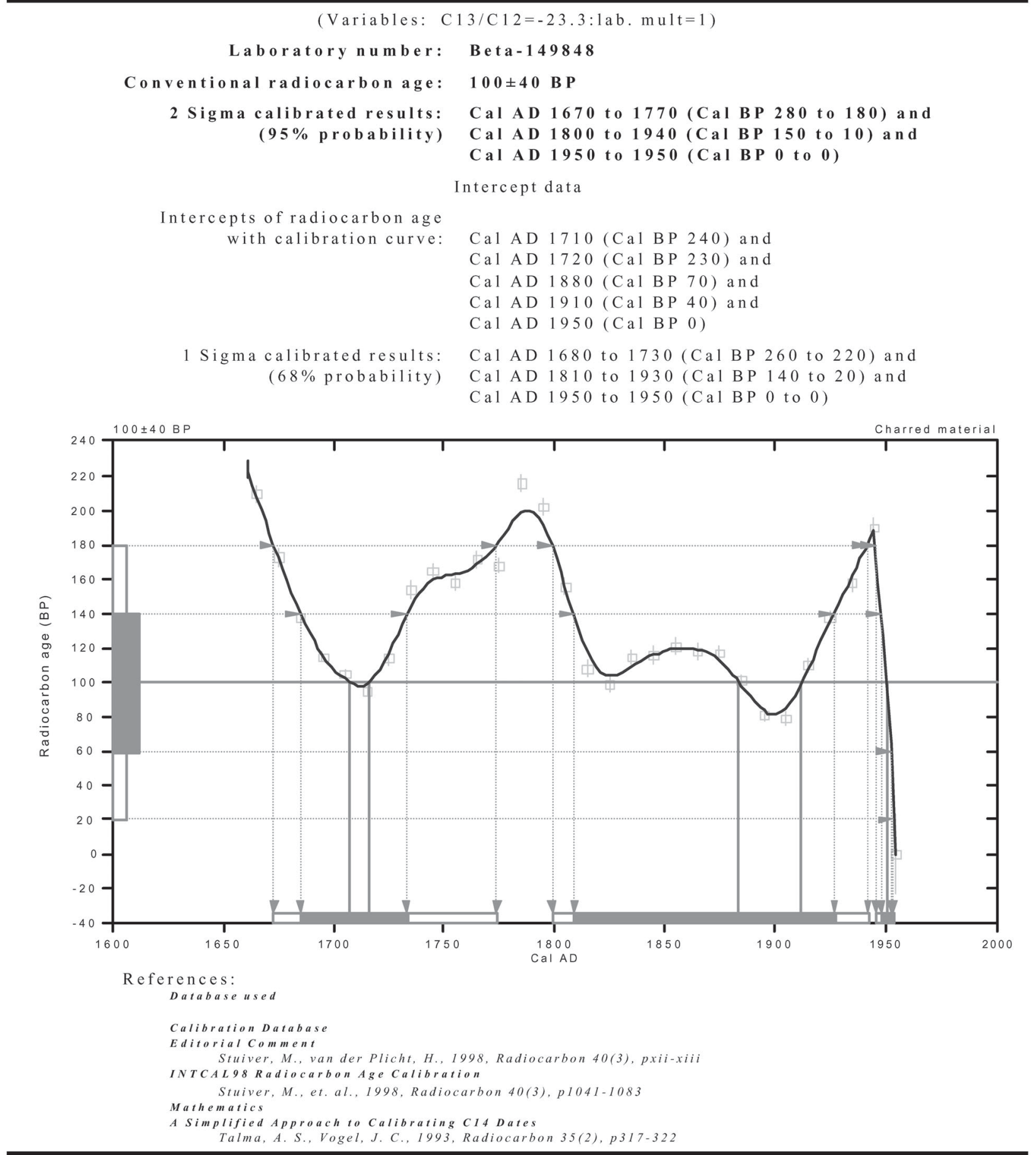

Beta Analytic Inc.

4985SW74 Court, Miami, Florida 33155 USA Tel: (305)6675167•Fax: (305)6630964・E-Mail: beta@radiocarbon.com 


\section{CALIBRATION OF RADIOCARBON AGE TO CALENDAR YEARS}
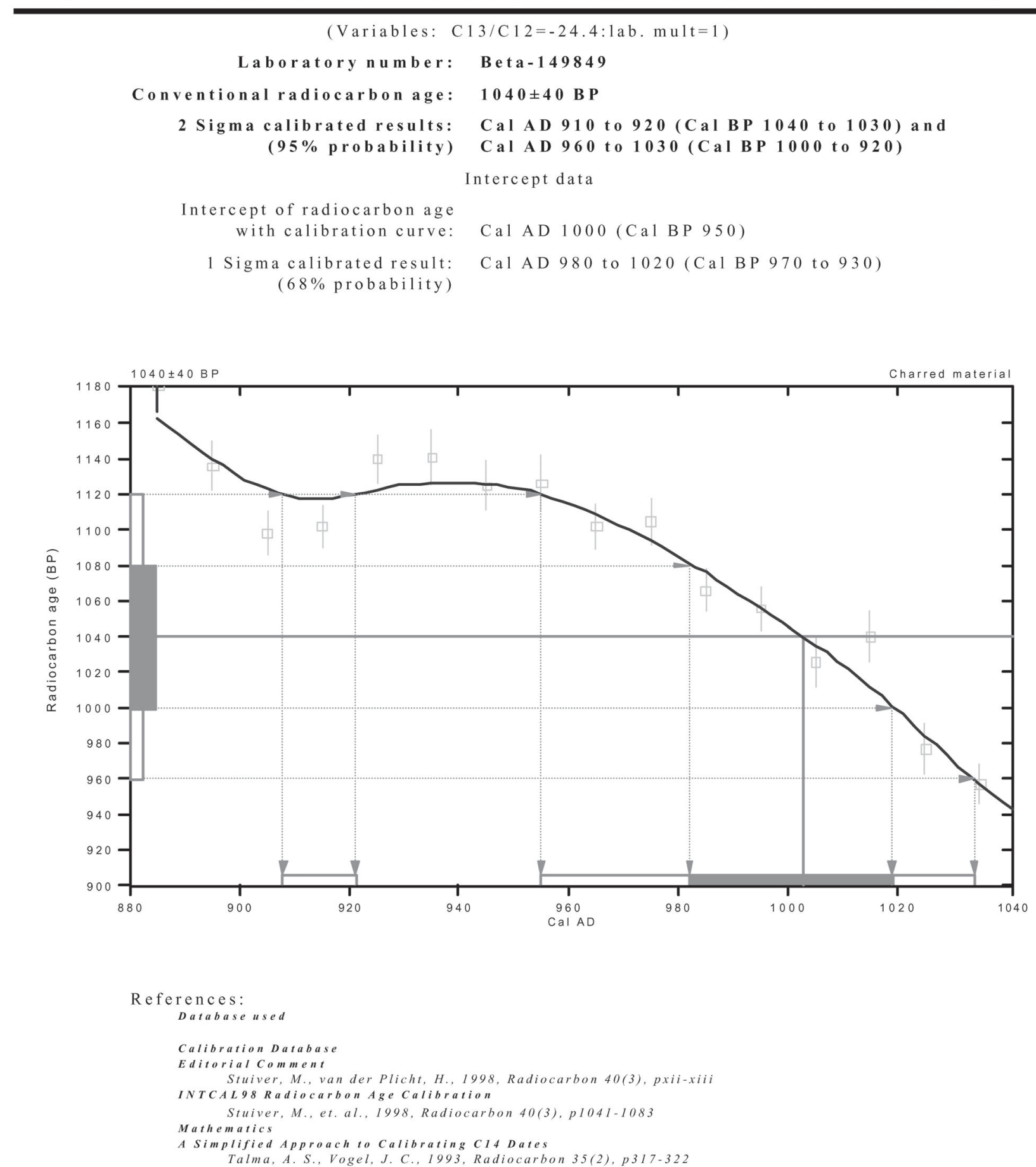

\section{Beta Analytic Inc.}




\section{CALIBRATION OF RADIOCARBON AGE TO CALENDAR YEARS}

$($ Variables: $\quad$ C $13 / \mathrm{C} 12=-22.8: 1 \mathrm{ab} . \mathrm{mu} 1 \mathrm{t}=1)$

Laboratory number: Beta-149850

Conventional radiocarbon age: $2130 \pm 40$ B P

2 Sigma calibrated results: Cal BC 350 to 300 (Cal BP2300 to 2250) and

$(95 \%$ probability) Cal BC 220 to 50 (Cal BP 2170 to 2000$)$

Intercept data

Intercept of radiocarbon age with calibration curve:

1 Sigma calibrated result: ( $68 \%$ probability)

Cal BC 170 ( Cal B P 2120)

Cal BC 200 to 100 (Cal BP 2150 to 2050 )

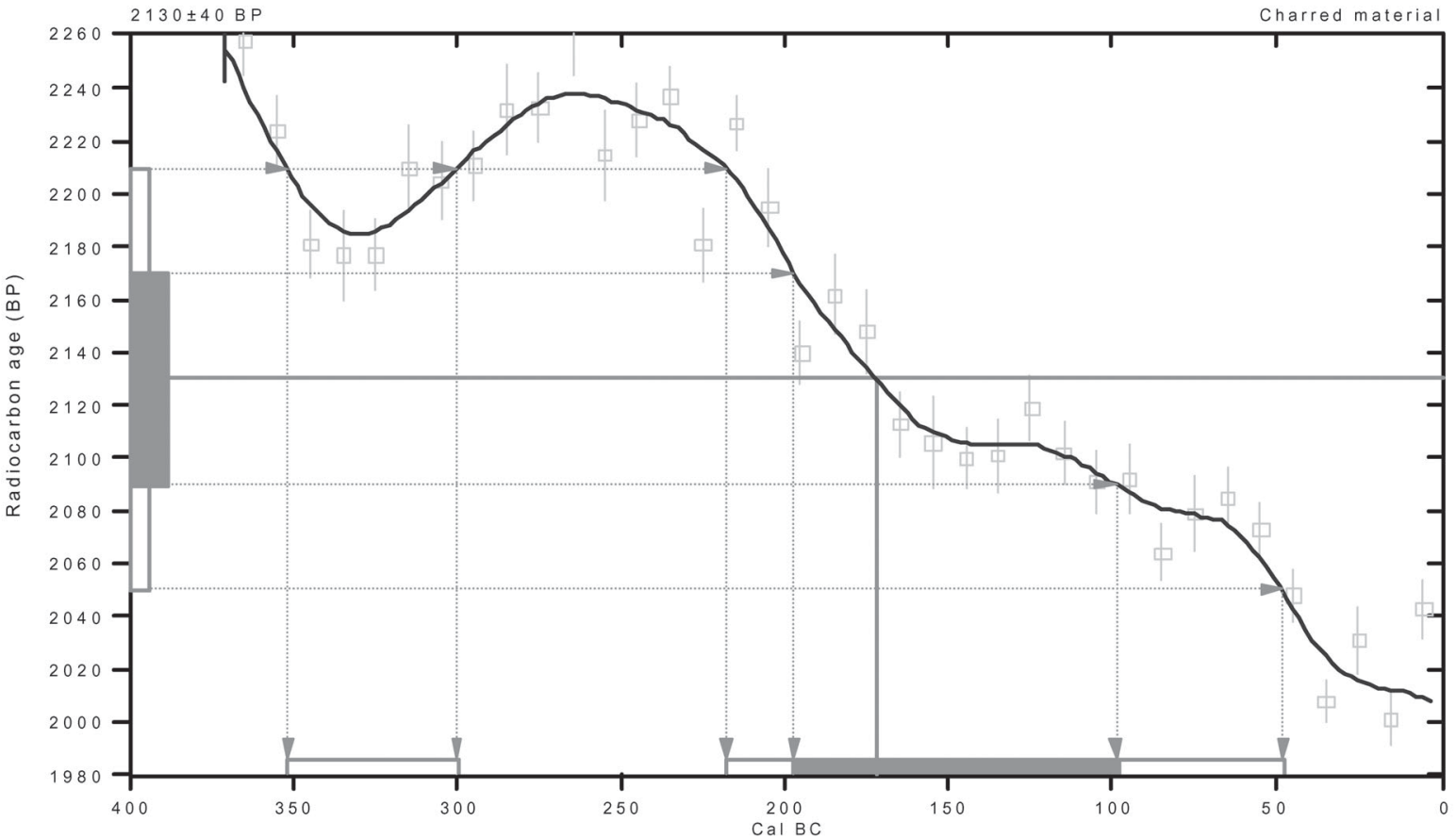

References:

Database used

Calibration Database

Editorial Comment

Stuiver, M., van der Plicht, H., 1998, Radiocarbon 40(3), pxii-xiii

INTCAL98 Radiocarbon Age Calibration

Stuiver, M., et. al., 1998, Radiocarbon 40(3), p1041-1083

Mathematics

Simplified Approach to Calibrating C14 Dates

Talma, A.S., Vogel, J. C., 1993, Radiocarbon 35(2), p317-322

\section{Beta Analytic Inc.}

4985 SW 74 Court, Miami, Florida 33155 USA Tel: (305)6675167・Fax: (305)6630964・E-Mail: beta@radiocarbon.com 


\section{CALIBRATION OF RADIOCARBON AGE TO CALENDAR YEARS}

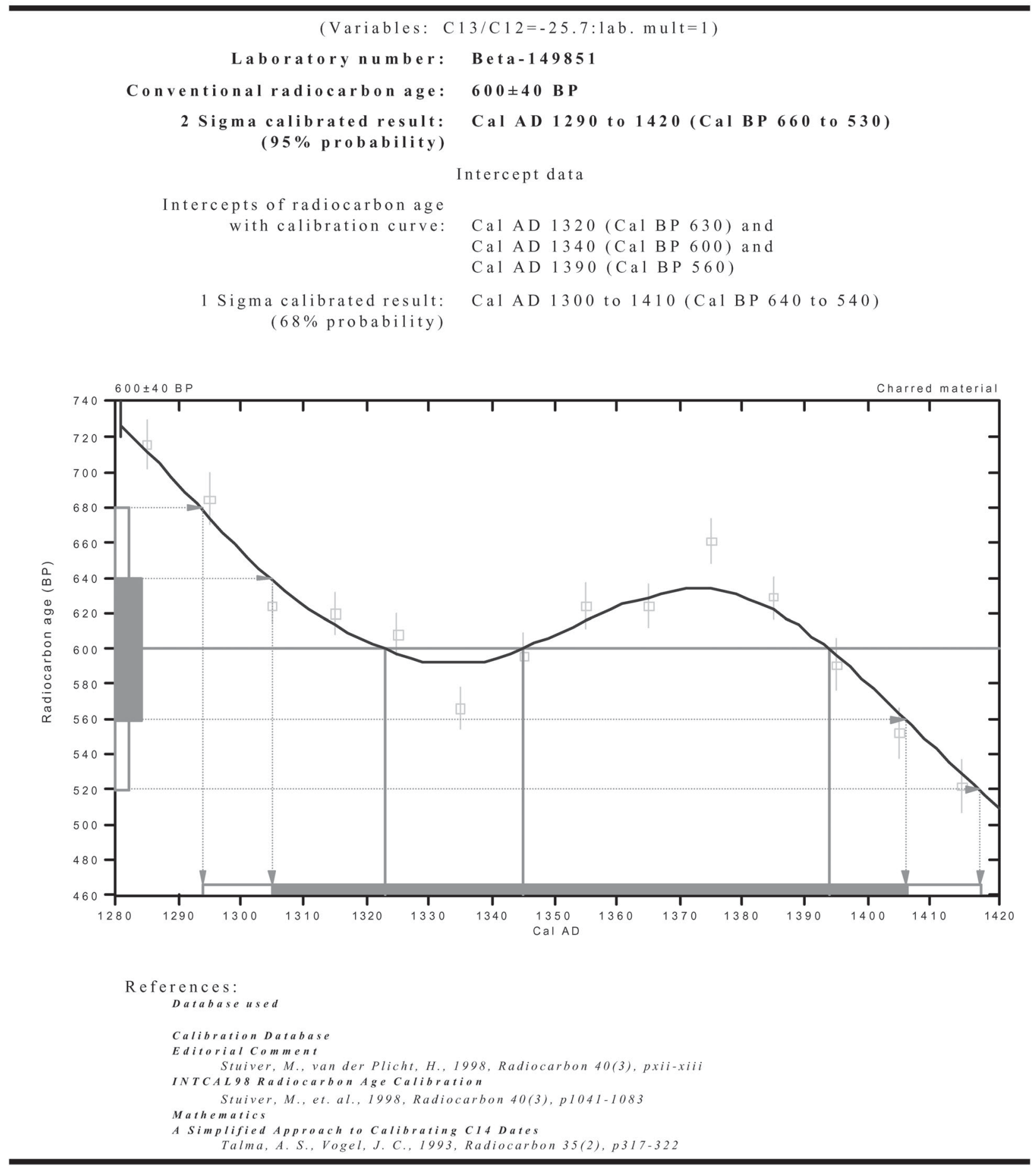

Beta Analytic Inc.

4985 SW 74 Court, Miami, Florida 33155 USA $\cdot$ Tel: (305)6675167•Fax: (305)6630964・E-Mail: beta@radiocarbon.com 


\title{
CALIBRATION OF RADIOCARBON AGE TO CALENDAR YEARS
}

\author{
$($ Variables: $\mathrm{C} 13 / \mathrm{C} 12=-26.8: \mathrm{lab}, \mathrm{mult}=1)$ \\ Laboratory n mber: 149852 \\ Conventional radiocarbon age: $480 \pm 80$ B P \\ 2 Sigma calibrated results: Cal AD 1300 to 1530 (Cal BP 640 to 420 ) and \\ ( $95 \%$ probability) Cal AD 1560 to 1630 (Cal BP 390 to 320 ) \\ Intercept data \\ Intercept of radiocarbon age \\ with calibration curve: Cal AD 1430 (Cal B P 520 ) \\ 1 Sigma calibrated result: Cal AD 1410 to 1460 (Cal B P 540 to 490) \\ (68\% probability)
}

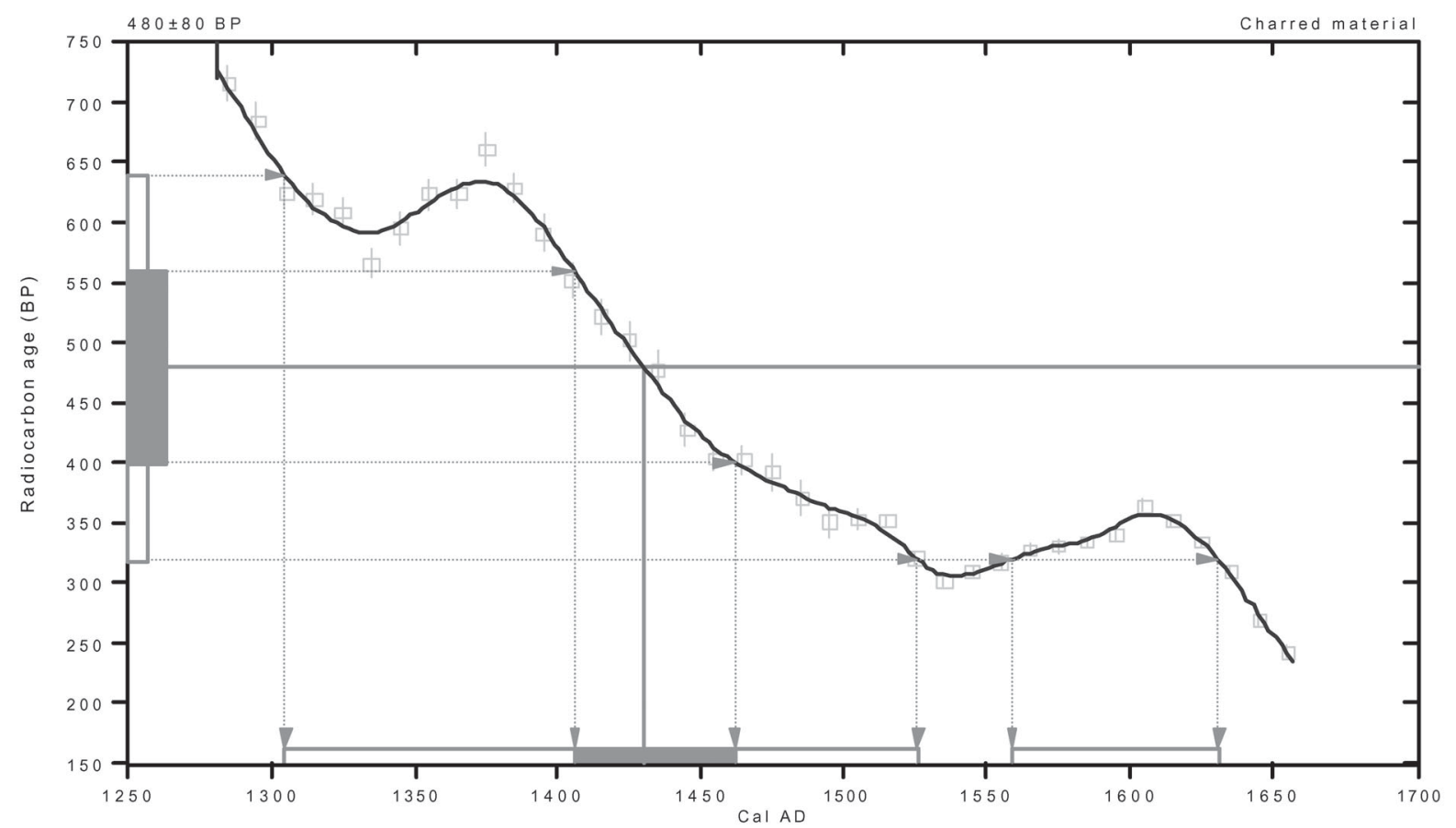

References:

Database used

Calibration Database

Editorial Comment

Stuiver. M., van der Plicht, H., 1998, Radiocarbon 40(3), pxii-xii

INTCAL98 Radiocarbon Age Calibration

Stuiver, M., et. al., 1998, Radiocarbon 40(3), p1041-1083

Mathematics

A Simplified Approach to Calibrating C14 Dates

Talma, A.S. Vogel, J. C., 1993, Radiocarbon 35(2), p317-322

Beta Analytic Inc.

4985 SW 74 Court, Miami, Florida 33155 USA Tel: (305)6675167・Fax: (305)6630964・E-Mail: beta@radiocarbon.com 


\section{CALIBRATION OF RADIOCARBON AGE TO CALENDAR YEARS}

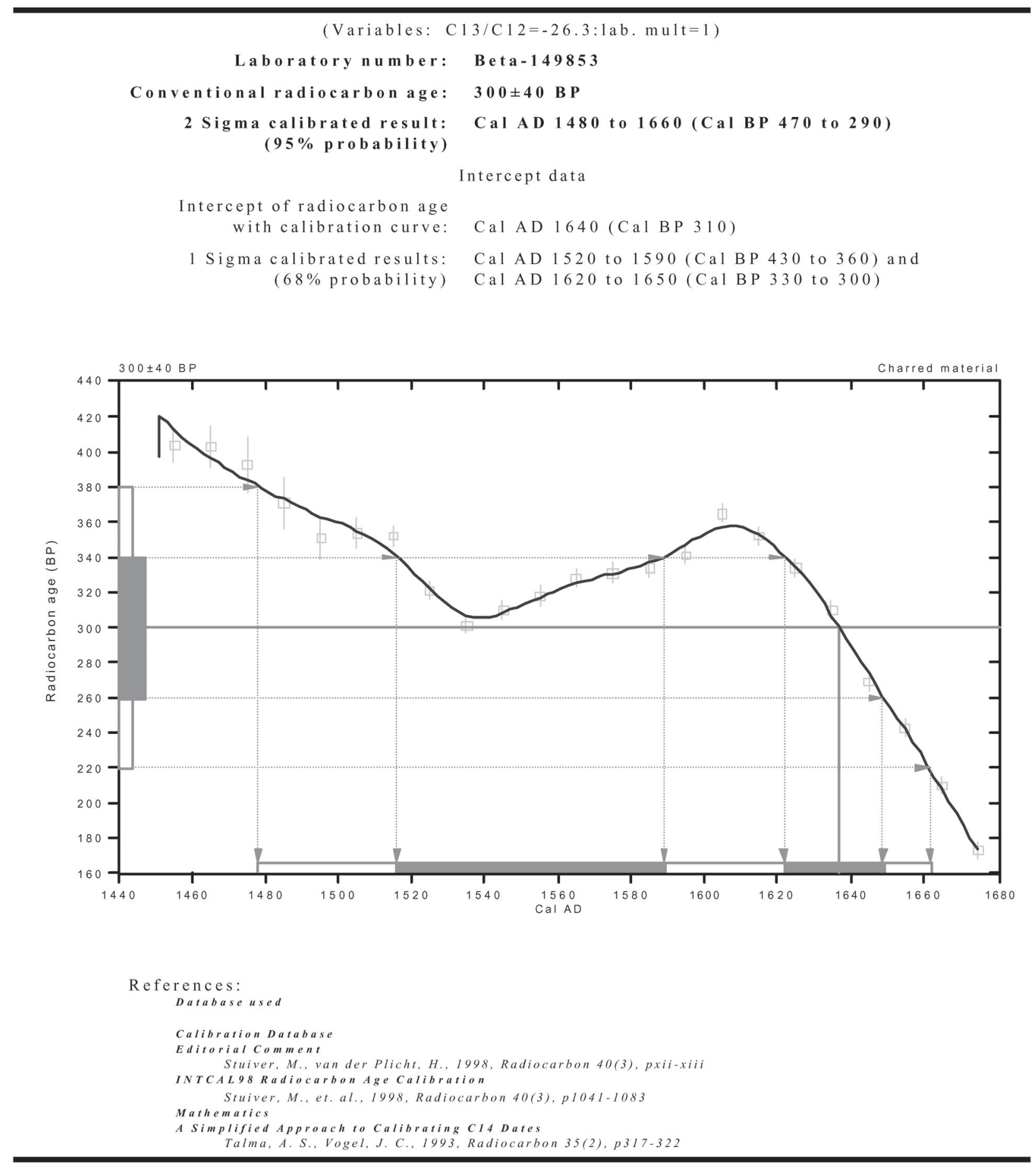

Beta Analytic Inc.

4985 SW 74 Court, Miami, Florida 33155 USA - Tel: (305)6675167・Fax: (305)6630964・E-Mail: beta@radiocarbon.com 


\section{CALIBRATION OF RADIOCARBON AGE TOCALENDAR YEARS}

(Variables: C $\left.13 / \mathrm{C} 12=-23.5: 1 \mathrm{ab} \cdot \mathrm{mu}_{1} \mathrm{t}=1\right)$

Laboratory number: Beta-149854

Conventional radiocarbon age:

$640 \pm 40$ B P

2 Sigma calibrated result: ( $95 \%$ probability)

Cal AD 1280 to 1410 (CaI BP 670 to 540$)$

Intercept data

Intercept of radiocarbon age with calibration curve:

1 Sigma calibrated results: Cal AD 1290 to 1320 (Cal BP 660 to 630 ) and ( $68 \%$ probability)

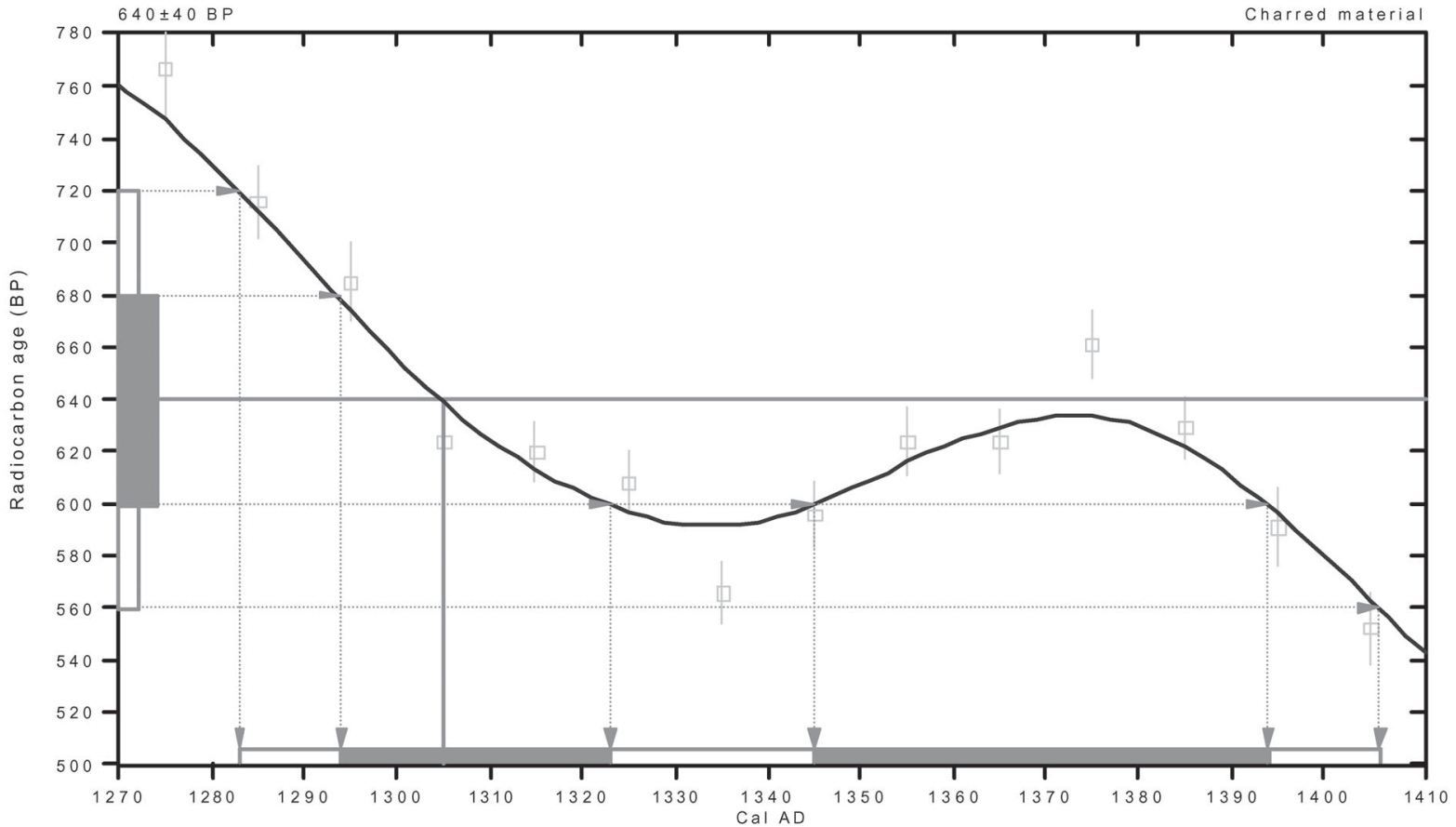

References:

Database used

Calibration Database

Editorial Comment

Stuiver, M., van der Plicht, H., 1998, Radiocarbon 40(3), pxii-xiii

INTCAL98 Radiocarbon Age Calibration

Stuiver, M., et. al., 1998, Radiocarbon 40(3), p1041-1083

Mathematics

A Simplified Approach to Calibrating Cl4 Dates

Talma, A.S.,Vogel,J.C., 1993, Radiocarbon 35(2), p317-322

\section{Beta Analytic Inc.}

4985 SW 74 Court, Miami, Florida 33155 USA Tel: (305)6675167・Fax:(305)6630964・E-Mail: beta@radiocarbon.com 


\section{CALIBRATION OF RADIOCARBON AGE TO CALENDAR YEARS}

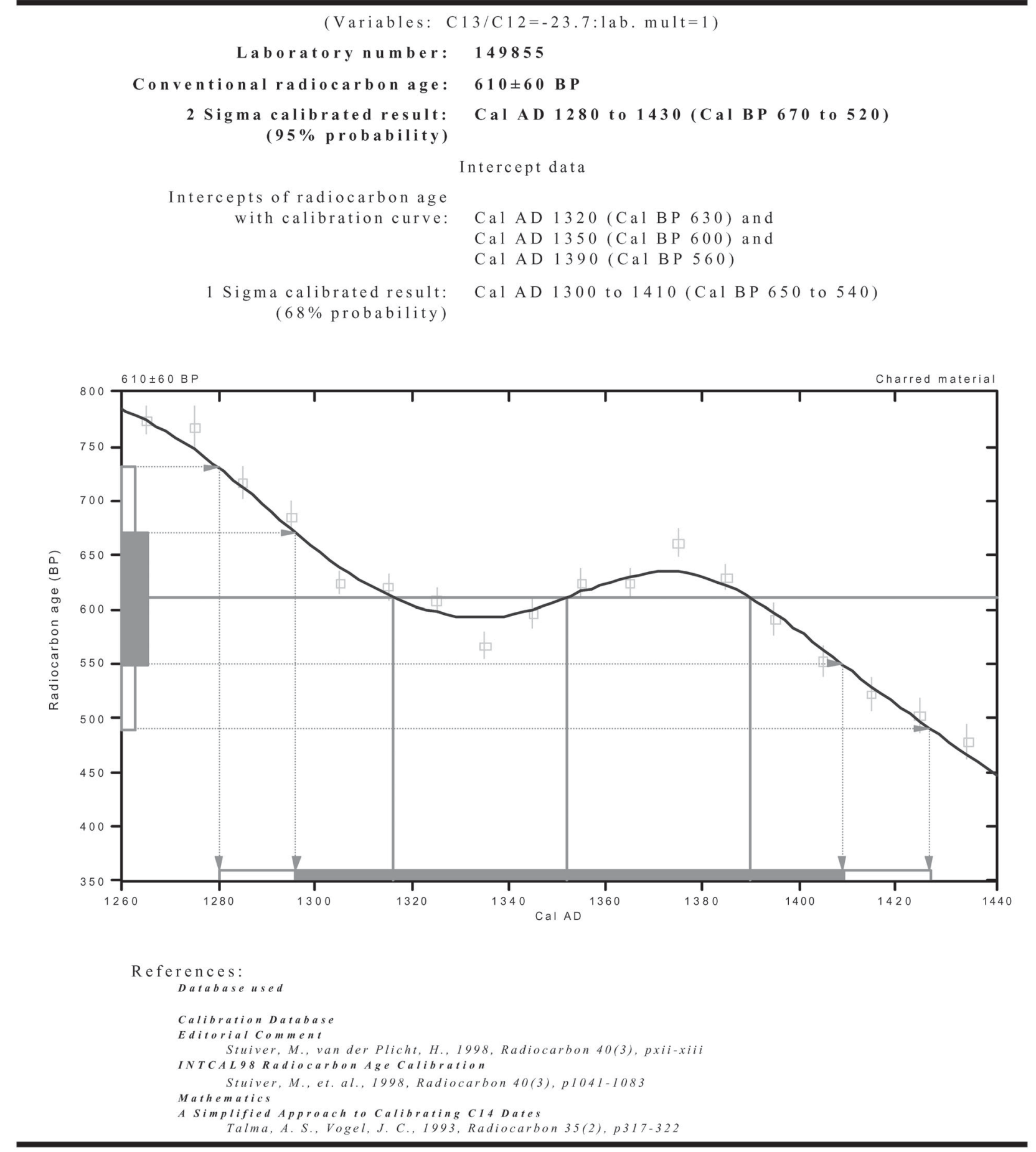

Beta Analytic Inc.

4985 SW 74 Court, Miami, Florida 33155 USA - Tel: (305) $6675167 \cdot$ Fax: (305) $6630964 \cdot$ E-Mail: beta@radiocarbon.com 


\section{CALIBRATION OF RADIOCARBON AGE TOCALENDAR YEARS}

$($ Variables: $\quad$ C $13 / \mathrm{C} 12=-23.9: 1 \mathrm{ab} . \mathrm{mu} 1 \mathrm{t}=1)$

Laboratory number: Beta-149856

Conventional radiocarbon age: $500 \pm 60$ B P

2Sigma calibrated results: Cal AD 1310 to 1360 (Cal BP640 to 590) and

(95\% probability) CaI AD 1390 to 1480 (Cal BP 560 to 470)

Intercept data

Intercept of radiocarbon age with calibration curve:

$1 \mathrm{Sigma} c \mathrm{librated} \mathrm{result:}$ (68\% probability)

Cal AD 1420 (Cal B P 530$)$

Cal AD 1410 to 1440 (Cal B P 540 to 510$)$

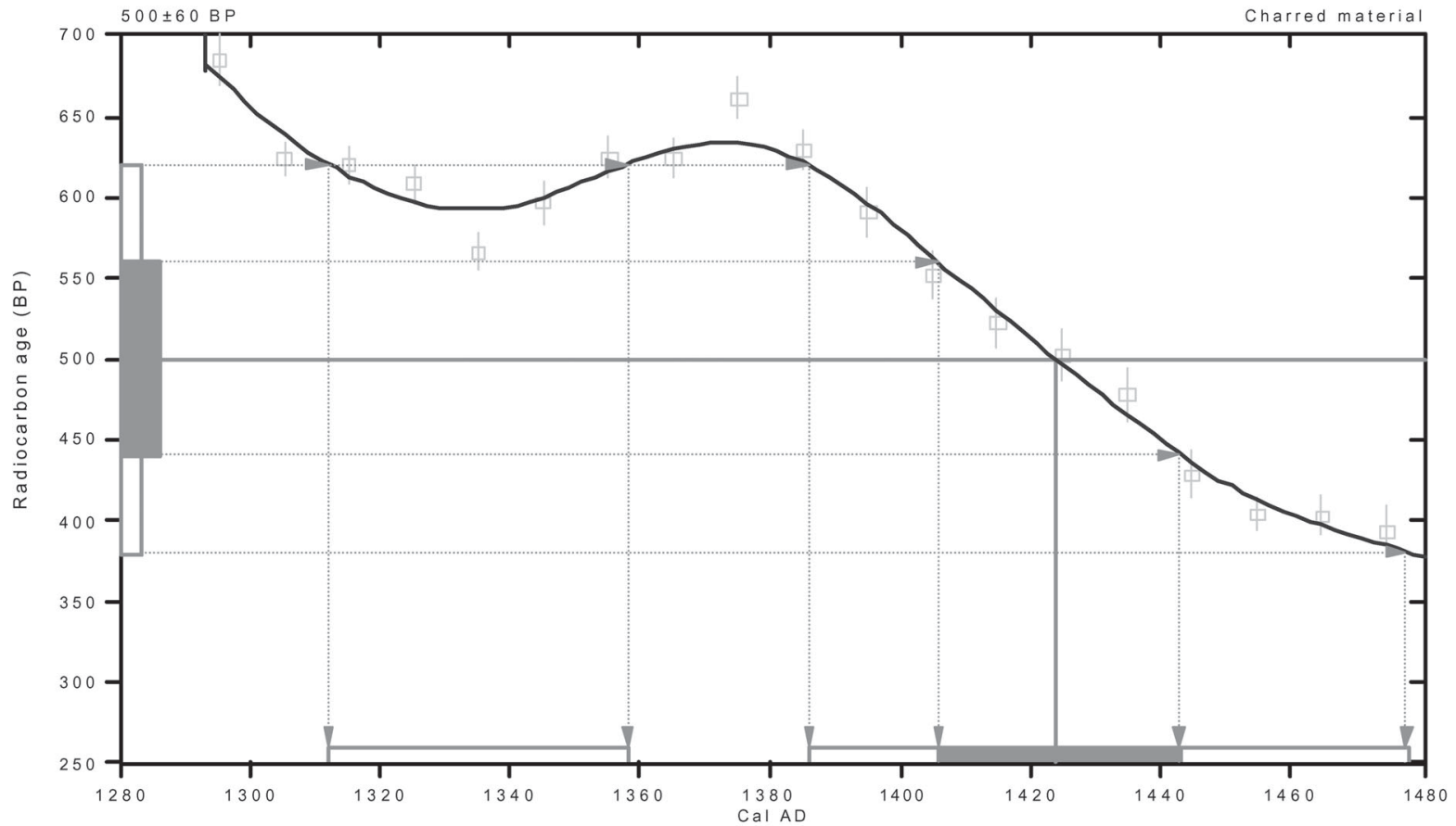

References:

Dat ab a se used

Calibration Database

Editorial Comment

Stuiver, M., van der Plicht, H., 1998, Radiocarbon 40(3), pxii-xiii

INTCAL98 Radiocarbon Age Calibration

Stuiver, M., et. al., 1998, Radiocarbon 40(3), p1041-1083

Mathematics

A Simplified Approach to Calibrating C14 Dates

Talma, A.S. Vogel, J. C. l993, Radiocarbon 35(2) p3l7-322

\section{Beta Analytic Inc.}

4985 SW 74 Court, Miami, Florida 33155 USA -Tel: (305)6675167•Fax: (305)6630964・E-Mail: beta@radiocarbon.com 


\section{CALIBRATION OF RADIOCARBON AGE TO CALENDAR YEARS}

(Variab1es: C $13 / \mathrm{C} 12=-25: 1 \mathrm{ab} . \mathrm{mu} 1 \mathrm{t}=1)$

Laboratory number: Beta-149857

Conventional radiocarbon age: $1710 \pm 50$ B P

2 Sigma calibrated result: Cal AD 230 to 430 (Cal BP 1720 to 1520)

( $95 \%$ probability)

Intercept data

Intercept of radiocarbon age

with calibration curve: Cal AD 350 (Cal B P 1600 )

1 Sigma calibrated result: Cal AD 250 to 400 (Cal B P 1700 to 1550 )

(68\% probability)

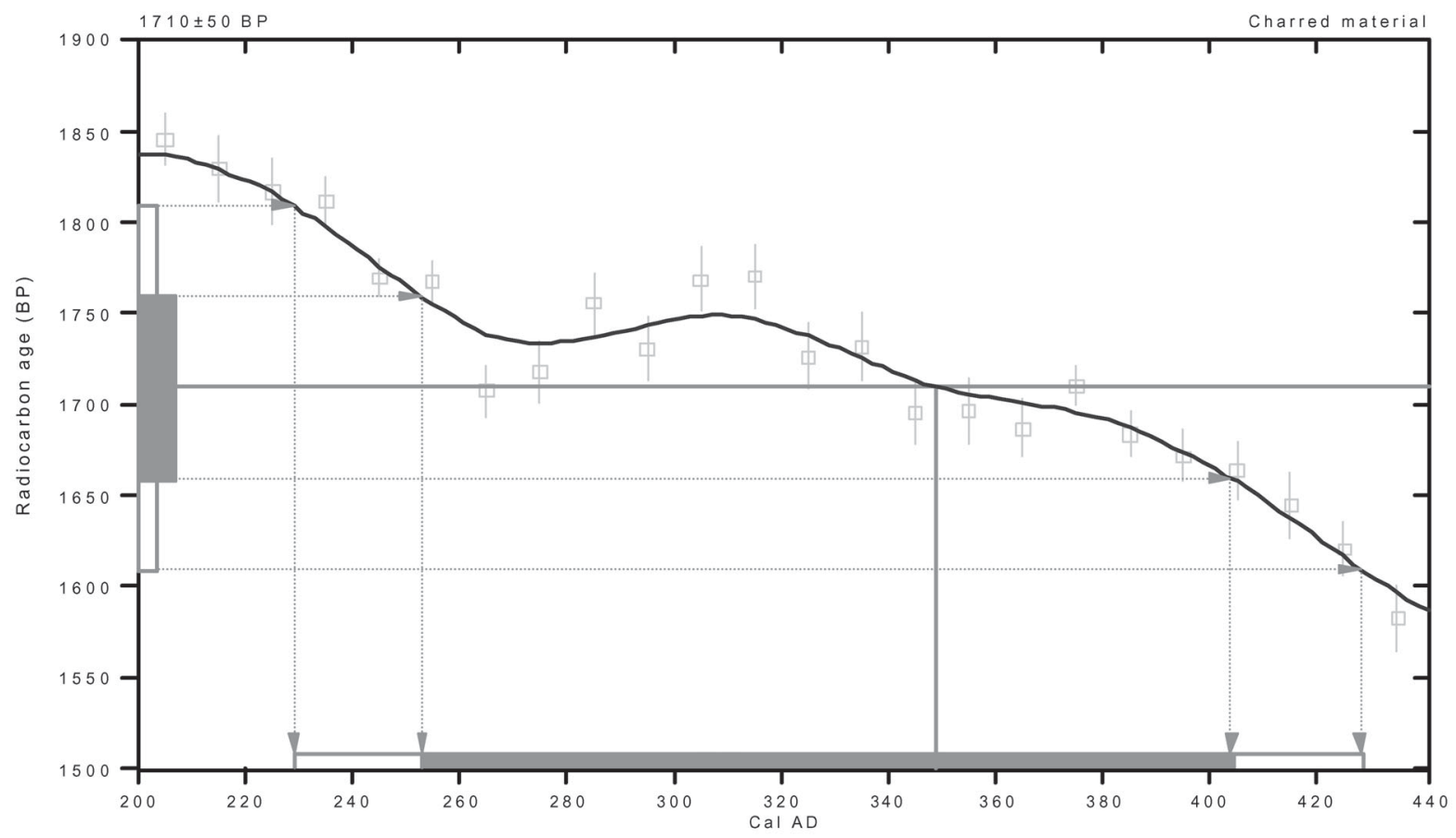

References:

Dat ab a se used

Calibration Database

Editorial Comment

Stuiver, M., van der Plicht, H., 1998, Radiocarbon 40(3), pxii-xiii

INTCAL 98 Radiocarbon Age Calibration

Stuiver, M., et. al., 1998, Radiocarbon 40(3), p1041-1083

Mathematics

A Simplified Approach to Calibrating C14 Dates

Talma, A S Vogel, J C l 993 , Radiocarbon 35(2), p3l7-322

\section{Beta Analytic Inc.}

4985 SW 74 Court, Miami, Florida 33155 USA -Tel: (305)6675167•Fax:(305)6630964・E-Mail: beta@radiocarbon.com 


\section{CALIBRATION OF RADIOCARBON AGE TO CALENDAR YEARS}

(Variables: $\mathrm{C} 13 / \mathrm{C} 12=-23.7: 1 \mathrm{ab} . \mathrm{mult}=1)$

Laboratory number: Beta-149858

Conventional radiocarbon age: $580 \pm 40$ BP

2 Sigma calibrated result: Cal AD 1300 to 1420 (Cal BP 650 to 530 )

$(95 \%$ probability)

Intercept data

Intercept of radiocarbon age

with calibration curve: Cal AD 1400 (Cal B P 550)

1 Sigma calibrated results: Cal AD 1310 to 1360 (Cal BP 640 to 590) and

(68\% probability) Cal AD 1390 to 1410 (Ca1 BP 560 to 540 )

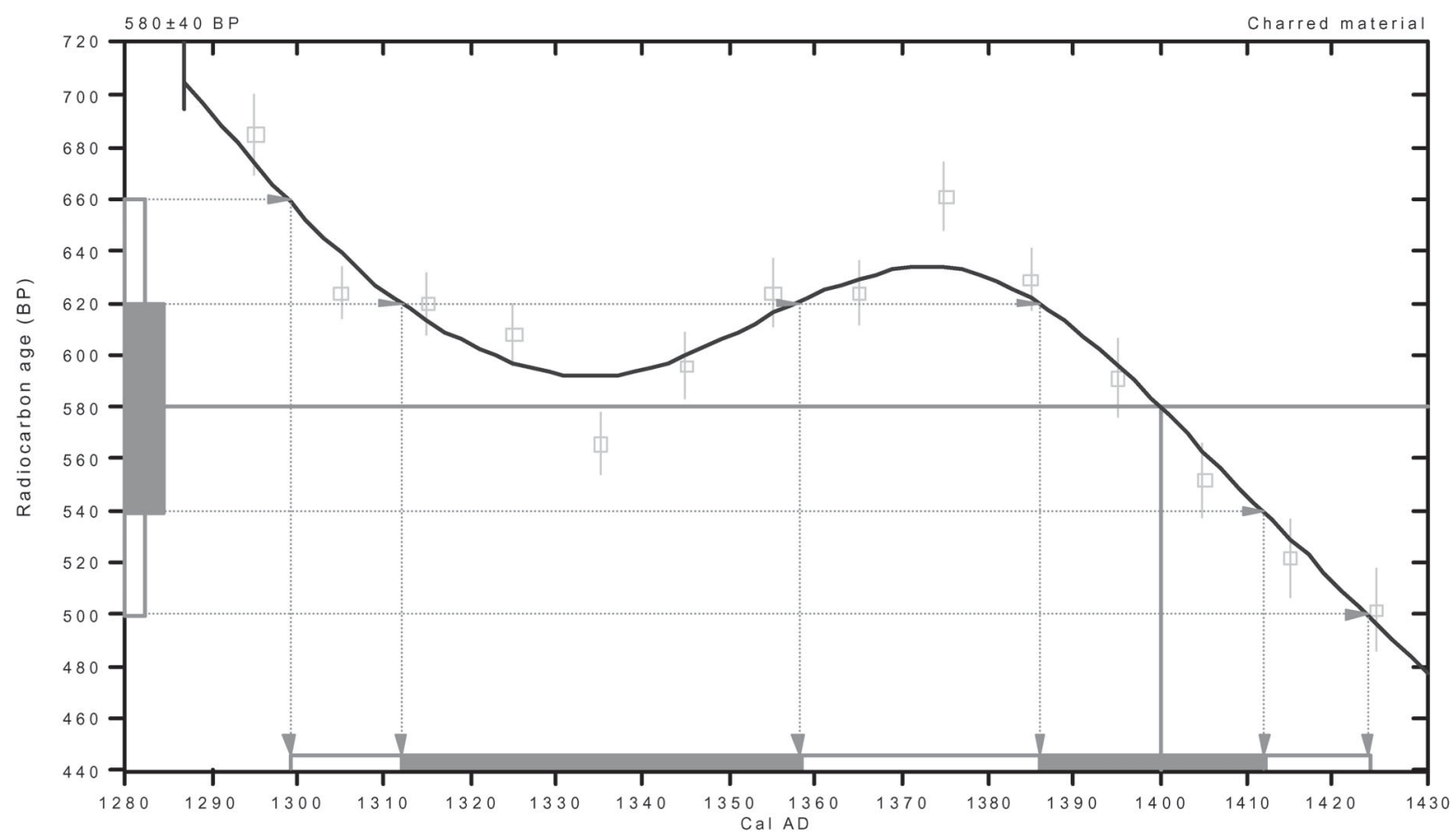

References:

Database used

Calibration Database

Editorial Comment

Stuiver, M., van der Plicht, H., 1998, Radiocarbon 40(3), pxii-xiii

INTCAL98 Radiocarbon Age Calibration

Stuiver, M., et. al., 1998, Radiocarbon 40(3), p1041-1083

Mathematics

A Simplified Approach to Calibrating CI 4 Dates

Talma, A. S., Vogel, J. C., 1993, Radiocarbon 35(2), p317-322

\section{Beta Analytic Inc.}

4985 SW 74 Court, Miami, Florida 33155 USA $\cdot$ Tel: (305)6675167・Fax: (305)6630964・E-Mail: beta@radiocarbon.com 


\section{CALIBRATION OF RADIOCARBON AGE TO CALENDAR YEARS}

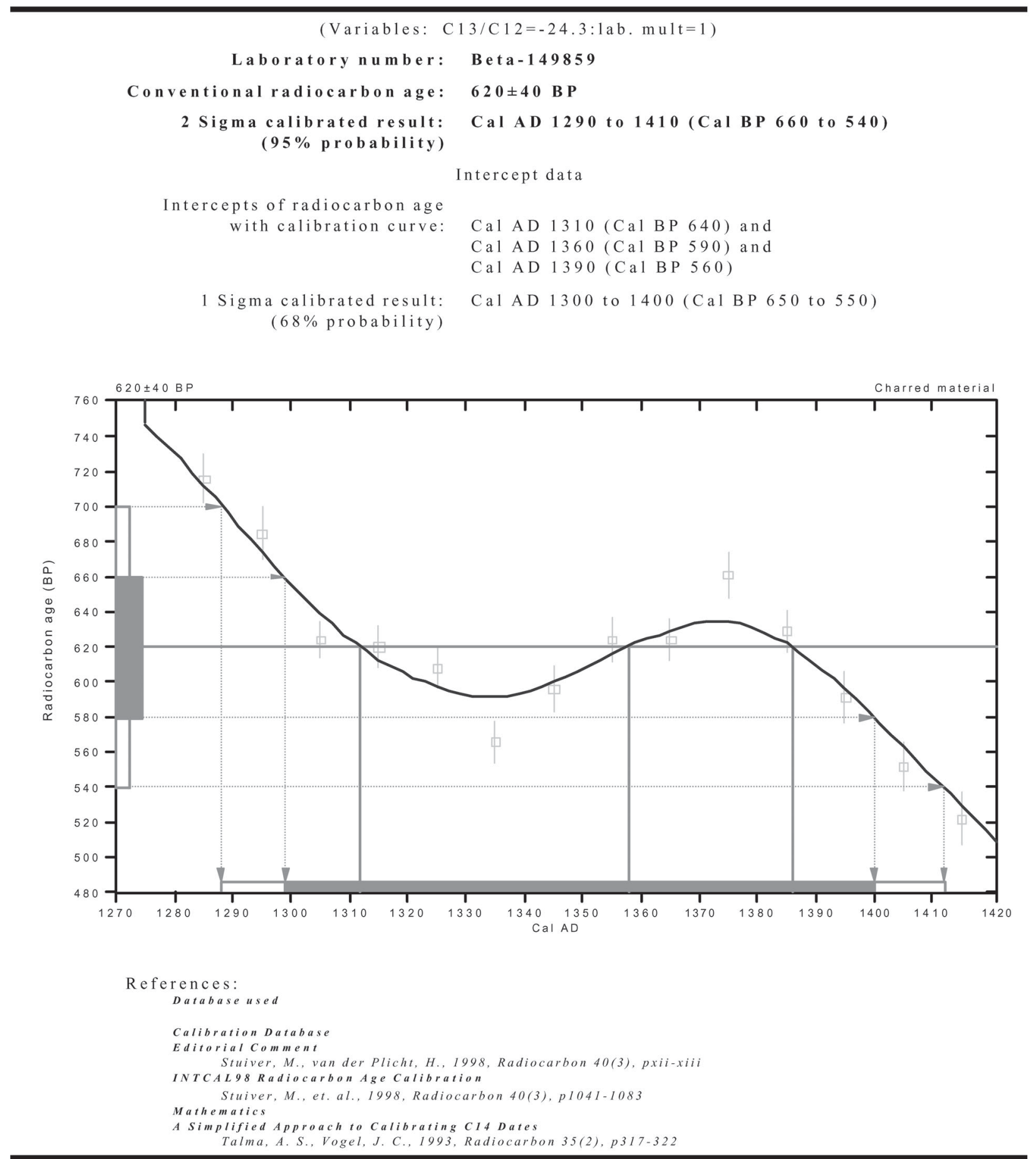

Beta Analytic Inc.

4985 SW 74 Court, Miami, Florida 33155 USA Tel: (305)6675167・Fax: (305)6630964・E-Mail: beta@radiocarbon.com 


\section{CALIBRATION OF RADIOCARBON AGE TO CALENDAR YEARS}

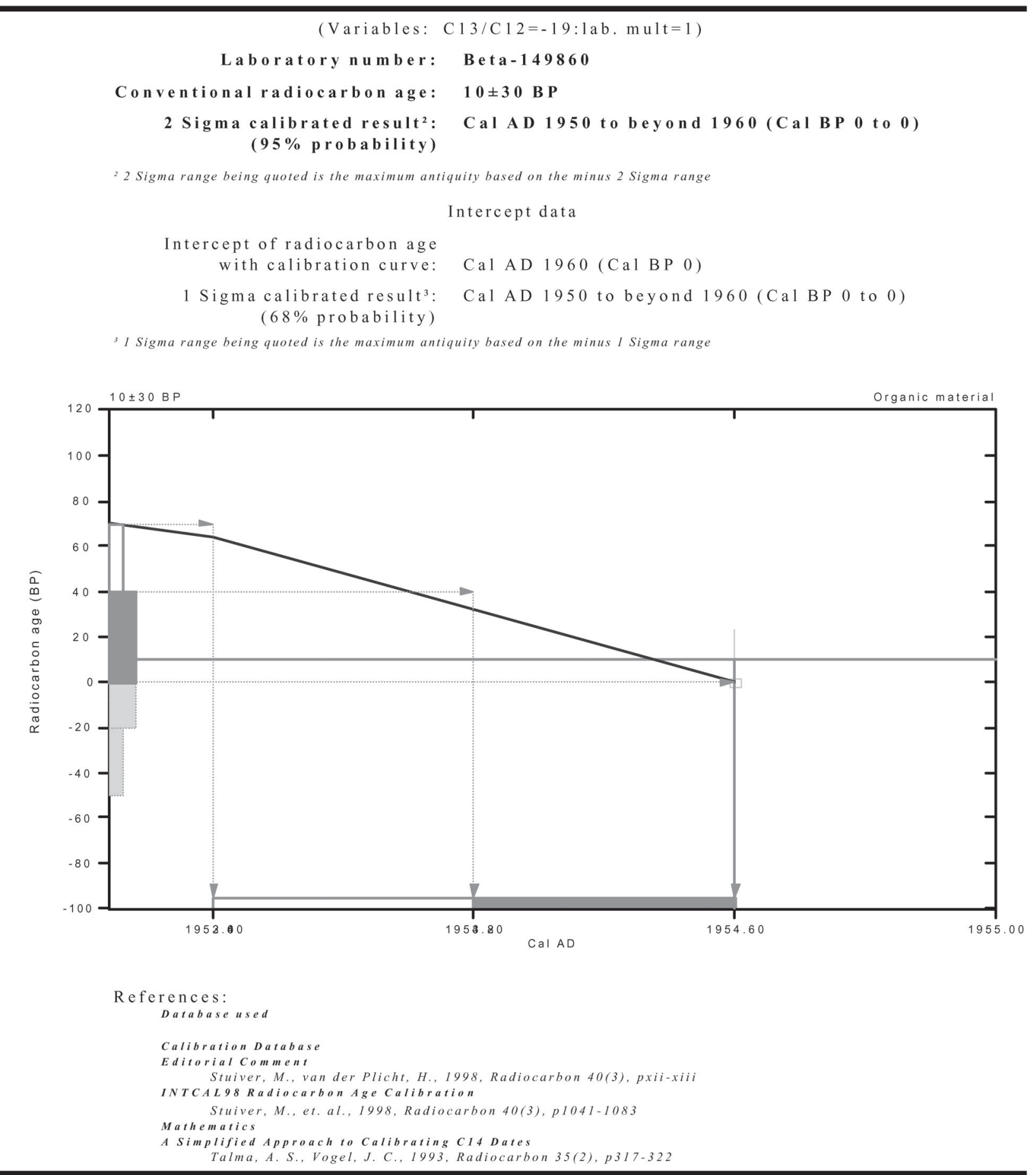

Beta Analytic Inc.

4985 SW 74 Court, Miami, Florida33155USA Tel: (305)6675167・Fax:(305)6630964・E-Mail: beta@radiocarbon.com 


\section{CALIBRATION OF RADIOCARBON AGE TO CALENDAR YEARS}

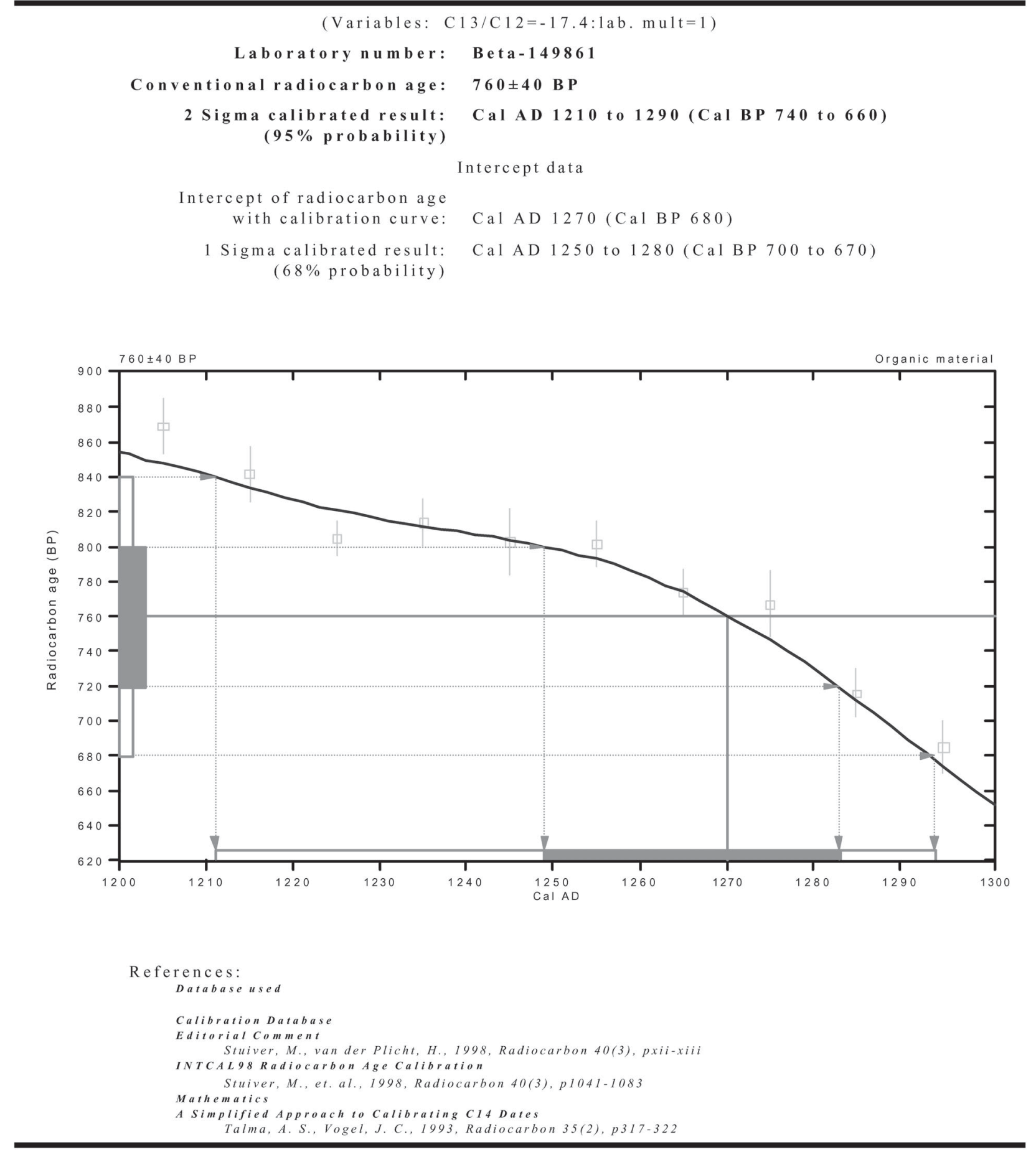

Beta Analytic Inc.

4985 SW74 Court, Miami, Florida 33155 USA Tel: (305)6675167・Fax: (305)6630964・E-Mail: beta@radiocarbon.com 


\section{CALIBRATION OF RADIOCARBON AGE TOCALENDAR YEARS}

(Variables: C $13 / \mathrm{C} 12=-21.6: 1 \mathrm{ab} \cdot \mathrm{mu} 1 \mathrm{t}=1)$

Laboratory number: Beta-149862

Conventional radiocarbon age: $3040 \pm 40$ B P

2 Sigma calibrated result: Cal BC 1400 to 1190 (Cal BP3350 to 3140 ) $(95 \%$ probability) Intercept data

Intercept of radiocarbon age with calibration curve: Cal BC 1300 (Cal B P 3250 )

1 Sigma calibrated result: Cal BC 1380 to 1260 (Cal B P 3330 to 3210 ) $(68 \%$ probability)

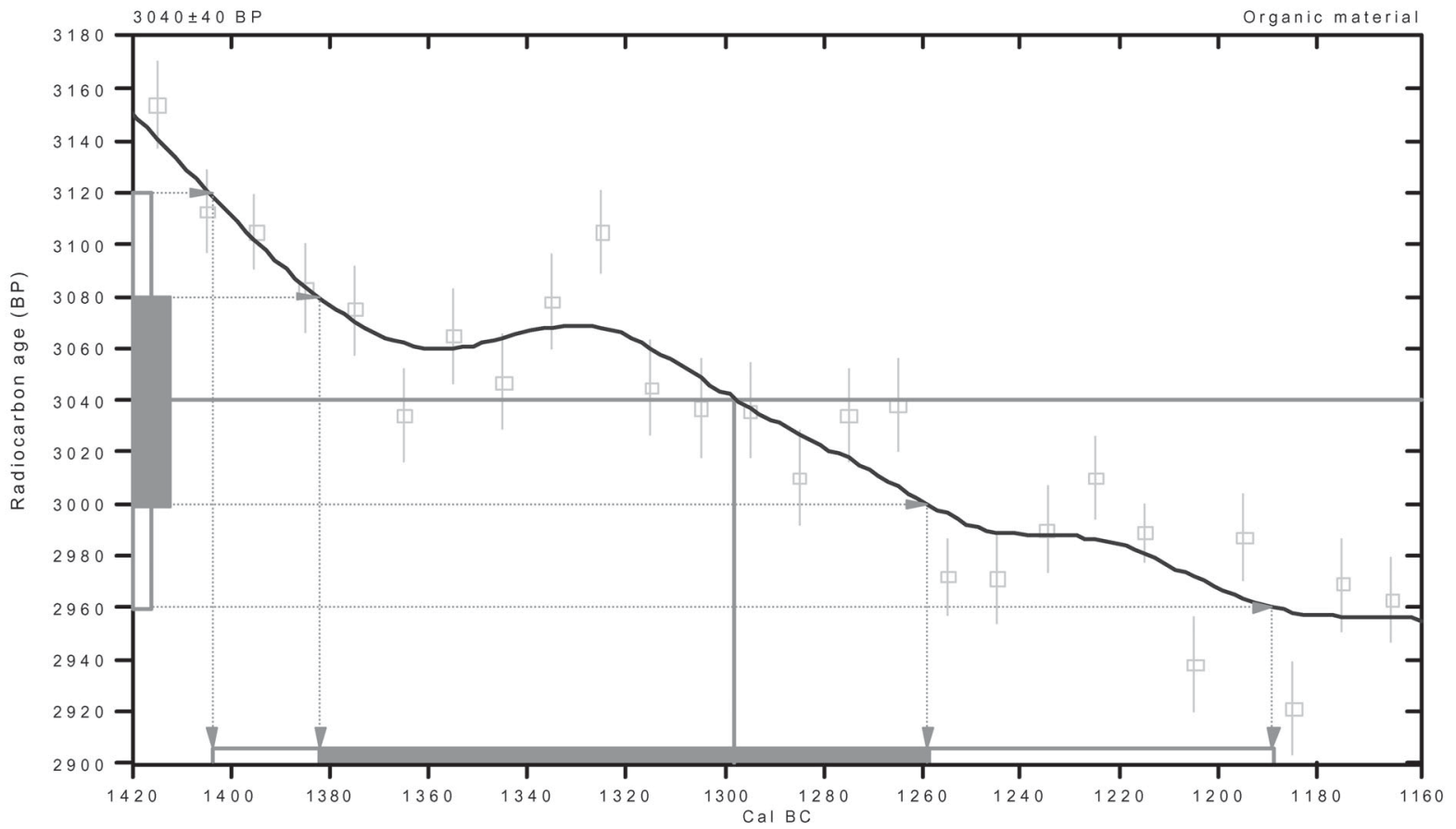

References:

Dat ab a se used

Calibration Database

Editorial Com men

Stuiver, M., van der Plicht, H., 1998, Radiocarbon 40(3), pxii-xiii

INTCAL98 Radiocarbon Age Calibration

Stuiver, M., et. al., 1998, Radiocarbon 40(3), p1041-1083

Mathematics

A Simplified Approach to Calibrating C14 Dates

Talma, A S , Vogel. J C 1993 , Radiocarbon 35(2), p317-32

\section{Beta Analytic Inc.}

4985 SW 74 Court, Miami, Florida 33155 USA Tel: (305)6675167・Fax: (305)6630964・E-Mail: beta@radiocarbon.com 


\title{
CALIBRATION OF RADIOCARBON AGE TO CALENDAR YEARS
}

\author{
(Variables: C $13 / \mathrm{C} 12=-25: 1 \mathrm{ab} \cdot \mathrm{mult}=1$ ) \\ Laboratory number: Beta-149863 \\ Conventional radiocarbon age: $3410 \pm 40$ B P \\ 2 Sigma calibrated result: CaI BC 1770 to 1620 (CaI BP 3720 to 3570) \\ $(95 \%$ probability) \\ Intercept data \\ Intercept of radiocarbon age \\ with calibration curve: Cal BC 1700 (Cal BP 3650 ) \\ 1 Sigma calibrated result: Cal BC 1750 to 1670 (Cal B P 3700 to 3620 ) \\ $(68 \%$ probability)
}
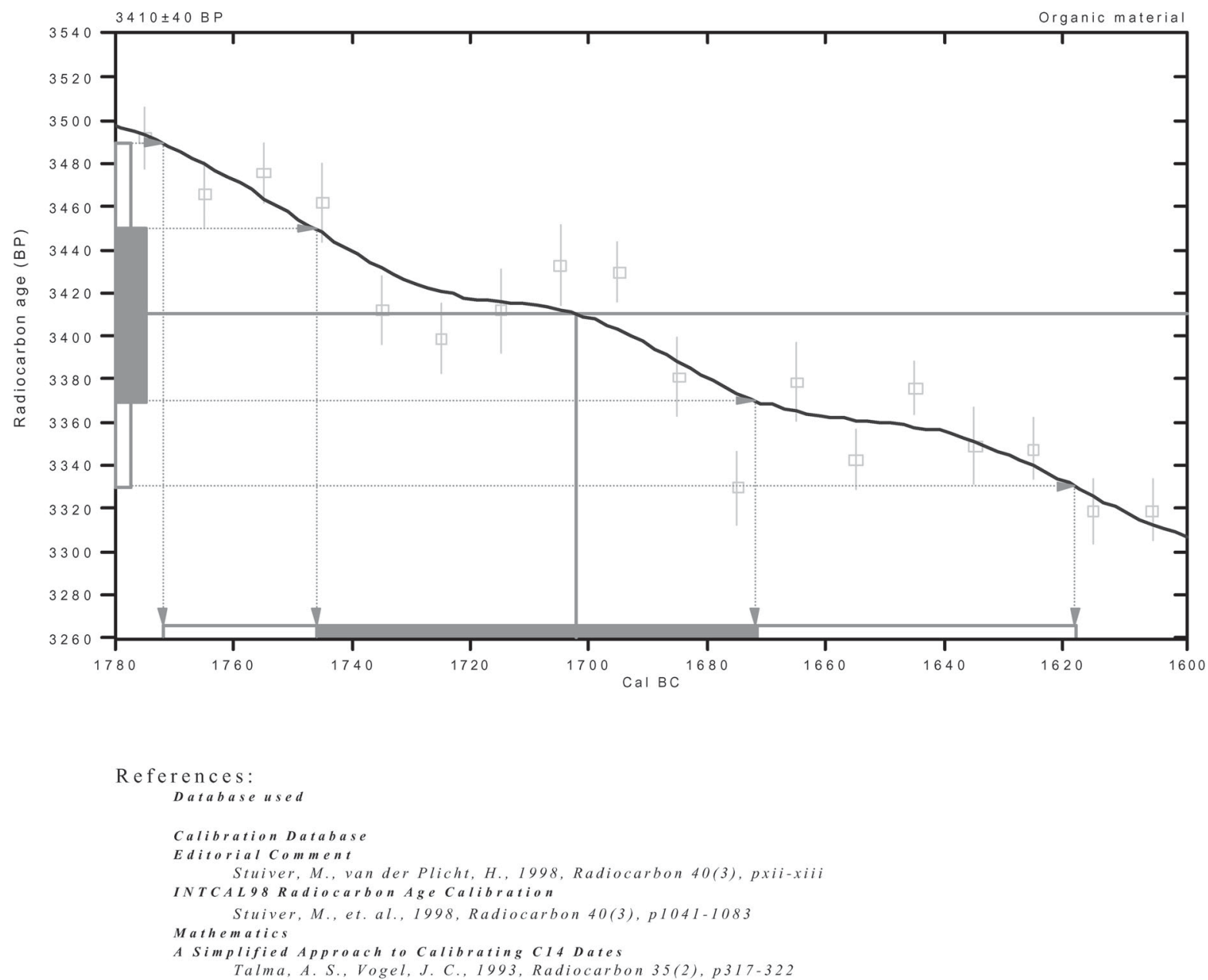

Beta Analytic Inc.

4985 SW 74 Court, Miami, Florida 33155 USA Tel: (305)6675167・Fax: (305)6630964・E-Mail: beta@radiocarbon.com 


\section{CALIBRATION OF RADIOCARBON AGE TO CALENDAR YEARS}

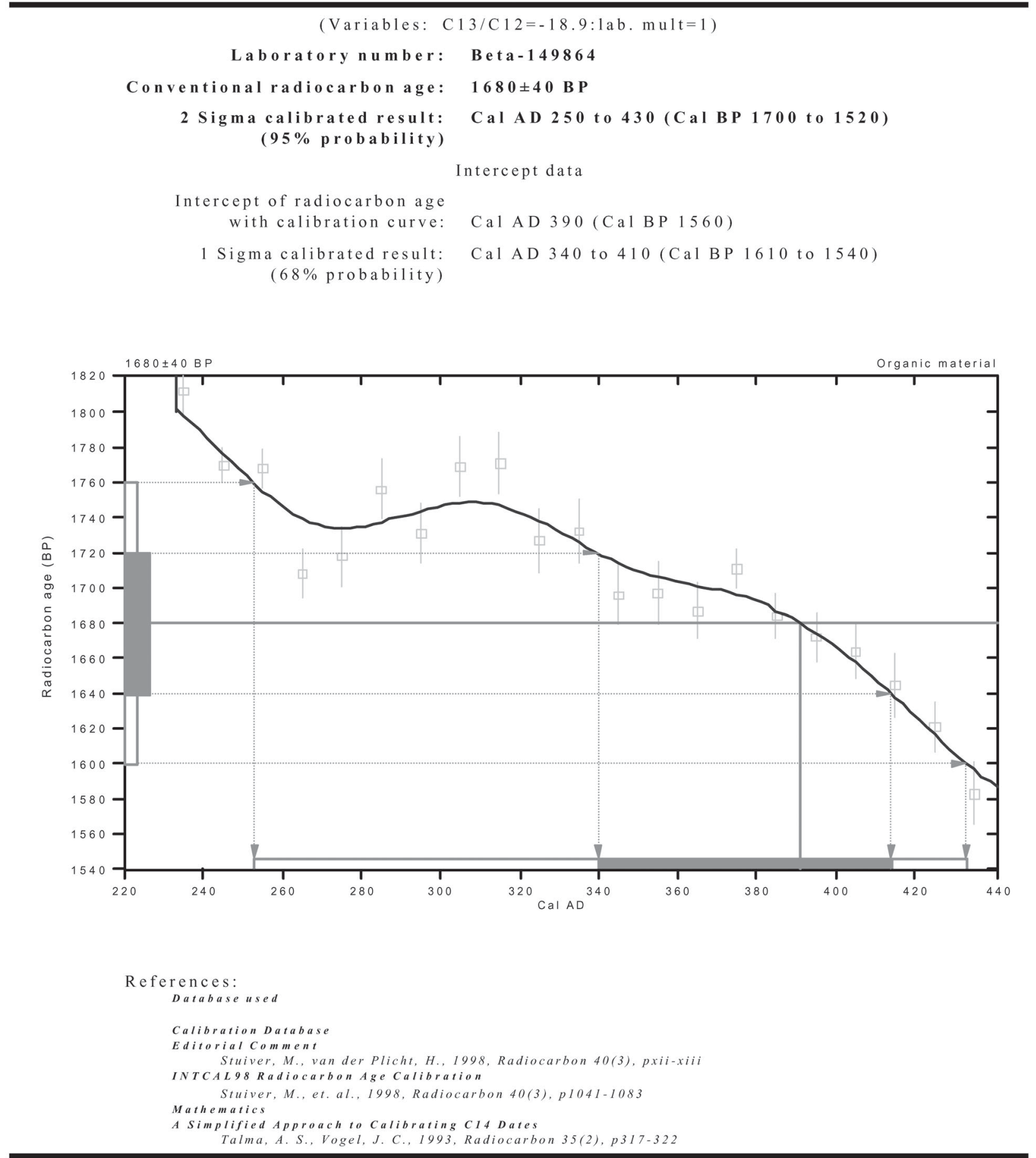

Beta Analytic Inc.

4985 SW 74 Court, Miami, Florida 33155 USA Tel: (305)6675167・Fax: (305)6630964・E-Mail: beta@radiocarbon.com 


\section{CALIBRATION OF RADIOCARBON AGE TO CALENDAR YEARS}

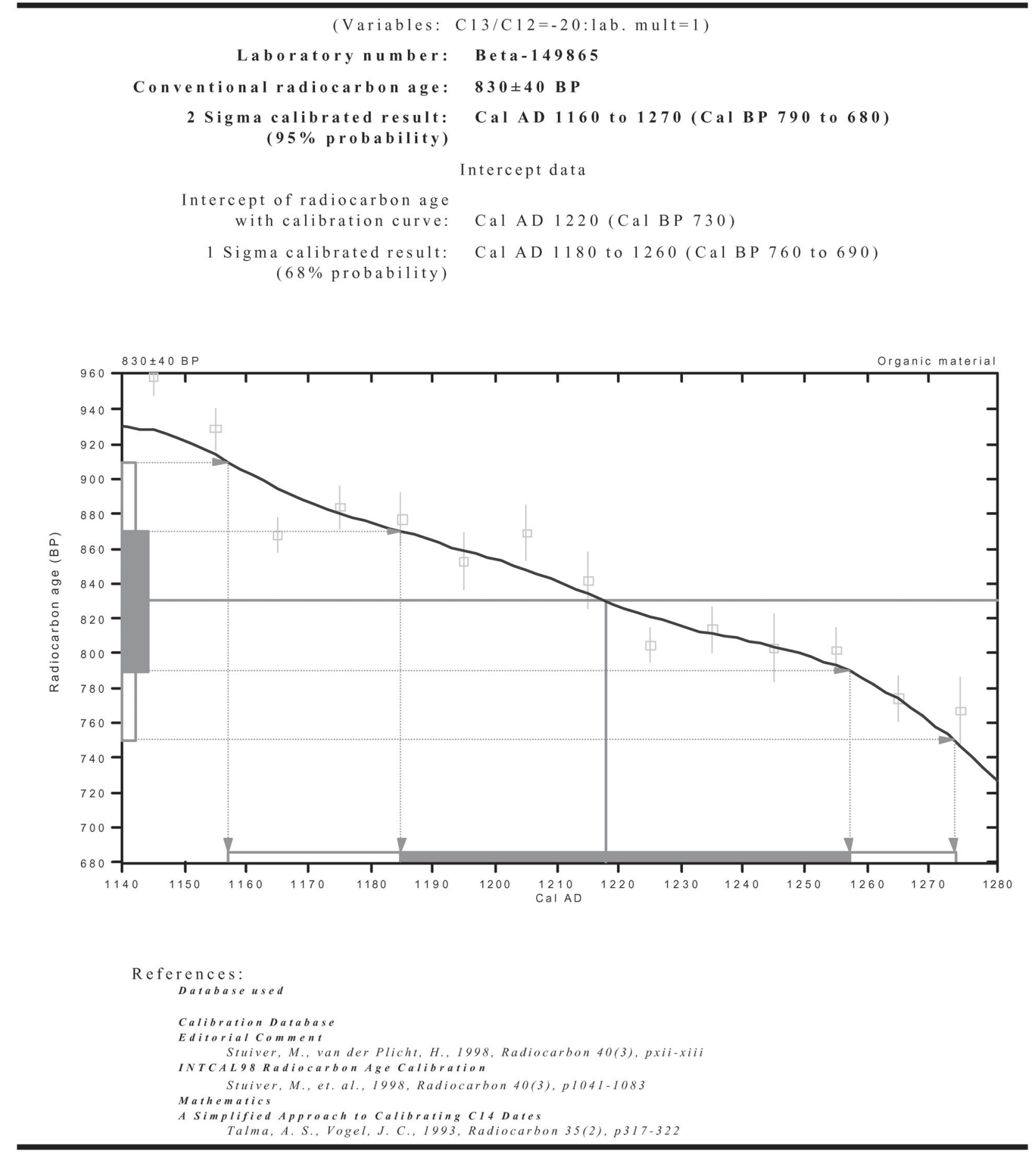

Beta Analytic Inc.

4985 SW 74 Court, Miami, Florida 33155 USA $\cdot$ Tel: (305)6675167•Fax: (305)6630964・E-Mail: beta@radiocarbon.com 


\section{CALIBRATION OF RADIOCARBON AGE TOCALENDAR YEARS}

$($ Variables: C $13 /$ C $12=-19.9: 1 \mathrm{ab} \cdot \mathrm{mult}=1)$

Laboratory number: Beta-149866

Conventional radiocarbon age: $960 \pm 40$ B P

2 Sigma calibrated result: Cal AD 1000 to 1180 (Cal BP 950 to 780 )

( $95 \%$ probability)

Intercept data

Intercept of radiocarbon age

with calibration curve:

Cal AD 1030 ( Cal B P 920)

1 Sigma calibrated results: Cal AD 1020 to 1060 (Cal B P 930 to 890 ) and

( $68 \%$ probability) Cal AD 1080 to 1150 (Cal BP 860 to 800 )

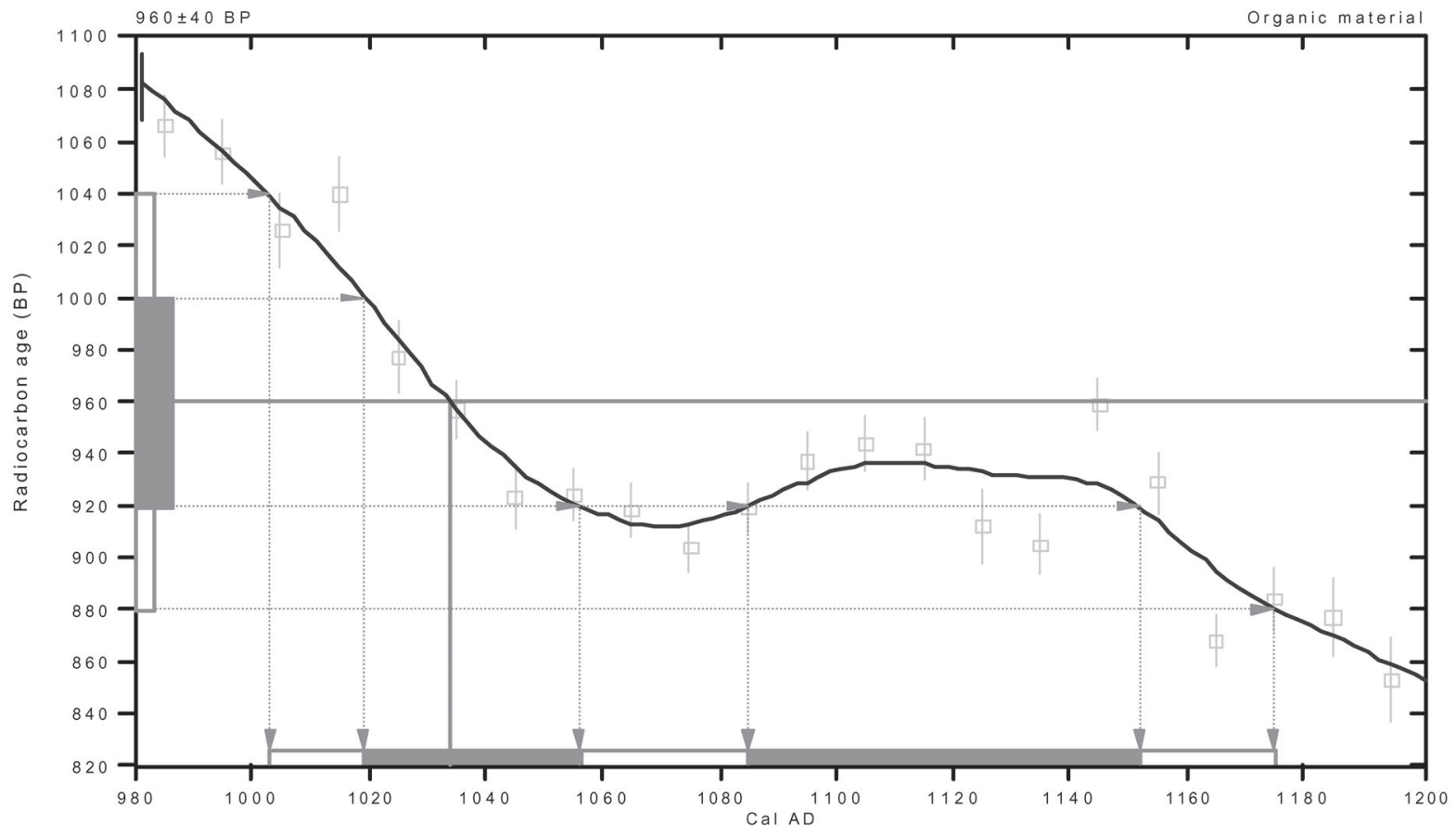

References:

Dat a b a se used

Calibration Database

Editorial Comment

Stuiver, M., van der Plicht, H., 1998, Radiocarbon 40(3), pxii-xiii

INTCAL98 Radiocarbon Age Calibration

Stuiver, M., et. al., 1998, Radiocarbon 40(3), p1041-1083

Mathematics

A Simplified Approach to Calibrating C14 Dates

Talma, A.S Vogel, J.C., 1993 , Radiocarbon 35(2), p317-32

\section{Beta Analytic Inc.}

4985 SW74 Court, Miami, Florida 33155 USA Tel: (305)6675167.Fax: (305)6630964・E-Mail: beta@radiocarbon.com 


\section{CALIBRATION OF RADIOCARBON AGE TO CALENDAR YEARS}

(Variables: C $13 / \mathrm{C} 12=-19.9: 1 \mathrm{ab} \cdot \mathrm{mu} 1 \mathrm{t}=1)$

Laboratory number: Beta-149867

Conventional radiocarbon age: $690 \pm 40$ B P

2 Sigma calibrated results: Cal AD 1270 to 1320 (Cal BP 680 to 630 ) and

(95\% probability) Cal AD 1350 to 1390 (Cal BP600 to 560)

Intercept data

Intercept of radiocarbon age

with calibration curve: Cal AD 1290 (Cal B P 660)

1 Sigma calibrated result: Cal AD 1280 to 1300 (Cal B P 670 to 650 )

$(68 \%$ probability)

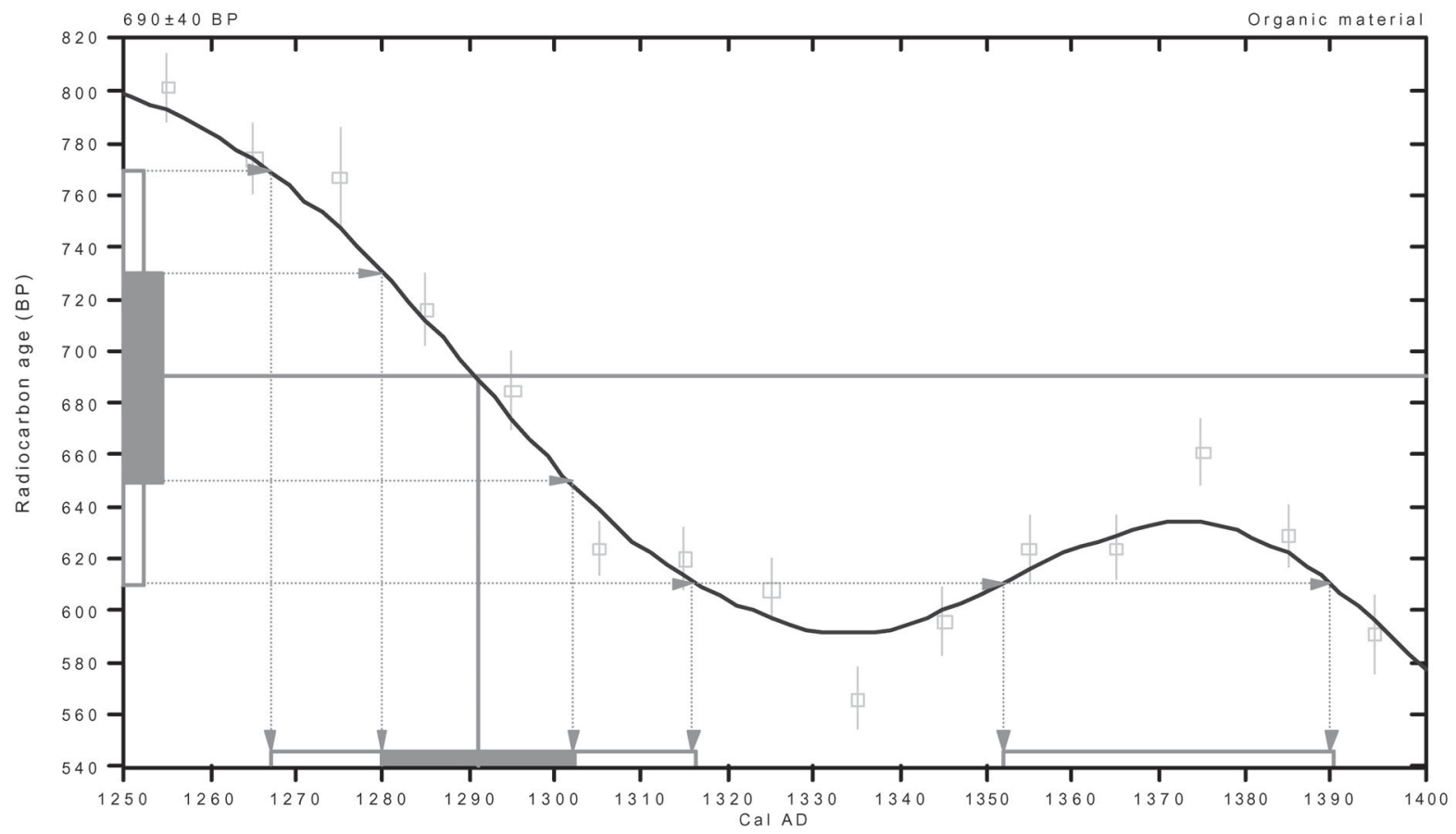

References:

Database used

Calibration Database

Editorial Comment

Stuiver, M., van der Plicht, H., 1998, Radiocarbon 40(3), pxii-xiii

INTCAL98 Radiocarbon Age Calibration

Stuiver, M., et. al., 1998, Radiocarbon 40(3), p1041-1083

Mathematics

A Simplified Approach to Calibrating C14 Dates

Talma, A.S Vogel, J.C. J993, Radiocarbon 35(2), p317-32

\section{Beta Analytic Inc.}

4985 SW 74 Court, Miami, Florida33155USA Tel: (305)6675167·Fax:(305)6630964·E-Mail: beta@radiocarbon.com 


\section{CALIBRATION OF RADIOCARBON AGE TO CALENDAR YEARS}

(Variables: C $13 / \mathrm{C} 12=-13.8: 1 \mathrm{ab} . \mathrm{mult}=1)$

\section{Laboratory number: $\quad$ Beta-149868}

Conventional radiocarbonage: $640 \pm 40$ B P

2 Sigma calibrated result: Cal AD 1280 to 1410 (Cal BP670 to 540)

$(95 \%$ probability)

Intercept data

Intercept of radiocarbon age with calibration curve: Cal AD 1300 (Cal B P 640 )

1 Sigma calibrated results: Cal AD 1290 to 1320 (Cal B P 660 to 630 ) and (68\% probability) Cal AD 1340 to 1390 (Cal BP 600 to 560 )

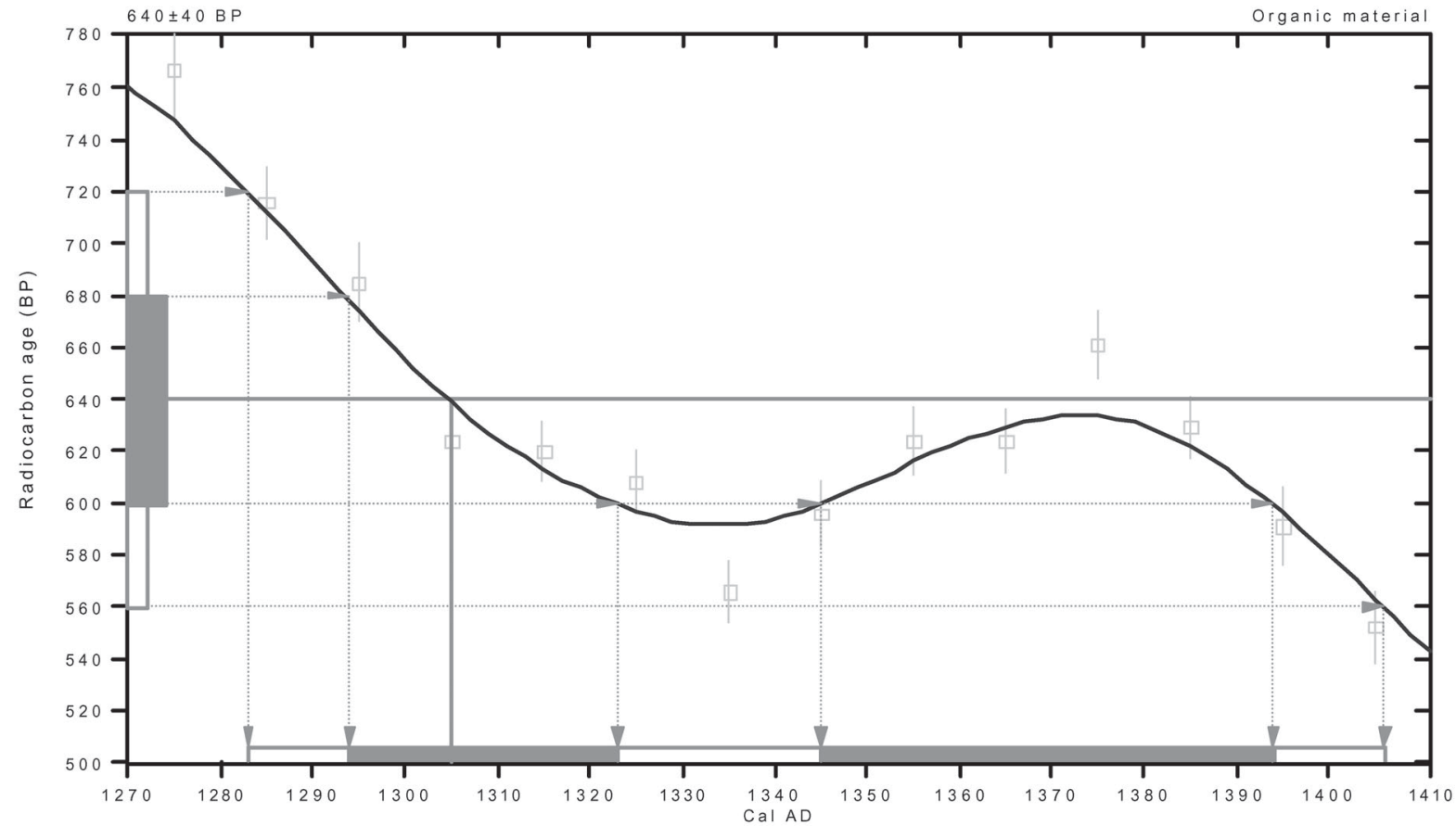

References:

Database used

Calibration Database

Editorial Comme

Stuiver, M., van der Plicht, H., 1998, Radiocarbon 40(3), pxii-xiii

INTCAL98 Radiocarbon Age Calibration

Stuiver, M., et. al., 1998, Radiocarbon 40(3), p1041-1083

Mathematics

A Simplified Approach to Calibrating C14 Dates

Talma A S Vogel I C 1993 Radiocarbon 35(2), p317-322

Beta Analytic Inc.

4985 SW 74 Court, Miami, Florida33155USA Tel: (305)6675167・Fax:(305)6630964・E-Mail: beta@radiocarbon.com 


\section{CALIBRATION OF RADIOCARBON AGE TO CALENDAR YEARS}

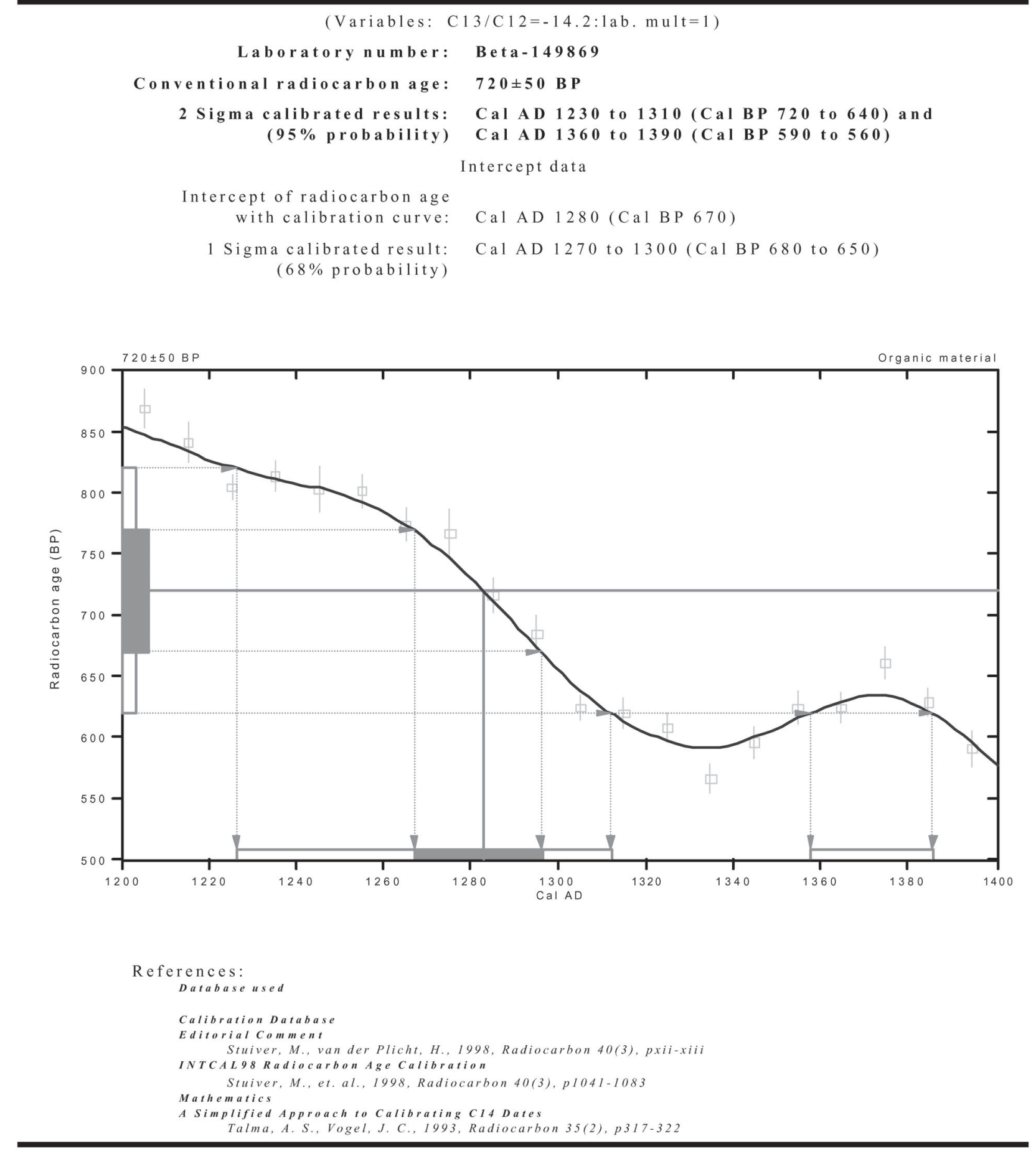

Beta Analytic Inc.

4985 SW 74 Court, Miami, Florida 33155 USA Tel: (305)6675167・Fax: (305)6630964・E-Mail: beta@radiocarbon.com 


\section{CALIBRATION OF RADIOCARBON AGE TO CALENDAR YEARS}

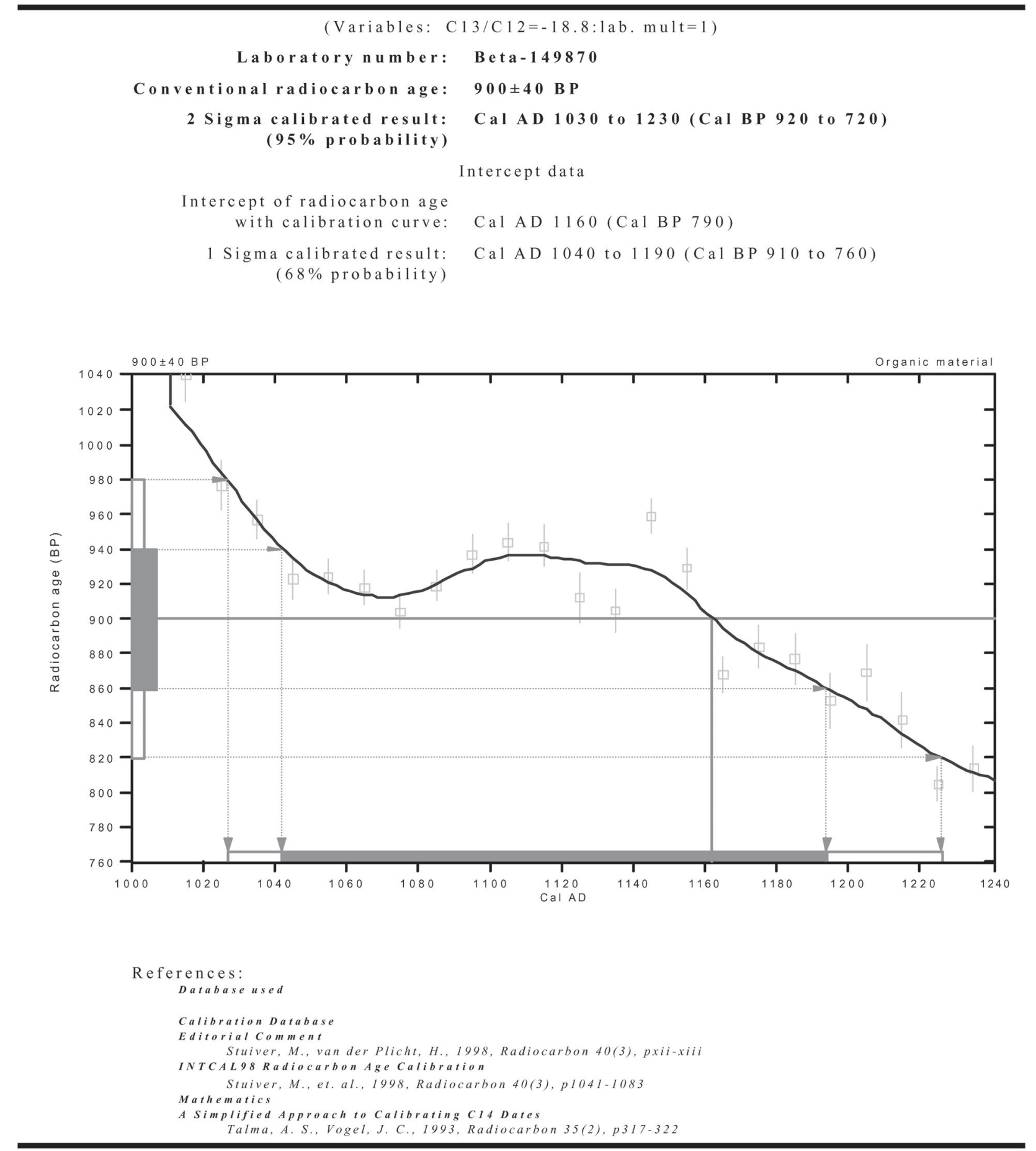

\section{Beta Analytic Inc.}

4985 SW 74 Court, Miami, Florida 33155 USA Tel: (305)6675167・Fax: (305)6630964・E-Mail: beta@radiocarbon.com 


\section{CALIBRATION OF RADIOCARBON AGE TO CALENDAR YEARS}

(Variables: $\mathrm{C} 13 / \mathrm{C} 12=-19.2: 1 \mathrm{ab} . \mathrm{mu} 1 \mathrm{t}=1)$

Laboratory number: Beta-149871

Conventional radiocarbon age: $\mathbf{6 4 0 \pm 5 0}$ BP

2 Sigma calibrated result: Cal AD 1280 to 1410 (Cal BP 670 to 540)

( $95 \%$ probability)

Intercept data

Intercept of radiocarbon age

with calibration curve: Cal AD 1300 (Cal B P 640)

1 Sigma calibrated result: Cal AD 1290 to 1400 (Cal B P 660 to 550 )

( $68 \%$ probability)

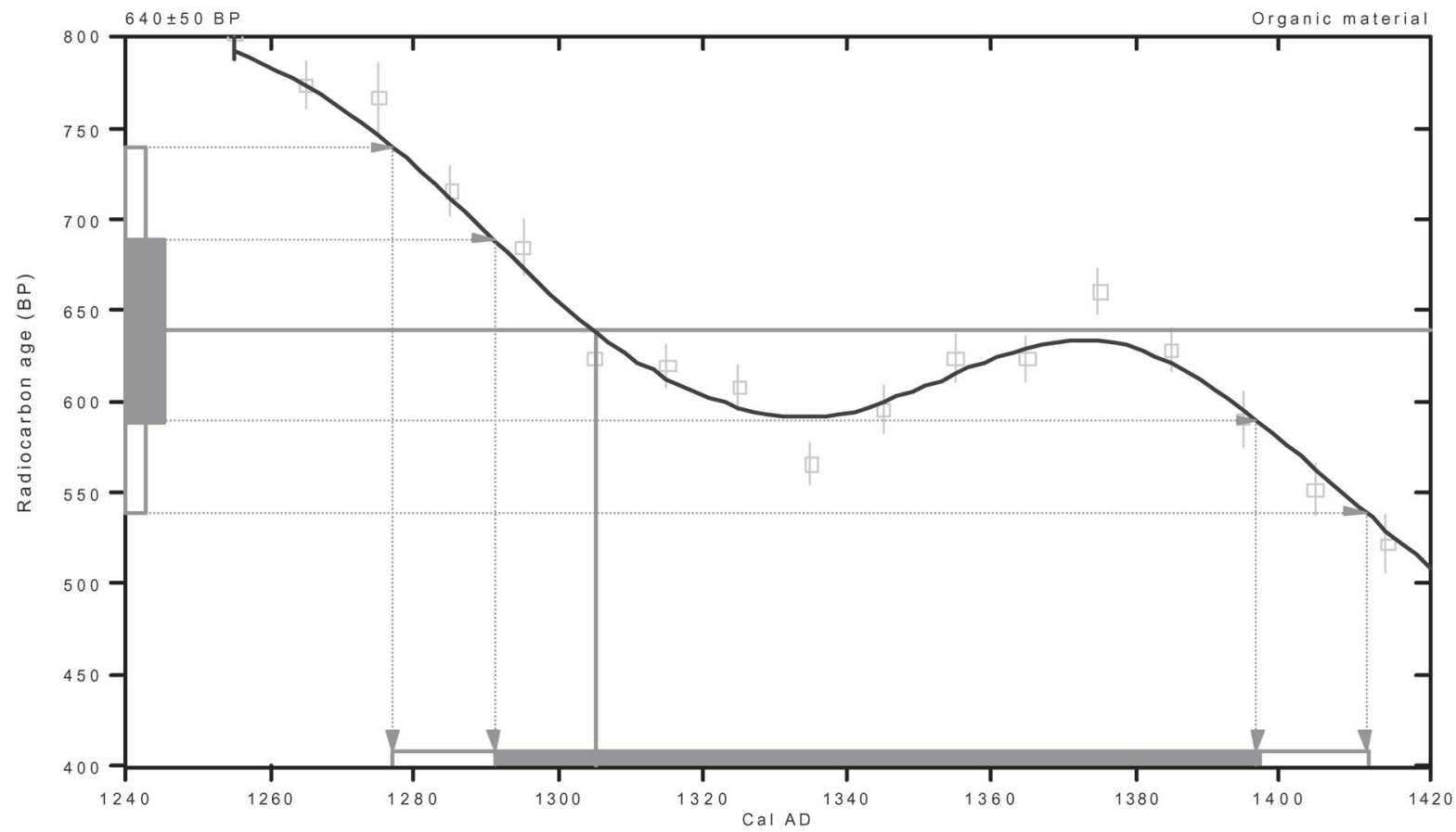

References:

Dat a b a se used

Calibration Database

Editorial Comment

Stuiver, M., van der Plicht, H., 1998, Radiocarbon 40(3), pxii-xiii

INTCAL98 Radiocarbon Age Calibration

Stuiver, M., et. al., 1998, Radiocarbon 40(3), p1041-1083

Mathematics

A Simplified Approach to Calibrating C14 Dates

Talma A S. Vogel, J.C., l993, Radiocarbon 35(2), p3 $17-322$

\section{Beta Analytic Inc.}

4985 SW74 Court, Miami, Florida33155USA.Tel: (305)6675167•Fax:(305)6630964・E-Mail:beta@radiocarbon.com 


\section{CALIBRATION OF RADIOCARBON AGE TOCALENDAR YEARS}

(Variables: C $13 / \mathrm{C} 12=-17.7: 1 \mathrm{ab} . \mathrm{mu} 1 \mathrm{t}=1)$

Laboratory numbr: Beta-149873

Conventional radiocarbon age: $340 \pm 40$ B P

2Sigma calibrated result: Cal AD 1450 to 1650 (Cal BP 500 to 300 )

$(95 \%$ probability)

Intercept data

Intercepts of radiocarbon age

with calibration curve: Cal AD 1520 (Cal BP 430) and

Cal AD 1590 (Cal BP 360 ) and

$\mathrm{Ca} 1 \mathrm{AD} 1620(\mathrm{Ca} 1 \mathrm{BP} 330)$

1 Sigma calibrated result: ( $68 \%$ probability)

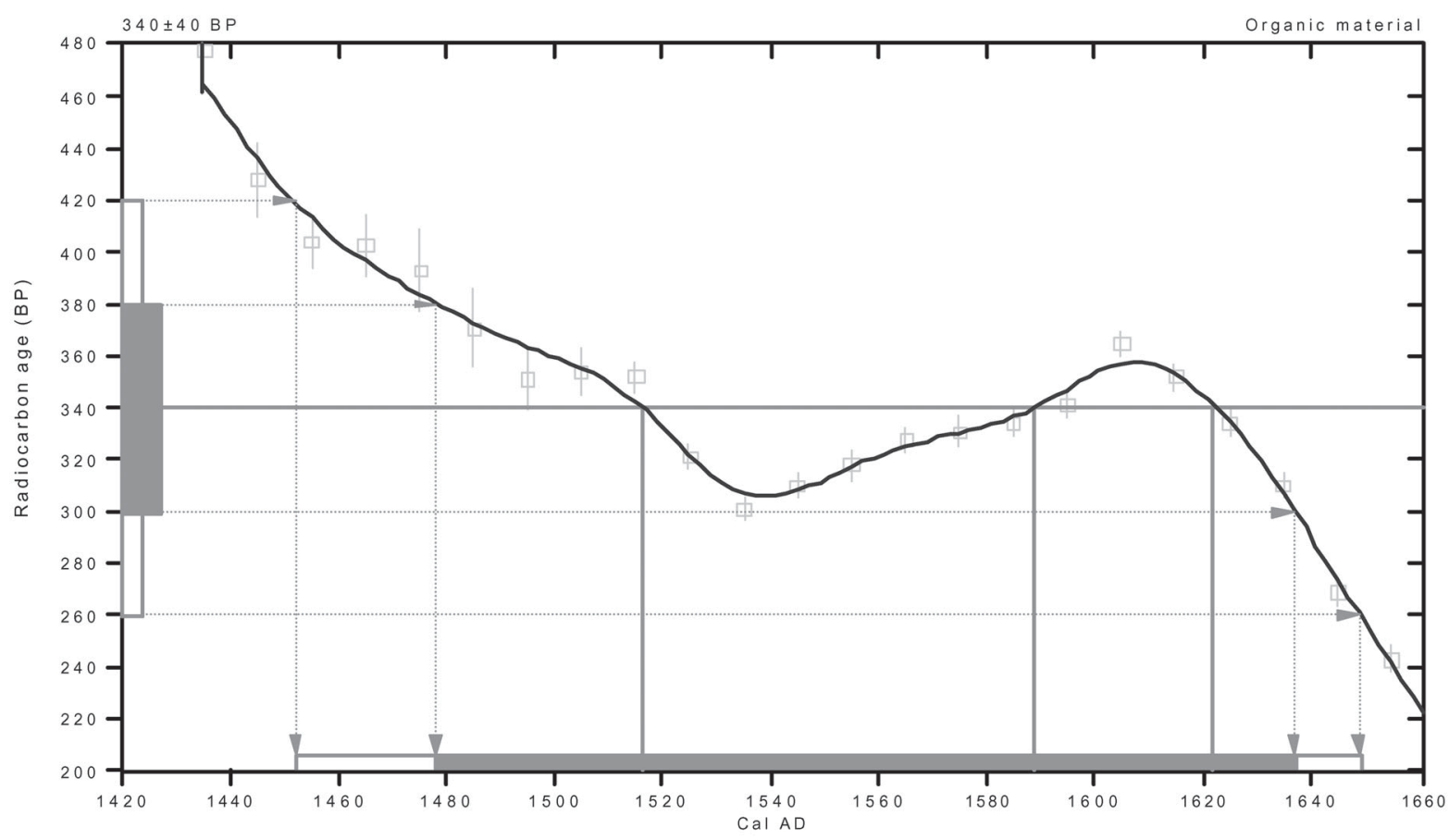

References:

Database used

Calibration Database

Editorial Comment

Stuiver, M., van der Plicht, H., 1998, Radiocarbon 40(3), pxii-xiii

INTCAL98 Radiocarbon Age Calibration

Stuiver, M., et. al., 1998, Radiocarbon 40(3), p1041-1083

Mathe matics

A Simplified Approach to Calibrating C14 Dates

Talma A.S. Vogel, J. C. 1993 , Radiocarbon 35(2), p317-32

\section{Beta Analytic Inc.}

4985 SW 74 Court, Miami, Florida 33155 USA Tel: (305)6675167·Fax: (305)6630964·E-Mail: beta@radiocarbon.com 


\section{CALIBRATION OF RADIOCARBON AGE TO CALENDAR YEARS}

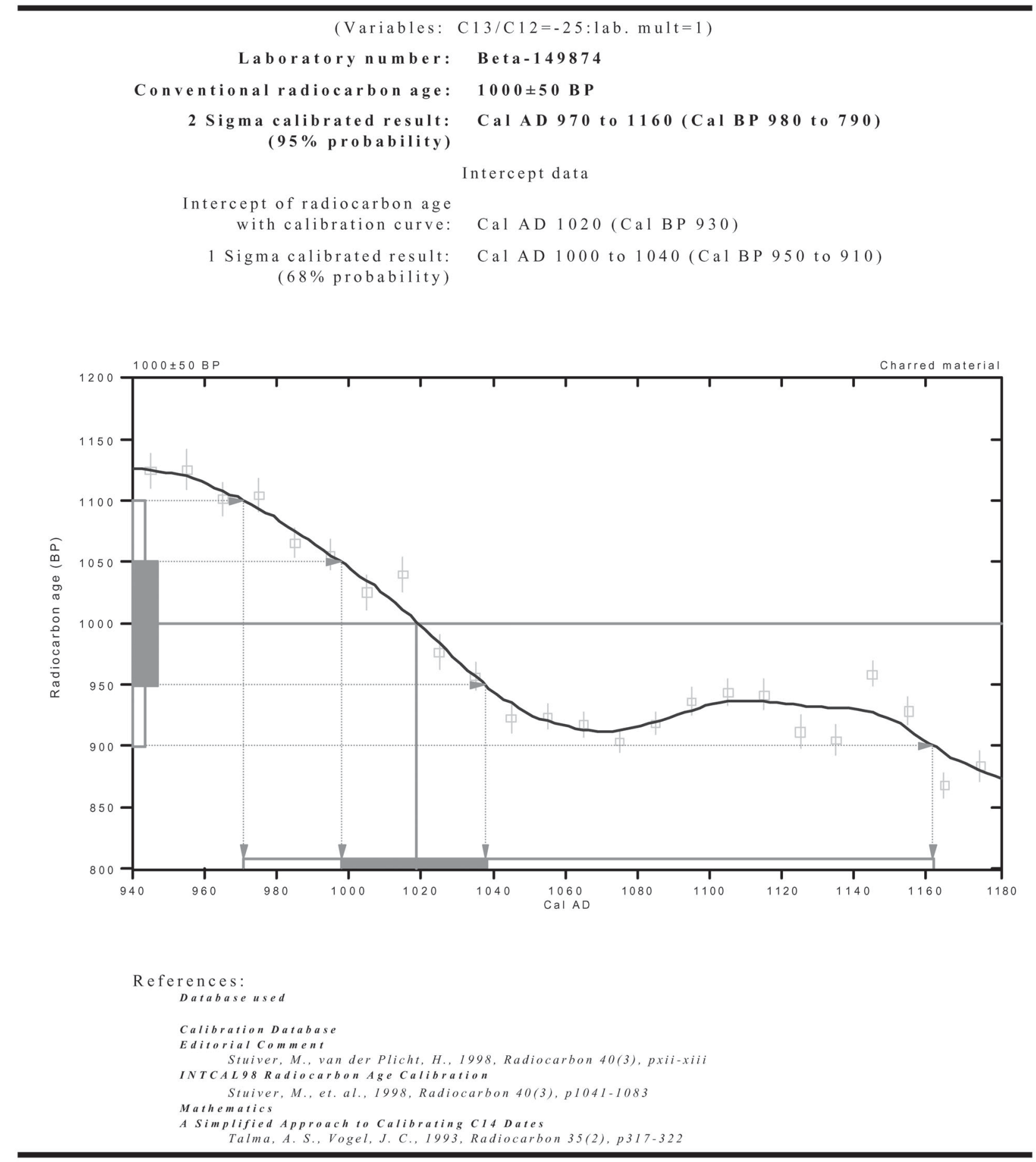

Beta Analytic Inc.

4985 SW 74 Court, Miami, Florida 33155 USA $\cdot$ Tel: (305) $6675167 \cdot$ Fax: (305) $6630964 \cdot$ E-Mail: beta@radiocarbon.com 


\title{
CALIBRATION OF RADIOCARBON AGE TO CALENDAR YEARS
}

\author{
$($ Variables: $\mathrm{C} 13 / \mathrm{C} 12=-19.8: 1 \mathrm{ab} \cdot \mathrm{mult}=1)$ \\ Laboratory number: Beta-149875 \\ Conventional radiocarbon age: $560 \pm 40$ B P \\ 2 Sigma calibrated result: Cal AD 1300 to 1430 (Cal BP 640 to 520 ) \\ ( $95 \%$ probability) \\ Intercept data \\ Intercept of radiocarbon age \\ with calibration curve: Cal AD 1410 (Cal B P 540$)$ \\ 1 Sigma calibrated results: Cal AD 1320 to 1340 (Cal BP 630 to 600) and \\ (68\% probability) Cal AD 1390 to 1420 (Cal BP 560 to 530 )
}
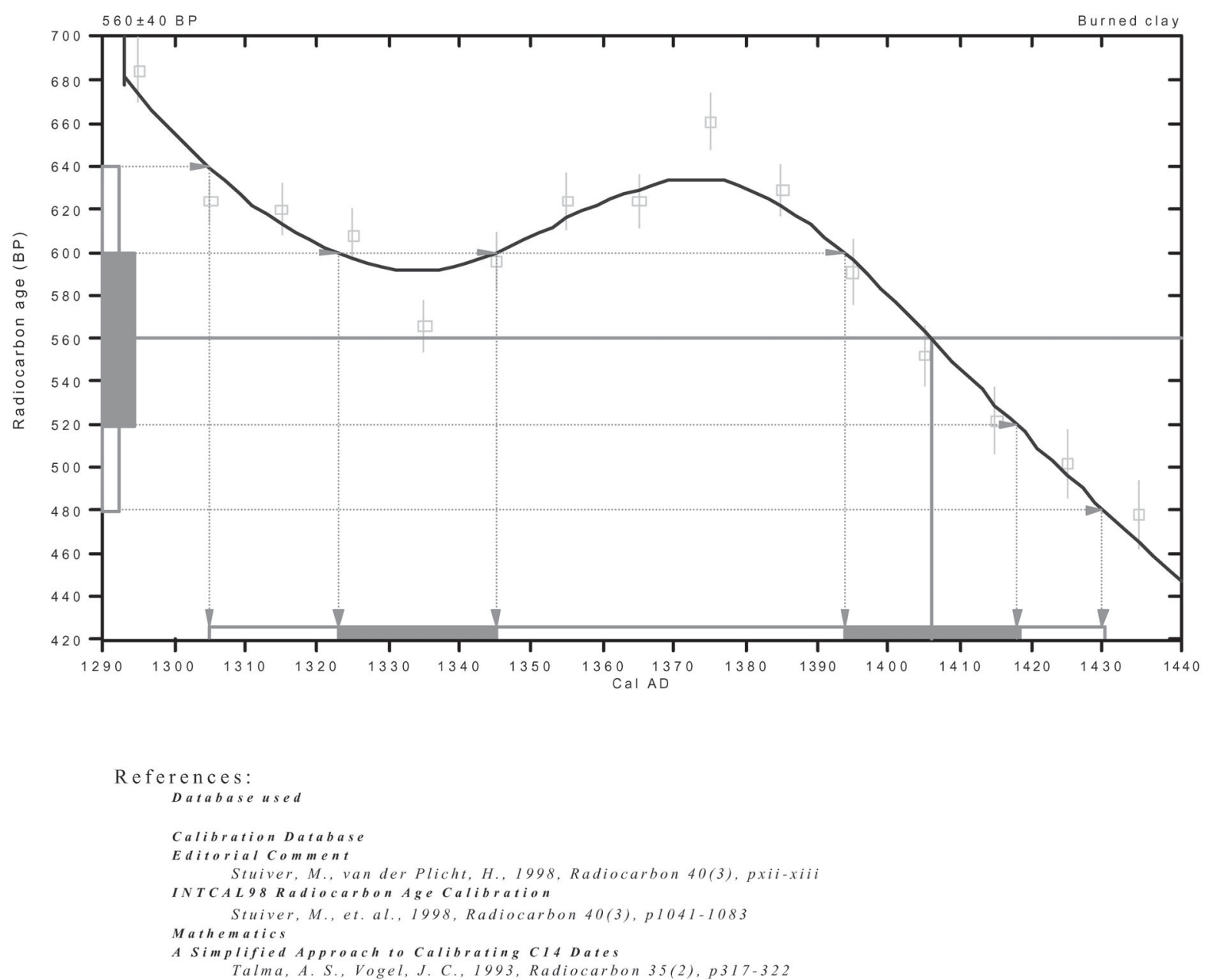

\section{Beta Analytic Inc.}

4985 SW 74 Court, Miami, Florida 33155 USA Tel: (305) $6675167 \cdot$ Fax: (305)6630964・E-Mail: beta@radiocarbon.com 


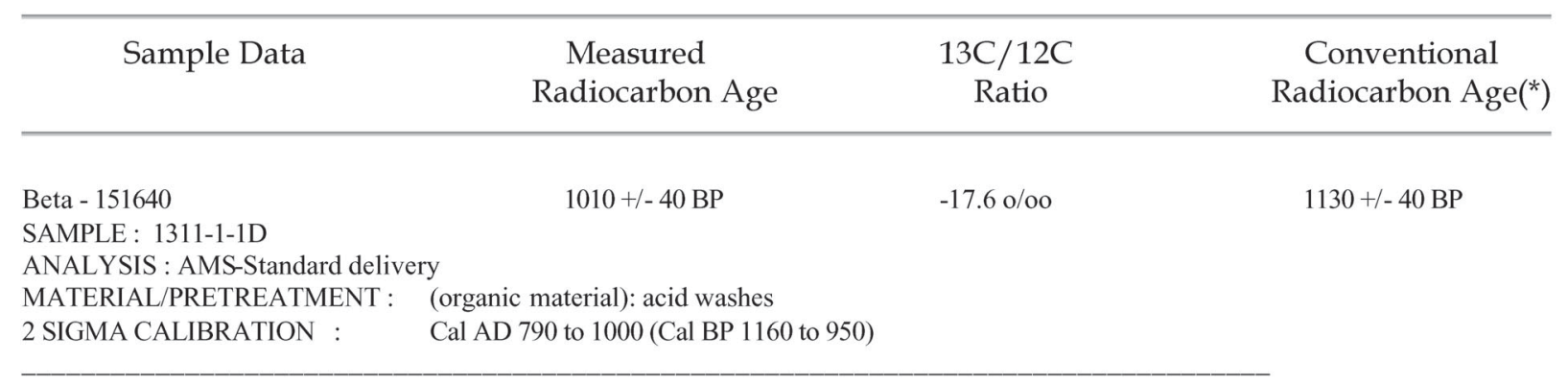




\title{
CALIBRATION OF RADIOCARBON AGE TO CALENDAR YEARS
}

\author{
(Variables: C $13 / \mathrm{C} 12=-17.6: 1 \mathrm{ab} . \mathrm{mult}=1)$ \\ Laboratory number: Beta-151640 \\ Conventional radiocarbon age: $1130 \pm 40$ B P \\ 2 Sigma calibrated result: Cal AD 790 to 1000 (Cal BP 1160 to 950 ) \\ ( $95 \%$ probability) \\ Intercept data \\ Intercept of radiocarbon age \\ with calibration curve: Cal AD 900 (Cal B P 1050 ) \\ 1 Sigma calibrated result: Cal AD 880 to 980 (Cal B P 1070 to 970 ) \\ $(68 \%$ probability)
}
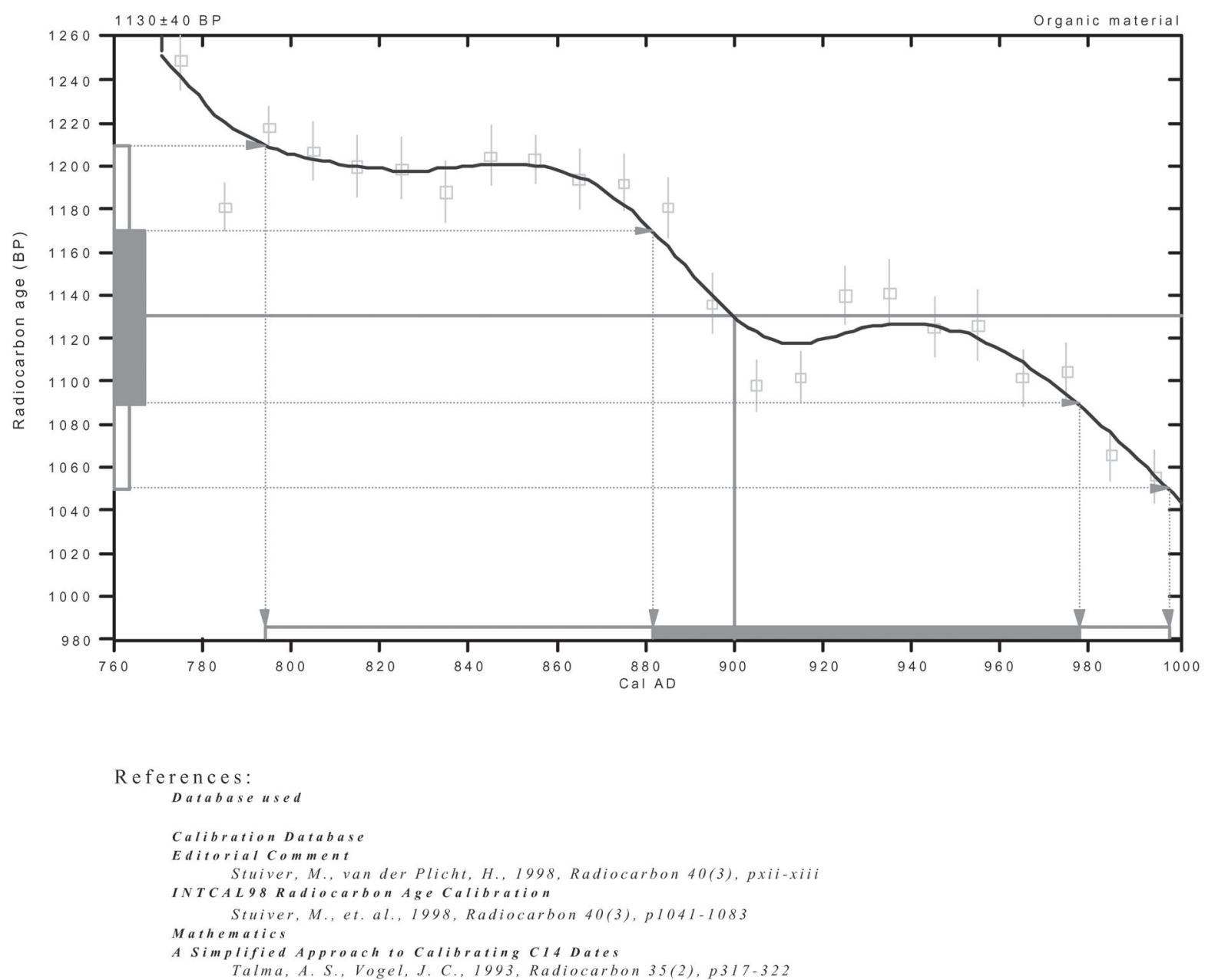

\section{Beta Analytic Inc.}

4985 SW 74 Court, Miami, Florida 33155 USA Tel: (305) $6675167 \cdot$ Fax: (305)6630964・E-Mail: beta@radiocarbon.com 



\section{Appendix C}

\section{Lipid Residue Analysis}

by

Mary E. Malainey and Kris L. Malisza 


\section{Appendix C: Analysis of the Fatty Acid Compositions of Archeological Residues from 41WB556}

\section{Introduction}

Mary E. Malainey and Kris L. Malisza

A total of 30 burned rocks was submitted for analysis. Sample size ranged between about 10 and $43.50 \mathrm{~g}$; where necessary, subsamples were taken from large rocks. Exterior surfaces were ground off to remove any contaminants. Samples were then powdered and absorbed lipid residues were extracted with organic solvents. The fatty acid components of the lipid extracts were analyzed using gas chromatography. Residues were identified using criteria developed from the decomposition patterns of experimental residues. The first section of this appendix outlines the development of the identification criteria. Following this, the analytical procedures and results are presented.

\section{Fatty Acids and Development of the Identification Criteria}

\section{Introduction and Previous Research}

Fatty acids are the major constituents of fats and oils (lipids) and occur in nature as triglycerides, consisting of three fatty acids attached to a glycerol molecule by ester-linkages. The shorthand convention for designating fatty acids, $\mathrm{Cx}: \mathrm{y \omega z}$, contains three components. The " $\mathrm{Cx}$ " refers to a fatty acid with a carbon chain length of $x$ number of atoms. The " $y$ " represents the number of double bonds or points of unsaturation, and the " $\omega z$ " indicates the location of the most distal double bond on the carbon chain, i.e., closest to the methyl end. Thus, the fatty acid expressed as $\mathrm{C} 18: 1 \omega 9$, refers to a monounsaturated isomer with a chain length of 18 carbon atoms with a single double bond located nine carbons from the methyl end of the chain. Similarly, the shorthand designation, C16:0, refers to a saturated fatty acid with a chain length of 16 carbons.

Their insolubility in water and relative abundance compared to other classes of lipids, such as sterols and waxes, make fatty acids suitable for residue analysis. Since employed by Condamin et al. (1976), gas chromatography has been used extensively to analyze the fatty acid component of absorbed archeological residues. The composition of uncooked plants and animals provides important baseline information, but it is not possible to directly compare modern uncooked plants and animals with highly degraded archeological residues. Unsaturated fatty acids, which are found widely in fish and plants, decompose more readily than saturated fatty acids, sterols or waxes. In the course of decomposition, simple addition reactions might occur at points of unsaturation (Solomons 1980) or peroxidation might lead to the formation of a variety of volatile and non-volatile products which continue to degrade (Frankel 1991). Peroxidation occurs most readily in fatty acids with more than one point of unsaturation.

Several attempts have been made to identify archeological residues using criteria that discriminate uncooked foods (Loy 1994; Marchbanks 1989; Skibo 1992). Marchbanks' (1989) percent of saturated fatty acids $(\% \mathrm{~S})$ criteria has been used to identify residues from a variety of materials including pottery, stone tools and burned rocks (Collins et al. 1990; Marchbanks 1989; Marchbanks and Quigg 1990). Skibo (1992:89) could not apply the $\% \mathrm{~S}$ technique and instead used two ratios of fatty acids, C18:0/C16:0 and C18:1/C16:0. He reported that it was possible to link the uncooked foods with residues extracted from modern cooking pots actively used to prepare one type of food; however, the ratios could not identify food mixtures. The utility of these ratios did not extend to residues extracted from archeological potsherds because the ratios of the major fatty acids in the residue changed with decomposition (Skibo 1992:97). Loy (1994) proposed the use of a Saturation Index (SI), determined by the ratio: $\mathrm{SI}=1$ [(C18:1+C18:2)/C12:0+C14:0+C16:0+C18:0)]. He admitted, however, that poorly understood decompositional changes to the original suite of fatty acids make it difficult to develop criteria for distinguishing animal and plant fatty acid profiles in archeological residues.

The major drawback of the distinguishing ratios proposed by Marchbanks (1989), Skibo (1992), and Loy (1994) is 
they have never been empirically tested. The proposed ratios are based on criteria that discriminate food classes on the basis of their original fatty acid composition. The resistance of these criteria to the effects of decompositional changes has not been demonstrated. Rather, Skibo (1992) found his fatty acid ratio criteria could not be used to identify highly decomposed archeological samples.

In order to identify a fatty acid ratio unaffected by degradation processes, Patrick et al. (1985) simulated the long-term decomposition of one sample and monitored the resulting changes. An experimental cooking residue of seal was prepared and degraded in order to identify a stable fatty acid ratio. Patrick et al. (1985) found that the ratio of two C18:1 isomers, oleic and vaccenic, did not change with decomposition; this fatty acid ratio was then used to identify an archeological vessel residue as seal. While the fatty acid composition of uncooked foods must be known, Patrick et al. (1985) showed that the effects of cooking and decomposition over long periods of time on the fatty acids must also be understood.

\section{Development of the Identification Criteria}

As the first stage in developing the identification criteria used herein, the fatty acid compositions of more than 130 uncooked Native food plants and animals from Western Canada were determined using gas chromatography (Malainey 1997; Malainey et al. 1999a). When the fatty acid compositions of modern food plants and animals were subject to cluster and principal component analyses, the resultant groupings generally corresponded to divisions that exist in nature (Table C-1). Clear differences in the fatty acid composition of large mammal fat, large herbivore meat, fish, plant roots, greens, and berries/seeds/nuts were detected, but the fatty acid composition of meat from medium-sized mammals resembles berries/seeds/nuts.

Samples in cluster A, the large mammal and fish cluster had elevated levels of C16:0 and C18:1 (Table C-1). Divisions within this cluster stemmed from the very high level of C18:1 isomers in fat, high levels of C18:0 in bison and deer meat and high levels of very long chain unsaturated fatty acids (VLCU) in fish. Differences in the fatty acid composition of plant roots, greens, and berries/seeds/nuts reflect the amounts of C18:2 and
$\mathrm{C} 18: 3 \omega 3$ present. The berry, seed, nut and small mammal meat samples appearing in cluster B have very high levels of C18:2, ranging from $35 \%$ to $64 \%$ (Table C-1). Samples in subclusters V, VI and VII have levels of C18:1 isomers from $29 \%$ to $51 \%$, as well. Plant roots, plant greens and some berries appear in cluster C. All cluster C samples have moderately high levels of $\mathrm{C} 18: 2$; except for the berries in subcluster XII, levels of C16:0 are also

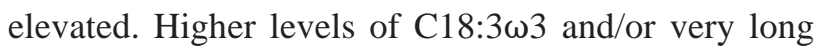
chain saturated fatty acids (VLCS) are also common except in the roots which form subcluster XV.

Secondly, the effects of cooking and degradation over time on fatty acid compositions were examined. Originally, 19 modern residues of plants and animals from the plains, parkland, and forests of Western Canada were prepared by cooking samples of meats, fish, and plants, alone or combined, in replica vessels over an open fire (Malainey 1997; Malainey et al. 1999b). After four days at room temperature, the vessels were broken and a set of sherds analyzed to determine changes after a short term of decomposition. A second set of sherds remained at room temperature for 80 days, then placed in an oven at $75^{\circ} \mathrm{C}$ for a period of 30 days in order to simulate the processes of long term decomposition. The relative percentages were calculated on the basis of the ten fatty acids (C12:0, C14:0, C15:0, C16:0, C16:1, C17:0, C18:0, $\mathrm{C} 18: 1 \omega 9, \mathrm{C} 18: 1 \omega 11, \mathrm{C} 18: 2)$ that regularly appeared in Precontact Period vessel residues from Western Canadian. Observed changes in fatty acid composition of the experimental cooking residues enabled the development of a method for identifying the archeological residues (Table C-2).

It was determined that levels of medium chain fatty acids (C12:0, C14:0 and C15:0), C18:0 and C18:1 isomers in the sample could be used to distinguish degraded experimental cooking residues (Malainey 1997; Malainey et al. 1999b). These fatty acids are suitable for the identification criteria because saturated fatty acids are stable and the mono-unsaturated fatty acids degrade very slowly, as compared to polyunsaturated fatty acids (deMan 1992). Higher levels of medium chain fatty acids, combined with low levels of C18:0 and C18:1 isomers, were detected in the decomposed experimental residues of plants, such as roots, greens, and most berries. High levels of C18:0 indicated the presence of large herbivores. Moderate levels of C18:1 isomers, with low levels of 


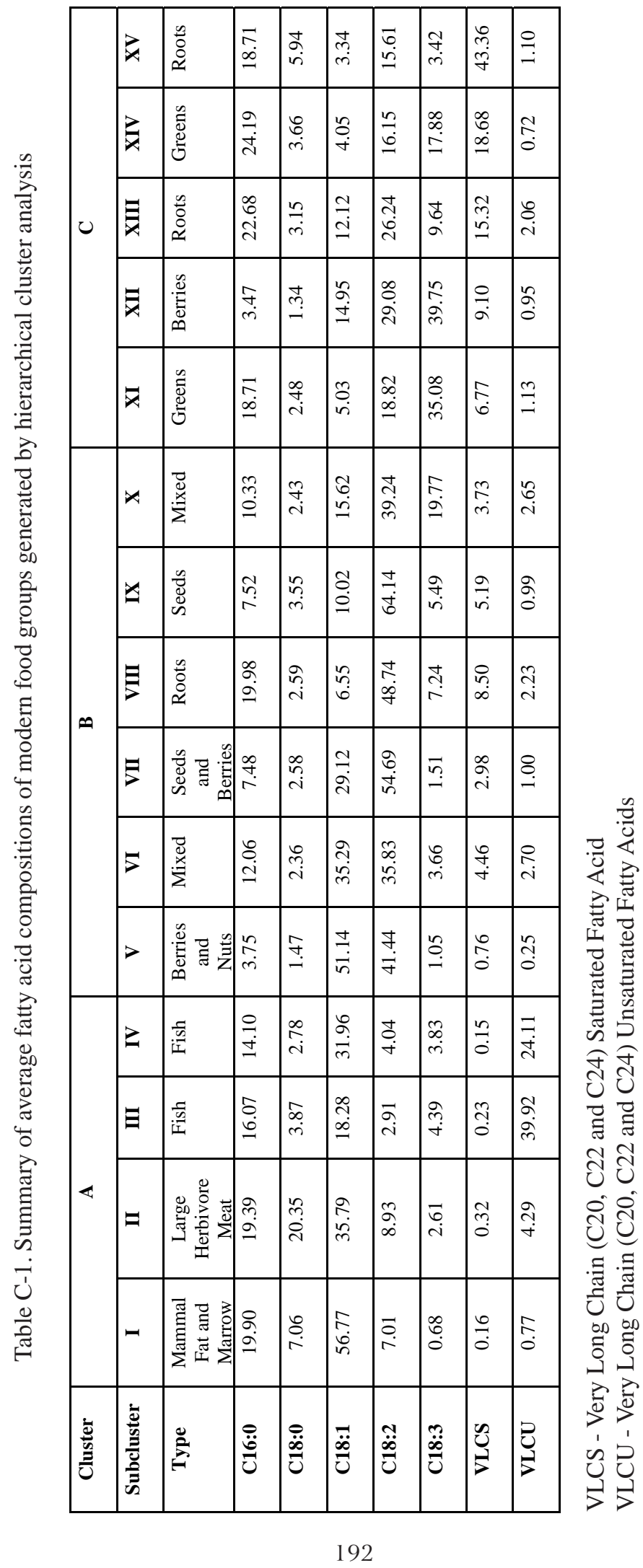


Table C-2. Criteria for the identification of archeological residues based on the decomposition patterns of experimental cooking residues prepared in pottery vessels

\begin{tabular}{|l|c|c|c|}
\hline Identification & Medium Chain & C18:0 & C18:1 isomers \\
\hline Large herbivore & $\leq 15 \%$ & $\geq 27.5 \%$ & $\leq 15 \%$ \\
\hline $\begin{array}{l}\text { Large herbivore with plant } \\
\text { OR Bone marrow }\end{array}$ & low & $\geq 25 \%$ & $15 \% \leq X \leq 25 \%$ \\
\hline Plant with large herbivore & $\geq 15 \%$ & $\geq 25 \%$ & no data \\
\hline Beaver & low & low & $\geq 25 \%$ \\
\hline Fish or Corn & low & $\leq 25 \%$ & $15 \% \leq X \leq 27.5 \%$ \\
\hline Fish or Corn with Plant & $\geq 15 \%$ & $\leq 27.5 \%$ & $15 \% \leq X \leq 27.5 \%$ \\
\hline Plant (except corn) & $\geq 10 \%$ & $\leq 15 \%$ \\
\hline
\end{tabular}

C18:0, indicated the presence of either fish or foods similar in composition to corn. High levels of C18:1 isomers with low levels of $\mathrm{C} 18: 0$, were found in residues of beaver or foods of similar fatty acid composition. The criteria for identifying six types of residues were established experimentally; the seventh type, plant with large herbivore, was inferred (Table C-2). These criteria were applied to residues extracted from more than 200 pottery cooking vessels from 18 Western Canadian sites (Malainey 1997; Malainey et al. 1999c, 2001b). The identifications were found to be consistent with the evidence from faunal and tool assemblages for each site.

Work has continued to understand the decomposition patterns of various foods and food combinations (Malainey et al. 2000a, 2000b, 2000c, 2001a; Quigg et al. 2001). The collection of modern foods has expanded to include plants from the Southern Plains. The fatty acid compositions of mesquite beans (Prosopis glandulosa), Texas ebony seeds (Pithecellobium ebano Berlandier), tasajillo berry (Opuntia leptocaulis), prickly pear fruit and pads (Opuntia engelmannii), Spanish dagger pods (Yucca treculeana), cooked sotol (Dasylirion wheeler), agave (Agave lechuguilla), cholla (Opuntia imbricata), piñon (Pinus edulis), and Texas mountain laurel (or mescal) seed (Sophora secundiflora) have been determined. Experimental residues of many of these plants, alone or in combination with deer meat, have been prepared by boiling foods in clay cylinders or using sandstone for either stone boiling (Quigg et al. 2000) or as a griddle. In order to accelerate the processes of oxidative degradation that naturally occur at a slow rate with the passage of time, the rock or clay tile containing the experimental residue was placed in an oven at $75^{\circ} \mathrm{C}$. After either 30 or 68 days, residues were extracted and analyzed using gas chromatography.

The results of these decomposition studies enabled refinement of the identification criteria.

\section{Methodology}

Descriptions of the 30 samples are presented in Table C-3. Possible surface contaminants were removed by grinding the exterior surface off with a Dremel ${ }^{\circledR}$ tool fitted with a silicon carbide bit. Immediately thereafter, the sample was crushed with a hammer mortar and pestle and the powder transferred to an Erlenmeyer flask. Lipids were extracted using a variation of the method developed by Folch et al. (1957). The powdered sample was mixed with a 2:1 mixture, by volume, of chloroform and methanol $(2 \times 30 \mathrm{~mL})$ using ultrasonication $(2 \times 10 \mathrm{~min})$. Solids were removed by filtering the solvent mixture into a separatory funnel. The lipid/solvent filtrate was washed with $16 \mathrm{~mL}$ of double distilled water. Once separation into two phases was complete, the lower chloroformlipid phase was transferred to a round-bottomed flask 
Table C-3. List of samples analyzed from site 41WB556

\begin{tabular}{|c|c|c|c|c|c|}
\hline Lab No. & Cat. No. & Unit & Level & Feat. & Sample Size \\
\hline UT 1 & 1492-4-1B & $\mathrm{N} 40 \mathrm{E} 14$ & 3 & 14 & $34.22 \mathrm{~g}$ \\
\hline UT 2 & $1492-4-2 B$ & N40 E14 & 3 & 14 & $39.62 \mathrm{~g}$ \\
\hline UT 3 & $1552-1-1$ & N41E10 & 4 & 15 & $33.86 \mathrm{~g}$ \\
\hline UT 4 & $1552-1-2$ & N41E10 & 4 & 15 & $34.63 \mathrm{~g}$ \\
\hline UT 5 & 217-1-1B & N41E10 & 6 & 16 & $42.99 \mathrm{~g}$ \\
\hline UT 6 & $217-1-2 B$ & N41E10 & 6 & 16 & $9.93 \mathrm{~g}$ \\
\hline UT 7 & $257-1-1$ & N41E13 & 7 & 17 & $24.96 \mathrm{~g}$ \\
\hline UT 8 & $257-1-2$ & N41E13 & 7 & 17 & $26.44 \mathrm{~g}$ \\
\hline UT 9 & $402-21-1$ & N42E10 & 3 & 18 & $42.92 \mathrm{~g}$ \\
\hline UT 10 & $402-21-2$ & N42E10 & 3 & 18 & $42.08 \mathrm{~g}$ \\
\hline UT 11 & 403-1-1B & N42 E11 & 3 & 19 & $41.99 \mathrm{~g}$ \\
\hline UT 12 & $403-1-2 B$ & N42 E11 & 3 & 19 & $40.91 \mathrm{~g}$ \\
\hline UT 13 & $684-1-1$ & N43E11 & 6 & 21 & $43.50 \mathrm{~g}$ \\
\hline UT 14 & $684-1-2$ & N43E11 & 6 & 21 & $37.83 \mathrm{~g}$ \\
\hline UT 15 & $684-1-3$ & N43E11 & 6 & 21 & $37.44 \mathrm{~g}$ \\
\hline UT 16 & 489-18B & N42 E15 & 7 & 22 & $23.32 \mathrm{~g}$ \\
\hline UT 17 & $489-6 \mathrm{~B}$ & N42 E15 & 7 & 22 & $33.24 \mathrm{~g}$ \\
\hline UT 18 & $865-1-1 \mathrm{~B}$ & N44 E13 & 5 & 23 & $38.93 \mathrm{~g}$ \\
\hline UT 19 & $865-1-2 B$ & N44 E13 & 5 & 23 & $11.91 \mathrm{~g}$ \\
\hline UT 20 & $804-1-1$ & N44E12 & 6 & 24 & $32.69 \mathrm{~g}$ \\
\hline UT 21 & $804-1-2$ & $\mathrm{~N} 44 \mathrm{E} 12$ & 6 & 24 & $33.03 \mathrm{~g}$ \\
\hline UT 22 & $804-1-3$ & N44E12 & 6 & 24 & $36.28 \mathrm{~g}$ \\
\hline UT 23 & $976-1-1 \mathrm{~B}$ & N45E11 & 4 & 25 & $29.08 \mathrm{~g}$ \\
\hline UT 24 & $976-1-2 \mathrm{~B}$ & N45E11 & 4 & 25 & $41.69 \mathrm{~g}$ \\
\hline UT 25 & $1223-1-1$ & N46E15 & 5 & 26 & $40.77 \mathrm{~g}$ \\
\hline UT 26 & $1223-1-2$ & N46E15 & 5 & 26 & $40.68 \mathrm{~g}$ \\
\hline UT 27 & $1223-1-3$ & N46E15 & 5 & 26 & $26.87 \mathrm{~g}$ \\
\hline UT 28 & 1311-1-1B & N43E09 & 4 & 27 & $35.99 \mathrm{~g}$ \\
\hline UT 29 & $1311-1-2 \mathrm{~B}$ & N43E09 & 4 & 27 & $40.23 \mathrm{~g}$ \\
\hline UT 30 & $1311-1-3$ & N43E09 & 4 & 27 & $37.54 \mathrm{~g}$ \\
\hline
\end{tabular}


and the chloroform removed by rotary evaporation. Any remaining water was removed by evaporation with benzene $(1.5 \mathrm{~mL}) ; 1.5 \mathrm{ml}$ of chloroform:methanol was used to transfer the dry total lipid extract to a screw-top glass vial with a Teflon ${ }^{\circledR}$-lined cap. The sample was flushed with nitrogen and stored in a $-20^{\circ} \mathrm{C}$ freezer.

A $600 \mu \mathrm{L}$ sample of the total lipid extract solution was placed in a screw-top test tube and dried in a heating block under nitrogen. Fatty acid methyl esters (FAMES) were prepared by treating the dry lipid with $6 \mathrm{~mL}$ of 0.5 $\mathrm{N}$ anhydrous hydrochloric acid in methanol $\left(65-70^{\circ} \mathrm{C}\right.$; $60 \mathrm{~min})$. Fatty acids that occur in the sample as di- or triglycerides are detached from the glycerol molecule and converted to methyl esters. After cooling to room temperature, $4 \mathrm{~mL}$ of ultrapure water was added. FAMES were recovered with petroleum ether $(3 \mathrm{~mL})$ and transferred to a vial. The solvent was removed by heat under a gentle stream of nitrogen; the FAMES were dissolved in $75 \mu \mathrm{L}$ of iso-octane transferred to a GC vial with a conical glass insert.

Solvents and chemicals were checked for purity by running a sample blank. The entire lipid extraction and methyl esterification process was performed and FAMES were dissolved in $75 \mu \mathrm{L}$ of iso-octane. Traces of contamination were subtracted from the sample chromatogram. The relative percentage composition was calculated by dividing the integrated peak area of each fatty acid by the total area of fatty acids present in the sample.

The step in the extraction procedure where the chloroform, methanol and lipid mixture is washed with water is standard procedure for the extraction of lipids from modern samples. Following Evershed et al. (1990), who reported that this step was unnecessary for the analysis of archeological residues, previously the solventlipid mixture was not washed. This step was recently adopted to remove impurities so that a clearer chromatogram could be obtained in the region where very long chain fatty acids (C20:0, C22:0, and C24:0) occur. It was anticipated that the detection and accurate assessment of these fatty acids could be instrumental in separating residues of animal origin from those of plant (Malainey et al. 2000a, 2000b, 2000c, 2001a).
In order to identify the residue, the relative percentage composition was determined first with respect to all fatty acids present in the sample (including very long chain fatty acids; see Table C-4) and secondly with respect to the ten fatty acids utilized in the development of the identification criteria (C12:0, C14:0, C15:0, C16:0,

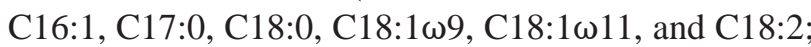
not shown). The second step is necessary for the application of the identification criteria presented in Table C-2.

It must be understood that the identifications given do not necessarily mean that those particular foods were actually prepared -different foods of similar fatty acid composition and lipid content would produce similar residues. It is possible only to say that the material of origin for the residue was similar in composition to the food(s) indicated.

\section{Gas Chromatography Analysis Parameters}

The GC analysis was performed on a Hewlett-Packard 5890 gas chromatograph fitted with a flame ionization detector connected to a personal computer. Samples were separated using a DB-23 fused silica capillary column ( 30 m x 0.25 mm I.D.; J\&W Scientific, Folsom, CA). An autosampler injected a $1 \mu \mathrm{L}$ sample using a split injection system with the ratio set at 1:20. Hydrogen was used as the carrier gas at a linear velocity of approximately $40 \mathrm{~cm} / \mathrm{sec}$. Column temperature was programmed from 155 to $215^{\circ} \mathrm{C}$ at $2^{\circ} \mathrm{C}$ per minute; lower and upper temperatures were held for four and seven minutes, respectively. The chromatogram peaks were integrated using ChromPerfect ${ }^{\circledR}$ software. Peaks were identified through comparisons with several external qualitative standards (NuCheck Prep, Elysian, $\mathrm{MN})$. Using this procedure, fatty acids are detectable to the nanogram $\left(1 \times 10^{-9} \mathrm{~g}\right)$ level. 


\section{Results of Archeological Data Analysis}

The fatty acid compositions of residues extracted from the 30 samples are presented in Table C-4. The term Area represents area under the chromatographic peak of a given fatty acid, as calculated by the ChromPerfect ${ }^{\circledR}$ software minus the solvent blank. The term Rel\% represents the relative percentage of the fatty acid with respect to the total fatty acids in the sample. Hydroxide or peroxide degradation products interfered with the integration of the C22:0 and C22:1 peaks; these fatty acids were excluded from the analysis.

The compositions of ten residues are consistent with large herbivore products, either cooked alone or with plants. Six residues, UT 3, 4, 14, 16, 18, and 19, with high levels of C18:0 were firmly identified as large herbivore meat. The C18:0 level is slightly lower in three other samples, UT 10, 13 and 20; they probably represent large herbivore meat, as well. In all cases, the meat was quite lean. The residue identified as large herbivore meat and plant, or large herbivore bone marrow, UT 9, has higher levels of C18:1 isomers and levels of C18:0 that are slightly lower than those generally observed in residues of large herbivore meat alone. The composition of the eleventh residue, UT 5, was on the border between 1) large herbivore meat cooked with plant, or large herbivore bone marrow, and 2) medium fat content food, such as mesquite or corn.

Six residues (UT 1, 25, 26, 27, 29, and 30) appear to result from the preparation of foods of medium fat content, such as mesquite or corn. Residue UT 2 is very similar in composition to UT 1, but it has slightly lower levels of C18:1 isomers and higher levels of C18:0. This may be due to traces of large herbivore products.

Other residues resemble those produced by cooking plants with medium-low fat content. The fatty acid compositions of residues UT 15 and 28 are consistent with those produced by cooking prickly pear fruit or another medium-low fat content plant. Two other residues, UT 11 and 12, have compositions that fall between 1) plants of medium-low fat content, and 2) medium fat content foods.
The composition of three residues, UT 17, 21, and 23, is characteristic of moderate-high fat content foods. These residues have relatively high levels of $\mathrm{C} 18: 1$ isomers and relatively low levels of C18:0. Examples of moderatehigh fat content foods include Texas ebony seeds and the fatty meat of medium-sized mammals, such as beaver.

Three residues, UT 7,8 , and 22 , are characterized by very high levels of C18:2, exceeding 20\%. This polyunsaturated fatty acid usually degrades very rapidly. In combinations of large herbivore meat and moderatehigh fat content seeds, such as Texas ebony, higher levels of C18:2 can be maintained (Malainey et al. 2000a, 2000b, 2000c; Quigg et al. 2001). Meat-seed residues are also characterized by $18: 1$ isomers over $30 \%$, which do not appear in any of the three samples. Residues UT 7,8 , and 22 are more characteristic of plants with a high initial level of C18:2 and a low initial level of C18:1 isomers, that has only partially decomposed; higher levels of C18:0 in UT 22 may be due to traces of large herbivore. These residues probably were never exposed to very high temperatures. Possible South Texas candidates include tasajillo berries, sotol, and cholla. Because of its higher total lipid content, cholla may be the best candidate; although, a more suitable plant may exist.

The fatty acid composition of two residues, UT 6 and UT 24, is not generally found in food residues. The fatty acids extracted from these rocks may be of natural origin.

\section{Residues in Site Context}

Multiple samples from 13 different features at 41WB556 were submitted for analysis. In six cases, the residues extracted from all burned rocks within a single feature were the same. Residues from Features 14 and 26 appear to represent medium fat content foods, similar to mesquite or corn; although, one of the Feature 14 residues has higher levels of C18:0 and lower levels of C18:1. Residues from Features 15 and 23 were identified as large herbivore meat. Both residues from Feature 17 have a very high C18:2 content and probably are of plant origin. The composition of residues from both Feature 19 samples fall between plants of medium-low and medium fat content foods. 
Residues from two features were of similar, but not the same, composition. One residue from Feature 18 was identified as large herbivore with plant or marrow; the other was probably large herbivore meat. Two residues from Feature 27 were identified as medium fat content foods; the third, plants of medium-low fat content.

Residues of two quite different compositions were extracted from samples from four features. Two residues from Feature 21 appear to represent large herbivore meat, the third represents a plant of medium-low fat content. One residue from Feature 22 was identified as large herbivore meat; the other probably resulted from the preparation of moderate-high fat content foods. The composition of one residue from Feature 16 fell between that of 1) large herbivore and plant or bone marrow, and 2) medium fat content foods; the second residue may be of natural origin. The composition of one residue from Feature 25 may also be of natural origin; the second residue was identified as moderate-high fat content foods.

The three samples submitted from Feature 24 all had quite different compositions. One was probably the result of preparing large herbivore meat; another was identified as moderate-high fat content foods; the last had a very high C18:2 content and probably is of plant origin. 


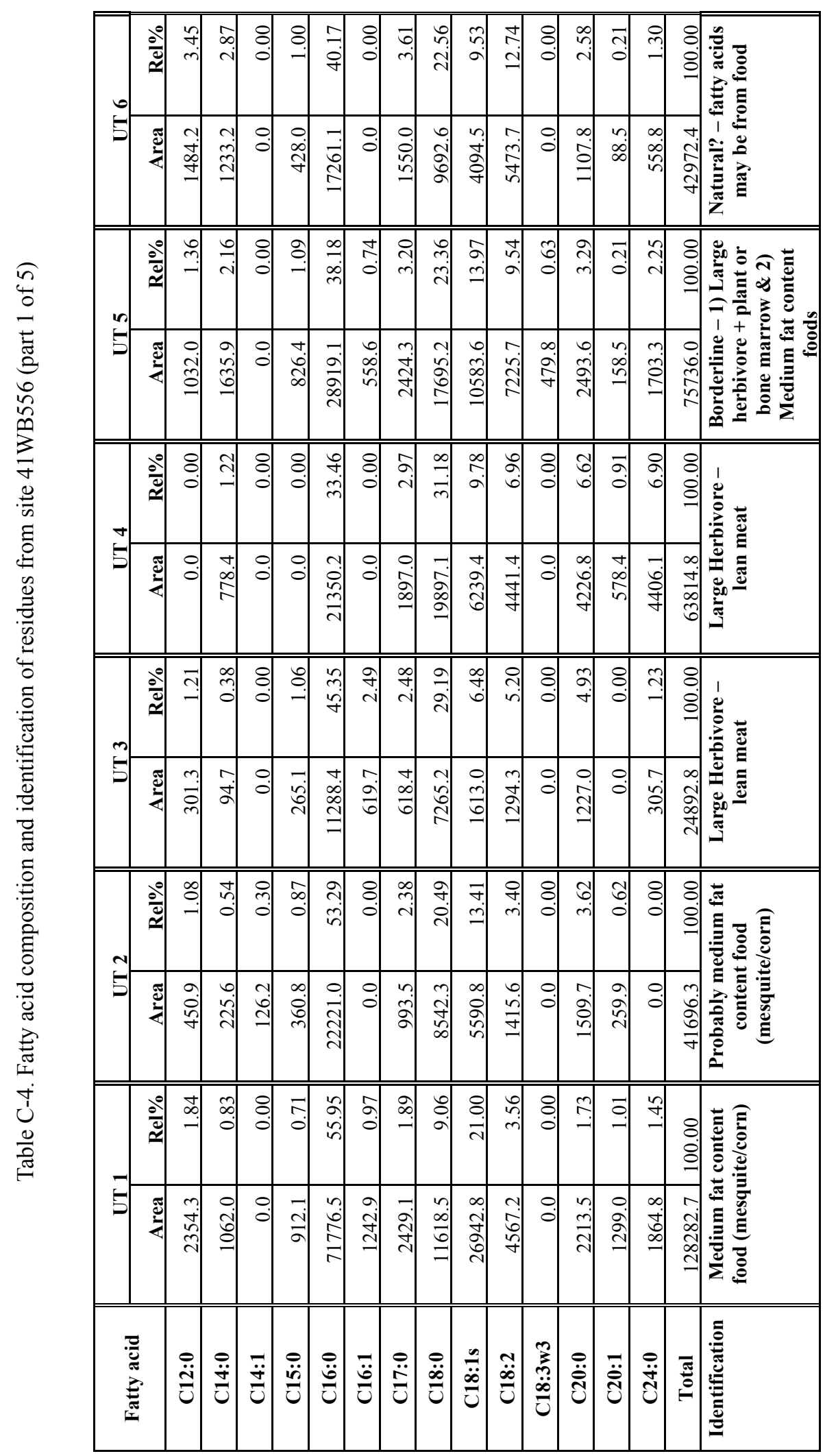




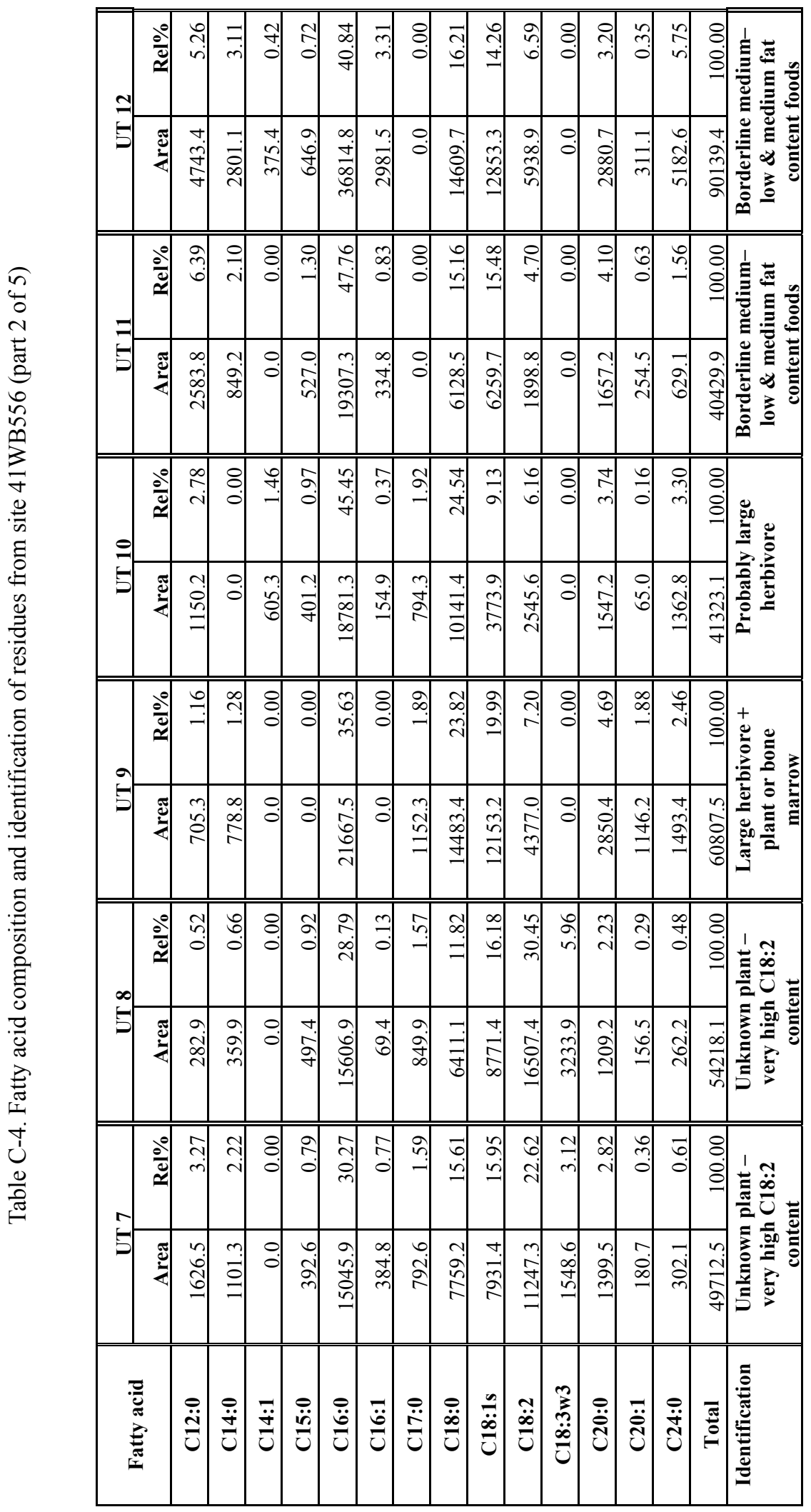




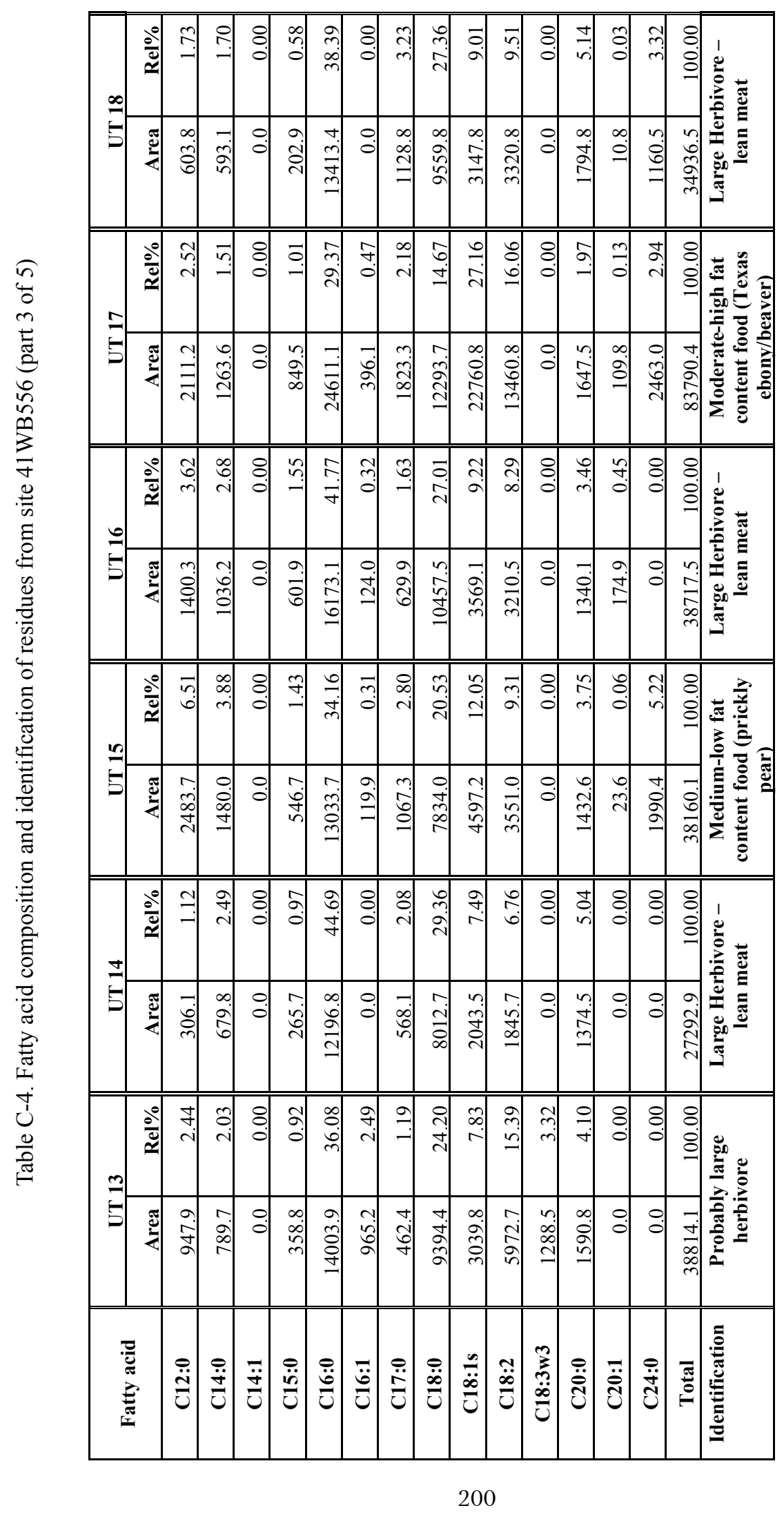




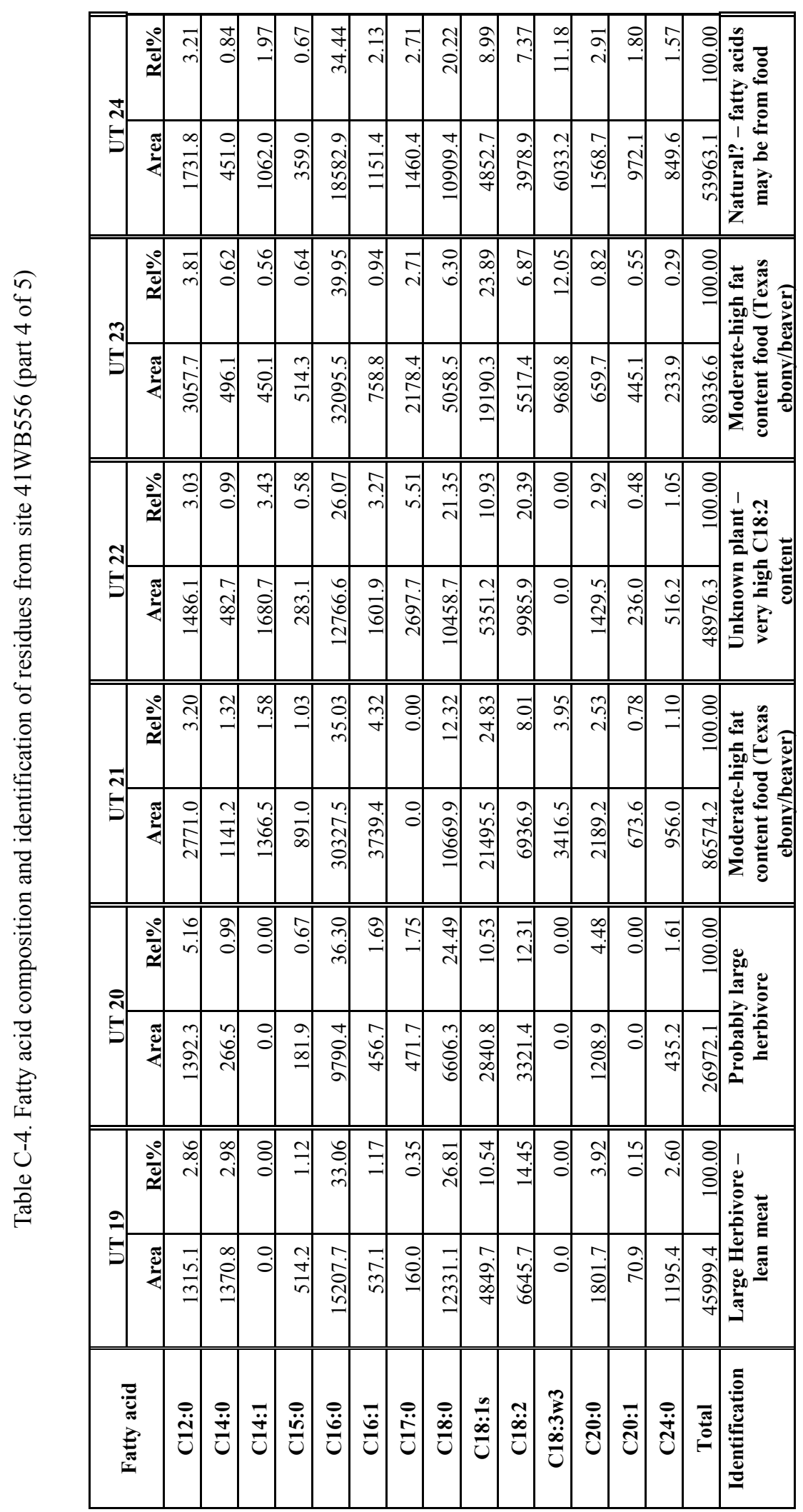




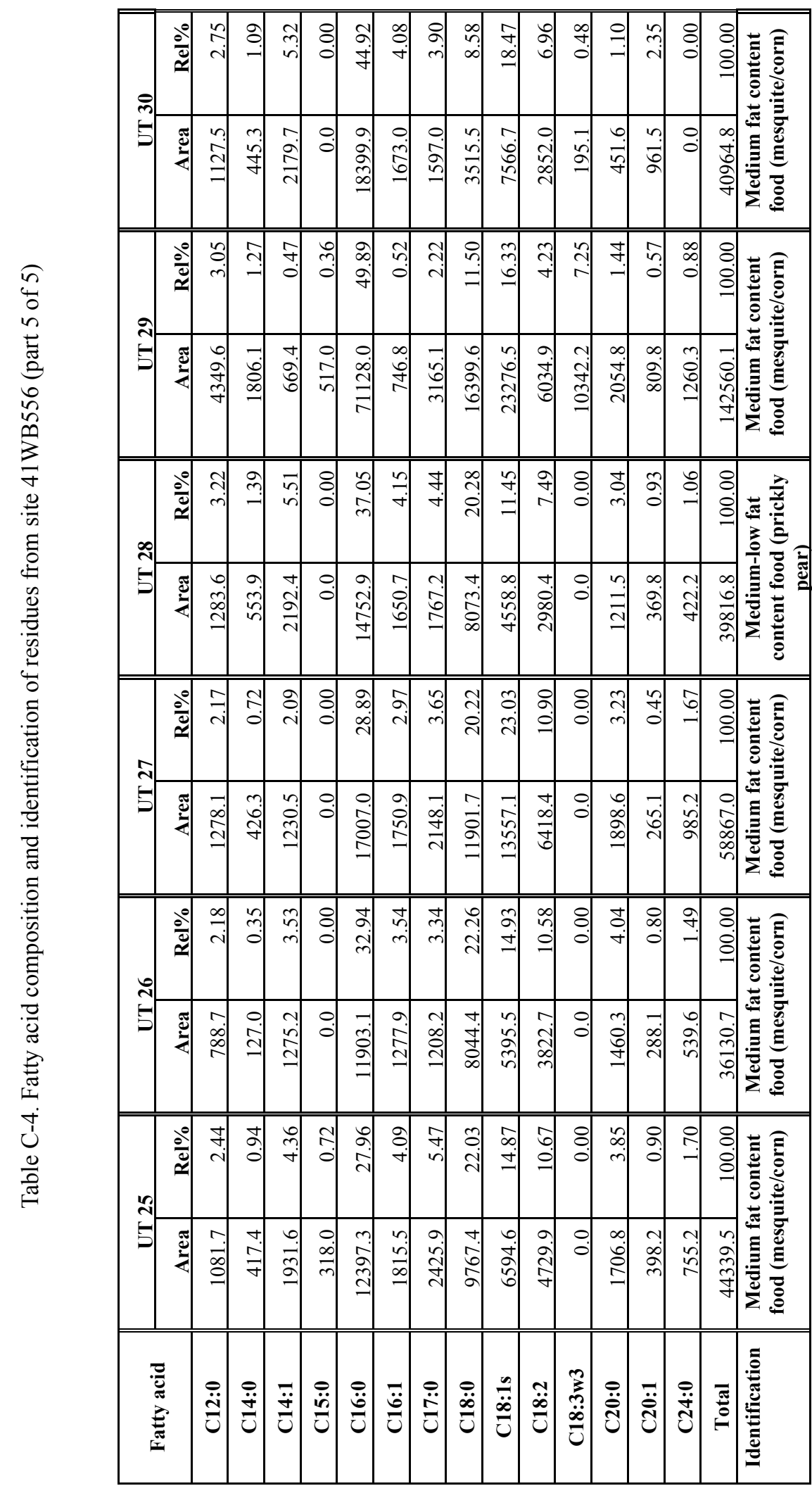




\section{References Cited}

Collins M. B., B. Ellis, and C. Dodt-Ellis

1990 Excavations at the Camp Pearl Wheat Site (41KR243): An Early Archaic Campsite on Town Creek, Kerr County, Texas. Studies in Archeology 6. Texas Archeological Research Laboratory, The University of Texas at Austin.

Condamin, J., F. Formenti, M. O. Metais, M. Michel, and P. Blond

1976 The Application of Gas Chromatography to the Tracing of Oil in Ancient Amphorae. Archaeometry 18(2):195-201.

deMan, J. M.

1992 Chemical and Physical Properties of Fatty Acids. In Fatty Acids in Foods and their Health Implications, edited by C. K. Chow, pp. 17-39. Marcel Dekker, New York.

Evershed, R. P., C. Heron, and L. J. Goad

1990 Analysis of Organic Residues of Archaeological Origin by High Temperature Gas Chromatography and Gas Chromatography-Mass Spectroscopy. Analyst 115:1339-1342.

Folch, J., M. Lees, and G. H. Sloane-Stanley

1957 A simple method for the isolation and purification of lipid extracts from brain tissue. Journal of Biological Chemistry 191:833.

Frankel, E. N.

1991 Recent Advances in Lipid Oxidation. Journal of the Science of Food and Agriculture 54:465-511.

Loy, T.

1994 Residue Analysis of Artifacts and Burned Rock from the Mustang Branch and Barton Sites (41HY209 and 41HY202). In Archaic and Late Prehistoric Human Ecology in the Middle Onion Creek Valley, Hays County, Texas, Volume 2: Topical Studies, by R. A. Ricklis and M. B. Collins, pp. 607-627. Studies in Archeology 19, Texas Archeological Research Laboratory, The University of Texas at Austin.

Malainey, M. E.

1997 The Reconstruction and Testing of Subsistence and Settlement Strategies for the Plains, Parkland and Southern Boreal Forest. Unpublished Ph.D. thesis, University of Manitoba.

Malainey, M. E., K. L. Malisza, R. Przybylski, and G. Monks

2001a The Key to Identifying Archaeological Fatty Acid Residues. Paper presented at the 34th Annual Meeting of the Canadian Archaeological Association, Banff, Alberta, May 2001.

Malainey, M. E., R. Przybylski, and B. L. Sherriff

1999a The Fatty Acid Composition of Native Food Plants and Animals of Western Canada. Journal of Archaeological Science 26:83-94.

1999b The Effects of Thermal and Oxidative Decomposition on the Fatty Acid Composition of Food Plants and Animals of Western Canada: Implications for the Identification of Archaeological Vessel Residues. Journal of Archaeological Science 26:95-103. 
1999c Identifying the former contents of Late Precontact Period pottery vessels from Western Canada using gas chromatography. Journal of Archaeological Science 26(4):425-438.

2001b One Person's Food: How and Why Fish Avoidance May Affect the Settlement and Subsistence Patterns of Hunter-Gatherers. American Antiquity 66(1):141-161.

Malainey, M. E., R. Przybylski, and G. Monks

2000a The identification of archaeological residues using gas chromatography and applications to archaeological problems in Canada, United States and Africa. Paper presented at The 11th Annual Workshops in Archaeometry, State University of New York at Buffalo, February 2000.

$2000 \mathrm{~b}$ Refining and testing the criteria for identifying archaeological lipid residues using gas chromatography. Paper presented at the 33rd Annual Meeting of the Canadian Archaeological Association, Ottawa, May 2000.

2000c Developing a General Method for Identifying Archaeological Lipid Residues on the Basis of Fatty Acid Composition. Paper presented at the Joint Midwest Archaeological \& Plains Anthropological Conference, Minneapolis, Minnesota, November 2000.

Marchbanks, M. L.

1989 Lipid Analysis in Archaeology: An Initial Study of Ceramics and Subsistence at the George C. Davis Site. Unpublished M.A. thesis, The University of Texas at Austin.

Marchbanks, M. L., and J. M. Quigg

1990 Appendix G: Organic Residue and Phytolith Analysis. In Phase II Investigations at Prehistoric and Rock Art Sites, Justiceburg Reservoir, Garza and Kent Counties, Texas, Volume II, by D. K. Boyd, J. T. Abbott, W. A. Bryan, C. M. Garvey, S. A. Tomka, and R. C. Fields, pp. 496-519. Reports of Investigations No. 71. Prewitt and Associates, Inc, Austin.

Patrick, M., A. J. de Konig, and A. B. Smith

1985 Gas Liquid Chromatographic Analysis of Fatty Acids in Food Residues from Ceramics Found in the Southwestern Cape, South Africa. Archaeometry 27(2):231-236.

Quigg, J. M., C. Lintz, G. Smith, and S. Wilcox

2000 The Lino Site: A Stratified Late Archaic Campsite in a Terrace of the San Idelfonzo Creek, Webb County, Southern Texas. Technical Report No. 237565, TRC Mariah Associates; Archeological Studies Program, Report No. 20, Environmental Affairs Division, Texas Department of Transportation, Austin.

Quigg, J. M., M. E. Malainey, R. Przybylski, and G. Monks

2001 No Bones About It: Using Lipid Analysis of Burned Rock and Groundstone Residues to Examine Late Archaic Subsistence Practices in South Texas. Plains Anthropologist 46(177):283-303.

Skibo, J. M.

1992 Pottery Function: A Use-Alteration Perspective. Plenum Press, New York.

Solomons, T. W. G.

1980 Organic Chemistry. John Wiley \& Sons, Toronto. 


\section{Appendix D}

\section{Macrobotanical Analysis}

by

J. Philip Dering 


\section{Appendix D: Rainfall Reconstruction Using Mesquite Wood Charcoal from Archeological Sites in Southern Texas}

\section{J. Philip Dering}

Climate histories are modeled using proxy data, including vegetation histories from pollen profiles, packrat middens or archeological sites. Other sources of proxy data can be developed through the disciplines of pedology, alluvial geomorphology, from vertebrate or invertebrate faunal assemblages from caves or other depositional sources, and even from isotopic analyses of spring water. Despite the potential wealth of data available to archeologists, it is becoming abundantly clear that accurate reconstructions of climate change have been difficult to achieve for most of southern and western Texas. Climate reconstructions in the region have been hindered due both to a lack of an adequate proxy database and to apparent regional variability in climate. Deeply stratified deposits with well-preserved data sources are rare if not absent from southern Texas, and the region is located at the boundary between large-scale regional circulation patterns and precipitation patterns, a condition which increases spatial climatic variability. For this reason it would be very useful to discover an adequate database that will serve as a proxy for climate -one that is distributed widely throughout the region, and that can be recovered from datable deposits.

It has been demonstrated recently that Holocene climate has been characterized by episodes of relative stability punctuated by intervals of rapid change (Bryson 1987; COHMAP 1988; Wright 1993). Across the earth, these intervals are time transgressive. Simply illustrated, at the same time one region is warming and suffering a moisture deficit, another region may be cooler and enjoying moister conditions (Wright 1976, 1993). For western North America much more so than eastern North America, regional variability is the rule rather than the exception (Neilson 1987). This climatic, hence biotic, regionalization is caused by large-scale atmospheric circulation controls mediated by smaller-scale topographic features and by the boundary effect present between the dominant atmospheric patterns (Mock and Bartlein 1995:425). Therefore, achieving accurate climate reconstructions is usually aided by two factors: 1) some regional continuity in climate patterns; and 2) surviving proxy data sources preserved in datable deposits.
While we cannot solve the problem of regional variability, we may be able to find and tap into a usable proxy database. The solution may lie in the analysis of wood charcoal. Wood charcoal is the most common plant material that is recovered from archeological sites in southern and western Texas. It has been recovered from hundreds of sites in the region, and has the advantage of being directly dated using AMS radiocarbon analysis. Archeologists are familiar with the fact that most climate studies of wood are based on the study of growth rings. The inherent problem with dendrochronology, however, is that all growth ring studies hinge on the assumption that a new growth ring is formed each year. This presents an obstacle to dendrochronological studies in many regions, because of the unpredictability of ring formation in most tree species. In addition, trees growing in areas that lack distinctive seasonal change, which includes most of the southern U.S. borderlands, pose a challenge to any analysis that assumes the formation of annual growth rings. However, there is another approach to the analysis of wood that is showing promise -an approach commonly referred to as xylem analysis.

\section{Wood (Xylem) Analysis}

Tree trunks and limbs function to 1) support the tree, 2) conduct water and minerals from the roots to the leaves, and 3 ) to conduct food produced by photosynthesis from the leaves back into the stems, trunk, and roots. Most of a tree is composed of xylem tissue, otherwise known as wood. Xylem is composed of several types of tissues and cells, including vessel elements and rays that conduct water, and several types of fibers that act as structural support for the tree. In seed-bearing plants, vessel elements act as the primary conduits for water that is transported from the roots to the leaves.

The shape and arrangement of these cells in wood (xylem) is unique to the genus or species of most trees, allowing for the tree to be identified from its wood. When wood is charred it usually retains its anatomical integrity, allowing charcoal to be identified by its characteristic 
arrangement of cell types. In other words, wood anatomy is specific to the genus or species of the tree, and it is preserved in the charring process.

As a reaction to local environmental conditions, wood anatomy can also vary within the basic pattern of a species. Recent studies in South Africa have demonstrated that trees adapt to differing moisture regimes, and that the anatomical characteristics of wood of the same tree species will vary accordingly. Within the same tree species, vessel elements, the primary water conductors in the wood of a tree, may vary in size and density according to local rainfall regimes (February 1992, 1994; February et al. 1995). Studies in South Africa have demonstrated that some tree species demonstrate predictable changes in vessel diameter and density according to changes in rainfall regime. Using two commonly occurring species, Protea roupelliae and Protea caffra, which are distributed across a wide range of annual precipitation, February (1994:103) has demonstrated that vessel diameter increases and vessel density decreases as rainfall increases across a geographic gradient.

In southern and western Texas, mesquite is the most common type of wood charcoal recovered from archeological sites. Not only is it an abundant wood type, but the most abundant mesquite tree species, Prosopis glandulosa, is distributed almost continuously across a broad precipitation gradient, from northern Mexico to the Texas panhandle, and from eastern Texas to New Mexico. Mesquite trees thrive in areas with rainfall regimes that range from 8 in $(203 \mathrm{~mm})$ to 39 in $(1,016$ $\mathrm{mm}$ ) per year. Such adaptability requires a certain plasticity in growth form, and it is these adaptive responses to precipitation that we wish to measure through xylem analysis of the charcoal recovered from archeological sites.

Several authors have demonstrated a direct relationship between xylem anatomy and rainfall (February 1992, 1994; Scholtz 1986; Tusenius 1989). Their work is based on the research of Carlquist (1975) and Baas (1982; Baas et al. 1983), who have concluded that vessel frequency decreases, and vessel diameter increases, when rainfall increases. Zimmerman (1983) has explained the advantage that is conferred to trees with wide vessel elements. A tree with fewer vessels with larger diameters has developed a more efficient means of transporting larger volumes of water, but the presence of fewer vessels increases risk if the tree is damaged. Higher densities of smaller vessels is less efficient, but trees with high vessel densities entail less risk if the tree is damaged. Many tree species produce more but smaller vessels during periods of lower precipitation, a reaction which Zimmerman (1983) argues reduces both risk and evapotranspiration. The latter characteristic helps the tree to conserve water in a dry environment.

\section{Methods}

The analysis of charcoal from 41WB556 and 41WB557 was conducted in two steps. First, all specimens ( $\mathrm{n}=41$ charcoal samples and six flotation samples) were sorted and identified. From the identified material, a total of 36 mesquite specimens was analyzed from the two sites. These specimens came from several feature and nonfeature contexts that have been dated to four general time periods. The youngest time frame ranges from $150 \mathrm{BP}$ to present. A second time period spans the period around 400 вр. Two sample sets bracket time periods around 600 BP and 800 BP. The analysis of these specimens should provide archeologists with data from the interesting Protohistoric period, which coincides with the Little Ice Age, and from the period around $800 \mathrm{BP}$, a time of regional drought which occurred in the greater Southwest, a condition not yet defined for southern Texas. When combined with data from the Lino Site (41WB437) and 41ZP364, the data from the current study should provide archeologists with more data on mesquite wood anatomy, and allow them to understand the parameters associated with mesquite wood.

\section{Scanning Electron Microscopy and Measurements}

\section{Specimen Analysis}

Each specimen was fractured along the transverse (crosssection) plane and secured to a $1 \times 1-\mathrm{cm}$ aluminum cylindrical stub using $12 \mathrm{~mm}$ wide carbon conductive tape. Samples were dried in an oven at $55^{\circ} \mathrm{C}$ for 72 hours, and then sputter-coated with gold-palladium to a thickness of $20 \mathrm{~nm}$ (nanometers). The JEOL T330A scanning electron microscope operating at $15 \mathrm{kv}$ was utilized to scan the specimens magnifications from $35 \mathrm{X}$ 
to $100 \mathrm{X}$. Images of each specimen were captured using Polapan 400 film.

Xylem analysis of each sample began by scanning each image into a bitmap file and opening that file in AutoCAD 2000i. Using the dimension tool, the tangential interior diameter of each vessel at its widest point was measured. Because of the irregular shape of vessels, it is important to take the measurements from the same orientation (e.g., tangential diameter) for every sample. Measurements of each vessel element follow a pattern by beginning in the upper left corner of the imaged sample and continuing across to the right corner and down the face of the image to the lower right corner of the photograph. The diameter of each vessel is calculated using the scale bar in the image that is calibrated with graticule placed on the stub alongside the sample.

\section{Data Presentation}

Three values are presented for each wood specimen. First, the mean vessel diameter is simply a sum of the measured vessel diameters divided by the number of vessels that were measured on the sample. The second value is the mean of the density of vessels in the wood, a figure expressed in vessels per $\mathrm{mm}^{2}$. To obtain vessel density, all vessel elements are counted in the image and divided by the area of wood covered by the image. The third value is termed the vulnerability index. It is the value calculated by dividing the mean vessel diameter by the mean vessel density for each wood sample. A higher vulnerability index results from the presence of fewer but larger vessels in the wood, a condition indicating wetter climate. A lower vulnerability index is a result of numerous but smaller vessels in the wood, a condition encouraged by low rainfall conditions.

\section{Results}

\section{Modern Reference Specimens}

Mesquite is distributed almost continuously along an east-west gradient from Brazos County to El Paso County. Because Texas also exhibits a continuous precipitation gradient along an east-west axis, it should be possible to establish a very detailed data set of xylem anatomy. To this end the reaction of mesquite to rainfall has been assessed by obtaining specimens from five different precipitation regimes. The modern wood samples were collected from five different counties situated along an east-west gradient with annual precipitation ranging from $39 \mathrm{in}(1,016 \mathrm{~mm})$ to 8 in $(203 \mathrm{~mm})$. Stems in the modern collection were restricted to a narrow size range. Only stems with a diameter measuring between 1.5-3 in (about 4-7.5 cm) were collected. Wood within this size range produces a very effective fire for heating rocks, can be broken and transported with reasonable ease, and is of the size most often encountered at archeological sites (see Shackleton and Prins 1992). The reference mesquite was cured in a woodshed for at least six months, then carbonized in an electric kiln by slowly raising the temperature to $600^{\circ} \mathrm{C}$. The material was analyzed using methods outlined for archeological specimens.

The counties, their annual precipitation amounts, and results of the xylem analysis are noted in Table D-1. There are distinct differences in the density and in the diameter of vessels in each set of wood samples and these changes occur predictably across the rainfall gradient, showing the potential for this approach. If, when the data set is considerably expanded, these distinctions remain, then we will have identified a quantifiable relationship

Table D-1. Xylem analysis of reference specimens

\begin{tabular}{|l|c|c|c|l|}
\hline & $\begin{array}{c}\text { Mean Vessel } \\
\text { Diameter }\end{array}$ & $\begin{array}{c}\text { Vessel Density } \\
\left(\mathbf{x} / \mathbf{m m}^{2}\right)\end{array}$ & $\begin{array}{c}\text { Vulnerability } \\
\text { Index }\end{array}$ & \multicolumn{1}{|c|}{ Precipitation } \\
\hline Brazos County $(\mathrm{n}=6)$ & 0.09 & 11.1 & 0.0081 & 39 in $(991 \mathrm{~mm})$ \\
\hline Bexar County $(\mathrm{n}=2)$ & 0.082 & 15.3 & 0.0054 & 29 in $(737 \mathrm{~mm})$ \\
\hline Webb County $(\mathrm{n}=2)$ & 0.062 & 19 & 0.0033 & 20 in $(510 \mathrm{~mm})$ \\
\hline Val Verde County $(\mathrm{n}=5)$ & 0.048 & 27 & 0.0018 & 17 in $(432 \mathrm{~mm})$ \\
\hline El Paso County $(\mathrm{n}=2)$ & 0.032 & 39 & 0.0008 & 8 in $(203 \mathrm{~mm})$ \\
\hline
\end{tabular}


between rainfall and mesquite xylem anatomy. However, many more reference samples need to be processed and analyzed, and more reference specimens from many different soil types and landform locations within a given rainfall regime need to be examined.

\section{Archeological Specimens}

Identifications of the 41 charcoal and six flotation samples are presented in Table D-2. Results of the xylem analysis of 36 mesquite charcoal samples appear in Tables D-3 and D-4. Most of the samples from both 41 WB556 and 41WB557 are mesquite. In addition to mesquite, guayacan, granjeno, huisache, desert olive, and bluewood were identified (Table D-2). These small trees and shrubs are typical of the shallow soils and gravels of southern Texas. Predominance of mesquite wood, which serves as excellent firewood, indicates that mesquite trees must have been plentiful in the immediate vicinity of the site.

Xylem analysis of feature material from both sites appears in Table D-3. Feature 23 was the only dated feature from 41WB556 included in the xylem analysis. Two radiocarbon ages from Feature 23 yielded a calibrated 2-sigma age range from approximately A.D. 1280-1480. Mean vessel diameter measured .076 and vessel density was 12.5 vessels $/ \mathrm{mm}^{2}$. Samples from Feature 27 produced a very wide range of measurements, perhaps indicating disturbance of materials within the feature deposits.

At 41WB557, several features were analyzed. Features 21 and 22 are very recent features that may be only a century old. Feature 25 is somewhat older, dating to the early Historic period. Feature 12 dates to the Late Prehistoric period, and Feature 18 does not have a radiocarbon analysis associated with it. If Features 21 and 22 are grouped together as a single data set, then the mesquite wood from these each of the features exhibit distinctive xylem characteristics. Features 21 and 22 each have a mean vulnerability index of .0054 , Feature 25 has a mean vulnerability index of .0072, and Feature 12 has a vulnerability index of .0041. In Table D-4, the nonfeature group of samples that was dated to between A.D. $900-1000$ has a vulnerability index of .0039 , very close to that of the earlier Feature 12. The single sample from BT 12, \# 234-1, has a vulnerability index of .0025, much lower than other dated values.

Measurements and vulnerability indices for the undated non-feature samples vary widely. Vulnerability indices from the south block samples are somewhat lower than for the north block samples, but the values vary quite widely from .0014 to .0062 . It is clear that no coherent trend can be detected in the south block samples unless they can be tied to occupation periods. However, the samples do establish a range of vessel diameters, vessel density, and vulnerability indices that may be associated with the region during the later Holocene.

\section{Discussion}

Xylem analysis of the archeological samples shows some patterns that are worthy of consideration. The modern analogs in Table D-1 provide us with an expected range of data that prove useful for comparison to the archeological samples. Although it is too early in the study to consider the modern data as a totally reliable proxy data source for precipitation change in the study region, the results are definitely intriguing. Modern reference specimens provide data strongly suggesting that there is a relationship between precipitation and the xylem anatomy in mesquite. The materials collected so far allow the analyst to begin to establish parameters for a range of vessel diameters and density in various rainfall regimes.

In the reference material, measured vessel diameters of mesquite vary from a minimum of .032 (El Paso County) to a maximum of $.090 \mathrm{~mm}$ (Brazos County). The smallest mean vessel diameter values in the archeological studies are .041 mm (Specimen 762-3) in the current study, .037 $\mathrm{mm}$ (Specimen 3604.4) from the Lino Site, and $.045 \mathrm{~mm}$ (Specimen 448) from 41ZP364. These diameters are somewhat larger than the material from El Paso County, but are very close to the measurements from Val Verde County. The largest vessel diameters measured $.081 \mathrm{~mm}$ (Specimen 1261-6a) from 41WB577, .074 mm (Specimen 5482) from the Lino Site, and $.064 \mathrm{~mm}$ (Specimen 155-1) from 41ZP364, somewhat smaller than the Brazos County samples. 
Table D-2. Identification of charred wood samples from 41WB556 and 41WB557

\begin{tabular}{|c|c|c|c|c|c|c|}
\hline Specimen & Unit & Vertical $(\mathrm{cm})$ & Feature & Grams & Name & Common \\
\hline $1677-9 a-a$ & N 144 & 22 & 22 east & 0.2 & Prosopis glandulosa & Mesquite \\
\hline $1677-9$ & N 144 & 22 & 22 east & 0.1 & Prosopis glandulosa & Mesquite \\
\hline $1676-7$ & N 144 & 22 & 22 & 0.2 & Prosopis glandulosa & Mesquite \\
\hline $1677-8$ & N 145 & $10-20$ & 22 & 0.2 & Prosopis glandulosa & Mesquite \\
\hline $1261-8 b$ & N 104 & $0-10$ & 21 & 0.05 & Prosopis glandulosa & Mesquite \\
\hline \multirow[t]{2}{*}{$1261-8$} & \multirow[t]{2}{*}{ N 104} & \multirow[t]{2}{*}{$0-10$} & \multirow[t]{2}{*}{21} & 3 & Prosopis glandulosa & Mesquite \\
\hline & & & & 0.6 & Guaiacum angustifolium & Guayacan \\
\hline $1261-6 \mathrm{a}$ & N 104 & $0-10$ & 21 & 3.7 & Prosopis glandulosa & Mesquite \\
\hline $1677-11 \mathrm{a}$ & N 144 & 21 & 22 east & 0.1 & Prosopis glandulosa & Mesquite \\
\hline $1677-11$ & N 144 & 21 & 22 east & 2.6 & Prosopis glandulosa & Mesquite \\
\hline $1261-8 \mathrm{a}$ & N 104 & $0-10$ & 21 & 0.05 & Prosopis glandulosa & Mesquite \\
\hline $652-4 \mathrm{a}$ & S 44 & 88 & 25 & 0.15 & Prosopis glandulosa & Mesquite \\
\hline $652-4$ & S 44 & 88 & 25 & 1.2 & Prosopis glandulosa & Mesquite \\
\hline $234-1$ & BT 12 & 150 & n.a. & 0.1 & Prosopis glandulosa & Mesquite \\
\hline $564-5 \mathrm{a}$ & S 37 & $150-160$ & n.a. & 0.15 & Prosopis glandulosa & Mesquite \\
\hline $564-5$ & S 37 & $150-160$ & n.a. & 0.1 & Prosopis glandulosa & Mesquite \\
\hline $494-3 a$ & S 32 & $90-100$ & n.a. & 0.05 & Prosopis glandulosa & Mesquite \\
\hline 494-3 & S 32 & $90-100$ & n.a. & 0.2 & Prosopis glandulosa & Mesquite \\
\hline $955-4 a-a$ & $\mathrm{~N} 75$ & $37-39$ & 12 & 0.05 & Prosopis glandulosa & Mesquite \\
\hline $955-4$ & N 75 & $37-39$ & 12 & 0.7 & Prosopis glandulosa & Mesquite \\
\hline $916-3 a$ & $\mathrm{~N} 71$ & $80-90$ & n.a. & 0.8 & Prosopis glandulosa & Mesquite \\
\hline 953-3 & $\mathrm{N} 75$ & $10-20$ & n.a. & 0.6 & Prosopis glandulosa & Mesquite \\
\hline 974-3 & N 77 & $20-30$ & n.a. & 1.0 & Prosopis glandulosa & Mesquite \\
\hline 984-4 & $\mathrm{N} 78$ & 19 & n.a. & 0.4 & Prosopis glandulosa & Mesquite \\
\hline $1007-6$ & $\mathrm{~N} 80$ & $8-20$ & n.a. & 0.1 & Prosopis glandulosa & Mesquite \\
\hline $1008-4$ & $\mathrm{~N} 80$ & $20-30$ & n.a. & 0.9 & Prosopis glandulosa & Mesquite \\
\hline $1495-5 \mathrm{a}$ & N 122 & $90-100$ & n.a. & 6.8 & Prosopis glandulosa & Mesquite \\
\hline $1651-6 \mathrm{a}$ & N 141 & $90-100$ & n.a. & 0.5 & Prosopis glandulosa & Mesquite \\
\hline $273-9 \mathrm{a}$ & S 16 & $76-79$ & $18 \mathrm{a}$ & 0.7 & Prosopis glandulosa & Mesquite \\
\hline \multirow[t]{2}{*}{$272-5-5$} & \multirow[t]{2}{*}{ S 16} & \multirow[t]{2}{*}{$60-70$} & & 3.2 & Prosopis glandulosa & Mesquite \\
\hline & & & & 0.5 & Celtis pallida & Granjeno \\
\hline \multirow[t]{2}{*}{$379-3$} & \multirow[t]{2}{*}{ S 24} & \multirow[t]{2}{*}{$40-50$} & & 0.5 & Prosopis glandulosa & Mesquite \\
\hline & & & & 0.1 & Acacia farnesiana & Huisache \\
\hline $621-7$ & S 42 & $30-40$ & & 0.2 & Prosopis glandulosa & Mesquite \\
\hline $742-3$ & S 52 & $20-30$ & & 0.1 & Prosopis glandulosa & Mesquite \\
\hline $751-4$ & S 52 & $110-120$ & & 0.3 & Prosopis glandulosa & Mesquite \\
\hline $762-3$ & S 53 & $60-70$ & & 0.4 & Prosopis glandulosa & Mesquite \\
\hline \multirow[t]{2}{*}{$778-3$} & \multirow[t]{2}{*}{ S 54} & \multirow[t]{2}{*}{$60-70$} & & 1.8 & Prosopis glandulosa & Mesquite \\
\hline & & & & 0.2 & Forestiera sp. & Desert olive \\
\hline $782-4$ & S 54 & $100-110$ & & 0.2 & Prosopis glandulosa & Mesquite \\
\hline $797-3$ & S 55 & $120-130$ & & 6.1 & Prosopis glandulosa & Mesquite \\
\hline $844-4$ & S 55 & $20-30$ & & 0.1 & Prosopis glandulosa & Mesquite \\
\hline $845-4$ & S 59 & $30-40$ & & 1.3 & Indeterminate & \\
\hline \multirow[t]{2}{*}{$864-3$} & \multirow[t]{2}{*}{ S 60} & \multirow[t]{2}{*}{$100-110$} & & 0.4 & Prosopis glandulosa & Mesquite \\
\hline & & & & 0.2 & Condalia sp. & Bluewood \\
\hline
\end{tabular}


Table D-3. XA Samples from features, 41WB556 and 41WB557

\begin{tabular}{|c|c|c|c|c|c|c|c|}
\hline Number & Unit & $\begin{array}{c}\text { Depth (cmbs) or } \\
\text { Level }\end{array}$ & $\begin{array}{c}\text { Feature } \\
\text { No. }\end{array}$ & $\begin{array}{c}\text { Mean Vessel } \\
\text { Diameter }\end{array}$ & $\begin{array}{l}\text { Vssl Density } \\
\left(\mathrm{vssl} / \mathbf{m m}^{2}\right)\end{array}$ & $\begin{array}{c}\text { Vulnerability } \\
\text { Index }\end{array}$ & $\begin{array}{c}2 \text { Sigma } \\
\text { Calibration Range }\end{array}$ \\
\hline \multicolumn{8}{|l|}{$41 \mathrm{WB} 556$} \\
\hline 772 & & Lvl 3 & 23 & 0.077 & 13 & 0.0059 & \\
\hline 772 & & Lvl 3 & 23 & 0.074 & 12 & 0.0062 & \\
\hline \multicolumn{4}{|c|}{ Mean values: Feature 23} & 0.076 & 12.5 & 0.0060 & (about AD 1288-1438) \\
\hline 1308 & & Lvl 4 & 27 & 0.067 & 12 & 0.0056 & \\
\hline 1312 & & Lvl 4 & 27 & 0.074 & 16 & 0.0046 & \\
\hline 1312 & & Lvl 4 & 27 & 0.055 & 17 & 0.0032 & \\
\hline 1314 & & Lvl 4 & 27 & 0.063 & 14 & 0.0045 & \\
\hline \multicolumn{4}{|c|}{ Mean values: Feature 27} & 0.059 & 15.5 & 0.0039 & No Date \\
\hline \multicolumn{8}{|l|}{ 41WB557 } \\
\hline $1677-9 a-a$ & N 144 & 22 & 22 east & 0.067 & 17 & 0.0039 & AD 1660 to 1950 \\
\hline $1677-9$ & N 144 & 22 & 22 east & 0.064 & 15 & 0.0043 & \\
\hline $1676-7$ & N 144 & 22 & 22 & 0.079 & 11 & 0.0072 & \\
\hline $1677-8$ & N 145 & $10-20$ & 22 & 0.082 & 15 & 0.0055 & \\
\hline $1261-8 b$ & N 104 & $0-10$ & 21 & 0.065 & 12 & 0.0054 & AD 1640 to 1950 \\
\hline $1261-8$ & N 104 & $0-10$ & 21 & 0.068 & 14 & 0.0049 & \\
\hline $1261-6 a$ & N 104 & $0-10$ & 21 & 0.082 & 11 & 0.0075 & \\
\hline 1677-11a & N 144 & 21 & 22 east & 0.077 & 14 & 0.0055 & AD 1650 to 1950 \\
\hline 1677-11 & N 144 & 21 & 22 east & 0.081 & 14 & 0.0058 & \\
\hline $1261-8 \mathrm{a}$ & N 104 & $0-10$ & 21 & 0.057 & 15 & 0.0038 & $\begin{array}{c}\mathrm{AD} 1520 \text { to } 1590,1620 \text { to } \\
1680,1930 \text { to } 1950\end{array}$ \\
\hline \multicolumn{4}{|c|}{ Mean values: Features 21 and 22} & 0.0722 & 13.8 & 0.0054 & \\
\hline $652-4 a$ & S 44 & 88 & 25 & 0.084 & 12 & 0.0070 & AD 1450 to 1650 \\
\hline $652-4$ & S 44 & 88 & 25 & 0.081 & 11 & 0.0074 & \\
\hline \multicolumn{4}{|c|}{ Mean values: Feature 25} & 0.0825 & 11.5000 & 0.0072 & \\
\hline 955-4a-a & N 75 & $37-39$ & 12 & 0.067 & 17 & 0.0039 & AD 670 to 880 \\
\hline $955-4$ & N 75 & $37-39$ & 12 & 0.064 & 15 & 0.0043 & \\
\hline \multicolumn{4}{|c|}{ Mean values: Feature 12} & 0.0655 & 16 & 0.0041 & \\
\hline \multicolumn{8}{|l|}{ Feature 18} \\
\hline $273-9 a$ & S 16 & 76-79 & $18 \mathrm{a}$ & 0.054 & 19 & 0.0028 & \\
\hline
\end{tabular}

Vessel density measurements follow a similar pattern, varying at 41WB577 from a minimum of 11 vessels $/ \mathrm{mm}^{2}$ (Specimen 1261-a) to a maximum of 29 vessels $/ \mathrm{mm}^{2}$ (Specimen 379-3). The measurements from the Lino site have a much narrower range, $18.5-26.3$ vessels $/ \mathrm{mm}^{2}$, and from 41ZP364 the range is still narrower at 17.8-23 vessels $/ \mathrm{mm}^{2}$. An interesting aspect of the vessel density is that lowest values are comparable to the lowest density of the reference material collected from Brazos County and indicative of a moister rainfall regime. On the other hand, the highest density of archeological material does not approach the 39 vessels $/ \mathrm{mm}^{2}$ noted in the mesquite wood from El Paso County.

Table D-5 compares the mean values of modern reference samples from Webb County to selected data from archeological specimens. We have already established a preliminary data set that demonstrates the relationship 
between vessel diameter and vessel density, and mean annual rainfall in a region. Generally speaking, the wood of mesquite growing in climates with more rainfall has larger but fewer vessels in low density. The wood of mesquite growing in climates with less rainfall has smaller vessels but these occur in much higher density.

We can approach the comparisons by tracking mean vessel diameter and vessel density separately, or by establishing a vulnerability index using these two direct measurements. The vulnerability index equals mean vessel diameter divided by the density of vessels in the wood. A higher vulnerability index is the result of larger diameter vessels occurring in lower density. High vulnerability means that the tree is adapted to moister climates. A low vulnerability index is a result of small vessels occurring in high density, and indicates a tree adapted to dry climates.
Examination of Table D-5 shows xylem analysis data associated with the major occupational periods at the three sites that have been studied thus far. Two of the sites are located in Webb County and one is located from adjacent Zapata County, which has a very similar average annual rainfall $(530 \mathrm{~mm})$ compared to Webb County (510 $\mathrm{mm})$. Although much more data needs to be gathered to provide sufficient data for statistical analysis, some trends appear to be emerging. For example, the highest vulnerability, indicating possibly moister than modern conditions, is recorded from 41WB577 in samples dated to the early Historic period (about $400 \mathrm{BP}$ ). By contrast the xylem analysis data suggest the driest periods come from samples dating to $3000 \mathrm{BP}$ and $4700 \mathrm{BP}$. Xylem analysis data comparable to modern samples from Webb County is noted in material from approximately 2000 BP. These data provide a very preliminary record of mesquite tree growth for the late Holocene.

Table D-4. XA samples from non-feature contexts, 41WB557

\begin{tabular}{|c|c|c|c|c|c|c|}
\hline Catalog & Unit & Depth & $\begin{array}{c}\text { Mean Vessel } \\
\text { Diameter } \\
\end{array}$ & Vessels/mm ${ }^{2}$ & $\begin{array}{c}\text { Vulnerability } \\
\text { Index } \\
\end{array}$ & Date \\
\hline $564-5 \mathrm{a}$ & S 37 & $150-160$ & 0.061 & 15 & 0.0041 & $\mathrm{AD} 970$ to 1160 \\
\hline $564-5$ & S 37 & $150-160$ & 0.067 & 18 & 0.0037 & \\
\hline $494-3 a$ & S 32 & $90-100$ & 0.061 & 14 & 0.0044 & $\begin{array}{l}\text { AD } 910 \text { to } 920 \text {, } \\
960 \text { to } 1030\end{array}$ \\
\hline 494-3 & S 32 & $90-100$ & 0.067 & 19 & 0.0035 & \\
\hline Mean values & & & 0.064 & 16.5 & 0.0039 & \\
\hline $234-1$ & BT 12 & 150 & 0.054 & 22 & 0.0025 & $\mathrm{AD} 1235$ to 1300 \\
\hline $916-3 a$ & N 71 & $80-90$ & 0.072 & 21 & 0.0034 & \\
\hline $1008-4$ & N 80 & $20-30$ & 0.066 & 14 & 0.0047 & \\
\hline $1495-5 a$ & N 122 & $90-100$ & 0.07 & 19 & 0.0037 & (label reads $1459-5 a)$ \\
\hline $1651-6 a$ & N 141 & $90-100$ & 0.074 & 24 & 0.0031 & \\
\hline Mean values & & & 0.03525 & 13.0 & 0.0037 & \\
\hline $742-3$ & S 52 & $20-30$ & 0.074 & 12 & 0.0062 & \\
\hline $751-4$ & S 52 & $110-120$ & 0.069 & 18 & 0.0038 & \\
\hline $797-3$ & S 55 & $120-130$ & 0.071 & 21 & 0.0034 & \\
\hline $864-3$ & S 60 & $100-110$ & 0.045 & 18 & 0.0025 & \\
\hline $379-3$ & S 24 & $40-50$ & 0.064 & 29 & 0.0022 & \\
\hline $778-3$ & S 54 & $60-70$ & 0.049 & 27 & 0.0018 & \\
\hline $782-4$ & S 54 & $100-110$ & 0.054 & 21 & 0.0026 & \\
\hline $762-3$ & S 53 & $60-70$ & 0.041 & 29 & 0.0014 & \\
\hline Mean values & & & 0.0467 & 17.5 & 0.0030 & \\
\hline
\end{tabular}


Table D-5. Comparative xylem analysis data

\begin{tabular}{|c|c|c|c|c|l|}
\hline Site & Time Period & $\begin{array}{c}\text { Mean Vessel } \\
\text { Diameter }\end{array}$ & Vessels/mm $\mathbf{m m}^{2}$ & $\begin{array}{c}\text { Vulnerability } \\
\text { Index }\end{array}$ & \multicolumn{1}{|c|}{ Preliminary Inference } \\
\hline 41WB556 & $150 \mathrm{BP}$ & 0.0640 & 16.5 & 0.0039 & Moderate vulnerability, slightly wetter \\
\hline 41WB556 & $400 \mathrm{BP}$ & 0.0825 & 11.0 & 0.0072 & High vulnerability, wetter \\
\hline 41WB557 & $600 \mathrm{BP}$ & 0.0760 & 12.5 & 0.0060 & Moderate vulnerability, wetter \\
\hline 41WB556 & $800 \mathrm{BP}$ & 0.054 & 22 & $\mathbf{0 . 0 0 2 5}$ & Low Vulnerability, drier \\
\hline 41WB437 & $2000 \mathrm{BP}$ & 0.0650 & 22.0 & 0.0030 & Modern conditions \\
\hline 41WB437 & $3000 \mathrm{BP}$ & 0.0470 & 26.0 & 0.0018 & Low Vulnerability, drier \\
\hline 41ZP364 & $4700 \mathrm{BP}$ & 0.0450 & 23.0 & 0.0021 & Low Vulnerability, drier \\
\hline Webb County & Modern & 0.062 & 19 & 0.0033 & Modern conditions \\
\hline
\end{tabular}

\section{Conclusions and Suggestions for Future Research}

\section{Conclusions}

Charcoal was identified in 41 charcoal and six flotation samples recovered from 41WB556 and 41WB557. Mesquite, guayacan, granjeno, huisache, desert olive, and bluewood, all of which are typical of vegetation in the southern Texas region, were noted in the samples. Mesquite charcoal occurred in 39 of the 41 charcoal samples and all of the flotation samples, making the material from this site ideal for further xylem analytical studies.

Xylem analysis of 36 samples revealed some identifiable trends in the wood anatomy of mesquite charcoal recovered from both modern contexts across Texas and from dated archeological contexts. There is a distinct difference in the size and density of vessels in mesquite wood collected from eastern Texas, southern Texas, and western Texas. In fact, at first blush the anatomy of mesquite wood follows very closely a similar pattern in the east-west precipitation gradient, as illustrated in mesquite wood from Brazos, Bexar, Webb, Val Verde, and El Paso counties (Table D-1).

Likewise, material from the early Historic context (41WB557, Feature 25, 400 вP) appeared to be adapted to much wetter conditions. Material from the recent features (41WB557, Features 21 and 22) had anatomical features of wood adapted to slightly wetter regimes than modern samples from the same area. Samples from the other sites show that xylem structure does change through time, at least in the temporal contexts that have been examined. For example, data from 41ZP364 suggest that the time period around 4700 BP may have seen drier conditions. Data from 3000 в at the Lino Site (41WB437) also suggest drier conditions, while the data from 2000 BP suggest precipitation amounts roughly similar to modern conditions.

The data indicate the distinct possibility that regional conditions for tree growth changed during the late Holocene, and that these conditions are reflected in mesquite wood charcoal. We have established that the approach holds promise for two reasons: 1) there is a lot of mesquite wood in archeological sites and this wood can be easily dated and analyzed; and 2) preliminary studies of modern mesquite wood strongly suggest that the tree does change the specific dimensions of the cells that make up its xylem (wood) anatomy, at the same time it retains its overall familiar form. The changes in wood anatomy are measurable and appear to coincide with differences in annual precipitation. More encouraging, the differences occur on an east-west rainfall gradient from Brazos County at 39 in $(1,016 \mathrm{~mm})$ to El Paso County at 8 in $(203 \mathrm{~mm})$, a linear distance of approximately $700 \mathrm{mi}(1,126 \mathrm{~km})$. Such a long and gradual gradient provides a very good potential for establishing a proxy record based on xylem analysis. 


\section{Future Research}

Although mesquite xylem analysis may provide a promising approach to the study of rainfall changes, many questions remain unanswered. Studies so far have been conducted to develop an approach to the laboratory analysis of the materials. That is, methods have been developed to devise a protocol for collecting, processing, preparing mesquite for imaging in a scanning electron microscope, and for making and recording the cell measurements. During the course of this study mesquite was collected from five different counties along the eastwest rainfall gradient in Texas. The preliminary research has provided promising results, however, many questions remain to be answered.

There are three primary suggestions for continuing xylem research:

1. Establish a large modern reference data set from each major precipitation regime, including samples from most landforms in the region;

2. Subject the data set to statistical analysis to establish the variability of mesquite xylem anatomy within a given precipitation regime; and

3. In all possible situations, pair the xylem analysis of a piece of wood charcoal with AMS dates to provide an accurate temporal context.

The data resulting from these procedures will be utilized to address the following issues in mesquite xylem analysis. First, how does mesquite wood react to groundwater sources? Does the presence of ground water mask changes in rainfall, or cause the pattern of woody tissue development to change? In order to examine this issue several mesquite trees need to be sampled from different positions on the landscape within the same general location. By this means a range of variation in mesquite wood anatomy may be established within a given precipitation regime. Before starting this project, the author discussed the issue of groundwater and mesquite wood anatomy with Steve Archer, a leading expert in mesquite ecology. He doubted that groundwater would significantly change wood anatomy (Steve Archer, personal communication 1997). Five samples collected from different locales in Brazos County, including a primary creek terrace, a secondary creek terrace, and two upland locations provided quite comparable results. However, this approach needs to be repeated in all of the study locations.

Other analytical issues may affect the accuracy of xylem analysis as a proxy for precipitation change. For example, we do not know how sensitive the archeological samples are to changes in rainfall. We know that mesquite stems (trunks) can live for at least 80 to 90 years (Steve Archer, personal communication 1997). Thus a tree with a particular genotype will survive long enough to provide a record with a temporal resolution similar to a good radiocarbon assay. However, if that tree is very plastic in its reactions to precipitation, the charcoal data set from an archeological feature may describe fluctuations that occur in five or ten year increments. Such a data set may be too sensitive to establish a trend that is identified by a radiocarbon date that has an accuracy of \pm 50 years. On the other hand, if mesquite does not react sufficiently quickly to precipitation changes, then xylem analysis is not sufficiently sensitive to provide us with a proxy data set. This might happen if the genetic information in a mesquite population does not allow it to adjust to changes in precipitation over a period of decades or centuries. In this case the tree (or the population of trees) is simply living through radical precipitation fluctuations and adjusting through other means such as leaf drop or root production rather than changes in xylem anatomy. Still, preliminary studies indicate that mesquite xylem is plastic and does change along a precipitation gradient.

Finally, even assuming that xylem analysis can provide us with a usable proxy data set for the reconstruction of past rainfall patterns, we still need to determine what constitutes an adequate sample size in a prehistoric context for the reconstruction of past environments. For this reason a much larger data set must be assembled and subjected to statistical analysis. At the present time there is not enough data to actually analyze statistically. We have observed apparent trends in the xylem analysis data that appear to logically follow precipitation gradients, but we still must establish the range of xylem variation within each precipitation regime. Once variation in the modern sample is established, we will be able to then determine the size of the archeological data set needed before it can be used as a proxy for prehistoric rainfall patterns. Consideration and successful resolution of these issues holds the promise of reconstructing Holocene rainfall patterns for much of the borderlands in southern North America. 


\section{References Cited}

Baas, $\mathrm{P}$.

1982 Systematic, Phylogenetic, and Ecological Wood Anatomy-History and Perspectives. In New Perspectives in Wood Anatomy, edited by P. Baas, pp. 23-58. Martinus Nijhoff, The Hague.

Bryson, R.

1987 On Climates of the Holocene. In Man and the Middle Holocene Climatic Optimum, edited by N. A. McKinnon and G. S. L. Stuart, pp. 1-13. Proceedings of the 17th Annual Chacmool Conference, University of Calgary Archaeological Association. Calgary, Canada.

Carlquist, S.

1975 Ecological Strategies of Xylem Evolution. University of California Press, Berkeley.

1977 Ecological Factors in Wood Evolution: A Floristic Approach. American Journal of Botany 64:887-896.

COHMAP Members

1988 Climatic Changes of the Last 18,000 Years: Observations and Model Simulations. Science 241:10431053.

February, E. C.

1992 Archaeological Charcoals as Indicators of Vegetation Change and Human Fuel Choice in the Late Holocene at Elands Bay, Western Cape Province, South Africa. Journal of Archaeological Science 19:347-354.

1994 Rainfall Reconstruction Using Wood Charcoal from Two Archaeological Sites in South Africa. Quaternary Research 42:100-107.

February, E. C., W. D. Stock, W. J. Bond, and D. Le Roux

1995 Relationships Between Water Availability and Selected Vessel Characteristics in Eucalyptus grandis and Two Hybrids. IAWA Bulletin 16:269-276.

Mock, C. J., and P. J. Bartlein

1995 Spatial Variability of Late-Quaternary Paleoclimates in the Western United States. Quaternary Research 44:425-433.

Neilson, R. P.

1986 High-Resolution Climatic Analysis and Southwest Biogeography. Science 232:27-34.

1987 Biotic Regionalization and Climatic Controls in Western North America. Vegetation 70:135-147.

Scholtz, A.

1986 Palynological and Palaeobotanical Studies in the Southern Cape. Unpublished M.A. Thesis. University of Stellenbosch.

Shackleton, C. M., and F. Prins

1992 Charcoal Analysis and the "Principle of Least Effort." Journal of Archaeological Science 19:631-637. 
Tusenius, M.

1989 Charcoal Analytical Studies in the North-Eastern Cape, South Africa. South African Archaeological Society Goodwin Series 6:77-83.

Wright, H. E., Jr.

1976 The Dynamic Nature of Holocene Vegetation: A Problem in Paleoclimatology, Biogeography, and Stratigraphic Nomenclature. Quaternary Research 6:581-596.

1993 Global Climates Since the Last Glacial Maximum. University of Minnesota Press, Minneapolis.

Zimmerman, M. H.

1983 Xylem Structure and the Ascent of Sap. Springer-Verlag, Berlin. 


\title{
Appendix E
}

\section{Magnetic Sediment Susceptibility}

by

\author{
Raymond P. Mauldin
}




\title{
Appendix E: Magnetic Sediment Susceptibility Testing
}

\author{
Raymond P. Mauldin
}

The magnetic susceptibility (MS) of a given sediment sample can be thought of as a measure of how easily that sample can be magnetized (Dearing 1999; Gose and Nickels 2001[1998]). At low magnetic field strengths, this measure is primarily related to the concentration and grain size of ferro- and ferromagnetic minerals in the sample (Gose and Nickels 2001[1998]). A number of processes can result in an increase in MS values in a sediment sample. Of these processes, those that are of concern here are related to an increase in the organic constitutes or changes in the mineralogy of sediments in a given sample (see Collins et al. 1994; McClean and Kean 1993; Singer and Fine 1989). Sediments with higher organic content tend to have higher magnetic susceptibility values, probably as a result of the production of maghemite, an iron oxide, during organic decay (Reynolds and King 1995). Pedogenic processes, such as soil formation and weathering, can result in the concentration of organic material, as well as alterations in the mineralogy of a given zone. These processes can significantly impact susceptibility readings. Cultural processes, such as the concentration of ash, charcoal, and refuse, would also produce higher MS readings. A measure of the magnetic susceptibility of a sediment sample, then, may provide information on both the presence of surfaces, as well as a measure of the concentration of cultural activity upon those surfaces.

\section{Collection Procedures and Laboratory Methods}

A total of 22 samples representing units N42/E10 (n=7), N44/E11 ( $n=7)$, and N44/E14 ( $n=8)$, was analyzed for magnetic sediment susceptibility from 41WB556. The samples were collected at $10-\mathrm{cm}$ intervals from the centers of these $1 \times 1-m$ excavation units. These samples were placed in plastic bags, and stored in the laboratory at CAR until analysis.

Sediment samples were air dried on a non-metal surface. After drying, the samples were then ground into a uniform grain size using a ceramic mortar and pestle.
This was done to standardize particle size and make the material both easier to handle and pack into sample containers. After each sample was ground, the mortar and pestle were washed with tap water and wiped dry with a paper towel to avoid cross-sample contamination. The ground sample was then poured into a sample container consisting of a plastic cube with external dimensions of $2.54 \times 2.54 \times 1.94 \mathrm{~cm}$. The cubes have an average weight of 4.86 grams. The sediment filled cube was then weighed, and the weight of the sample calculated by subtracting the empty cube weight. This was done to correct for differences in mass. Assuming that sample volume and material is constant, larger samples should have higher susceptibility values simply as a function of greater mass.

The cube was then placed into a MS2B Dual Frequency Sensor that, in conjunction with a MS2 Magnetic Susceptibility Meter, provided a measure of the magnetic susceptibility of the sample (see Dearing 1999). For each cube, a single reading was taken using the SI (standard international) scale. The value, referred to as volume specific susceptibility and noted with the symbol $\mathrm{K}$ (Kappa), is recorded on a scale of $10^{-5}$, though there are no units associated with the value. That is, the value is dimensionless (Dearing 1999).

In order to correct for differences in sample weight, and provide units to the value $K$, the mass specific susceptibility value (X) was calculated using the formula

$$
\mathrm{X}=(\mathrm{K} / \mathrm{p})
$$

where $\mathrm{p}$ is the sample bulk density expressed in $\mathrm{kg} \mathrm{m}^{-3}$. The bulk density is determined by dividing the sample mass by volume. However, as all samples were measured in identical cubes, and all cubes were full, the sample volume is assumed to be constant. Only the mass of the sample varied. Mass specific susceptibility can be determined by

$$
X=K * \text { calibrated mass/ sample mass }
$$


where sample mass is determined by subtracting the cube weight from the total sample weight (Dearing 1999). Calibrated mass is assumed to be 10 grams.

While the resulting values now have both a scale and associated units, the critical element for the current discussion is related to relative differences between $\mathrm{X}$ sample values within a given profile or site, rather than absolute differences. That is, the principal interest is in rapid changes in the mass specific susceptibility values along a profile. This change may signal either a buried surface and/or cultural activity at that location. Comparisons of absolute values between samples from different areas, especially when the parent material of the soils is different, are of limited utility given our current goals.

This can be seen in Table E-1, which lists a variety of examples of mass specific susceptibility values for several different materials. In all cases, the analysis was performed following the procedures outlined previously. Note that the values differ widely, from a low of -1.47 for tap water, to a high of 97.62 for sediments collected from a burned rock midden. Samples 5 and 6 are on two different clays from the same general setting, far northern Lamar County in north Texas. The mass specific susceptibility is different for these samples, probably as a function of different frequencies of trace elements that, though small in absolute quantity, can dramatically impact the susceptibility values.

The potential impacts of cultural processes on susceptibility values can be seen by considering a data set collected from an archeological site located in Brown County, 41BR473. A total of 279 sediment susceptibility samples was collected from each level of over 50 shovel tests placed at this site. In all cases, the analytical procedures followed those outlined previously. Table E-2 presents summary data on all 279 cases, along with susceptibility scores for those settings that had FCR or chipped stone present. If cultural inputs result in higher susceptibility values, then it should be the case that significantly higher susceptibility values will be present in levels that have cultural material.

An examination of Table E-2 will demonstrate that this is indeed the case. Levels that have FCR present do have higher scores relative to those that lack FCR. Similarly,

Table E-1. Magnetic sediment susceptibility data for a variety of substances

\begin{tabular}{|c|c|c|c|c|c|c|c|}
\hline Sample Type & $\begin{array}{c}\text { Total } \\
\text { Wt. (gr.) } \\
\end{array}$ & $\begin{array}{c}\text { Sample } \\
\text { Wt. (gr.) }\end{array}$ & $\begin{array}{c}\text { Reading } \\
1(\mathbf{k})\end{array}$ & $\begin{array}{c}\text { Reading } \\
\mathbf{2}(\mathbf{k})\end{array}$ & $\begin{array}{c}\text { Reading } \\
\mathbf{3}(\mathbf{k})\end{array}$ & $\begin{array}{c}\text { Average } \\
\text { K }\end{array}$ & $\begin{array}{l}\text { Corrected } \\
\text { Mass }(\mathbf{X}) \\
\end{array}$ \\
\hline $\begin{array}{l}\text { 1) Sandy sediment } \\
\text { with organics }\end{array}$ & 13.7 & 8.85 & 27.9 & 28 & 28.1 & 28.00 & 31.64 \\
\hline $\begin{array}{l}\text { 2) Modern } \\
\text { mesquite charcoal } \\
\text { and sediment }\end{array}$ & 9.4 & 4.55 & 10.7 & 10.8 & 10.7 & 10.73 & 23.59 \\
\hline $\begin{array}{l}\text { 3) Modern oak } \\
\text { wood ash }\end{array}$ & 7.5 & 2.65 & 16.1 & 16.2 & 16.2 & 16.17 & 61.01 \\
\hline $\begin{array}{l}\text { 4) Sediment from } \\
\text { burned rock } \\
\text { midden }\end{array}$ & 11.3 & 6.45 & 62.9 & 63 & 63 & 62.97 & 97.62 \\
\hline $\begin{array}{l}\text { 5) Grey clay- no } \\
\text { human occupation }\end{array}$ & 12.6 & 7.75 & 10.4 & 10.3 & 10.4 & 10.37 & 13.38 \\
\hline $\begin{array}{l}\text { 6) Red clay-no } \\
\text { human occupation }\end{array}$ & 10.8 & 5.95 & 11.9 & 12 & 12 & 11.97 & 20.11 \\
\hline 7) Sandstone & 14.7 & 9.85 & 6.9 & 7 & 7.1 & 7.00 & 7.11 \\
\hline 8) Limestone & 12.7 & 7.85 & -0.5 & -0.5 & -0.5 & -0.50 & -0.64 \\
\hline 9) Tap water & 10.5 & 5.65 & -0.8 & -0.8 & -0.9 & -0.83 & -1.47 \\
\hline
\end{tabular}


Table E-2. Presence/absence of cultural material and mass specific sediment susceptibility scores for shovel tests at 41BR473

\begin{tabular}{|c|c|c|c|c|c|}
\hline & All Cases & $\begin{array}{c}\text { FCR } \\
\text { Present }\end{array}$ & $\begin{array}{c}\text { FCR } \\
\text { Absent }\end{array}$ & $\begin{array}{c}\text { Chipped Stone } \\
\text { Present }\end{array}$ & $\begin{array}{c}\text { Chipped Stone } \\
\text { Absent }\end{array}$ \\
\hline $\begin{array}{c}\text { Number } \\
\text { of Samples }\end{array}$ & 279 & 84 & 195 & 38 & 241 \\
\hline Mean Value & 48.3 & 56.9 & 44.6 & 55.2 & 47.2 \\
\hline $\begin{array}{c}\text { Standard } \\
\text { Deviation }\end{array}$ & 17.2 & 17.7 & 15.6 & 16.1 & 17.1 \\
\hline
\end{tabular}

\section{Results}

those levels that have chipped stone present have a higher average mass specific susceptibility score relative to those that lack chipped stone. As the distribution is approximately normal, a t-test was used to test the overall significance of these differences. In both the FCR and chipped stone comparisons, the test confirms that those levels with cultural material have significantly higher scores than those without cultural material (FCR t-statistic $=5.804, \mathrm{df}=277, \mathrm{p}<.001 ;$ chipped stone t-statistic $=2.674, \mathrm{df}=277, \mathrm{p}=.008$ ). Our preliminary investigations, then, coupled with the previous work, clearly suggest that an analysis of the magnetic susceptibility of sediment can provide additional information on both the presence of buried surfaces, as well as the impact of cultural material on those surfaces.
Table E-3 presents the results of the susceptibility analysis of the 22 samples at 41 WB556. An examination of the data for each of the $1 \times 1-\mathrm{m}$ units will demonstrate that most values range between 33 and 40, though there are four cases between 25 and 30 . This relatively small range for the 22 cases suggests that no well-defined surface is reflected in these samples. In Unit N44/E14, there is an increase in readings associated with the Level 4 sample, but the increase is slight. The only anomalous reading in any of the columns is in unit N42/E10, at Level 4, which sees a rapid drop of values relative to Levels 3 and 5 .

The overall homogeneity of the readings, coupled with a lack of any significant, consistent deviations between levels, suggests that buried surfaces are not reflected in the current samples. While more closely spaced sampling may have provided evidence of such surfaces, the current sample readings are consistent with a turbated sediment. 
Table E-3. Sediment susceptibility data for 41WB556

\begin{tabular}{|c|c|c|c|c|c|c|}
\hline $\begin{array}{c}\text { Sample } \\
\text { Lot \# }\end{array}$ & North & East & Level & $\begin{array}{c}\text { Total } \\
\text { Weight (gr.) }\end{array}$ & $\begin{array}{c}\text { Reading } \\
(\mathbf{K})\end{array}$ & $\begin{array}{l}\text { Corrected } \\
\text { Value (X) }\end{array}$ \\
\hline 328 & 42 & 10 & 1 & 13.4 & 33.9 & 39.70 \\
\hline 338 & 42 & 10 & 2 & 14 & 33.1 & 36.21 \\
\hline 360 & 42 & 10 & 3 & 14 & 35.2 & 38.51 \\
\hline 434 & 42 & 10 & 4 & 14.6 & 25.3 & 25.98 \\
\hline 449 & 42 & 10 & 5 & 13.9 & 32.3 & 35.73 \\
\hline 594 & 42 & 10 & 6 & 13.8 & 31.2 & 34.90 \\
\hline 687 & 42 & 10 & 7 & 13.6 & 29.1 & 33.29 \\
\hline 727 & 44 & 11 & 1 & 13.3 & 28.1 & 33.29 \\
\hline 745 & 44 & 11 & 2 & 13 & 27.5 & 33.78 \\
\hline 767 & 44 & 11 & 3 & 13.7 & 29.9 & 33.84 \\
\hline 789 & 44 & 11 & 4 & 14.10 & 32.2 & 34.85 \\
\hline 822 & 44 & 11 & 5 & 13.3 & 30.5 & 36.14 \\
\hline 846 & 44 & 11 & 6 & 13.3 & 31.2 & 36.97 \\
\hline 858 & 44 & 11 & 7 & 14.7 & 34.6 & 35.16 \\
\hline 668 & 44 & 14 & 1 & 13 & 24.1 & 29.61 \\
\hline 682 & 44 & 14 & 2 & 13.6 & 25.3 & 28.95 \\
\hline 697 & 44 & 14 & 3 & 13.2 & 24.1 & 28.90 \\
\hline 708 & 44 & 14 & 4 & 14.9 & 33.8 & 33.67 \\
\hline 729 & 44 & 14 & 5 & 12.9 & 27.3 & 33.96 \\
\hline 810 & 44 & 14 & 6 & 14.3 & 34.4 & 36.44 \\
\hline 862 & 44 & 14 & 7 & 13.9 & 30.6 & 33.85 \\
\hline 883 & 44 & 14 & 8 & 14.2 & 32.0 & 34.26 \\
\hline
\end{tabular}




\section{References Cited}

Collins, M. B., W. A. Gose, and S. Shaw

1994 Preliminary Geomorphological Findings at Dust and Nearby Caves. Journal of Alabama Archaeology 40: $35-56$.

Dearing, J.

1999 Environmental Magnetic Susceptibility. Chi publishing, Kenilworth, England.

Gose, W. A., and D. L. Nickels

2001[1998] Archaeomagnetic and Magnetic Susceptibility Analyses. In Test Excavations at the Culebra Creek Site, 41BX126, Bexar County, Texas, by D. L. Nickels, C. B. Bousman, J. D. Leach, and D. A. Cargill, pp. 204-214. Archaeological Survey Report No. 265, Center for Archaeological Research, The University of Texas at San Antonio. Archeology Studies Program, Report 3, Environmental Affairs Division, Texas Department of Transportation, Austin.

McClean, R. G., and W. F. Kean

1993 Contributions of Wood Ash Magnetism to Archeomagnetic Properties of Fire Pits and Hearths. Earth and Planetary Science Letters 119:387-394.

Reynolds, R. L., and J. W. King

1995 Magnetic Records of Climate Change. U.S. National Report to I.U.G.G., 1991-1994. American Geophysical Union. <http://www.agu.ong/revgeophys/reyno100/reyno100.html> Accessed April 2001.

Singer, M. J., and P. Fine

1989 Pedogenic Factors Affecting Magnetic Susceptibility of Northern California Soils. Soil Science of America Journal 53:1119-1127. 


\section{Appendix F}

\section{Artifact and Ecofact Recovery by Unit and Level}




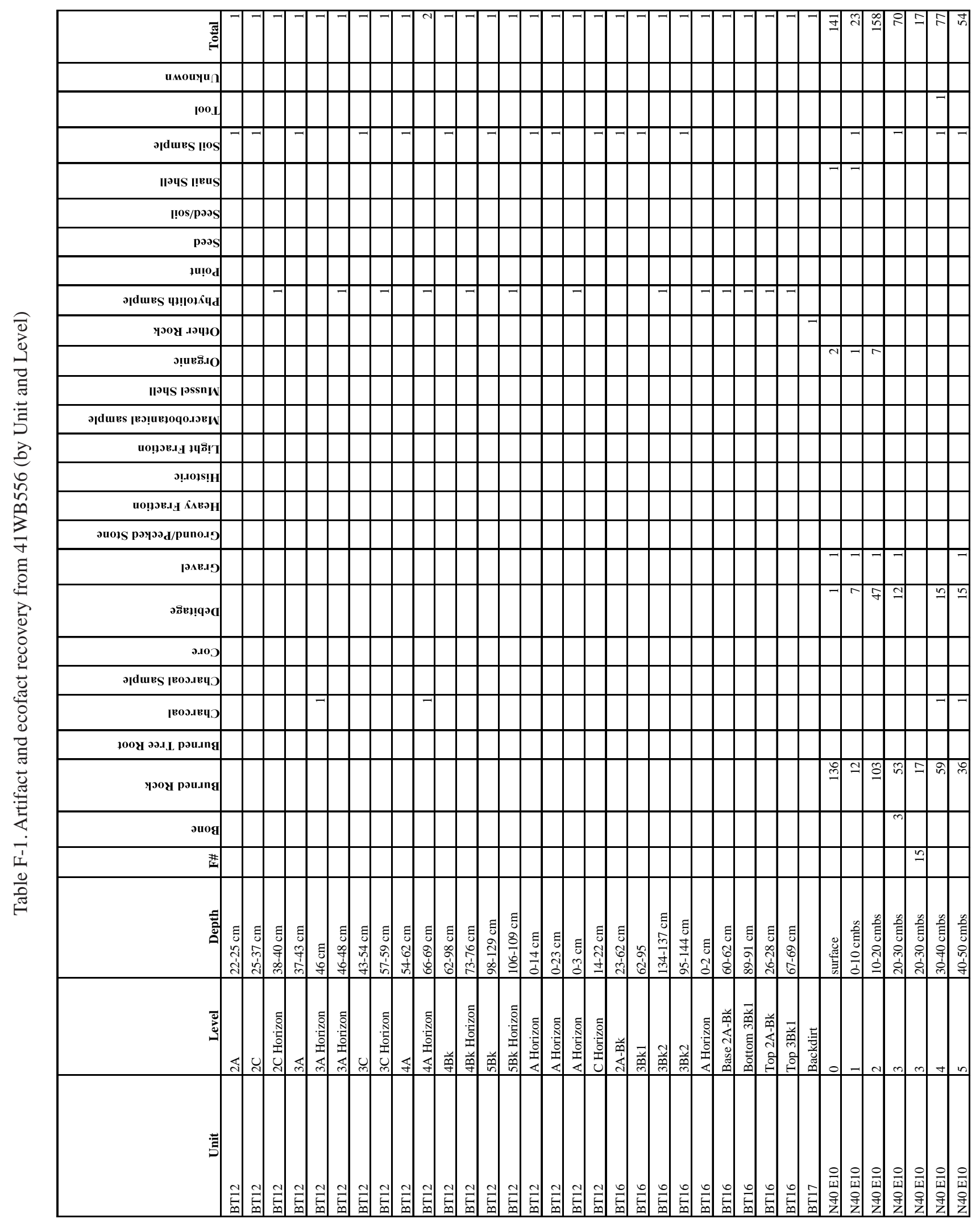




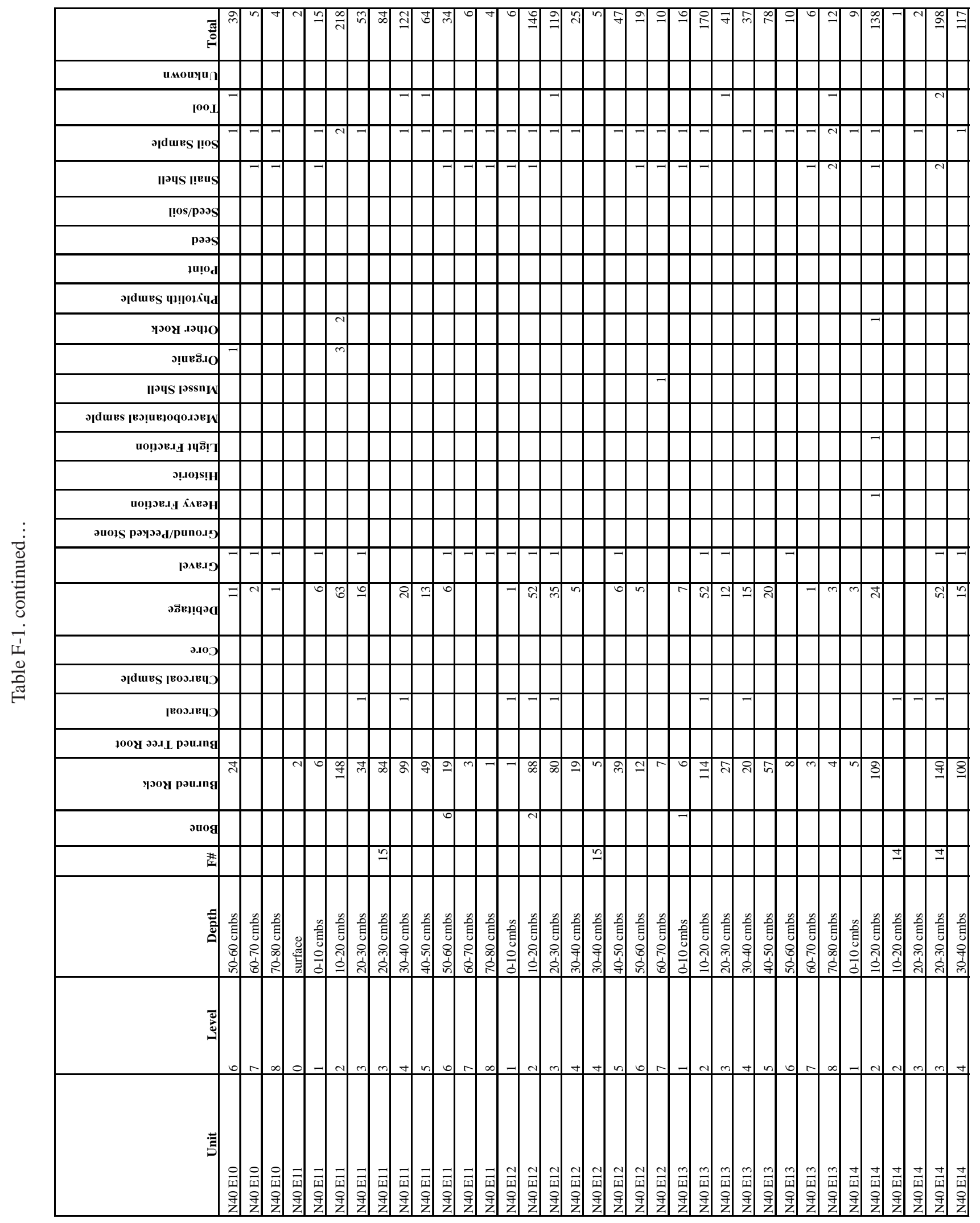




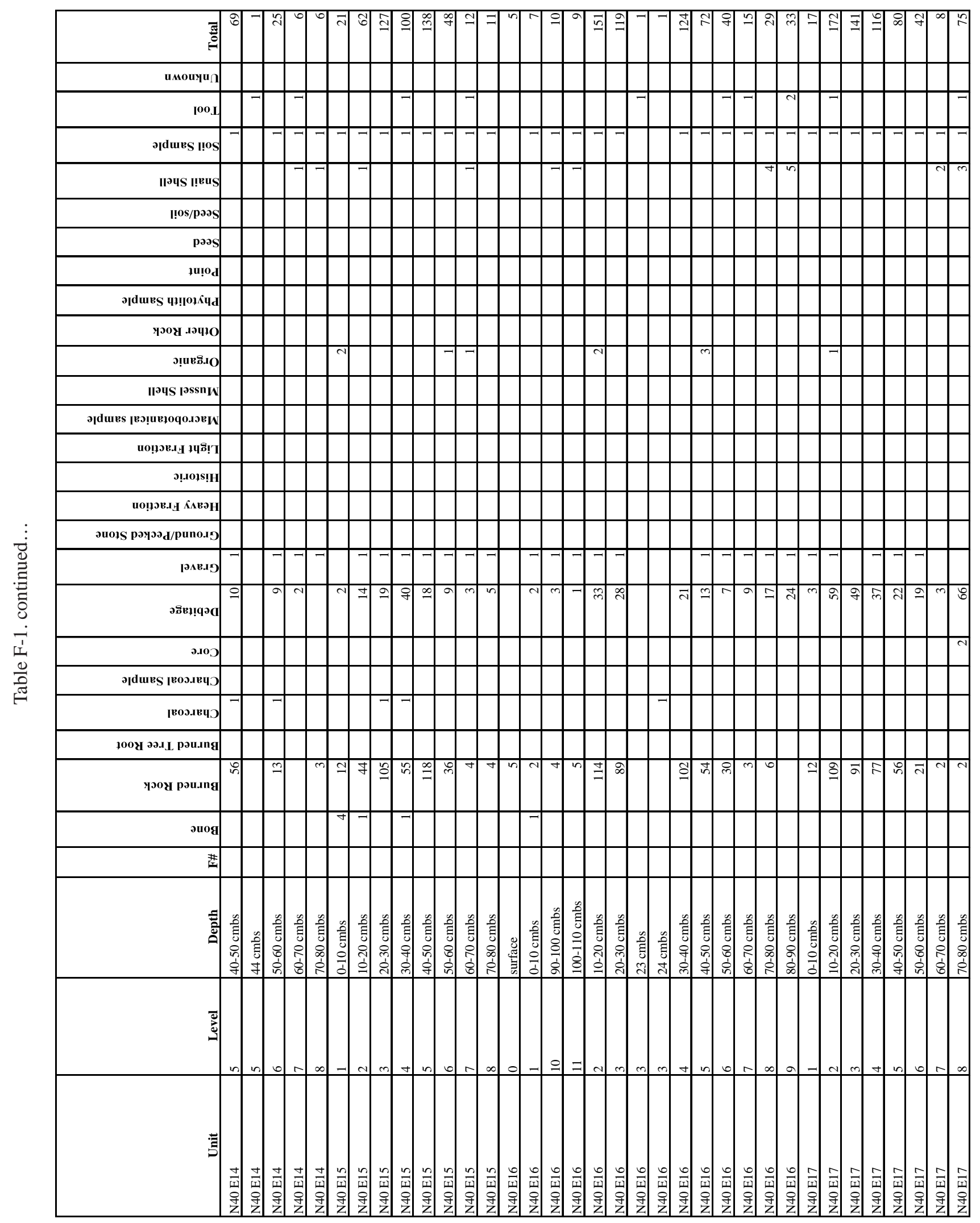




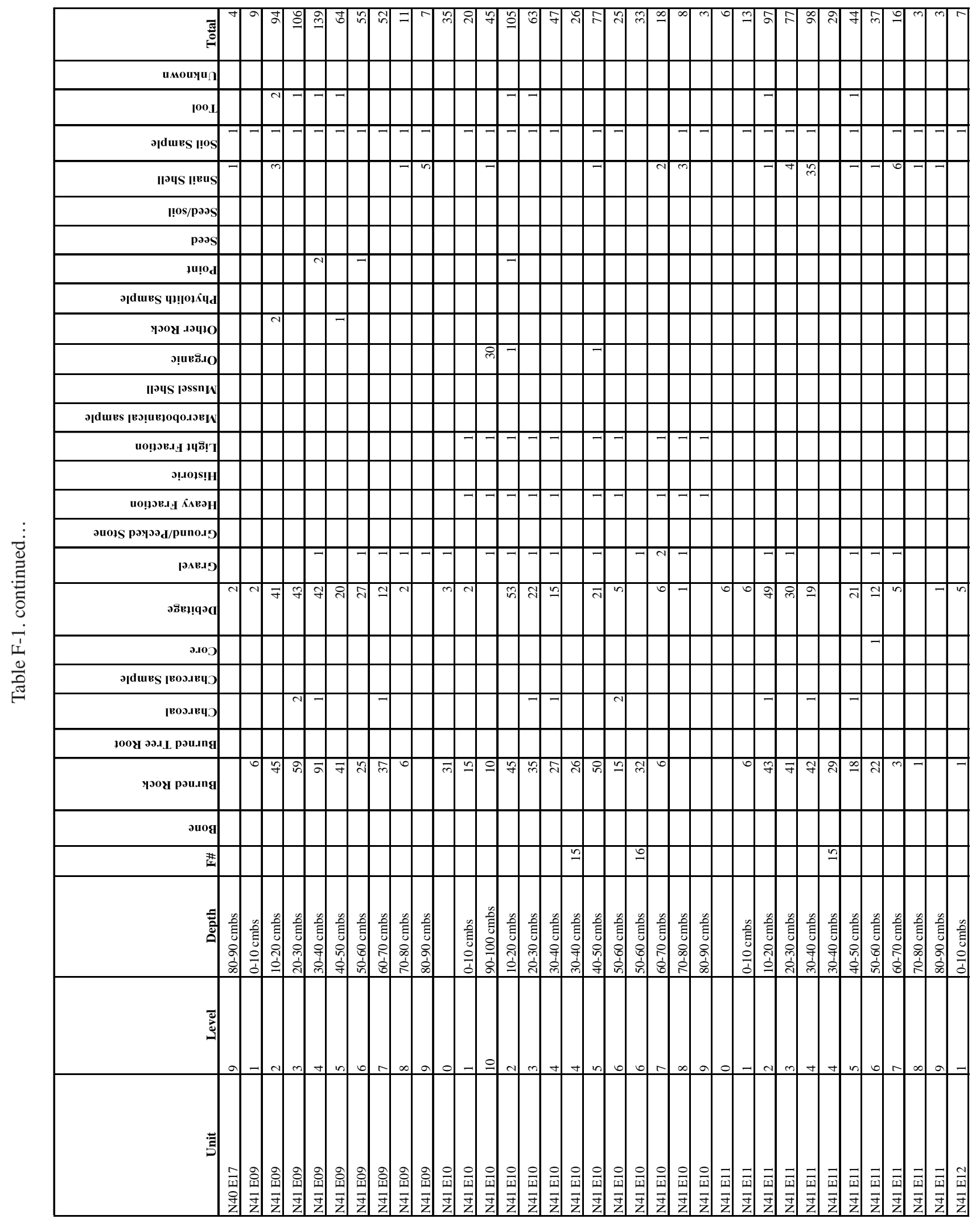




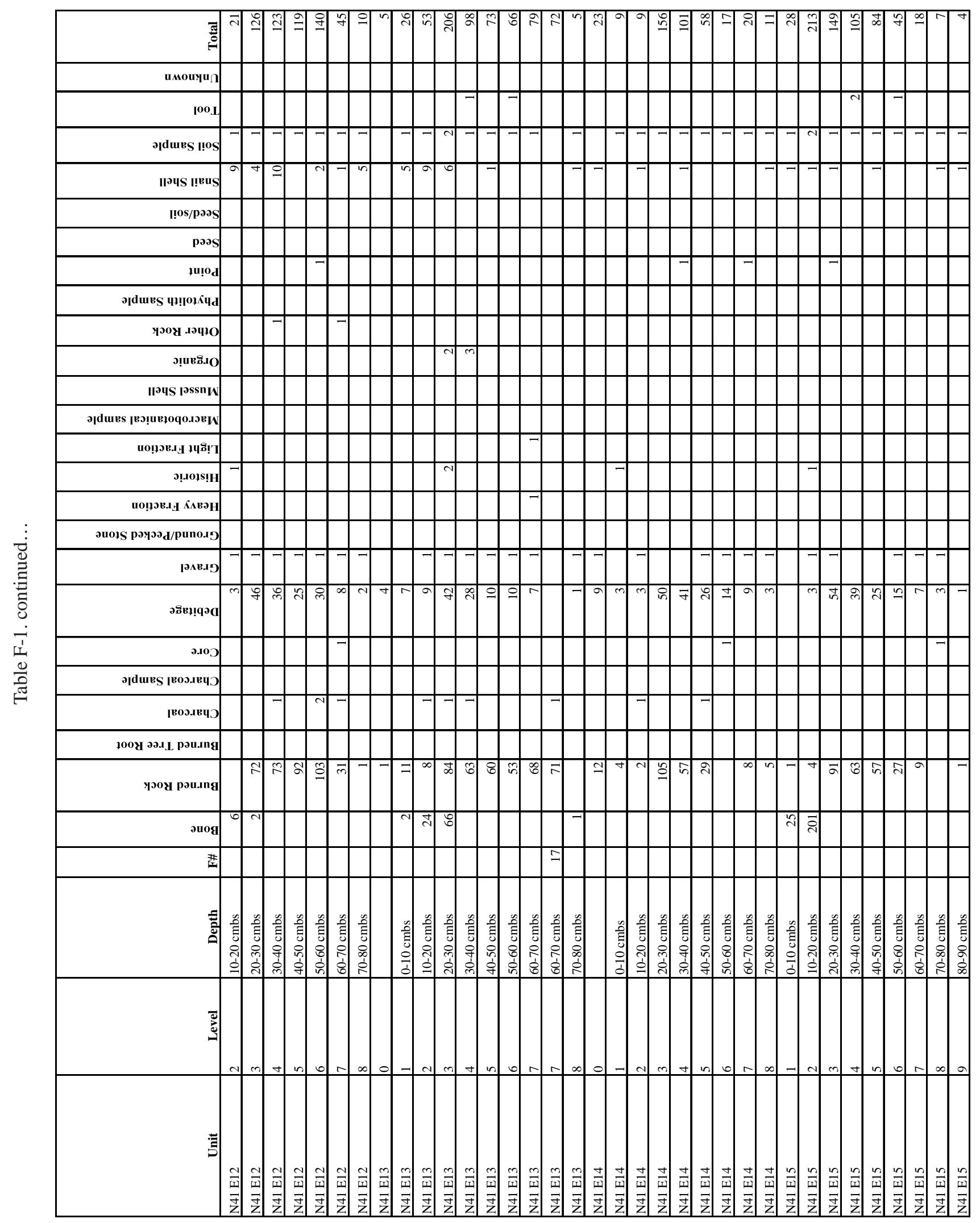




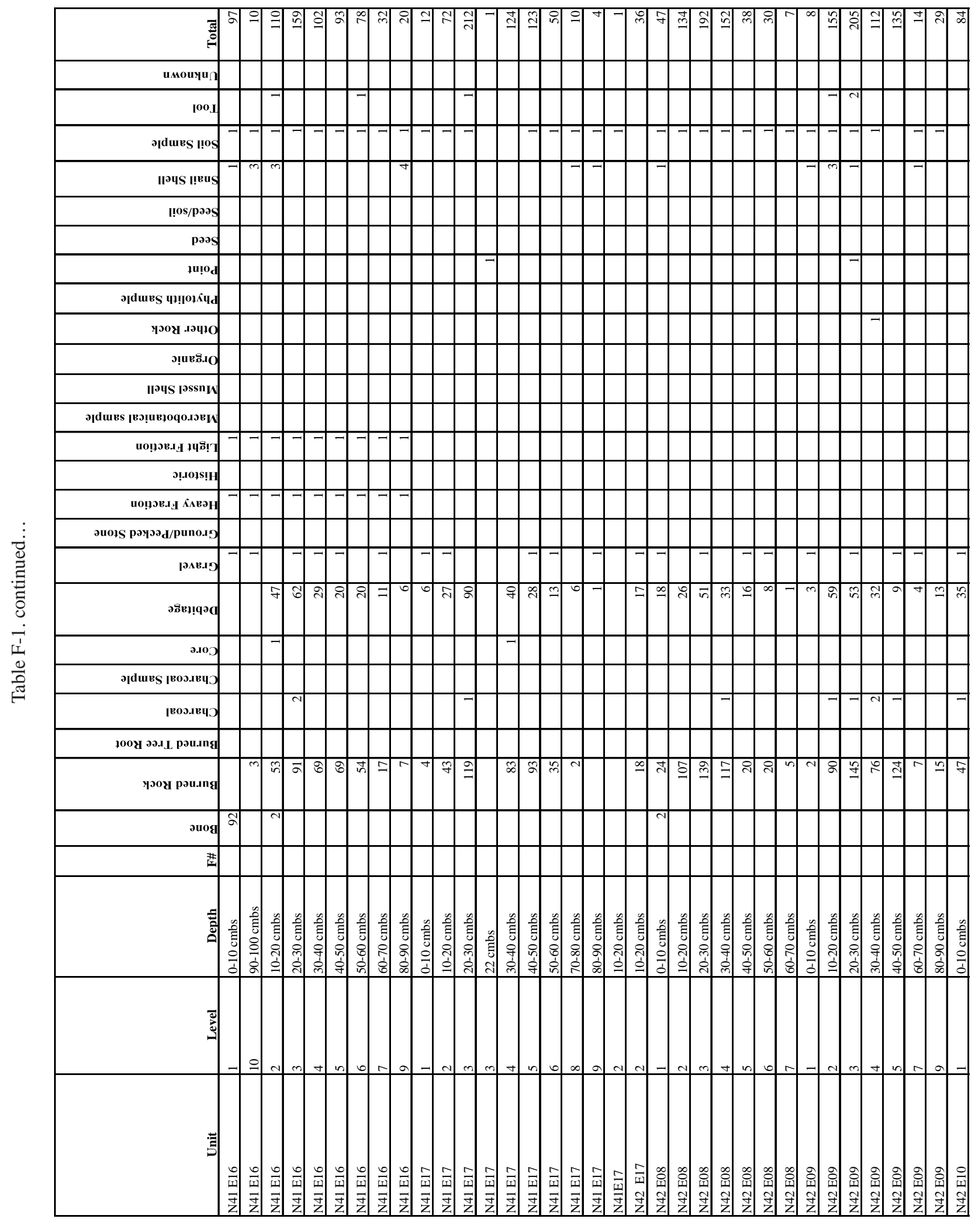




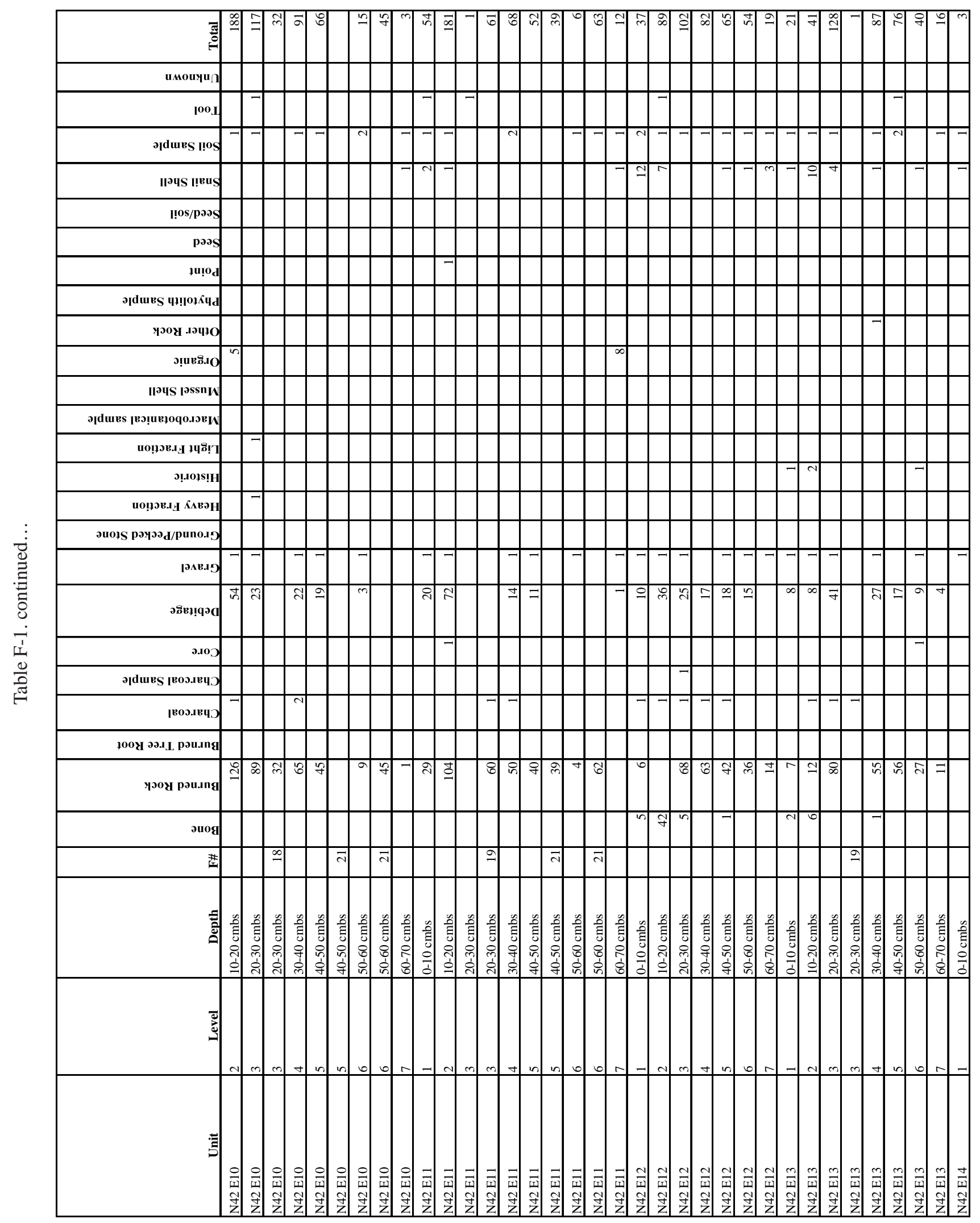




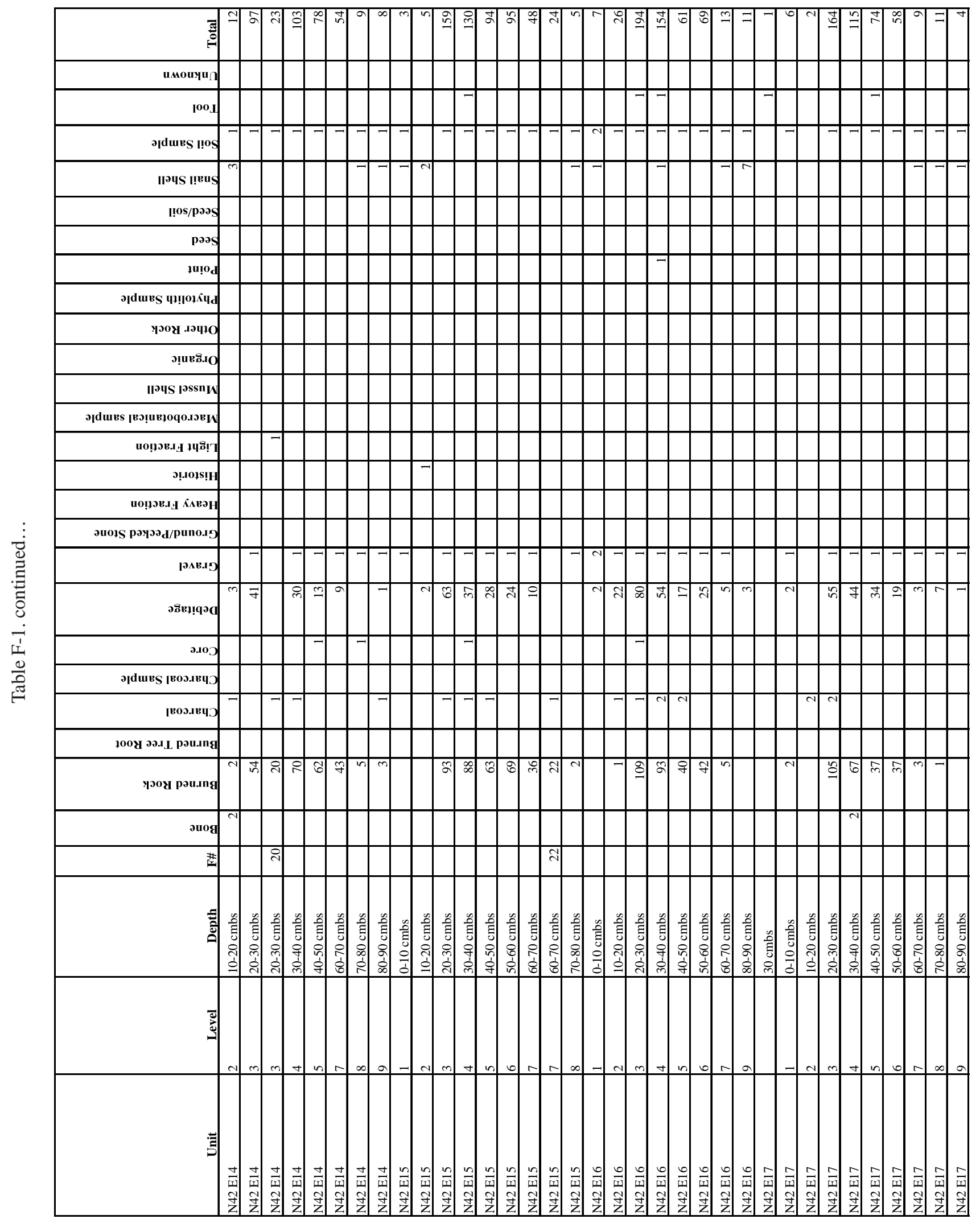




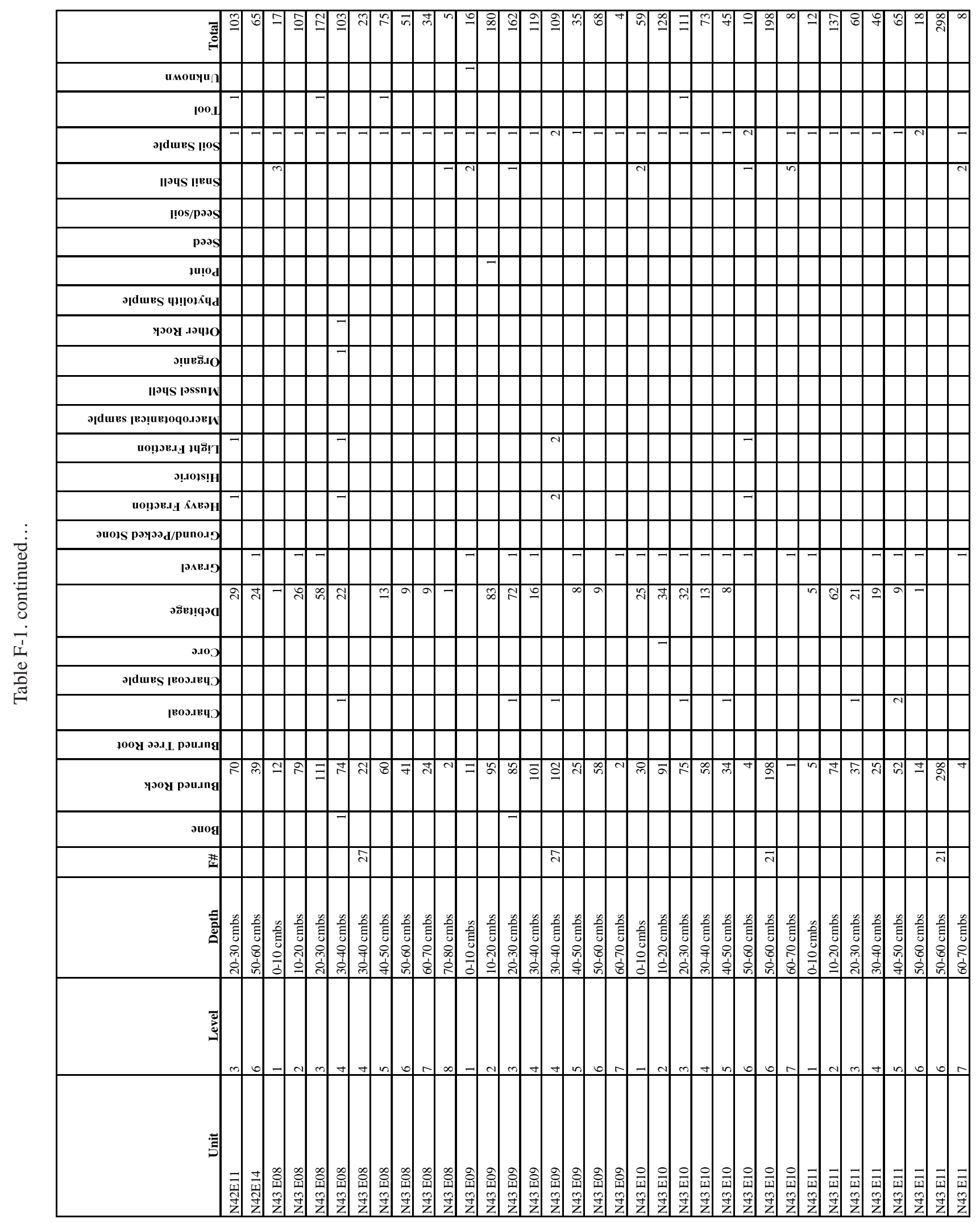




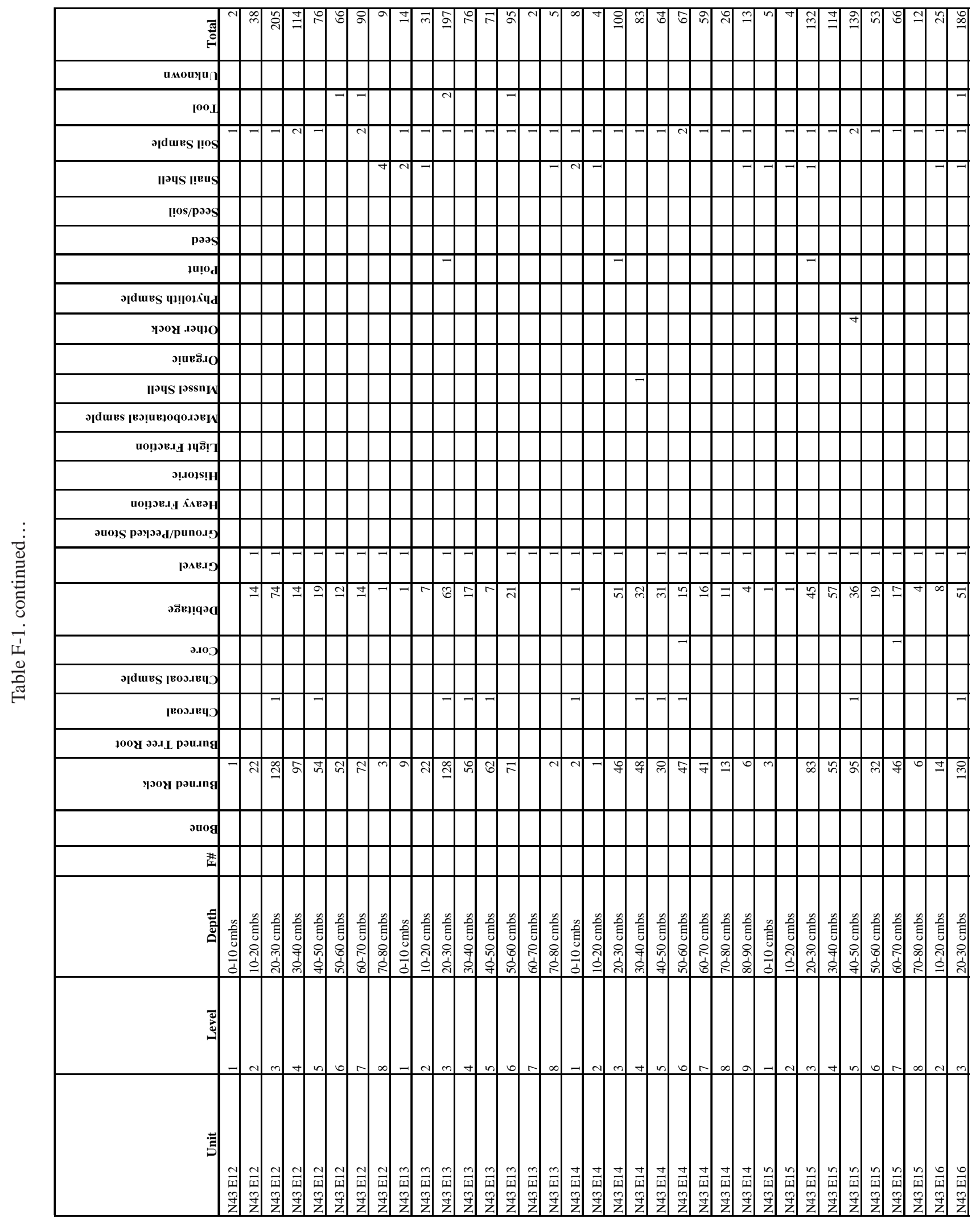




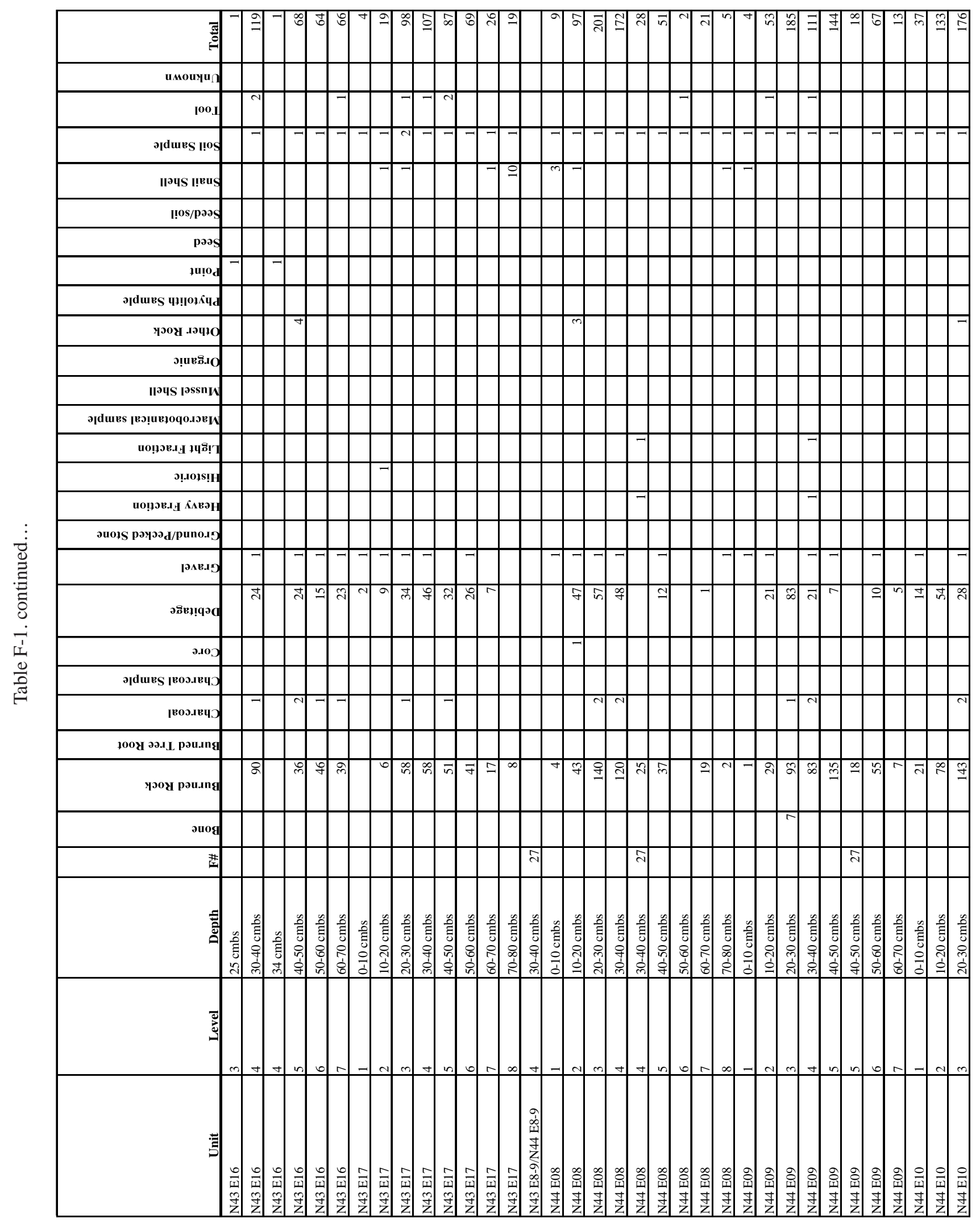




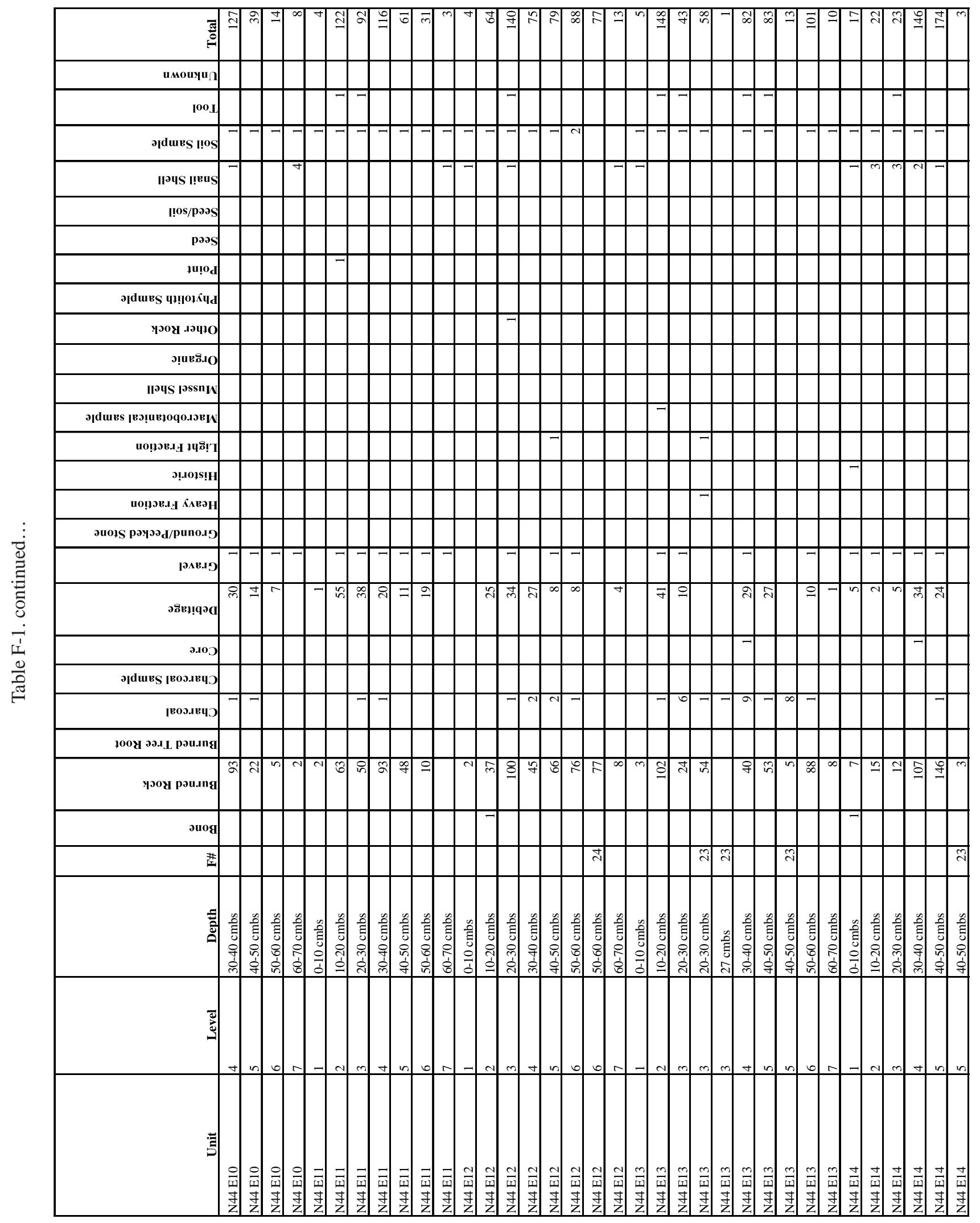




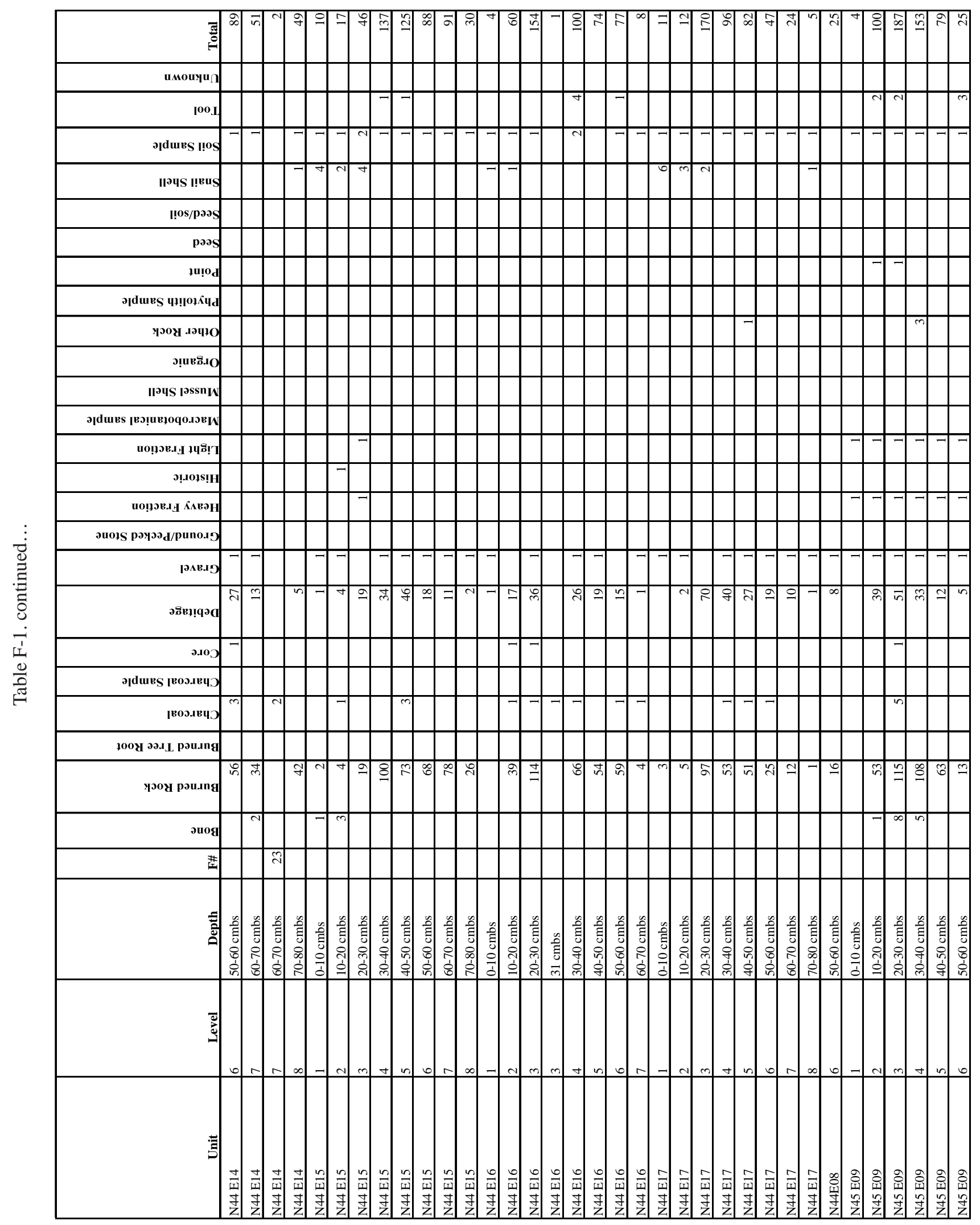




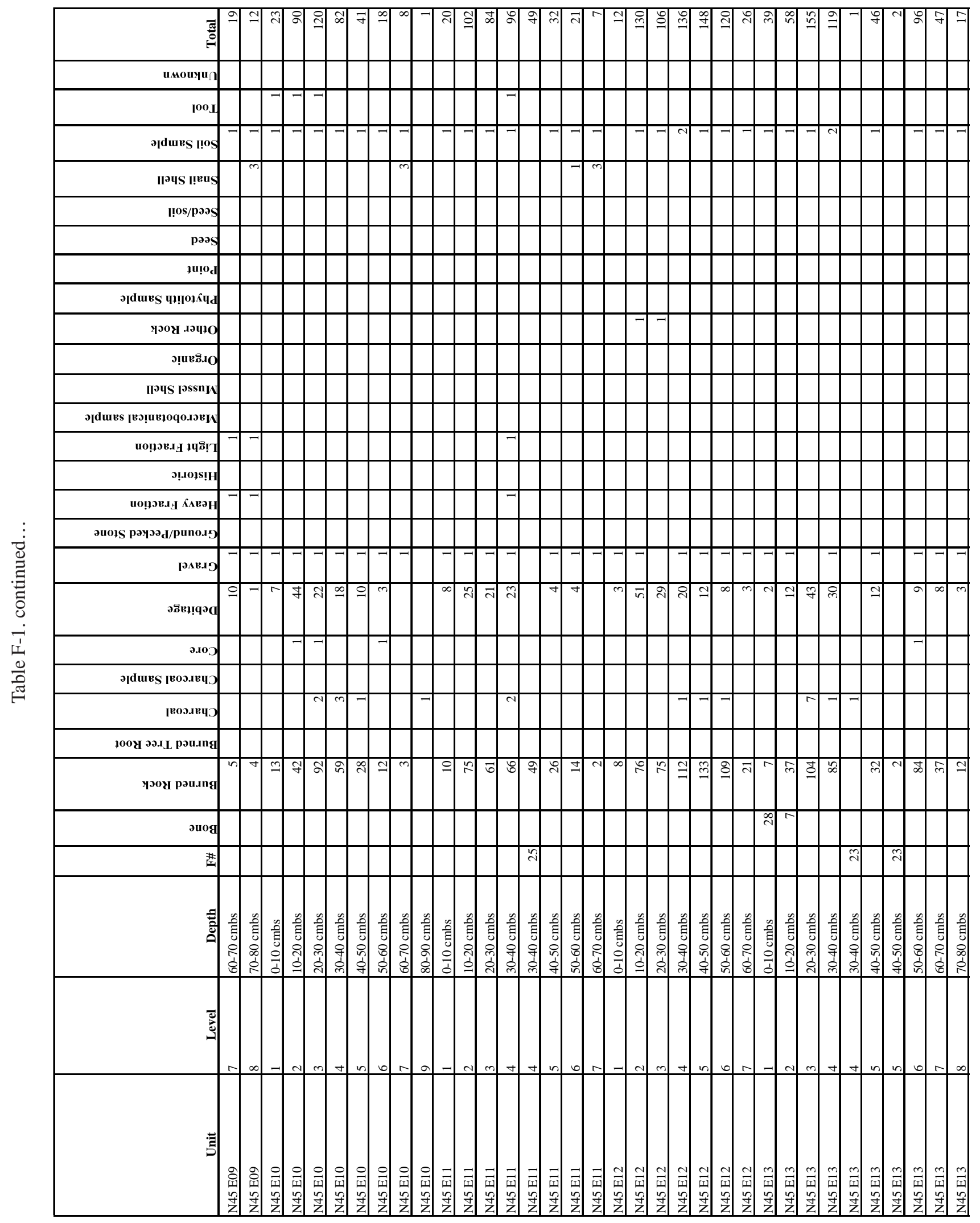




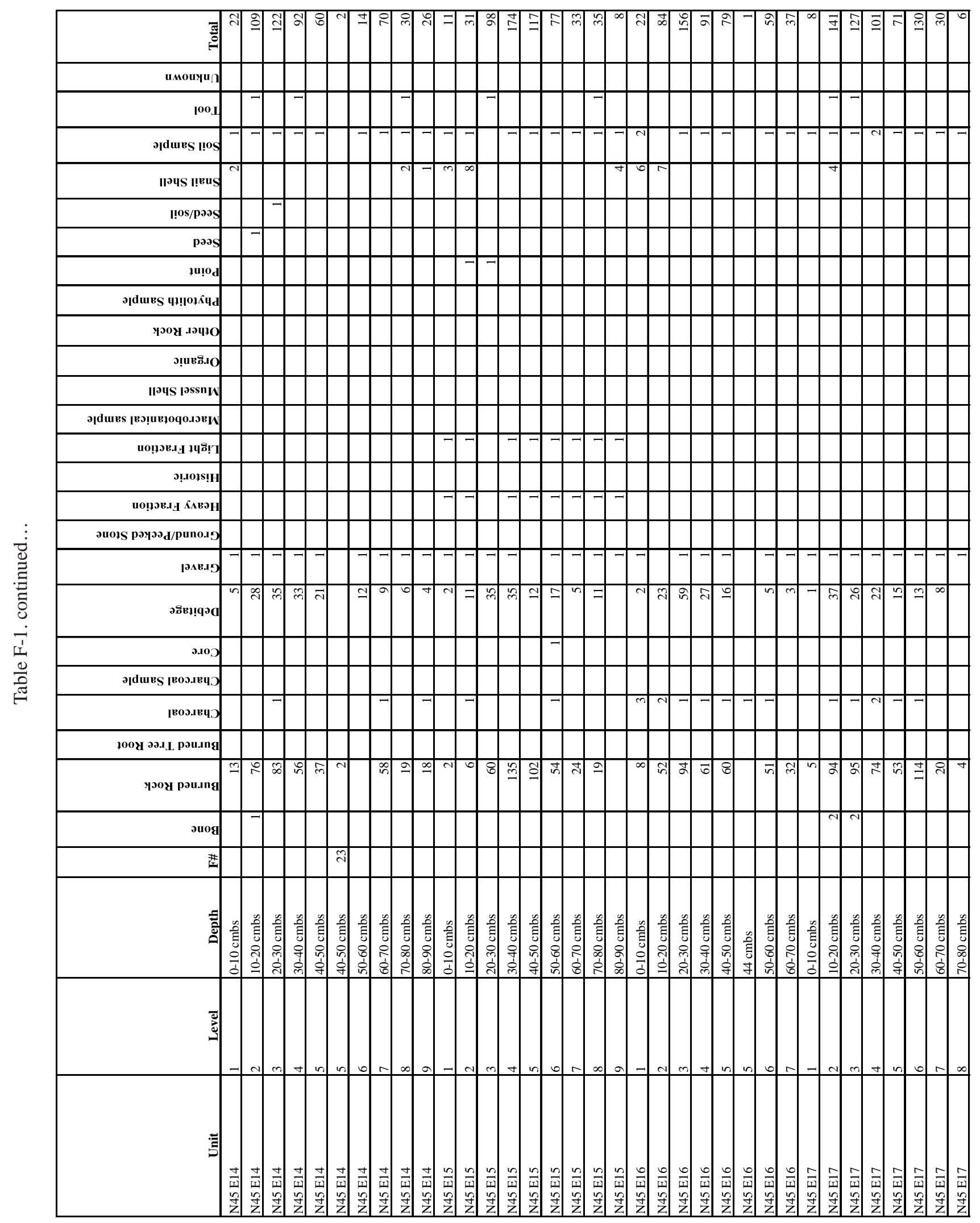




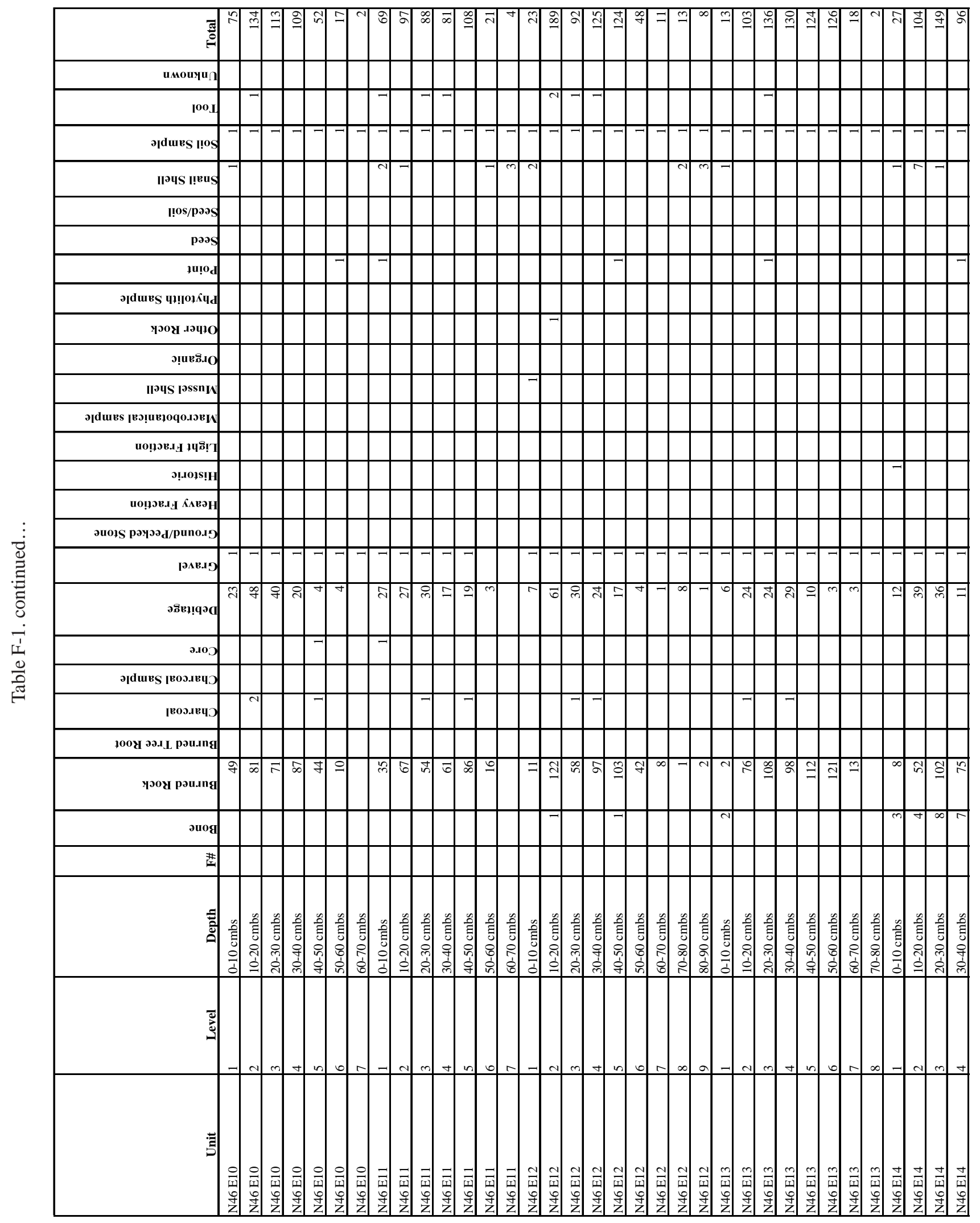




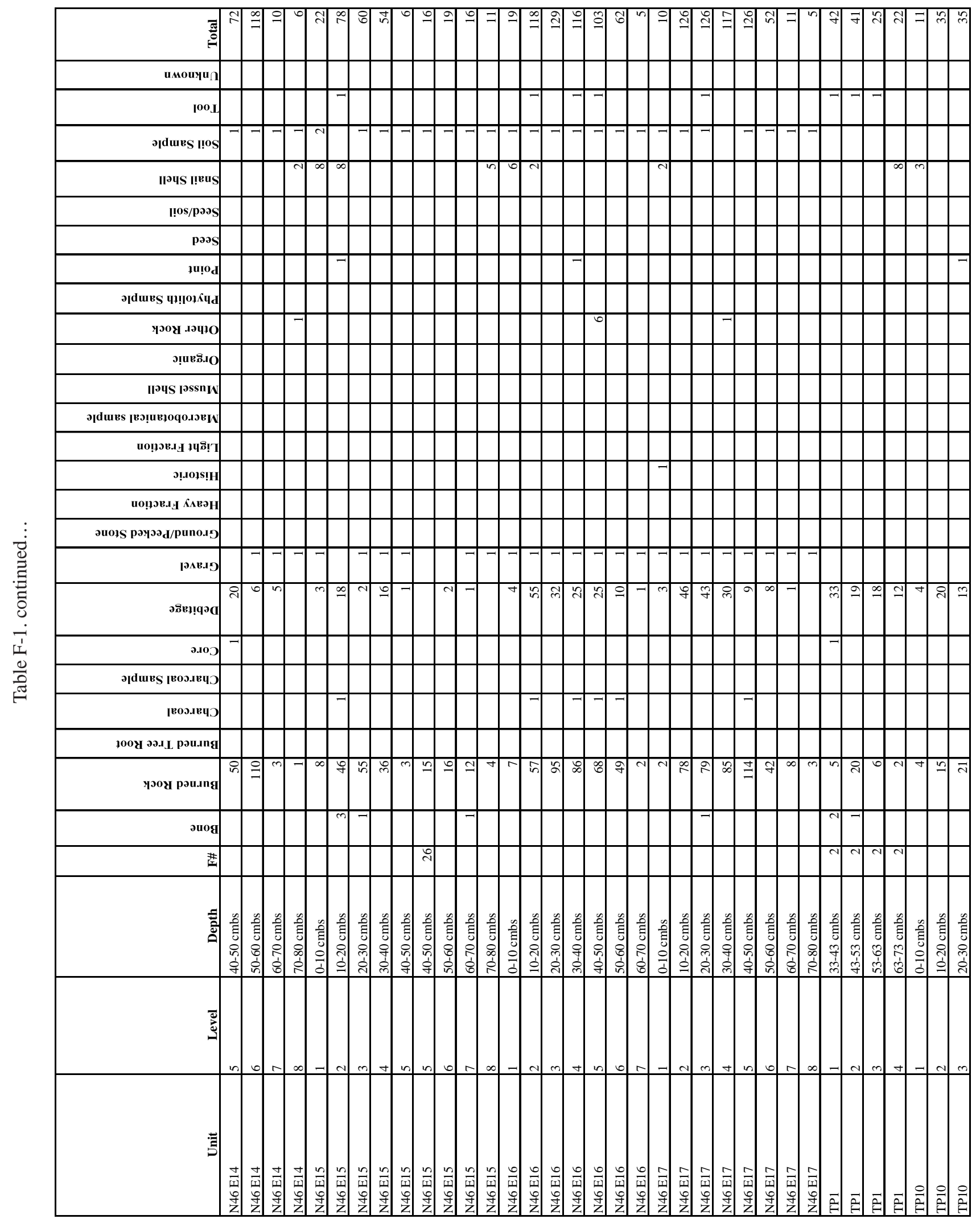




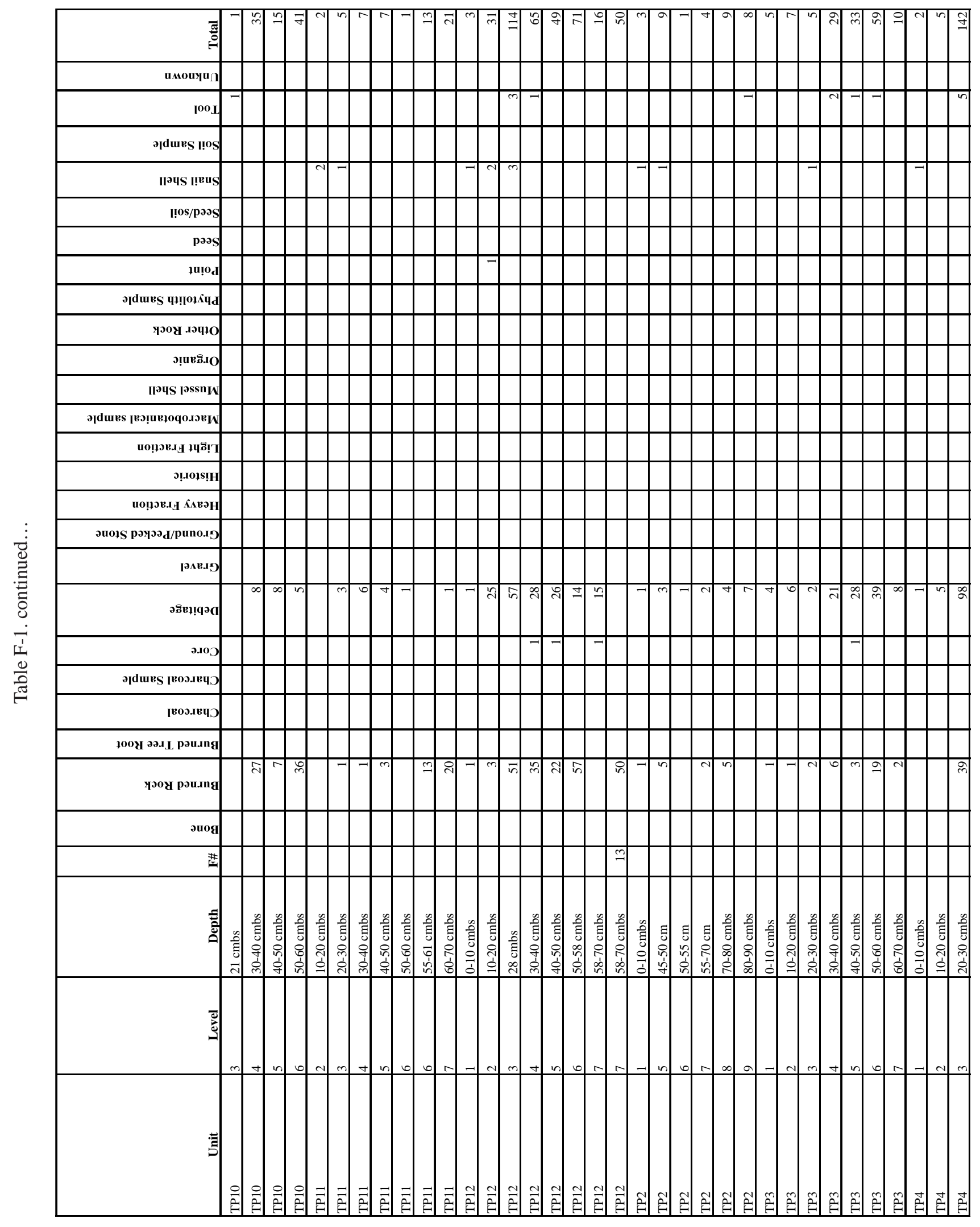




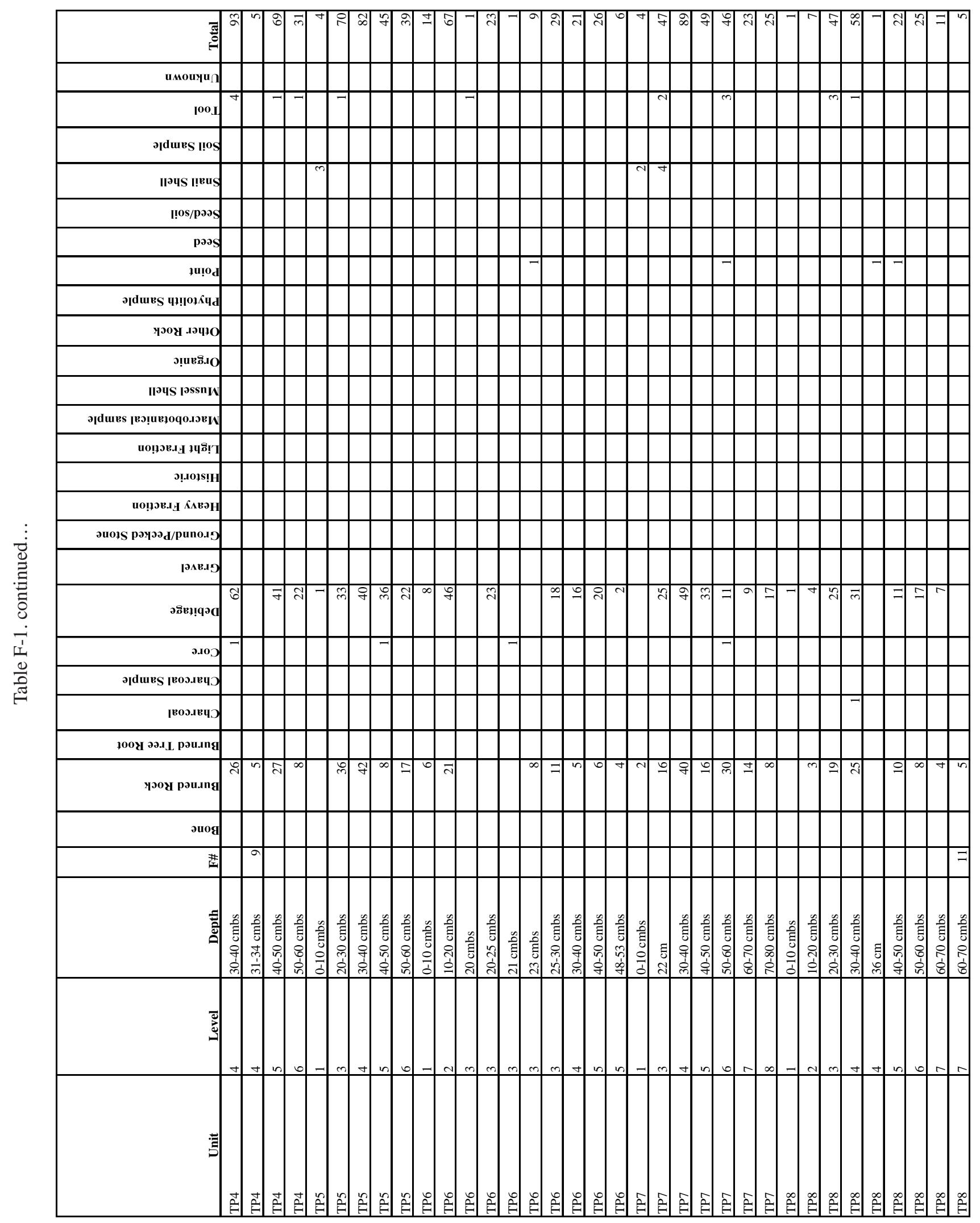




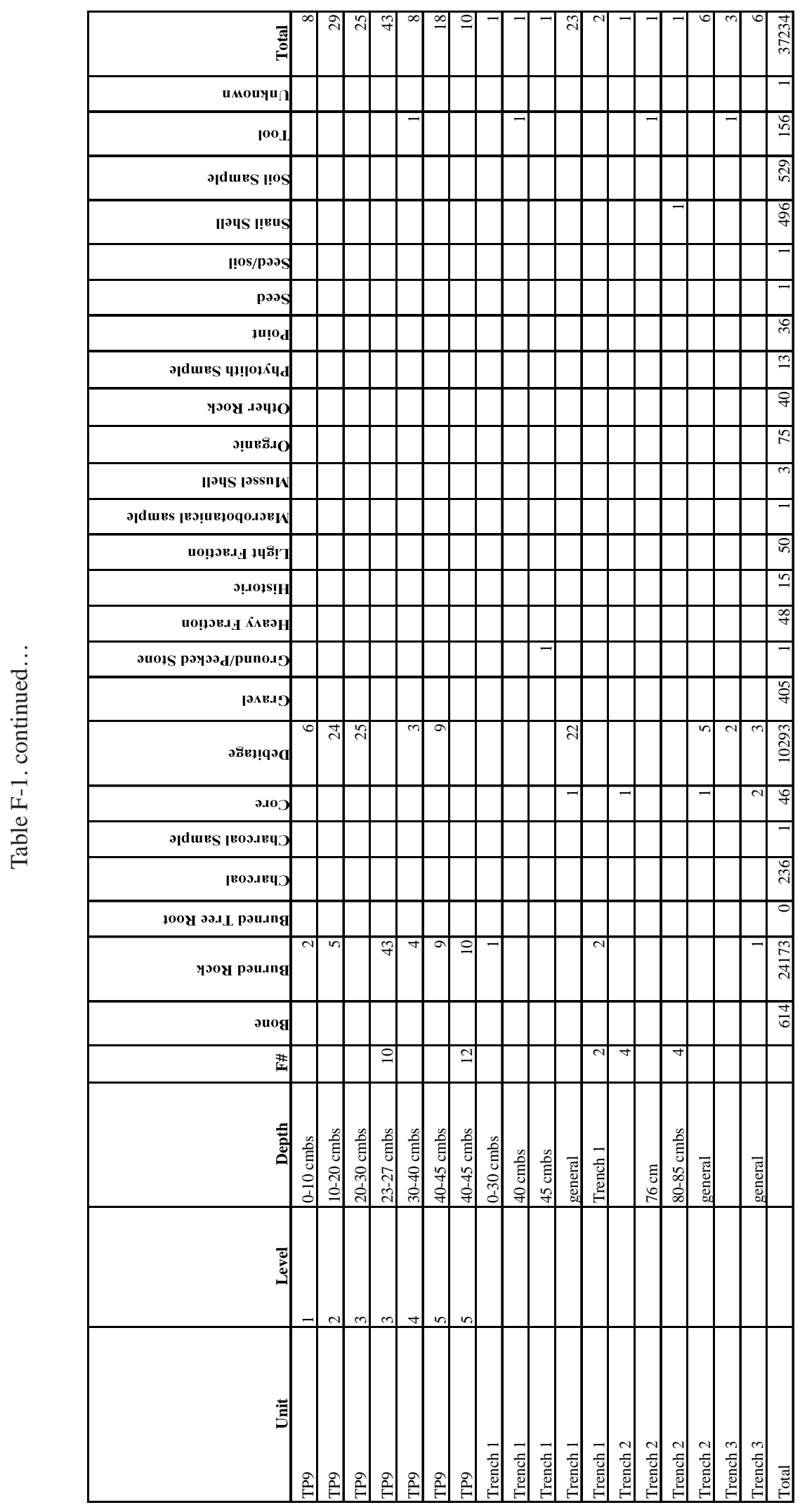





\section{Appendix G}

\section{Glossary of Lithic Analysis Terms}




\section{Appendix G: Glossary of Lithic Analysis Terms}

Break cause: The identification of the cause of break of incomplete artifacts; it could consist of a range of possibilities including manufacture, use, postdepositional, or combinations of these; established based on comparisons of break morphology with experimentally replicated specimens; use-wear presence/absence and stage of manufacture may also be considered and often reliance on more than one criteria is necessary; greatest degree of experimental replications done on bifacial artifacts (projectile points, knives, etc.).

Manufacture break: Artifact breakage occurring during manufacture and resulting from too much force being applied to artifact edge, imbedded fracture lines in the material, incorrect blow and support dynamics; break morphology described as perverse and characterized by twisting and bending as it progresses from one edge to the other across the width of the biface; often results in two fragments but may also create a third wedge-shaped fragment; breakage may occur perpendicular to longitudinal axis or tangentially to it, depending on the orientation of the original blow.

Use break: Artifact breakage occurring during tool use and representing material fatigue; often referred to as a snap break, most of the time oriented perpendicular to the longitudinal axis and having a rounded appearance with smooth edges; the break morphology differs on the two broken fragments.

Post-depositional: Artifact breakage occurs postdepositionally due to mechanical means; fracture initiation is usually from one or the other face of the artifact and often begins in the center of the body rather than the margins; break morphology is rather angular or radiating from a central point.

Bulb of percussion: A bulge on the ventral surface of the flake found immediately below the platform; it represents the Hertzian cone which forms in the process of conchoidal fracture formation; typically hard hammer percussion produces pronounced bulbs, while soft hammer (billet) flaking produces diffuse bulbs. Using careful control of removal angles and force, it is possible to produce diffuse bulbs with a hard hammer percussor.

Burin blades: Blade-like flakes that are detached from a worn graver tip to resharpen the graver tip; the first burin resharpening flake removed from a projectile point would have a triangular crosssection and contain the bifacially flaked edge on the dorsal face; the next burin flake would have a rectangular cross-section with the previous removal scar on its dorsal face.

Scars: Result from the removal of burin blades either through use, as on Olmos bifaces, or rejuvenation. A similar scar also can result from impact and may be seen on projectile points.

Core: Raw material from which a flake or multiple flakes have been removed by direct or indirect percussion or pressure; cores can be classified in terms of degree of "exhaustion," (e.g., tested vs. exhausted), direction of removals (unidirectional, multidirectional), type of product (e.g., flake vs. blade).

Nodule core: A naturally occurring nodule used for flake removals or biface manufacture.

Flake blank/core: A flake removed from a core and in turn used to manufacture chipped stone artifacts.

Flake: A piece of flint or chert removed by direct or indirect percussion or pressure from a parent material or core.

Platform: Surface where the force that initiated flake detachment was applied either by percussion or pressure; often referred to as "striking platform."

Complete flake: A flake possessing a platform and a feathered or hinged termination. 
Proximal flake fragment: A flake possessing a platform while missing a feathered or hinged termination.

Medial flake fragment: A flake fragment missing both platform and feathered or hinged termination.

Distal flake fragment: A flake fragment missing a platform but with feathered or hinged termination.

Primary flake: A complete flake with dorsal surface entirely covered by cortex; platform surface may or may not be covered by cortex.

Secondary flake: A complete flake with dorsal surface partially covered by cortex; platform surface may or may not be covered by cortex.

Tertiary flake: A complete flake without cortex on its dorsal surface; platform surface may or may not be covered by cortex.

Ventral face of flake: Surface of flake that was on the inside of the parent material immediately prior to flake removal; face that has the bulb of percussion.

Dorsalface offlake: Surface of flake that was on the outside of the parent material immediately prior to flake removal, face opposite the bulb, it is either fully or partially corticated or has previous flake removal scars.

Biface thinning flake: Tertiary flakes removed by soft hammerstone or billet, exhibiting a moderate to large number of dorsal flake removal scars, shallow flake scar ridges, and moderate to slight longitudinal curvature. Thinning flakes removed from moderately convex bifaces will have moderate curvature, flakes removed from lenticular crosssectioned bifacial artifacts (i.e., thin bifacial knives) will have only slight longitudinal curvature. Striking platforms are usually multifaceted and ground with some lipping on the ventral edge of the platform. Flake shape might range from relatively broad to narrower flakes with parallel edges to more trapezoidal and/or expanding triangular.
Rejuvenation: Commonly refers to the resharpening of a worn working edge into a fresh state; it may also be applied to the repair of a failed or broken tool form into a newly functional form (e.g., the flaking of a new tip on a broken projectile point blade).

Recycling: Refers to two different prehistoric behaviors -the remanufacture of failed artifacts into new functional types (e.g., the remanufacture of a dart point proximal fragment into a perforator), and the picking up of abandoned tools from a living surface and their reuse by people that did not manufacture the artifact.

Stage of reduction: The degree to which a naturally occurring piece of raw material has been reduced (altered) along a biface manufacture sequence or trajectory; the term applies to biface manufacture strategies and reflects a type of morphological classification system; the classification is independent of whether an artifact is finished and a usable tool or not; that is, even early reduction stage bifaces can be finished tools in a functional sense.

Early reduction stage biface: A thick bifacially flaked core that retains a large amount of cortex, and has a rather sinuous edge; commonly referred to as an edged biface (flakes removed only along the edges of the core); some flake scars might be rather deep since most flakes are removed with hard hammerstones.

Middle reduction stage biface: A moderately thin bifacially flaked artifact with most if not all of the cortex removed, relatively well-aligned edges, and shallow flake scars that result from soft hammer percussion; some changes may have already been made to the original outline or shape of the core or parent material.

Late reduction stage biface: A well-thinned bifacially flaked artifact with no cortex, a combination of soft hammer-produced flakes and pressure flakes employed in artifact shaping; edges are very well aligned or straight and transverse cross-section is lenticular. 
Morphological artifact classifications: Artifacts are classified strictly on the basis of form or morphology (e.g., Form I biface, Group I core) and/or manufacture strategy (e.g., biface, uniface), or a combination of these (e.g., distally beveled uniface, distally beveled biface).

Uniface: A nodular or, more commonly, a flake core with flake removals only from one face (most commonly dorsal face); it refers to a morphological artifact category

Biface: A nodular or flake core with flake removals originating from both faces of the same edge; it refers to a morphological artifact category.

Functional artifact classifications: Artifacts are classified strictly on the basis of inferred function or use (e.g., knife, drill, scraper); establishment of these categories relies on microscopic wear analysis at low (30-80X) or high (300-400X) powered magnification; many archeological reports use a mix of morphological and functional classifications.

Adzes: Bifacially flaked specimens characterized by plano-convex and more often biconvex transverse and longitudinal cross-sections, straight to slightly convex and moderately beveled working edges, and exhibiting polish and rounding of protruding flake scar ridges on both faces of the tool and microflaking primarily on the ventral face. The specimens grouped into this category often but not always exhibit haft wear on both faces of their proximal ends. Unresharpened portions of the working edges exhibit moderate to considerable rounding and polish while the unbeveled faces of the working edges often contain step-fractured microflake scars. Both faces of heavily worn specimens retain a considerable amount of polish and rounding of the flake scar ridges well behind the working edge. The working edges are straight to moderately convex but never concave, and resharpening is present on both the ventral and dorsal faces of the blades.
Gouges: Triangular and/or trapezoidal unifacially or bifacially flaked specimens with plano-convex transverse and longitudinal cross-sections, straight to concave steeply beveled working edges and use polish concentrated primarily on the ventral face of the tool; the distribution of use wear, in the form of heavy polish and microflaking on the ventral surface, indicates that gouges were used in a manner similar to modern-day planes.

Knives: Tools with acute working edges, with or without unifacial and/or bifacial retouch, and exhibiting use wear, in the form of scalloped working edges on unmodified flakes (i.e., expedient knives), and flake scar ridge rounding, polish, and striations parallel to the longitudinal axis on both faces of unifacially and bifacially flaked working edges; includes both knives used in meat processing as well as saws and sickles used in similar fashion but in the processing of plant or vegetal matter.

Projectile points: Unifacially and/or bifacially flaked, stemmed specimens with a triangular to leaf-shaped blade segment, a sharply pointed distal end, sharp lateral blade edges, and in many cases a barbed or shouldered proximal blade portion.

Projectile point preforms: Manufacture-failed arrow and dart points that have sufficiently complete or well-finished stems to be classified into an existing type are considered preforms of the appropriate type (e.g., Montell preform, Pedernales preform).

Projectile point blanks: Manufacture-failed points that were broken so early in the manufacture sequence that their stems were not yet formed sufficiently to associate them with defined types.

Multi-functional tools: Many prehistoric tools, such as projectile points, were utilized for the performance of a number of distinct tasks (e.g., piercing and cutting), and some tools have multiple working edges each used for different tasks (e.g., expedient scraping and cutting edges on edge-modified flakes). 